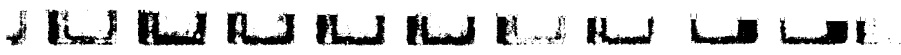

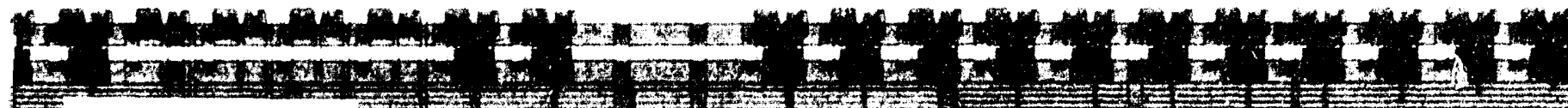

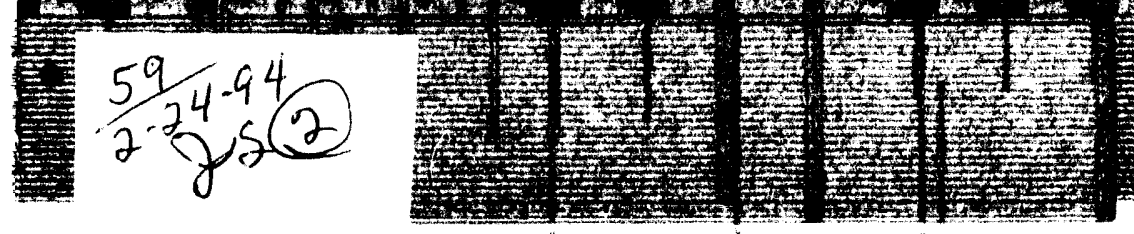
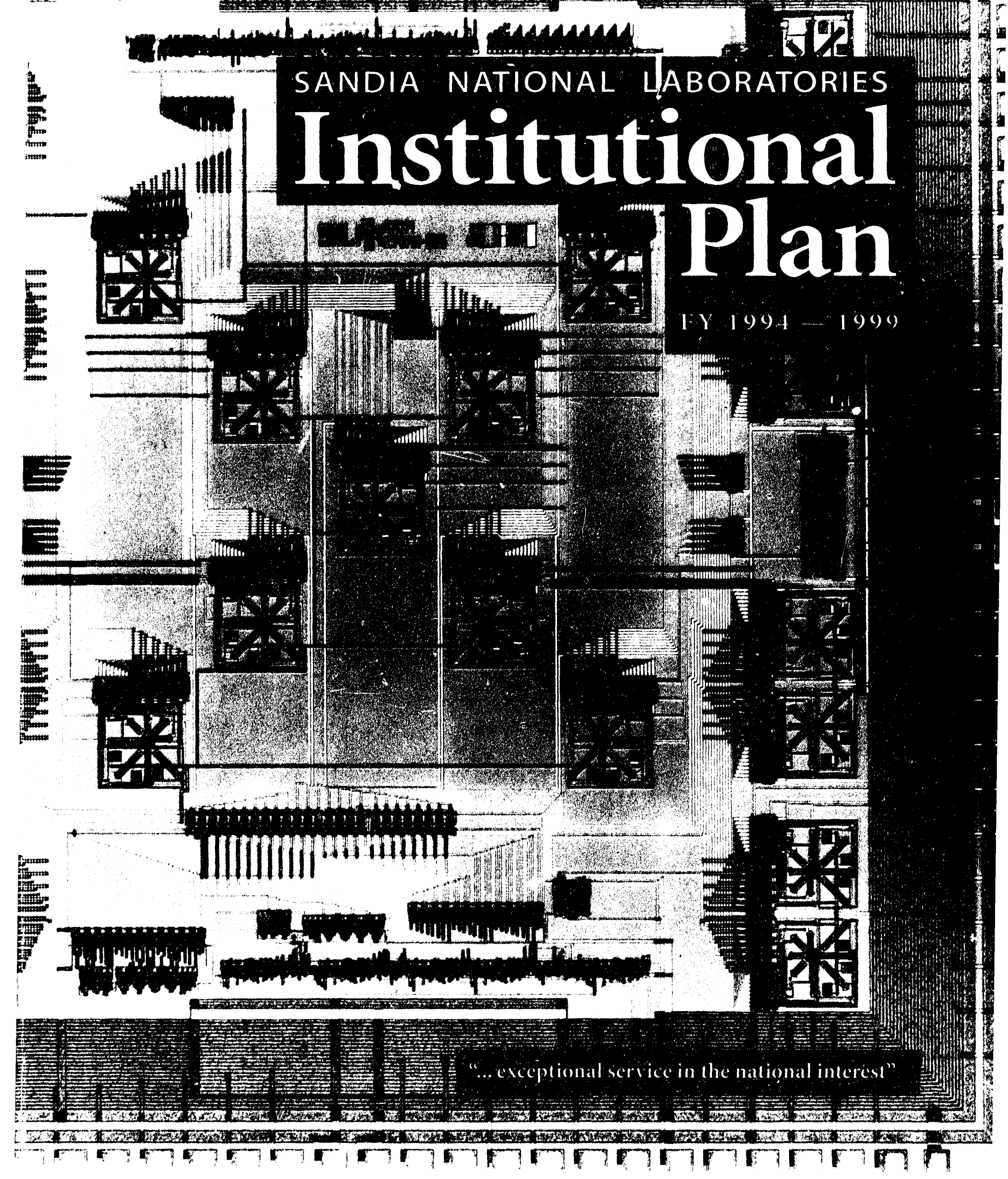


$\begin{array}{lr}\begin{array}{l}\text { Director of Strategic and Operational Planning } \\ \text { Manager of Institutional Planning }\end{array} & \begin{array}{r}\text { Joel Weiss } \\ \text { Bruce Dale }\end{array} \\ \text { Photographers } & \begin{array}{r}\text { Randy Montoya } \\ \text { Mark Poulsen }\end{array} \\ \text { Design and Production } & \text { Kay Rivers-Stroup } \\ \text { Illustrator } & \text { Carl Hamberg, TRI } \\ \text { Publications Administrator } & \begin{array}{r}\text { Debbie Johnson } \\ (505) 844-4902\end{array}\end{array}$

On the cover/title page:

The ATCO4 is the latest member of a family of assembly test chips designed and built by Sandia National Laboratories. These chips are used by the microprocessor industry to monitor microelectronics packaging processes and assist in the development of new packaging technologies. These chips contain a variety of sensors that can determine whether the assembly and packaging of semiconductor devices have resulted in any damage or functional degradation. Transducers measure such conditions as corrosivity, mechanical damage, electrostatic threat, mechanical stress, bond pad degradation, and moisture content.

The ATC 04 contains an array of 25 stress sensing cells, approximately 200 micrometers on a side, with a diode thermometer in the center of each cell. Each cell contains four n-type and four p-type piezoresistors for mechanical stress measurement and a diode for temperature measurement. The chip also contains two ring oscillators. Cells are individually and sequentially addressable. Measurements are made using a four-terminal or Kelvin technique, with two connections for a current source and two for a voltage measurement device.

Assembly test chips are used by the microelectronics industry in three ways: as manufacturing line Monitor in evaluation of new micro packaging techniques, and as electronic system monitors over years of use.

This device is a product of Sandia's core competencies in microelectronics and photonics, engineering sciences, processes and materials, and computational sciences. It also represents Sandia's strategic thrusts in advanced manufacturing technology and electronics. This work was recognized by R\&D Magazine with a 1993 R\&D 100 award.

SAND93-2069

DOE Distribution Category UC700 


\title{
SANDIA NATIONAL LABORATORIES Institutional Plan
}

FY 1994-1999

\author{
Albuquerque, New Mexico \\ Livermore, California
}

October 1993

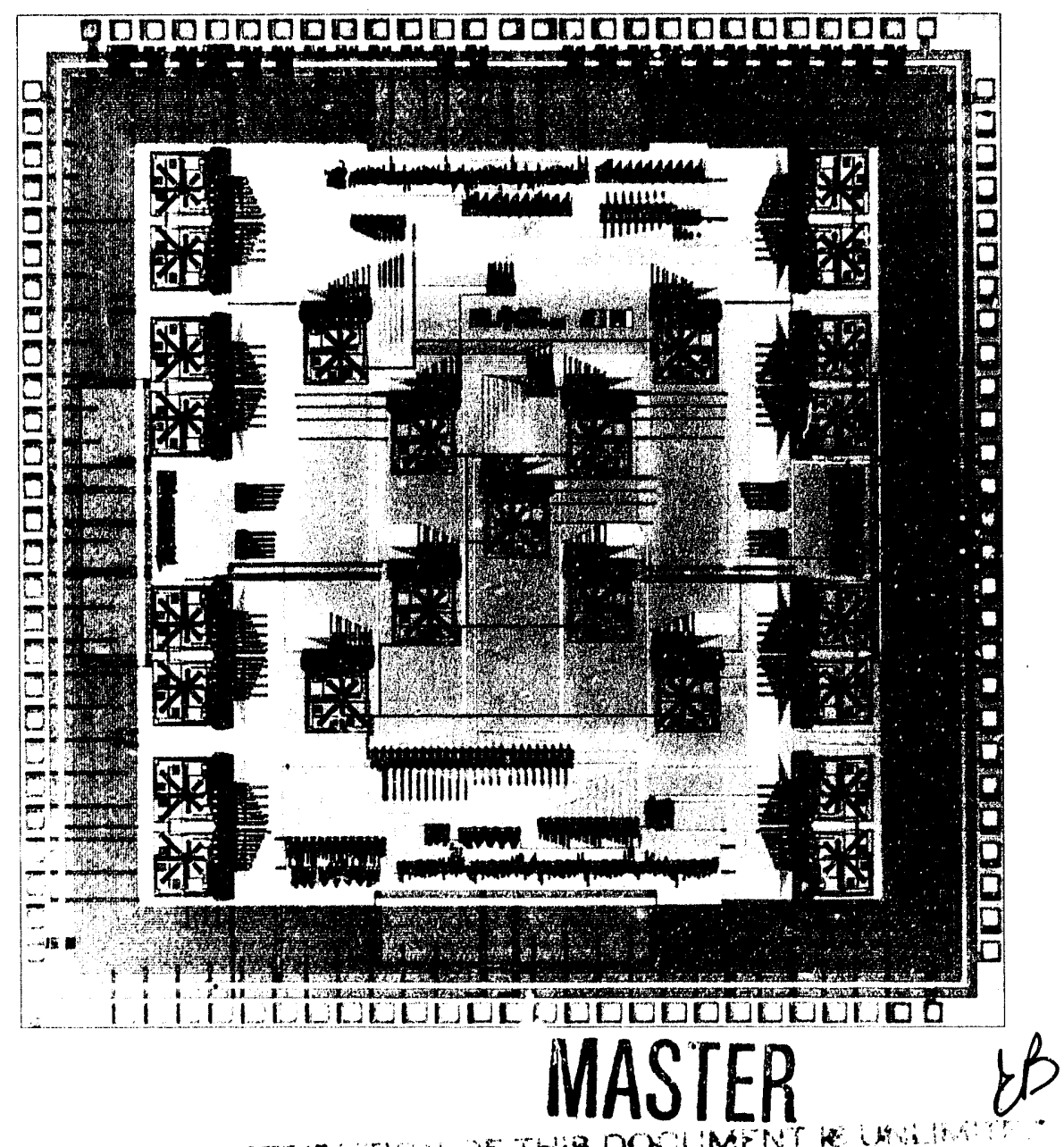

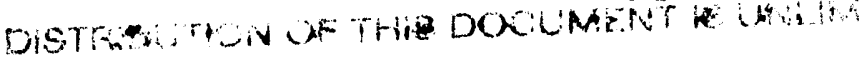




\section{Contents}

President's Statement $\quad$ 1-1

$\diamond$

$\diamond$

$\diamond$

Executive Overview

$\diamond$

Laboratories Strategic Plan

4-1

$\diamond$

Major Initiatives

5-1

Advanced Manufacturing Technology

Electronics

$5-13$

Information and Computational Technology

$5-25$

Transportation Energy Technology and Infrastructure

$5-35$

Environmental Technology

$5-40$

Energy Research and Technology Development

$5-48$

Biomedical Systems Engineering

$5-60$

Post-Cold War Defense Imperatives

$5-63$ 
Programs for the Department of Energy

Weapons and Waste Cleamup Programs

$7 \cdots 2$

Assistant Secretary for Defense Programs

$7-5$

Office of Intelligence and National Security

$7-46$

Office of Environmental Restoration and Waste Management $\quad 7-52$

Energy Programs

$7-60$

Assistant Secretary for Energy Efficiency and Renewable Encrgy $7-60$

Office of Civilian Radioactive Waste Management 7-65

Assistant Secretary for Fossil Energy $\quad$ 7-66

$\begin{array}{ll}\text { Office of Nuclear Energy } & 7-68\end{array}$

Science and Technology Programs $\quad 7-70$

Office of Fnergy Research $7-70$

Office of Science Education and Technical Information $7-80$

Work for (Other Department of Energy Locations, Contractors, and Offices 7-88

Work for Non-DOE Entities ("Work for Others") 7-90)

Department of Defense $7-9()$

Nuclear Regulatory Commission $\quad 7-96$

$\begin{array}{ll}\text { Department of Transportation } & \text { 7-97 }\end{array}$

National Aeronautics and Space Administration 7-99

Department of State $\quad 7-100$

Environmental Protection Agency $\quad 7-100$

$\begin{array}{ll}\text { Other Federal Agencies } & 7-101\end{array}$

All Other Reimbursables $\quad 7-102$

Laboratory-Directed Research and Development Program 7-103

Information Resources Management 8-1

$\diamond$

Environment, Safety, and Health

9-1

$\widehat{\gamma}$

Human Resources Management

10-1

$\diamond$

Sites and Facilities

11-1

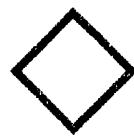

Resource Projections

12-1 


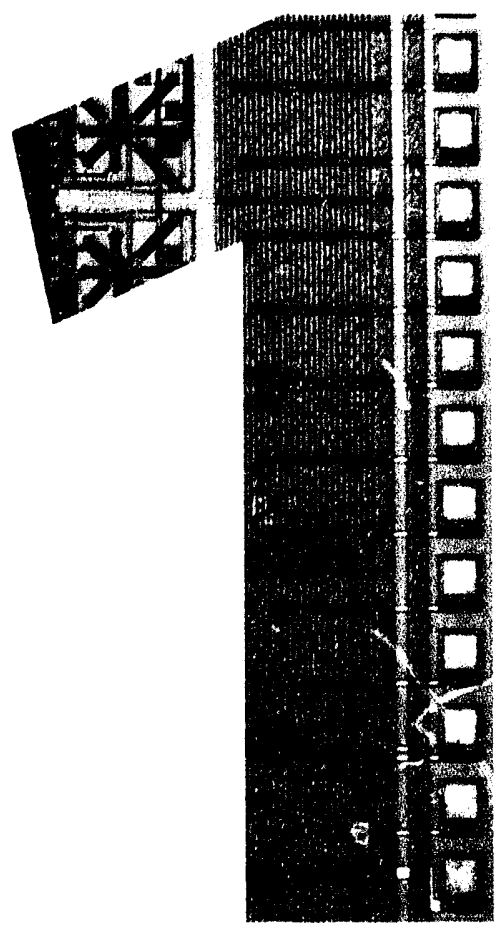




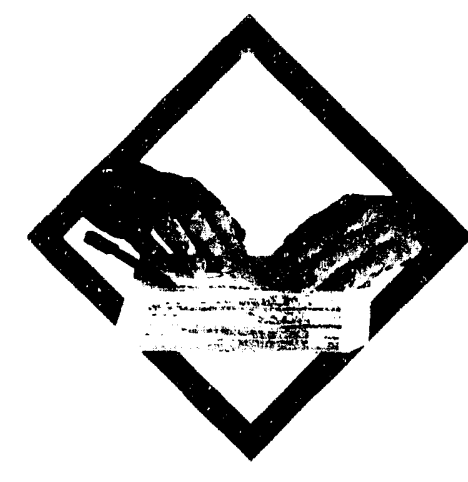

\section{President's Statement}

Sandia began a new era on October 1, 1993, when Martin Marietta Corporation took over operating and management responsibilities for the Laboratories from A'T\& T. AT\&'T served the nation well during its tenure, and Martin Marietta will continue the dedication to "exceptional service in the national interest" that has always characterized Sandia's work.

The new management team faces a formidable challenge. Post-cold war economics dictate a substantial contraction in defense research and development, and the nuclear weapons complex must bear some of that burden. The Department of Energy national laboratories must learn how to execute their enduring mission responsibilities in an environment of diminishing resources.

The challenge we face as managers is to implement the changes needed to address this reality without eroding the capabilities that support the Laboratories' ability to perform. We share this challenge with DOE. Sandia and the other DOE Defense Programs laboratories embody the technical capability of the nation to respond prudently to strategic uncertainties, both in the requirements for future deterrence and in the risks of nuclear confrontation anywhere in the world. The future of these laboratories must be planned and managed very carefully.

The Department of Energy is taking bold steps

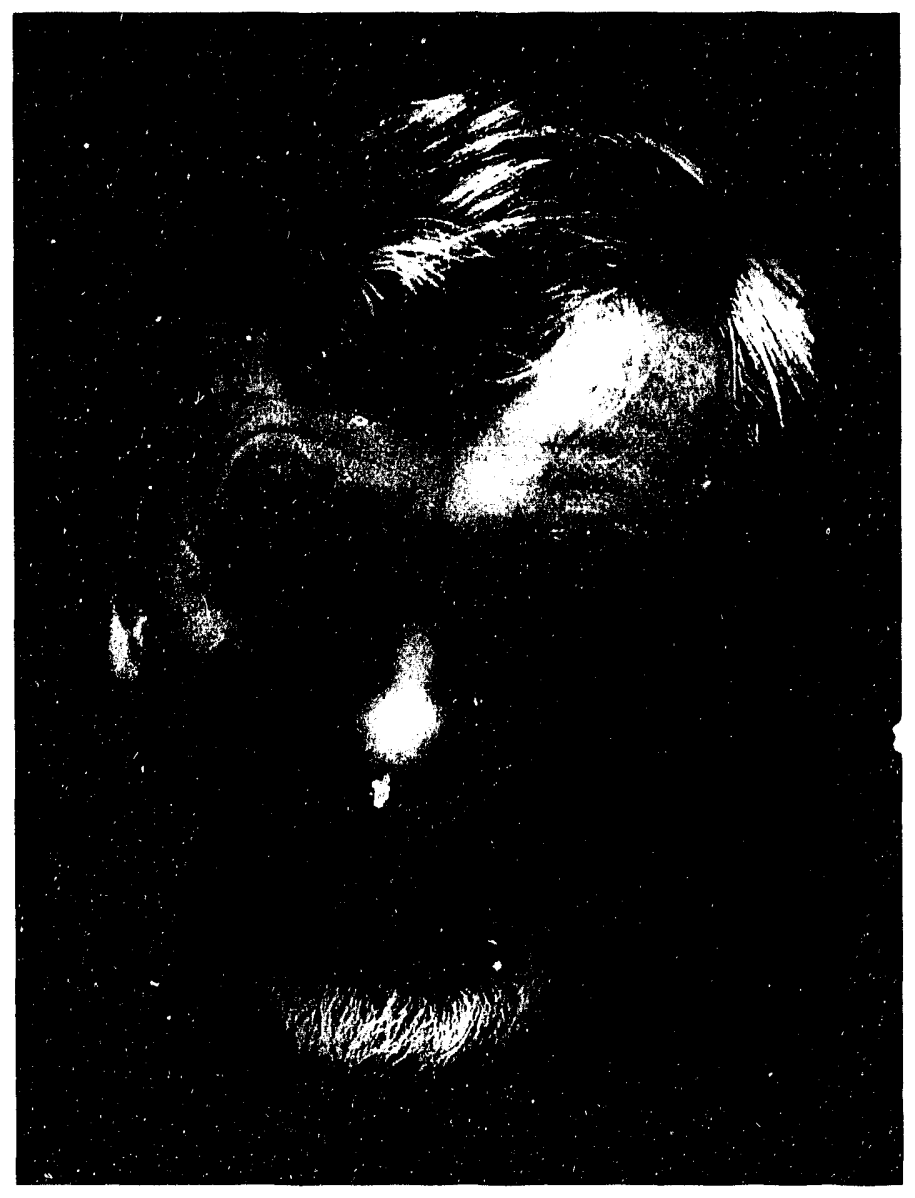


to reshape the way it does business in order to meet the challenge's of the future. Its core values and mission put the customer first and emphasize the importance of people as the ultimate creative resource for solving national problems. I)E's customer is, of course, the taxpaying public as represented by its elected officials. This has always been truc, but in the past this fact was not internalized as a motivational focus.

I believe the Department of Energy is undergoing fundamental change. If it succeeds with this change process - a redefinition of what it is and how it does business - the Department will become a leadership force for meeting the science and technology needs of the nation in the next century. It is our intention to belp DOE succeed, as it must, for the good of the nation.

Four years ago, we at Sandia also made a commitment to change. We adopted the principles of Total Quality Management to improve our performance, stretch our shrinking resources, and increase our efficiency. We established processes to evaluate our performance in terms of our customers' expectations. We now apply the scoring system of the Malcolm Baldrige award criteria to laboratory performance, and we benchmark our progress against that of other world-class rescarch and development organizations.

But even with improvements in efficiency and execution, the Laboratories will not have sufficient resources from the nuclear weapons program alone to sustain the capability and facilities required for responsible stockpile stewardship. However, the technology base that supports the nuclear weapons stockpile features core competencies that have enormous dual-use potential. Consequently, our strategy will be to base our program portfolio on the core competencies that we need to fulfill our nuclear weapons mission responsibilities, and we will manage all of our work to produce technologies that are applicable to civilian sector needs as defined by the federal government and U.S. industry.

To implement this strategy and help the Department of Energy project leadership for the technology needs of the next century, we will pursue eight strategic initiatives that crosscut our customer base and address large-scale technology problems facing industry and the nation:

Advanced Manufacturing Technology - A robust manufacturing sector will always be the foundation of our nation's security. As the federal government responds to industry's need for technologies to fuel advances in the manufacturing sector, it is logical that it should turn to the DOE laboratories as a resource.

Sandia has become the leader among federal laboratories for advanced manufacturing technologies as a consequence of its responsibilities in design engineering, production process development, intelligent machines research and development, and oversight of most U.S. nuclear weapon components. Sandia's National Center for Advanced Manufacturing Technology, National Center for Advanced Information Components Manufacturing, and the Integrated Manufacturing Technologies Laboratory at Sandia/California all support the requirements of DOE and industry for technology and process development in manufacturing.

Electronics - Advanced electronics is essential for modern weapon systems, and an indigenous capability for microelectronics manufacturing is key to our economic security.

Sandia's electronics capabilities and programs are a comprehensive integration of the entire electronics component realization process. ()ur outstanding capabilities in this arena are unmatched among DOE laboratories.

Sandia's Microelectronics Development Laboratory, Semiconductor Equipment 'lechnology Center, Microelectronics Quality and Reliability (enter, and other facilities are significant national resources. We are a contributing team player with industry in developing processes for flat-panel display manufacturing and soft $x$-ray lithography, technologies that have the potential to provide a competitive advantage. A substantial portion of our program consists of cooperative arrangements with SEMATECH and industry associations for precompetitive technology development that helps the entire U.S. microelectronics industry. 
Information and Computational Technology-Computational simulation has always been important to Sandia's national security and energy missions. But its potential impact on commercial manufacturing is likely to be on the scale of a new industrial revolution. In the future, it will be cheaper, more accurate, and much faster to use computational technology for product design and production than contemporary experimental or trial-and-error methods.

Sandia's Massively Parallel Computing Research Laboratory has led the development of massively parallel computing algorithms and applications since its award-winning introduction of massively parallel techniques for real engineering applications in 1987. The laboratory currently houses the world's fastest parallel processing computer, and it leads in the development of algorithms for large-scale engineering and industrial problems. The Center for Computational Engineering at Sandia/California is an interdisciplinary group helping industry with problems in chemistry, materials, and biochemical modeling.

Transportation Energy Technology and Infrastructure - Transportation issues are closely related to the goal of improving national economic performance. (ireater energy efficiency and an improved national transportation infrastructure would help realize gains in productivity and reduce environmental impacts.

Sandia has performed lead functions in transportation for the Department of Energy for many years, particularly in technologies associated with the safe and secure movement of defense materials. Our strengths in real-time control systems, failure and risk analysis, and sensors and remote monitoring can be useful in integrating the design requirements of vehicle systems.

Sandia's Combustion Research Facility has been active in energy-related issues associated with internal combustion engines since the 1970s. And our experience in developing long-life, high-energy batteries for nuclear weapons makes us a valuable partner in the industry-led search for a practical battery for electric vehicles.

Environmental Technology - The D)E laboratories have a mission responsibility to develop solutions for problems in waste management, site remediation or stabilization, and enviro'mentally conscious manufacturing and to share those solutions with industry. Environmental issues associated with manufacturing and waste management are at the top of industry's agenda. Solutions must be technically feasible and affordable if they are to be widely adopted.

I believe that industry will ultimately be made responsible for the environmental consequences of its products in the complete cycle from fabrication to disposal. Sandia has taken a leadership role in introducing environmentally conscious design and manufacturing into the nuclear weapons production complex. We are now having to design for product disposal, as well as for product function. We have researched and developed substitutes for materials and processes that formerly required or generated hazardous wastes, such as fluxless soldering and safe solvents. Some of these processes are now being widely adopted by industry.

Energy Research and Technology Development - Energy security is a vital component of national security. Sandia is one of the nation's premier contributors to energy technology, particularly in renewable energy (such as solar, wind, and geothermal), fossil energy, and nuclear power - always with the goal of minimizing environmental impacts.

We are at a threshold of significant new thrusts in renewables, building on our pioneering successes in this area. For many years, Sandia has operated the National Solar Thermal Test Facility' for 1 OE, and we provide support to industry for the development of Solar Two, a utility-scale solar power tower. Sandia's Photovoltaic Design Assistance (enter has helped U.S. manufacturers compete in the emerging international market for photovoltaic systems. We are also collaborating with industry and the Bonneville Power Administration to expand commercial utilization of geothermal resources in the Pacific Northwest. 
Renewable energy designs must be easily manufacturable to be commercially viable. Sandia's rich capability in manufacturing engineering and systems design brings an industrial focus to renewable energy research and development that is unmatched at any other 1 ) OE laboratory.

Biomedical Systems Engineering - Health care costs in the United States are increasing rapidly and are one of the factors impeding U.S. economic competitiveness. The proper application of advanced technologies to biomedical engineering could significantly reduce some aspects of cost without compromising or rationing health carc.

The core competencies that support our $10 \mathrm{OE}$ missions frequently have application to problems in biomedical engineering. For example, we have demonstrated that pattern recognition algorithms for identifying military targets can be modified to help detect tumors in $x$-ray images. High-speed computation can quickly reduce imaging data and help physicians "see" internal organs. We have used technology developed in the weapons program to create a noninvasive glucose sensor that has been transferred to industry for commercialization.

Post-Cold War Defense Imperatives - The proliferation of weapons of mass destruccion is a serious challenge to international stability and peace. Sandia will expand its efforts in intelligence and treaty-verification technologies. The Center for National Security and Arms Control, now under construction at Sandia/New Mexico, will house the largest aggregation of intelligence, nonproliferation, and arms control research and development work in the world.

Other post-cold war developments will also require adjustments and new work. The recently extended moratorium on underground nuclear testing will require upgraded capabilities for aboveground simulation so Sandia can continue to certify weapon components for radiation environments. Nuclear weapon use-control systems must be enhanced to support a smaller stockpile with greater flexibility. We must meet and exceed public expectations for weapons safety in transportation and staging. Nonnuclear component manufacturing must be reconfigured to be more cost-effective. These new requirements, which stem from fundamental changes in nuclear weapons policy, are primary responsibilities of Sandia and will be vigorously pursued.

As much as possible, all of this work will include a high degree of collaboration with industry, universities, and other federal laboratories through cost-sharing arrangements. Moreover, we will help support the research and development needs of small and mid-level businesses through special cooperative arrangements and technology out-reach programs.

The fraction of our total workload devoted to technology transfer is growing rapidly. Industry partners who were initially attracted to Sandia by the match of our core competencies to their needs are finding that we not only have something to offer, but that we can work effectively with them. Similarly, we have discovered that our own capabilities are enhanced by this synergy. We are striving to achieve the greatest possible utilization of laboratory capabilities to meet defined national technology goals. In doing so, we will sustain the research foundations and integrated capabilities that will define the future of this institution.

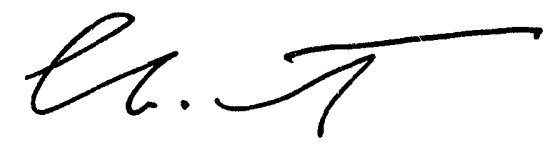




$$
2
$$




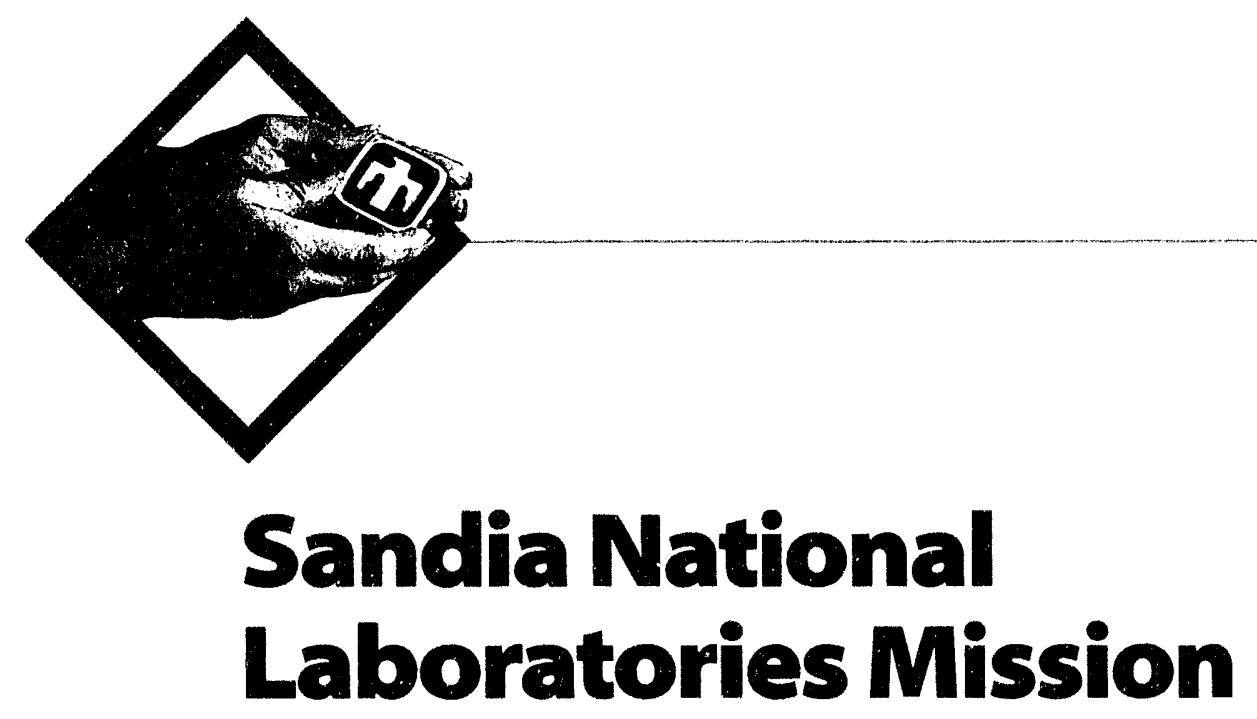

In 1949, President Harry Truman suggested that the management and operation of what is now Sandia National Laboratories afforded an opportunity to offer "exceptional service in the national interest." This ethic has served as our guiding principle and strategic intent over the years.

Consistent with this intent, the mission of Sandia National Laboratories is

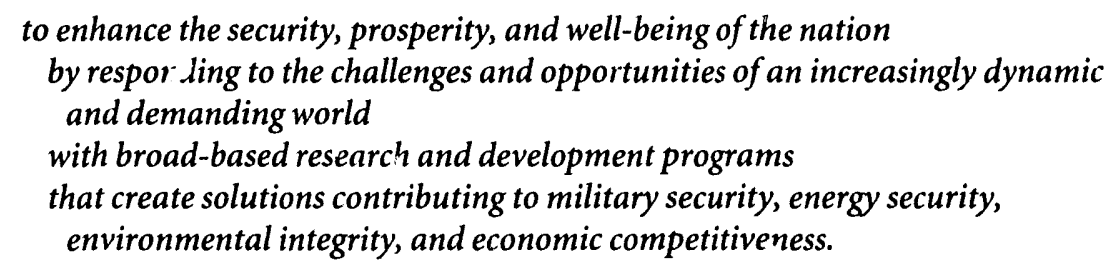

Our longest standing program (within the military security mission area) is to implement the nation's nuclear weapon policies through research, development, and testing in nuclear ordnance, arms control, and weapon surety. As a Department of Energy multiprogram laboratory, we also serve the nation through a variety of programs that directly contribute to both national energy security and environmental integrity. By working in partnerships with industry and academia based on "road maps" generated by industry, Sandia is able to assist in the development of multiple national infrastructures (such as manufacturing, information and transportation systems, and cost-effective health care technologies) that are critical to our mission of economic security and that also are key to the objectives of programs in Sandia's other mission areas. In this context, Sandia technologies and contributions exhibit a "dual-use" character.

All of Sandia's programmatic contributions are based on a set of core technical competencies that are the product of the integrated expertise of laboratory staff and the special facilities in which they work. These core competencies are a part of the Department of Energy's technology base that supports DOE missions and other national technology initiatives. The research foundation categories for these competencies are:

- Engineered processes and materials

- Computational and information sciences

- Microelectronics and photonics

- Engineering sciences

In addition to the contribution of each research foundation to each program within each mission area, the integrated capabilities that have been developed at Sandia to service program needs have demonstrated a special distinctiveness for this laboratory. Some of these integrated capabilities are: 
- Surety technology (safety, security, and control)

- Experimental, computational, and analytical evaluation

- Advanced manufacturing technology

- Pulsed power technology

- Engineered systems

A primary objective in all of Sandia's programmatic responsibilities is to exceed customer expectations for performance, cost, and schedule. To ensure the accomplishment of this objective, staff who are involved in each program area (and in each cross-cutting functional area such as environment, safety and health; human resources; and facilities management) work to continuously improve the performance of processes that are key to success. This commitment to Total Quality Management is made to customers representing essentially every organization within the Department of Energy as well as a diversity of other federal agencies, including the depariments of Defense, Commerce, Transportation, and State; Environmental Protection Agency; Nuclear Regulatory Commission; National Institutes of Health; and National Aeronautics and Space Administration. A growing number of both individual private companies and industry consortia also benefit from the value of technology transferred from Sandia.

\section{Mission Focus}

\section{Established Responsibilities}

Established responsibilities include programs that add value directly to the nation's security, in cooperation with the private sector where appropriate, and for which the federal government is the principal customer.

- Nuclear weapons programs (Department of Energy and Department of Defense)

- Stewardship for and development of an evolving nuclear weapons stockpile

- Implementation of new structures and approaches to meet the smaller production requirements of the future

- Development of arms control and nonproliferation technologies, and analysis of intelligence

- Restoration of contaminated Sandia sites to a state of compliance with applicable environmental laws and regulations

- Energy and environmental programs (Department of Energy and the Nuclear Regulatory Commission)

- Improvement of the economics, safety, and environmental compatibility of energy conversion and utilization

- Development of waste management solutions and technologies for industrial waste reduction

- Work other than for DOE ("Work for others")

(Department of Defense, other federal agencies, and nonfederal entities)

- Application of unique Sandia capabilities to help other federal government agencies and nonfederal entities (such as state and local governments, private industry, and universities) succeed in their missions

- Technology transfer 


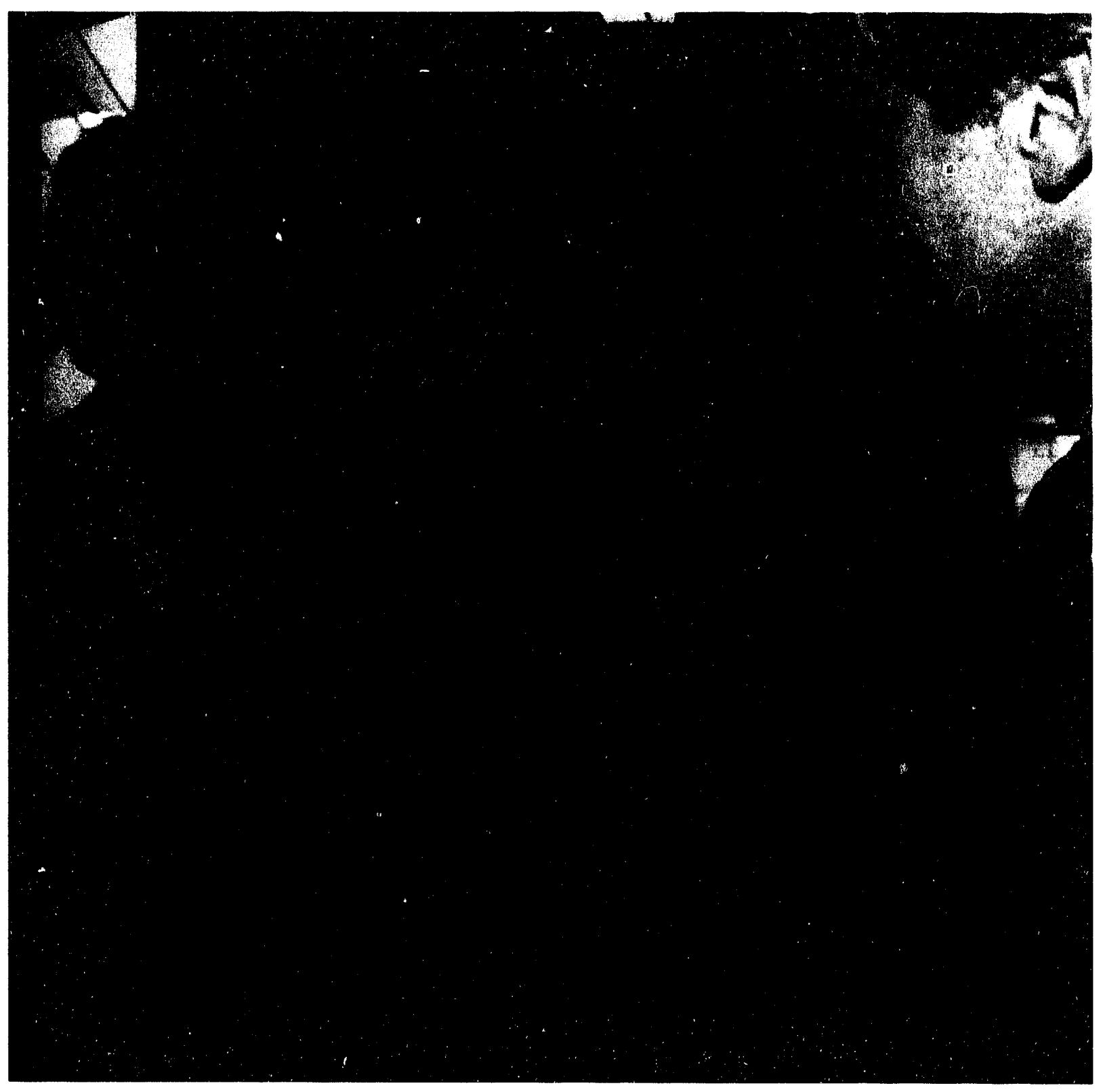

Presidential candidate Bill Clinton and Sandians AI Narath and Paul Robinson discuss a printed circuit board that was fabricated using environmentally conscious manufacturing techniques pioneered by Sandia. The circuit board is a product of the Laboratories' emerging responsibilities in advanced manufacturing technology and electronics, and its established mission responsibility in environmental technology.

\section{Emerging Responsibilities}

Emerging responsibilities include programs in partnership with industry that enhance the safety, security, reliability, and cost-effectiveness of multiple national infrastructures and that directly contribute to Sandia's established mission responsibilities. These efforts are key to enhancing the 
global competitiveness of U.S. industries. The private sector will be an important judge of the value of Sandia's contributions.

- Advanced manufacturing technology

- Electronics

- Information and computational technology

- Transportation energy technology and infrastructure

- Biomedical engineering

\section{Approach}

\section{Program Prioritization}

Sandia will concentrate on challenges and opportunities that add value to the nation. In addition, it will-

- Respond rapidly to national emergencies and other urgent government requirements

- Build on and strengthen Sandia's core technical competencies and other essential Laboratories capabilities

- Anticipate emerging trends and proactively help sponsors and customers invent their future

- Provide teamwork opportunities with industry, universities, and other institutions

- Create synergies among Sandia's program sectors and functional organizations

\section{Program Execution}

Sandia strives to achieve customer delight by meeting or exceeding expectations and by -

- Emphasizing our corporate values of teamwork, integrity, quality, leadership, and respect for the individual, and demonstrating our commitment to the safety of the individual and environmental protection

- Realizing continuous improvement of the Laboratories' performance, guided by Malcolm Baldrige National Quality Award criteria

- Taking maximum advantage of the special characteristics of the New Mexico and California laboratories and other Sandia locations

\section{Mission Assignments}

Sandia's missions for DOF encompass five major categories of a tivity:

1. Research, development, and engineering associated with advancing nuclear explosives to integrated, functional weapons for Dol) weapon delivery systems (nuclear ordnance). Activities include component development, design definition, and systems integrattion; nuclear weapon surety, including safety, command and control, and security; evaluation of new weapon concepts; testing and weapon effects simulation; production and dismantlement support; and stockpile surveillance. 
2. Other DOE defense-related programs, including the development of verification and control technologies to support progress towards arms reduction agreenents and to provide intelligence on foreign technologies and weapon systems; concepts and systems for the safeguarding and security of nuclear materials and assets.

3. Research, development, and engineering of technologies for safe storage, processing, transport, and disposal of hazardous and radioactive wastes from nuclear materials and weapons production; development of manufacturing processes and substitute materials to minimize hazardous by-products in the production of nonnuclear components of nuclear weapons; research, development, and engineering of processes and technologies for remediation and restoration of weapon production sites.

4. Implementation of the National Energy Strategy through rescarch and development of concepts for increasing energy efficiency in utilization, storage, and transmission; securing future energy supplies through improved recovery technigues, conversion technologies, and development of alternative energy sources; protecting the environment through characterization and assessment of environmental change phenomena and research and development of cost-effective technology applications for ameliorating environmental degradation; fortifying the foundations of our national energy strategy by deepening our understanding of the basic energy sciences, improving the mathematics and science education opportunities of our youth, and enhancing the general technical literacy of the public.

5. Supporting the economic security of the United State: by helping U.S. industry compete effectiv ly in international markets through the transfer of federally owned or originated technology to private industry, state and local governments, and universities or nonprofit organizations.

An important part of our mission also includes performing work for entities other than the Department of Energy when such work contributes directly to a DOE program or is judged to exercise and strengthen Sandia's capabilities in areas germane to our DOE missions. Such work is frequently an effective means of accomplishing technology transfer, a mission assigned to the lab-. oratories by the 1989 amendment to the Atomic Energy Act. It provides access to Sandia's unique facilities, services, and expertise and often makes available technology developed in the nuclear weapons program that is not obtainable from industry, university, or non-DOE government sources. 



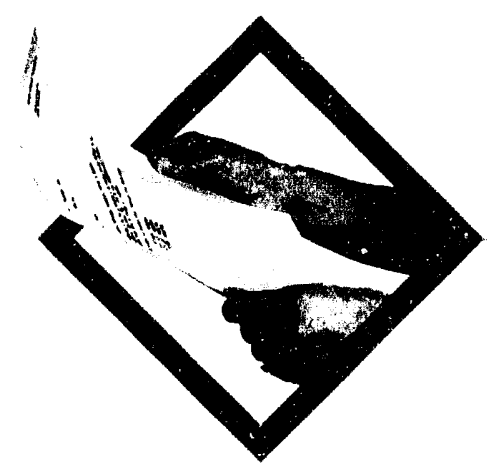

\section{Executive Overview}

Sandia National Laboratories, operated for the United States Department of Energy, is one of the nation's largest and most diverse research and development laboratories. In 1979, it was designated by Congress as a multiprogram national laboratory. Martin Marietta Corporation succeeded AT\&T as Sandia's management and operating contractor on October 1, 1993.

\section{Total Quality Management}

Total quality is Sandia's overarching management and operating philosophy. Quality is more than one of Sandia's five corporate values; it is an ethos and a methodology that permeates all of our programmatic and institutional activities.

'This commitment to total quality management is stated in the Laboratories' quality policy:

To be the best demands that we integrate quality in all our work. At Sandia National Laboratories, we apply the following quality fundamentals, consistent with sound business practices, to reinforce our reputation for excellence:

Provide the greatest value to our customers by understanding and meeting their expectations.

Not only must we satisfy our customers' spoken and written requirements, we must understand our customers' needs and how the rustomers' expectations influence their perception of quality with respect to cost, schedule, and performance. T'o ensure customer satisfaction, both internal and external, we must continually review our customers' expectations while negotiating their requirements.

Focus on prevention rather than correction.

While fixing problems as they arise is important, preventing problems from occurring is the goal Therefore, we must approach each task with the appropriate amount of planning to consider potential problems and to build prevention into each step of the process.

Measure progress using data.

Metrics are needed to set objectives, monitor our processes, assess customer satisfaction, and ensure that resources are focused on the most "value-added" areas. We will judge our performance against the best using the Malcolm Baldrige National ( Quality Award criteria to measure our progress.

Contimually improve our skills, processes, products and services.

Quality improvement is ongoing. As our customers' requirements change, our capabilities 
must change accordingly. (ontinually learning and improving our skills will allow us to service our customers better. Since all work is part of a process, we must continually' seck ways to improve our work to provide the highest value products and services to our customers.

Committing to this policy requires some means of ascertaining that we are actually implementing it. Our guiding principles for implementing quality at Sandiat are the Malcolm Baldrige National Quality Award criteria. In 1992, S.ndia submitted an application for the AT'\&T' (hairman's ( )uality Award (AT\&T"s equivalent of the Malcolm Baldrige Award). (Our score was 429, which is very good for a research and development laboratory undergoing rapid change. We are using the opportunities for improvement identified in the feedback from our application to advance our rate of progress in quality implementation. This feedback is referred to as "Baldrige feedback" in this cliscussion.

Sandia will prepare a Baldrige assessment for scoring and feedback in 1994 and continue to use the Baldrige principles and processes for guidance.

The seven examination categories of the Malcolm Baldrige National (Quality Award are a useful construct for systematically assessing our progress towards meeting the goals of our quality policy.

\section{Category 1-Leadership}

Sandia's president, vice presidents, and directors of Quality, Human Resources, Planning, and Environment, Safety, and Health, compose the Sandia ( Quality Council, which meets monthly to identify and measure activities that will ensure success in advancing our rate of quality progress. Members of the Sandia Quality Council extensively promote the Laboratories' commitment to quality outside Sandia with special emphasis on the application of quality in a research and development environment. To demonstrate their commitment to total quality management, the president and his management council created, published, and distributed a corporate strategic plan in 1990) that emphasized quality. In 1993, our quality policy was updated, signed by the president, and distributed to employees.

Corporate values and customer focus are the basis of Sandia's organizational structure. Sandia is organized into three program sectors that account for all the programmatic work performed at the Laboratories. The three sectors and their major responsibilities and customers are:

- Defense Programs Sector-Provides for the stewardship and development of the nation's nuclear weapons stockpile; implements new approaches to meet the smaller nuclear weapon production requirements of the future; and develops arms control and nonproliferation technologies and analysis of intelligence.

Principal customers:

- DOE Defense Programs

- DOE( )ffice of Intelligence and National Security

- DOE (Office of Environmental Restoration and Waste Mannagement

- Energy and Environment Sector - Performs research and development to improve the efficiency, safety, and environmental compatibility of energy conversion and utilization; develops waste management solutions and technologies for industrial waste reduction. Principal customers:

- 1)( ) : linergy lifficiency and Renewable linergy

- 1)(o) (office of linergy Research

- 1)(O) loossil Energy

$-1)(0)$ Nuclear linergy 
- DOE Office of Envi "mental Restoration and Waste Management

- DOE (Office of Civ" ?adioactive Waste Management

- Nuclear Regulatory commission

- Work-for-Others Sector-Applies unique Sandia capabilities to assist other government agencies in solving their problems.

Principal customers:

- Department of Defense

- Department of Transportation

- National Aeronautics and Space Administration

- Other governt:lent agencies

This structure was implemented to increase cur ability to address customers' requirements. Indicators of how well the structure is meeling those requirements are based on employee and customer-satisfaction data.

Each of the three program sectors is overseen by a sector manager who is a Sandia vice president. Because Sandia employs a program/function matrix, these vice presidents have organizational obligations in addition to their program sector management responsibilities. There are a total of ten corporate organizational divisions, managed by vice presidents, all of which support the program sectors. The support they provide may be in the form of direct programmatic work, technical support, administrative support, or laboratory indirect activities.

Corporate organizational divisions support sector programs. The intended result is that the program sectors and their customers are the focus of all laboratory activity. This structure institutionalizes the Total Quality Management requirement for a dominant customer focus throughout the organization.

Strategic direction is provided by the Sandia Management Council (SMC), chaired by the Laboratories' president. SMC establishes corporate goals and makes decisions for infrastructure, capital, and staffing requirements for the ten-year planning horizon. It establishes the long-term strategy for core competencies and core support activities. The council integrates corporate policy with business planning requirements and projected customer needs.

The activities of the three program sectors are coordinated in the Sandia Program Council, chaired by the laboratory director. The Program Council develops direct program guidance for the three-to-five-year planning horizon. It anticipates funding and spending trends and sizes laboratory resources appropriately. It plans for core competency and core support needs and develops short-term strategies for investment or disinvestment in core competencies and technical support capabilities. The committee also onursees Sandia's laboratory-directed research and development (L.DRD) program and resolves cross-sector issues.

Sandia is a member of the National Laboratories (ommittec on Improving Laboratory Performance, a coordinating group made up of representatives of the 1 ) (o) Laboratories. This committe meets to conduct comparative evaluations and share best practices.

Public responsibility is very important to Sandia and is also an important part of the leadership category of the Baldrige criteria. This responsibility is demonstrated in our policy on the health and safety of workers and the public as w'ell as the protection of the environment. (Our ES\&H (Environment, Safety, and Health) Policy, approved by Sandia's president, clearly states this responsibility.

Based upon the Baldrige feedback, a multi-disciplinary Sandia team developed seven comprehensive recommendations for accelerating our rate of progress in quality. The Sandia Quality Council enthusiastically adopted these recommendations. Relative to the lededership category, the recommendation adopted was, "I )evelop and review at every Sandia ( Quality ( Council meeting metrics that are corporate-ivide, results-focused, and customer-oriented." These metrics provide 
measures of actual accomplishments against goals for important facets of our work and are being reviewed at each meeting.

\section{Category 2-Information and Analysis}

Sandia's quality improvement process rests on a foundation of systems for collecting, andylying, and disseminating data and information that will help Sandia better meet its customers reguirements. 1) ata related to corporate planning, program and project planning, product and service quality, human resource planning, and compliance performance are used in all three program sect irs. IVe use this information to measure, evaluate, and control processes; to foreciast performance and results; and to identify opportunities for improvement. Kach program sector has a support office to manage such data.

From the Baldrige feedback, the recommendation to "develop a Hexible system that facilitates management decision-making based on data" was presented and adopted by the Sandia (2uality" Council. Key managers from the program sector offices are completing the development of this system and have begun to implement aspects of it.

Benchmarking, an important element of this category, cuts across all of the other caltegories as well. Again from the Baldrige feedback came a recommendation, now adopted and being implemented, to "benchmark one key process each from corporate-wide processes, each sector, core competencies, and critical support services." Benchmarking is critical to world-class performance, and Sandia is measuring its processes against those of leaders in many fields and adjusting according to the results.

\section{Category 3-Strategic Quality Planning}

Sandia has engaged in planning for many years. Sandia's plans have taken an institutional perspective, describing the range of technical and administrative activities in progeess, along with initiatives, facilities, and taffing reguired to pursue new technical work up to five years into the future. These five-year plans are rolled forward one year at a time. 'Typically, these decuments incorporate continuous trend plamning assumptions.

As Sandia approached the 1990), changes in its external enviromment began to occur at an accelerating rate. 'The probability that significant discontinuities might be experienced increased dramatically. In recognition of these new realities, Sandia undertook its first truly strategic plamning effort. Wr helieve that this and subsequent efforts incorporated many of today's modern quality principles: continuons improvement, customer satisfaction, employee satisfaction, and yuality by design.

Sandia's tirst strategic planning effort inwolved all of its top management team. The effort produced a strategic plan that was notable both for its visionary content and for its brevity. The plan incorporated a mission statement that broadened the laboratories' traditional focus on the defense aspects of national security by challenging it to enhance "the security, prosperity, and well-being of the nation." The plan also articulated a statement of corporate value's and a set of strategic corporale objectives. (Quality, in all its aspects, was considered and wowen into these values and objectives.

To carry through on commitments outlined in its first strategic plan, Sandial created organizations devoted to quality and to the orderly management of change. It also developed the Sormdia Quality Policy, stated earlier. Every employee was given a copy of the strategic plan.

In the spirit of entinuous improvement, new planning processes were executed during 1992. To supplement the original strategic plan, we now have al one -page statement explaining the mission,

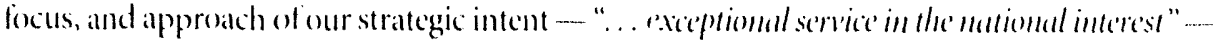
developed with input from 120 employees at all levels of the laboratories. 


\section{Sandia Sector Management Structure}
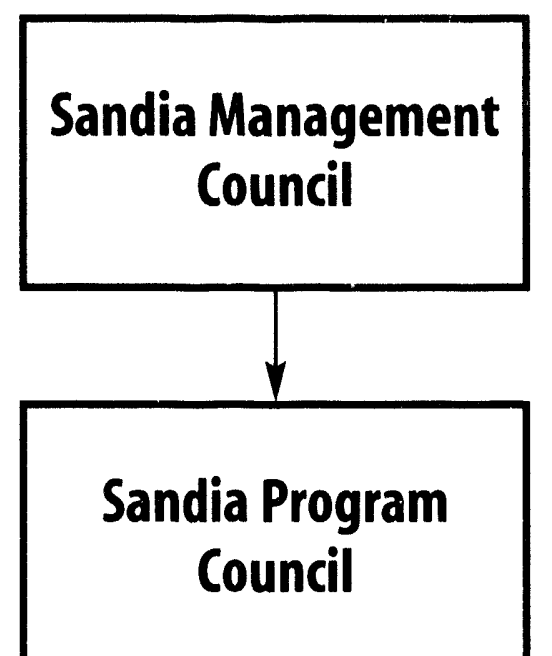

Plans and directs technical programs and core support and core competency functions. Provides input to the management of indirect programs. Creates strategies for program development and investment or disinvestment in the 3-5 year horizon.

Develops corporate strategies in the 1-10 year horizon and establishes corporate goals and policies. Integrates corporate policy, plans, and long-term customer needs. Makes major laboratory and site decisions.

Conduct technical programs for sponsors. Develop customer interactions and satisfy customer expectations. Ensure core competency support. Negotiate resource requirements with division manlagers.

Execute or support sector programs. Build and maintain organizational resources and capabilities.

\section{Laboratory Divisions}

In parallel with this planning process, Sandia brought in a nationally known firm to perform an employee satisfaction survey and analysis. The "Stanek Survey" provided management with much diagnostic information that has been used to develop training programs and provide feedback on managerial behariors. We will repeat this survey to measure the degree to which our efforts have resulted in greater employee satisfaction.

We are now engaged in designing our business planning process with yuality principtes in mind. Our business plans will, of necessity, focus on customers' needs and the products and services the laboratories offers to meet their needs. Business plans will provide program mantagers and organizattions with clearer direction, and consequently should positively impact employeces' satisfaction. 


\section{Category 4-Human Resource Development and Management}

Sandia recognizes that its employees are its most important strategic asset in mecting customer requirements and fulfilling its strategic intent of "exceptional service in the national interest." We are committed to the quality principle that the degree to which Sandia meets the requirements and achieves employee satisfaction will be the degree to which Sandia meets customers' requirements.

To support Sandial's performance in human resource management, we completed our first Strategic Humban Resource Plan in 1992. The plan was developed by a cross-functional team representing all parts of Sandia. The team based the plan on recuirements gathered from executive management, a random sample of other managers, and the 1991 Sandia Perspective, which documented survey results from employees and selected members of management. This plan will guide our actions in human resources in four key areas: staffing, performance management, leadership and management development, and diversity. The plan will be updated periodically to assure continuous relevance and a hieve continuous improvement.

Based on the Baldrige evaluation, we developed and adopted the following activity in this category: "Use industry 'best practices' to establish a corporate education and training program." Important elements of this activity include the development of a laboratory-wide education policy and a mechanism for funding the implementation of this policy.

A second human resources category activity based on the Baldrige evaluation is to "align the performance and recognition system with the corporate values and sector goals." Implementation of this recommendation began with the establishment of a performance management system for all vice presidents and directors.

As part of the Baldrige categories involving corporate metrics, we will be conducting regular employee satisfaction surveys, similar to the 1991 Sandia Perspective survey, to provide more Hexibility in administration and shorter cycle time in responding to results.

\section{Category 5-Management of Process Quality}

Sandia's approach to managing process quality is tailored to fit the particular product or service delivered to the customer. We identify customer expectations, clarify them through discussion, and translate them into specific requirements. Although all program sectors use standard project management techniques, including multilevel work breakdown structures, task metrics, and critical path networks, individual approaches will vary depending on the sector and customer requirements.

Our largest sector, Defense Programs, has evolved an claborate prevention-based system to assure the safety, performance, and reliability of U.S. nuclear weapons. (ireat rigor, attention to exacting requirements, well-defined processes, exacting engineering development, and extreme attention to all aspects of quality have been the hallmarks of this work for over forty years.

All three sectors use a graded approach to determining the level of formality to use in meeting customer requirements. In the Work-for-()thers and Energy and Environment sectors, requirements for some activities (such as the Yucca Mountain and Waste Isolation Pilot Plant nuclear waste repository projects) are set by statute.

Customer requirements are often subject to change during the life of programs and projects. The Baldrige feedback provided us an opportunity to improve in this areal and resulted in the development and adoption of a recommendation to "develop a structured but flexible approach to managing customer interfaces." The three sectors are implementing this recommendation through structured approaches to customer interactions, defined responsibility in interactions with customers, customer databases, and customer satisfaction surveys. We anticipate improved ability to achieve customer satisfaction through these new approaches to customer interfaces. 


\section{Category 6-Quality and Operational Results}

In the Defense Programs sector, a key product metric of interest to customers in the departments of Energy and Defense is the reliability of the weapons in stockpile. The emphasis on reliability starts with the weapon development program and continues through the entry of weapons into stockpile. Reliability assessments are made by an organization that is independent of design responsibility. Continuous quality improvement has led to significant improvements in all indicators, such as decreases in component failure, decreases in average defects per weapon, reduced need for tests in the stockpile evaluation program, and a downward trend in investigations of significant findings.

In the Work-for-Others sector, the Aerospace Systems Development program and the Remote Sensing and Verification program have identified key measures for product or service puality. For Aerospace Systems Development, the key measure is the percentage of Hight test objectives met. This measure indicates a continuous trend upward for over twenty-four years. For Remote Sensing and Verification, mean time between failures for flight payload is measured. This key measurement indicates a failure rate of less than one per billion operating hours. A mission failure has not occured in thirty years of fielding satellite systems.

Sandia has an excellent history in meeting customer cost, schedule, and performance requirements. Success depends on the support of internal organizations including Information Systems, Purchasing, and Facilities and Maintenance to make this quality success possible. These organizations are making greater use of customer satisfaction surveys to identify and implement opportunities for improvement.

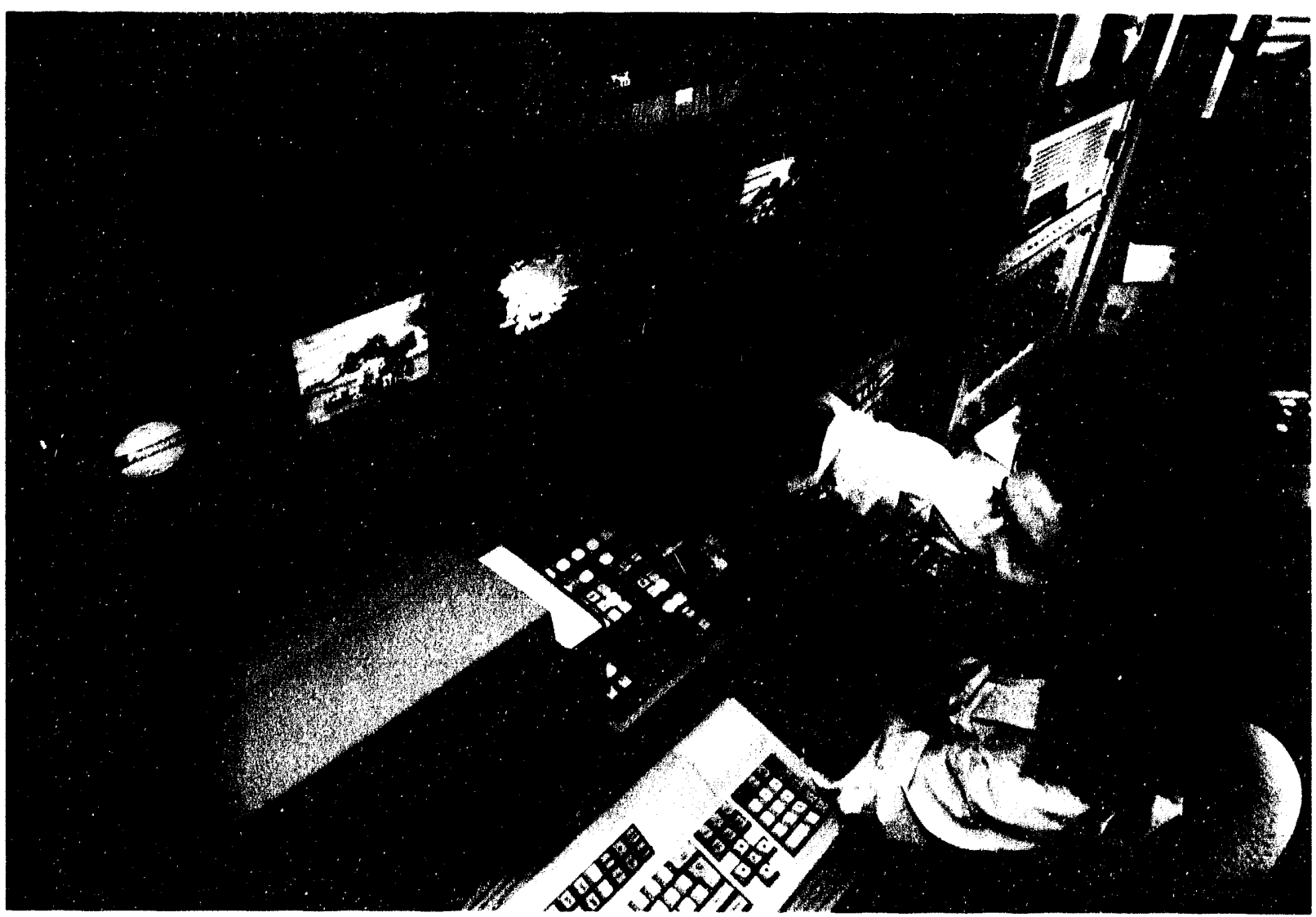

Quality techniques and the quality ethos are being propagated throughout all Laboratories' activities. Video technician Regina Valenzuela was one of those recognized during National Quality Moıth for success in applying quality principles to their work. 


\section{Category 7-Customer Focus and Satisfaction}

The Department of Energy is Sandia's principal customer. The Department of Defense is also a key customer. There are many other $\mathrm{DOE}$ and reimbursable customers for Sandia's products and services. Newly emergent among our customers are private sector partners in cooperative rescearch and development and other beneficiaries of our technology transfer efforts. Sandia is implementing a process to manage customer interfaces to achieve continuous improvement in customer focus and satisfaction. Each program sector has developed specific organizations and processes for providing customer focus.

The development and implementation of the DOE Laboratory Appraisal System for Sandia was a direct effort to improve the extant appraisal process. We worked directly with $\mathrm{D}$ (OE to develop and introduce the improved process. An important aspect of this new process is that D()E co-owners are invited to attend Sandia appraisal team meetings.

We are working with DOE on the appraisal process to put greater emphasis on costs. In the future, funding for nuclear weapons programs will almost certainly decline, and we are using the appraisal system to jump-start cost reduction activities.

Sandia's commitments to its Defense Programs customer begin with directives and interagency agreements and are implemented through formal requirements, documents, and procedures. These commitments are for the life of a weapon.

The primary commitment with work-for-others customers is the reimbursable agreement signed by Sandia and approved by 1 OOE. All reimbursable proposals and agreement packages are reviewed for quality, ability to perform, and adherence to DOE and federal requirements.

The growing number of industrial and other private-sector partners in unclassified research and development will have profound effects on the way Sandia interfaces with customers. This trend will require cultural change, changes in procedures for controlling new types of information, and physical changes to sites and facilities, including the development of more open laboratory campuses in a research park environment in both New Mexico and California.

\section{Core Competencies}

Sandia's core competencies represent a distinguishing integration of skills, capabilities, technologies, and facilities needed to perform the Laboratories' mission and achieve strategic objectives. They make it possible for the Laboratories to attack a wide variety of technical problems, and they represent a complex harmonization of individual skills and technologies that would be very difficult for other laboratories to duplicate. Each of our core competencies makes a significant contribution to the value of the products and services for which Sandia is responsible, and many groups within Sandia rely upon the Laboratories' core competencies to accomplish their work.

Our core competencies model is a matrix of research foundations and integrated capabilities. Research foundations provide the technology base on which the Laboratories' integrated capabilities depend. Because this technology base represents specific disciplines, each of the foundations can be managed for optimum utility and technological leadership. Integrated capabilities are more diffuse and represent endemic and unique laboratory differentiators.

In this model, core competencies are jointly managed at the intersecions of the matrix by managers who maintain research foundations and those who exercise laboratory integrated capabilities.

\section{Research Foundations}

Engineered Processes and Materials - synthesis, characterization, and processing of metallic, ceramic, organic, and composite materials: A distinguishing strength of this competency is 
the development of advanced materials and processes that are tailored to meet the specific needs of an application. Facilities include the Applied Materials Laborattory, which is jointly managed by Sandia, Los Alamos National Laboratory, and the University of New Mexico.

Computational and Information Sciences- - technologies to advance the state-of-the-art in computer use while maintaining the accuracy, security, and accessibility of information: I )istinguishing strengths of this competency include the development of advanced computing networks and facilities, computational methods for emerging computer technologies, mathematical techniques for information surety, and computer-based techniques for intelligent machines. lacilities include the Massively Parallel Computing Research Laboratory and Central Computing Facility.

Microelectronics and Photonics - technologies required for the development, fabrication, and production of microelectronic and photonic devices: Distinguishing strengths of this competency include materials growth and development, device design, fabrication technologies for silicon and compound semiconductor devices, and design of processes and equipment for the manufacture of integrated circuits. Facilities include the Microelectronics Development Laboratory, Compound Semiconductor Research iaboratory, and Center for Microelectronics Technologies.

Engineering Sciences - fluid and thermal sciences, solid and structural mechanics, radiation transport, aerospace sciences, geosciences, and combustion sciences: A distinguishing strength of this competency is the development of interdisciplinary capabilities and an integrated computational and experimental approach for solving complex engineering problems. Facilities include the Fluid and 'Thermal Sciences Laboratories, Experimental Mechanics Laboratory, Experimental Aerodynamics Laboratory, Geosciences Laboratories, and the Combustion Research Facility.

\section{Integrated Capabilities}

Surety Technology - technology to deliver products that meet the highest levels of safety, security, and control: Extensive use is made of systems and engineering analysis, computational modeling and simulation, reliability methods, quality assurance, and safety and probabilistic risk assessment. Applications of this competency are distinguished by the simultaneous optimization of safety, security, and control. Examples of these applications include nuclear weapon design and surety assessment, development of technologies and security systems for the protection of nuclear materials and facilities, reliability assessment of semiconductor manufacturing equipment, and probabilistic risk assessment of nuclear reactors.

Experimental, Computational, and Analytical Evaluation - experimental, computational, and analytical methods to perform the numerous kinds of evaluation that are required during the development, production, retirement, and disposal of engineered systems: The required types of cvaluation include problem solution, performance validation, process design, and system safety and reliability assessment. Applications of this competency are distinguished by an integrated use of engineering mechanics, physical simulation and testing methods, computational and numerical methods, risk and safety assessment methodologies, and measurement and diagnostic techniques. These applications often require expertise ranging from fundamental research through full-scale system testing.

Advanced Manufacturing Technology-technology to meet the manufacturing needs of U.S. industry and the nuclear weapons complex: Examples of such needs include concurrent engineering, intelligent machines for hazardous and Hexible operations, computer-aided 
design/engineering/manufacturing, engineered processes and materials, environmental protection and control, and an infrastructure to support product realization. The applications of this competency are distinguished by an emphasis on precompetitive research and development for market-driven technologies, which are guided by the reconfiguration of the nuclear weapons complex and industry-led consortia such as SEMATECH, USCAR, and the Specialty Metals Processing Consortium.

Pulsed Power Technology - technology to generate and apply energetic beams and high-power energy pulses: It is distinguished by the development of repetitive pulsed power technologies, $\mathrm{x}$-ray and energetic beam sources, and electromagnetic and radiation-hydrodynamic codes for a wide variety of applications. Examples of these applications include nuclear survivability and hardness testing, light-ion beam inertial confinement fusion, materials processing, waste and product sterilization, and food purification. Facilities include the Saturn X-Ray Source, Hermes III gamma ray source, and the Particle Beam Fusion Accelerator II.

Engineered Systems - technologies to design complex, relatively unique products to meet customer needs that may be only partially defined: This is accomplished by integrating the engineering design disciplines with the fabrication and production technologies required to implement a design as a real product that meets a specific customer need. This competency is distinguished by the ability to catalyze and focus research, systems studies, and engineering design on the unique challenges presented by the requirements of the customer. It also provides the crucial link between our technical and infrastructure capabilities that results in prototype development, testing, documentation, and transfer of production capability to the customer.

In addition to providing the basis for the products and services Sandia provides to its customers, our core competencies also serve as a continuing source of new initiatives. An example is the initiative, Technology Information Environment for Industry (TIE-IN, see page 5-31). The objective of this initiative is to extend the benefits of Sandia's diverse scientific and engineering capabilities to the six million small and medium size companies in the United States. Its success will depend critically on advances in the Computational and Information Sciences and Engineering Sciences research foundations, as well as the Surety Technologies and Experimental, Computational, and Analytical Evaluation integrated capabilities.

Funding for the enhancement of Sandia's core competencies is obtained from multiple sources, including the Defense Programs Research and Development progran and Basic Energy Sciences. Additionally, Sandia has earmarked a significant fraction of its Laboratory-Directed Research and Development program for enhancing core competencies. When a proposal is submitted to this program, it is reviewed for its technical content and potential contribution to the strength of Sandia's core competencies. Only proposals that exhibit technical excellence and hold potential for advancing the laboratories' core competencies are funded.

\section{Facilities}

The Laboratories' executive management offices and larger laboratory complex are on Kirtland Air Force Base at the southeastern edge of Albuquerque, New Mexico. This site, referred to as Sandial New Mexico, comprises five technical areas and an expansive outdoor testing field covering 17,750 acres. This location benefits from its proximity to other major defense laboratories and testing facilities and the emergent high-technology industrial climate in the Rio Grande research corridor.

Another Sandia laboratory complex in Livermore, California, occupies 413 acres at the eastern edge of the San Francisco Bay area. The site benefits from its proximity to world-class research 
universities and the intense high-technology environment of the region. Sandia/California is strategically important to the Laboratories' missions by serving as a window to the leading industrial centers of the West Coast and a connection to the challenges of twenty-first-century urban Americi.

Sandia operates a wide variety of technical facilities, the collection of which constitutes one of the world's premier research, development, and testing complexes.

Extensive research laboratories in the physical and chemical sciences, materials and processes, computational and computer sciences, microelectronics and photonics, pulsed power, and the engineering sciences contain the most modern instrumentation and laboratory equipment. Similarly, extensive engineering development laboratories contain unparalleled facilities for component development, particularly in electronics, manufacturing, and processes.

Collectively, Sandia's array of environmental testing facilities is not duplicated anywhere in the world. In addition to shock, temperature, vibration, and acceleration test facilities used to subject a variety of components and systems to a wide range of extreme environments, the Laboratories operates a variety of special-purpose test facilities, some of which are unique. Examples include a radiant heat facility; a multiple-stroke lightning simulator; a low-field, broadband electromagnetic radiation facility; blast tubes capable of operating from 1 to 2000 pounds per square inch; a facility to provide large quantities of molten metal oxides for studying nuclear reactor accident conditions; light-initiated and other high explosives test facilities; a 5000-foot aerial cable for impact tests; a 10,000-foot rocket sled track; and two of the world's largest centrifuges.

Many of Sandia's specialized facilities constitute major national resources, utilized for a variety of both defense and nondefense research and development programs. A few examples include:

- A full range of computing facilities, from modern workstations to the leading capability in massively parallel computing, to support the Laboratories' pervasive use of computation for the simulation and modeling of complex phenomena and concurrent research, development, and engineering;

- A sophisticated multi-vendor corporate inter-network and comn 'mications infrastructure providing ready access to Sandia's supercomputers and storage servers from both the California and New Mexico locations and their distributed networks;

- Robotics laboratories for basic scientific research and engineering development of prototype advanced systems with application to DOE weapon production efforts, ST'ART'-mandated nuclear weapon dismantlement activities, and to retrieving and repackaging radioactive wastes;

- Facilities and equipment to study semiconducting and other specialized materials, including the Center for Microelectronics Technologies and the Integrated Materials Research Laboratory;

- Advanced facilities for materials synthesis and growth, processing, and diagnostics, including molecular beam epitaxy and metallorganic chemical vapor deposition growth, accelerators for ion-beam analysis and ion implantation of surfaces, solid-state and gas-phase lasers for spectroscopy and remote sensing, and numerous surface analytical techniques for microstructure and materials property analysis;

- Advanced manufacturing technology capabilities - including the Integrated Manufacturing Technologies Laboratory and the National Center for Advanced Information Components Manufacturing - for developing integrated and agile solutions to manufacturing problems with both industrial and government partners; dual-use and commercial relevance are priority requirements as we look to the future; 


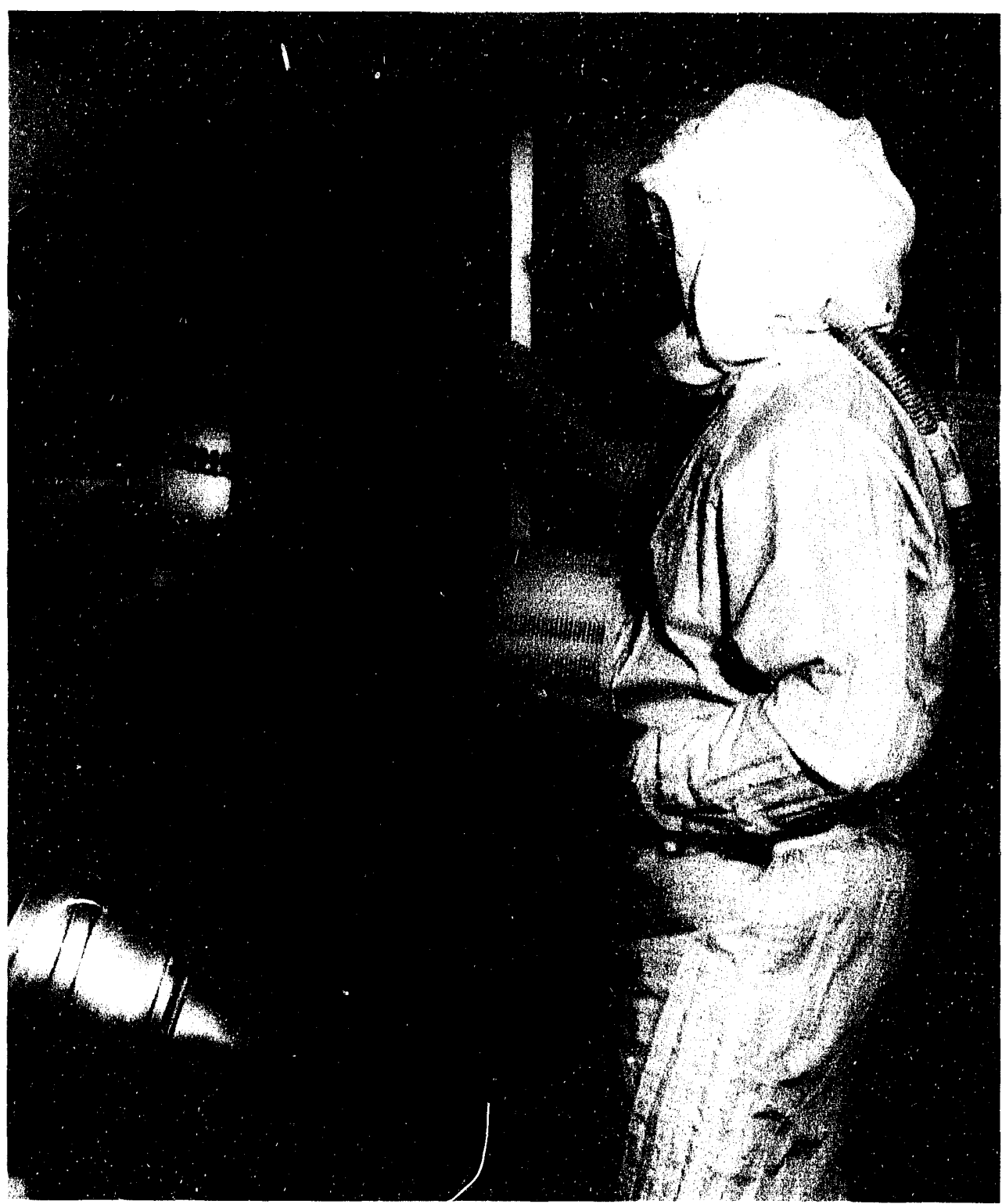

A technician extracts a 6-inch diameter silicorı disk from a metal deposition system at Sandia's Microelectronics Development Laboratory ciass-1 clean rorsm.

- The Combustion Research Facility 11 California, which is addressing problems in combustion science, energy, and the environment;

- The National Solar Thermal Test Facility and other solar thermal facilities for testing both central and distributed receivers and studying high-temperature materials and processes;

- An advanced photovoltaics facility for testing both flat-plate and concentrator systems;

- Reactor facilities to simulate internal environments of power reactors and to evaluate the effects of nuclear weapons on components; 
- Pulsed-power accelerators - including the Particle Beam Fusion Accelerator II (PBFA II), the Saturn $x$-ray simulator, and the Hermes III gamma-ray accelerator - to simulate nuclear weapon effects and to study pulsed power approaches to fusion energy; and

- Dedicated facilities and test equipment at DOE's Pantex plant in Amarillo, 'Texas, for quality assurance and stockpile evaluation operations.

Sandia's 900 buildings provide laboratory, shop, and office floor space of approximately 5.9 million square feet, most of which is located on about 30 square miles of the southern part of Kirtland Air Force Base. At original acquisition cost, the facilities available at Sandia represent nearly $\$ 1.5$ billion of U.S. government assets, consisting of about $\$ 900$ million in capital equipment, more than $\$ 500$ million in buildings and structures, and more than $\$ 50$ million in utilities and land improvements. The investment in technical equipment amoun s to more than a quarter million dollars per technical employee.

As its mission evolves, Sandia, like other national laboratories, is working much more closely' with U.S. industry than ever before. Relationships with industrial partners require easier site access and appropriate security management. We are exploring concepts for changes in campus configuration at both our New Mexico and California sites to facilitate access by industrial users. Changes are likely to affect classified and unclassified business areas, traffic circulation, parking, and other infrastructure. A significant investment will be required to perform this site conversion work to improve the logistics of working closely with industry on national, industry-lead initiatives.

\section{Staff}

Even more than the laboratories and facilities, the heart of every research and development organization is its technical staff. Our nearly 5,300 technical personnel are drawn from all disciplines of engineering and the phrsical sciences. Averaging almost 15 years of service to the nation, the staff represents an impressive store of almost 78,000 man-years of experienced technical talent. That reservoir of expertise has produced more than 60 patents during the past two years alone.

About 60 percent of the 3,750 Members of Technical Staff have engineering backgrounds, with the majority holding degrees in electrical, mechanical, or chemical engineering. The remaining 40 percent provide expertise in a variety of technical disciplines, including nuclear engineering, mathematics, physics, computer science, aeronautics, and materials science. Almost 80 percent of the Members of Technical Staff have earned graduate degrees, $45 \%$ of which are Ph.1).s, many awarded by the very top universities.

Supporting the professional technical staff are 1,550 technicians who bring to our work hands-on technical experience across a variety of technical specialties. Administrative and indirect support is provided by more than 800 Members of Laborator; Staff, 900 Administrative Staff Associates, and 1,550 graded employees who perform the many necessary security, craft, maintenance, and clerical functions.

While most of our nearly 8,600 employees are based in New Mexico, about 1,000 are employed at our (alifornia facility; another 150 personnel comprise small groups at the DOF: Pantex plant in Amarillo, Texas, and at our testing sites at Kauai and Tonopah.

By being greater than the sum of its parts, the exceptional combination of outstanding technical staff and unmatched research, development, and testing facilities continues to permit us to leverage technology to address important national problems. 


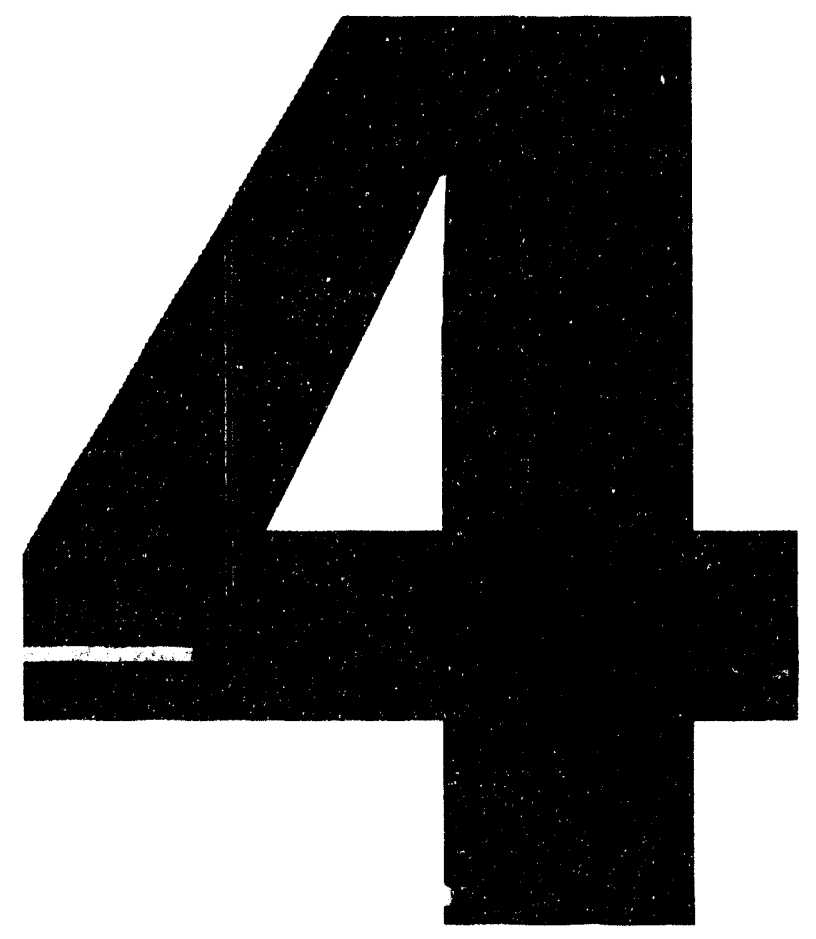




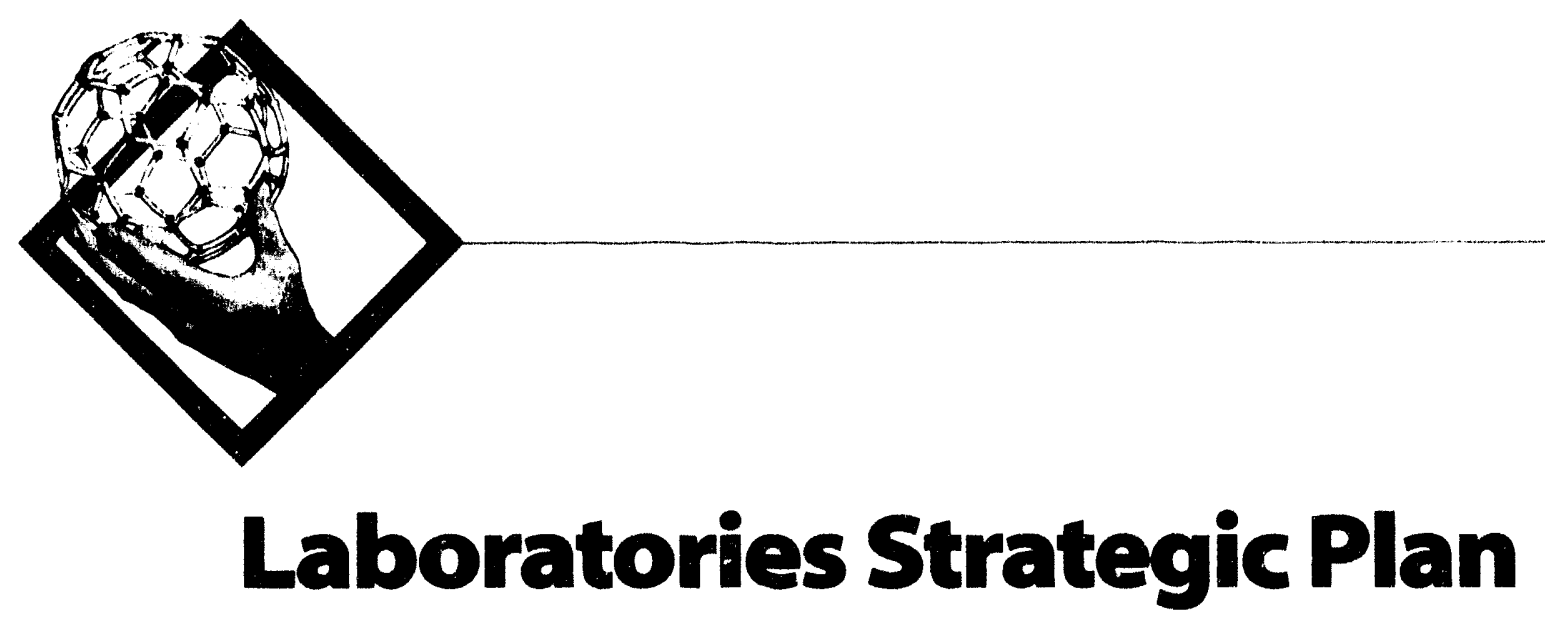

Sandia was chartered in 1949 with the sole purpose of supporting the development, production, and stockpiling of nuclear weapons. Today, Sandia National Laboratories is an extensive, multiprogram, multiple-location, research and technology development organization. The genesis of Sandia's technical diversity can be traced to its attempts to stay ahead of what Theodore Levitt calle! "fast history":

More than ever before, [organizational] survival and success require getting comfortable with a rapidly arriving and disruptive future, but a future that cannot be specifically foretold ... Things change and always have changed. Fast history is an environment of intensifying and unexpected changes, of rapid acceleration. This creates special problems and also special opportunities.'

To help prepare for a future with diverse n'w challenges, management established a formal strategic planning process in 1989. In early 1990, Sandia's first high-level strategic plan was developed, beginning a process of reassessment and cultural change throughout the organization. (We expect to revisit and update the high-level strategic plan in the fall of 1993 after Sandia's new managing contractor takes over.)

In 1991, management continued strategic planning with an examination of the Laboratories' strategic intent and core competencies. After the DOE Tiger Team visit and assessment that year, management refined its strategic intent and commissioned an exhaustive reevaluation of core competencies that continued through 1992 and into 1993. In 1993, the Laboratories' programmatic sectors began formalized program planning. The cumulative results of Sandia's concerted planning efforts are presented in this chapter.

\section{Situation Analy'sis}

We live in a time when changes in national priorities are creating unrest and anxiety. The outlook for the nation's long-term economic vitality is unclear. The American public is becoming increasingly averse to risk. Many people doubt the veracity of the policy-making process and question the value of government-supported institutions. Confidence in science and technology is diminishing.

A principal impediment to increasing prosperity and employment in the United States arises from the aspirations, energies, and competencies of other nations that appear to be managing their national resources more strategically than we. The aspirations of other nations cannot and should not be ignored. In the long run, our nation may well benefit from the intensity of effort demanded by global competition and the resultant technological progress. While technology by itself cannot

\footnotetext{
I'Theodore levitt, Thinking About Management, The Free Press, New York, 1991, p. 70.
} 
ensure conomic growth, it is cortainly a major determinant of envirommentally' sustainable prosperity in any industrial society. However, scientific and technological altivities do not antomatically conhance prosperity in direct proportion to the nation's investment in those activities.

We are beginning to understand that spontaneous creation of national wealth firom the fruits of scientific inquiry and technological exploration is simply too slow and inefficient a process in today's fast-paced, ruthlessly competitive global conomy. While scientific rescarch may stimulate revolutionary discoveries, it does not, by itself, provide the linkages and incentives for sustained commercial exploitation of new breakthroughs.

Given this understanding, and the increasing skepticism of the public, it is no surprise that the social contract that has guided the U.S. scientific and rescarch community is changing. As Hagships of $t^{\prime}$ ' research community, the I )epartment of Energy national laboratories are confronted with the challenge of focusing their science and technology to provide tangible benefit to the nation's economic, infrastructural, and social spheres to a degree that will help sustain prosperity over the long term.

The Secretary of Energy stated our challenge thus:

Our challenge within the I epartment of linergy, and its national laboratorics, is to draw out the vast and diverse technol gical capabilities that have been amassed over the past five decades in the interests of defense needs, scientific investigations, and energy research, and to structure new ways to quickly support the important national goal of enhancing our economy and international competitiveness:

In acepting this challenge, we must avoid the hubris of believing that technology can solve all problems. Technology provides tools; the cultural, social, and political dimensions of our national problems must be properly addressed to permit effective utilization of these tools. Mloreover, some national problems simply cannot be effectively addressed by technology.

Still, there are technical dimensions to most large-scale nattonal problems. $A$ systems approach that integrates supporting technologies in an interdisciplinary, multi-agency, multi-sector assault may hold the only realistic hope of solution for some probleins. ()pportunities abound for sub-

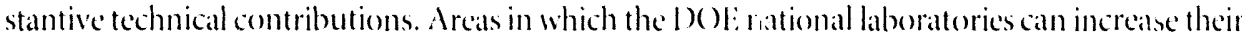
impact on national well-being indude military security, encigy and environmental security, and economic security.

\section{Military Security}

The global power eyuation has changed dramatically. The consecuences of that change have forced national security planners to rethink the fundamentals of our strategie posture.

The domestic political climate has also shifted. At a time when it has become difficult to foresece workl events that may atfect the security of the nation, we are constrained lo plan and act within strict policy and economic limits. The expression of a pent-up demand for the federal gevernment to address issues of economic competitiveness, energy supply, and envirommental yuality has scized the attention of policy makers.

The federal government and the 1 ) () l national laboratories face great difficulties in susiaining the nuclear weapons capability that constitutes our fundamental strategic deterent. 'The comomic pressures on the federal budget ane formidable, and the defense community will not be insulated from them. Inded, the new economies of defense dictate a rapid dewnsizing of defense industry capacity, with the nuclear weapons complex bearing its share of the burden.

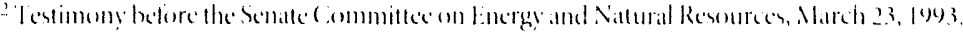


At the same time, we recognize that the deterrent value of the nuclear weapons stockpile depends on the confidence that the United States, its allies, and any potential adversaries have that these weapons will function reliably if required. Yet, as we move into the twenty-first century, many weapons in the stockpile will be reaching the end of the lifetimes for which ther were designed. It will be necessary to discover the effects of aging and engineer replacemems or modifications for critical components in those systems that will not be replaced by new designs. It will also be necessary to make greater use of commercial sources for such components.

The advanced age of most nuclear weapon production plant and equipment and the emergence of stringent new environn ental laws and regulations require a major reconfiguration of the nuclear weapons complex into a smaller, nedern, more efficient, and more environmentally appropriate form. The success of reconfiguration will depend on the development and introduction of new production and waste management technologies, on installation of a modern capability for agile manufacturing and concurrent design, and on the development of alternatives for materials and processes that must be discontinued.

Surety i a a term that embraces the safety, security, and use-control features and issues associated with nuclear weapons. The Department of Energy has continued to refine the definition of surety roles, responsibilities, and processes to guide surety programs and facilitate accurate dual-agency surety evaluations. Production of new weapons and modification of existing warheads will continue to be prioritized to emphasize nuclear detonation safety, plutonium disper ial safety, and enhanced security and use control. Research and development will continue toward the realization of weapon architectures that provide intrinsic safety and enhanced security and cortrol.

Attention will be devoted to the need for evaluating the response o' U.S. weapon systems and components, both nuclear and nonnuclear, to nuclear weapon effects. W'ith the President's extension of the moratorium on nuclear testing, the urgency of aboveground simulation to assure the reliability of the enduring nuclear weapon stockpili has become apparent. There is a need for sustained support during the remainder of the decade to develop, build, and bring on-line the simulators necessary to produce the full range of nuclear effects against which our own weapon systems must be made survivable.

The development of strategies for verifying compliance with arms control treaties and containing the proliferation of nuclear weapons technology and capability is both complex and urgent. Successful verification and nonproliferation measures depend on our ability to sense weapon-related activities, to manage the deluge of data produced by sensors, to recognize and interpret relevant data, and to convey results in a manner that facilitates decision-making for appropriate responses. Great value will be placed on the technologies of microelectronics, high-performance computing, and information surety, together with the capabilities of systems engineering and integration.

Economic constraints dominate strategic thinking as we face the requirement to preserve nuclear weapon development sapability while the companion requirement for nuclear weapon production capacity declines to a lower plateau. The nation simply does not have the resources to pay the full cost of sustaining these twin requirements from the expected level of nuclear weapons program resources alone. Since the technology base that supports nuclear weapon development and the nuclear weapons stockpile embraces core competencies that can readily serve civilian and commercial applications as well, all realistic strategies for managing this issue involve some form of dual-use technology development.

Indeed, the application of limited resources will have to be reinforced further through multiple use. Technical resources applied to DOE's defense-related missions will have to be leveraged through application to other D()E mission areas. These same resources will be multiplied further through application to the needs of the private sector. This approach seems to be the only f actical way to preserve the capabilities required for a smaller but viable nuclear weapons program while contributing materially to the strength of the U.S. economy. 


\section{Energy and Environmental Security}

The U.S. economy is energy-driven and environmentally controlled. To remain globally competitive, the nation will benefit from integration of energy, environment, and economic development on d large scalc. Economic growth will depend in large part on revolutionary changes in technolengy associated with manufacturing and transportation, both of which have critical energy and environmental aspects that the United States will be forced to address.

There is a growing, worldwide concern for the environment, which drives a demand for research in energy conservation, alternative ways of treating and disposing of hazardous and toxic wastes, and reduction of the environmental consequences associated with energy supply and use. Identifying waste reduction technologies and practices has become critically important in enabling the U.S. manufacturing sector to maintain a competitive edge in the global market.

The Department of Energy will maintain a very large effort in environmental restoration and waste management within the nuclear weapons complex. Technology developed in support of this effort will be developed with industrial partners to facilitate expeditious application to other waste sites and develop a strong U.S. environmental industry.

\section{Economic Security}

Most economists consider the revival of the U.S. manufacturing sector to be a necessary precondition for future economic security. Applying laboratory competencies to the advanced manufacturing technology needs of industry is an efficient vehicle for implementing our strategy of multiple use.

Because of our responsibility for manufacturing technology for the nuclear weapons program, Sandia has become a living laboratory for the technology required by the new paradigm of agile manufacturing. Much of what we have accomplished in the weapons program for 1 ()E is directly applicable to agile manufacturing in the civilian sector.

New waste reduction technologies are critically important in enabling the U.S. manuacturing sector to achieve a competitive edge in world markets while meeting the rising environmental expectations of our citizens. Environmentally conscious manufacturing minimizes hazardous waste, reduces energy consumption, utilizes materials more efficiently, and improves the operational safety of manufacturing pucesses. It offers economic leverage over the traditional approach of "produce first, manage waste later." 'The inefficiency of the traditional approach is clearly visible in the sizable, long-term DOE program for envisummental restoration and waste management within the nuclear weapons complex.

In helping to meet tomorrow's challenges, the 1 ) (OE national laboratories can and will make a real difference, but not by chance. (Once in a great while there appears a window of opportunity to implement a change in paradigm, and such an opportunity exists today. If the national laboratories are to realize their full potential as an economic factor, they will have to move closer to the mainstream of industrial development. The imperative is to reconnect, quite deliberately, advances in fundamental scientific understanding and technological innovation to the real marketplace of global competition. The laboratories are strategically positioned in terms of technical capabilities, size, and established relationships with government, academia, and (increasingly) industry, to catalyze large-scale research and development collaborations among public and $p$.ivate institutions.

The Defense Programs national laboratories were extremely effective when the nuclear mission (with its diverse applications: nuclear weapons, nuclear energy, nuclear medicine, etc.) was clearly defined. The raboratories attacked problems through a vertically integrated organization, stretching from fundamental science to engineering solutions. T'oday, the needs and missions are not so crisply defined - or perhaps they are just more interdisciplinary - and the national laboratories are ciprable of contributing far more than they are currently delivering. Basic research is still producing world- 
chass science, but as the original product focus has become diffuse, much of the research effort has become decoupled from real applications, and its impact on industry and society has been diminished.

'The national laboratories' operational performance has been subject to mounting criticism. The continuing value of the government-owned, contractor-operated arrangement has come under increasing scrutiny.

Unfortunately, very few objective standards are employed to measure the laboratories' p. formance. National laboratories will increasingly be evaluated by the nation's private sector. In partnership with government, the private sector will become dominant as a consumer of the laboratories' products and services, under the general rubric of technology transfer.

Technology transfer is a more complex, more inclusive process than the name alone might indicate. The process can be accomplished using several distinct channels:

- Broad DOE mission-related technology development

- User facilities

- Visiting scientist/engineer programs and educational outreach

- Information dissemination

- Cooperative research and development agreements (CRAI)As)

- Creation of technology-based start-up companies

Cooperative research among industry, government, universities, and the national laboratories will be a new model for technology development in the post-cold war era. Here, Joe Kubas tests the breaking strength of soldered joints as part of a Sandia-Motorola collaboration aimed at eliminating ozonedepleting solvents used in some manufacturing operations.

Each of these channels has been shown to be effective. The (CRADA mechanism in particular has increased technology transfer opportunities dramatically because it permits laboratory capabilities to be accessed even by industries whose products are not directly related to 1$)(\mathrm{OE}$ programs. By the end of the first quarter of calendar year 1993, the Department of Energy had entered into approximately 370 cooperative research and development agreements; Sandia National Laboratories is a party to almost onethird of those agreements.

Each of the D()F national laboratories is distinguished by the depth and breadth of its technology base: its core competencies. These core competencies are, for the most part, well matched to both the near-term and long-term technology needs of industry. The challenge that confronts the laboratories is how to confer maximum economic benefit from the dual-use character of laboratory core competencies.

There are four principal questions that need to be addressed in responding to this challenge:

1. How will 1)( )E mission responsibilitics evolve in the future, and what impact will these mission changes have on laboratory core competencies and related capabilities? (That is, How will the mission changes affect the value of laboratory core competencies to U.S. industry?)

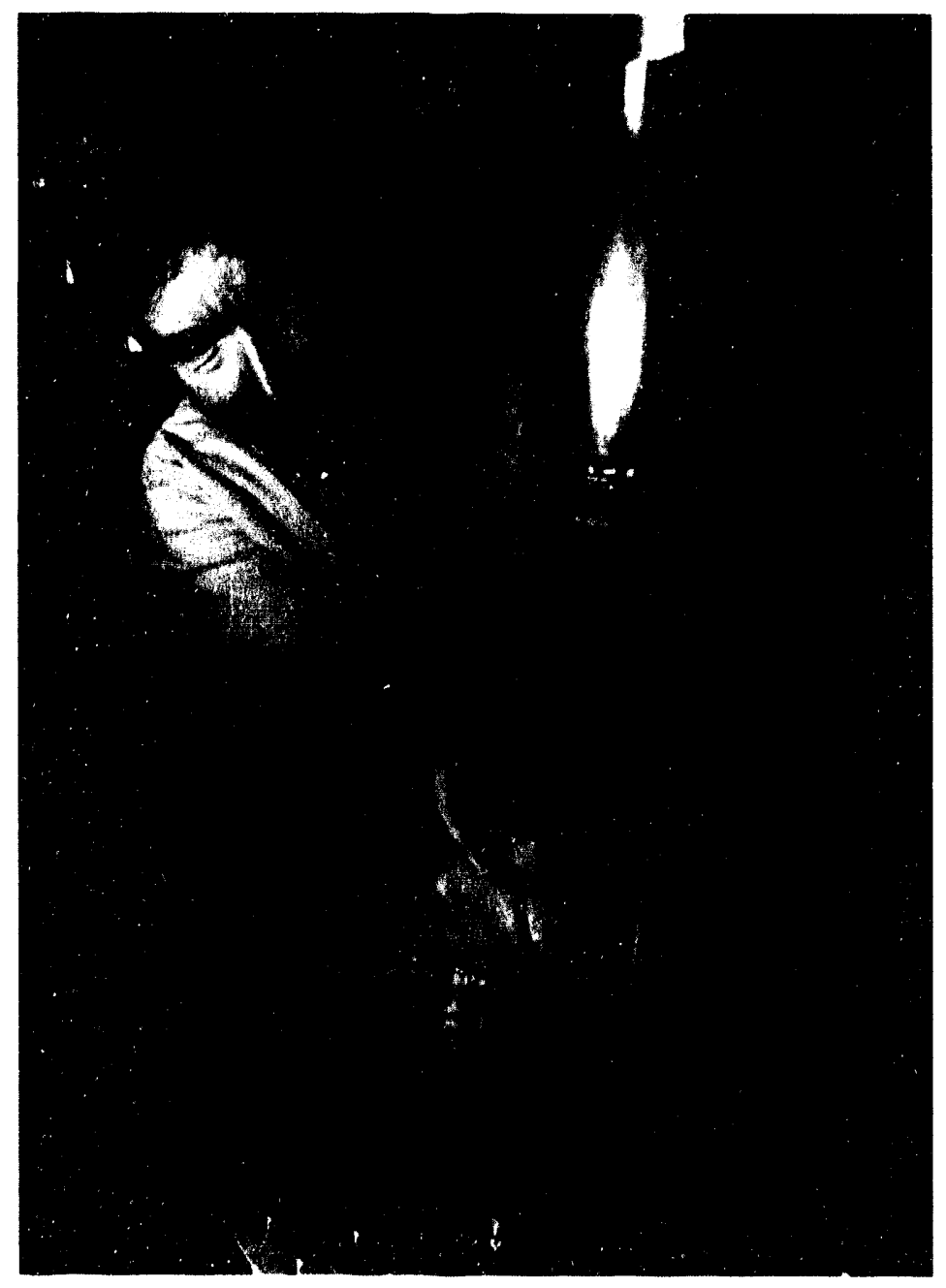


2. How should the impact of laboratory technology transfer efforts be asse'ssed?

3. How can technology transfer be provided with a suitable, sustainable level of funding?

4. How can the (RAI) A process be improved to respond better to industry's needs?

One obstacle to an effective response to these yuestions is the threat of "business as usual." "Business as usual" means a continuation of the situation in which various constituencies of the science and technology community clamor for a larger share of the federal rescirch and development budget on the basis of their individual "unique" technical capabilities. (onsequently: "husine'ss as usual" leads to fragmentation of federal research and development investments, duplication of effort, lack of responsiveness to market-driven industry needs, and inaccurate alignment of federal agency mission responsibilities with national needs and priorities. It also keeps in place the barriers that impede constructive interaction between our nation's scientific and business interests.

Many of the best opportunities to apply the technology base at the Department of linergy national laboratories will be missed if we continue to do "business as usual." The federal government will get a poor return on its investment if it lacks the courage to break down the obstacles that impede access to the Department of Energy laboratories by other federal agencies. ()pportunities will be missed if the laboratories lapse into internecine competition for set-asides to fund participation in a long list of small (CRAI)As that lack a strategic theme. And they will be missed if the imperative of reduced defense spending is compounded by a reluctance on the part of the federal government to embrace a multiple-use strategy for preserving the technology base of the national laboratories.

If we do not change this business-as-usual mentality, small, low-impact (CRAI)As will likely proliferate. Much good work will be done and anecdotal evidence of the value of federal research and development in support of industry will be trumpeted. But we will fail to make a measurable difference in the outcome of the economic battle in which our nation is engaged. Even large-scale joint efforts with individual industrial companies will not change that conclusion. Such efforts will inevitably collide with our ideological national aversion to federal cooperation with the private sector.

Federal research and development investment in support of economic competitiveness will achieve maximum return when at least two critical requirements are met:

1. The investments must target major national technology goals that are market-driven, industry-defined, and precompetitive.

2. The investments must lead to a high degree of collaboration among industry, university, and federally supported laboratories utilizing government-industry cost-sharing arrangements to the extent possible.

Realizing the full potential of federal participation in addressing the goals set by industry will require a degree of intra-agency and interagency cooperation and coordination greater than has yet been demonstrated. However, satisfying these requirements has been made more feasible by a rapid expansion in the scope of cooperation in the nation's high technology industries and by the attendant growth in joint industrial research and development activities. Incouraging evidence for this trend includes the emergence of broad industrial alliances along with precomperitive technology strategies or "road maps."

(Our focus on large-scale cooperation should not be construed as a denial of the continuing value of small ('RAI) $\mathrm{A}$ s that respond to targets of opportunity. Neither should we overlook the importance of other modes of federal involvement in the diverse technological enterprises from which the nation draws so much economic strength. We are highlighting the need to break down barriers that have traditionally impeded the flow of ereative energy from bench-scale science to products and services that can meet the challenge of global competition. There is an urgent need to get on with the task of mobilizing our scientific and technological resources for a coordinated attack on our highest priority, market-driven, technological challenges. 


\section{Strategic Issues}

'The analysis of the global, national, and institutional situation presented above highlights many issues of strategic importance. In resolving this collection of concerns, we believe that the princi. ples of total quality management should apply. The focus should be on identifying and execeding customers' reyuirements for performance, schedule, and cost. The commitment should be to continuously improve our collective ability to meet the needs of the nation for military, energ!: envirommental, and comomic security. 'The path should be fo design quality into all the processes by which our institutions relate to each other and by which we crealte value for our customers. The judgment of whether we have achieved what we set out to achieve should be determined through the application of nationally recognized, objective performance standards. The need to apply these yuality principles in all that we collectively do is, for Sandia, the overarching strategic isste and concern.

Linder that broad umbrella, we have looked hard at ways to maintain the nuclear weapons competence needed to support the nation's posture of strategie deterrence. The analysis above has pointed to our adoption of a strategy of multiple-use as the only sensible way forward. We encourage enthusiastic support for this strategy by the Department of Energy.

()ur dedication to technology transfer and our experience with cooperative research and development agreements ( $C R A D)$ As) lead us to recommend that the l)epartment of Finergy and the laboratory community work together to improve the ( $R A D) A$ process to respond better to industry needs. In addition, more work could be done to encourage fuller participation of universities in (.RAl) As.

We believe that cooperative research and development agreements will remain important vehickes for technology transfer for the foresecable future. To the degree that (.RAI)As are built around themes that are identified by industry and market-drisen, the value of the $(R A D) A$ mechanism for technology transter can be improved.

As our situation analy'sis illustrated, now is not the time for institutions to engage in destructive turf battles. (conperation and collaboration should include federal government agencies, industry, academia, and the laboratories. There is much that needs to be accomplished, and much opportunity for all of our nation stechnical institutions to contribute. Performance is the only metric that hats value for determining who plays and who sits on the sidelines.

These institutions should work together to explore critical issues that are standing in the waty of progress:

- How dowe organize and direct larger, more focused efforts involving more extensive leaming arrangements among government, industry, university, and laboratory participants?

- How dowe assure politically acceptable tairmess of access to publicly supported resources and arroid contlicts of interest?

- Ifow dowe increasc federal lunding to required levels, withont necessitating incremental appropriations that our nation camnot afford (i.e., I low dowe adlust our priorities?)?

- Ifow dowe establish objective measures of performance for the laboratories and universities an a guide to government and industry inestment decisions?

Asefforts are made to lower the institutional barriers toconperation and collabonation and more effectively harness the lechnical resources of the nation, plans should be judged against appropriale criteria to ensure that progress alleady made is not undenc. We suggest the following items as critcria that woukd be useful in this application:

1. Will this effort improse the efficient utilization of existing federal rescarch and develop. ment assets in serving the national interest?

2. Will the effort encourage teamwork among federal agencies, miversities, L.s. industry, and the national laboraturies? 
3. Will industry accept the terms of this effort and participate in the activitics it calls for?

4. Will this effort contribute to maintaining at the leading edge those core competencies of the laboratories needed for the defense mission while addressing needs in the civilian sector?

\section{Vision and Strategic Objectives}

At Sandia, we believe that change presents opportunity. The Sandia of yesterday is recognizable today only in the strength and diversity of its core competencies and in the way it does business. The Sandia of tomorrow will continue to provide "exceptional service in the national interest." Our basic culture of excellence and performance will prevail, but our customers, and their expectations, will change. Our adherence to the principles of total quality management will cause us to remain aware of, and perhaps anticipate, our customers' changing expectations. We will continuously improve our processes, products, and services and continue to design quality into them. We will assess our performance as a laboratory against objective, nationally recognized standards.

We envision a future in which we remain dedicated to the technical stewardship of the nuclear weapons stockpile, with emphasis on reliability and surety. The nuclear weapons complex will be downsized significantly from what it is today, but will also be streamlined and more efficient. Dismantlement and production activities will be carried out in a safe and environmentally conscious manner. The nudear weapons complex will depend heavily on commercial suppliers for components and subsystems used in any limited production or system upgrade work. Environmental restoration and remediation at sites throughout the nuclear weapons complex will benefit from the application of appropriate technology.

Sandia will rely on its core competencies to carry out its responsibilities in this vision. We will stretch and grow those competencies through synergistic application to the nation's broader needs for economic growth and competitiveness, as well as energy and environmental security.

We will find ourselves linked with other national laboratories, universities, and industrial partners in many of our endeavors. We will focus on meeting the technology development and application needs of entire industries, guided by industry-defined, market-driven technology road maps. Many government agencies will be involved in these collaborative ventures, and DOE will play a leadership role among them.

Access to Sandia will be user-friendly, although classified or proprietary information entrusted to or generated by Sandia will continue to be appropriately protected. We will have developed appropriate means by which to share and protect proprietary information. Sandia will have fully integrated information and computing capabilities. Our facilities will permit collaborative work among Sandians, university researchers, and technical experts from industry.

Regardless of who Sandia's new operating contractor will be, the government will be best served by retaining the government-owned, contractor-operated arrangement under which most Department of Energy laboratories have functioned for many years.

A few years ago, Sandia developed its first strategic plan, Strategic Plan 1990). While some of the planning assumptions on which that plan was based are now outdated, the strategic objectives laid out in the plan remain as relevant as they were when they were written:

1. Achieve an empowered Sandia culture: Sandia will be a customer-oriented, energetic, dynamic, enthusiastic, participative organization in which people have the freedom to have impact.

2. Demonstrate Sandia leadership with comprehensive, innovative, creative, and cost-effective solutions in areas of vital national importance.

3. Exhibit leadership in defining, creating, and exercising stewardship of the nuclear weapons stockpile for a changing world. 
4. Become a national leader in quality and quality progress.

5. Strengthen and broaden the Department of Energy's mission.

Within the last year, Sandia's top management team reiterated the Laboratories' strategic intent, originally articulated by President Harry Truman: ". . exiceptional service in the national interest."

Sandia enhances the security, prosperity, and well-being of the nation by responding to the challenges and opportunities of an increasingly dynamic and demanding world with broad-based research and development programs that create solutions spanning military security, energy security, environmental integrity, and economic competitiveness.

Achieving our strategic intent and the Laboratories' strategic objectives will help us realize this vision.

\section{Laboratories Strategy}

In pursuing our strategic intent and our strategic objectives, we adhere to modern quality principles and our corporate values.

Modern quality principles demand four fundamental commitments:

- Delight the customer. (Exceed the customer's expectations and requirements for performance, schedule, and cost.)

- Continuously improve. (No process, product, or service is perfect, and efforts to identify and implement improvements should be made on a continuous basis.)

- Design quality in. (It is much more effective to start from a quality perspective when bringing up a new process, product, or service than it is to make fundamental re-adjustments later.)

- Satisfy employees. (It has been shown repeatedly that the three imperatives listed above are virtually impossible to achieve without making it possible for employees to achieve satisfaction in their working lives.)

Modern quality principles also drive organizations to assess their performance through benchmarking against world-class counterparts, as well as against objective, nationally recognized standards (e.g., the Malcolm Baldrige National Quality Award criteria).

Sandia's corporate values constitute a framework for decision making at all levels of the Laboratories. These values have found their way into all our operations and considerations:

- Teamwork

- Integrity

- Quality

- Leadership

- Respect for the individual

On the premise that corporate strategies are guides to decision making and action, it is fair to say that modern quality principles and our corporate values envelop this laboratory.

We divide our strategy into five broad categories:

1. Customer Cognizance of our Capabilities

2. Conception and Development of Laboratory Capabilities

3. Increasing Productivity and Impact

4. Organization and Management

5. Resources 


\section{Customer Cognizance of Sandia's Capabilities}

Estabiished customers in the departments of Energy and Defense are well aware of Sandia's strengths. Processes and controls are in place to ensure that our established customers' requirements are met. Our intent is to continuously improve those processes and delight those customers.

The technology transfer program has permitted and encouraged us to make untraditional customers similarly aware of these same capabilities and of the novel ways in which they can be applied. We have pursued this opportunity aggressively.

In large part, CRADA partners select Sandia because it can solve specific technology problems of interest to them. While such work is very important, especially to small and medium-sized companies, Sandia's strategy is to create even greater impact. Consequently, we will focus on several high-leverage strategic initiatives. (These initiatives and their component programs and projects are described in greater detail in chapter five, "Major Initiatives.")

Advanced Manufacturing Technology - Elements of this challenge involve concurrent engineering and agile manufacturing. Virtual companies and factories are also part of the challenge, in which information surety and computer-driven manufacturing play a large part. The challenge also involves total systems manufacturing, which minimizes energy consumption, waste generation, and environmental impact, while maximizing the recyclability of the products and byproducts manufactured.

Electronics - Electronics is the largest industry in the world and the largest provider of quality manufacturing jobs in the United States. Electronics underlies all high-technology areas. Advances in semiconductor technology, in such areas as process integration, materials and processes, equipment design and modeling, interconnections, packaging, lithography, and so forth, are required to maintain the United States at the forefront of the electronics industry.

Information and Computational Technology - This challenge is an enabling one in that establishment of a ubiquitous information infrastructure allows the accessibility and power of information (data, text, graphics, voice, video, etc.) to enable a host of applications. Highperformance computing, high-speed networking, information surety, location transparency, communications protocols, data compression, etc., are all components of this challenge.

Transportation Energy Technology and Infrastructure - Advanced transportation will encompass improvements in both mass and personal transportation systems. High-speed mass transit will require enhanced aeronautical technologies, advanced ship designs, magnetic levitation technologies, advanced propulsion systems, and more. Personal transportation will involve the development of "green" vehicles using alternative fuels, recyclable materials, energyefficient propulsion systems, advanced battery technologies, and so forth. The transportation infrastructure must be improved using technology to advance the design, construction, and maintenance of intelligent roadways, railways, runways, and harbors.

Environmental Technology - Environmentally conscious manufacturing, waste minimization, waste transport, and recycling technologies will continue to grow in importance as the world pursues a vision of sustainability. Advanced, cost-effective technologies will be required to remediate existing environmentally degraded sites, for water and air purification, and so forth. Activities related to the global climate will involve monitoring, analyzing, and "controlling" the changes that occur in the carth's atmosphere, using advanced sensors, high-performance computing, detailed physical and chemical models. 
Energy Research and Technology Development - Viable renewable energy technologies with low environmental impacts will be an important part of our nation's energy' mix. In addition, cleaner and more efficient utilization and recovery of petroleum fuels and coal must be developed, because these sources will continue to be the most heavily used for some time.

Biomedical Systems Engineering - Application of systems engineering, diagnostic/sensors, bio-engineered procedures, computer-designed pharmaceuticals, computer-analyzed scans, etc., will be required as part of the nation's health care cost-cutting measures. Effectiveness of health care delivery can be improved through application of information technology to reduce administrative costs and improve access to records, diagnoses, and information.

Post-Cold War Defense Imperatives - We must improve our national capability to detect and characterize the clandestine development or illicit acquisition of weapons of mass destruction. Moreover, we must develop facilities that will permit us to maintain the credibility of the nuclear weapons stockpile and other military systems without the necessity of underground nuclear testing. It will also be very important to continuously improve safety and control technologies and incorporate them into the stockpile.

\section{Conception and Development of Laboratory Capabilities}

At Sandia, we conceive of ourselves as a collection of competencies aimed at achieving an overall strategic intent. Some of these competencies are embodied in very special facilities, many of which are unique. Other competencies are more intangible, but are absolutely core to our ability to provide exceptional service in the national interest.

Over the last few years, we have worked especially hard to understand the nature and scope of our core competencies. Starting with a short and necessarily general list, we have moved to a new understanding based on an exhaustive review of the Laboratories' enabling technical capabilitip and on limited benchmarking against other high-technology organizations outside the DOE family. The capability conception and development component of our corporate strategy now incorporates a core competency set with two subsets. The first subset includes our research foundations:

- Engineered processes and materials (materials science and technology, modeling of synthesis and processing, product realization)

- Computational and information sciences (software and mathematical techniques for metacomputing, information surety, and data and image processing, specialized codes)

- Microelectronics and photonics (semiconductor fabrication facilities, $x$-ray lithography, projection electron-beam lithography)

- Engineering sciences (fluid/thermal sciences, radiation transport, solid/structural mechanics, aerospace sciences, geosciences, and combustion research)

While these technical foundations may not, by themselves, distinguish Sandia from other national laboratories, they most certainly find distinguishing expression in the second subset of our core competencies, our integrated capabilities:

- Surety technology (design and surety assessment of nuclear weapons; safeguards for nuclear materials, facilities, and transportation; probabilistic risk assessment and other forms of risk analysis; semiconductor equipment reliability) 
- Experimental, computational, and analytical evaluation (proofing of complex mechanical/electrical systems; reactor satety, development, and advanced fuels research; defense and commercial transportation; simulation with experimental verification)

- Advanced manufacturing technology (advanced materials and processes, microelectronics, precision casting and machining, joining technology, integrated information systems, environmentally conscious processes, and intelligent machines)

- Pulsed power technology (modeling and control of inherently unstable systems, simulation of radiation effects in electronic and photonic systems)

- Engineered systems (design of technically complex, relatively unique products against incomplete requirements specifications; linkage of capabilities for research, design, development, prototyping, testing, and documenting to production)

To nurture and develop these and other capabilities at Sandia, we make appropriate use of funding provided to the Laboratories through DOE's Assistant Secretary for Defense Programs. We supplement that funding with the only discretionary funding permitted to the Laboratories, Laboratory-Directed Research and Development funds. We also rely heavily on opportunities to challenge our competencies through dual-use applications to DOE programs other than those related directly to nuclear weapons. Often, our core competencies are tapped to support cooperative research and development agreements under the technology transfer program. Stability in the nurture and development of our core competencies is of utmost importance to Sandia, since they als the wellspring of technical innovation that permits us to meet the needs of missions.

\section{Increasing Productivity and Impact}

As Sandia begins to respond to new customers who have new needs with new products and services, the technical challenges we face become less predictable. The challenge is magnified by the cost constraints we quite appropriately face in these times of national reprioritization. We have a compelling interest, therefore, to include concerns over productivity in our laboratory strategy mix. Here we rely on our understanding of and commitment to modern quality principles. We also seek opportunities to collaborate with industry, academia, and other national laboratories to create productivity multiplier effects.

From a laboratory strategy standpoint, it is important to note that the price of not conforming to customers' requirements for performance, schedule, and cost is too high in today's fiscally constrained world. Any opportunity to cost-effectively improve a process by eliminating steps that do not add value is an opportunity to improve our productivity. Designing-in quality certainly reduces wasteful expenditure of resources in redesign and rework. Our efforts to apply quality principles and to increase our productivity are intimately related.

At its heart, Sandia's strength lies with its skilled workforce. Therefore, to support them in remaining productive and creative, especially as the work they traditionally have done shifts to respond to new customers and new needs, we seek to develop our employees through training, education, and through matching the right people with the right challenges.

Another focus for Sandia, one that undergirds our ability as a laboratory to remain productive, is the improvement and integration of our information systems and networks. This becomes doubly important as we seek to respond to the nation's needs for informaton sciences and high-performance computing. We therefore achieve a double measure of productivity improvement by using ourselves as a test bed for information sciences and high-performance computing. We work together more productively while ensuring the utility of products and services for external customers.

Outside the Laboratories, we do whatever we can to encourage teamwork and collaboration to improve productivity throughout the entire DOE family. Resource constraints and public skepticism 
are even more keenly felt between laboratories than they are within a laboratory, and the pressures will only increase. Only through cooperation and collaboration can we as a laboratory community earn the right to continue to create value for the nation.

\section{Organization and Management}

One component of our overall strategy focuses on organizing and managing the Laboratories in a way that exemplifies the principles of total quality management.

Over the past three years, we have refocused our programs into customer-oriented sectors in order to improve our understanding of our customers' requirements. We have eliminated one layer of management, flattened the organization, and pushed responsibility for decision-making to the lowest levels possible, while continuing to exercise good stewardship for public funds - all to empower the organization and create greater employee satisfaction. We have identified our core competencies, and we actively manage them to make certain that the quality of our products and services is not degraded through erosion of the base on which they depend. Finally, we have aggressively pursued planning, benchmarking, and assessment activities to highlight opportunities to improve our processes, products, and services.

\section{Resources}

We can pursue none of these components of corporate strategy without adequate funding. We are aware of the declines envisioned in the short term for Defense Programs, the traditional mainstay of our funding, and we know that funding from other, perhaps newer, sponsorship sources may be limited.

Our strategy during the uncertain times ahead will be a conservative one. We will conserve resources by encouraging outsourcing and entering into cost-sharing partnership arrangements with other public and private entities. We anticipate a continued substantial level of cooperative research and development agreements with industry. We will manage the flow of work into the laboratory to ameliorate the impact of a sudden shift in funding levels. Staffing will be controlled within a range appropriate for anticipated conditions.

Funding requirements for the planning period are shown in Chapter 12, "Resource Projections." We will manage our resources and programs to live within the constraints of actual funding levels as they become known.

Our multifaceted laboratory strategy is based entirely on the total quality management principles that have been woven into the fabric of Sandia. It focuses on the opportunities that change can bring and does not require that all uncertainties be washed away. As national priorities shift, we believe that our customer-focused strategy will permit us to continue rendering ". . exceptional service in the nutional interest." 


$$
5
$$




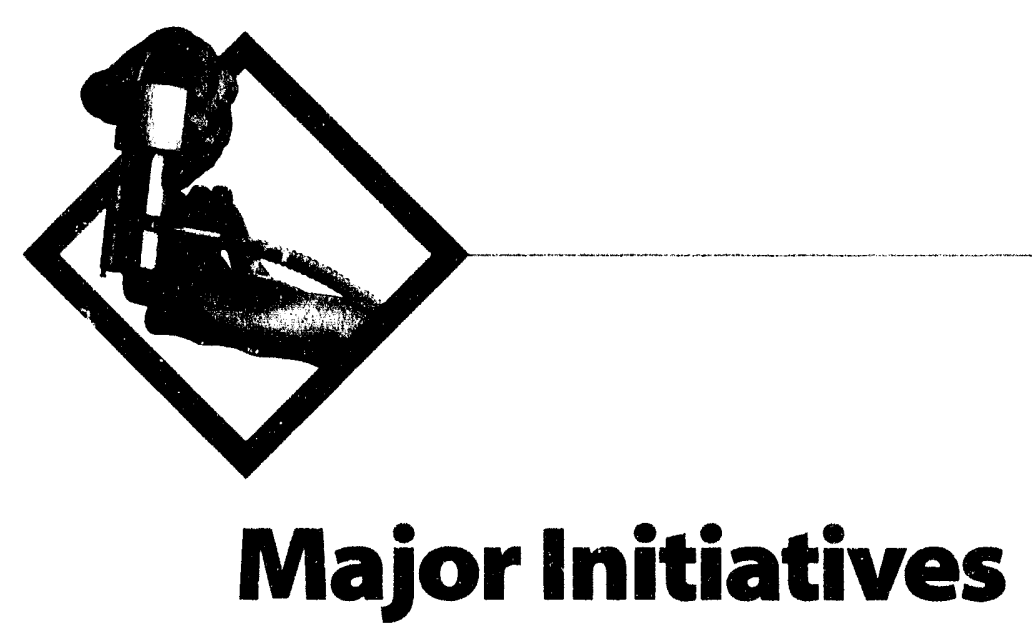

This chapter presents initiatives for consideration by the Department of Energy or reimbursable sponsors.

Sandia has identified eight strategic thrust areas which it regards as defining the future frogrammatic direction of the Laboratories. These thrust areas are defined by the intersection of large-scale, strategic national needs and established, differentiating laboratory capabilities:

- Advanced Manufacturing Technology

- Electronics

- Information and Computational Technology

- Transportation Energy Technology and Infrastructure

- Environmental Technology

- Energy Research and Technology Development

- Biomedical Systems Engineering

- Post-Cold War Defense Imperatives

All of these strategic thrusts are defense-related because every one of them supports or is derived from essential defense industrial capabilities. In addition, all support the initiatives identified by the Federal Coordinating Council for Science, Engineering, and 'Technology and included in the President's FY 1994 budget - some in obvious ways and others in ancillary or indirect ways.

Most of these strategic thrusts crosscut Sandia's program mix and customer base. All extend naturally from our experience base and core competencies. None are ventures that will require the Laboratories to acquire costly new competencies that have not historically been related to its missions. All offer opportunities to address strategic national needs cost-effectively by exploiting the existing federal investment in our core competencies.

Our strategy for implementing each of these strategic initiatives is fourfold:

1. We will continue to enter into cooperative research and development agreements (CRADAs) with individual companies to help them address their proprietary needs.

2. Projects under these initiative categories may either respond to market-driven needs defined by industry or they may introduce novel technologies that have the potential to push new classes of commercial applications.

3. As much as possible, all work will include a high degree of collaboration among industry, universities, and other federal laboratories through cost-sharing arrangements.

4. We will help support the research and development needs of small and mid-level businesses through special cooperative arrangements and technology out-reach programs. 
Some projects may not be able to utilize this strategy because they may involve classified work. However, even in those cases we will attempt to exploit commercial capabilities to the extent possible, and we will diligently identify and aggressively exploit dual-use developments.

The sections that follow discuss the established capabilities, experience base, and laboratory strengths that make Sandia a valuable and perhaps unique resource for each of the thrust areas. Then, each section presents a package of project proposals for new, currently unfunded work, work that is funded for start-up purposes, or major program enhancements that require additional resources. Funding and personnel required for these proposals are in addition to ongoing programmatic funding summarized in chapter 12, "Resource Projections."

The inclusion of a particular project proposal within a thrust area does not imply $D O E$ approval, nor does it represent a commitment by Sandia to implement it. However, each of the major initiative areas represents a strategic commitment on the part of Sandia management. Each derives its technologies from Sandia's established core competencies and is an activity in which Sandia is acknowledged to have made substantial contributions or significant new progress. Moreover, these major initiatives are intended to implement long-term national and agency goals.

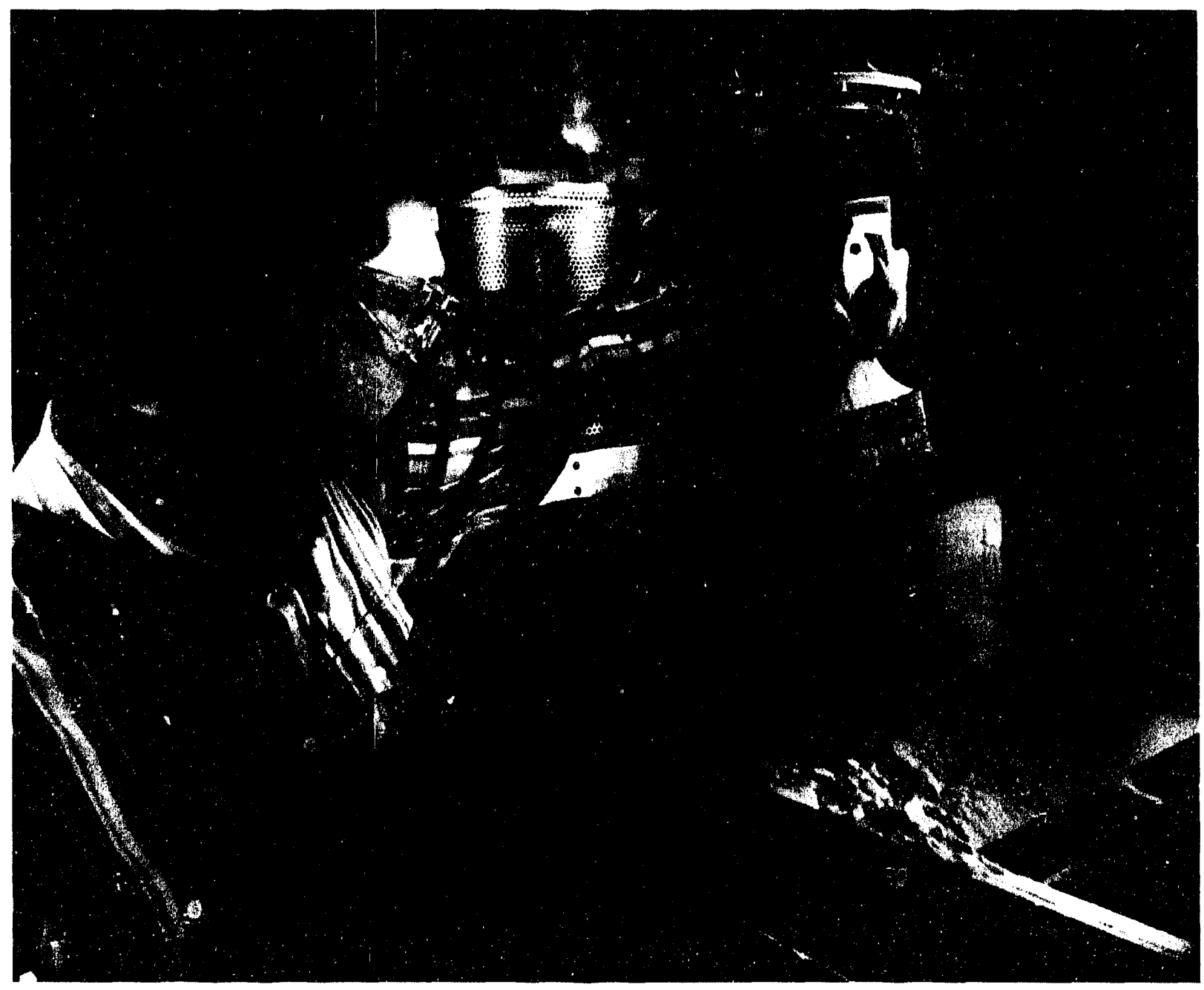

Brian Pardo brushes excess powder away from a wax part that was solidified using a carbon dioxide laser. Design problems were first identified and corrected on a 3-D computer-aided design (CAD) drawing. The technique, called selective laser sintering, eliminates certain machining steps and reduces the time it takes to get a finished part. 


\section{Advanced Manufacturing Technology}

As a consequence of its responsibilities in systems and design engincering, production process development, intelligent machine research and development, and oversight of the performance and reliability of most U.S. nuclear weapon components over the last forty years, Sandia National Laboratories has become the leader among Department of Energy laboratories for advanced manufacturing technologies. Manufacturing support technologies are central to our mission for Defense Programs and constitute a large fraction of our technology base.

The problems the DOE nuclear weapons c iplex faces are a preview of those that will be faced by the U.S. manufacturing community as a whole. The future operating environment will require manufacturing agility and cost-effectiveness. We will have to design and manufacture to the highest standards of quality. Production will have to be performed in an environmentally conscious manner. The nuclear weapon laboratories must continue to design for the total life cycle, including retirement, disn antlement, and disposal or recycling of components and materials. As a form of "virtual deterrence," the complex will need to demonstrate the capability to get new designs into production quickly. It must be able to create manufacturable designs with a minimum of iterations and validate production processes through simulation. Central to achieving these objectives will be an effective information communication and management system that integrates the design-to-productionto-disposal process using teamwork relationships that allow activities to proceed concurrently.

The Department of Energy cannot accomplish this mission in isolation from the nation's manufacturing community. Conversely, the manufacturing community stands to benefit from the DOE laboratories' research and development in manufacturing.

The National Center for Advanced Manufacturing Technology has been established at Sandia/New Mexico to maximize the value of the Laboratories' technology base to the manufacturing needs of both the DOE nuclear weapons complex and industry. The center will coordinate its efforts with other government agencies, universities, U.S. industry, and other government laboratorics to ensure maximum value to the nation. The center will also help transfer and apply advanced manufacturing technologies developed in Sandia's defense programs to commercial manufacturing, thus helping to strengthen U.S. industry's competitiveness. Much manufacturing technology transfer is already taking place through many cooperative research and development agreements (CRADAs) with industry.

Sandia's California location is strategically important to our advanced manufacturing initiative as a point of contact with the high-technology industries of the West Coast. The Integrated Manufacturing Technologies Laboratory, a new facility, focuses on the development and integration of advanced manufacturing technologies. It conducts research and development in materials and processes, process simulation, engineering design, and manufacturing technology support. It also performs research in prototype fabrication and demonstration techniques for agile manufacturing, both for DOE and the domestic industrial sector. Current work focuses on metal removal and welding, weld process simulation, composites fabrication, high-speed communication of manufacturing data, and on-line monitoring and control.

The thrust of many of these activities and initiatives is to leverage our knowledge in much the same way that machines leverage our muscles. Because this initiative cuts across all of Sandia's technical capabilities, activities that are of direct value to and supported by ad anced manufacturing also appear in other major initiatives. Examples include the recently established National Center for Advanced Information Components Manufacturing, a partnership effort involving the Advanced Research Projects Agency, the Department of Energy, and industry. Industry requires further developments in the manufacturing of optoelectronics and flat-panel displays. This work will be enhanced by activities under Sandia's other major initiatives, such as Hectronics, Information and Computational Technology, and the Defense-related initiatives intended to make Complex 21 a model of agile manufacturing. 


\title{
Project Proposals for the Major Initiative in Advanced Manufacturing Technology
}

\author{
Advanced Materials and Manufacturing Technology \\ [for the Assistant Secretary for Defense Programs (GB)]
}

Two federal government initiatives, the Advanced Materials and Processing Initiative and the Advanced Manufacturing Initiative, have emphasized the importance of materials research and technology development. The intent of Sandia's Advanced Materials and Manufacturing Technology initiative is to work with industry to address its critical needs in the areas of materials synthesis and processing. A long-range objective is to improve the flexibility of manufacturing processes and facilitate the application of artificial intelligence to manufacturing operations by applying tools and concepts of concurrent engineering and computer-integrated manufacturing.

The reconfiguration of the nuclear weapons complex will require development of external industrial suppliers for a large variety of components. Low rates of weapon production and stockpile retrofits will require the design agencies to reduce costs for weapons research by developing and applying new materials and processing technologies. Such technologies will include computer design of advanced materials, computer modeling of materials processing, and development of sensors and real-time diagnostics for materials processing. These technologies can cut costs by accelerating the development of new materials and processes and by reducing the need for prototype hardware. They will enable product design engineers to work 'oncurrently with materials process engineers on component designs. They will permit more rapid prototyping by simulating and validating process options on a computer, rather than on the factory floor. Moreover, such technologies will promote computer-integrated manufacturing by furnishing manufacturers with process controllers and process control software.

Planners of Advanced Materials and Manufacturing Technology have identified several specific activities for the initiative. These activities include thermomechanical processing; electromagnetic synthesis and processing; development of sensors, process diagnostics, and smart materials; synthesis and characterization of optoelectronic materials; and synthesis, processing, and characterization of composite materials.

Interaction with industry will be facilitated by the recently established Advanced Materials and Processes for Economic Competitiveness (AMPEC) alliance between Sandia, Los Alamos, the Air Force Phillips Laboratory, three New Mexico universities, and the New Mexico Economic Development Department, as called for in the Department of Energy Laboratory Technology Partnership Act of 1992. Industrial interns will be centrally located at the Advanced Materials Laboratory in the University of New Mexico Research Park.

\section{Intelligent Manufacturing Science and Engineering} [for the Assistant Secretary for Defense Programs (GB)]

Department of Energy contractors have found that standard industrial robots, which are designed primarily for high-volume manufacturing, have limited applicability to their operations, which typically call for small-lot production. However, with a modified approach to robotics research and development, intelligent manufacturing systems can be designed that are specifically applicable to $D O E$ requirements but incorporate standard industrial robotic hardware. Such work will advance the capability of robotics tools available for agile manufacturing in industry.

Sandia's approach is to eliminate entirely the manual process of teaching and programming robots. Instead, we are developing algorithmic and software techniques that will let robot systems 
generate their own programs. New systems based on these techniques will be able to generate plans of action, program the required devices, and use sensors and instrumentation to react appropriately to changes in the workspace. New sensor and model-based controls are obviating the requirement for precise fixtures and jigs for piece parts. Real-time sensory capabilities will permit flexible production systems to have other desirable features, such as automated compensation for tool wear, in-process inspection, and automated error detection and correction.

'The Intelligent Manufacturing Science and Engineering project will draw upon Sandia's base of robotics technology expertise. During the past several years, Sandia has carried out robotics development for the Assistant Secretary for Defense Programs, the (Office of (ivilian Radioactive Waste Management, and the Office of Environmental Restoration and Waste Management. We are currently transferring robotic technologies to several I)()E sites, including Pantex, Mound, Y-12, Savannah River, Allied Signal, and Rocky liats. Furthermore, we are consulting with several other organizations in the production complex and are performing research and development in advanced manufacturing for $\mathrm{DOOE}$ mission applications.

In many ways, 1 OOE's design and production activities are a microcosm of the future of commercial manufacturing. The Intelligent Manufacturing Science and Ingineering project, because it will play a key role in reconfiguration and moden nization of the nuclear weapons complex, offers an opportunity for DOF to help U.S. manufacturers strengthen their competitiveness.

The initiative will push research in automated programming and planning, geometric modeling and reasoning, and high-speed, sensor-driven control-areas key to the broad application of robotics to DOE problems. In addition, we will construct prototypes of advanced systems targeted for specific applications within Defense Programs. Managers from across the DOE complex will be consulted regularly on the thrust and scope of developmental activities. Also, to facilitate technology transfer, engineers from the DOE production plants will help evaluate prototype systems. Sandia developers will continue to participate actively as full-scale production systems are built and brought into operation.

\section{Rapid Response Manufacturing [for the Assistant Secretary for Defense Programs (GB)]}

Manufacturing is a crucial component of the defense technology base and a principal factor in U.S. economic security. The new weapons procurement strategy calls for ongoing development of advanced weapon systems to retain America's technological edge in military systems. In contrast to past practice, however, these new weapon systems maly not be immediately produced in quantity. Instead, the nation will retain the capability to produce them quickly when needed in response to threatening world conditions.

This strategy of virtual forces affects the U.S. military's ability to maintain both a substantive fighting capability and a credible deterrent in several ways. First, the concept of readiness will have to be expanded to include the infrastructure that will create weapons systems. This infrastructure includes both captive production facilities and industrial production capacity. These industrial production facilities will require unprecedented flexibility to produce a mix of military and nonmilitary products. The nation will need new methods for monitoring and assuring the readiness of this large production complex to meet its critical, time-limited needs in periods of crisis.

Second, accredited production processes will need to be developed that can be operated at lowor no-volume for many years and then be "turned on" for volume production with no loss of quality. The technological implications of this requirement are profound. 'The manufacturing processes must be validated to high quality standards with only small sample sizes. The corporate memory for those processes must be preserved in a way that it can be recalled without incurring a lengthy learning curve. In addition, there must be procedures to revalidate the reinstated processes (and periodically modernize processes) without lengthy pilot production runs. These needs are beyond the current state-of-the-art in manufacturing. 
Third, the defense production infrastructure will need an agility that it does not possess today. If a decision to rearm should be made, it is likely that modifications to extant weapons systems will be specified at the same time. Those modifications will be based on an assessment of the specific threat to be countered. The engineering and design functions needed to accomplish these changes will have to exhibit the same agility as the tabrication systems that produce them. 'Thus, highly integrated, paperless, concurrent design and analysis systems will have to function seamlessly with the rest of the procurement and production infrastructure. It will be a great challenge to make the agile manufacturing concept a reality in the defense procurement arena.

These challenges facing defense manufacturing must also be addressed by the Department of Energy, and in some cases the problems will be even more difficult. The production volumes of nuclear weapons will almost certainly be extremely small, but the standards for quality will remain uniquely high. Moreover, the ability to resume quantity production must be retained. As actual production experience diminishes, it will become more difficult to sustain the ability to produce high-quality product unless agile manufacturing technologies and practices are available and have been demonstrated. DOE must become a leader in integrated engineering, design, and production in order to meet its responsibilities in the twenty-first century.

\section{Information-Driven Manufacturing [for the Assistant Secretary for Defense Programs (GB)]}

Information technology holds the key to achieving the objectives of the modernized Defense Programs design and production complex and to enabling an economically competitive U.S. manufacturing infrastructure. Future DOE manufacturing systems will depend heavily on a range of computing tools, from design at a workstation to real-time computer control of individual production processes.

Recent research and prototyping work at Sandia has demonstrated feasibility of very tight coupling of design and production processes. Application-specific development of information technologies (such as networking and computer science, design analysis, data processing and storage, information surety, and intelligent production systems, processes, and equipment) is required for Complex 21.

DOE weapons designers have long used computers to design products, manage and process data, and analyze the performance of their designs. Now these methods are being extended to analysis of the producibility of designs, to assessment of the environmental consequences of designs, and to automated generation of the controls and programs used by the factory floor production systems. Information technologies will permit designs to be validated in "virtual factories" before they are approved for release.

In a likely scenario of future manufacturing, designs are created at a computer-aided design workstation and their performance is evaluated by integrated computational tools. The same electronic design information is then coupled with computer models of production processes developed through simulation and limited experimental validation. These models are available to product designers for assessment of various producibility issues. (This process/product assessment is termed manufacturing validation in current literature.) Once designers are satisfied with the design, control algorithms for production equipment are automatically generated using the product design database and the computer model of the process. (Automated programming of production equipment will be an important element of agile manufacturing.) In turn, the plant model permits real-time control of the process based upon information sensed from process and product.

Such manufacturing systems will make heavy use of information sciences and technologies; consequently, we use the term information-driven manufacturing. Information-driven manufacturing technologies will make possible many of the desired attributes of the 1 )epartment of Energy's Complex 21. Weapon system designers will be able to determine quickly if their designs are manufacturable 
with the available production systems. Production agencies will be able to remove workers from hazardous operations and, in the process, cut down on waste resulting from contaminated protective clothing. Furthermore, because much of the design and production expertise will be embodied in algorithms and software, the cadre of trained engineers and technicians required to operate the complex will be reduced without degrading the ability to respond to national emergencies. These assertions are based on a review of ' Technology Assessment and Selection Panel documents and discussions on future needs for robotics and automation with Panel leaders and managers of the $\mathrm{DOE}$ production agencies.

Sandia and the Department of Energy will retain a leadership position in informationdriven manufacturing as a result of this initiative. These technologies are key elements of U.S. industrial initiatives in agile and intelligent manufacturing.

\section{Manufacturing Energy Conservation [for the Assistant Secretary for Energy Efficiency and Renewable Energy (ED)]}

Sandia's work in DO)E's Industrial Waste Reduction Program is focused on changing the initial processes used in manufacturing to reduce both the waste generated and the energy used in manufacturing. This approach has great potential to help industry because it improves the entire manufacturing process. Industry supports this program because of its promise to yield huge savings and to help protect the environment.

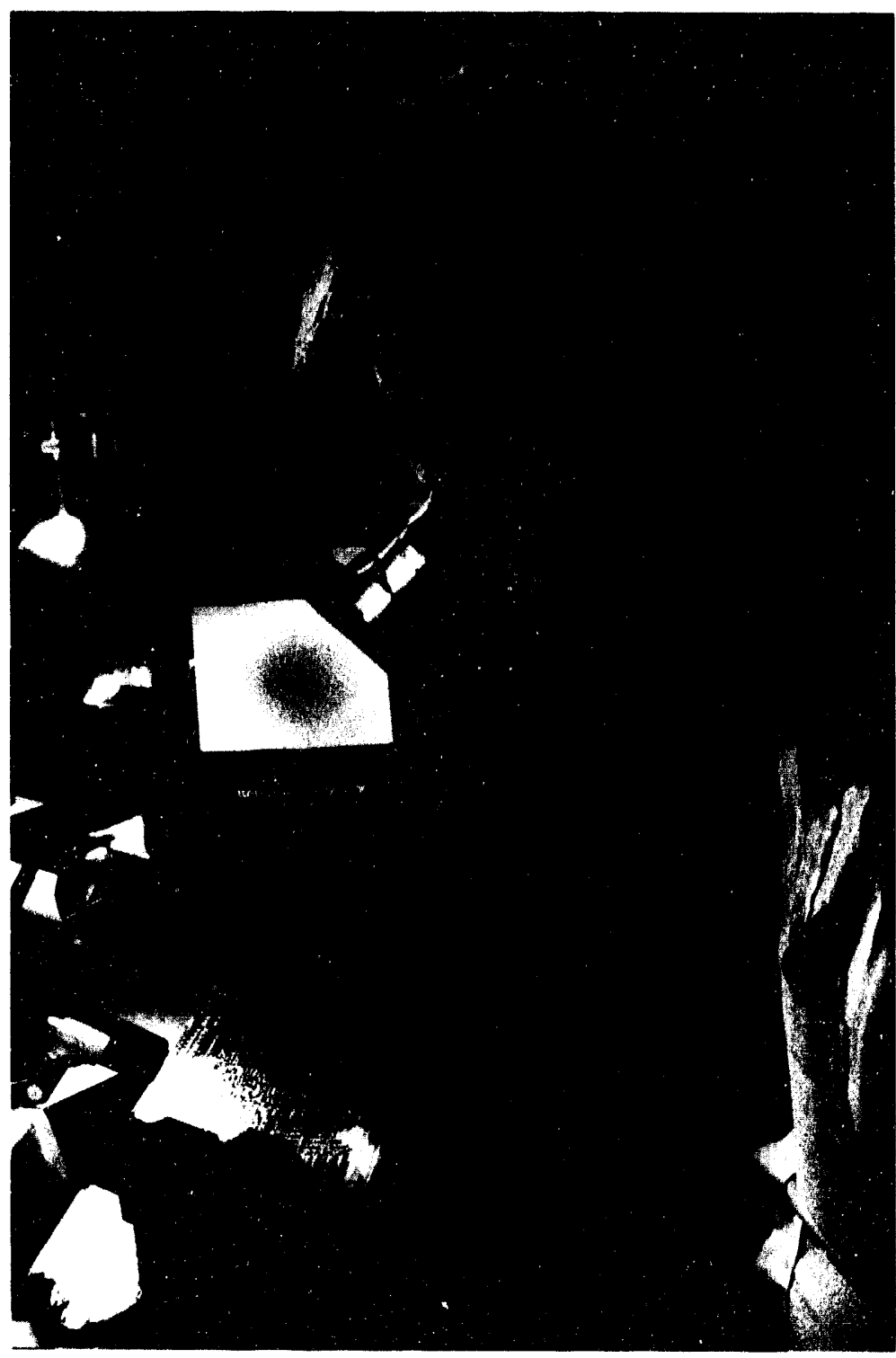

Fred Yost, a team leader in solder science, examines a printed wiring board under a microscope. A five-year project with the National Center for Manufacturing Sciences will make Sandia's leading capability in soldering technology available to industry.

Sandia supports the Department of Energy in areas that bring opportunities to cnhance advanced manufacturing, such as Industrial Waste Reduction and Environmentally (onscious Manufacturing. Integrating concepts and lessons learned from these projects into the baseline planning for tomorrow's manufacturing programs will enhance U.S. competitiveness by making products less costly and more desirable in worldwide environmental markets.

The waste reduction program has already proved itself of value to United States industry. It is currently industry driven, market-based, and cost-shared with industry, and leverages investments already made by the federal government in the national laboratories.

In a parallel effort, Sandia has been coordinating demonstrations of environmentally conscious manufacturing in the $\mathrm{DOE}$ weapons complex. Sandia uses an integrated systems approach that 
attempts to reduce the ecological impacts of industrial activity and improve efficiency of energy use without sacrificing quality, reliability, or performance. ( over the next five years, our strategy for the program is to concentrate on the application of envirommentally conscious manufacturing through collaboration and partnership with industry and by making Sandia a national center for the methodology.

This proposal requests specific support to integrate environmentally conscious manuficturing and energy reduction into the design of advanced manufacturing processes. Known approaches, such as solvent substitution, materials conservation, and process monitoring and control, will be applied where possible. In cases where opportunities for significant energy conservation present themselves, new approaches will be developed.

\section{Smart Material Systems}

[for the Assistant Secretary for Defense Programs (GB)]

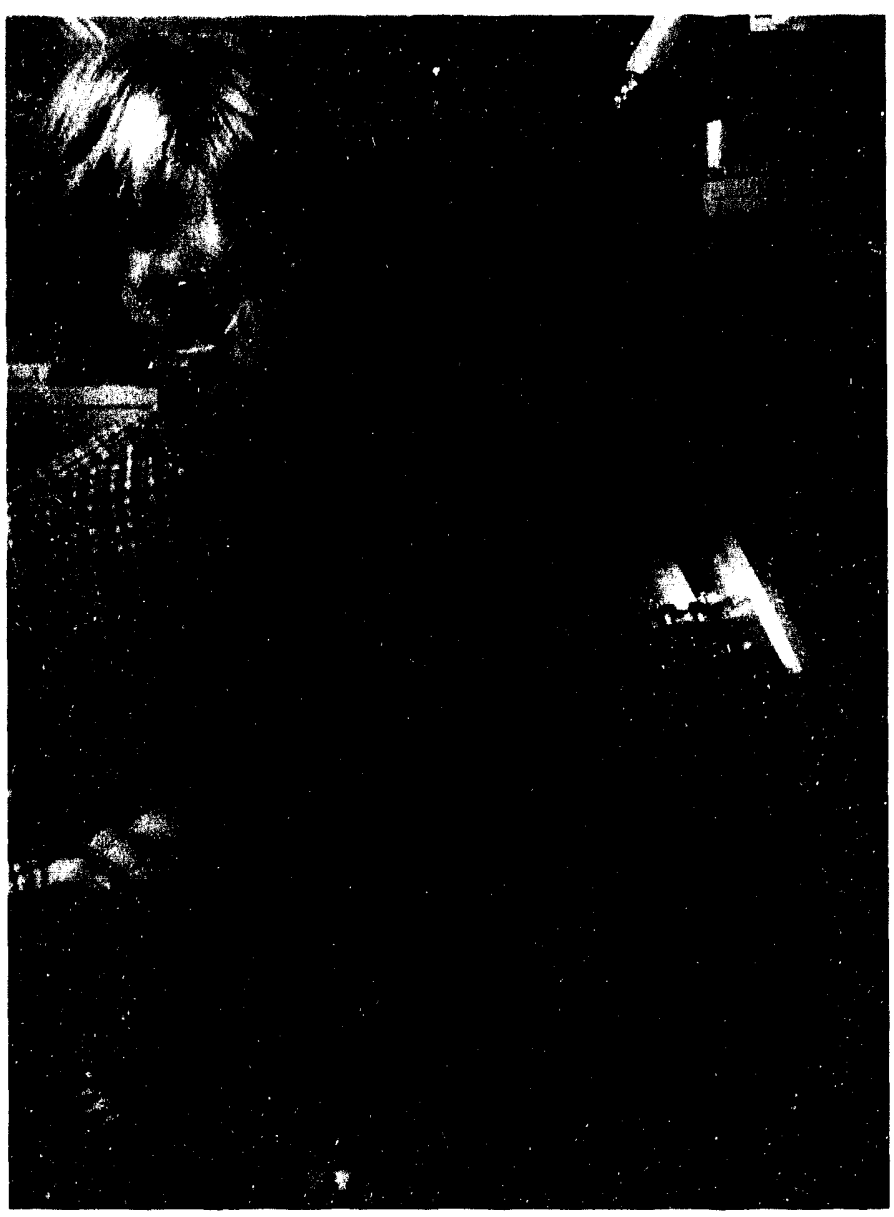

Advanced manufacturing is a major initiative based on the Laboratories' historical strengths in manufacturing process development. Sandia helped Pratt \& Whitney develop this robotic deburring system that automatically grinds edges of jet engine turbine wheels during fabrication. The system uses computer-aided design models and computer vision and force control sensors to match the part to precise specifications.
Many improvements in manufacturing technologies can be made using smart material systems technology. These are materials and structures that have the ability to beneficially respond to internal and external stimulation through intelligent sensing, processing, and controls. This technology provides the designer an expanded capability and new design methodology in the materials and structures area that can be employed for a variety of manufacturing tasks, including the design of new products or manufacturing systems.

First, smart material systems enable a designer to use light-weight structural systems to accomplish high-precision tasks. Second, smart material systems convey information about the current structural health of the system and use this information to adapt and achieve a desired goal. Third, smart material systems technology facilitates manufacturing process control via embedded sensors. Intelligent material and structural systems often involve flexible structure control problems. These systems have sensory and actuating characteristics that can respond in real time to the environment and modify responses to overcome undesirable and unexpected stimuli. The solution to these problems is directly related to complementary technologies in intelligent process control and intelligent machines.

The goal of reducing cost and time to manuficture can be achieved through application of smart material systems. This capability is made possible because of recent advances in a number of related technologies, including materials, sensing and actuating, processing, reliable structural modeling and simulation, and microdevices. It is now often less expensive to incorporate sensors, actuattors, and 
computing than to use heary structures to achices the accuracy and precision reyuired for a reliable design or manuticturing task. It is a requirement of agile manufacturing that the process be able to adapt to new families of design, and this ad aptability is inherent in smart material and structural sy'sems.

'on maintain accuracy in precision manufacturing, operations will repuire an ability to sense and actively control the vibration inherent in many procedures. This use of active vibration control is needed for advanced lithography mathines for semicondectors or flat pands to achieve the desired precision. Structural systems and equipment used to produce weapon parts in agile mantatacturing operations will require intelligence and adaptability. Also reguired are very accurate modeling and simulation capabilitices to conable virtual prototyping of weapons, thus ano oiding costly hardware iterations. ()n-line system identification is recuired for control of flexible structural systems, for detection of the onset of chatter and suppression of vibration, for precision machine tool manuficturing systems requiring vibration reduction, and other precision cutting or grinding operations.

()ther manufacturing applications of smart materials indude embedded sensors to monitor the cure cycle for composite materials; damage detection and "health monitoring" of sensitive structural systems; use of shape memory alloys as clamping devices for automated production line handling to diminate environmentally damaging hydraulic clamping sy'stems currently used; process control of extruded and injected molded plastics; temperature and wear compensation; precision oscillating equipment; and nonintrusive sensing of manufacturing process parameters internal to material processing.

Current efforts in the fiedd of smart material and structural systems by the private sector and other government agencies have increased significantly in recent years. Sandia has a unicue opportunity to bring its resources to bear on a technology area of great importance to this country. Advances in this field require the resources of an organization that has both breadth and depth in the individual technologies that make up this multidisciplinary field. Such expertise requires the integration of experimental and analytical research and development in materials, structures, processing, sensors, and controls, plus a capability for prototype device development and systems engincering - skills that are well established at Sandia.

\section{Technology-Based U.S. Product Reliability Leadership [for the Assistant Secretary for Defense Programs (GB)]}

1)( )l and commercial industry have similar repuirements for high-reliabiiity systems and components. Meeting these repuirements - a serious challenge for the nuclear weapons complex today - will become a critical issue as production downsizes and we move toward agile manulacturing.

(Quality will be vital in meeting sponsors' expectations for reliable systems. The key issue will be to achieve high reliability competitively; that is, to produce extremely low failure rates while producing the produce at lower cost.

Two essential components for performance and leadership in quality are a cuality culture and the application of reliability technologies. (Quality culture refers to the values and principles of individuals and organizations. Relielbility tectmologie's refers to the base of technical competencies repuired for a practical, competitive implementation of a yuality culture. This base includes such competencies as reliability physics, failure analysis, nondestructive testing, process control, and design for manufacturing.

The military and economic security of the United States demands that the nation achieve and sustain competency and leadership in technologies for (uality and reliability. This initiative propose's a multiorganizational National Center for Ultra-Reliability Engineering (NCURE). Sandia possesses strong qualitications for leadership in a cooperative NC URE program. The extreme conseguences of a nuclear weapen failure have reguired Sandia to develop and maintain a broad base ol expertise in cyuality and reliability technologies. NC:URL: will use capabilities from 
throughout the DOE complex and will broadly support U.S. industry and government programs. Sandia will transfer and disseminate advanced quality technologies.

In addition, NCURE will sponsor quality research and development in other arcas:

- Quality in Agile Manufacturing - Strategies for ensuring high quality and reliability in the small-lot, high-product-mix environment of downsized defense production and agile manufacturing will be identified. We will also define key reliability technology' drivers of the future and pursue related research and development.

- Reliability Technology Leadership in Dual-use Technologies - NCURE will identify key dual-use technologies and work with industry to establish and maintain world-class quality technology capabilities in these areas - for example, providing concurrent engineering support for developing advanced electronic technologies, such as flat panel displays, high-speed electronics, and high-temperature electronics.

- Expert Systems - All organizations are susceptible to the loss of valuable expertise as key technical people retire. This problem has particularly important implications for DOE because it has responsibility for nuclear weapons that have service lives longer than the careers of the original designers. An important goal of NCURE will be to develop practical expert-system methodologies to preserve the knowledge of such individuals.

\section{Concurrent Engineering Practices [for the Assistant Secretary for Defense Programs (GB)]}

Sandia has initiated an effort to create, in the near term and for Complex 21 , the process both to build small quantities of weapons on a replacement schedule and to mobilize quickly for volume production upon command. This program will develop processes for weapon product realization in Complex 21-DOE's vision of a smaller, more cost-effective nuclear weapon complex (NWC) to support dismantlement, stockpile manngement, and new weapon development. It is not intended to support direct research and development of new technologies for weapon products. Instead, it tightly couples the product cycle from design through dismantlement, resulting in efficient, Hexible, and affordable design and production.

The nuclear weapon complex functions with traditional industrial engineering processes for product realization. A more modern approach is needed. This initiative in concurrent engineering will define and implement concurrent engineering processes for the realization of weapon products. Concurrent engineering (in the context of DOE Defense Programs weapons production) is defined as a process for product realization that improves cycle time by using teamwork from concept to disposal, with special emphasis on up-front engineering of all process and life-cycle requirements. Concurrent engineering offers a systematic approach to the integrated, simultaneous design of products and their associated fabrication processes. This approach is intended to cause weapon developers to consider all elements of the product life cycle from concept to disposal, including quality, cost, schedule, and performance.

To implement this initiative, Sandia will conduct activities in two major areas: First, an integrated systems approach will be employed for weapon design and manufacturing that encompasses the entire life cycle of weapon components. Building on the STEP, MAST, PRESS, Focal Point, and other demonstration programs, the initiative will focus on a few pilot product realization projects. These pilot projects will be the vehicles for development cycle activities.

Specific subsystems and components will be selected as pilot projects. The two initial candidates will be a MAST fireset/programmer and the Focal Point paste explosives system. The entire integrated 
approach will be exercised on these prototypical applications, including systems management (emphasizing rapid cycle time), design for manufacturability and cost, process characterization (focused on feedback to the design process), continuous improvement of all processes, waste minimization, and demonstration of industrial partnerships. New pilot projects will be selected as the new process gains momentum.

A second major area to be addressed is the formation of multidisciplinary teams to apply concurrent engineering principles to design, manufacturing, and dismantlement processes. These teams will include designers, manufacturing engineers, materials and process scientists, environmental safety and health engineers, waste management specialists, information management specialists, and so forth. By improving the manufacturability of current nuclear weapon components, engincers can generate ideas that may benefit stockpile and dismantlement activities and achieve better designs for future production.

A project management approach will ensure that this initiative develops according to planned strategic intent, that resources are properly aligned with requirements, and that effective linkages are maintained between customers and support groups.

\begin{tabular}{|c|c|c|c|c|c|}
\hline \multicolumn{6}{|c|}{$\begin{array}{l}\text { Funding Requirements for Initiative Project Proposals in Advanced Manufacturing Technology } \\
\text { (Dollars in constant FY } 1994 \text { millions; personnel in FTEs) }\end{array}$} \\
\hline & Year: 1 & Year 2 & Year 3 & Year 4 & Year 5 \\
\hline \multicolumn{6}{|c|}{ Advanced Materials and Manufacturing Technology } \\
\hline Operating & 10.0 & 10.0 & 15.0 & 15.0 & 20.0 \\
\hline Capital Equipment & 5.0 & 10.0 & 10.0 & 10.0 & 5.0 \\
\hline Total Cosi & 15.0 & 20.0 & 25.0 & 25.0 & 25.0 \\
\hline Direct Personnel & 40 & 40 & 60 & 60 & 60 \\
\hline \multicolumn{6}{|c|}{ Intelligent Manufacturing Science and Engineering } \\
\hline Operating & 6.0 & 10.0 & 15.0 & 15.0 & 20.0 \\
\hline Capital Equipment & 1.0 & 2.0 & 2.0 & 2.0 & 1.0 \\
\hline Total Cost & 7.0 & 12.0 & 17.0 & 17.0 & 21.0 \\
\hline Direct Personnel & 25 & 40 & 50 & 50 & 50 \\
\hline \multicolumn{6}{|c|}{ Rapid Response Manufacturing } \\
\hline Operating & 10.0 & 20.0 & 31.0 & 31.0 & 31.0 \\
\hline Capital Equipment & 2.0 & 4.0 & 7.0 & 7.0 & 5.0 \\
\hline Total Cost & 12.0 & 24.0 & 38.0 & 38.0 & 36.0 \\
\hline Direct Personnel & 50 & 100 & 115 & 115 & 115 \\
\hline \multicolumn{6}{|c|}{ Information-Driven Manufacturing } \\
\hline Operating & 4.0 & 5.0 & 8.0 & 12.0 & 18.0 \\
\hline Capital Equipmerit & 1.0 & 2.0 & 2.0 & 2.0 & 1.0 \\
\hline Total Cost & 5.0 & 7.0 & 10.0 & 14.0 & 19.0 \\
\hline Direct Personnel & 15 & 20 & 30 & 45 & 60 \\
\hline
\end{tabular}




\begin{tabular}{|c|c|c|c|c|c|}
\hline \multicolumn{6}{|c|}{$\begin{array}{l}\text { Funding Requirements for Initiative Project Proposals in } \\
\text { Advanced Manufacturing Technology (Continued) } \\
\text { (Dollars in constant FY } 1994 \text { millions; personnel in FTEs) }\end{array}$} \\
\hline & Year 1 & Year 2 & Year 3 & Year 4 & Year 5 \\
\hline \multicolumn{6}{|c|}{ Manufacturing Energy Conservation } \\
\hline Operating & 6.0 & 10.0 & 15.0 & 15.0 & 15.0 \\
\hline Direct Personnel & 10 & 18 & 20 & 20 & 20 \\
\hline \multicolumn{6}{|l|}{ Smart Material Systems } \\
\hline Operating & 2.5 & 5.0 & 8.0 & 13.0 & 14.0 \\
\hline Capital Equipment & 0.5 & 2.0 & 2.0 & 2.0 & 1.0 \\
\hline Total Cost & 3.0 & 7.0 & 10.0 & 15.0 & 15.0 \\
\hline Direct Personnel & 10 & 20 & 35 & 50 & 50 \\
\hline \multicolumn{6}{|c|}{ Technology-Based U.S. Product Reliability Leadership } \\
\hline Operating & 5.0 & 10.0 & 12.5 & 12.5 & 12.5 \\
\hline Capital Equipment & 1.0 & 2.0 & 2.0 & 2.0 & 1.0 \\
\hline Total Cost & 6.0 & 12.0 & 14.5 & 14.5 & 13.5 \\
\hline Direct Personnel & 25 & 40 & 50 & 50 & 50 \\
\hline \multicolumn{6}{|c|}{ Concurrent Engineering Practices } \\
\hline Operating & 8.0 & 8.0 & 6.0 & 6.0 & 6.0 \\
\hline Direct Personnel & 32 & 32 & 24 & 24 & 24 \\
\hline \multicolumn{6}{|c|}{ Total, Advanced Manufacturing Technology } \\
\hline Operating & 51.5 & 78.0 & 110.5 & 119.5 & 136.5 \\
\hline Capital Equipment & 10.5 & 22.0 & 25.0 & 25.0 & 14.0 \\
\hline Total Cost & 62.0 & 100.0 & 135.5 & 144.5 & 150.5 \\
\hline Direct Personnel & 207 & 310 & 384 & 414 & 429 \\
\hline
\end{tabular}




\section{Electronics}

Sandia's electronics capabilities and programs provide at a single site a comprehensive integration of the entire electronic component realization process. Our outstanding capabilities in this arena are unicue among U.S. government facilities. We apply our resources to developing custom components for specialized DOE applications as well as precompetitive technologies for customers in the private sector.

Sandia's broad-based activities provide a focus for 1 ) OE's response to industry-generated technology road maps, such as those prepared by the Semiconductor Industry Association and the Optoelectronics Industry Development Association. In addition, we provicle a direct mechanism for transitioning university research into manufacturable clectronics products and processes.

Sandia's Center for Microelectronics Technologies provides a unique capability for industry. relevant research and development. This capability is being accessed by industry through a 5 -year, $\$ 100$ million cooperative research and development agreement (CRADA) with the U.S. semiconductor industry consortium SEMATECH as well as through CRADAs with individual companies. The center is supported by a large range of semiconductor and microelectronics capabilities.

Activities of the center in support of the U.S. semiconductor industry include the Semiconductor Equipment Technology Center (SETEC) and the Contamination-Free Manufacturing Research Center, both joint projects with SEMATECH.

The Center for Microelectronics Technologies conducts joint projection $x$-ray lithography and projection electron beam lithography programs with industrial partners to develop the next generation of processes and processing equipment. The center is also the site for developing environmentally conscious manufacturing and environmentally safe and healthful procedures for semiconductor manufacturing. Sandia is working with SEMATECH and the U.S. equipment manufacturers represented by SEMI/SEMATECH to develop a Semiconductor Equipment Design (enter in SETEC.

Sandia's Microelectronics Development Laboratory is a 74,000 -square-foot facility' that includes 30,000 scuare feet of cleanroom space with 12,500$)$ square feet of

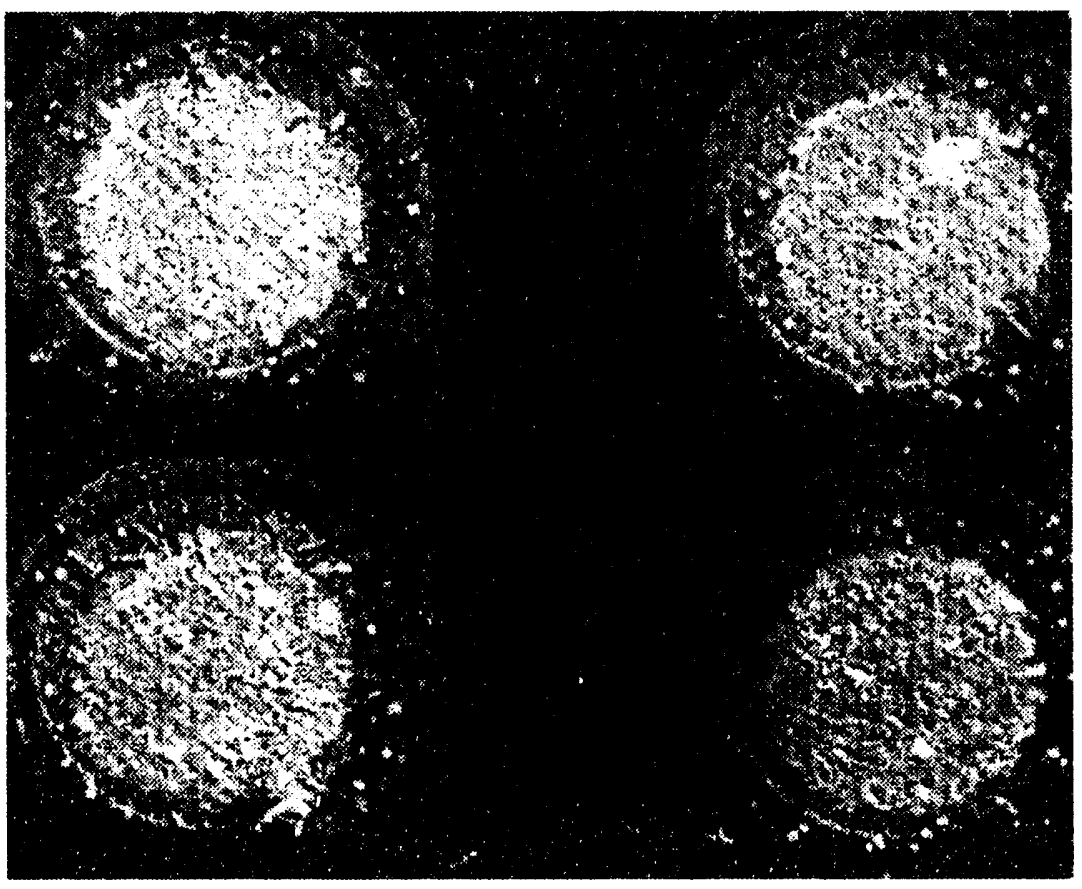

A new family of water-based chelating etches using organic acids was developed by a Sandia research team and has been used to process a variety of superconductor and ferroelectric devices. The etches provide selectivity, minimize surface deterioration, are capable of etching submicron feature sizes, can be tailored for particular materials, can be used to produce either vertical-edge profiles or sloped profiles, and have been shown to cause minimal change in surface resistance of the high-temperature superconductors (HTS).

Previously, large increases in surface resistance had led to impressions that water-based solutions could not be used for processing HTS thin films requiring small feature sizes or high-speed operation. The Sandia researchers recognized that the problem was not the water but reactions involving carbonates in the solution. They developed a decarbonated chelating process that uses nitrogen to decarbonate the solution and a chemical agent to provide proper etching before deleterious surface reactions can occur. The researchers can tune the reaction rate for specific metals, further controlling the selectivity of the etching.

This work won a 1993 R\&D 100 award. 
Class I clean space in 22 separate clean rooms. The laboratory's design provides maximum flexibility for new processing equipment and device technologies and is unicjucly contigurable to support the joint Center for Contamination-Free Manufacturing. A large donation of equipment and technology by IBM provides a state-of-the-art submicrometer silicon integrated circuit research and development line. The Microelectronics Development Laboratory's complete equipment set supports the total semiconductor development cycle including research, design, fabrication, test, prototype delivery, qualification, and technology transfer. These facilitics also support "smart" micromachining, intelligent sensor, and display research and directly impact electronics packaging and assembly activities.

Sandia's Microelectronics Quality and Reliability Center provides staff and equipment to evaluate and verify electrical and mechanical properties of microelectronic materials, design, verification, and construction at the components level. Sandia's reliability physics and engineering efforts draw upon materials science programs that develop basic understandings of failure mechanisms such as electromigration or stress voiding, defects in insulators and metalizations, and defects in semiconductors.

The Center for Contamination-Free Manufacturing at Sandia was formalized by a cooperative research and development agreement with SEMATECH in 1992. This center exploits the unique layout of Sandia's Microelectronics Development Laboratory to conduct experiments to verify advanced semiconductor manufacturing concepts and equipment which reduce contamination that limits the yield of integrated-circuit manufacturing processes.

The center conducts and coordinates research in cost-effective contamination-free manufacturing technologies involving features sizes as small as 0.2 micrometers and removal of defects as small as 0.01 micrometers (the size of bacteria). Research focuses on the effects of chemical particulates and electrostatic, thermal, and electromagnetic (including light) radiation contamination on circuit yield and performance. 'The center also supports development of equipment and processes, improved equipment reliability through software quality, ergonomics and modeling, as well as new lithography devices, material components, and equipment. These activities are an extension of Sandia's historic development of the laminar-flow clean room, which made possible the entire microelectronics and industry.

Sandia was a pioneer in the development of compound semiconductors. Our Center for Compound Semiconductor Science and Technology pioneered the strained-layer-superlattice (SLS) material and such SLS-based devices as pseudomorphic high-electron mobility transistors (P-HEMTs) and circuits, and such semiconductor photonic devices as vertical cavity surface enitting lasers (VCSELs). It was in this laboratory that Sandia engineers demonstrated the advantages of strained-layer superlattices, which today are responsible for the highest-speed, highest-efficiency, and longest-lived semiconductor lasers, transistors, and integrated circuits available in the world.

The center supports the full range of theoretical and experimental activities for solid-state physics, materials science, crystal growth, device and circuit design, and fabrication to develop the next generation of compound semiconductor electronic and optoelectronic devices. Facilities include extensive molecular beam epitaxy and metal-organic chemical vapor deposition crystal growth capabilities, ion implantation, and electron beam lithography in a 6,000-square-foot, (lass 100 clean room with state-of-the-art processing equipment.

Sandia's program for sensor development currently employs over 100) technical professionals who extend the state of the art in sensor technologies for manufacturing and other applications. Among the unique facilities utilized are the Microelectronics Development Laboratory (described above); the Intelligent Machine/Robot Advanced Sensor and Control Laboratory, consisting of 25 different development labs containing the latest commercially available robots, 5 -axis computer-numerically controlled (CNC) machines, mobile platforms, state-of-the-art rescarch robots, and advanced controllers; the Microsensors Research and Development Laboratory, including 15 separate research, engineering, and development labs that fabricate, package, and integrate new sensors into fieldable subsystems; and the Sensor Test and Modeling Laboratory, 
which has numerical modeling and equipment characterization facilities for environmental, chemical, electromagnetic, stress, and thermal testing.

The Process Development Laboratory is a ficility for advanced prototype manuficturing housed in a $100,00(1-$ square foot building featuring equipment for hybrid microcircuits, thin films, printed circuits, ceramics, plastics, and rapid prototyping. The laboratory coordinates its activities with the Integrated Manuficturing 'lechnologics laboratory at Sandia's (allifornia facility.

The charter of this manufacturing process design center is to focus on reliability and yuality of manufacturing processes through understanding and pualification of manuficturing processes. Particular emphasis is given to automution and robotic handling through complementary progranns both in software and in robotic hardware.

This facility also acts as a proving ground for custom sensors for manufacturing processes. Bmphasis is placed on developing new approaches to joining and sealing dissimilar materials that have particular relevance to advanced packaging concepts. (collaborations with the laccoca Institute at l.e.high University have led the Process Development Laboratory to support empirical investigations of higherlevel manufacturing issues such as control, optimization of material flow, and workspace organization.

To realize custom designs for its customers, Sandia has developed an integrated approach to the design of microdectronic ormponents and systems. As part of these activities, Sandia writes custom support software to commercial vendors, which has become the basis for multiple commercial design packages. Sandia's integrated software environment conbines circuit-level simulators, logic-level simulations, as well as looth analeg and digital system-level simulators with complete verification from chip to multichip module to printed circuit board.

Sandia's capabilities and facilities in electronics are conprehensive and span the development cycle from research to manuficturing support. This competency is certainly unique among U.S. government facilities and is competitive with the best electronics research and development facilities in the world. The following package of initiative project proposals is designed to exploit these capabilities to the maximum to benefit both defense and dual-use needs.

\section{Project Proposals for the Major Initiative in Electronics}

\section{Electronics Applications Center [for the Assistant Secretary for Defense Programs (GB)]}

Fiectronice are at the heart of every weapon system and nearly every commercial product. Hectronic products range in complexity and sophistication from portable radios to sophisticated computers, "smart" bombs, and life-support systems. Blectronics have revolutionized not only the ways in which the nation defends itself, but nearly all aspects of our lives: Our automobiles now go farther than 30,000 miles without the need for a tune-up, due in large part to electronic fuel-delivery systems. Our homes include a suite of electronically controlled appliances, entertainment devices, security systems and, in some cases, medical devices that help sustain peoples' lives.

For over forty years Sandia has designed manufacturable electronics systems that meet the stringent surety reguirements of nuclear weapons. As outstanding as this accomplishment is, we need to broaden our applications in order to meet 1$)$ ()F's s changing requirements and help improve U.S. industry's ability to compete globally.

We propose the establishment of a new Electronics Applications Center at Sandia to meet the dual-use needs of 1$)($ )E while providing enabling technologies that help U.S. industry. The center will accomplish these objectives by dramatically improving the electronic product realization processes and associated technologies. The success of the center will be likeasured in the ability of 
the technologies it introduces to simultancously shorten the concept-to-preduct development cyck, reduce development and manufacturing costs, and minimize product environmental impacts.

The near-term focus of the center's work will be to improve design and performance modeling tools. Currently, the hest electronic product design and modeling tools reguire an experienced, well-trained designer and often a significant capital investment in hardware and software. liven under the best of conditions, there exist very few common ties in data input formats between the various tools. Consequently, the product designer must enter design data into the initial computeraided design file in one format, then reenter the design data in a second format to perform circuit electrical performance modeling, then a third time to do thermal and mechanical analysis, and a fourth time to do circuit board physical layout for fabrication, and so forth.

An initial thrust in the Blectronies Applications Center work will be to devetop overlay expert systems that obviate the necessity for costly duplications of effort. The cost of correcting multiple entries is seen not only in the time and talent consumed by the current process, but also in errors introduced and propagated at each data entry point. These errors often lead to multiple iterations of prototypes and delay introduction of the product into the marketplace.

Sandia designers were recently able to demonstrate a dramatic decrease in development cost and cycle time. We successfully developed a complicated, high-value defense product from concept-toproduct without ever building a physical prototype. The prototype existed only on computer. The use of this "virtual prototyping" resulted in a well characterized design and a robust product. The development period was characterized by rapid design iterations and tremendous savings in cost and development time. This work exemplifies the promise and payoff of the proposed center.

The development and use of these advanced product realization technologies in Sandia's Blectronics Applications ('enter will ensure the Laboratories' capability to meet I)(O)E's changing needs. It will, as a result of this initiative, be capable of delivering manufacturable designs in much less time, at reduced development cost, with higher product surety than at any time in its past.

Another thrust in the Electronic Applications (Center initiative will be the development of a design assistant to lead engincers through the concept-to-product cycle in an expert manner. This computerbased design assistant will facilitate skilled engineers' use of various twols while simultaneously' augmenting less skilled engincers' capabilities to select and use the most appropriate design tools and processes. This capability is viewed by many in the electronics industry as a key enabler of global marketing success for American industry. At the conclusion of this phase of the initiative, the technologies of the Electronics application (enter will be a truly dual-use capability - fully capable of meeting 1 ()E needs while providing a strategic capability for the nation's electronics industry.

A subsequent phase of this initiative is to operate the Blectronics Application Center for the dual purposes of national security and national coonomic competitiveness for U.S. electronics manu icturers. Response to D()E and ease of access by industry will be the hall marks by which this center's viability will be determined.

Crosscutting this initiative is the need and desire to collaborate with other advanced manuficturing initiatives in both industrial consortia and other federal agencies. The National Information Infrastructure initiative of the National Institute of Standards and Technology and the Envirommentally Conscious Manufacturing program of the National Center for Manufacturing Sciences are two examples of potential synergistic relationships that will be explored.

\section{Center for Microelectronics Technologies [for the Assistant Secretary for Defense Programs (GB)]}

The electronics industry, the largest manufacturing sector in the United States (providing three times as many jobs as the entire domestic automobile industry), is being steadily eroded by fierce, government-subsidized foreign competition. This competition threatens the U.S. economy by attacking its largest manufacturing sector. () ecual importance, forcign competition in microelectronics 
and photonics threatens the security of the United States by reducing the number of domestic manufacturers of advanced components critical to modern defense systems.

Facing such pressures, the U.S. semiconductor industry has draw'n together in unprecedented fashion. Recently, the U.S. Semiconductor Industry Association released a technology plan for the U.S. microelectronics industry through the year 2013 that was assembled by 179 of the top U.S. semiconductor experts from industry, government, and universities. This road map identifies opportunities for the government laboratories to help industry address their generic technology needs.

In response to the Semiconductor Industry Association's directly stated needs, Sandia established the Center for Microelectronics Technologies to assist the industry in dual-use projects. This center is created by combining the existing Microelectronics Development Laboratory (MI)L.) with a major donation of equipment and technology valued at over $\$ 63$ million from IBM.

The center will create a centralized site and spawn partnership projects with the U.S. microelectronics industry and universities to develop the technologies, manufacturing equipment, and advanced processes upon which the future of both commercial and defense electronics depends. The center will also serve as the arena through which future generations of U.S. graduate students will be trained in the most advanced integrated circuit technologies in the world.

A combined geverning board will select projects that combine teams of researchers selected from U.S. universities, businesses, and the national laboratories with major industry partners who agree to commercialize the results. The center's major impacts are on processing methods and equipment (singled out as critical elements of this technology on page 87 of the DOE Defense Programs Critical Technology Plan) and on U.S. semiconductor manufacturing equipment, another key goal.

The federal government is the major beneficiary of this work, both through custom products for government applications and through support for the domestic manufacturing base that provides these products. Consequently, it should provide a sustaining level of funds for center operations. Industry will benefit through specific projects that will be cost-shared with government. Initial government support should be $\$ 50$ million per year and should grow to $\$ 100$ million per year in five years, an increasing percentage of which will be supported by industry organizations such as SEMATECH through dual-use programs.

\section{National Optoelectronics Initiative [for the Assistant Secretary for Defense Programs (GB)]}

Optoelectronics will provide the hardware for the information highways that will carry the United States into the twenty-first century. Optoelectronic elements will provide the high-data-rate communication links between remote manufacturing sites to create the agile enterprises in the DOF nuclear weapons complex for cost-effective realization of future weapon systems. Over shorter distances, optoelectronics will become the means by which computers communicate with storage and output devices and even among multichip modules that will provide the intelligence within computer workstations in the future.

In the private sector, optoelectronics-based information networks will pervade the lives of citizens by providing access to vast quantities of data for commerce, information, education, and entertainment. Information highways based on optical components will soon become as critical to our commercial and defense infrastructure as bridges and highways.

Despite having pioneered the components responsible for this revolution, the U.S. optoclectronics industry is watching its position in the world marketplace erode. Japan has increased optoetectronics production from $\$ 700$ million in 1980 to over $\$ 32$ billion in 1990, a 32 -fold increase in ten years. During this decade U.S. producers have lost world market share from $50 \%$ in 1980 to less than $15 \%$ in 199(). If foreign producers cement their dominant position in optoclectronics, it is unlikely that U.S. producers will ever recapture sufficient market share to sustain domestic production of these critical enabling components. 
Similar to the Semiconductor Industry Association for integrated-circuit techmology, the U.S. Optoelectronics Industry Development Association (()ID A) is creating a fechnology road map to chart a course for common action. ()IDA selected five critical areas: display's, optical communications, optical data storage, optical interconnection and switching, and hard copy output. (I )isplay's are responsible for half the sales volume of electronic products; consecyuently, a separate project proposial has been formulated for displays.)

Remarkably, advances in the four other critical areas (other than display's) are enabled by just two key competencies: optoelectronic materials and opteclectronic manuficturing, especially processes and production equipment. These are areas of particular strengths at Sandia. We proposic applying the resources of the Compound Semiconductor Science and lechnology (ienter to sipport a national optoelectronics initiative in a dual-use partnership with the U.S. optoelectronics industry.

Optoelectronics manufacturing relies on expensive facilities with specialized production equipment. Sandia's Compound Semiconductor Science and Technology ('enter provides the ideal facility at which cost-leveraged partnerships between U.S. industry, universities, and government reseirchers will perform the pre-competitive development of the design tools, processes, and related production equipment essential for U.S. optoelectronics manufacturers.

An advisory board will recommend projects that combinc teams of researchers from multiple organizations. These teams will include major industry partners who will commercialize the results. This initiative will have major impacts on processing methods and equipment and on manufacturing equipment, which are as critical for optoelectronics as they are for silicon integrated-circuit production.

\section{Emissive Flat-Panel Display Technology Center [for the Assistant Secretary for Defense Programs (GB)]}

Displays form the critical interface between humans and the intelligent microelectronic chips that operate today's smart systems. In the future, displays will pervade the defense and commercial sectors. Not only are displays critical because of their applications, but the manufacturing technologies for displays also increasingly overlap those needed for multichip module integration, semiconductor component manufacturing, and even the underlying electronic materials and process development. Advanced flat-panel displays are predicted by the Japanese Optoelectronics Industry Trade Development Agency (OITDA) and the U.S. Optoelectronics Industry Development Association (OIDA) to represent a $\$ 20$ billion dollar per year component market by 2000 .

Despite having pioneered the technologies responsible for all modern displays, the United States has seen Japanese firms capture $95 \%$ of the global display market through their concentration of resources in a single technology, Active-Matrix Liquid-Crystal Displays (AMILCD)). However, AMLCD technology is deficient in such key attributes as power consumption, color, brightness, and ability to operate at video rates. AMLCD) technology also suffers from poor manufacturing yields due to unavoidable process complexity because each picture unit (pixel) must be operated by a functioning transistor.

Consequently, an opening exists for competing technologies to overcome the market lead of AMLCD technology. However, to impact global markets, these technologies must not only demonstrate performance advantages but also cost and manufacturing advantages. A critical weakness of these technologically promising display alternatives is the lack of an infrastructure of manufacturing equipment and processes to permit the transition to volume production. Such infrastructure is beyond the means of any one institution or corporation and requires a common, neutral site for cost-leveraged development of enabling, pre-competitive technologies.

Sandia proposes applying selected elements of its Microelectronics Development Laboratory (MDL) and Process Development Laboratory (PI)L.) to support the development of technologies and manufacturing infrastructure for emissive flat-pand displays. Particular programmatic emphasis 
will be given to automation and robotic handling through compleme'ntary programs both in softwalre and in robotic hardware. These facilities also can act as proving grounds for custom sensors for manufacturing processes. Additional emphasis will be placed on novel approaches to joining and sealing technologies for dissimilar materials required for advanced display concepts.

Display manufacturing relies on expensive facilities with specialized production equipment. Sandia provides the ideal location for cost-leveraged partnerships for generating the precompetitive infrastructure of design tools, processes, and related production equipment essential for U.S. display manuficturers. This display initiative will have major impacts on processing methods and manufacturing épuipment.

\section{Electronics Packaging \\ [for the Assistant Secretary for Defense Programs (GB)]}

Electronics packaging is a key technology for the U.S. electronics industry. As packaging requirements have become more stringent and the number of interconnections have multiplied, it has become obvious that the success of complex electronic assemblies depends on the development and implementation of workable packaging strategies. Since high-reliability electronic assemblies are at the heart of transportation and telecommunications infrastructures, packaging failures can affect the safety and security of people (e.g., in automobiles and airplanes) and the stability of national infrastructure systems (e.g., telecommunications, banking, commerce, etc.).

Sandia is unique among the national laboratories in having the responsibility for delivering packaged components for insertion in DOE weapon systems. We have developed a broad-based scientific and technical infrastructure supporting the DOE nuclear weapons programs that design, develop, and certify manufacturable processes for packaging electronic components. This infrastructure includes package design at all levels; advanced materials and processes for packaging; computer simulation of the thermal, mechanical, and electromagnetic responses of packages; development of reliability diagnostics; analysis of packaging failures; and facilities for manufacturing processes and prototype packages and evaluating package integrity.

U.S. industry has recognized Sandia's unique, integrated capability in packaging. Sandia is now working on packaging-related Cooperative Research and Development Agreements with the auto industry for under-the-hood electronics, the National Center for Manufacturing Sciences for twentyfirst century printed circuit board interconnect technology, and the microelectronics and photonics industries for high-reliability manufacturing processes, integrated diagnostic environments, and advanced materials for optical interconnects.

The Electronics Packaging Initiative will expand our packaging manufacturing capabilities in the area of large-area lithography for multichip modules, flat-panel displays, and printed circuit boards. It will create a packaging "island" as part of Sandia's T'echnology Information Environment for Industry (TIE-IN) project and support materials and process development through the Center for Microelectronics Technologies and the Center for Compound Semiconductor Technology. It will develop hierarchical reliability testing through Sandia's National Center for Ultra-Reliability Engineering (NCURE). Finally, it will provide an educational platform to transition university research in packaging into manufacturable processes. The initiative will be coordinated by Sandia systems engineers and modeled after the successful development of the Mark 5 arming, firing, and fuzing program.

This initiative will be funded by l efense Programs in support of its mission to produce high-reliability electronics subsystems. However, beciuse of its dual-use nature, it will also receive support from U.S. industry through cooperative research and development agreements and from the Advanced Research Projects Agency (ARPA) through the National (enter for Advanced Information Components, addressing advanced silicon microelectronics and flat-panel display packaging concerns. ()utyear funding can also be expected from the ARPA follow-on to the Technology Reinvestment Project. 


\section{Communication Hardware Development Center [for the Assistant Secretary for Defense Programs (GB)]}

High-data-rate, high-bandwidth communications devices will pervade future electronics, from compact subassemblies to large terrestrial and space communications systems. The litectronics Industrial Association ( $\mathrm{B} A \mathrm{~A}$ ) road map predicts that future integrated circuits and high-density, multichip-module (ACCM ) packaging will contain thousinds of interconnects, resulting in data rates of tens to hundreds of gigabits per second.

Current interconnect schemes cannot accommodate the packing densities, size reduction, signal timing, and low crosstalk required by high-density, high-data-rate signals. To resolve these issues, MCM-to-MCM and board-to-board interconnects will cmploy ribbon-fiber optics and free-space photonic interconnects. Terrestrial and space-based communications, as well an local and long-distance networks between workstations, will employ similar high-bandwidth technology.

Future defense and commercial communications systems will obtain their performance from compound-semiconductor devices and circuits, including photonic devices, optoelectronic integrated circuits, high-speed digital integrated circuits, microwave and millimeter-walve devices and circuits, and photonic interconnects. Due to the combined requirements of high speed, high frequency, and high density, future communications systems will require low-power devices and circuits with device feature sizes below 0.25 microns.

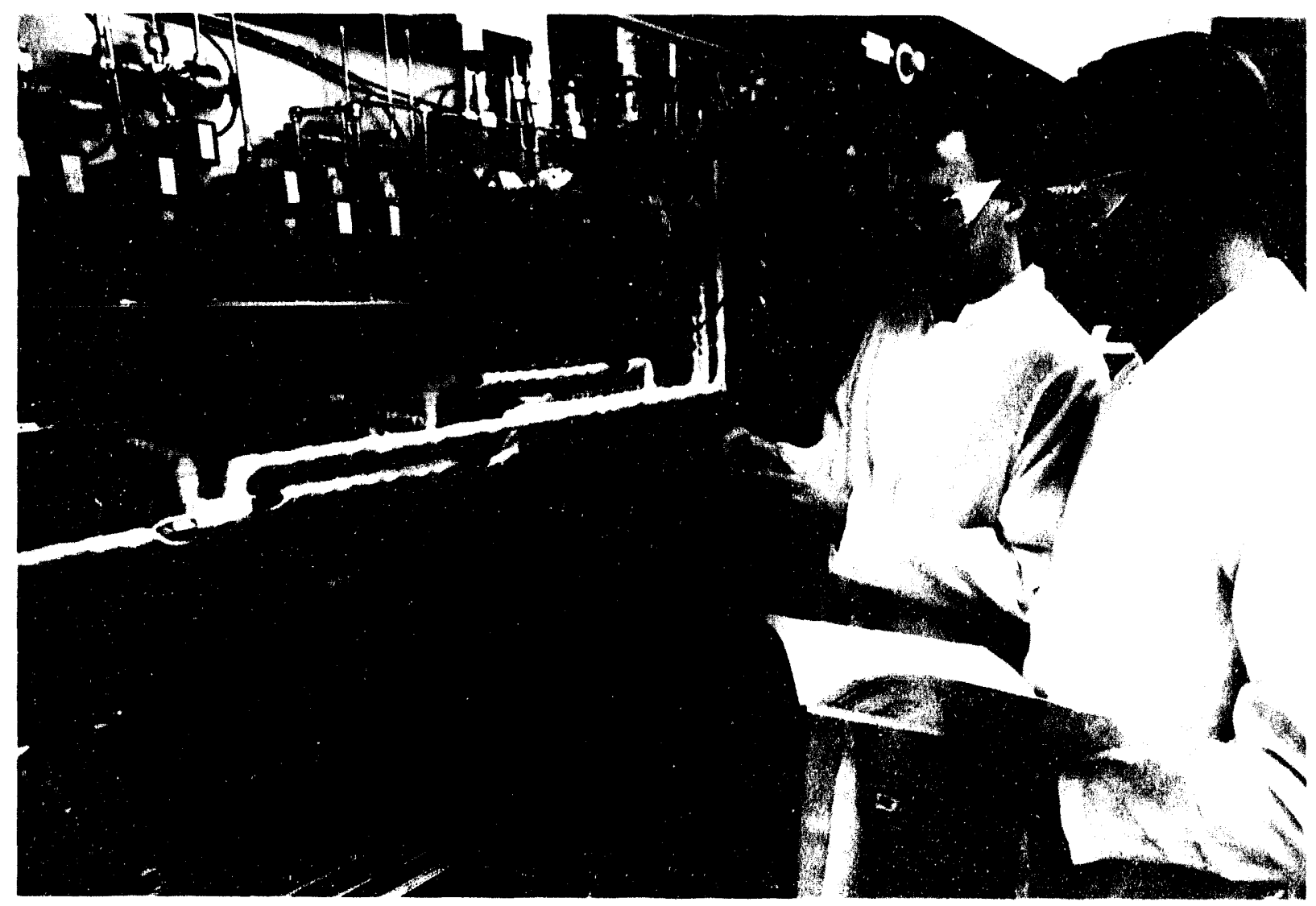

Sandian Rick Schneider and Lim Lott (U.S. Air Force) were members of a team that produced the first electrically injected visible-light vertical-cavity surface emitting lasers (VCSEL). They are standing by a metallorganic vapor phase epitaxial growth system from which wafers containing the lasers are produced. This development builds on the strained-layer superlattice technology that was pioneered by Sandia in the 1980s. 
We propose to employ prototype communications hardware as platforms for inserting highimpact compound-semiconductor technology into future defense and commercial sy'stems. W'e will exploit the capabilities of our Center for Compound Semicondector Science and Technology (CCST) to form partnerships with U.S. industry in developing the design, process, and manuficturing infrastructure necessary for developing and manufacturing these advanced communications components. Sandia will serve as neeutral site for technology test beds for fiber-optic and free-space interconnects, workstation networks for both local area and long distance, and microwalve and millineter-wave terrestrial and space-based communications.

Sandia has recently invented a red V' CSEL (vertical cavity surfice-emitting laser) for low-cost, rugged, plastic optical-filer networks and reflection amplitude modulators for both $1.06-\mu$ un and 1.32$\mu$ moptical wavelengths. Sandia inventions are critical enablers for these proposed communication technologies. ( nngoing Sandia efforts on compound semiconductor complementary digital circuits will create novel components and systems for applications requiring low-power, high-speed computing.

This communications hardware initiative will leverage Sandia's pioneering work in Switched Multimegabit Data Service/Asynchronous Transfer Mode (ATM) links. ATM has been endorsed by the international standards community and has been chosen by Sandia as the enabling technology for establishing national computing and communications leadership in the Department of Energy.

Sandia will address next-generation computer architectures and communications hardware issues by combining high-impact compound semiconductor technology and advanced hardware technology. Results will benefit the National Information Infrastructure by addressing high-capacity computer networks as well as satellite communications (using Sandia's 6) gigahertz satellite crosslink) for advanced transportation initiatives and wireless communications.

By directly supporting enabling technologies that will lead to smaller, higher-speed computers, this initiative will address several $D$ ()E defense-critical technologies. It will enhance signal processing and data fusion for synthetic aperture raddars engaged in real-time imaging for D()E defense applications. Size reduction will enhance embedded computer systems for flight demonstrations of "smart" bombs. This initiative also supports the 1)(OE technology base by focusing and employing both microelectronics and photonics and engineered materials technologies.

\section{Sensors}

[for the Assistant Secretary for Defense Programs (GB)]

Advanced sensors are the means by which "intelligent" (computer-controlled) processors monitor and control the operation of systems and manufacturing processes. Sandia has developed novel families of sensors that sense a range of chemical, thermal, electrical, and mechanical properties for defense and commercial applications, including weapon state-of-health monitoring, manufacturing process control, detection of envirommentally hazardous chemicals, and other dual-use monitoring applications.

Such sensors, fabricated with Sandia's unique microelectronic and materials technologies, enable broad new applications in remote monitoring, industrial process improvement, and real-time control. commercial applications include assessing the reliability of packaged microclectronic products, continuous evaluation of the guality and viscosity of vehicle engine oil, identifying the presence of environmental pollutants, and indicating the presence and concentrations of explosive gases.

Other applications of Sandia's sensor technology directly impact the weapons stockpile, weapons surety, advanced weapons designs, and process sensing/control for Complex 21 . An example of such applications envisions advanced, chemically selective sensors and the integration of radiation sensors and sensor arrays to detect very low levels of corrosion byproducts to monitor the integrity of the stockpile and indicate the potential for problems. (hemical sensors are now being used to monitor weapon production processes by providing real-time control of possible chemical emissions into effluent streams at I) OE manufacturing facilities. This is an application for which laboratorysized analytical instruments are not cost-effective or suitable due to power and space limitations. 


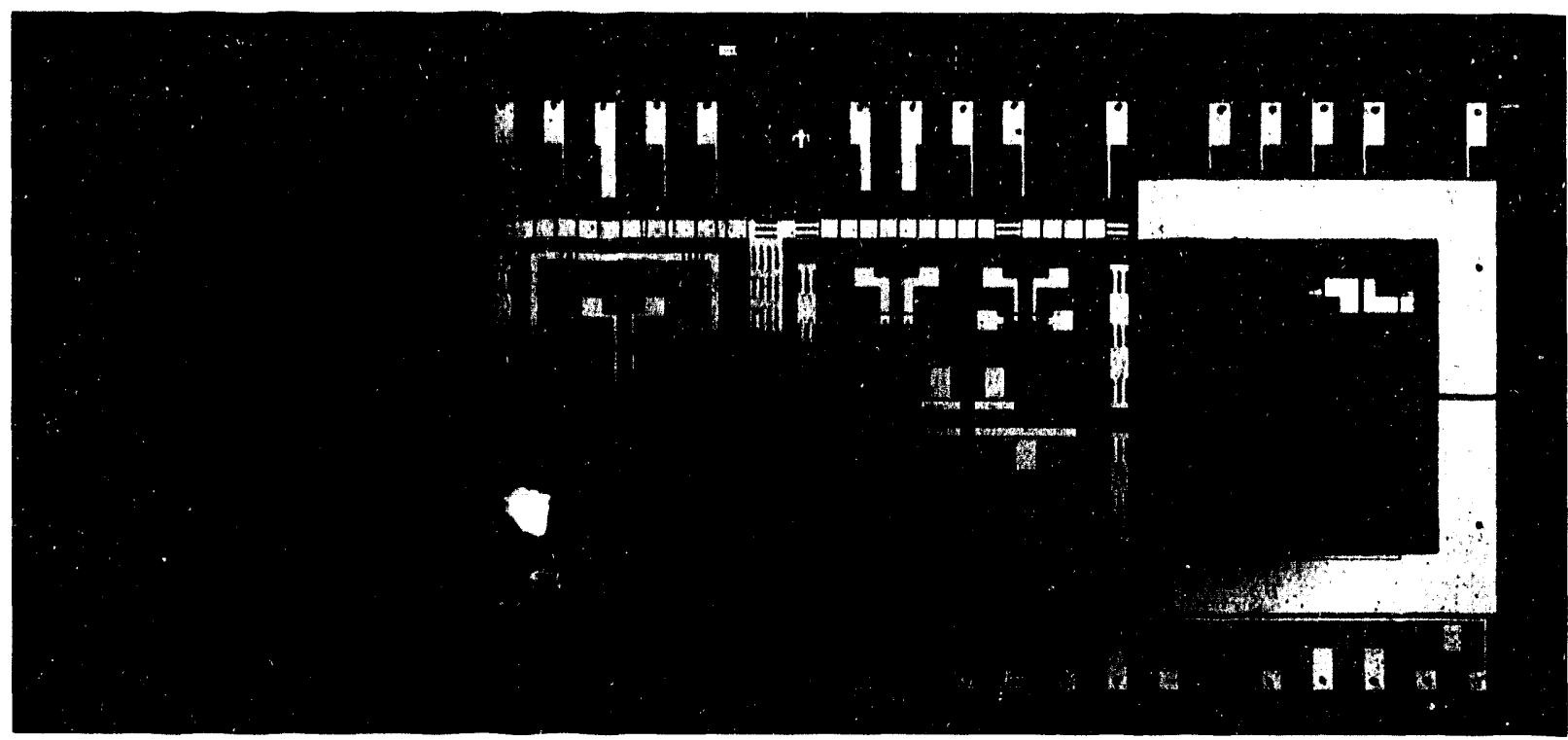

Sandia's hydrogen microsensor garnered a 1993 R\&D 100 award. Hydrogen, encountered in a large variety of industrial, space, and military applications, poses a significant fire and explosion hazard. Sandia's hydrogen microsensor has many advantages over older techniques. It is smaller, lighter, faster, and less expensive than older instruments and works over greater dynamic and temperature ranges. Each microsensor contains palladium-nickel gate MOS (metal oxide semiconductor) transistors. The threshold voltage of the transistors shifts in response to the concentration of hydrogen in the ambient air. The palladium-nickel alloy is unique in that it allows detection of hydrogen at the parts-per-million level but does not fail at higher concentrations. Fabrication of the control electronics and temperature-regulation devices on the same chip as the sensor provides miniaturization, manufacturability, sensitivity, and stability. Use of microelectronics fabrication techniques allows batch fabrication of more than 8,000 identical sensors per production run.

This new technology is already being used in ground-based test facilities at the National Space and Aeronautics Administration and has been included as part of a robotic test probe developed to monitor underground radioactive waste storage tanks. No previous hydrogen detection technology would have met the stringent requirements of these applications.

The suite of Sandia sensor technologies is being continuously refined and augmented with related Sandia microelectronic, materials science, signal processing, packaging, and subsystem technologies to expand the range of applications. We propose to integrate these sensor activities into a unified program for maximum synergy with a multitude of government, university, and industrial customers. By forming partnerships with industry to develop sensor manufacturing merhodologies and leverage development costs, Sandia will serve as the nucleus around which the nascent U.S. sensor industry can generate the technologies and produce the components it needs to transform the production and operation of future commercial and defense systems.

These sensor technologies have significant dual-use interest for manuficturing oriented appliciations, particularly for the semiconductor industry, the automotive industry, the machine tool industry, the textiles industry, and the petroleum industry. Sandia's novel transducer developments, based on ultrasonic, fiber-optic, and solid-state technologies, have solved characterization and monitoring problems for improved manufacturing yield, quality, environmental compliance, and functionality.

\section{"Smart" Micromachines}

[for the Assistant Secretary for Defense Programs (GB)]

Micromechanics is an emerging field which uses microelectronic fabrication techniques to build ultra-miniature mechanical structures with micrometer-dimensioned feature sizes. The small size, 
low power requirements, and ruggedness of micromachined elements are highly attrat tive in modern systems and applications. Conseyuently, micromachining is truly a dual-use enabler. Enormous markets for micromachined components are likely in the automotive, biomedical, alerospace, and robotics industries, as well as in emvirommental monitoring and restoration, for the sensors and actuators that can be built using these techniques. The same families of micromachined structures are important for such Detense Programs applications as ultra-rugged, ultra-miniature clock structures for use in weapon systems and a micro-mechanically fabricated version of a stronglink switch.

Micromachining technology is still in its infancy. A major advance in the evolution of micromachined components will occur when micromachines are integrated with low-power, complementary metal-oxide semiconductor ( $C M I O S)$ integrated circuits on a single chip. The benefits of integrating CMOS integrated circuits with mechanical microstructures are greater accuracy, performance, and additional functionality, and they derive from improved signal processing and reduced noise and parasitics.

While it is widely recognized that most applications would greatly benefit from the ability to integrate control electronics on the same chip as the micromachines, few micro-mechanical efforts in the United States have the infrastructure, capacity, or capability to both develop this integrated technology and make it available to industry. Sandia proposes to collaborate with U.S. industry to revolutionize the manufacturability, functionality, and applicability of micromachined devices through the on-chip integration of micromachines with control electronics. This activity will exploit our unique Microelectronics L evelopment Laboratory for sub-micrometer-dimension integratedcircuit technology, as well as our extensive experience base in micromachining technology.

The proposed smart micromachining effort will allow U.S. industry and universities to pursuc specific projects that require an integrated micromechanics technology. This project will be operated by a government-industry-university partnership for cooperative development and highly leveraged fabrication of this unique technology. This activity would lead to a low-cost, manufacturable "smart" $\mathrm{n}$ icromachines technology and demonstration platforms that can be applied both to defense and commercial needs.

\begin{tabular}{|c|c|c|c|c|c|}
\hline \multicolumn{6}{|c|}{$\begin{array}{l}\text { Funding Requirements for Initiative Project Proposals in Electronics } \\
\text { (Dollars in constant FY } 1994 \text { millions; personnel in FTEs) }\end{array}$} \\
\hline & Year 1 & Year 2 & Year 3 & Year 4 & Year 5 \\
\hline \multicolumn{6}{|c|}{ Electronics Applications Center } \\
\hline Operating & 4.5 & 8.0 & 8.0 & 8.0 & 6.5 \\
\hline Capital Equipment & 1.0 & 3.0 & 2.0 & 2.0 & 1.0 \\
\hline Total Cost & 5.5 & 11.0 & 10.0 & 10.0 & 7.5 \\
\hline Direct Personnel & 20 & 35 & 35 & 35 & 30 \\
\hline \multicolumn{6}{|c|}{ Center for Microelectronics Technologies } \\
\hline Operating & 45.0 & 60.0 & 75.0 & 90.0 & 100.0 \\
\hline Capital Equipment & 12.0 & 15.0 & 18.0 & 18.0 & 20.0 \\
\hline Total Cost & 57.0 & 75.0 & 93.0 & 108.0 & 120.0 \\
\hline Direct Personnel & 90 & 120 & 150 & 180 & 200 \\
\hline \multicolumn{6}{|c|}{ National Optoelectronics Initiative } \\
\hline Operating & 25.0 & 33.0 & 45.0 & 60.0 & 70.0 \\
\hline Capital Equipment & 10.0 & 13.0 & 16.0 & 18.0 & 20.0 \\
\hline Total Cost & 35.0 & 46.0 & 61.0 & 78.0 & 90.0 \\
\hline Direct Personnel & 50 & 66 & 90 & 120 & 140 \\
\hline
\end{tabular}




\begin{tabular}{|c|c|c|c|c|c|}
\hline \multicolumn{6}{|c|}{$\begin{array}{l}\text { Funding Requirements for Initiative Project Proposals in Electronics (Continued) } \\
\text { (Dollars in constant FY } 1994 \text { millions; personnel in FTEs) }\end{array}$} \\
\hline & Year 1 & Year 2 & Year 3 & Year 4 & Year 5 \\
\hline \multicolumn{6}{|c|}{ Emissive Flat-Panel Display Technology Center } \\
\hline Operating & 25.0 & 33.0 & 45.0 & 60.0 & 70.0 \\
\hline Capital Equipment & 10.0 & 13.0 & 16.0 & 18.0 & 20.0 \\
\hline Total Cost & 35.0 & 46.0 & 61.0 & 78.0 & 90.0 \\
\hline Direct Personnel & 50 & 66 & 90 & 120 & 140 \\
\hline \multicolumn{6}{|l|}{ Electronics Packaqing } \\
\hline Operating & 13.5 & 18.0 & 24.0 & 30.0 & 35.0 \\
\hline Capital Equipment & 4.5 & 4.5 & 6.0 & 6.0 & 6.0 \\
\hline Total Cost & 18.0 & 22.5 & 30.0 & 36.0 & 41.0 \\
\hline Direct Personnel & 27 & 36 & 48 & 60 & 70 \\
\hline \multicolumn{6}{|c|}{ Communication Hardware Development Center } \\
\hline Operating & 7.0 & 8.5 & 10.0 & 12.0 & 14.0 \\
\hline Capital Equipment & 3.0 & 4.0 & 5.0 & 5.0 & 3.0 \\
\hline Total Cost & 10.0 & 12.5 & 15.0 & 17.0 & 17.0 \\
\hline Direct Personnel & 13 & 15 & 18 & 18 & 18 \\
\hline \multicolumn{6}{|l|}{ Sensors } \\
\hline Operating & 12.3 & 14.1 & 15.5 & 16.8 & 18.1 \\
\hline Capital Equipment & 1.2 & 1.7 & 2.3 & 2.6 & 3.1 \\
\hline Total Cost & 13.5 & 15.8 & 17.8 & 19.4 & 21.2 \\
\hline Direct Personnel & 52 & 60 & 65 & 70 & 76 \\
\hline \multicolumn{6}{|l|}{ "Smart" Micromachines } \\
\hline Operating & 13.5 & 18.0 & 24.0 & 30.0 & 35.0 \\
\hline Capital Equipment & 4.5 & 4.5 & 6.0 & 6.0 & 6.0 \\
\hline Total Cost & 18.0 & 22.5 & 30.0 & 36.0 & 41.0 \\
\hline Direct Personnel & 27 & 36 & 48 & 60 & 70 \\
\hline \multicolumn{6}{|l|}{ Total, Electronics } \\
\hline Operating & 145.8 & 192.6 & 246.5 & 306.8 & 348.6 \\
\hline Capital Equipment & 46.2 & 58.7 & 71.3 & 75.6 & 79.1 \\
\hline Total Cost & 192.0 & 251.3 & 317.8 & 382.4 & 427.7 \\
\hline Direct Personnel & 329 & 434 & 544 & 663 & 744 \\
\hline
\end{tabular}




\section{Information and Computational Technology}

Computational simulation is playing an ever increasing role in enhancing the security and conomic prosperity of the United States. In the future, it will be both cheaper and faster, as well as more accurate and informative, to use computational simulation when designing, optimizing, or simulating a system or process than to perform costly trial-and-error experimentation.

Computational simulation has historically been important to Sandia's national security and energy nissions and is also key to the future of Sandia and the Department of Energy. The advent of revolutionary massively parallel and distributed hardware, software, and communications capabilities in high-performance computing (in which Sandia has played a seminal role) is redoubiing the importance of simulation.

Major applications in nuclear weapons design and safety are being joined by new strategic applications in materials and chemistry, including chemical vapor deposituon and chemical reactors, semiconductor processing and device simulations, band-gap engineering of new electronic and optoelectronic materials, simulation of enzymes and synthetic catalysts, as well as design of polymeric materials. For the oil and gas industry, new massively parallel simulations are allowing huge leaps in our ability to process and interpret seismic exploration data and in our ability to simulate reservoir production and management. The metallurgy industry is benefiting from rapid prototyping of new case parts made possible by the integration of cietailed computational simulation of the casting process into the design of investment castings. Enhanced national security applications in radar imaging and signal processing are growing out of hundredfold increases in simulation capability. Design of synthetic enzymes is leading to new schemes for remediation of hazardous pesticides from the environment. Porous flow modeling is allowing accurate mapping of groundwater transport of hazardous wastes.

Over five hundred Sandia engineers and scientists are involved in the development and application of computational technologies. One of our distinguishing strengths in this area is the ability to develop and integrate theoretical models, advanced numerical methods, and computing technologies to create robust, state-of-the-art tools for simulating complex systems and processes.

The Massively Parallel Computing Research Laboratory at Sandia is a national resource for research in high-performance computing and for its application to problems in science and engineering. An interdisciplinary team of over 60 research staff carries out projects in computational and computer science as well as discrete and numerical mathematics. These staff have access to unicpue massively parallel computers, including the new Intel PARA $(\mathrm{ONN}$, with nearly 2,000) processors, 40 gigabytes of memory, and peak speed of 140 gigaflops; a 1,00()-processor nC CUBE: 2; and a 16,000-processor Connection Machine.

The Massively Parallel Computing Research Laboratory has led the development of massively parallel computing algorithms and applications since its award-winning introduction of massively parallel techniques for real engineering applications in 1987. A total of five awards have been received since 1987 recognizing Sandia's seminal contributions to massively parallel computer technology. Major thrusts of the laboratory include the DOE (irand Challenge in (computer Design of Catalysts and Biocatalysts and development of a broad spectrum of massively parallel applications, including turbulent fluids, chemical vapor deposition, Knudson flows, porous media, yuantum monte carlo for molecules and many-particle systems, massively parallel electromagnetics, and signal processing.

In developing these strategic applications, researchers at the laboratory have made a series of algorithmic innovations, including highly effective massively parallel linear algebra methods, innovative new algorithms for molecular mechanics and dynamics, highly scalable methods for quantum chemistry, automatic finite-element adaptive mesh generation techniques, and powerful domaindecomposition and load-balancing techniques, as well as new massively paralled data visualization methods. Advances in systems technology include portable, light-weight parallel and distributed 


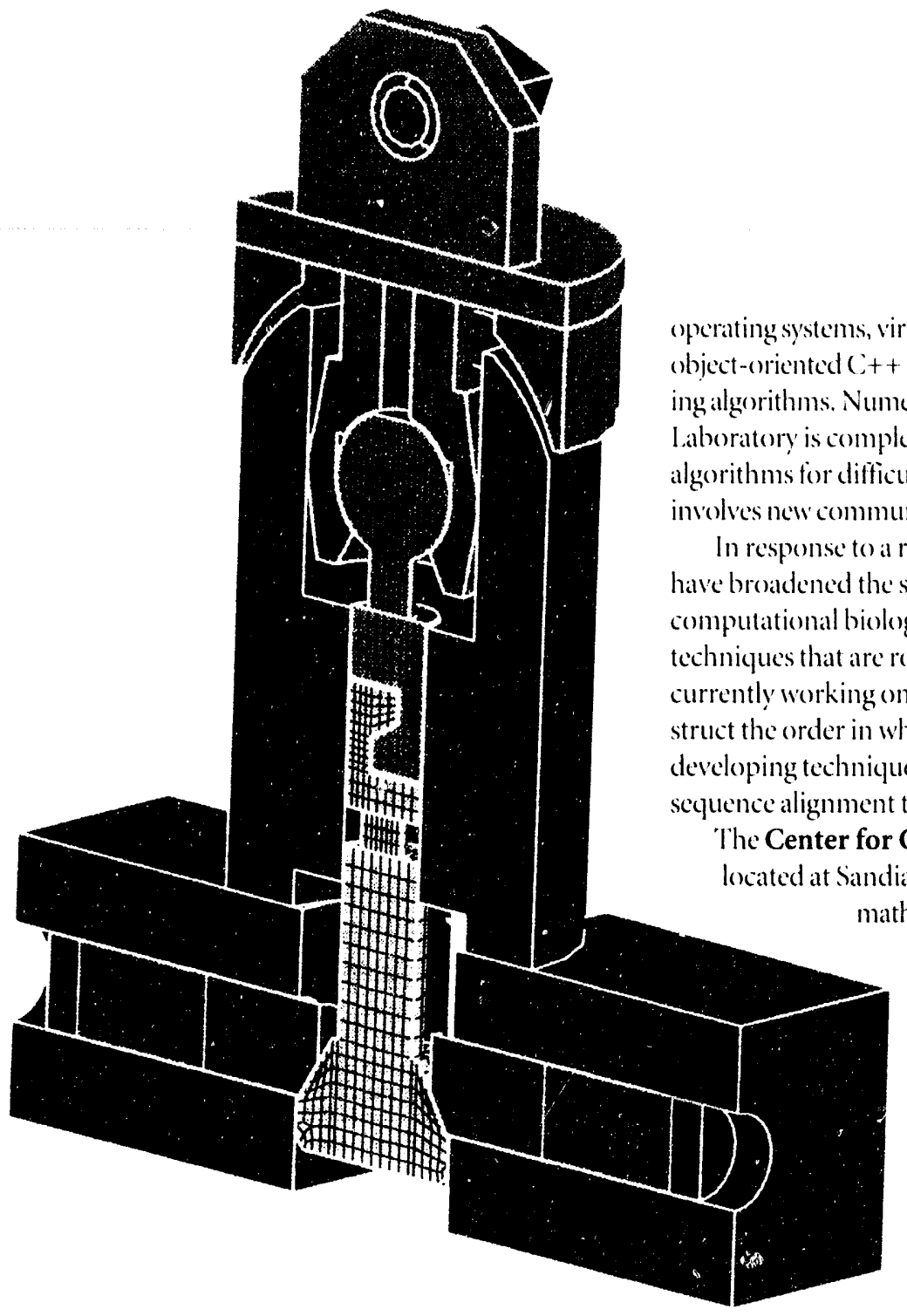

Sandia researchers have developed an innovative mesh-generating algorithm that can drastically reduce the time required for computeraided design of industrial products. This work won a 1993 R\&D 100 award.

Before computer analysis can be applied to the design of any complex object, the analyst must generate a customized geometric grid or "mesh." First, the domain of the problem must be descrioed in mathematical terms. The resultant model often shows the object as a solid three-dimensional shape or a representation of surfaces. Second, a computational mesh must be inscribed in the domain. This task involves breaking the problem into appropriately sized pieces - representing the surfaces in discrete regions that are all connected. The resulting computational mesh, defining the points where equations are to be solved, conforms to the surfaces. A welldefined mesh is finer where the variables of the problem are known to change rapidly and coarser where they do not.

Designing meshes is a difficult and time-consuming task. Mesh generation is a limiting factor for analyses in support of product design. For example, to generate the mesh for an automobile for a computer simulation of a crash requires six to eight weeks - too long for engineers to perform iterative design work effectively.

The Sandia three-dimensional surface-meshing algorithm called "Paving" does much of this process automatically. It can generate a mesh in a unique manner that exceeds conventional methods. with a broad external community. The center focuses on applications and works directly with customers !o help find the most cost-effective solutions to their problems.

One major thrust of the Center for Computational Engineering is computational chemistry for chemical and biochemical modeling. Work in this area ranges from quantum chemistry representation of small molecules (less than fifty atoms) through molecular dynamic simulations of intermediate-size molecules (hundreds of atoms) to macroscopic diffusion processes involving molar quantities of atoms. Significant recent results have included understanding the binding of eyclophosphamide (a cancer drug) to cell I) NA and using advanced genetic algorithms to determine the molecular structures of biologically interesting proteins. ( ne realizable product of this computational chemistry expertise is rational drug design, wherein biologically active chemicals can be designed from first principles to reduce the staggering cost of developing pharmaceuticals.

Other work at the (enter for Computational Enginecring includes modeling to assist in the development of plasma flat-panel displays and to understand the movement of contaminated groundwater through geological media. In addition, simulations are performed of manufacturing operations and health care delivery systems. Bach of these activities is being pursued with a different external customer.

A major driving force in the rise of the information age is the development of low-cost, high-performance workstations. The availability of these workstations is stimulating the explosive growth of multimedia technology (merging voice, video, and data) that will form the basis for a wide spectrum of applications linking people 
together electronically. Sandia has been concentrating on object-oriented design to develop a fully integrated distributed system that ties together the factors "required to solve a problem": computational analysis; communication (multimedia and mail); and storage and access (networking, graphical front-ends).

We have established the Heterogeneous Environment and Test-bed (HEAT), consisting of the latest workstations from each of the five major workstation vendors linked together. The objective of the HEAT project is to develop techniques for implementing clustered heterogeneous computing and the network optimizations required to increase the applicability of this technology. We have also developed metacomputing tools such as the Parallel Object-(Oriented Environment and Toolkit (POET) and the Distributed Audio-Video Environment (DAVE) as intelligent system interfaces to enhance the productivity of users. In both cases, our efforts have focused on applications to assure that requirements are met for collaborative engineering in support of advanced manufacturing.

Computer networking and wide-area communications have undergone explosive growth in performance and capability in the past few years. One consequence of this improvement has been a rapid transition to computing environments that are distributed over long distances, in which users working at powerful but relatively inexpensive workstations can remotely access large supercomputers and database servers at a few centralized locations.

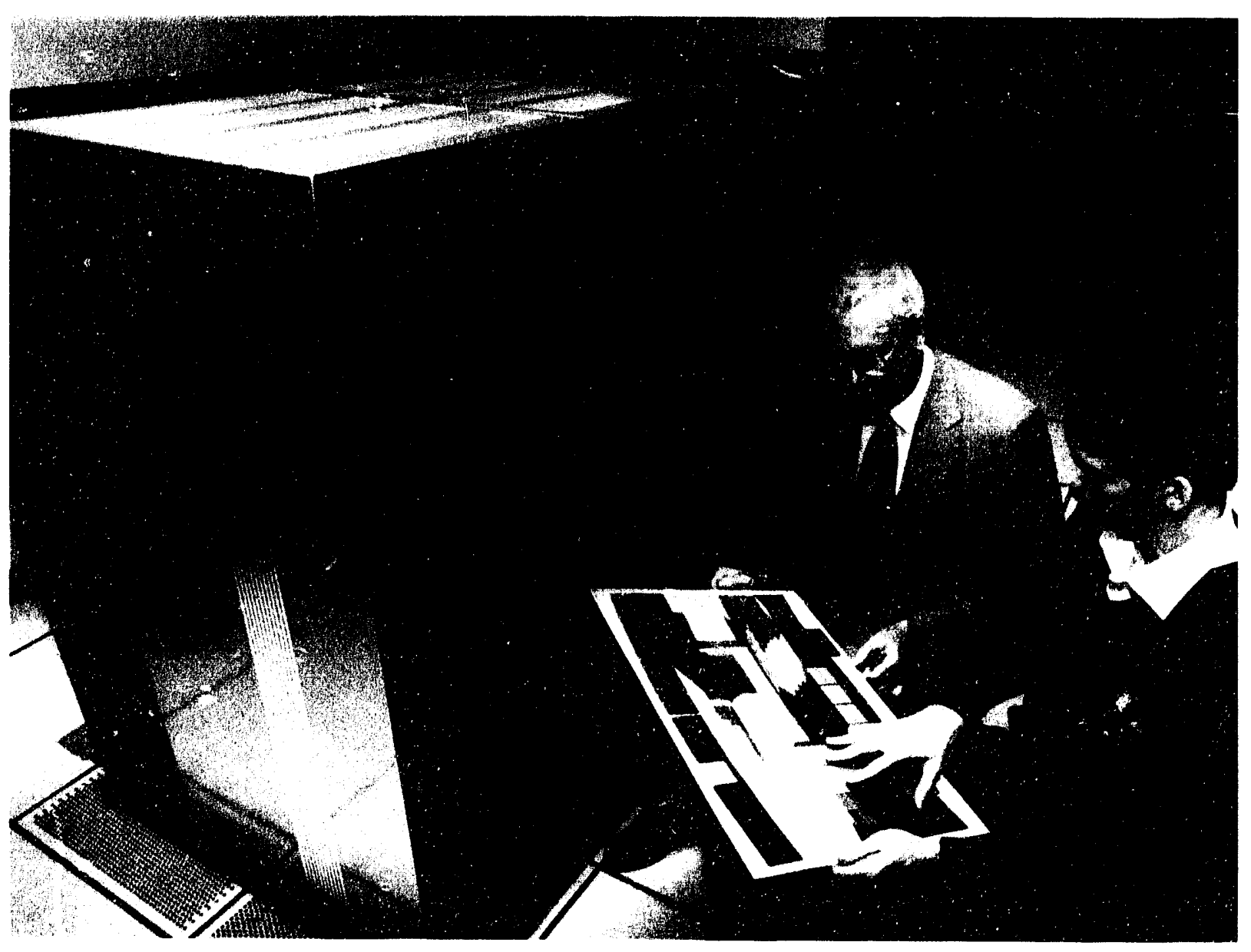

Paul Fleury and David Womble discuss output from Sandia's massively parallel Intel PARAGON supercomputer. At this writing, the computer is the world's fastest computational machine, operating at 140 gigaflops (billion floating-point operations per second). Sandia computer scientists will use the computer to help find solutions to currently unsolvable problems. 
These enviromments are leading to versatile new approaches to multiple party interactions in which people can participate from afar - induding classroom education, medical treatment, collaborative engineering projects, and scientific experiments - and are serving as the model for information dissemination nationwide. Sandia, uniquely positioned with two widely separated major locations, has already moved to such a model by centralizing its supercomputers at Albuquerque under its supercomputer consolidation project. This effort, which provides ready access to Sandia's supercomputers and storage servers from both the California and New Mexico locations, will result in substantial savings in the cost of computing resources and has permitted us to develop the technology base for achieving a robust information infrastructure both within and outside the Laboratories. For example, we developed a 1$) \$ 3$ (45 megabits per second) delay and error simulator that we used to design and test our intersite network in the laboratory. As a result, the network worked the first time when installed in the field.

This work, as well as our other networking activities, will enable Sandia to play a major role in creating an information infrastructure that will place the United States in a dominant position to compete in a global information-based society. Our capabilities in networking and communications were recognized by Interop in presenting us the Interop Achievement Award for excellence in implementing the most sophisticated multi-vendor corporate internetwork, and for making the most effective use of inter-networking technology to further our business goals.

Information surety is concerned with protecting information from unauthorized access, from unauthorized or accidental modification, and from loss of access. This field has been and will continue to be an essential discipline for Sandia's responsibilities in command and control of nuclear weapons. Consequently, we have developed extensive capabilities in information surety at Sandia. These capabilities include the design and analysis of cryptographic algorithms and protocols; adversarial analysis of hardware, software, and total systems; design and analysis of access control systems; development of high-speed communication network security systems; development and fielding of use control systems; development and testing of tamper resistant technologies; testing of biometric identification techniques; and development of computer security techniques. We regard our synthesis of these capabilities in one organization as a differentiating strength.

\title{
Project Proposals for the Major Initiative in Information and Computational Technology
}

\author{
Computational Manufacturing \\ [for the Assistant Secretary for Defense Programs (GB)]
}

Realistic simulation of product, process, and production is one of the key capabilitics in realizing information-driven manufacturing (see page 5-6). Complex 21 will require increased usc of computational systems design, simulation of prototyping and manufacturing processes, and simulation of system performance and reliability under design conditions as well as in response to abnormal environments. Thus, the development of rapid prototyping and agile manufacturing techniques I: $\ldots$ build on emerging simulation capabilities that are so advanced that they enable virtual prototyping and processing and, ultimately, computational design of entire systems. These technologies depend on Sandia's new thrusts in developing engineering simulation environments.

New user-friendly, powerful environments are beginning to combine solid modeling, automatic mesh generation, and domain decomposition for parallel processing with algorithms for heat transfer, materials mechanics, fluid flow, and chemistry. Techniques are being devel pped for real-time, desktop visualization of simulation data; they will be important new additions to the engineer's computational toc! kit. 
The needs of Complex 21 are mirrored in U.S. industry, where requirements for cver-diminishing product development cycles demand constant innovation. T'odiay and tomorrow, one of the most important advantages will come from the use of computational virtual prototyping of processing tools. Sandia's leading-edge high-performance computing simulation capabilities are already being transferred to U.S. industry in partnerships facilitated by cooperative research and development agreements (CRADAs). Our computational simulation technologies are a major research and development resource for American industry.

\section{Center for Industrial High-Performance Computing Applications [for the Assistant Secretary for Defense Programs (GB)]}

The Massively Parallel Computing Research Laboratory is rapidly becoming a major center for industrial applications of high-performance computing and communications. More than a dozen cooperative research and development agreements (CRADAs) have already been funded for high-performance computing technology partnerships with U.S. industry in the first year of DOE's Technology Transfer Initiative.

These CRADAs, and some conventional work-for-others arrangements, include leadership of a major initiative in computational materials and a major partnership with industry to develop new massively parallel database technologies and light-weight massively parallel operating systems. Advanced simulation techniques are being applied to new problems in biology, including development of new defibrillation techniques and design of new medical compounds. Innovations developed for scientific and engineering simulations are finding new application in the field of volumetric medical imaging for diagnosis and surgical intervention and are the basis of several partnerships with the health care industry.

New thrusts in discrete mathematics are having both scientific and industrial impact and will play a major role in developing the new national information infrastructurc. They include combinatorial methods for computational biology and many kinds of networks. Research in surety, security, and privacy for communications and computing is anticipating the needs of "Info-America" and is finding immediate application in the financial and medical industries.

Advances in high-performance computing and communications technologies are providing revolutionary new capabilities for designing and optimizing products on computer. These technologies are already a key to numerous Sandia partnerships with companies in the computer, microclectronics, manufacturing, health care, and energy and environment industries, and they support all of Sandia's core competencies and program sectors.

The Center for Industrial High-Performance Computing Applications will help coordinate and foster the development and application of critical high-performance computing and communications technologies at Sandia's many designated and undesignated user facilities (e.g., the Massively Parallel Computing Research Laboratory, the Center for Computational Engineering, the Combustion Research Facility, the Center for Microelectronics Technologies, the Advanced Manufacturing Center, the National Center for Advanced Information Components). The center will help form interdisciplinary teams to solve nationally important problems and accelerate the development of software through expanded collaborations.

This initiative moves the Massively Parallel Computing Research Laboratory toward providing industry with one-stop access to comprehensive assistance in high-pertormance computing. The Center for Industrial High-Performance Computing Applications will strengthen the Sandia rore as executive director of the 1 )()E Forum for Industrial High-Performance Computing with a mission to act as the point-of-contact for industry regarding computing and to develop software interoperability for massively parallel machines in partnership with industry. 


\section{Metacomputing Environment and Tools [for the Office of Energy Research (KC07)]}

The next major phase of our distributed computing and networking program expands to include the optinization of the communications stack and the development of a software super architecture to integrate the distributed components into a transparent system. In this next phase, we will apply the experience we have gained from our current work to the design of a communications stack optimized at all levels: protocols, message passing libraries, and the underlying hardware.

This work will result in a system with less latency and greater bandwidth, increasing the range of applications that will achieve optimal performance in a distributed environment. Simultaneously, we $\mathrm{w}$ ill investigate methods for supporting an architecture that incorporates the elements of our distributed infrastructure in an object-oriented framework to permit rapid prototyping and flexible support of information science applications. The environmcitt will contain a set of tools that can be collected for processing a problem. Networking software and communication capabilities will enable the rapid and transparent movement of data between the set of software tools.

By utilizing object-oriented techniques, these software tools will be suitable for a wide range of applications. This environment will reduce the cost of software by accelerating software development, increasing the reuse of software, and decreasing software maintenance. The metacomputing environment will be used for distributing and controlling software, assigning multiple computers to a task, and obtaining information from multiple sources for a task.

Our technology transfer activities range from applications with partners such as Alcoa, Ellery Systems Software, AT\&T, anci others, to technology infrastructure with such partners as Fore Systems, Digital Equipment Corporation, Hewlett-Packard, Sun Microsystems, IBM, AT\&T, and others. In all of our efforts, we are collaborating with industry to ensure the highest quality and broadest applicability of the resulting products.

\section{Information Surety \\ [for the Assistant Secretary for Defense Programs (GB)]}

Sandia is applying its outstanding capability in cryptology and command and control to new problems of national importance. Information surety is an essential technology for the development of the National Information Infrastructure and a national information conomy. In an information economy, the value of information will be such that information will become a lucrative target for criminals and national adversaries. As with other form of security, not only will it be necessary to develop a national information security system, but it will also be necessary to constantly reassess and improve the security of the system in light of unpredicted advances in technology.

Sandia is well-positioned to lead a national research and development effort in information surcty. Projects have been started to develop the high-speed netivork security systems that will be required. U.S. industry has already shown an interest in collaborating with Sandia to develop technologies to provide security in computerized medical records and to improve the security of financial transactions.

As the DOE nuclear weapons complex moves toward agile manufacturing systems, information surety will play a critical role. Moreover, this area will continue to be an essential technology foundation for Sandia's responsibilities in command and control of nuclear weapons. ( )ne of the many' technologies that must be developed is a robust method for identifying individuals, either in person or remotely. An identification card could be designed that prevents impersonation by combining cryptography, tamper-resistant data storage, and biometric identification. Such a card would be used to improve the security of many current identification needs, such as credit ards and other bank cards; controlled access to secure facilities; shopping, banking, and voting by telephone; and access to sensitive information. Sandia could develop identification methods that would satisfy the demands of all of these applications and reduce vulnerabilities for fraud. 


\section{National Information Infrastructure Test Bed [for the Assistant Secretary for Defense Programs (GB)]}

The U.S. government is committed to accelerating the development of information technologies and a National Information Infrastructure that will respond to the economic and social demands of the twenty-first century and meet the needs of Department of Energy missions in nuclear weapons, energy, environment, and education. We have formed a collaboration with industry, universities, and other government laboratories to establish a nationwide high-performance test bed called the National Information Infrastructure Test Bed, to develop and evaluate the performance and interoperability of networking technology and distributed computing applications for the National Information Infrastructure.

The test bed will provide a forum to facilitate exchange of precompetitive information and practical experience on information technologies and applications. It will expedite and support near-term implementation of the National Information Infrastructure as an active collaboration between U.S. industry, government, and universities. This initiative builds directly on our capabilities in distributed computing and networking and is ultimately connected to our interests in metacomputing environment and tools.

\section{Technology Information Environment for Industry (TIE-IN) [for the Assistant Secretary for Defense Programs (GB)]}

A new tool for technology transfer, the Technology Information Environment for Industry (TIEIN), is being developed at Sandia. The two primary goals of TIE-IN are to increase the levurage of Department of Energy technology transfer efforts with a system that can reach hundreds or thousands of businesses and to reduce the investment required by industry to utilize national laboratory technologies.

TIE-IN will use advances in information and computer technologies to build smart front-ends for many DOE technical capabilities and electronically guide users through the process of obtaining solutions. These smart front-ends will provide leverage for DOE by minimizing direct staff interaction with users. It will also minimize the required industrial investment by relieving users of the need to obtain or maintain specialized technical expertise and equipment.

TIE-IN will be supported by a user facility that operates as an electronic extension service to allow users to obtain solutions to problems from remote locations. These users would not require a high level of specialized technical expertise, nor would they incur the very large expenses associated with employing specialized analysts, maintaining software libraries and a software maintenance staff, developing custom databases, and purchasing and operating high-performance computing and experimental equipment.

\section{Massive Data Processing, Storage, and Management [for the Assistant Secretary for Defense Programs (GB)]}

On-line, high-speed access to distributed multi-terabyte databases can enable new paradigms for scientific and engineering collaboration, for interacting with computational simulations, and for disseminating scientific and computational results. The infrastructure for storage, query, and search and retrieval of "mixed media" (large--scale numerical data, graphics, and video) databases remains to be developed.

A project at Sandia is needed to maximize return on such computational simulation initiatives as TIE-IN and Sandia's leadership role in the National Consortium for High-Performance Computing. The effort will develop: 
1. Software for efficient manipulation and querying of mixed media data,

2. Technology for seamless inter-operation of storage servers distributed around the country,

3. Associated user and high-speed network interfaces to enable users to interact with data in new ways, and

4. Standards in concert with appropriate commercial and government entities.

These technologies will be incorporated into interfaces for massively parallel servers, including the Intel Paragon and nCUBE 3 supercomputers, via collaborative research and development with industrial partners such as Oracle Systems, Inc., and major research universities such as MIT, Stanford, and the University of California.

The concept of "data," which traditionally has been regarded as text and numbers, has now been broadened to include text, graphics, video, sound, animation, and the temporal links between data types during presentation to the end user. In addition, high-performance computing and distributed processing will lead to orders-of-magnitude increases in the volume and geographical distribution of data associated with any particular event. New techniques are needed to provide storage for such multimedia data in a manner that is efficient and transparent to the end user. Such techniques must include methods to store data as a conglomerate of different types and allow for distributed locations of individual components. They must also provide fetch, store, and translation mechanisms for a wide variety of computing equipment and rely on high-performance communication networks to make data location irrelevant.

\section{Wireless}

\section{[for the Assistant Secretary for Defense Programs (GB)]}

Wireless technology will play a key role in futurc multimedia communications. It is an important component of providing mobility and quick set-up in locations devoid of other communications. It may also be the only way to provide reliable communication with individuals who move about but must be monitored for purposes of control or protection (for example: life systems monitoring of individuals with high-risk medical conditions; stress monitoring of security personnel; location monitoring of offenders who do not require incarceration).

Today's cellular phone technology illustrates the concept of this kind of portability, but it is incapable of supporting the high bandwidths and global availability required for the wide variety of multimedia applications now emerging. Today's wireless technologies must be enhanced to provide high-bandwidth secure communications, high reliability, and global availability while minimizing the weight, power, and possible health risks (from pı olonged, proximate exposure to radio-frequency radiation) associated with the use of such portable communication terminals. Other required advances in technology include:

1. Efficient methods of frequency sharing and re-use,

2. Compression techniques for data, particularly video and image data,

3. Efficient cryptographic techniques to ensure privacy, integrity, and authenticity of communications, and

4. Integration into larger, nonportable, multimedia communication systems. 


\begin{tabular}{|c|c|c|c|c|c|}
\hline \multicolumn{6}{|c|}{$\begin{array}{l}\text { Funding Requirements for Initiative Project Proposals in Information and Computational Technology } \\
\text { (Dollars in constant FY } 1994 \text { millions; personnel in FTEs) }\end{array}$} \\
\hline & Year 1 & Year 2 & Year 3 & Year 4 & Year 5 \\
\hline \multicolumn{6}{|c|}{ Computational Manufacturing } \\
\hline Operating & 4.0 & 6.0 & 8.0 & 8.0 & 8.0 \\
\hline Capital Equipment & 1.0 & 0.5 & 1.0 & 0.5 & 0.5 \\
\hline Total Cost & 5.0 & 6.5 & 9.0 & 8.5 & 8.5 \\
\hline Direct Personnel & 12 & 15 & 20 & 20 & 20 \\
\hline \multicolumn{6}{|c|}{ Center for Industrial High-Performance Computing Applications } \\
\hline Operating & 4.0 & 5.0 & 6.0 & 8.0 & 9.0 \\
\hline Capital Equipment & 1.0 & 20.0 & 1.0 & 20.0 & 1.0 \\
\hline Total Cost & 5.0 & 25.0 & 7.0 & 28.0 & 10.0 \\
\hline Direct Personnel & 10 & 15 & 20 & 25 & 30 \\
\hline \multicolumn{6}{|c|}{ Metacomputing Environment and Tools } \\
\hline Operating & 7.0 & 9.0 & 10.0 & 10.0 & 10.0 \\
\hline Capital Equipment & 1.0 & 1.0 & 1.0 & 1.0 & 1.0 \\
\hline Total Cost & 8.0 & 10.0 & 11.0 & 11.0 & 11.0 \\
\hline Direct Personnel & 25 & 30 & 35 & 35 & 35 \\
\hline \multicolumn{6}{|l|}{ Information Surety } \\
\hline Operating & 9.0 & 11.0 & 11.0 & 11.0 & 11.0 \\
\hline Capital Equipment & 0.5 & & 0.5 & & 0.5 \\
\hline Total Cost & 9.5 & 11.0 & 11.5 & 11.0 & 11.5 \\
\hline Direct Personnel & 35 & 40 & 40 & 40 & 40 \\
\hline \multicolumn{6}{|c|}{ National Information Infrastructure Test Bed } \\
\hline Operating & 6.0 & 8.0 & 9.0 & 9.0 & 9.0 \\
\hline Capital Equipment & 1.0 & 1.0 & 1.0 & 1.0 & 1.0 \\
\hline Total Cost & 7.0 & 9.0 & 10.0 & 10.0 & 10.0 \\
\hline Direct Personnel & 20 & 25 & 30 & 30 & 30 \\
\hline \multicolumn{6}{|c|}{ Technology Information Environment for Industry (TIE-IN) } \\
\hline Operating & 7.0 & 9.0 & 10.0 & 10.0 & 10.0 \\
\hline Capital Equipment & 0.5 & 0.5 & 0.5 & 0.5 & 0.5 \\
\hline Total Cost & 7.5 & 9.5 & 10.5 & 10.5 & 10.5 \\
\hline Direct Personnel & 25 & 30 & 35 & 35 & 35 \\
\hline \multicolumn{6}{|c|}{ Massive Data Processing, Storage, and Management } \\
\hline Operating & 3.0 & 3.0 & 4.0 & 4.0 & 4.0 \\
\hline Capital Equipment & 1.0 & 1.0 & 1.0 & 1.0 & 1.0 \\
\hline Total Cost & 4.0 & 4.0 & 5.0 & 5.0 & 5.0 \\
\hline Direct Personnel & 10 & 10 & 15 & 15 & 15 \\
\hline
\end{tabular}


Funding Requirements for Initiative Project Proposals in

Information and Computational Technology (Continued)

(Dollars in constant FY 1994 millions; personnel in FTES)

Year1 Year 2 Year 3 Year 4 Year 5

Wireless

$\begin{array}{llllll}\text { Operating } & 4.0 & 4.0 & 4.0 & 6.0 & 8.0\end{array}$

Capital Equipment

Total Cost

\begin{tabular}{lllll}
4.0 & 4.0 & 4.0 & 6.0 & 8.0 \\
& 0.5 & 0.5 & 0.5 & \\
\hline 4.0 & 4.5 & 4.5 & 6.5 & 8.0
\end{tabular}

$\begin{array}{llllll}\text { Direct Personnel } & 10 & 10 & 10 & 20 & 20\end{array}$

Total, Information and Computational Technology

Operating

Capital Equipment

Total Cost

$\begin{array}{lllll}44.0 & 55.0 & 62.0 & 66.0 & 69.0\end{array}$

$\begin{array}{lllll}6.0 & 24.5 & 6.5 & 24.5 & 5.5\end{array}$

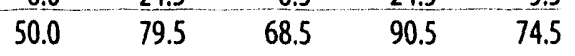

Direct Personnel

$147 \quad 175 \quad 205$

$220 \quad 225$ 


\section{Transportation Energy Technology and Infrastructure}

Improving the nation's economic competitiveness will depend heavily on greater energy efficiency and transportation modernization to allow our industries to mect upcoming challenges. Advances in these areas should be pursued through an integrated initiative, since transportation accounts for a large portion of national energy consumption.

Weaning the transportation system from exclusive reliance on petroleum fuels would reduce the nation's vulnerability to oil supply and price shocks. This result can be achieved through the development of cost-competitive alternative fuels such as ethanol and methanol and greater use of natural gas and electricity. Increasing transportation energy efficiency by improving the efficiency of vehicles and the transportation system as a whole is aiso required.

While major reductions in vehicle emissions have been achieved during the last twenty years through federally mandated improvements in vehicle fuel efficiency, the Department of Transportation (DOT) forecasts that total emissions will begin to increase again after 1996. This reversal will occur (despite the fact that more stringent fuel efficiency standards will be in effect) because total vehicle miles traveled is increasing faster than improvements in fuel efficiency. Federal air quality standards cannot be achieved or maintained in the long term unless significant changes occur in urban transportation systems.

The safety and efficiency of the transportation infrastructure can be greatly improved. Americans now lose over two billion work hours per year from traffic congestion, and several major cities are forecast dramatic decreases in average freeway speeds over the next several years. Transportation issues are also closely tied to the goal of improving national economic competitiveness, and they will have an even greater impact in the coming years. The interactive nature of a growing and changing economy is significantly affected by the availability and cost of transportation. If transportation systems impose a relatively high burden on U.S. producers, they will face an institutionalized impediment to competitiveness. This realization is evident in the aggressive modernization of transportation systems in Japan and Europe.

Technological innovation is needed to modernize our systems in order to ensure a secure and prosperous future. The enabling legislation to address these needs is the Intermodal Surface Transportation Efficiency Act (ISTEA) of 1991. This act sponsors the creation of the nation's future transportation system and encourages the Department of Transportation to enlist the competencies of the Department of Energy national laboratories in this task. The solutions to the nation's transportation problems can be achieved through a systems approach that integrates and applies the talents of these two agencies, the national laboratories, and industry.

Sandia has conducted lead functions in transportation for the Department of Energy for four decades. These functions are broad in scope, serving several DOE customers and benefiting from synergy in several areas.

Sandia has been the lead laboratory for transportation technologies associated with the safe, reliable and monitorable movement of defense hardware since its inception. This historical mission role includes infrastructure issues in geographic information system tracking of trucks, full vehicle system design and production oversight, and reliability and safety integration. For nearly twenty years, we have held a similar lead role for transportation systems for radioactive and hazardous materials for both the Department of Energy and the Department of Transportation. This role has dealt with infrastructure issues, including the geographic information system, cask design and certification, safety, performance assessment, and manufacturing. 'These two mission responsibilities have also allowed Sandia to play important roles internationally in transportation of special materials in the former Soviet Union and in ocean and air transport of reactor fuel around the world. 
Sandia's energy-related transportation responsibilities have been primarily focused on lead laboratory responsibilities in engine combustion technology and advanced batteries. The engine program is a model government/university/industry partnership and has demonstrated to industry the valuable contributions the national laboratories can make. Because of these successes, Sandia has seen enormous interest from the U.S. auto industry in secking our participation in their recent thrusts for improvement. In the past year, numerous cooperative research and development agreements have been formulated between Sandia and the auto industry.

Because of these broad system successes at Sandia - information systems, propulsion systems, storage systems, vehicle system design and manufacture, reliabilitv and safety integration, and multilab coordination - we are embarking on this initiative with the objective of playing an even larger role in the U.S. tiansportation infrastructure and vehicle system technology development. Our historical competency in systems integration, coupled with our experience in transportation, should be utilized by the departments of Energy, Transportation, and Commerce to maximize their mission successes. This major initiative proposes to direct Sandia's core competencies toward practical solutions to transportation problems.

\title{
Project Proposals for the Major Initiative in Transportation Energy Technology and Infrastructure
}

\author{
Transportation Energy Technology \\ [for the Assistant Secretary for Energy Efficiency and Renewable Energy (AK, AL, EE)]
}

Sandia's Advanced Transportation Energy Technology Program is focused on improving the energy efficiency of our transportation system, thus improving the country's economic competitiveness while protecting the environment. To this end, Sandia has entered into a number of cooperative research and development agreements with industries connected with transportation, notably USCAR, a consortium of automobile manufacturers; the Emissions Consortium, devoted to the need to reduce emissions from internal combustion engines; and the United States Advanced Battery Consortium, which is developing an improved battery for electric vehicles.

Sandia's Engine Combustion Technology Project works to develop new technologies to improve efficiency, increase fuel flexibility, and reduce emissions in automobile and truck engines. The Transportation Materials Initiative includes catalysts for emission reduction, and fuel cell applications, lightweight structural materials, hydrogen storage materials, and other new, engineered materials for transportation applications. The following projects provide a foundation for expanded effort in developing energy-efficient transportation solutions:

1. Advanced Energy Storage. Sandia has considerable expertise in energy storage development, which includes carbon materials for double-layer capacitors and sodium/sulfur and zinc/air batteries. Much of this expertise is being applied in supporting the United States Advanced Battery Consortium (USABC). The consortium is a partnership of General Motors, Ford, and (Chrysler, with participation by the Electric Power Research Institute (EPRI) and industry. It was formed to develop advanced batteries for commercial use in electric vehicles by 1998. An initiative in California requiring a percentage of vehicles sold in 1998 to be zero-polluting was a stimulus for the formation of the group. Sandia's role with USABC includes materials development, battery design, and testing. 
2. Hybrid Vehicles. Hybrid vehicles powered by an electric system such as batteries or fuel cells in conjunction with each other or with an internal combustion engine also will contribute to fuel substitution and environmental protection. Sandia's battery technology base and its combustion expertise, located at DOE's Combustion Research Facility at Sandia/California, coupled with our systems enginecring capabilities, give us the tools necessary to contribute to this program.

3. Alternative Fuels. Optimizing engine designs for emissions control and high efficiency is important to the expanded use of hydrocarbon fuels. Wider use of natural gas or multifuel engines will also support expanded use of such fuets. Sandia's Combustion Research Facility supports this work and can play a key role in solving these problems. In addition, our expertise in catalysis can contribute to the direct use of alternative fuels in fuel cells, and our experience in storing and transferring hydrogen isotopes (gained in the nuclear weapons program) can contribute to the practical utilization of hydrogen as a fuel.

4. Emissions Consortium. A consortium is being formed by the "Big-3" auto companies to address emissions reduction. Lean-burn catalysts are needed to reduce emissions of nitrogen oxides. Understanding the distribution of exhaust gases and developing sensors and controls are areas where Sandia can contribute. Expanded utilization of alternative fuels will also generate new requirements for understanding emission processes and improving catalysts.

\section{Transportation Infrastructure} [for the United States Department of Transportation]

The U.S. Department of Transportation is embarking on a program to improve the safety and efficiency of surface transportation by applying the latest technology in sensors, data fusion, communications, and information and control. This effort, the Intelligent Vehicle and Highway System (IVHS) program, envisions "smart" highways and vehicles that will improve safety and reduce congestion, energy consumption, and pollution. The technology involves vehicle tracking systems, collision avoidance sensors, traffic control centers, automatic vehicle control systems, and roadside sensors.

In addition to the technology program associated with highways and automobiles, new programs to enhance public transit systems and commercial vehicle operations can be uniquely supported by Sandia's system integration capabilities. A current initiative is to direct Sandia's core competencies toward practical solutions for these transportation infrastructure problems. Research and development in several areas will be conducted in conjunction with the private sector and universities to foster rapid development and commercialization:

1. High-Speed Computation and Systems Analysis. Decisions on future transportation systems will need to balance the interrelated issues of energy security, environmental quality, cost, and transportation efficiency. It will be prudent and responsible to perform large-scale computer simulations and systems analyses before making major commitments or allocating resources to technology development and commercialization. Sandia's experience in modeling and analysis will be employed to perform analysis at all levels of system design.

The current study to examine the technical and economic feasibility of the proposed Santa Teresa Intermodal Facility is a prime example of this type of effort. The proposed facility will likely cover ten square miles near the border of New Mexico and Mexico and could dramatically improve the efficiency of moving commercial vehicle and railroad freight across the border. 
2. Intelligent Vehicle and Highway system. Much of the technology for the Intelligent Vehicle and Highway System is an extension of work already underway at the DOE laboratories. The Safe Secure Transport (SST) program has developed reliable, secure systems for transporting nuclear weapons and materials. DOE has developed a command and control system called STARBASE to operate and manage the SST fleet and provide a capability for emergency response. The Department of Transportation has expressed interest in building upon this extensive information system to develop a Geographic Information System for Transportation to collect and manage the vast amount of information that will be generated by the legally mandated upgrades to the transportation infrastructure and its management.

Sandia has developed many types of robust, unattended ground sensors. This technology may be important to the IVHS program in developing roadside sensors for monitoring commercial vehicle safety, "weighing" passing trucks, and automatically assessing tolls. We have also developed many versions of teleoperated and autonomous vehicles.

3. Transportation of Radioartive and Hazardous Materials. A significant requirement in waste management is the safe and economical transportation of hazardous materials and wastes, including radioactive wastes. A major thrust in energy and environmental research and development is the application of technology to provide safer and more economical answers for these problems. Sandia supports the DOE in transportation-related efforts in several ways, including the development of transportation packagings for the Office of Civilian Radioactive Waste Management and support of the Transportation Management Program for the Office of Environmental Restoration and Waste Management. These efforts include policy analysis, packaging improvements, regulatory and standards support, testing and development of materials for design, and testing of packages. The application of modern risk assessment techniques and performance analysis provide an oppor conomical safety improvements in these operations.

4. Allian insportation Research. Sandia has entered into a partnership with the University on vew Mexico, New Mexico State University, Los Alamos National Laboratory, and the New Mexico State Highway and Transportation Department for transportation research. The alliance brings together a unique combination of partners with wide-ranging technical capabilities and facilities and a thorough understanding of current problem areas and future needs for the nation's transportation infrastructure. The alliance is dedicated to providing solutions to the nation's transportation needs by forming teams with other research organizations and industry in application-oriented research and development.

5. Transportation System Risk Assessment. Key information in the selection of tomorrow's transportation systems involves a thorough understanding of the risks associated with the introduction of new fuels and energy storage elements into the system.

The extensive use of combustible fuels in the United States gives rise to a varicty of safety and security concerns. Combustible fuels include both fossil fuels (petroleum and petrochemical products) and biomass fuels (alcohol, methanol, vegetable oils, wood, fuels derives from manufacturing waste and other refuse). Accidents related to the everyday use of combustible fuels occur frequently; the resulting loss of life is unnecessary and the economic and environmental cost. are enormous.

To ensure against accidents (whether the result of abnornal occurrences, misuse, or sabotage), systematic risk assessment, supported by appropriate testing, should be conducted on every step of the combustible fuel chain (extraction, transportation, storage, processing, and consumption/disposal). Each step is subject to environmental, safety, and health risks because work sites (for example, off-shore oil platforms), tools (pipelines), 
methods of transportation (trucks, railroad cars, tanker ships), storage tanks (both underground and aboveground), processing methods, and disposal facilities are all part of the process of preparing the fuel for consumption.

Sandia can help the DOE in its responsibility to regulate the nation's energy supply and also help the Department of Transportation ensure ES\&H compliance and promote safe transportation. We are well-positioned to conduct risk assessment studies and testing from a systems-level point of view, addressing both safety and security. As the originator of probabilistic risk analysis methodologies for nuclear power systems and nuclear weapons, we can apply the same or similar techniques to address economic issues and risk-related scenarios.

Sandia's capabilities can be useful in an integrated transportation initiative combining the technology for energy sources and system solutions for tomorrow's transportation infrastructure.

\begin{tabular}{|c|c|c|c|c|c|}
\hline \multicolumn{6}{|c|}{$\begin{array}{l}\text { Funding Requirements for Initiative Project Proposals in } \\
\text { Transportation Energy Technology and Infrastructure } \\
\text { (Dollars in constant FY } 1994 \text { millions; personnel in FTEs) }\end{array}$} \\
\hline & Year 1 & $\underline{\text { Year } 2}$ & Year 3 & $\underline{\text { Year } 4}$ & Year 5 \\
\hline \multicolumn{6}{|c|}{ Transportation Energy Technology } \\
\hline Operating & 6.0 & 10.0 & 15.0 & 20.0 & 20.0 \\
\hline Direct Personnel & 15 & 25 & 37 & 50 & 50 \\
\hline \multicolumn{6}{|c|}{ Transportation Infrastructure } \\
\hline Operating & 5.0 & 15.0 & 20.0 & 25.0 & 25.0 \\
\hline Direct Personnel & 12 & 30 & 50 & 60 & 60 \\
\hline \multicolumn{6}{|c|}{ Total, Transportation Energy Technology and Infrastructure } \\
\hline Operating & 11.0 & 25.0 & 35.0 & 45.0 & 45.0 \\
\hline Direct Personnel & 27 & 55 & 87 & 110 & 110 \\
\hline
\end{tabular}




\title{
Environmental Technology
}

Environmental issues are a growing national and international concern. Unfortunately, technologies for dealing with environmental problems are often immature or costly. D) ()E has a major responsibility for developing and applying environmental technologies and sharing solutions with industry and other agencies. Seeking to support DOE and the nation in this endeavor, Sandia has initiated a program to apply its wide range of technical competencies to environmental issues.

Sandia has an extensive base of experience in environmental technologies, particularly with systems for transporting and storing radioactive waste. For many years, the Laboratories has had a major responsibility for testing and performance assessment for the Waste Isolation Pilot Plant repository. We were recently appointed by DOE as lead laboratory for conducting the assessment of compliance for the Greater Confinement Disposal site at the Nevada Test Site.

Since 1978, Sandia has been the DOE center for research and development for packaging and transporting radioactive materials. These efforts have been associated chiefly with waste management aspects of DOE programs, but the technology has found application in Defense Programs, Naval Reactors, and Nuclear Energy programs as well. In addition, other agencies have funded aspects of the program, including design of packaging for moving chemical munitions to demilitarization sites, development of routing guidelines, evaluation of safety program operations, and development of performance standards for toxic inhalants.

In 1990, Sandia assumed a leadership role in moving the DOE production complex toward environmentally conscious manufacturing for nonnuclear components. We have developed and introduced suitable substitutes for materials and processes that required or generated hazardous wastes.

For many years, the DOE Combustion Research Facility at Sandia/California has contributed an understanding of the mechanisms that create pollutants in combustion processes and developed concepts for cleaner energy conversion processes. The solar thermal program at Sandia/New Mexico has helped develop an innovative process for destroying organic compounds in waste water using solar energy. Competencies developed in defense and energy programs form a useful foundation for environmental research and technology development.

\section{Project Proposals for the Major Initiative in Environmental Technology}

\author{
Environmentally Conscious Manufacturing \\ [for the Assistant Secretary for Defense Programs (GB) and the Assistant Secretary \\ for Energy Efficiency and Renewable Energy (ED)]
}

Environmentally conscious manufacturing is the deliberate attempt to reduce the ecologically harmful byproducts of industrial processes and improve energy efficiency without sacrificing quality, reliability, or performance. It is a value-added transformation of materials and energy into products in a manner that adds environmental considerations to the manufacturing process.

Successful implementation of environmentally conscious manufacturing requires a total systems approach to very complex problems, utilizing the disciplines of engineering, chemistry, information systems, reliability and risk analyss life cycle analysis, and advanced manufact ring.

Since coining the term environmentally conscious manufacturing (ECM), Sandia has led the way in practical application through an integrated systems approach for implementing $1: C M$ processes and demonstrating the benefits of ECM in DOE programs. In the past, application of a fully integrated approach has focused on weapon components, including prototyping system providing analysis 
tools and coordinating the first ECM demonstration in the DOE nuclear weapons complex (electronics and electromechanical component fabrication at Allied-Signal/Kansas City).

Over the next five years, Sandia will pursue a strategy for bringing the benefits and techniques of environmentally conscious manufacturing to U.S. industry:

1. We will develop and demonstrate ECM methods and technologies with high dualuse payoff.

Sandia will develop methodologies for easier ECM implementation, such as expert-system decision tools to allow consideration of environmental impact in product design and manufacturing process decisions. Sandia will collaborate with the Environmental Protection Agency for such development as refinement of prototype life-cycle analysis tools. We will test its feasibility and complete its development into a user-friendly tool for industrial use. We will evaluate available technologies for environmentally conscious manufacturing, identify technology needs, and initiate programs to develop and provide new ECM technologies that have been fully tested and validated (e.g., advanced soldering and cleaning techniques).

\section{We will concentrate on the application of ECM through collaborative programs} with partners from U.S. industry and other government agencies.

We will develop industry-driven collabor ative programs in environmentally conscious manufacturing with a goal to assemble a track record of successful government/industry technology transfers. These programs will emphasize active solicitation of industry's needs, measurement of our effectiveness in meeting those needs, effective dissemination of information on ECM to industry, and identification of opportunities for transfer of industrially developed technologies to the defense complex.

New approaches will be used in these programs, including expanded use of industry advisory groups and market research, adoption of performance metrics accepted by industry, and more active collaboration with industry trade associations for opportunity assessment and information dissemination. We will expand the present work in transferring technology to the microelectronics industry and extend it to other industries (e.g., textiles, automotive, chemicals, pulp and paper) with modifications as appropriate. These Sandia programs will cover technologies such as solvent substitution; soldering (no-clean and lead-free, and advanced technologies); polymers engineered for reuse/recycle; "green" printed wiring board fabrication; advanced process monitoring and control; and replacement of hazardous materials in surface coating, metal finishing, and precision machining.

We will initiate new multiple agency collaborative programs, especially with the Environmental Protection Agency and the Department of Commerce, to more effectively address regulatory and technology transfer issues. Programs to integrate EPA and DOE techniques for process waste assessment and environmental and energy audits into a single assessment tool are proposed. We will collaborate with EPA and Commerce through the Manufacturing Technology Centers of the National Institute of Standards and Technology to evaluate the impact of new environmentally conscious manufacturing processes, to make ECM benefits more visible to all U.S. industry. 'We will coordinate with other DOE offices and DoD to eliminate redundancies and assure that ECM technology development is applicable throughout the complex.

3. We will establish Sandia as a national resource for environmentally conscious manufacturing with an emphasis on increasing the adoption of ECM by small business.

We will establish Sandia as a national ECM resource by evaluating our current capabilities and developing them accordingly. We will survey commercial ECM resources and develop programs in which Sandia can serve as a focal point, referencing and collaborating with 


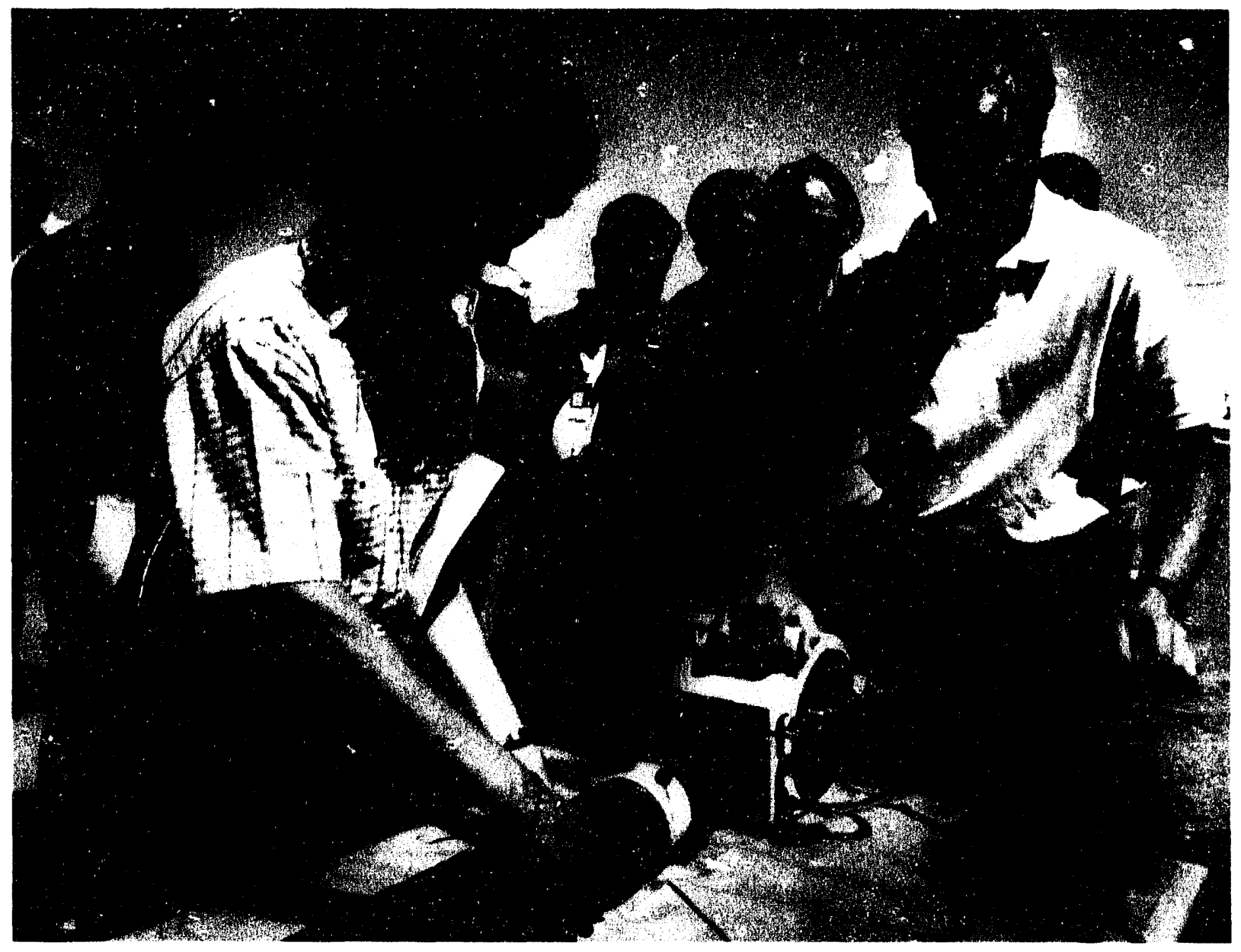

SEAMIST, an environmental restoration technology under development at Sandia, is an inflatable membrane that can carry sampling instrumentation into boreholes to measure subsurface conditions such as soil moisture, soil content, etc. Sandian Cecelia Williams and Dave Cremer (Science and Engineering Associates) demonstrate SEAMIST to industry representatives.

manufacturers to add the ECM dimension. This work will involve increased emphasis on Sandia as a "one-stop shop" provider of ECM technology, including development, feasibility demonstration, assistance in deployment, and dissemination of information.

New programs will be initiated to focus on coordination of state and federal resources to deploy ECM technologies to industry, particularly small businesses. An example is a currently proposed joint DOE-EPA-Commerce Environmental Extension Enabling Program in which Sandia will work with extension entities of the National Institute of Standards and Technology (NIST) to identify small business aeeds. We will help develop and commercialize technologies and facilitate technology deployment by training and providing advisors for NIST, state extension agents, and small businesses. New programs will focus on developing a complete on-line ECM knowledge base, an electronic "ECM information-on-dernand" network, improving ECM education (via a teaching factory at Sandia and simulation tools for retraining practicing engineers), and increasing effectiveness of ECM information dissemination through an extensive outreach program including a speakers bureau, videotapes, joint activities with industry trade groups, workshops and e:hibitions, and a widely distributed Envirommentally Conscious Mamufacturing Newsletter. 


\section{Waste Management \\ [for the Assistant Secretary for Defense Programs (GB); the Assistant Secretary for Energy Efficiency and Renewable Energy (ED); and the Office of Environmental Restoration and Waste Management (EW)]}

New waste management technologies are needed to address both regulatory and political requirements. Sandia is actively involved in developing treatment and disposal processes and recycling techniques.

Extending our technologies to commercial electronics is a major goal of our current activities. In the future, there will be great demand for advanced waste management technologies. As a nation, we are faced with an ever-growing need to deal with waste plastics, municipal wastes, hazardous chemicals, and obsolete slectronics. In addition, many government agencies, including the departments of Energy and Defense, are faced with challenging requirements for handling radioactive wastes, high explosives, propellants, and chemical wastes.

For radioactive materials, such as Hanford tank wastes, waste management strategies that use a full suite of techniques for pretreatment, characterization, recycling, minimization, stabilization, and storage will need to be explored. For other hazardous wastes, such as high-explosive propellants and chemicals, special treatment issues must be faced. Waste management technologies will be needed to solve both technical and social issues, including public acceptance, regulatory compliance, sample waste characterization, monitoring, destruction or treatment techniques, risk assessment, risk management, stabilization, minimization, liability, and cost.

Many Sandia-developed technologies will be brought to bear on these issues. We plan to extend our expertise in robotic systems, radioactive materials safety, intrusion systems, chemical and thermal processing, risk assessment, and sensor systems to solve these problems. Because so many waste management problems facing $\mathrm{DOE}$ are similar to those faced by the nation as a whole, we hope to use our technologies to solve many of the waste management problems faced by industry.

\section{Environmental Restoration [for the Assistant Secretary for Defense Programs (GB) and the Office of Environ- mental Restoration and Waste Management (EW)]}

Environmental restoration focuses on the cleanup of contaninated sites. Technologies and systems that lead to quicker, safer, and more efficient remediation of sites are needed. Literally tens of thousands of suspected contaminated sites are the responsibility of the departments of Energy and Defense, as well as problems on lands administered by the departments of Agriculture and Interior. In addition, virtually every municipality must deal with contamination from industrial or extractive activities.

In the future, there will be a growing need for more efficient ways to clean up contaminated sites. Advanced sensing systems involving airborne or even space-borne sensors, together witl rapid sampling and analysis techniques providing real-time data on the extent of contamination, may be useful. Because the cost of cleanups will continue to skyrocket, there will be a need for more cost-effective solutions using publicly acceptable waste stabilization and barrier technologies that have high reliability and permanence. Technologies to verify the integrity of in situ containment structures and for placement of structures beneath buried waste, tanks, and spills will be needed. Long-term, subsurface dosimetry instrumentation for detecting leakage of hazardous or radioactive substances will be needed to ensure that risk to public health and safety is minimal.

Information is key to making appropriate restoration decisions. Expansion and update of information systems such as the Enviro TRAD)E database management system will be critical in giving site managers information concerning progress from other worldivide sites. Also key in making timely decisions are tools for assessment of risk and for prioritization and bencfit. Work on such tools will be an important new initiative for Sandia. 
The restoration initiative will also focus on problems beyond $\mathrm{D}(\mathrm{)E}$, ind luding mine tailings, septic tank drain fields, agricultural pollution, and abandoned municipal landfills. As more military bases are closed, techniques for identifying and containing contaminants and performing site cleanup will need to become efficient and acceptable to regulators and the public. Finally, a growing concern with respect to contamination and restoration of ports, harbors, and marine estuaries will require advanced technologies for characterizing and cleaning up ocean sediments.

Cost-effective solutions to these problems that balance public health and safety against cleanup costs will become a national priority. Sandia's capabilities in sensor systems, physical and chemical analysis, and systems integration, together with its geophysical experience and knowledge, can directly support such activities.

\section{Hazardous Materials Transportation}

[for the Assistant Secretary for Defense Programs (GB); the Office of Environmental Restoration and Waste Management (EW); and the United States Department of Transportation]

The growing public environmental awareness and risk consciousness focuses on governmental activities that have the potential to produce harm. One of the most visible of all such activities is the packaging and transportation of all hazardous materials, not just radioactive wastes.

DOE will be challenged to demonstrate safety as it begins to remediate sites and send wastes to repositories or move materials to permanent disposal areas. For example, interim storage and transportation of unprocessed spent fuel from the nuclear weapons program, as well as research reactor spent fuel that DOE has committed to accept under the Research Reactor Spent Fuel Return Program, constitute a formidable problem. Also, programs in site decontamination and decommissioning are expected to produce large quantities of waste to be moved to repositories.

There will be a growing need for careful consideration of the systems aspects of proposed solutions to these challenges, as weil as innovative package designs, new package materials, and demonstrations of package and operations safety - all of which are key strengths of Sandia's program. New program initiatives include:

- Hazardous Waste Containers - As DOE remediates sites, we propose to develop containers to store and transport hazardous and mixed hazardous materials. This effort builds on current expertise but is more demanding because of the requirement to maintain container integrity and elastometric materials in the face of attack by corrosive and organic solvents that may be components of the waste.

- Geographic Information Systems - Applications of CIS as an enabling technology are proposed in risk assessment, routing, and emergency management as an important addition to our existing capabilities. Increased emphasis in DOE on interactions with stakeholders in cleanup campaigns requires the development of GIS tools to illustrate actions to be taken and provide the software interface in guiding activity.

- Multipurpose Containers - Spent fuel from DOE weapons production and from research reactors will probably not be reprocessed. Instead, interim storage and geological disposal are considered as options. We propose to evaluate the multipurpose container (MPC) as a means of avoiding multiple handling of the fuci as a consolidation measure and to facilitate robotic operations in the repository. This evaluation may lead to a systems study and development of an optimized package. 
- Electronic Emergency Response Systems - We are proposing development of a group of rugged, cost-effective sensors to detect accidents, store information about accident events, summon response teans, and provide information and dircetion to responders. With the increased awareness and risk-aversion of the public toward hazardous material in the environment, this technology will provide hazardous materials operations with effective tools to help protect the environment in the event of accidents.

\section{Unmanned Aerospace Vehicles and Small Satellites for Climate Studies [for the Office of Energy Research (KP)]}

Over the past several years, global climate change and sustainable conomic development have come to the forefront of the world's and the nation's science and policy agendas. While most scientists agree that energy related emissions will give rise to a man-made "greenhouse" warming trend, there

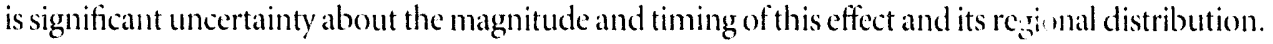
Policy decisions made in the face of this uncertainty will have substantial and widespread economic impact, emphasizing the impor tance of improved understanding of climate change.

To better understand these issues, the federal government has embarked on a U.S. (ilobal Change Research Program, with the Department of Energy a major participant. DOE has asked Sandia to serve as Technical Director of a multi-laboratory, multi-agency initiative in global change. To support D()E: in this role, we propose to draw on our expertise in remote sensing (from ground, air, and space), field testing, systems engineering, and massively parallel computing to form a Core (iroup in (ilobal Change $T$ echnologies with complementary expertise at other laboratories to address two key areas:

1. Three-dimensional remote sensing of the atmosphere, emphasizing clouds, water vapor, and aerosols; and

2. The use of massively parallel processing to significantly increase the throughput of a wide range of climate models.

Much of the effort in these areas to date has been in support of D()E's Atmospheric Radiation Measurement Program. This program seeks to improve the understanding of the carth's radiation balance and its interaction with clouds, the major uncertainty in current climate models and the top scientific issue for the U.S. Global Change Research Program.

The initial phases of the program have emphasized ground-based measurements. However, in the future the proposed core group will exploit air and space platforms to provide measurements of radiative fluxes, water-vapor profiles, and cloud top properties in the atmosphere and to extend the range of these measurements to regional and global scales.

Current aircraft and satellite measurements can meet a part of this need, but have, major limitations. For example, piloted aircraft provide many important atmospheric measurements but lack the combination of endurance and altitude capabilities (multi-day-flights at 20 kilomet ers altitude) needed for radiation-cloud studies in the critical tropical Pacific region. Similarly, con cemporary satellites provide excellent cloud imagery but fall significantly short of meeting the needs for mealsuring cloud properties such as droplet phase and size and for measuring water-vapor profiles.

An emerging generation of small, unmanned aerospace vehicles and small satellites offers the most timely and cost-effective waly to fulfill these key, unmet climate research needs. Recognizing that the 1993 U.S. Cilobal ( Change Research Program Plan calls for new starts in global change research, Sandia's core group will support 1 ()E in development of unmanned aerospace vehicles and smiall satellites, including the lightweight instrumentation needed to take full advantage of such small plattorms. 


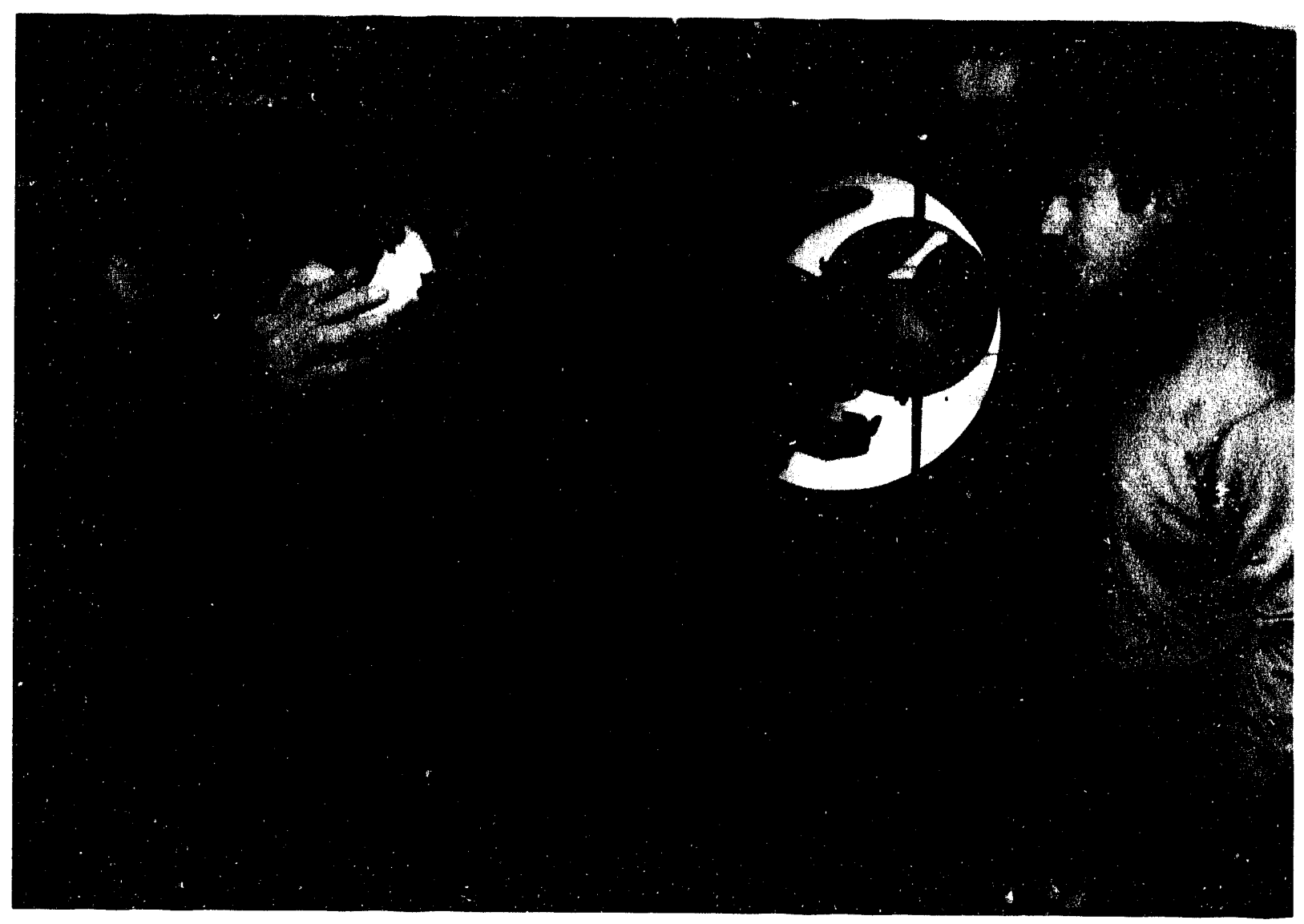

Marshall Lapp, Scott Bisson, and John Goldsmith discuss the optics of a Raman lidar device they are developing in partnership with researchers at NASA's Goddard Space Flight Center. The instrument will collect data on water vapor in the first three miles of the atmosphere. Clouds and water vapor must be better understood to improve computer models for predicting climate heating.

This team will provide overall program direction and infrastructure, contribute to the science, and draw on sensing technology developed for defense applications to prototype some of the improved miniature climate instrumentation. A broad-based science team, including significant university and interagency participation (such as NASA, the National Oceanographic and Atmospheric Administration, and the Environmental Protection Agency), will provide scientific direction. Industry will be strongly involved in the development of unmanned aerospace vehicles, the small satellites, and some of the instrumentation.

Early demonstration of the climate research capabilities of unmanned aerospace vehicles using existing instruments and unmanned aircraft will be conducted in the first year. Improved climate instrumentation development and enhanced unmanned aerospace vehicle capabilities will follow over the next two year. Miniature climate instrumentation would be available for application in small satellites a year after their application in unmanned aerospace vehicles.

DOE and its national laboratories have significant capabilities and experience that make it well suited to this role. This experience has been gained through decades of involvement in the design and development of both nuclear and nonnuclear weapon systems, in more than twenty-five years of development experience for advanced satellite instrumentation, and in envirommental initiatives such as the Atmospheric Research Measurement Program. The proposed Core Group in Climate (Change Research Technologies will be vital to Sandial's continued support of the D()l: and national programs in this important area. 


\begin{tabular}{|c|c|c|c|c|c|}
\hline \multicolumn{6}{|c|}{$\begin{array}{l}\text { Funding Requirements for Initiative Project Proposals in Environmental Technology } \\
\text { (Dollars in constant FY } 1994 \text { millions; personnel in FTEs) }\end{array}$} \\
\hline & Year 1 & Year 2 & Year 3 & Year 4 & Year 5 \\
\hline \multicolumn{6}{|c|}{ Environmentally Conscious Manufacturing } \\
\hline Operating & 6.0 & 10.0 & 15.0 & 20.0 & 20.0 \\
\hline Direct Personnel & 20 & 25 & 30 & 55 & 55 \\
\hline \multicolumn{6}{|l|}{ Waste Management } \\
\hline Operating & 9.0 & 18.0 & 28.0 & 36.0 & 42.0 \\
\hline Direct Personnel & 30 & 60 & 100 & 120 & 140 \\
\hline \multicolumn{6}{|c|}{ Environmental Restoration } \\
\hline Operating & 9.0 & 18.0 & 27.0 & 36.0 & 45.0 \\
\hline Direct Personnel & 40 & 80 & 120 & 160 & 200 \\
\hline \multicolumn{6}{|c|}{ Hazardous Materials Transportation } \\
\hline Operating & 15.2 & 18.6 & 22.8 & 23.9 & 28.0 \\
\hline Direct Personnel & 50 & 65 & 85 & 90 & 100 \\
\hline \multicolumn{6}{|c|}{ Unmanned Aerospace Vehicles and Small Satellites for Climate Studies } \\
\hline Operating & 13.0 & 14.0 & 14.0 & 15.0 & 15.0 \\
\hline Capital Equipment & 1.0 & 2.0 & 2.0 & 1.0 & 1.0 \\
\hline Total Cost & 14.0 & 16.0 & 16.0 & 16.0 & 16.0 \\
\hline Direct Personnel & 25 & 28 & 30 & 30 & 30 \\
\hline \multicolumn{6}{|c|}{ Total, Environme ..al Technology } \\
\hline Operating & 52.2 & 78.6 & 106.8 & 130.9 & 150.0 \\
\hline Capital Equipment & 1.0 & 2.0 & 2.0 & 1.0 & 1.0 \\
\hline Total Cost & 53.2 & 80.6 & 108.8 & 131.9 & 151.0 \\
\hline Direct Personnel & 165 & 258 & 365 & 455 & 525 \\
\hline
\end{tabular}




\section{Energy Research and Technology Development}

Under this majo, nitiative, we propose new projects in the areas of renewables, fossil energy, and nuclear power. The c proposals take advantage of Sandia's existing technical cappabilitics, ficilities, and industry relationships and are consonant with the Department of Linergy's strategic direction in energy.

The motivation for Sandia's energy work is our mission of assuring the nation's encrgy security, coupled with an urgent concern for the global environment. For this reasen, Sandia and its industrial partners continue to develop systems-level solutions to energy needs. We are one of the nation's premier contributors to energy technology in the areas of renewables, fossil energy, and nuclear power - always with consideration for environmental well-being.

Sandia's technical competencies and systems orientation have traditionally driven our responsibilities in energy technology. For this reason, our chemical sciences effort has focused on developing tools and fundamental knowledge that relate directly to our work with engine combustion, furnace combustion, and fossil fuel combustion. Likewise, our geosciences staff provides basic tools and knowledge to improve our effectiveness in reservoir characterization and repository design. Our materials sciences engineers have a major component of advanced electronic materials design to support our other efforts, such as photovoltaics, advanced semiconductors, and even our environmentally conscious manufacturing st'dies.

We are at a threshold of significant new thrusts in renewables, building on our historic strengths in this area. For many years, we have operated the National Solar Thermal Test Facility for DOE. We provide support for the development of Solar Two, a utility-scale solar power tower in California. Sandia's Photovoltaic Design Assistance Center has helped U.S. manufiacturers compete in this emerging international market. We are also collaborating with industry and the Bonneville Power Administration to expand commercial utilization of geothermal resources in the Pacific Northwest. Renewable energy technologies rely on Sandia's contributions of reliable, wellengineered system designs, such as these examples, to make the leap from laboratory novelties to manufacturable, high-volume commercial products.

Our fossil energy programs have already resulted in $1_{1}$ : us breakthrough in combustion research, coal liquefaction, oil and gas exploration, and $\mathrm{r}$. . characterization and production. We plan to use our Oil Recovery Technology Partnershy I model for involving industry in other partnership endeavors. We propose a Geoscience Re i Laboratory at Sandia modeled after a successful experience with Sandia's Combustion Research user facility.

Sandia's nuclear energy program is largely built around our Nuclear Regulatory (ommission experience in severe accident phenomenology and risk assessment. We have drawn extensively upon these capabilities and Sandia's broader competencies to assist 1)()E in its programs in reactor design and in plant life extension. Sandia will continue to help 1)( )t: address plant life problems, and we intend to begin a new program in decommissioning and decontamination of plants whose design lifetimes have expired.

Sandia's energy efficiency projects are built around our engine combustion and battery design work. These projects are discussed under the major initiative, "Transportation Energy l' lechnology" and Infrastructure" on page 5-35.

Sandia continually builds on its capabilities and facilities to improve ongoing programs and suggest offshoots that build on our successes, such as those proposed below. 


\title{
Project Proposals for the Major Initiative in Energy Research and Technology Development
}

\author{
Photovoltaics Industry Development \\ [for the Assistant Secretary for Energy Efficiency and Renewable Energy (EB)]
}

Drasing upon the wide spectrum of expertise at the Laboratories, Sandia has provided the engineering design, testing, and evaluation that have been significant in the development of today's solar energy' industry. Important new thrusts are now possible based on this work, which Sandia spearheaded. The proposals we list below are designed to help industry overcome current barriers in manufacturing and infrastructure that inhibit photovoltaics from becoming a truly sustainable technology. Sustainability is key to the health and growth of the photovoltaics industry and is an area where Sandia's technical expertise is vital.

\section{Federal, State, and Regional}

Government Agency Photovoltaics Initiative [for the Office of Utility Technology]

This initiative will develop photovoltaic applications for government agencies. Sandia's technical competencies in photovoltaic applications can enable DOE to demonstrate how photovoltaic systems can improve the economic operation of federal and other government agencies. If successful, the initiative will stimulate the local and regional infrastructure for photovoltaic systems, thereby creating jobs and markets for the industry.

For example, cost-effective applications exist today in the federal government in agencies including the Bureau of Land Management, Department of Defense, Department of Agriculture, and Department of Interior (parks and remote facilities).

Sandia's Photovoltaic Systems Design Assistance Center, with its proven record of success, will work interactively with agencies to ensure that applications are developed for appropriate needs. In addition, the center will support and complement activities in the established Photovoltaics for Utilities (PV4U) organization of state working groups. This work will initiate fielding of systems with wide-scale repeatability. It involves state energy officials, representatives from the photovoltaics industry, and staff from utility companies working cooperatively to foster the use of photovoltaics.

\section{Photovoltaic Collector Manufacturing Process Development [for the Office of Solar Electric Conversion]}

A goal of the DOE National Photovoltaic Program is to provide a clean, renewable, and economical source of electric power that will reduce fossil fuel consumption while improving the competitiveness of U.S. industry. To remain internationally competitive, indusiry must both reduce manufacturing costs and continuously improve the quality of photovoltaic systems.

This proposal in photovoltaics collector manufacturing process development will improve products and manufacturing processes by working collaboratively with industry to address manufacturing issues affecting collector durability and cost. Industry has expressed interest in leveraging its limited research and development resources through the analytical services and photovoltaics fabrication 
capabilities available at Sandia. Sandia's Photovoltaic Collector l. ifetime Project is already working with several major photovoltaic collector manufacturers to identify mechanisms limiting durability under operating conditions.

Under the proposed program, Sandia will investigate issues involving collector design and reliability, collector manufacturing and cost, and environmentally conscious manufacturing of collectors. We will use our laboratory capabilities to fabricate and evaluate collector design and process alternatives, especially in the areas of soldering, encapsulation materials, and bonding.

In addition to using the resources of Sandia's Collector Fabrication and Assembly Laboratory, the program plans to leverage other Sandia centers of expertise: for example, the Photovoltaics Device Fabrication Laboratory for solar cell processing; the Photovoltaics Technology Lvaluation Laboratory for environmental durability testing; and the Center for Advanced Manufacturing Technology for environmentally conscious manufacturing, robotics, and advanced manufacturing processes.

This program will provide a flexible, industry-oriented support capability that will be responsive to industry needs as the technology develops and matures.

\section{Photovoltaic Balance-of-Systems Manufacturing Technology [for the Office of Solar Electric Conversion]}

Approximately one-half the cost of a utility-interconnected photovoltaic energy system is in photovoltaic modules. The other half is in balance-of-systems, e.g., system interconnections, power conditioning, control systems, support structures, and installation.

This initiative addresses balance-of-systems technology improvements that will reduce costs and develop hardware to allow U.S. industry to compete successfully in larger markets. A cost-shared balance-of-systems manufacturing initiative (BOSMaT) will reduce manufacturing costs for photovoltaic power conditioning and control systems. Balance-of-systems cost reductions and reliability improvements, coupled with decreases in module costs, will encourage utilities to include photovoltaic generation in grid support, demand-side management, remote power, and other specialized applications.

In addition, development of manufacturable power conditioning and control systems for diesel generator/photovoltaic hybrid systems greater than 100 kilowatts is necessary if photovoltaics is to expand into the diesel replacement market. This market includes systems for village-scalc power in developing countries and systems that can meet environmental requirements while supplying power for military and other government applications. This option will be especially attractive in environmentally sensitive areas.

Sandia has collaborated with the U.S. photovoltaics industry to develop systems hardware that has reduced costs, improved performance, and opened new markets both domestically and internationally. This $\$ 50$ million initiative will develop the manufacturing capability of the U.S. balanceof-systems industry over a five year period so it can continue to compete in world photovoltaic systems markets. The balance-of-systems initiative has strong support from the U.S. photovoltaic industry, which would share program costs.

The Office of Solar Electric Conversion, through the Photovoltaics Division, is funding an ongoing program, the Photovoltaic Manufacturing Technology Program (PVMa'T), to reduce the manufacturing costs of photovoltaic modules. PVMaT is addressing photovoltaic module manufacturing technology problems through cost-shared contracts with photovoltaic module manufacturers. The intent of PVMaT' is to reduce the cost of modules by at least half by providing the manufacturing technology improvements necessary for the industry to increase production. But the photovoltaics industry now recognizes that it will also be necessary to reduce balance-ofsystems costs if large-scale utility adoption of photovoltaic technology is to become a reality. 


\section{Photovoltaic Systems Lifetime Improvement [for the Office of Solar Electric Conversion]}

Ten years of field data from a variety of photovoltaic systems and components show that power loss from balance-of-system degradation typically ranges from $10 \%$ to $15 \%$ and that irreversible module degradation and mismatch losses add another $10 \%$ to $15 \%$. Since the success of photovoltaic technology will depends on its reliability, the Photovoltaic Systems lifetime Improvement effort is aimed at assisting the industry in achieving a photovoltaic technology with a thirty-year lifetime that degrades in performance by less than $10 \%$ in that period.

A team of representatives from industry, the Department of Energy program, and users of photovoltaic technologies will capitalize on the strengths of each to identify ways to eliminate the failure mechanisms responsible for the power losses now observable in five- to ten-year-old systems. The team will also establish an evaluation program for current manufacturing processes aimed at early mitigation of reliability problems.

The program's working group will perform field evaluations of installed systems and identify causes of observed degradation. Degradation typically includes browning, high resistance in solder bonds, interconnect corrosion, changes in balance-of-systems components' performance, module delamination, cell metallization adhesion, cracks in the back surface polymer, and electrical mismatch.

The working group will make recommendations for improving manufacturing processes or developing new materials to solve reliability problems. It will also recommend utilization of DOE capabilities in photovoltaics testing, materials and process sciences, and nondestructive testing where they can be useful.

The program requires a long-term commitmeitt from both $\mathrm{D})(\mathrm{)}$ ) and industry. It will begin with a minimum commitment of $\$ 20$ million over a five-year period to address the degradation issues that have surfaced from initial investigations.

\section{Utility Photovoltaics [for the Office of Solar Electric Conversion]}

Because utility companies are major suppliers of electricity for the nation, they could be a major customer for photovoltaic systems, using them to supply energy where grid connection is expensive or impossible. This initiative is important in assuring that utilities use photovoltaics. Sandia can add its technical experience and expertise to demonstrate that photovoltaic systems can be used in a number of ways to help them and save the customer money.

This initiative is a cooperative partnership to accelerate the use of photovoltaics within the utility sector. The partners in this effort include the photovoltaics industry; the established Utility Photovoltaic Group; utility representative organizations such as Edison Electric Institute, American Public Power Association, National Rural Electric Cooperative Association, and Electric Power Research Institute; and individual unlity companies.

Objectives are to identify and maximize the benefits obtained by the utilization of photovoltaics in applied systems for utilities or their customers. These applied systems are developed for a sustainable, economically driven market. Building on Sandia's established network of relationships with utilities and the photovoltaics industry, higher-value remote, in-lieu-of-line extension, and grid-connected applications will offer the photovoltaics industry market entry vehicles into the utility sector. The ability of photovoltaic systems to serve remote loads will be the foundation for the transition to larger and significant fuel-offset systems and eventual specialized grid-connected applications. These applications will capitalize on the technology's characteristics of no fuel use, low operating costs, modularity, reliahility, and energy sustainability. 
The initiative will be based on the needs of the utilities and their customers. Starting with analyses of feasibility and opportunity, applications will be developed based on current hardware and the ability of photowoltaics to uniçuely meet customer requirements for energy in an environmentally acceptable way at the point of use. Further, the systems will, to a certain extent, bypass traditional means of electricity delivery. (irid-connected systems owned by customers offer a means of demand-side supply. Successful implementation of systems will be communicated to stakeholders and the economic advantages (including job creation) fully determined.

\section{Advanced Materiais for Energy' Conversion [for the Assistant Secretary for Energy Efficiency and Renewable Energy (EB); and the Assistant Secretary for Fossil Energy $(A A, A B)]$}

A series of government and private studies have concluded that new materials will drive advances in many industrial sectors. The need for government-sponsored research and development leading to advances in materials technology has been clearly delineated. The National Energy Policy Act of 1992 mandates a five-year national advanced materials program plan.

Advanced materials will play a major role in the area of energy conversion in coming years. The need for materials with higher performance in extremes of temperature, pressure, and corrosive environments, as well as the need for energy savings and environmental sensitivity, requires major advances in structural and functional materials. Research and development in structural materials includes structural ceramics, intermetallics and alloys, coatings, and joining. Functional materials research and development includes the areas of catalysts, membranes, filters, insulators, and adsorbents. This initiative focuses on research and development in both structural and functional materials for energy applications.

\section{Structural Materials}

Advanced structural materials that can operate at higher temperatures and pressures and that are more corrosion-resistant will allow the use of new, higher efficiency energy conversion and industrial processes. However, these high-performance materials often have drawbacks, including high cost, corrosion sensitivity, and difficulty of forming and joining parts. Proposed rescarch and development in structural materials includes new processing methods for increasing ductility and workability of high-temperature chromium-niobium alloys; synthesis of nanometer-size silicon nitride and carbide powders for high-temperature ceramics with enhanced sintering performance; novel joining technologies for advanced ceramic and alloy structural materials; thermal spray technology for corrosion and impact resistance; and high-temperature coatings. In each area, we are building on expertise resident at Sandia and on specific structural materials requirements in the D)( ) F fossil Energy and Energy Efficiency and Renewable Energy programs.

\section{Functional Materials}

Products of catalytic processes impact almost every aspect of our lives, including our food, clothing, ransportation, energy, environment, health care, and defense. Because catalytic processes account for 20 percent and one trillion dollars of the United States' gross domestic product, research and development leading to improvements in catalysts and catalytic processe's can have a substantial positive impact on the U.S. conomy.

Catalysts create a $\$ 180$ billion export market in chemicals and contribute $\$ 12$ billion toward a positive U.S. trade balance. (atalytic research and development areas addressed in this initiative will include emissions control, catalytic membrane reactors, conversion of hydrocarbon resources, 
and fuel cells. This effort combines established strengths at Sandia in computer-aided molecular design, massively parallel computation, process chemistry and reaction engineering, materials science, and catalyst characterization and evaluation to focus on an integrated theoretical, experimental, and engineering approach to the design of advanced catalytic materials.

Porous materials are another multibillion dollar technology that broadly impacts industrial processes. Porous materials often replace more expensive, energy-intensive processes in conergy conversion applications as membranes and adsorption media for s, arations, ion exchange, storage, and purification; environmental and industrial process sensors; electrodes for battery and fuel cell applications; supports for catalysts; insulators; and lightweight structural materials. Porous materials research and development areas that will be addressed in this initiative include corrosion- and impactresistant high-temperature filters for gas filtration; unique catalytic membrane reactors; other microand meso-porous catalyst support materials; controlled pore size membranes and coatings for light gas separations; extremely high selectivity crystalline silicotitanate ion exchange materials for industrial and radioactive waste; porous electrodes for fuel cells; and fast-cycle, high-capacity hydrogen and methane storage media. The broad range of capabilities described above would be employed to take advanced porous materials from concept through technology transfer to industry.

\section{Solar Dish-Stirling Systems for Utility Applications} [for the Assistant Secretary for Energy Efficiency and Renewable Energy (EB)]

Modular solar-dish/engine systems can effectively address near-term, high-value utility applications, such as remote generation and end-of-line capacity additions. To accelerate the introduction of this technology, we will initiate several dish/engine system development and commercialization projects.

\section{Sandia and three private companies won a 1993 R\&D 100 award for $a$ 7.5-kilowatt parabolic- dish/Stirling-engine system for generating electricity. The system}

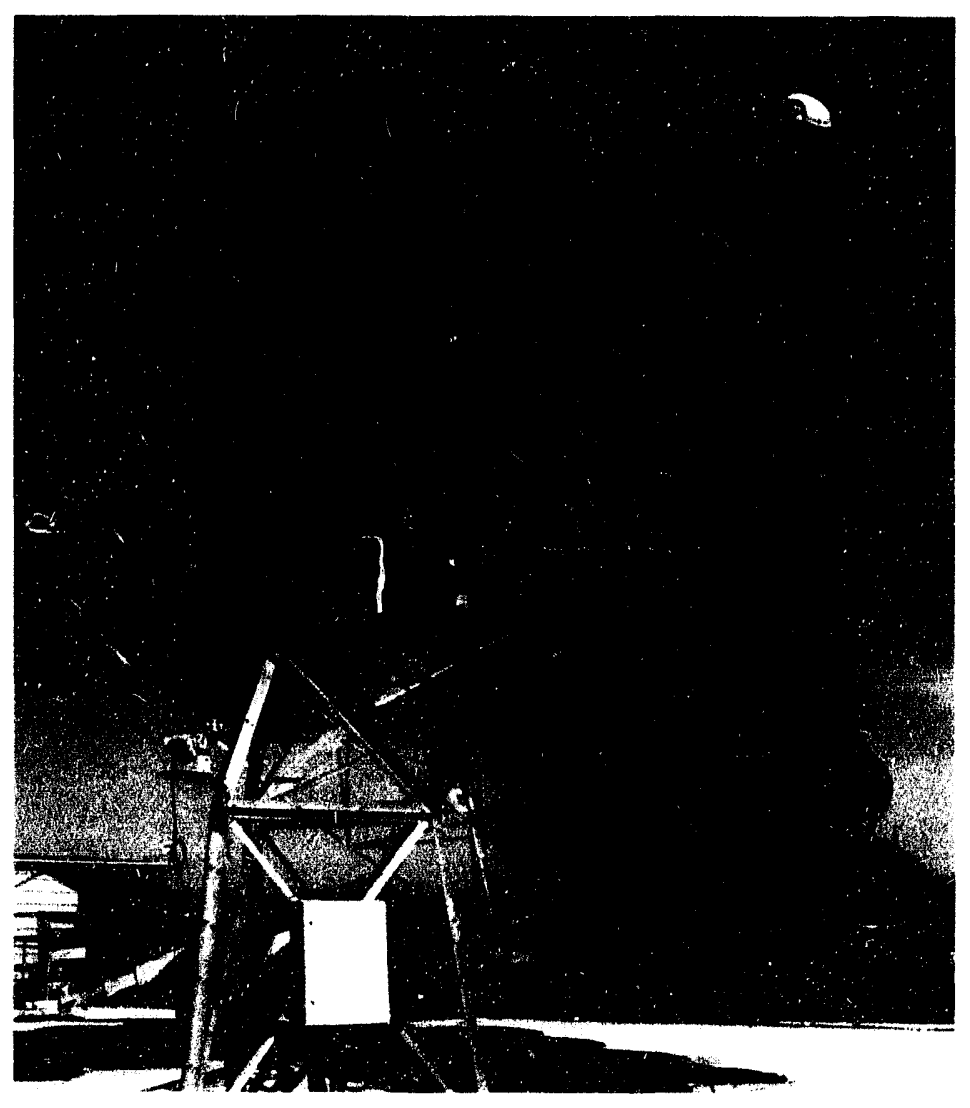

was designed by a team of engineers from Cummins Power Generation, Inc., Sandia researchers, and engineers from Sunpower and Thermacore corporations. It is the first commercial application of a free-piston Stirling engine.

Dish-Stirling technology is named for its two major components, dish-shaped solar concentrators and a Stirling heat engine. In the Cummins Power Generation system, low-cost stretched-membrane concentrators track the sun and focus the sun's rays onto a receiver located at the focal point. Each concentrator dish is a unit that can track the sun independently or as part of a group of dishes.

Inside the receiver, vaporized sodium metal condenses on the Stirling engine's heater head. The condensing sodium heats helium gas inside the free-piston Stirling engine. The helium is shuttled between the heater head and the cooler side of the engine by a displacer piston. The alternating heating and cooling and cyclic pressure drives the power piston and alternator to make electricity.

The main application of this system is to provide electricity to remote communities not connected to a utility grid. The system competes in costs with other renewable energy systems and is easier to maintain than diesel generator systems. 
These activities will be patterned after our successful remote-power dish-Stirling joint venture with Cummins Power Generation.

The objective of these new joint ventures will be to develop distributed solar thermal systems of approximately 25 kilowatts per module suitable for utility markets. like the Cummins joint Venture, the Utility-Scale Joint Venture Program will include equal cost-sharing between the I ) epartment of Energy and industry. An industrial partner capable of marketing and supporting commercialization of the technology will be a requirement, as will participation by utilities. Significant industry direction in developing marketing plans, product development, and program planning and exccution will be expected. To meet the goal of prototype system demonstrations at utility sites, large-scale demonstrations are planned to begin in three to five years.

This program could include non-Stirling cycle converters if chosen by industry. Recent technical advances and manufacturing cost reductions suggest a Brayton-cycle-based system may be economically competitive in the projected time frame of the Utility-Scale Joint Venture Program.

DOE funding for the initial phases of each of three ne " utility-scale joint venture programs is expected to be $\$ 3$ to $\$ 5$ million per year for about five years. Progression to the large-scale demonstration phase will require about $\$ 5$ million per year for two years for each joint venture program.

\section{Integrated Utility Systems Energy Storage}

[for the Assistant Secretary for Energy Efficiency and Renewable Energy (EB)]

The Integrated Utility Systems Energy Storage program will address generation, transmission, distribution, and end-use energy storage needs. The nation's total energy use is projected to increase from 85 quads today to between 102 and 112 quads by 2010. The share of primary energy consumed to produce energy is projected to increase from 36 to 39 percent. This estimate corresponds to expanding generating capacity by as much as 245 gigawatts. During this period, to optimize baseload capacity and substation transformer loading, energy storage will become an essential capability in an integrated electrical network.

This program matches Sandia integrated systems capabilities in storage technologies (e.g., batteries, superconducting magnetic energy storage, capacitors, and so forth) with the needs and experience of industry and the Department of Energy. Although certain energy storage technology programs are underway in the private sector and elsewhere in the federal government, there is a major role to be filled. First, to formulate long-range energy policy, a comprehensive and integrated understanding of energy storage technologies and their relative applications is required. Second, a balanced research portfolio that accelerates the incorporation of present technologies and identifies new storage technologies should be developed. Finally, joint demonstration programs involving industry, I)E, and the national laboratories are needed to move these developing technologies to the private sector.

The successful implementation of this program will help maintain the continued growth of U.S. industry by keeping the cost of electricity down, improving the utilization of fossil cincrgy resources, and minimizing the environmental impact of sustained industrial growth.

\section{Wind Turbine Manufacturing [for the Assistant Secretary for Energy Efficiency and Renewable Energy (EB)]}

In the past ten years, the wind power industrv in the United States has progressed to over 15,000 turbines supplying 1,500 megawatts of power to several utilities, primarily in California. With the complete phase-out by 1945 of most of the tax incentives that helped create the wind energy market, wind energy conversion systems will have to compete with conventional sources of power and produce energy in the range of 4 to 5 cents per kilowatt- iur. 


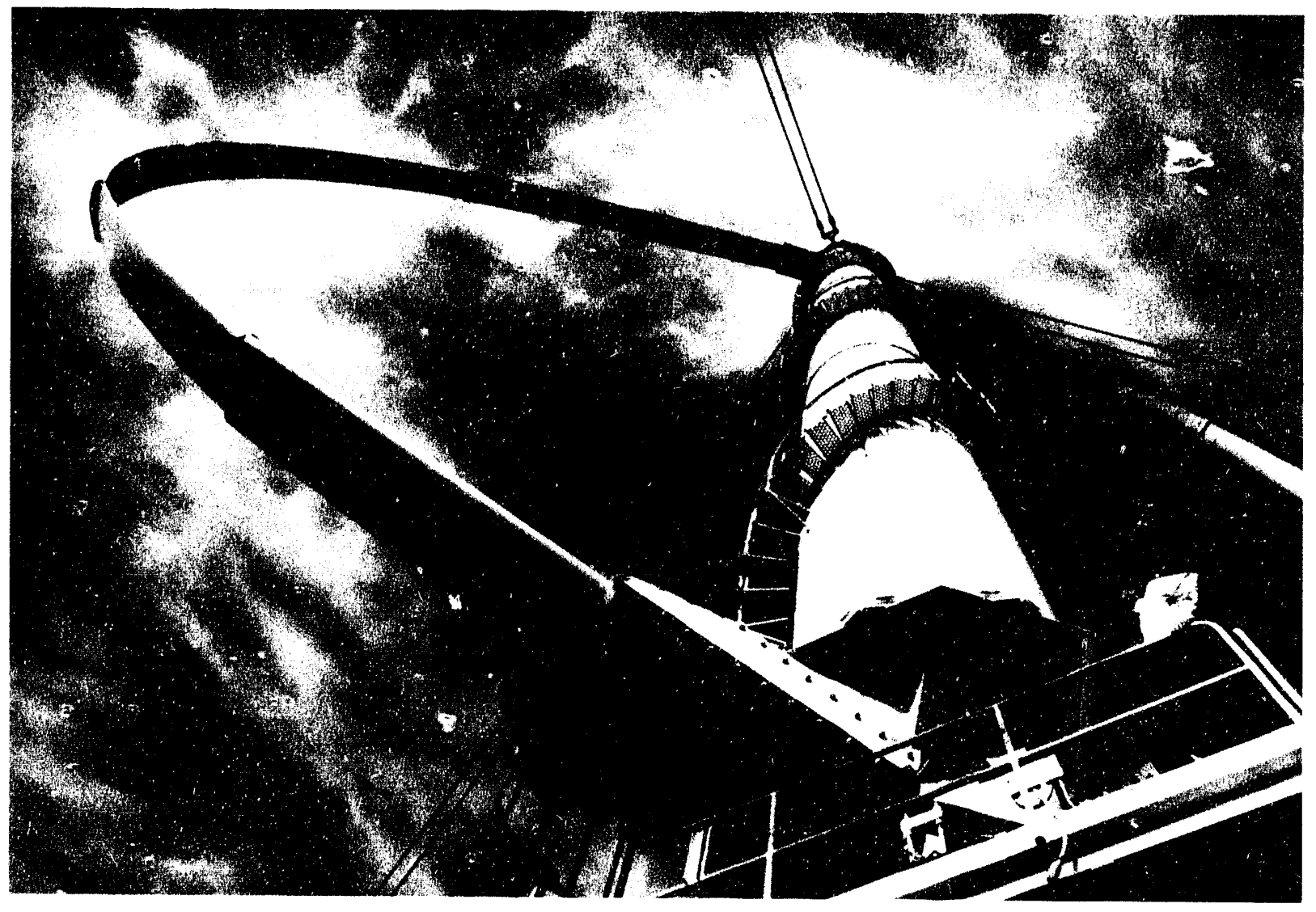

Three years of testing on this 50-meter-tail vertical-axis wind turbine (VAWT) in Bushland, Texas, has shown that certain design features result in greater efficiency and lower operating costs. The VAWT, designed by Sandia, uses multiple-section, tailored blades and a generator that works at various speeds-features that minimize stresses and maximize energy capture.

Sandia proposes a new project entitled W'ind Mamuficturing T'chlmology to identify and support advanced manufacturing technologies that can foster cconomic growth, energy efficiency, and competitiveness in the wind industry. Breakthroughs in wind turbine manufacturing will provide the extra boost needed to make wind energy competitive with conventional power sources. Technical improvements in several areas can impact wind turbine manufacturing. They include composite design, advanced materials, structural design, systems integration, robotics, cost/performance tradeoff analysis, serviceability and inspectability, and airfoil design. Application of modern concepts of agile manufacturing will improve production.

The Wind Manutacturing l lechnology project is currently divided into two phases. Phase I is designated Integrated Rotor Analysis and Manufacturing and concentrates on ways to improve the manufacturing of rotors and blades. Phase Il is termed Integrated System Manufacturing and will seck ways to impact the manufacturing of non-rotor components and the wind turbine system as a whole.

\section{Gas and Oil Technolıgy Partnership [for the Assistant Secretary for Fossil Energy $(A B, A C)$ ]}

The (ais 'nd Oil Technology Partnership is based on the suceessful model of the ()il Recovery' Technolegy Partnership, which matched the Laboratories' capabilities with industry needs on a limited scale. This joint venture between Sandia and Los Alamos National Laboratory is cost-shared 
with industry, and is Hexible in approach; moreover, industry helps prioritize its projects. The new (ias and (Oil Technology Partnership reflects the nation's continued need for oil and gas despite declining domestic production and a reliance on imports. ()il and gas production share industry infrastructure, so it is expected that the program can benefit both.

The partnership will match Sandia's capabilities with industry's needs and experience and, through joint collaborative programs, will provide the research and development to address the technological challenges faced by the industry. 'These challenges span a spectrum from exploration, to drilling and recovery, to transportation and storage, to refining and conversion, and finally to consumption - all while minimizing waste and environmental impact.

Successful implementation and support of the program will have a positive impact on the petroleum industry by providing a needed, versatile technology base and helping to create jobs. It will also maintain a leading technology base within the Department of Energy's national security laboratories.

Funding recuested is $\$ 10$ to $\$ 15$ million per laboratory in the first year to identify the technology areas, establish industry interactions, and initialize vital projects. Funding will gradually inc rease to $\$ 15($ ) million per year per laboratory over the remainder of the decade to permit the laboratories to conduct a full range of research and development identified by industry.

\section{Hydrogen Storage and Utilization [for the Office of Energy Research (KC)]}

The environmental impacts of contemporary energy utilization and our national dependence on foreign supplies are a source of growing public concern. 'This concern highlights the importance of developing alternative energy carriers for transportation, utility, and industrial utilization. In particular, hydrogen is an abundant and versatile energy form which offers significant advantages over other alternative fuels, including the potential to reach zero pollutant emission levels, burn without carbon dioxide production, and be clomestically produced.

There are significant challenges to hydrogen utilization, including cost-competitive energy production, efficient storage, effective conversion systems, and an infrastructure for distribution. These problems cut across several technology areas, and solving them will require the application of many disciplines. Development and demonstration of critical technologies for a hydrogen energy system is a high-risk, long-term effort in which the government, through the Department of Energy, should play a pioneering role.

Sandia is unicuely positioned to contribute to this program because we are the recognized leader in hydrogen isotope systems (developed in our nuclear weapons mission) and because our organization has multidisciplinary depth. Weapons programs will benefit from the dual-use aspects of this technology and the synergistic maintenance of our core technical expertise. The hydrogen energy program will be leveraged by our existing programs and facilities. Sandia's (ombustion Research Facility, which has a complete spectrum of hydrogen combustion experimental and modeling capabilities, will play a central role in this program in basic and applied research.

The program will explore storage development and utilization and work toward an integrated demonstration of a complete storage, delivery, and conversion system. The storage element will develop alternative storage concepts aimed at maximizing energy density and engineering those concepts into storage device subsystems that can supply an internal combustion engine or fuel cell. Specific storage concepts will be high-pressure, lightweight tanks, adsorption systems, and a lightweight hydride. (Other required storage system components, such as sensors, filters, and valves, will also be developed and integrated into the subsystem design.

The utilization element will focus on internal combustion engine modeling and testing, development of a hydrogen-burning conventional engine, and the development of a hydrogen-burning internal combustion engine optimized for efficiency and dean emissions at a single specd/load condition. 
Now is the time to explore and develop alternatives for the nation's future energy needs. 'This program will impact this need by helping to determine the viability of hydrogen as a major encrgy carrier and vill develop some of the critical technologies required to implement this vision.

\section{Combustion Dynamics [for the Office of Energy Research (KC)]}

The Combustion Dynamics Intiative is a joint propesal by Sandia National Laboratories and the Lawrence Berkeley Laboratory in support of the l department of Energy's national role in combustion research. The goal of the initiative is to improve the efficiency of combustion processes while minimizing pollutants and other undesirable effects.

The Combustion Dynanics Initiative comprises two important facilities: completion of the unfinished Combustion Research Facility Phase Il project at Sandia, and construction of the Chemical Dynamics Research Laboratory at Lawrence Berkeley Laboratory.

Research at the (ombustion Dynamics facilities will produce predictive combustion models by using data from experimental and theoretical studies. These models could be very useful to U.S. industry in designing next-generation combustion systems. Research at the Combustion Research Facility will emphasize development of optical diagnostics for combustion, studies of chemical kinetics and reacting flows, and complementary studies in chemical physics. In collaboration with researchers from universities and industry, Sandia and Lanwence Berkeley will develop and apply advanced instrumentation for combustion studies.

These activities will result in new insights into the elementary reactions involved in hydrocarbon combustion, the structure and dymamics of highly excited molecular species, and molecular energy flow proresses, all of which are critical for advancing combustion technology. Research results from fundamental studies of chemical reactivity and fluid mechanics will be incorporated into computer models to improve the design of engines, burners, boilers, furnaces, and gas turbines. The proposed modeling effort already has several industrial participants, including Allison Cas 'Turbine Co., Cummins Engine, and the John Kink Company.

The (ombustion Dynamics Initiative will offer unparalleled resources for users to study funda mental and applied combustion processes. Rescarchers at Sandia's Combustion Research Facility will be able to utilize advanced laser systems to study ultra fast processes in chemistry ancicombustion, and perform two- and three-dimensional imaging of the physical and chemical properties of turbulent reacting Hows.

\begin{tabular}{|c|c|c|c|c|c|}
\hline \multicolumn{6}{|c|}{$\begin{array}{l}\text { Funding Requirements for Initiative Project Proposa's in Energy Research and Technology Development } \\
\qquad \text { (Dollars in constant FY } 1994 \text { millions; personnel in FTEs) }\end{array}$} \\
\hline & Yedr1 & Year 2 & Year 3 & Year 4 & Year 5 \\
\hline \multicolumn{6}{|c|}{ Photovoltaics Industry Development } \\
\hline \multicolumn{6}{|c|}{ Federal, State, and Regional Government Agency Photovoltaics Initiative } \\
\hline Operating & 3.0 & 4.5 & 6.0 & 6.0 & 5.5 \\
\hline Direct Personnel & 4 & 5 & 7 & 7 & 6 \\
\hline \multicolumn{6}{|c|}{ Photovoltaic Collector Manufacturing Process Development } \\
\hline Operating & 2.5 & 3.0 & 4.0 & 4.5 & 5.0 \\
\hline Direct Personnel & 6 & 8 & 9 & 10 & 11 \\
\hline
\end{tabular}




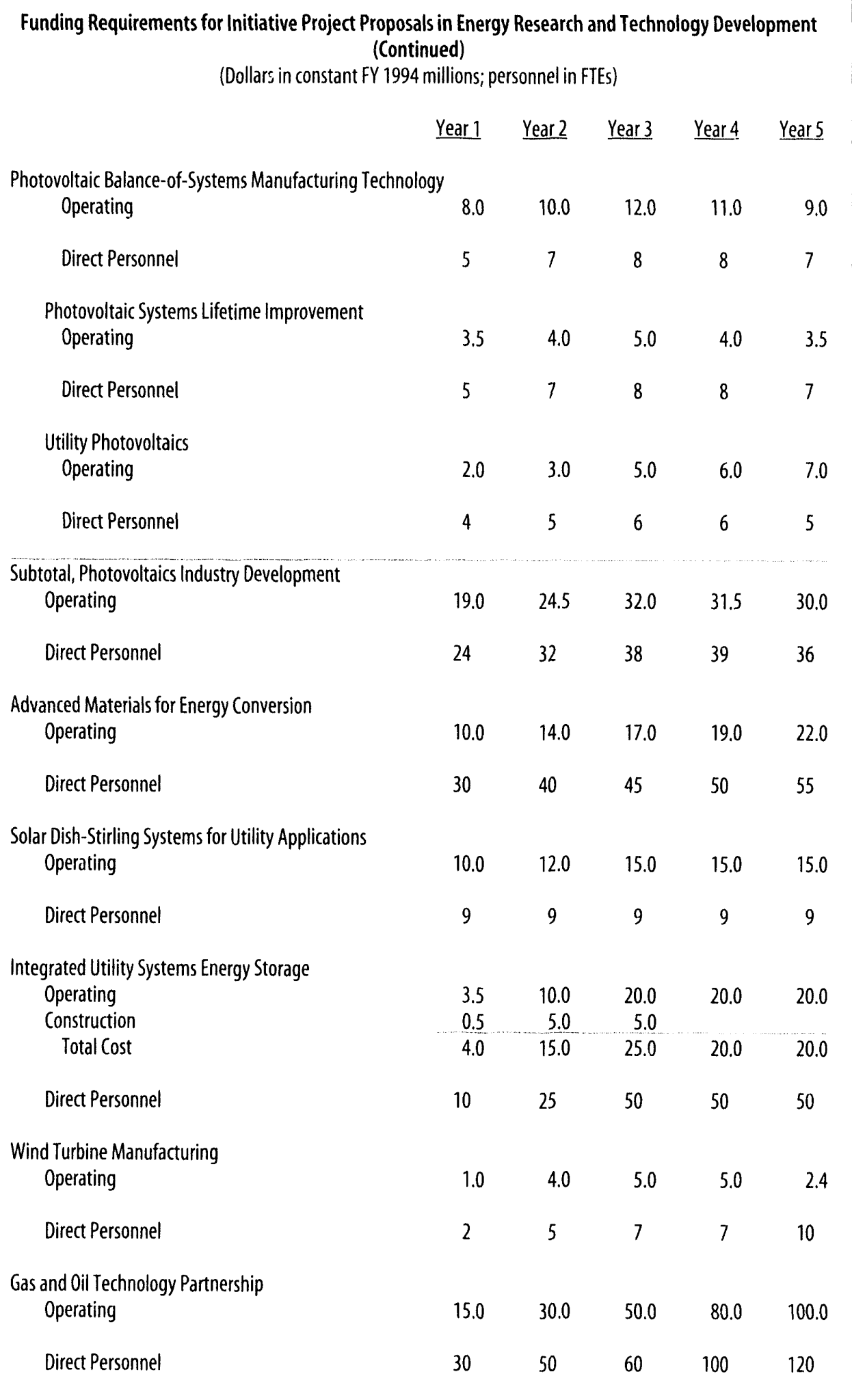




\begin{tabular}{|c|c|c|c|c|c|}
\hline \multicolumn{6}{|c|}{$\begin{array}{l}\text { Funding Requirements for Initiative Project Proposals in Energy Research and Technology Development } \\
\qquad \text { (Continued) } \\
\qquad \text { (Dollars in constant FY } 1994 \text { millions; personnel in FTES) }\end{array}$} \\
\hline & Year 1 & Year 2 & Year 3 & Year 4 & Year 5 \\
\hline \multicolumn{6}{|c|}{ Hydrogen Storage and Utilization } \\
\hline Operating & 2.0 & 2.5 & 3.0 & 3.0 & 3.0 \\
\hline Direct Personnel & 5 & 7 & 10 & 10 & 10 \\
\hline \multicolumn{6}{|l|}{ Combustion Dynamics } \\
\hline Operating & 5.0 & 5.0 & 5.0 & 5.0 & 5.0 \\
\hline Construction & 10.0 & 9.8 & & & \\
\hline Total Cost & 15.0 & 14.8 & 5.0 & 5.0 & 5.0 \\
\hline Direct Personnel & 25 & 25 & 25 & 25 & 25 \\
\hline \multicolumn{6}{|c|}{ Total, Energy Research and Technology Development } \\
\hline Operating & 65.5 & 102.0 & 147.0 & 178.5 & 197.4 \\
\hline Construction & 10.5 & 14.8 & 5.0 & & \\
\hline Total Cost & 76.0 & 116.8 & 152.0 & 178.5 & 197.4 \\
\hline Direct Personnel & 135 & 193 & 244 & 290 & 315 \\
\hline
\end{tabular}




\title{
Biomedical Systems Engineering
}

Health care costs in the United States are increasing rapidly. These cests are a major concern to the public and contribute to the decline in U.S. economic competitiveness. The proper application of advanced technologies through biomedical engineering could significantly reduce some aspects of the overall cost without compromising or rationing health care.

The national laboratories possess a wealth of engineering and scientific expertise that can be applied to this critical need. However, the expertise resident in these entities has not yet been used to develop technologies that can help reduce health care costs. Research in biology (for example, the human genome project) is underway at several Department of Energy laboratories. I Iowever, there is little focused effort directed at developing biomedical technologies that have the potential to reduce health care costs.

\section{Project Proposals for the Major Initiative in Biomedical Systems Engineering}

\author{
National Biomedical Engineering Institute \\ [for the Assistant Secretary for Defense Programs (GB); \\ the Office of Health and Environmental Research; \\ and Advanced Research Projects Agency]
}

Development of affordable technologies to drive down health care costs reguires both technical innovation and a thorough understanding of the medical community's requirements. We propose to establish the National Biomedical Fingineering Institute to lead the country's efforts in applying technology to reduce health care costs.

The institute would form interdisciplinary teams with members from the national laboratories, university medical schools, and industry to guide technology development. These teams, dispersed throughout the Linited States and connected via an information infrastructure, would identify the largest cost drivers in health care delivery, define areas where technology could impact those costs, conduct focused research and development programs, and arrange for the transfer of resultant technologies to industry. A multidisciplinary approach will combine state-of-the-art technology development by the national laboratories and industry with insight from the medical commoninty.

The major emphasis will be on a systems engineering appreach to defining the role of technolegy in reducing health care costs. Prior to beginning technology development, a comprehensive study will be conducted to identify areas in the health care delivery system where technology cann reduce costs.

Sandia has al ready developed several biomedical applications that hold potential for reducing costs and improving diagliosis or treatment. For example, a set of computer algorithms developed by Sandia computer scientists to find mobile targets in combat operations has been used to interpret digitized mammegrams. Use of these algorithms has been shown to increase tumor detection rates. In collaboration with the Baylor University Medical ( Center, Sandia is applying massively parallel computational techniques to cuhance the utility of magnetic resonance imaging in diagnesis of breast cancer and brain disorders. We plan to continue impreving the target recognition algorithms in a dual-use fashion to serve both military and civilian needs for image processing.

High-performance computing is also enabling great advances in the ficld of computational biology. In cooperation with a major pharmaceutical company, Sandia is applying massively paralled computing to unravel the interactions between I NA molecules and drug molecules. This work provides insight into drugs that might eventually cure cancer and dIIIS. 
One of the most promising new developments in the field of medicine is that of minimally invasive diagnostics and procedures. Sandia has already demonstrated competence in the development of noninvasive sensors. For example, a spectroscopic blood monitor has been demonstrated to measure blood glucose noninvasively, making it possible for people with diabetes to more accurately manage the disease. This technology has now been licensed for commercial development. It uses computer software originally developed with DOE Defense Programs funding for evaluating explosives in the stockpile. In addition, we are defining a program with Johns Hopkins University, Massachusetts General Hospital, IBM, and others to develop three-dimensional imaging technicues, micro-surgical instruments, data fusion techniques, and physician workstations to improve the ability of surgeons to perform laparoscopic and endoscopic surgery. DOE's Office of Health and Environmental Research has expressed interest in this program.

We have participated in discussions with National Institutes of Health, National Institute of Standards and Technology, private health care providers, and the Veterans Administration on the need for modeling and simulating the nation's health care delivery system. Such a project would make it possible to evaluate the cost effectiveness of various treatment options, provide a database for research on outcomes of treatment, and help in the identification of technology development road maps that could lead to reductions in health care costs.

A new trend in medicine is toward more home health care to reduce the average length of hospital stays and to allow infirm people to remain at home while being monitored. 'To facilitate this trend,

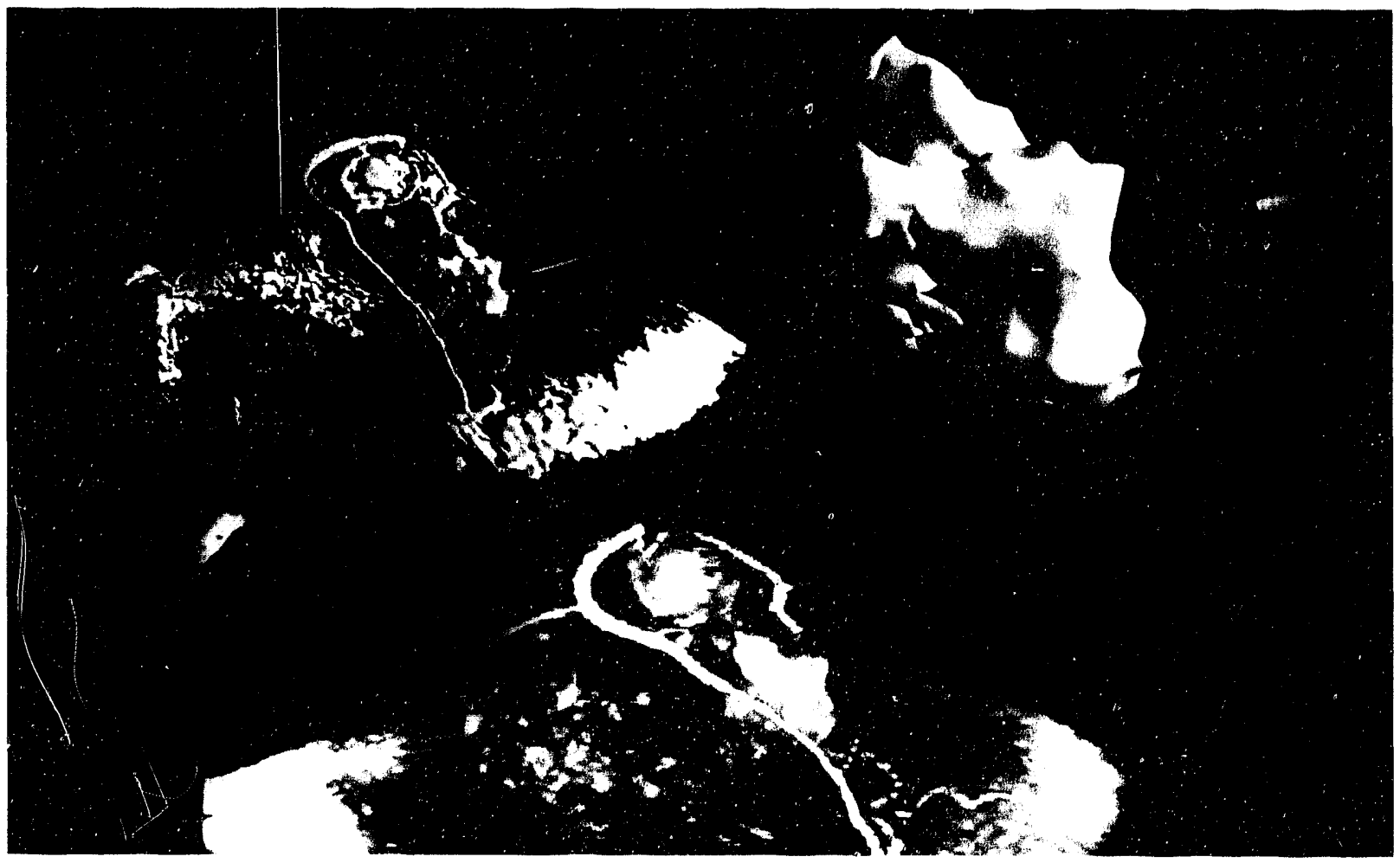

This computer-generated composite illustrates a potential application of Sandia's work using massively parallel computation to process conventional magnetic resonance (MR) image data. In the bottom image, a Connection Machine supercomputer produced a "synthetic $x$-ray" of an entire MR scan, revealing a clouded area representing a lesion. The image is one of hundreds of different views thai would be instantly available to radiologists for analysis. In the upper left image, Sandia's Intel super-computer processed the MR scan to produce a geometric interpretation of the bottom image. The region of interest is enlarged in the upper right corner. The information could be used to mechanically guide a biopsy, as illustrated by the needle. 
small, low-cost sensors with communications capability are desirable for monitoring the state of health of outpatients, post-operative patients, and home-bound patients. Such devices are also of interest to the military for monitoring the health status of troops on the battlefield. We are discussing a program in this area with ARPA and several private companies.

Development of biologically compatible materials is an increasingly important area of medical research. Sandia's role in the nuclear weapons program has led to a strong capability in engineered materials. Applications of this capability to the field of biomedical engineering will lead to new biologically compatible materials for implantable sensors, bone and hip replacements, and skin grafts. Specifically, microcellular foams, long used for packaging nuclear weapon components, are currently being evaluated for applicability in bone replacement. Adhesives for permanently repairing meniscal tears have been proposed for funding through our laboratory-directed research and devclopment program. In addition, the combination of the bioactivity of silicate glasses with the mechanical properties of structural materials may lead to the development of more useful prosthetic devices.

\section{National Medical Information \\ and Communications System Design}

\section{[for the Office of Health and Environmental Research; Advanced Research Projects} Agency; and the Veterans Administration]

Many studies have shown that one of the major contributors to rapidly growing health care costs is the lack of timely, accurate information on patient records. 'This lack of information frequently results in redundant medical tests that add to health care costs.

In conjunction with major medical research institutions, the Advanced Research Projects Agency; the Veterans Administration, and the National Library of Medicine, Sandia is exploring the application of its capabilities in data and network surety, high-speed communication links, and highperformance computing to a program for designing a national medical information infrastructure. In addition to patient records, the system could also provide high-speed image processing capability to increase the utilization factor of expensive equipment, such as magnetic resonance imaging (MRI) instruments. Substantial cost reductions appear to be possible if such a system is developed.

\begin{tabular}{|c|c|c|c|c|c|}
\hline \multicolumn{6}{|c|}{$\begin{array}{l}\text { Funding Requirements for Initiative Project Proposals in Biomedical Systems Engineering } \\
\qquad \text { (Dollars in constant FY } 1994 \text { millions; personnel in FTEs) }\end{array}$} \\
\hline & Year 1 & Year 2 & Year 3 & Year 4 & Year 5 \\
\hline \multicolumn{6}{|c|}{ National Biomedical Engineering Institute } \\
\hline Operating & 10.0 & 25.0 & 50.0 & 100.0 & 100.0 \\
\hline Direct Personnel & 50 & 100 & 200 & 200 & 200 \\
\hline \multicolumn{6}{|c|}{ National Medical Information and Communications System Design } \\
\hline Operating & 5.0 & 10.0 & 10.0 & 15.0 & 20.0 \\
\hline Direct Personnel & 20 & 50 & 50 & 70 & 100 \\
\hline \multicolumn{6}{|c|}{ Total, Biomedical Systems Engineering } \\
\hline Operating & 15.0 & 35.0 & 60.0 & 115.0 & 120.0 \\
\hline Direct Personnel & 70 & 150 & 250 & 270 & 300 \\
\hline
\end{tabular}




\section{Post-Cold War Defense Imperatives}

The demise of the Soviet Union has diminished the strategic threat to the United States. However, we continue to face two strategic security challenges as a nation. First, the threat posed by the continuing existence and spread of technologies of mass destruction challenges us to sustain a credible nuclear deterrent and to preserve the national capability and capacity to rebuild our forces in response to currently unforeseen circumstances. Second, the impact and effect of an increasingly competitive global economy challenges us to ensure that our concepts of national interest and security remain current, realistic, and sufficiently comprehensive to encompass the full range of potential threats to our national integrity.

We advance the following set of coordinated nonproliferation and other defense-related proposals that will respond aggressively to the evolving challenges facing DOE in its enduring responsibilities in defense and intelligence. Care has been taken to avoid unnecessary mission expansion. In each case, these initiative proposals extend established responsibilities and capabilities. Each of them will provide expanded benefit to the nation and serve to exercise, sustain, and build upon core competencies that are essential to meeting programmatic requirements. In this sense, each of these initiatives has been developed as a means of extending the benefits and reaping further "value added" from existing assets and resources.

\section{Project Proposals for Post-Cold War Defense Imperatives}

\section{Nonproliferation Technologies Center [for the Office of Intelligence and National Security (GC, GJ, and NT)]}

Preventing the proliferation of nuclear weapons has been an important policy and technology problem for decades. Unfortunately, the principles of nuclear weapon development and production are increasingly accessible to determined governments. This proposed initiative will focus on improving our national capability to detect and characterize clandestine nuclear activities, including materials production, weapon engineering development or weaponization, and weapon proof testing.

Sandia has one of the oldest and largest programs in the area of arms control and nonproliferation. Since the 1950s, the Laboratories has developed instrumentation to verify compliance with the Limited Test Ban Treaty. Our current activities include efforts to improve the sensitivity of satellite sensors that can detect and locate nuclear bursts in the atmosphere and to assist Los Alamos National Laboratory in providing an enhanced capability for detecting bursts in space. Our seismic detection systems provide the capability to monitor underground nuclear testing, and we support DOE's Office of Intelligence and National Security by conducting assessments of foreign weapon development capabilities and developing export control guidance. Sandia also originated a variety of systems that are used by the International Atomic Energy Agency in fulfilling its containment, surveillance, and nonproliferation responsibilities.

The need for better technologies for detecting nuclear materials production was underscored in 1991 by the startling extent to which Irac had pursued the production of weapon-grade uranium without detection. In fact, past failures to detect or control the proliferation of nuclear weapon technologies in Iraq and South Africa certainly resulted in part from our lack of sufficient means to determine the status of development programs in those countries.

Sandia has extensive experience in the development of nuclear radiation detection and other sensor systems and the analysis of collected data. Established capabilities also exist in adversarial analysis, vulnerability analysis, foreign systems technical analysis, and foreign capabilities analysis. 
Sandia has developed promising new concepts for advanced sensors that may significantly improve our detection capability in this difficult area. Ground-based or airborne air-sampling systems and airborne or space-based imaging radiometry and differential absorption lidar may be effective. Advanced seismic, electromagnetic pulse, and radiometric sensors would be useful for detecting low-yield weapon proof tests.

Technologies for monitoring declared nuclear activities for compliance with international safeguards are also needed to increase the visibility of activities in potential proliferant nations. Confidence in such "transparency measures" (surveillance measures approved by the host country) is essential to providing assurance to nations that pledge not to build nuclear weapons that proliferation can and will be detected and exposed. The Open Skies Treaty is a transparency measure that opens most of the northern hemisphere to overflights by surveillance aircraft. A variety of airborne sensor systems can and must be developed to take full advantage of this measure and obtain data that can be analyzed to effectively track weapon activities.

Our capability to respond to proliferation after international nonproliferation constraints have failed and a nuclear capability exists is rapidly becoming a significant national security concern. While preventing the spread of nuclear weapons is and must remain a top priority, proliferation will continue to occur. The nation must have a full range of options for countering this threat.

Sandia's counterproliferation efforts specifically address improvements in our ability to protect vital national security interests against threats posed by proliferated nuclear weapons. We are exploring system architectures and technologies that will provide options ranging from eliminating a proliferant's capability, lowering his motivation to threaten our interests, reducing our vulnerability to the use of such a device, and, as a last resort, minimizing the consequences of an attack.

The potential threat of a covertly emplaced nuclear device, under circumstances similar to the bombing of the World Trade Center, underscores the need to improve our ability to prevent such an occurrence. New sensor and information technologies are needed to better determine the capabilities and intentions of a proliferant, to detect and locate devices, to disable such a device when discovered, and to perform the forensic analysis that can identify the source of such devices and deter covert use.

The development of the Nonproliferation Technologies Center will strengthen our national capabilities by serving as a focal point for research and expertise and as a clearinghouse for information on the development and application of nonproliferation technologies. In addition, this center will also serve to address the problem of managing, synthesizing, and communicating the deluge of data from sensors and other sources and generating useful knowledge about a country's weapon activities. Sandia is developing knowledge synthesis systems, based on neural networks and rule-based proliferation profiles, to manage the fusion of data consisting of multiple formats or derived from multiple sensors or sources. These systems have the potential to greatly increase analysts' productivity.

The Nonproliferation Technologies Center will bolster U.S. nonproliferation capabilities through advanced technology development and analysis. It addresses known deficiencies and proposes specific enhancements that can provide new classes of proliferation data. The availability and reliability of such information will become increasingly important in the new multipolar world.

\section{Enhanced Transportation Surety [for the Office of Intelligence and National Security (GD)]}

Sandia has played a major role in transportation surety since the early 1970s, when the Department of Energy's Transportation Safeguards System was conceived and implemented. Sandia has extensive capabilities in the safe, secure transport of nuclear weapons, special nuclear material, and related weapon components. Indeed, nearly every major component of the existing system, including Safe Secure Trailers, special armored tractors, and the Secure Communications System, was designed by Sandia. Much of the technology that has been developed in these areas is now used in the secure transportation of high-value commercial goods. 
As we enter the next century, the transportation of nuclear weapons and weapon components will continue to receive increasing public scrutiny. While the current 130 ) transportation safeguards system has certainly served the nation well over the past two decades, the increasingly dynamic international environment, coupled with the rapid rate of technological change, clearly demonstrates the need to upgrade and enhance both safety and security in the transportation of nuclear weapons.

Sandia is currently engaged in the design, development, and prototyping of a next-generation transporter called the SafeGuards Transporter. The focus of this effort is to incorporate modern safety and security technologies into a new design that will ultimately replace the twenty-year-old Safe Secure Trailer design. The Safe juards Transporter will incorporate improvements identified in recent risk assessments and tests conducted in support of a full transportation safety analysis; however, it will be only one part of a much-needed comprehensive systems modernization that should address all aspects of the system, including operations and procedures.

This Enhanced Transportation Surety initiative will build upon the work already being done in conjunction with the Safe Guards Transporter exercise and take advantage of Sandia's established capabilities. It will also address other important issues and concerns that need further attention.

The goals of the Enhanced Transportation Surety Initiative are to significantly improve overall system security and safety, reduce manpower requirements, and extend these enhancements to operational movements within both the DOE nuclear weapons complex and the Department of Defense. Specific areas to be investigated include the development of improved probability risk assessment tools, consequence modeling, and accident databases; the incorporation of commercially available satellite-based mobile communications systems; and the development of satellite-based tagging and tracking. Rapid prototyping of cost-effective, application-specific solutions will be emphasized. Sandia's intimate knowledge of the current transportation safeguards system, as well as our involvement in the complex reconfiguration task, will allow system upgrades to be rapidly implemented in the field.

The enabling technologies developed through this effort will offer benefits to the private sector, including the capability to implement worldwide, satellite-based, real-time inventory of high-value goods in transit (of potential value to shipping industries) and enhanced dynamic modeling and simulation of accidents (of potential value to the automotive industry).

\section{Next-Generation Nuclear Weapon Controls [for the Assistant Secretary for Defense Programs (GB)]}

Sandia has responsibility for both use-control features within nuclear weapons and the use-control ancillary equipment that is deployed worldwide and used by the Department of I efense to support assurance of weapon use when authorized by the President and to assure against unauthorized use. The changing workd environment has made it highly desirable to introduce a number of enhancements to the use-control features in existing nuclear weapons stockpile and in the use-control ancillary equipment systems. In addition, it would now be highly desirable to enhance the flexibility within I)(ol) for conducting peacetime logistics operations and for dynamic operational response to future crises.

This proposal consists of five "focal efforts" that will take advantage of our established capabilities to develop vital enhancements.

\section{Focal Effort One: Enhanced Weapon Use Denial}

After the Department of Energy, the Fail-Safe and Risk Reduction Study Advisory (ommittec, and the Secretary of 1 )efense were bricfed on recent assessments of the use-control affectiveness of weapons in the stockpile, the advisory conmittec recommended that efforts be undertaken to enhance weapon use-denial effectiveness. This focal effort will consist of a technology development program that applies Sandia's existing materials science, explosives, and component design capabilities, in coordination with Los Alamos and Lawrence livermore national laboratories, to enhance the current level of use-denial effectiveness. A thrust of this effort will be to establish approaches that 
can be applied to the existing stockpile, as well as any future weapons. The customers for this effort will be the departments of Energy and Defense.

\section{Focal Effort Two: Integrated Safety and Use Control}

Since the introduction of permissive action links (PALs), nuclear safety and use-control features within weapons have been separated. This approach was largely driven by technologies available to the design community during the 1960s and 1970)s. With development completed on a new PAL (the code-activated processor), the greater feasibility of optical technologies, and Sandia's capabilities in miniature mechanisms design, an opportunity exists to integrate safety and usc-control functions within the weapon. Such integration will enhance nuclear safety and use-control effectiveness.

Our second proposed focal effort will undertake this integration of safety and use control. The technology developed through this process could have application for upgrading the surety of existing weapons, enhancing conventional munitions safety, and providing additional command and control capabilities for both governmental and commercial applications. 'The customers for this effort will be the departments of Energy and Defense.

\section{Focal Effort Three: Remote Permissive Action Link and Inventory Operations}

Sandia has developed permissive action link devices that have the capability for encrypted communications. Encrypted communication with the weapon opens the possibility of remote secure permissive-action-link recode and verification and weapon inventory. It offers a means of direct, secure communication with the weapon while it is in storage or being deployed. Full implementation of these highly desirable capabilities is dependent upon the further development of a nuclear-safe means of transmitting information, eventually consisting of an electrical signal, into the weapon.

Our third proposed focal effort will undertake the development of this enabling technology in the form of the capability for optical transmission of energy and information directly to permissive action link devices contained within weapons. This optical interface will provide the required nuclear safety electrical isolation while providing a continuous, real-time communication link. Such a link would enable real-time communications between the weapon and the military command headquarters responsible for mission planning and execution and peacetime logistics support.

Customers for this effort will be the military services and headquarters commands. However, the enabling technologies developed in this work will also have application in inventory and control of high-value commercial goods.

\section{Focal Effort Four: Multilevel Secure Information Systems}

Sandia routinely develops s. .ure information systems for itself and its customers and has well-established capabilities and assets in this area. The currently accepted strategy for developing secure information systems is to isolate them from all potential threats. However, this approach has some significant disadvantages. Customers must duplicate information systems for different levels of classified data, and these systems are not flexible enough to rapidly or adequately respond to changes in requirements.

The open literature is full of challenges, from both government and industry, to develop better ways to manage sensitive information. (Our fourth proposed focal effort will utilize Sandia's established capabilities in this area to undertake the development of better techniçues for managing multiple levels of classified data. Pursuing and meeting this challenge will exercise and sustain essential capabilities, demonstrate necessary technological leadership, and make a major contribution to the operations of both the government and the private sector, especially in this new era of increasing commercial and industrial espionage activity.

Customers for this work include virtually all government agencies and contractors and many elements of the private sector that need to protect sensitive or proprietary information. 


\section{Focal Effort Five: Use-Control Assessment}

Use-control effectiveness assessments for nuclear weapons are conducted when weapons first enter the stockpile and when changing conditions indicate that the assessments should be tipdated. A recent reassessment of the effectiveness of all weapons in the stockpile has indicated that it would be desirable to update and refine the methodologies used in conducting these assessments. Fullscale experiments will be required to validate these new methodologies as well as the results of the recently completed assessments.

Our fifth proposed focal effort will update the current use-control assessment methodology and conduct full-scale use-control effectiveness experiments to validate the updated methodology. The results will provide information to $\mathrm{D}(\mathrm{)E}$ and $\mathrm{DOl})$ concerning the use-control effectiveness of the stockpile. (Customers will be senior management in the departments of Energy and Defense.

\section{National Center for Risk Assessment [for the Assistant Secretary for Defense Programs (GB)]}

Sandia has extensive responsibilities in the areas of nuclear safety and stockpile surety. Over the past few years, our efforts in these areas have been expanded to include the reapplication of advanced risk assessment methods, techniques, tools, and databases that were originally developed in our nuclear reactor safety program. The application of these techniques to weapons concerns is already providing DOE and DoD Customers with unique perspectives on the surety of weapon systems.

This initiative proposes to expand these efforts to provide decision makers with a greater range of technically defensible and timely information on the risks associated with both the stockpile and other issues of importance to the nation, and to strengthen these capabilities through the formation of a National Center for Risk Assessment. This center will serve as a focai point for expertise and a clearinghouse for inormation from the international weapons community, DOE, and the national laboratories. On a broader scale, this center will stimulate the utilization of modern risk assessment capabilities, from the current focus on the surety of our enduring stockpile to a wider range of "dual use" applications, to other advanced technology or potentially hazardous operations both within the governmental arena and throughout the national strategic industrial base. Thus, the center will promote beneficial incraction between government, industry, and academia with regard to the development and implementation of risk management methodologies.

\section{Nonnuclear Component Manufacturing [for the Assistant Secretary for Defense Programs (GB)]}

The Department of Energy faces a significant challenge in reconfiguring the nuclear weapons complex from the current system of laboratories, production agencies, and supplier networks to a streamlined, smaller, and more modern and efficient system. The reconfigured complex should be capable of reducing operating costs while maintaining the readiness and credibility of the enduring stockpile and rapidly responding to unforeseen developments.

In recent years, as the pressures of international industrial competition have intensified, many of our domestic industries have faced similar challenges and have responded with innovative mixtures of new technology and modern business methods. Most of our domestic industries, however, are still challenged to improve their ability to deliver a product mix that is tailored to highly specific and rapidly evolving market requirements. This situation is made even more challenging by the fact that modern market requirements invariably include unprecedented demands for product quality and reliability at extremely competitive costs. It is the similarity of the challenges facing the nuclear weapons complex and our domestic industrial sector that sets the stage for a new and productive partnership between 1)()E: and the nation's strategic industrial base. 
Although the existing nuclear weapons complex has met the need for a safe and reliable stockpile, the current complex is much too large, too widely edistributed geographically, too expensive, and too outdated in relation to both current requirements and modern envirommental safety and health standards. I) ()E's strategy for consolidating and updating the complex focuses on integrating the essential competencies within the weapon laboratories and production plants with both specialized new capabilities that must be developed to meet the unicue needs of the complex and the broader capabilities available within the private sector.

To be suceessful, the $\mathrm{D}(\mathrm{)E}$ will need to make progress along two parallel fronts. First, investments and progress must be made in refining and implementing advanced manufacturing processes, technologies, technicues, and materials that are either developed within the nuclear weapons complex or adaptively reapplied to its needs. Examples in this category include computer-aided design, computer-aided engineering, and computer-aided manufacturing (CAD )/( $A \mathrm{Al} / \mathrm{C} A \mathrm{AM})$; process simulation and automation; information networks; emvironmentally conscious materials, design, and manufacturing; concurrent engineering; and the flexible integration of research and development and production sites into seamless "virtual" factories.

Second, new approaches to business processes and weapon system realization will be necessary. Examples in this category include supplier partnerships, innovative procurement strategies, and, possibly, a greater emphasis on standardized, commercially available, components. For the most part, these are the same investments and the same new approaches that our domestic industries are exploring in order to build their strengths in an increasingly competitive world market.

Some of these investments and approaches have already been explored and are being further developed at Sandia. Some progress has already been made in concurrent engineering, automation and robotics, electronic information networks, privatization of weapon component manufacturing and procurement, and new approaches to quality. However, much more work remains.

This Nomndelear Component Manufacturing Initiative will build upon Sandia's established capabilities, existing assets, and current efforts and extend our current responsibiliti s to provide full integration of the weapon system realization process. This effort will involve some production responsibilities. However, of most importane, it will reffect the vision to implement a more responsive and efficient, cradle-to grave approach extending from initial weapon conceptualization through production and service life to final retirement, dismantlement, and disposal.

Successfully implemented, this effort will reach well beyond the requirements of the nuclear steckpile and create within the nuclear weapons complex a national resource for the exploration and demonstration of integrated research, development, and productic an operations; a test bed for the development of advanced industrial processes; a model for hest industrial practices; and a vehicle for $\mathrm{I})(\mathrm{)}$ E contributions to advanced manufacturing and technology transfer. I leary direct industry participation in the Nonnuclear Component Manufacturing Initiative will be the means by which costs can be minimized and value to both 1 ) ()E and the private sector can be miximized.

\section{Jupiter X-Ray Simulation Facility [for the Assistant Secretary for Defense Programs (GB)]}

Sandia has the responsibility of ensuring that the nonnuclear components of U.S. strategic nuclear systems are safe, reliable, and capable of surviving hostile radiation enviromments. $A$ s long as the United States maintains a nuclear deterrent, this will continue to be a critical responsibility.

The Defense Nuclear Agency (I)NA) has the complementary responsibility of ensuring that strategic weapons and space systems are also capable of surviving hostile radiation environments. (iven these parallel missions, a strategic alliance between Sandia and 1) NA was forged in 19y), with both organizations agrecing to work cooperatively in developing advanced pulsed-power systems and radiation simulation capabilities in support of their respective mission requirements. 


\section{Potential Technology for Jupiter Single Pulse-Forming Module (Conceptual Schematic Representation)}

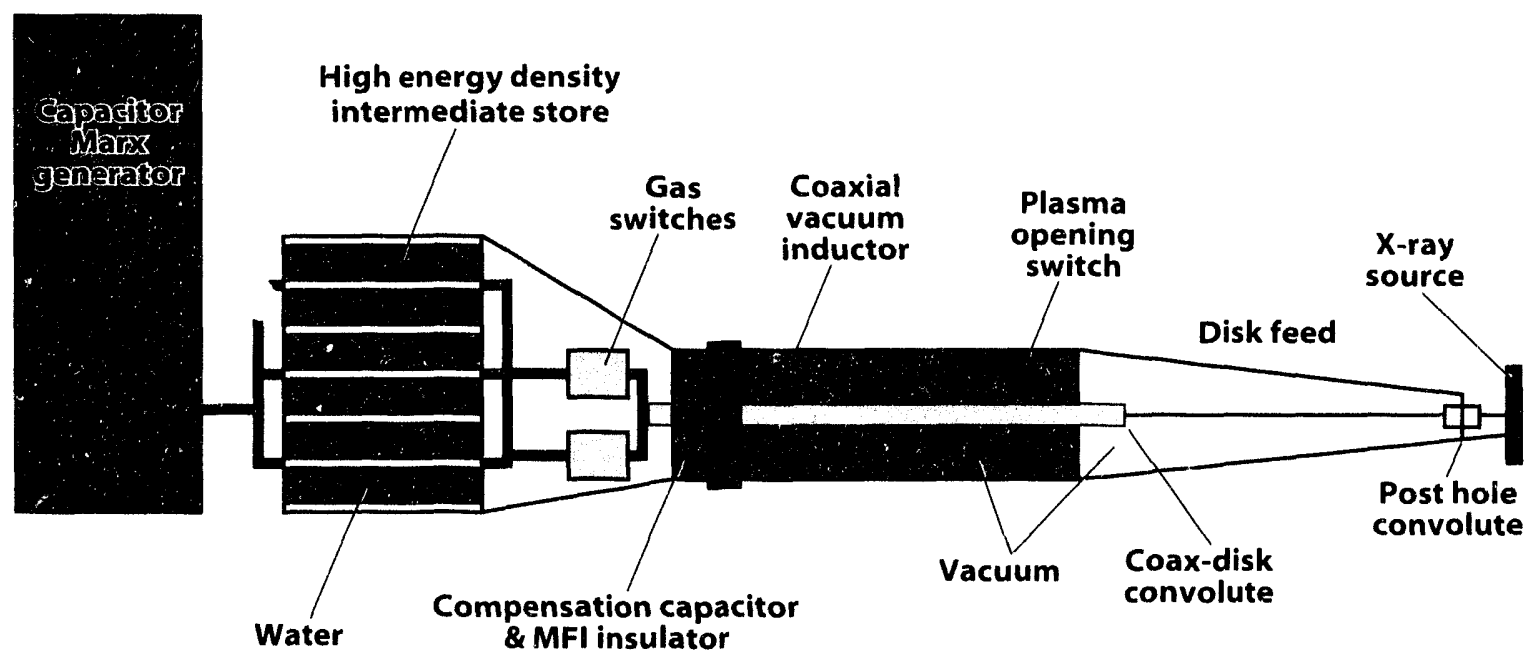

The directed cessation of underground nuclear tests has created a critical need to significantly' improve our national aboveground radiation testing capabilities. We will be required to certify' that all nuclear weapon subsystems provided by Sandia will remain survivable and provide such certification without the radiation test environments that are now obtainable only through underground nuclear testing. In addition, Dol) must certify their space-based or missile defense systems to meet specified radiation survivability criteria.

The construction of a new $x$-ray simulation facility will substantially improve our capability to test with a significant quantity of cold and warm $x$-rays to produce intense fluences over large areas, a capability that can now be met only through underground testing. Such a simulator would fulfill an imperative need for both DOE and Dol) radiation effects testing, and it is being pursued as a joint effort to be funded equally by both agencies.

This required facility, Jupiter, will be a cold and warm $x$-ray facility that will permit testing of both materials and components that currently can now only be tested in underground tests. The facility will build upon Sandia's established capabilities extended through the application of new technologies developed at Sandia, other government laboratories, universities, and industry. This ficility will have a pulsed power generator to drive a $\%$-pinch implosion to produce $x$-rays with energies up to 20,000 electron volts over much larger exposure areas than are possible with contemporary aboveground simulators. This capability will provide excellent simulation fidelity for the radiation effects testing of optics, materials, and weapon components. Jupiter will also provide opportunities for weapon physics research and $x$-ray physics testing with 5 to 20 megajoules of thermal $x$-rays.

The possible werse of existing stockpile components in new configurations represents a major design and certit. .tion effort. Likewise, Dol) space systems, satellites, and har dware are new and developing designs that are required to meet radiation survivability criteria. X-ray effects on these reentry vehicles and space systems, which now can only be tested underground, would be tested aboveground in high-fidelity radiation environments. The Jupiter X-Ray Simulation Facility is key to ensuring a survivable nuckear stockpile and supporting strategic space systems for the United States. 


\section{National Center for RSTAKA (Reconnaissance, Surveillance, Target Acquisition, Kill, and Assessment) [for the Assistant Secretary for Defense Programs (GB) and the Department of Defense]}

The demise of the Soviet strategic threat has been accompanied by growing ethnic conflicts and fracturing of formerly stable relationships. At the same time, we are witnessing a rapid proliferation of weapons of mass destruction. This increasingly unstable world raises the specter of new regional conflicts with very destructive outcomes. Much of the development of these weipons is carried out in buried facilities that are difficult to attack. In addition, they may be located in densely populated areals where civilian cisualties could occur in the event premptive actions are undertaken. Warheads for this application would have to be delivered with extremely high precision, and include such options as conventional explosives, carth penetrators, kinetic energy projectiles and low-yield nuclear weapons.

In addition to countering weapons of mass destruction, the United States must confront a multipolar threat of conventional conflict in a regional context, and it must do so with a smaller military capability. To deter these threats, the United States must demonstrate its ability to rapidly' project force and dominate a battlefield quickly to achieve military objectives with very few friendly casualties and with low collateral damage.

Success in either environment requires real-time, exquisite situation awareness through application of sensors, communications, and data analysis. The systems solution we envision for countering these threats is an integrated information and precision weapon-delivery system that would include elements of reconnaissance, surveillance, target acquisition, kill, and assessment (RSTAKA).

Contemporary battle management systems are severely challenged in several ways. Reconnaissance systems provide limited coverage, are not all-weather, and are not directly taskable by war-fighting commanders. Mobile targets are hard to find and acquire. (ommand and control systems are too stow to acquire, assimilate, and reduce data, present action options to commanders, and direct responses to targets. Strike systems lack the speed and accuracy to destroy mobile and fixed assets from stand-off positions with low collateral damage and with impunity.

Improving RSTAKA capabilities will require advances in ground, air, and space-based sensors to fully characterize the battlefield and understand an enemy's order of battle deep behind his lines. Command and control systems must be made extremely responsive with rapid data fusion and real-time decision capability. Fast, high-precision, retargetable, stand-off strike weapons. must be developed with appropriate warheads. Noreover, such advances must be closely integrated and furnished with a facile user interface for theater commanders.

A coordinated RSTAKA program could be managed by a joint I)( )I:/ )ol ) program office tasked to identify critical needs and the research and development initiatives required to meet them. Teamwork among industry, universities, and the federal laboratories would be coordinated to permit rapid resolution of eritical technical issues. Such partnerships should be encouraged and managed for the optimum benefit to the program. Industry partnerships can be very uscful for engineering producibility into rapidly prototyped demonstration projects.

Sandia has developed competency in advanced technologies that would be important to a RSTAKA program. U'nique capabilities that have emerged from our ongoing technology base activities include unattended ground sensors, data fusion software, all-weather day/night synthetic aperture radar imaging systems, and hypervelocity weapon delivery systems.

Sandia also has an extensive testing infrastructure that can make a unicue contribution to the RSTAKA effort. In particular, the Tonnopah Test Range in Nevada, and possibly facilities at the Nevada l'est Site, are superbly suited to a large-scale, integratted RSTIAKA demonstration with instrumentation, telemetry, and simulation to support a variety of flight testing with high fidelity 
when these facilities are linked to distributed national simulation facilities. Designating the

Tonopah lest Range a user facility for" TAKA demonstrations woukd be a cost-effective and technically astute application of this $1 . .$. standing defense research and development asset.

The gross funding estimate for Sandia participation in a national RSI'AKA initiative is based on the expectation of intensive utilization of Sandia's laboratory and test capabilities. Costs will vary depending on the mix of activities conducted. We expect that the installed capital base of test facilities will be a cost advantage to U.S. government and participating industry users.

\begin{tabular}{|c|c|c|c|c|c|}
\hline \multicolumn{6}{|c|}{$\begin{array}{l}\text { Funding Requirements for Project Proposals in Post-Cold War Defense Imperatives } \\
\text { (Dollars in constant FY } 1994 \text { millions; personnel in FTEs) }\end{array}$} \\
\hline & Year 1 & Year 2 & Year 3 & Year 4 & Year 5 \\
\hline \multicolumn{6}{|c|}{ Nonproliferation Technologies Center } \\
\hline Operating & 110.0 & 130.0 & 140.0 & 140.0 & 140.0 \\
\hline Capital Equipment & 8.0 & 10.0 & 10.0 & 10.0 & 10.0 \\
\hline Total Cost & 118.0 & 140.0 & 150.0 & 150.0 & 150.0 \\
\hline Direct Personnel & 317 & 375 & 405 & 405 & 405 \\
\hline \multicolumn{6}{|c|}{ Enhanced Transportation Safety } \\
\hline Operating & 5.5 & 7.0 & 7.0 & 5.0 & 5.0 \\
\hline Capital Equipment & 0.1 & 0.2 & 0.1 & 0.1 & 0.1 \\
\hline Total Cost & 5.6 & 7.2 & 7.1 & 5.1 & 5.1 \\
\hline Direct Personnel & 25 & 30 & 30 & 25 & 25 \\
\hline \multicolumn{6}{|c|}{ Next-Generation Nuclear Weapon Controls } \\
\hline Operating & 17.1 & 17.0 & 17.0 & 17.0 & 17.0 \\
\hline Capital Equipment & 1.7 & 2.0 & 2.0 & 2.0 & 2.0 \\
\hline Total Cost & 18.8 & 19.0 & 19.0 & 19.0 & 19.0 \\
\hline Direct Personnel & 84 & 84 & 84 & 84 & 84 \\
\hline \multicolumn{6}{|c|}{ National Center for Risk Assessment } \\
\hline Operating & 11.2 & 15.0 & 18.0 & 20.0 & 20.0 \\
\hline Capital Equipment & 1.0 & 0.5 & 1.0 & 1.0 & 1.0 \\
\hline Total Cost & 12.2 & 15.5 & 19.0 & 21.0 & 21.0 \\
\hline Direct Personnel & 60 & 75 & 90 & 100 & 100 \\
\hline \multicolumn{6}{|c|}{ Nonnuclear Component Manufacturing } \\
\hline Operating & 50.0 & 75.0 & 100.0 & 125.0 & 150.0 \\
\hline Direct Personnel & 135 & 200 & 265 & 335 & 400 \\
\hline \multicolumn{6}{|c|}{ Jupiter X-Ray Simulation Facility } \\
\hline Operating (Developm & & & & & \\
\hline DOE & 15.0 & 15.0 & 16.0 & 18.0 & 16.0 \\
\hline DNA & 6.0 & 4.0 & & & \\
\hline Total Operating & 21.0 & 19.0 & 16.0 & 18.0 & 16.0 \\
\hline
\end{tabular}




\begin{tabular}{|c|c|c|c|c|c|}
\hline \multicolumn{6}{|c|}{$\begin{array}{l}\text { Funding Requirements for Project Proposals in Post-Cold War Defense Imperatives (Continued) } \\
\text { (Dollars in constant FY } 1994 \text { millions; personnel in FTEs) }\end{array}$} \\
\hline & Year 1 & Year 2 & Year 3 & Year 4 & Year 5 \\
\hline \multicolumn{6}{|l|}{ Construction } \\
\hline DOE & & & 10.0 & 10.0 & 10.0 \\
\hline DNA & & 15,0 & 20.0 & 34.0 & 41.0 \\
\hline Total Construction & & 15.0 & 30.0 & 44.0 & 51.0 \\
\hline Total Cost & 21.0 & 34.0 & 46.0 & 62.0 & 67.0 \\
\hline \multicolumn{6}{|l|}{ National Center for RSTAKA } \\
\hline Operating & 30.0 & 50.0 & 70.0 & 90.0 & 90.0 \\
\hline Construction & 10.0 & 20.0 & 20.0 & 10.0 & 10.0 \\
\hline Total Cost & 40.0 & 70.0 & 90.0 & 100.0 & 100.0 \\
\hline Direct Personnel & 75 & 125 & 175 & 200 & 200 \\
\hline \multicolumn{6}{|c|}{ Total, Post-Cold War Defense Imperatives } \\
\hline Operating & 244.8 & 313.0 & 368.0 & 415.0 & 438.0 \\
\hline Capital Equipment & 10.8 & 12.7 & 13.1 & 13.1 & 13.1 \\
\hline Construction & 10.0 & 35.0 & 50.0 & 54.0 & 61.0 \\
\hline Total Cost & 265.6 & 360.7 & 431.1 & 482.1 & 512.1 \\
\hline Direct Personnel & 696 & 889 & 1,049 & 1,149 & 1,214 \\
\hline
\end{tabular}





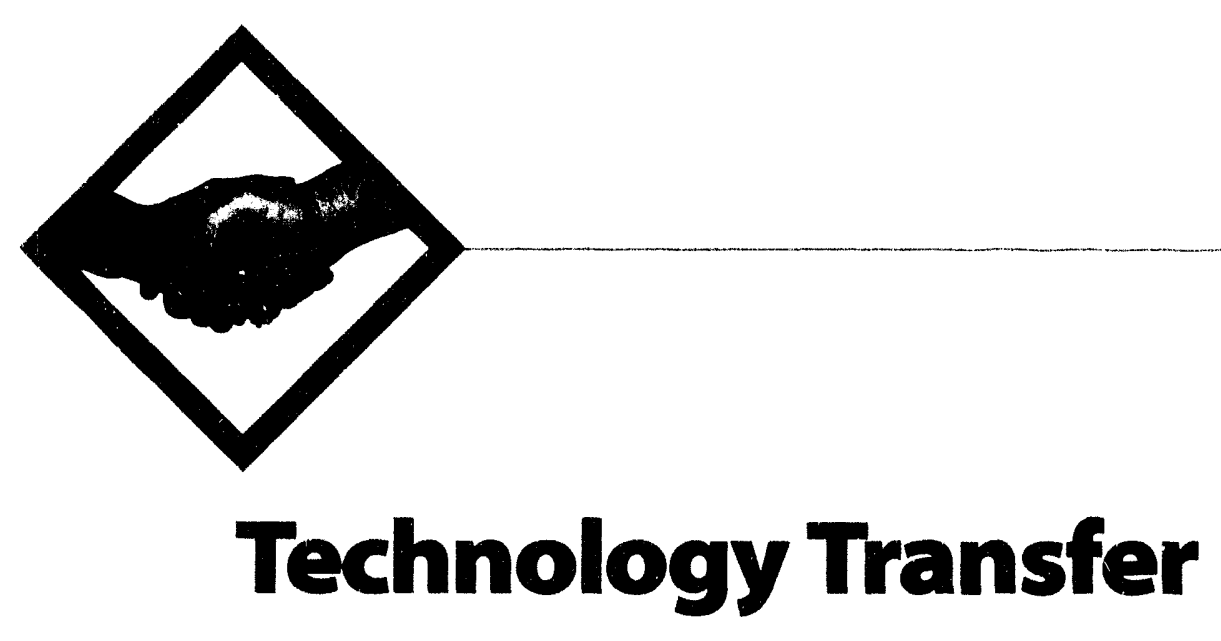

Sandia's technology transfer program promotes and facilitates the transfer of federally developed technologies, processes, and special tachnical know-how to the private sector. The mission of our technology transfer program is to enhance U.S. economic competitiveness by applying laboratory strengths to problems of national importance, emphasizing partnerships with industry and universities. As we pursue this important new mission, we are committed to protecting national security interests, providing fairness of opportunity to industry, creating lasting value to the taxpayer, and adhering to the highest ethical standards to avoid even the appearance of conflicts of interest.

Sandia has a history of transferring technologies developed in weapons and energy programs to the civilian industrial sector that predates the legislative mandate for technology transfer by more than three decades. Long before technology transfer became a mission assigned to Sandia by the National Competitiveness Technology Transfer Act of 1989, we learned that teamwork with industry, both in technology development and transfer, is a smart business practice that enhances our ability to meet our obligations.

We consider the use of our core competencies to help improve the U.S. econony to be a natural extension of our defense and energy missions. Effective government/industry/university collaboration - the mutual exchange of expertise and knowledge - enables the national laboratories to maintain the core competencies that make them important national assets and allows the private sector to leverage its research and development resources by taking advantage of the federal defense research and development investment. Sandia's major program initiatives (Chapter 5) strongly support this vision of technology transfer.

Technology transfer at Sandia takes many forms. We are engaged in a variety of technology transfer activities, including personnel exchanges, patent licensing, use of facilities, cost-shared contracts, technical assistance, information dissemination, participation in industrial consortia, and cooperative research and development agreements (CRADAs). However, since 1991 (the first year that our legislative mandate was codified), the CRADA has become our most successful technology transfer mechanism. CRADA projects are distributed more or less evenly over five broad technical areas: advanced manufacturing and precision engineering, computer architecture and applications, energy and environment, materials and processes for manufacturing, and microelectronics and photonics. Since our first CRADA was signed in June 1991, we have initiated more than 100 CRADAs with a total value of approximately $\$ 400$ million.

During this period, our strategy has evolved from maximizing the number of small CRADAs to seeking large-scale alliances with industry and universities. Throughout 1991, our efforts were focused on developing technology transfer policies, putting internal operating procedures in place for preparing and processing CRADAs, and working with the DOE Albuquerque Operations (Office to refine and streamline those procedures. Our strategy at that time was to exercise and hone the system by initiating many small CRADAs with individual companies. As difficulties with the new processes were resolved, we began to focus on teamwork with clusters of companies 
and larger-scale alliances in which the capabilities of laboratories, industry, and universities are joined to pursue broad, industry-driven research agendas.

To help ensure that the broad range of Sandia's talents and facilities is directed effectively toward meeting national needs, our new technology transfer organizational structure features product-area engineers (people with technical backgrounds and trained in business). Product-area enginecrs, together with technical area coordinating teams composed of specialists from industry, laboratories, and the academic research community, will integrate technology transfer considerations into the planning and conduct of all laboratory research and development.

Our current strategy in technology transfer encompasses three major elements: market-driven partnerships, national industrial challenges, and a small-business initiative:

Market-Driven Partnerships - Cooperative research and development agreements have become our most successful mechanism for structuring collaborative work arrangements between Sandia and partners in the private sector. This mechanism is simpler than conventional government contracts, protects a company's confidential information, and permits wide latitude in the assignment of intellectual property. Under the terms of a (RAJ)A, Sandia may contribute facilities, property (including intellectual property), and personnel to the cooperative effort. Sandia may also pay costs associated with the participation of its personnel or the contribution of property and facilities but may not provide cash funds to a participant. Sandia's partners in the private sector may provide funds to Sandia as well as personnel, services, facilities, equipment, or other resources needed to advance the proposed work. Implicit in a (RADA is the idea that the participants are equal partners who bring to the interaction complementary, identifiable capabilities that will lead to a new or improved product.

National Industrial Challenges - While we continue to believe that much good work is accomplished through joint efforts with individual industrial partners, we believe that large-scale government/industry/university alliances afford the best opportunity of making a measurable impact on U.S. economic competitiveness. Such alliances can target major national technology goals that are market-driven, industry-defined, and precompetitive. Such alliances are most effective when industry is strongly involved in setting priorities, developing plans, and moving technologies toward commercial application.

Small-Business Technology Transfer Program - In conjunction with Lawrence Livermore and Los Alamos national laboratories and Y -12 at Oak Ridge, Sandia has established a SmallBusiness Technology Transfer Program. This program is a follow-on to our successful National Small-Business Technology Exchange Program. The mission of the Small-Business Technology Transfer Program is to make the laboratories' resources available to small and medium-sized businesses. We work with small-business development centers, cooperative extension services, bankers, chambers of commerce, state economic development agencies, and vocational education teachers to identify technology partners. Included in the program are regional, short-term technical assistance programs in New Mexico, California, Arizona, Texas, and the Midwest. Also included are partnerships with industry associations to reach a greater number of small business clients by addressing common problems and opportunities and matching Sandia capabilities with the needs of small businesses.

\section{Collaborative Projects with Industry}

Our ( $R A D$ ) A process is very inclusive. Sandia (RAD)A partners include municipal governments, universities, industrial consortia, other laboratories, and large and small businesses. Many of our 
CRADA projects involve clusters of companies representing a substantial segment of a specific industry or involve working with organizations that represent an entire industry.

We are working with a cluster of companies under a (CRAl)A with MacNeal Schwendler (Corp. PDA Engineering, Fluid 1)ynamics International, and Ford Motor Company. This Sandia-led consortium is conducting precompetitive generic research to develop mesh-gencration computer software. Each industry participant will use the software to develop a commercial product or service in the area of computer-aided-engineering software or in applications for finite-element analysis - a powerful numerical method for determining the physical behavior of an object and useful in many industrial fields, including structural mechanics, electrical engineering, and fluid mechanics.

Our CRADA with the United States Advanced Battery Consortium exemplifies our agreements with industrial consortia. The consortium is a partnership of Chrysler, Ford, and Ceneral Motors with the Electric Power Research Institute and some individual electric utilities. It was formed in 1991 to research and develop rechargeable battery technologies fir electric venicles.

Sandia will conduct applied research and testing to meet the objectives established by the industrial partners of the consortium, which include demonstrating production capability for a battery with a five-year life that could be produced in the late 1990s and, by 1994, a battery with a ten-year life that could go into production sometime after 2000. Development of advanced batteries will help auto manufacturers meet the 1998 deadline set by several states for the introduction of electric vehicles.

\begin{tabular}{|c|c|c|c|c|c|c|c|}
\hline \multicolumn{8}{|c|}{$\begin{array}{l}\text { Technology Transfer Effort } \\
\text { (Dollars in millions; staffing in FTEs) }\end{array}$} \\
\hline & $\underline{\mathrm{FY} 93}$ & FY94 & FY95 & $\underline{\mathrm{FY} 96}$ & FY97 & FY98 & FY99 \\
\hline \multicolumn{8}{|l|}{ Funding: } \\
\hline ORTA activity & 4.6 & 4.7 & 4.7 & 4.7 & 4.7 & 4.7 & 4.7 \\
\hline Patent/licensing activity & 0.8 & 0.8 & 0.8 & 0.8 & 0.8 & 0.8 & 0.8 \\
\hline CRADA funding - federal & 80.0 & 100.0 & 100.0 & 100.0 & 100.0 & 100.0 & 100.0 \\
\hline CRADA funding - industry & 100.0 & 120.0 & 120.0 & 120.0 & 120.0 & 120.0 & 120.0 \\
\hline Total funding & 185.4 & 225.5 & 225.5 & 225.5 & 225.5 & 225.5 & 225.5 \\
\hline \multicolumn{8}{|l|}{ Staffing: } \\
\hline ORTA activity & 23 & 25 & 25 & 25 & 25 & 25 & 25 \\
\hline Patent/licensing activity & 9 & 12 & 15 & 15 & 15 & 15 & 15 \\
\hline CRADA activity & 10 & 12 & 12 & 12 & 12 & 12 & 12 \\
\hline Total staffing & 42 & 49 & $5 \overline{2}$ & 52 & 52 & 52 & 52 \\
\hline
\end{tabular}

Technology developed under this CRADA will be available to the consortium and its licensees. The project will enhance the competitive position of the United States in battery and automotive markets and help assure a viable and competitive domestic battery industry.

Similarly, in an agreement with the Specialty Metals Processing Consortium, we are working with the small but critically important U.S. specialty metals industry to improve the technology base for molting processes used in manufacturing specialty metals. Specialty metals, such as high-performance steel and titanium or nickel-based alloys, are critical to American economic competitiveness in areas ranging from microelectronics to airplanes and are vital to national security.

The Specialty Metals Processing Consortium has conducted several major investigations. Most of the research has taken place within Sandia's Melting and Solidification Laboratory complex, which features the only large-scale, fully instrumented research furnace in the country. Results of the industry-selected research projects are enabling or generic in nature so that each member company can develop its own proprietary processes and products. Patents resulting from this work will be made available to consortium members through a royalty-free licensing arrangement. 
Sandia participates in the Alliance for Photonic Technology, a cooperative venture of Los Alamos National Laboratory, Sandia, the Air Force Phillips L aboratory, and the University of New Mexico Center for High-Technology Materials. The mission of the alliance is to enhance the competitiveness of U.S. industry in the critical technology of photonics by accelerating the transfer of federally funded photonics technology to industry.

A five-year CRADA with SEMATECH is amed at developing improved semiconductor manufacturing technologies for the next generation of integrated circuits, including equipment that reduces manufacturing costs while increasing yield. This work should help U.S. semiconductor equipment manufacturers compete with foreign suppliers. The new (CRAD) A builds on a relationship established with SEMATECH in 1989 when Sandia's Semiconductor Equipment 'Technology Center was formed. It also extends a 1992 agreement that established the Contamination-Free Manufacturing Research Center at Sandia to study ways to reduce trace levels of contamination in semiconductor manufacturing, a critical problem facing microelectronics manufacturers.

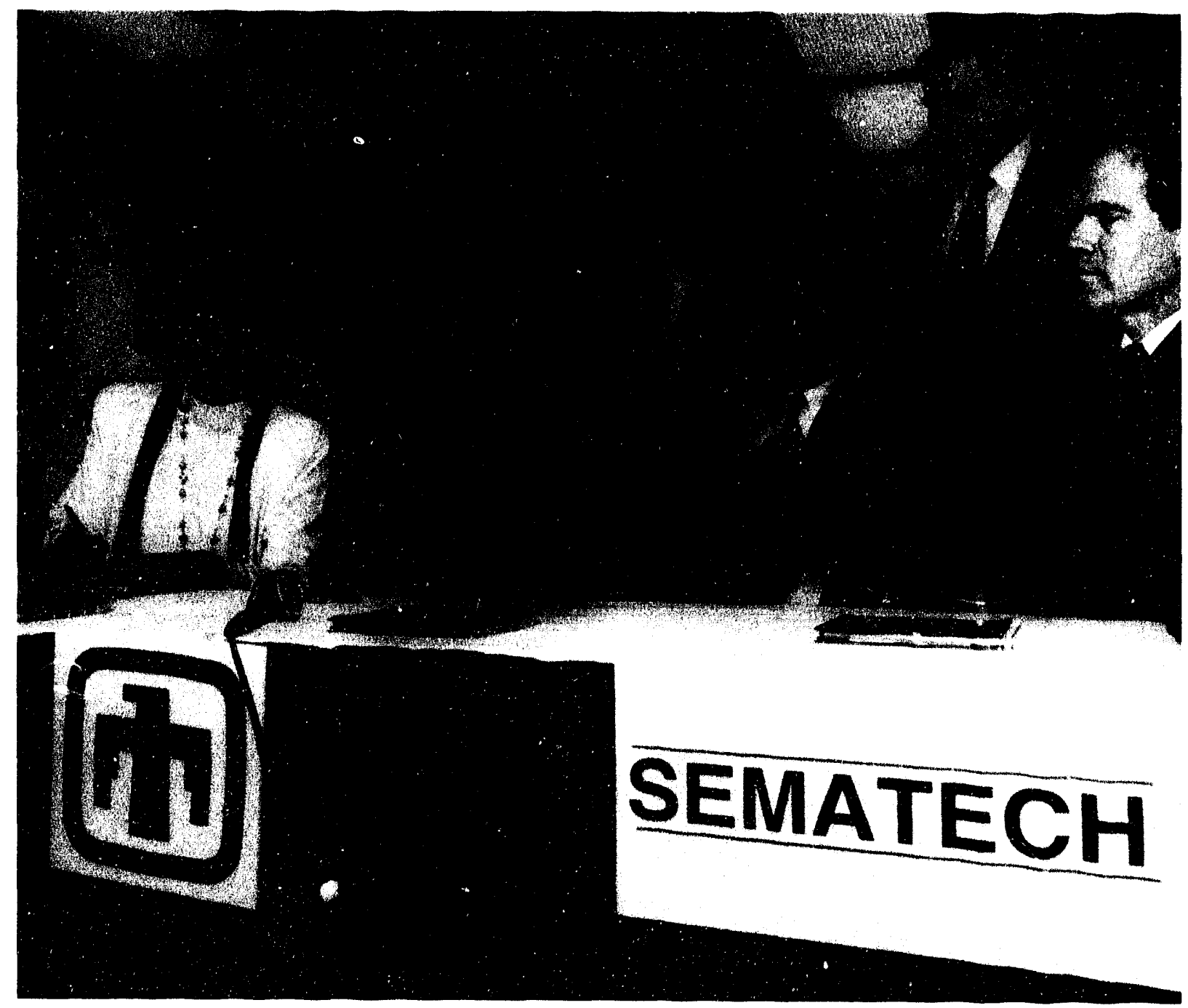

Secretary of Energy Hazel O'Leary signed an enabling document for a $\$ 100$ million cooperative research and development agreement between Sandia and SEMATECH in 1993. Looking on are Sandia president AI Narath, Congressman Steve Schiff, SEMATECH chief executive officer Bill Spencer, New Mexico governor Bruce King, and U.S. senator Jeff Bingaman. 
Sandia is a participant in the American Textile Partnership (AMTEX), a research and development collaboration between the Department of Energy, DOE's multiprogram laboratories, universities, and the textile industry. The goal is to strengthen the competitiveness of the integrated U.S. textile industry by pursuing a broad, industry-driven research agenda. AMTEX institutions are the Institute of Textile Technology, Textile/Clothing Technology Corporation, Textile Research Institute/ Princeton, Cotton Incorporated, and the National Textile Center, a consortium of four leading textile research universities.

\section{Patent and Software Licensing}

Sandia averages about 30 patent applications per year. However, many invention disclosures filed by Sandia as a result of its work for DOE have not been patented or licensed for use by industry.

To encourage a higher level of licensing, an action team including researchers, the patents and legal organization, and the Technology Transfer Center is working to establish a process for making our intellectual property assets more readily available to industry. The process will include reviews of invention disclosures to identify good candidates for patenting and licensing. These candidates will then be broadly advertised, and workshops will be held to select the best qualified contenders to compete for specific licenses, and ultimately, enter into licensing negotiations.

Sandia has also expanded its licensing program to facilitate the transfer of technologies through a variety of licensing options. Through commercial licenses (exclusive or nonexclusive, as appropriate) private companies can obtain the right to manufacture and sell technologies patented by Sandia in exchange for license fees and royalties.

To promote the effective use of our technologies in as many ways as possible, we try to license a given technology nonexclusively or exclusively to different users for specific fields of use. Nonexclusive licenses can sometimes ensure rapid and effective transfer of the technology into commercial or scientific uses, but we also recognize that a license may at times require various kinds of protection, including exclusivity, to protect a firm considering a large investment in a new technology. Our aim is to remain flexible and take into account the unique circumstances of each technology and licensee.

\begin{tabular}{|c|c|c|c|c|c|}
\hline \multicolumn{6}{|c|}{$\begin{array}{l}\text { Licensing Income and Use } \\
\text { (Dollars in thousands) }\end{array}$} \\
\hline & & & \multicolumn{3}{|c|}{ Projected } \\
\hline & $\underline{\mathrm{FY} 92}$ & $\underline{\mathrm{FY} 93}$ & FY94 & FY95 & $\underline{F Y 96}$ \\
\hline \multicolumn{6}{|l|}{ Licenses: } \\
\hline Number of new licenses & 8 & 35 & 50 & 75 & 75 \\
\hline License income & 45 & 250 & 500 & 1,000 & 1,000 \\
\hline \multicolumn{6}{|l|}{ Use of income: } \\
\hline Invention \& ORTA administration & 12 & 75 & 150 & 300 & 300 \\
\hline Scientific or applied R\&D & 13 & 75 & 150 & 300 & 300 \\
\hline Awards \& inventor payments & 10 & 50 & 100 & 200 & 200 \\
\hline Education or training & 10 & 50 & 100 & 200 & 200 \\
\hline
\end{tabular}




\section{Technology Transfer Achievements}

- Researchers at Sandia and the University of New Mexico School of Medicine have patented a sensor that measures blood glucose without drawing a blood sample. By providing an accurate, painless method for measuring serum glucose, the technology could greatly improve the quality of life for people with diabetes and reduce the incidence of complications from the disease. Indeed, a recent study by the National Institute of Diabetes and I Digestive and Kidney Diseases showed that a program of controlling blood sugar to near normal levels through frequent monitoring can dramatically reduce the risk of developing eye disease and kidney disease and incurring nerve ctamage.

Dr. Ries Robinson, a Sandia postdoctoral fellow and University of New Mexico School of Medicine resident, demonstrates a laboratory prototype sensor developed by Sandia and UNM to monitor serum glucose. The technology may make it possible for people with diabetes to accurately monitor blood sugar levels and trends without drawing blood samples. Sandia has transferred the rights to develop a commercial product based on this technology to UNM, which will select a company fo $r$ product development.

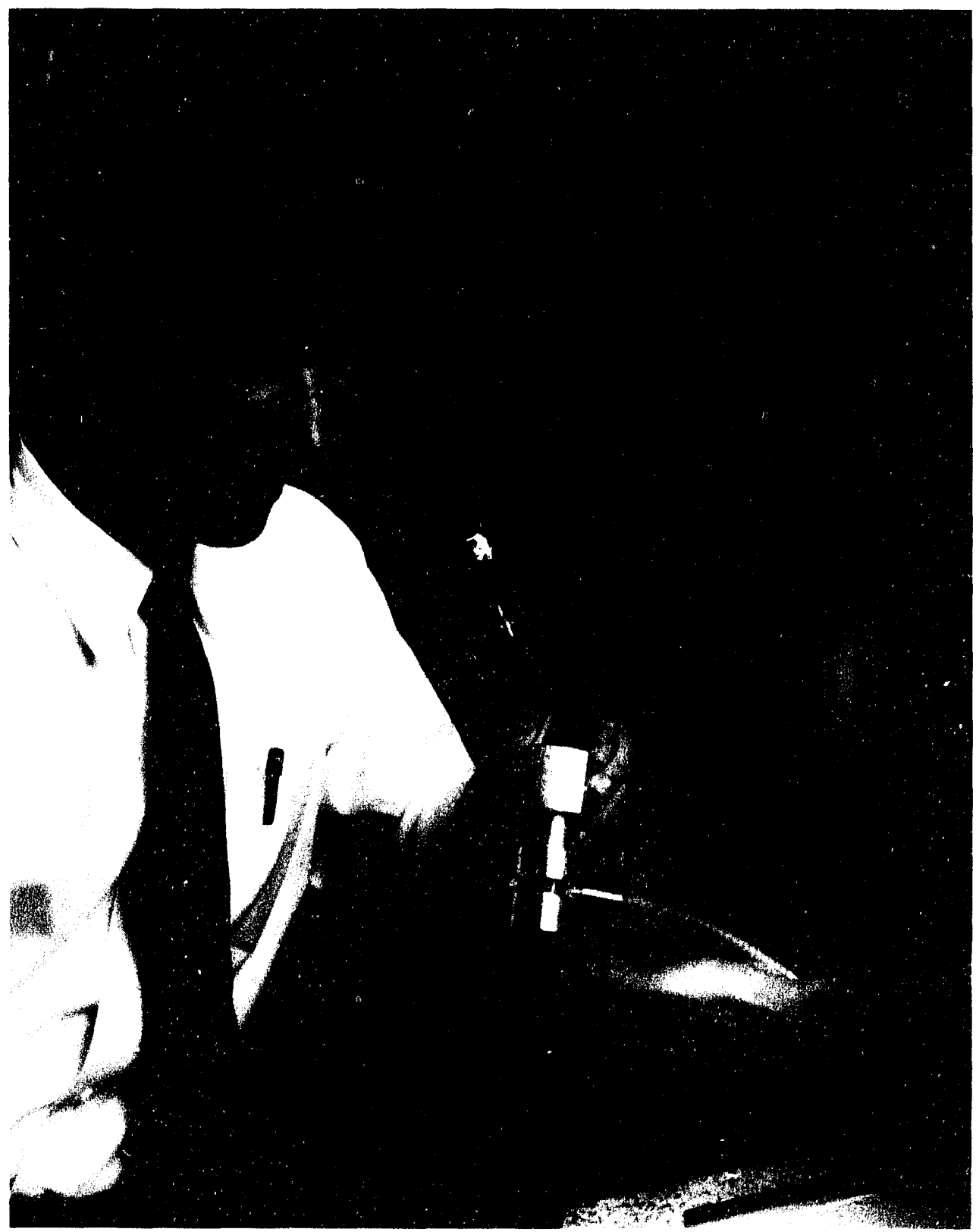


The sensor employs infrared spectroscopy and statistical techniques for processing spectral data. Near-infrared light is used, which has a slightly longer wavelength than visible light and can penetrate skin. When the light is transmitted through a finger inserted in the monitor, a portion of the light at each of various wavelengths is absorbed by the components in the tissue and blood, including glucose. After passing through the finger, the light is dispersed into a spectrum and the spectral data are analyzed for glucose-specific absorptions to determine glucose concentrations.

In the 1970s, Sandia developed and transferred to industry a miniaturized implantable insulin pump. The pump was tested in about 700 patients worldwide. If the glucose sensor - which may permit continuous monitoring, not just point-in-time measurements - were combined with an insulin pump, an artificial pancreas could possibly be developed.

- Sandia and Hewlett-Packard have developed improved process monitoring, active control, and feedback systems for the fabrication of advanced optoelectronic devices. Improved epitaxial materials and processes yield higher reliability compound semiconductors, transistors, and optoelectronic devices for commercial and defense applications. This laboratory/industry partnership helps maintain state-of-the-art device fabrication capabilities in a period of reduced weapon manufacturing. Through this partnership, the critical device prototyping capabilities of Sandia are maintained and enhanced.

- Sandia and SCB Inc., a small New Mexico business, have developed a very safe and economical semiconductor bridge initiator for civilian and military explosives applications. These devices have enhanced electrostatic discharge and no-fire safety and operate at much lower energies than is possible with contemporary hot-wire technology. The device will eliminate the need for weapon components made with known or suspected carcinogenic compounds. It could also be incorporated in automobile airbags for application in multi-bag systems with stringent safety requirements that cannot be satisfied with currently available technology.

- LSI Logic, one of DOE's largest suppliers of integrated circuits and a leading supplier to the commercial electronics market, is using an induced voltage alteration technique developed at Sandia to locate failure sites in defective integrated circuits as they are fabricated. This technique is capable of locating failures in an hour or less, a considerable improvement over the two weeks normally required when using an electron microscope. As a result, LSI has improved the efficiency of its fabrication and has eliminated a six-month backlog in its failure analysis.

In a related effort, Signetics and Sandia jointly developed an advanced wafer level reliability microelectronics and therefore a need to identify, characterize, and control the same failure mechanisms. Improvements such as these helped the U.S. microelectronics industry surpass foreign competition for the first time in a decade.

- Sandia and BIOSYM Technologies, Inc. worked together to develop computer software that helps design polymer alloys. Polymer alloys are leading candidates to meet the evolving need for high-strength, lightweight, inexpensive, environmentally acceptable materials. This new software, called PRISM, has been licensed by BIOSYM to a recently formed consortium of polymer manufacturers. The molecular modeling capabilities resulting from this project should be of great utility to the U.S. polymer industry since polymer alloying is less expensive and more versatile than synthesizing and developing entirely new polymers. The information gained from this program will aid the development of high-performance polymer blends and copolymers for various weapon applications. New materials that could result include highstrength encapsulants for packaging electronic subsystems in nuclear weapons, lightweight structural supports for nuclear weapons, and new optical materials for nuclear safety. 
- Sandia and Martek Lasers, Inc., developed a high-powered continuous-wave laser welding system. The company was recently purchased by Hobart Brothers Company, one of the top U.S. manufacturers of welding equipment. This state-of-the-ant system helps the U.S. retain its position in the high-technology laser welding market. These laser welding systems are now fully commercialized and used by organizations that include the U.S. Navy and the major automobile manufacturers. Weapon systems use a diverse range of materials in challenging geometries, and precision welding and joining are critical processes. Improved laser welding technology helps the weapons program fulfill these demanding requirements.

- Sandia and SEMATECH have been working together since 1989 on several programs to enhance the performance of precision microelectronics fabrication equipment, improve and assure the quality of microelectronics components, and explore advanced chemical processes for producing co nplex integrated circuits in an environmentally responsible way. A reliability training program, derived from quality assurance techniques developed for nuclear weapons, has been developed for the SEMATECH member companies. Sandia has also modified weapon design and analysis technologies to improve integrated circuit fabrication processes. Through this partnership, DOE Defense Programs and the microelectronics industry both obtain improved microelectronic fabrication processes. The partnership has proved so successful that SEMATECH and Sandia have announced another five-year, $\$ 100$ million partnership to jointly develop equipment to produce the next generation of computer chips.

- Sandia is working with J. W. Harley, a small business in Ohio, to commercialize a fiber optic hydrogen sensor, originally developed at Sandia, to monitor nuclear facilities. The sensor provides a warning when hydrogen gas builds up inside electrical transformers. Use of the sensor in large power transformers can prevent explosions. Transformer explosions can result in millions of dollars in financial loss and even loss of life. This hydrogen sensor has global commercial market potential. DOE Defense Programs will have a reliable, affordable commercial source for sensors to improve worker safety in nuclear facilities. Similar sensors hold promise for other applications, such as monitoring the cleanup of weapons facilities.

\section{Laboratory Centers and User Facilities}

The following laboratory centers and facilities are focal points for coordinating research and development of applied technologies. Two of them, the Combustion Research Facility and the National Solar Thermal Test Facility, are designated DOE: user facilities that have been important vehicles for collaboration with the private sector for many years.

All these centers and facilities are vital mechanisms for technology transfer and are available to industrial partners to ensure that U.S. indu:try gets maximum benefit from technologies and capabilities developed at Sandia. The research and technology development activities conducted in these facilities satisfy a broad spectrum of dual-use needs for government and industry.

Aging Aircraft Nondestructive Inspection and Validation Center - The mission of this center is to encourage the development of nondestructive inspection techniques applicable to aircraft structural inspection, to validate this technology through assessing its reliability and cost-effectiveness, and to interface the inspection portion of the Federal Aviation Agency's National Aging Aircraft Program to the civil aviation industry.

The center occupies 27,000 square feet of hanger space at Albuquerque International Airport and includes 125,000 square feet of pad space. It is supported by a staff of 11 people and operates on a budget of approximately $\$ 3$ million per year from the Federal Aviation Agency. 
Center for Contamination-Free Manufacturing - This center was formalized by a cooperative research and development agreement between SEMATECH and Sandia in 1992. The center exploits the unicue layout of Sandia's Microelectronics Development laboratory to conduct experiments to verify advanced semiconductor manufacturing concepts and equipment which can reduce contamination that limits the yield of integrated-circuit manufacturing processes.

Center for Liquid-Metal Processing Technology - This center uses industrial-scale processing equipment under research or development to improve liquid-metal processing technicues and associated control methodologies. Current industrial collaborations include work on vacuum arc remelting, electroslag remelting, electron beam melting, investment casting, and thermal spray processing (plasma spray, flame spray, wire arc spray). Interdisciplinary research is in progress to define process physics, advance equipment technology, provide industrial process monitoring capabilities, develop robust multi-variant control methodologies, and establish agile manufacturing capabilities, including rapid prototyping.

The center wicupies more than 12,000 square feet of space and is supported by a staff of approxima is s. will be a key element in the formation of two industrial consortia, one in investment casting and another in refractory metals.

Center for Microelectronics Technologies - The capabilities offered by this center are accessed by industry through a five-year, $\$ 100$ million cooperative research and development agreement with SEMATECH, as well as through (CRAD)As with individual companies. Center activities in support of the U.S. semiconductor industry include the Semiconductor Equipment Technology (Center (SETEC) and the Contamination-Free Manufacturing (CFM) Research Center. The Center for Microelectronics 'Technologies conducts projection $x$-ray lithography and projection electron-beam lithography programs jointly with industrial partners to develop the next generations of processes and processing equipment. The center is the site for developing environmentally conscious procedures for semiconductor manufacturing.

Center for Solder Science and Technology - This center addresses a mixture of old and new soldering problems that hinder the rapid evolution of micro lectronic technologies. Environmentally compatible renlacements in ozone-depleting chemicals are being developed in anticipation of new EPA regulations.

The center is also developing a variety of fluxless soldering technicues that can eliminate solvents and hazardous wastes generated during electronic soldering. It is currently developing lead-free solders and solder pastes as alternatives to lead-containing solders used throughout the electronics industry.

The center operates on an annual budget of $\$ 1.7$ million and is supported by a 2()-person staff. We expect that the center will continue to concentrate on environmental problems caused by soldering and investigate technologies required for future printed wiring boards, multi-chip modules, and hybrid microcircuits.

Combustion Research Facility - The Combustion Research Facility, opened in 1980) at Sandia's California site, provides an excellent example of the Laboratories' commitment to partnerships with industry and universities. The facility is a designated DOE user facility chartered to conduct a broad range of fundamental and applied research and development in combustion science and technology. Research is conducted in collaboration with visiting scientists and engineers from industry, academia, and federal laboratories. Advanced experimental techniques, emphasizing laser-based diagnostics and advanced computational models, are used in the combustion science and technology programs. Novel sensors and computational models from the programs are in active use in major U.S. industries. 


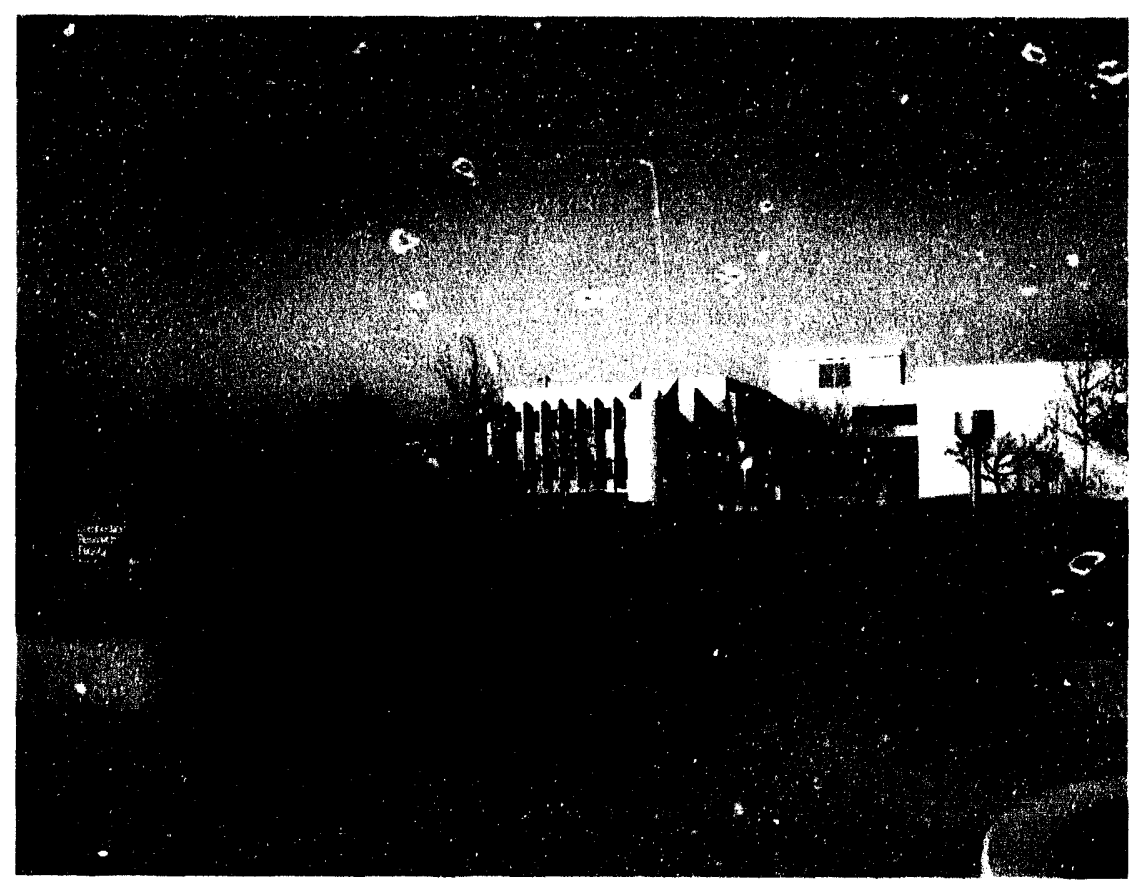

The Combustion Research Facility at Sandia/California is a designated DOE user facility attracting researchers from industry and universities around the world.
This $50,0(0)$-square-foot user ficility is supported by a staff of approximately 70 people. The Combustion Research Facility operates on a budget of approximately $\$ 20$ million per year with principle support coming from the l)( )f: offices of Energy Research and Energy Efficiency and Renewable Energy:

\section{Compound Semiconductor} Research Laboratory - This facility encompasses the full range of activities required to develop the next generation of compound semiconductor electronic and optoelectronic devices. Facilities include extensive molecular beam cpitaxy and metal-organic chemical vapor deposition crystal growth capabilities, ion implantation,

and e-beam lithography in a 6,000)-square-foot, Class-100 clean room with state-of-the-art processing equipment.

Environmentally Conscious Process Center - This center addresses the development of cost-effective processes for reducing wastes and improving cnergy utilization efficiency in manufacturing processes. It promotes the idea that designers, process engineers, and materials engineers must be included in a cradle-to-grave, totally integrated systems approach to all phases of advanced manufacturing.

Center activity is focused on life cycle analysis; solvent and chemical substitutes; soldering (including lead-free solders); cleaning technologies; electroplating and surface finishing; sensors for environmental monitoring, reliability and cost/benefit/risk analysis; alternative polymers and foams; vendor compliance; small-business outreach; and dismantlement, recycling, and reuse. Industrial sectors of particular interest include automotive, electronics, chemical, and textiles.

The center's future is directed to "ard three kcy areas: (1) creating a user facility to demonstrate improved life-cycle environmental designs; (2) protot!ping a demonstration facility for the integrated design and production of "green" printed wiring boards; and (3) developing an education, training, and industry outreach program for environmentally conscious manuficturing processes.

Integrated Manufacturing Technologies Laboratories - This collection of laboratories comprises an interdisciplinary mix of equipment and personnel focused on the development and integration of technologies for advanced manufacturing. (reated in 1992 at Sandia/California, the facility will be fully functional in 1994. Activities include materials and process research and development, process simulation, engineering design, and manufacturing technology support. Within the $9(0,00(0$-scuare-foot fac lity, significant space is dedicated to prototype fabrication research and a demonstration area for agile manufacturing. Activities of these laboratories are supported by a staff of 80 people and an annual budget of approximately $\$ 7$ million. 
During the start-up phase, the focus has been on projection x-ray lithograping, welding, precision machining, metrology, and composites tabrication. These atctivitics will be stupported by high-speed, fiber optic communications and on-line monitoring and control sy'stems. Flagship programs include SMAR'TW'ELI ), an integration of modeling, simulation, and sensors with actual welding processes to allow fabrication of eritical components without extensive development time and costs; and soft $x$-ray projection lithography (SXPL.), where a laboratorybased machine will be scaled-up to demonstrate integrated circuit fabrication at sub-micion line widths.

Intelligent Systems and Robotics Center-This facility is a filly integrated rescarch-to-development-to-application center that rovides technologies for intelligent and agile manufacturing. Specific areas include design for manuficturing and assembly, work environment design, systems engineering and integration, process modeling and simulation, precision machining, joining. assembly', automated inspection, integration frameworks, software enginecring, artificial intelligence, expert systems, robotics, machine/cell/process control, and sensors/sensor fusion. The center is the focal point for Sandia's work in information-driven manufacturing and has more than 40 laboratories available for collaborative $\mathrm{n}$ earch and development.

'The center occupies more than 27,00() square feet of space and is operated by al staff of 100 employees. The robotics center operates on a budget of approximately $\$ 31$ million per year with primary support coming from l)efense Programs and the ()fice of lenvirommental Restoration and Waste Mamagement.

Microelectronics Development Laboratory - The 74,00()-syuare-foot Microclectronics Development laboratory (MII)I.) includes ,30,000 square feet of clean-room space with 12,50) square feet of (Class 1 clean space in 22 separate clean rooms. The laboratory's design provides maximum flexibility for new processing equipment and device technologies and is uniquely configurable to support the joint Center for Contamination-lirec Manufacturing. A major donation of equipment and technology by IBNI provided a state-of-the-art, sub-micromicter, silicon integrated-circuit research and development line. The laboratory's complete equipment set supports the total semiconductor development cycle, induding rescarch, design, fabrication, test, prototype delivery, qualification, and technology transfer.

Four bays of the MI ) L are planned to be dedicated to activities of the Multi-Chip Module Foundry Consortium and will be used as an equipment applications haboratory. 'This unit will be an industry-shared site with all next-generation manufacturing equipment and will offer manufacturers, material suppliers, and equipment vendors an efficient way to perfect equipment, materials, and processes.

National Center for Advanced Information Components Manufacturing - Beginning in 1993, the Advanced Research Projects Agency is sponsoring the National center for Advanced Information (omponents Manufacturing at Sandia to provide a resource for integrating federal and commercial research and development of advanced information components. 'This integrattion will provide the capability for the United States to greatly compress the time to translate research and development into commercial and defense products. Los Alamos and Lawrence Livermore national laboratories will also support the center, along with representatives from industries and universities.

The center will allow industry and government rescarchers to exploit a range of competencies in microelectronics and photonics, electronics systems packaging, materials science and processes, printed-circuit fabrication, and other product development tools.

Research will concentrate on agile manufacturing technologies associated with advanced silicon untegrated circuits, high-speced optoelectronic communications, and electronic systems 
and subsy'stems. Research in large, flat-panel displays will benefit from the consolidation of supporting technologies at a single site. Manufacturing research will focus on developing agile manutacturing processes for flat-pand products for both defense and industry.

National Center for Advanced Manufacturing Technology -- This center was cistablished at Sandia in 1991 to maximize the value of the Laboratories' technology base to the manufiaturing needs of both the 1$)$ () nuclear weapons complex and industry. The center will help transler and apply advanced manufacturing technologies developed in Sandia s detense programs to commercial manufacturing, thus helping to strengthen L'.S. industry's competitiveness. The center sern es as a gateway by which private industry, acade: via, and government agencies can gain access to the technical capabilities provided at Sandia.

Because the term "manufacturing" is very broad, the National center for Adranced Manufacturing Technology is an "umbrella" center to several of the supporting centers and user facilities described in this section. The center's activities are coordinated by a seten-person staff, and it operates on an ammual budget of approximately $\$ 1.5$ million.

National Center for Ultra-Reliability Engineering (NCURE) - This center secks a U.S. comy titive advantage in high-value products :m/ systems through leadership in the technolog! that makes it possible to achieve high quality. Activities include research and development on how devices fail, advanced approaches to reliab lity assurance, and multidisciplinary test and evaluation capabilities. The center will support a reliability "SWAT team." A particular emphasis of NCURE is assuring high reliability in smali-lot agile manufacturing. The NC.URL program has a dedicated staff of three people with approximately 100 people working on various aspects of reliability technology.

National Solar Thermal Test Facility - This facility was constructed in 1977 ats a designated 1)()E user facility. It is used by industry and government for tests requiring intense heat and for collecting light with large-scale optics. Specific high-thermal Hux applications include investigating the thermophysical propertices of materials and testing various solar applications. Large-scale optics can be used for astronomical observations and atmospheric sounding with lidar. 'lesting is done in support of several joint venture agreements involving 1)( )F, Sandia, and industry, as well as reimbursable programs for customers such als the L.S. Navy, Air force, and I )efense Nuclear Agency.

Test areas include a fied of 222 computer-controlled heliostats that reflect concentrated solar energy onto a tower 61 meters (200)-feet) high, two 10.8-meter (36-foxt) diancter parabolic dishes, two solar furnaces, and a series of line-focus parabolic troughs that track the sun in one axis to concentlate solar power in a line.

$\lambda$ staff of 14 Sandians and 13 contractors supports the operations of the National Solar Thermal Test facility. A unique feature of the facility is that it is open to the general public for tours. A few thousand people visit each year, including school groups, groups from technical conferences, and individuals.

Process Development Laboratory - This laboratory is a center for advanced prototype manufacturing housed in a $100,(0)(0$-square fout facility at Sandia/New Mexico featuring hybrid microcircuits, thin films, printed circuis, ceramics, plastics, and rapid prototyping capabilities. The laboratory coordinates its activities with the Integrated Manufacturing lechnologies Laboratory at Sandia's California site. The charter of the laboratory is to focus on coliability and yuality of manufacturing processes through understunding and yualification of manufacturing processes. This facility also acts as a proving ground for custom sensors for manufacturing processes. 
Semiconductor Equipment Technology Center (SETEC) - SETEC 'W ws established in mid1989 to support SFMATEC.H in improving the competitive position of the U.S. semiconductor industry. The program has three goals: (1) improving equipment reliability, (2) developing diagnostic technicyues for monitoring processes and adapting these techniques to improved process control, and (3) developing models for describing and optimizing manufacturing equipment design and processes. SETEC operations are supported by a staff of approximately 35 people and a cooperative research and development agrement with SlMATliCH.

SETEC is yielding significant improvements in a number of areas critical to ensuring that the U.S. microelectronics industry will have the reliable, high-quality equipment it needs to remain competitive in global markets. The center's operations are expected to expand into other areals including semiconductor equipment design, semiconductor equipment characterization and improvement, and semiconductor manuficturing control and diagnostic sensor technologies. 


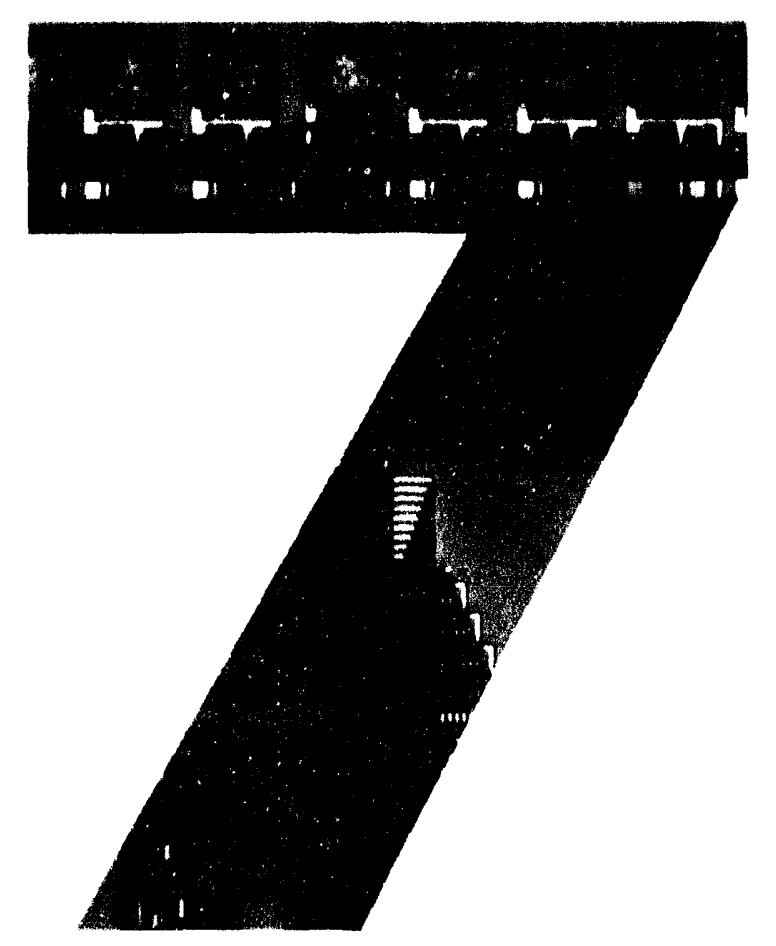




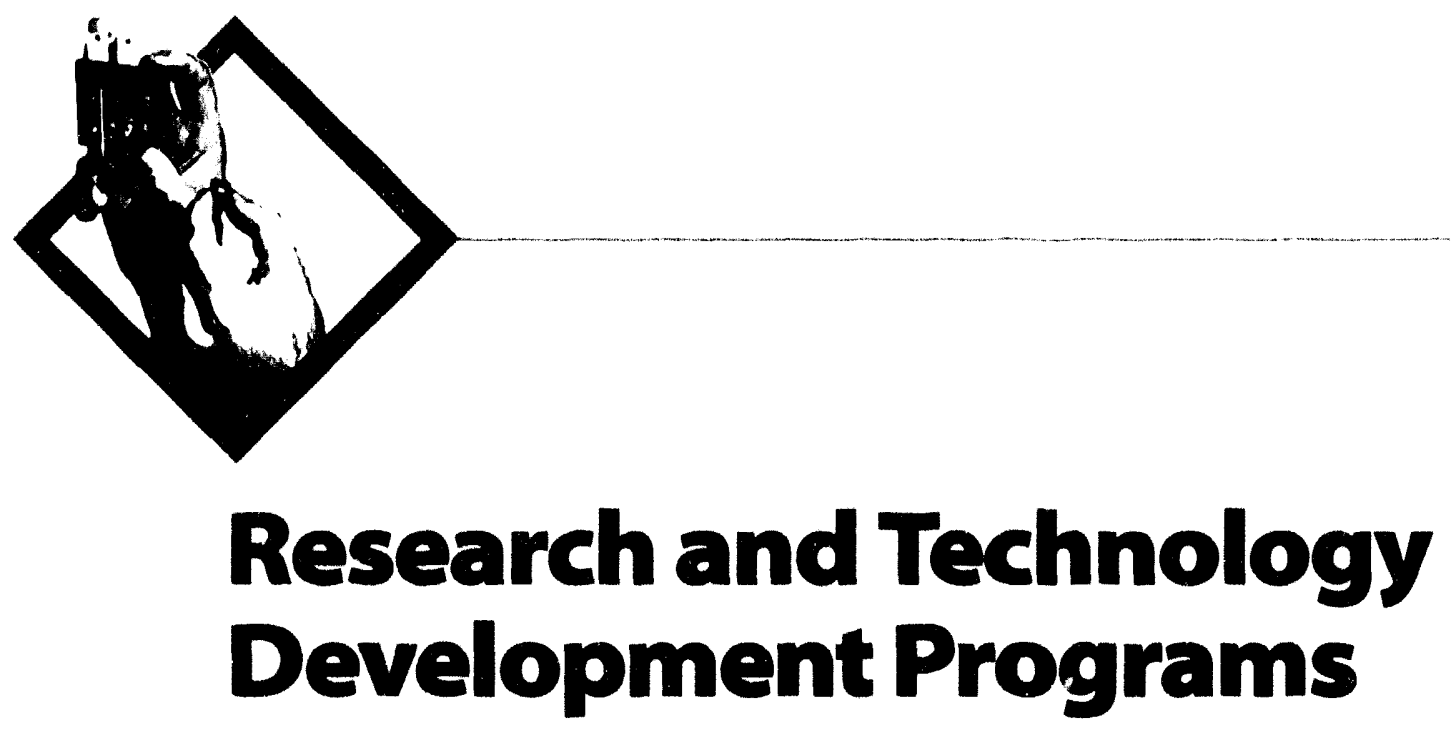

Three quarters of Sandia's operating budget is for programs for 1 ()):. The remainder is reimbursable fundin : provided by other federal agencies (principally $[$ ol )) for work in national security and other national-need programs. Operating funds by major customer are shown in the table.

\begin{tabular}{|c|c|c|c|c|}
\hline \multicolumn{5}{|c|}{$\begin{array}{l}\text { Program Funds by Major Customer } \\
\text { (Operating BA in } \$ \text { million) }\end{array}$} \\
\hline Program Title & FY92 & FY93 & FY94 & FY95 \\
\hline \multicolumn{5}{|l|}{ Department Of Energy } \\
\hline \multicolumn{5}{|l|}{ Weapons and Waste Cleanup Programs } \\
\hline Assistant Secretary for Defense Programs & 651.8 & 591.0 & 617.4 & 616.1 \\
\hline Office of Intelligence and National Security & 66.5 & 79.8 & 100.1 & 94.5 \\
\hline Office of Environmental Restoration and Waste Management & 87.9 & 126.6 & 138.3 & 144.4 \\
\hline Office of New Production Reactors & 7.1 & & & \\
\hline Total, Weapons and Waste Cleanup Programs & 813.3 & 797.4 & 855.8 & 855.0 \\
\hline \multicolumn{5}{|l|}{ Energy Programs } \\
\hline Assistant Secretary for Energy Efficiency and Renewable Energy & 49.2 & 46.0 & 57.9 & 60.9 \\
\hline Office of Civilian Radioactive Waste Management & 16.6 & 15.6 & 25.2 & 25.4 \\
\hline Assistant Secretary for Fossil Energy & 9.7 & 8.8 & 12.1 & 8.5 \\
\hline Assistant Secretary for Nuclear Energy & 5.8 & 2.0 & 6.4 & 7.3 \\
\hline Total, Energy Programs & 81.3 & 72.4 & 101.6 & 102.1 \\
\hline \multicolumn{5}{|l|}{ Science and Technology Programs } \\
\hline Office of Energy Research & 28.8 & 28.7 & 27.5 & 33.2 \\
\hline Office of Science Education and Technical Information & 1.0 & 3.0 & 2.1 & 2.0 \\
\hline Total, Science and Technology Programs & 29.8 & 31.7 & 29.6 & 35.2 \\
\hline Other DOE Locations, Contractors, and Offices & 33.6 & 31.3 & 40.1 & 41.8 \\
\hline Total DOE & 958.0 & 932.8 & $1,027.1$ & $1,034.1$ \\
\hline Other than DOE & 352.1 & 378.2 & 347.5 & 356.8 \\
\hline Total & $1,310.1$ & $1,311.0$ & $1,374.6$ & $1,390.9$ \\
\hline \multicolumn{5}{|c|}{$\begin{array}{l}\text { Note: Dollars used in the funding summary tables for Defense Programs and other assistant secretarial offices in } \\
\text { this chapter are not adjusted to compensate for anticipated inflation. }\end{array}$} \\
\hline
\end{tabular}




\section{Programs for the Department of Energy}

\section{Weapons and Waste Cleanup Programs}

Although great changes have swept the world in the past few years and significantly reduced the threat of nuclear conflict, nuclear deterrence is still a vital cornerstone of U.S. defense strategy and will remain so for as long as technologies of mass destruction pose any threat to our nation. The urgency of the cold war has passed; however, Sandia's atomic energy defense programs still face a full range of challenging responsibilities.

()ur nation must remain consistently able to face an uncertain and possibly hostile world with the confidence that can only come from a safe and highly reliable nuclear deterrent, a nuclear deterrent that is under the assured control of appropriate national authorities.

Those weapons th at are being retired from the active stockpile in response to the end of the cold war must be dismantled in a safe, secure, and efficient manner and in a manner that is fully sensitive to public concerns with regard to risk, security, and environmental protection.

In further response to the end of the cold war, to the fiscal realities now confronting the nation, and to the need to place greater emphasis on environmental safety and health, the nuclear weapons production complex must be streamlined, modernized, and reduced in both size and cost of operation. This effort must be accomplished without the loss of either the capacity to design and build replacements for current weapon components as those components reach the ends of their useful service lives, or the capability to resume the design and production of new weapons in response to currently unforeseen world events or technological advances.

In response to increasing and often legitimate public concerns with regard to environmental safety and health, many sites within the nuclear weapons complex are in need of environmental restoration, and many operations within the complex must be improved from the standpoint of waste management and minimization.

Possible proliferation activities, anywhere in the world, must be reliably detected, accurately characterized, and constantly monitored, regardless of the strategies, tactics, or technologies employed to conceal them. The means to accomplish this task must be further developed, refined, consistently updated, and fully implemented. Successfully monitoring and controlling nuclear proliferation will be a vital element of keeping the peace in the new multipolar world.

With the exception of environmental restoration and nuclear waste management, all of these challenges fall within the direct responsibility of Sandia's Defense Programs sector. Rather than diminishing with the end of the cold war, the challenges facing the Defense Programs sector have actually grown. In recognition of the continuing threat posed by the existence and spread of military technologies, the sector must and will continue to ensure the safety and credibility of the nuclear deterrent. However, in recognition of an increasingly competitive global economy, the sector is also responding to a much broader range of potential challenges to our national interests, security, and vitality. Thus, we will continue to meet critical responsibilities in the areas of nuclear deterrence, arms control and nomproliferation, and associated intelligence, while placing an increasing emphasis upon the further development and maintenance of our national strategic industrial base and the economic vitality of the nation.

Sandia's Defense Programs sector is addressing these responsibilities with a balanced approach from two directions. From one direction, the programmatic areas that are of greatest current importance are being highlighted, and appropriate thrusts have been established and are being maintained in each of these areas. These are the "strategic programmatic thrusts" of the sector, strategic thrusts that reflect vital, but changing, program priorities that evolve through time. There are currently five such programmatic thrusts: 
1. Nonproliferation and Intelligence-- This thrust has two broad but related ispects. First are those activities specifically related to monitoring and supporting arms control agreements and treaties with the former Soviet Union. These activities cover a wide range, including preparations for potential agreement provisions concerning inspection of the steckpiles and facilities within the weapons complexes. Second are the activities focused toward monitoring and preventing the further spread of nuclear weapon technologies. As the collapse of the bipolar cold war balance gives way to a far more dynamic multipolar world scenc, these critical nonproliferation responsibilities are becoming very important.

2. Reconfiguration and Conversion - The end of the cold war, environmental and budget concerns, and the advanced age of many nuclear production facilities combine to drive the reconfiguration of the nuclear weapons complex into a smaller, more efficient, more modern, and more envirommentally appropriate form. The success of these efforts will greatly depend on the development and introduction of new and appropriate production and waste management technologies, on new and more modern approaches to the integration of design and manufacturing, and on the development of appropriate alternatives for those materials and processes that must be discontinued and those sites that must be reassigned to other functions. In the future, Sandia will emphasize commercial procurement of most parts, small-lot manufacturing of essential parts, and standardization. Sandia generally, and its Defense Programs sector specifically, have critical responsibilities in all of these areas.

3. Strategic Surety - Surety, defined as safety, security, and use control, is an increasingly critical area involving issues raised by the Drell Panel, concerns related to transportation and handling, logistics associated with retirement and dismantlement, the surety requirements of a smaller and more flexible stockpile, and increased public sensitivity to environmental safety and health issues. The goal of this thrust is to embed, in all of the laboratories' efforts and products, the principle that the surety of any product or operation, regardless of its expected service life, is too critical to be allowed to degrade and must be constantly updated and modernized.

4. Essential Competence and Capabilities - This thrust includes subsets of the physical and intellectual capabilities essential for the long-term viability of Sandia's D) OE defense programs and initiatives that are not supported by other strategic thrusts or sectors. Each element underlies and supports multiple 1) efense Programs thrusts and often, multiple programs and initiatives of other Sandia program sectors.

Research and development activities include critical supporting sciences and crosscutting exploratory technology assessments and developments. Exceptional science and technology foundations are necessary to respond quickly to problems, to facilitate the movement of the Laboratories in new directions, to respond to technology advances, and to stimulate outside interactions. Key facilities and capabilities may be underutilized and yet be essential for meeting the long-term requirements of 1 () I : defense programs and initiatives. Important elements of the program include supporting capabilities (shops, engineering, drafting, simulation and modeling, computing), specific developmental testing facilities, underground test capabilities, aboveground test facilities for radiation-effects assessments, and physical and chemical sciences capabilities.

5. Stewardship of the Enduring Stockpile - Credible nuclear deterrence remains a fundamental element of $L$.S. national security policy. This deterrence is and will continue to be based upon an enduring nuckear stockpile and the stewardship of that stockpile, which has been a fundamental Sandia mission for over forty years. 'The foundation of these stewardship 
responsibilities is the monitoring of the stockpile to ensure that the credibility of the deterrent remains high. In addition, increasing public awareness and expectations in the areas of safety and the environment are placing greater demands on the stockpile stewardship process, particularly with regard to weapon retirement and dismantlement.

Sandia's Defense Programs sector has fundamental responsibilities in all phases of this process. It is addressing current dismantlement challenges through an increased emphasis on the systematic integration of the retirement and dismantlement process, on a "(radde-tograve" approach to the entire life span of the weapon, and on the beneficial implementation of new technologies, including the use of robotics to reduce both waste and human exposure. In other areas, budget concerns and troop strength reductions, coupled with changes in priorities at the end of the cold war, will make many of their stockpile maintenance responsibilities increasingly burdensome for the military services. The Defense Programs sector's critical responsibilities in these areas demand that it be prepared to monitor these trends and assist the military services whenever necessary. This assistance could range from greater participation in the process of limited life component exchange to studies to assess operational feasibility or technological threats.

The sector is also approaching its responsibilities from a second direction: In addition to recognizing vital programmatic areas and establishing appropriate programmatic thrusts, the sector has established some broad and enduring performance criteria against which plans and strategies can be judged and, if necessary, modified or reinforced. These are the Strategic Imestment Criteria for the Defense Programs sector. They reflect the fundamental principles of the sector and its long-term commitment to remaining a relevant and contributing entity. Five criteria are currently being applied to virtually all projects undertaken by the sector.

1. Customer Obligations - Sandia is a customer-focused organization. Each of its sectors' efforts and activities are routinely scrutinized and monitored with regard to robust agreement with customer requirements.

2. Dual-Use - The sector recognizes the need to respond to a broader range of challenges to our national interests. Thus, we are committed to a balanced program that is heavily focused upon the exploration and development of dual-use technologies that can benefit both domestic industry and the nuclear weapons program. This approach emphasizes mecting the sector's needs in the areas of manufacturing, high-performance computing, electronics, nonproliferation, risk assessments, safety, and security. At the same time, the sector will place a high priority on technology transfer for the further development and maintenance of our national strategic industrial base and the economic competitiveness of the nation.

3. Strategic Partnerships - The responsibilities carried by the Defense Programs sector with respect to maintaining the credibility of the nuclear deterrent represent the original mission of the DOE Defense Programs laboratories. These laboratories have evolved from special-purpose sites dedicated to a single program to multiprogram institutions addressing a wide range of national interests. The impacts and effects of the increasingly competitive international environment are actually strengthening and accelerating this trend. Teamwork, both internal and between Sandia and other national laboratories, universities, national research institutions, and the industrial sector is essential for bringing the full potential of our capabilities to bear on complex national issues.

4. Nurturing Technical Strengths - In all of the sector's efforts, it maintains essential elements of national vigilance against the possibility of technological surprise. In this context, the 
sector is obligated to continuoisisy monitor, explore, and exercise the most modern and advanced elements of technologies that are likely to have an impact on the interests and security of the nation. The sector has a further responsibility to exert technological leadership to ensure that the resources of the Laboratories are constantly challenged to grow and develop, and that the full potential of their benefit to the nation is realized.

5. Strategic Reconfiguration - To remain relevant national assets, the sector and the Laboratories are continuously monitoring, reassessing, and realigning their organizational goals, strategies, and structures, constantly adjusting their responses to dynamically changing customer requirements. In this way, the sector strives to ensure that its activities consistently reinforce the strategic directions that have been established for the Laboratories and the nation.

\section{Assistant Secretary for Defense Programs}

The Assistant Secretary for Defense Programs is the cognizant secretarial officer for Sandia National Laboratories. The Weapons Activities program for the Deputy Assistant Secretary for Military Application employs half of Sandia's direct personnel and comprises Research and Development, Testing, Inertial Confinement Fusion, Stockpile Support,

Reconfiguration, Emergency Response, and Special Projects including cooperative measures with the former Soviet Union and foreign technology assessments. Furthermore, the technology base developed and preserved by the Deputy Assistant Secretary for Military Application is the wellspring of the Defense Programs Technology Transfer Initiative. And although arms control and nonproliferation and defense waste cleanup activities are no longer a direct responsibility of the Deputy Assistant Secretary for Military Application, the technology base developed and preserved by the Deputy Assistant Secretary for Military Application is essential in the execution of those programs.

One mission of Defense Programs that is of increasing importance is to assist the preservation of our national strategic industrial base and promote national economic growth through partnerships with domestic companies and technology transfer of appropriate dual-use technology to the private sector. While this objective is the sole mission of the Technology Transfer Initiative (GB0106), it also weaves through and forms

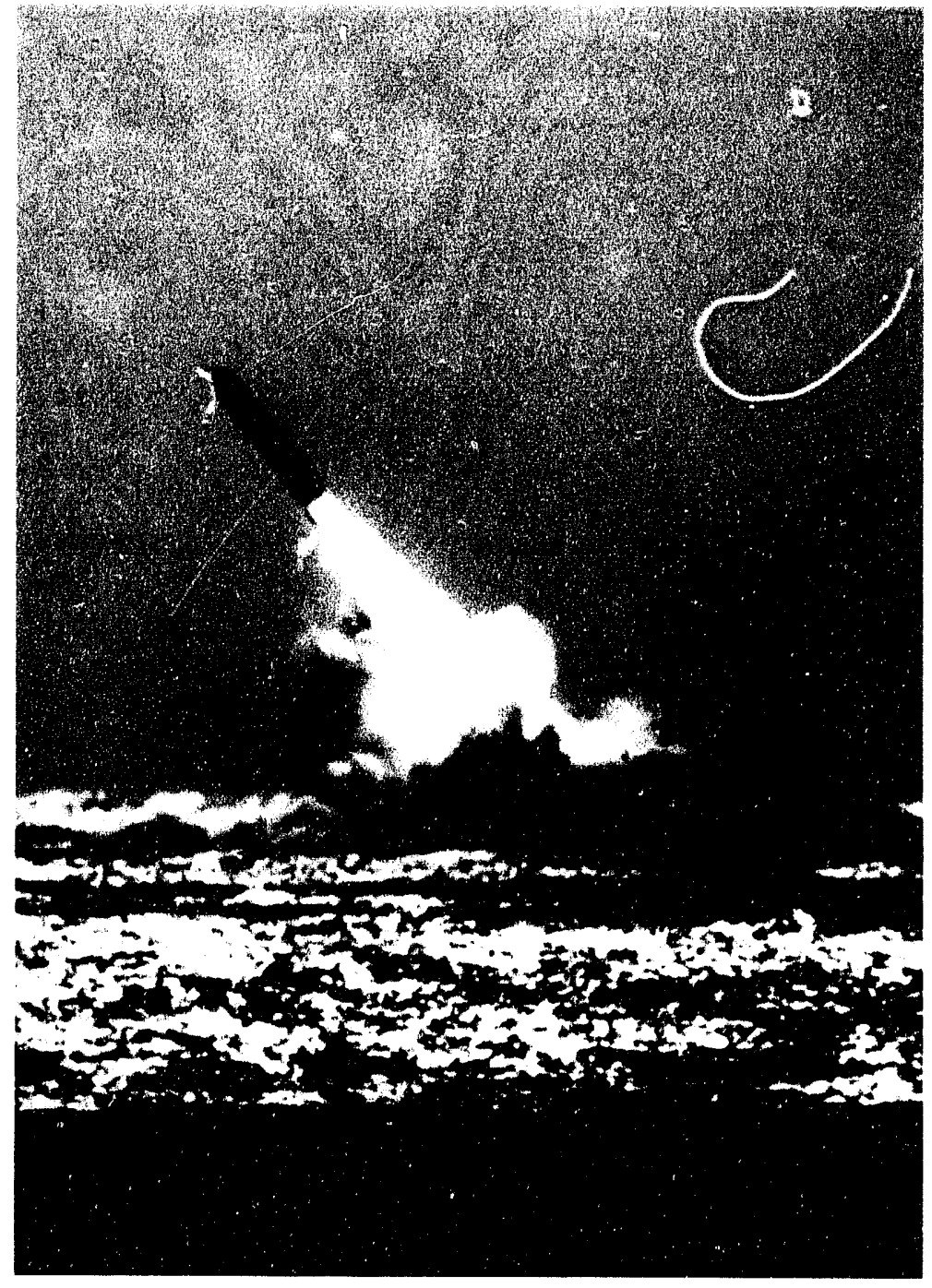

Test firing of a Trident II D5 missile. Sandia played a major role in the design and systems integration of the W88 warhead for Trident II. After the terms of START II are implemented, Trident II will remain as the centerpiece of the nation's strategic nuclear deterrent. 
the fabric of every l lefense Programs project at Sandia. Starting in FY 1994, we are putting into effect a review process to evaluate every project, new or ongoing, to determine its potential for dual-use application. Faced with a decline in the direct funding that has historically' supported the technology base for weapon activities, we expect our technology transfer efforts and our other industrial partnerships to help preserve and grow those core capabilities of the Laboratories that are necessary to carry out our Defense Programs responsibilities.

We expect our manpower level of effort in Defense Programs in FY 1994 and each year thereafter through 1999 to be close to its present size; but the program mix among the various categories is expected to change significantly. Additional staff will be required for both stockpile support and reconfiguration activities to accommodate an expanded role in manufacturing, dismantlement, and stockpile maintenance.

\begin{tabular}{|c|c|c|c|c|c|}
\hline \multirow[b]{2}{*}{ B\&RCode } & \multicolumn{3}{|c|}{$\begin{array}{l}\text { Summary of Programs for Assistant Secretary for Defense Programs } \\
\text { (Operating BA in \$ million) }\end{array}$} & \multirow[b]{2}{*}{$\underline{\mathrm{FY} 94}$} & \multirow[b]{2}{*}{ FY95 } \\
\hline & Program Title & FY92 & $\underline{\mathrm{FY} 93}$ & & \\
\hline GB & Weapon Activities & 651.0 & 589.6 & 616.8 & 615.6 \\
\hline \multirow[t]{3}{*}{ GE } & Materials Production - Reactor Operations & 0.8 & 1.4 & 0.6 & 0.5 \\
\hline & Total & 651.8 & 591.0 & 617.4 & 616.1 \\
\hline & Percent of total operating funds & $50 \%$ & $45 \%$ & $45 \%$ & $44 \%$ \\
\hline
\end{tabular}

\section{Research and Advanced Technology (GB010301)}

Activities supported by this budget and reporting category provide the science and technology infrastructure, including technical expertise and facilities, needed to support multiple Defense Programs missions, programs, and initiatives. It emphasizes those research and technology development activities necessary to maintain and improve our understanding if the science of complex nuclear weapon systems and to advance the technologies that enable their design, engineering, production, certification, and, eventually, their dismantlement and the disposal of associated hazardous materials. It also sustains the core capabilities needed to support all atomic energy defense activities, including those falling outside the direct responsibility of the Deputy Assistant Secretary for Military Application, such as arms control, nonproliferation, and environmental restoration and waste management. A Munitions Technology Development Program jointly funded by DOE and 1)ol) under a 1985 Memorandum of Understanding pursues innovative weapon technologies of interest to both agencies ( see page 7-95).

An additional mission of increasing importance is to facilitate technology transfer to the private sector and otherwise assist L!S. industry with precompetitive development of commercially promising technologies.

From a budgetary standpoint, Research and Advanced Technology and the Research and Technology Development Division, Defense Programs-242, essentially coincide. To effectively address their broad responsibilities, the division subdivides the activities into nine specific technology areas or program elements. The desired levels of capability in these program elements are monitored against the needs and objectives of the research and development activities that utilize and exercise them. Efforts to directly augment or enrich program elements are made only when programmatic activities within ongoing Defense Programs initiatives are temporarily unable to fully sustain necessary capabilities. In the following paragraphs, we summarize our efforts in the eight program elements in which Sandia has significant activity: 


\section{Conceptual Design and Assessments}

Conceptual design and assessment, along with physics, computation, and modeling, form the core of the science of complex nuclear weapons systems and associated subsystems. The work in this program element generates and evaluates new weapon and weapon component concepts. These exploratory concepts are generally not predicated in the current requirements of the Stockpile Stewardship initiative. Rather, conceptual design and assessment typically consists of groundbreaking projects where new weapon and weapon component concepts are developed until they reach sufficient maturity to be properly integrated into one of the Defense Programs initiatives or into one of the other, more structured, program elements. Thus, concepts that prove promising for weapons applications, whether for improved capability, reduced life cycle cost, or safety advantages, are born in conceptual design and assessment but are pursued within this program element only through proof-of-concept demonstration. They are then transferred for further development to another program element (often to Systems lingincering Science and Technology) or to one of the prog, wims within the Stockpile Stewardship initiative.

The goal of conceptual design and assessment is to explore ideas that have the potential to support multiple defense missions, programs, or initiatives and, if successful, lead to advances in performance, capability, utility, surety, or to reductions in life cycle costs. Examples of the work currently supported by this program include methods to enhance electrical nuclear detonation safety and innovative concepts that potentially offer greatly enhanced nuclear safety.

Although hardware development is not typically a major part of this activity, experimentation to demonstrate concept feasibilit? is frequently required. The work is offen computationally intensive. Current areas of emphasis include enhanced surety, alternatives to hazardous materials, new weapon capabilities, and prevention of technological surprisc. Because this progran element looks beyond proven concepts and traditional methods, these capabilities are of critical importance to the Office of Intelligence and National Security with regard to assessment of possible nuclear weapon proliferation activities in foreign countries.

\section{Physics}

This program element forms a second part of the core science of complex nuclear weapons systems and associated subsystems. Physics maintains and expands our knowledge of the scientific principles that govern the performance of nuclear weapon components. The laws of physics govern virtually" every phase of weapon design, em wineering, testing, and certification, and the understanding sustained by the work within this program element touches every aspect of maintaining a credible deterrent.

Physics provides much of the basis for the 'lest Ban Readiness and Stockpile Stewardship initiatives as well as the capability for predicting the effects of nuclear explosives on military targets and the vulnerability of nuclear weapons to nearby nuclear explosions. Physics principles not only underpin the design and testing of nuclear weapon sy'stems, they also underlie many of the unicue manufacturing processes for weapon components as well as the design of facilities used to test these components. These principles also govern the design of complex experiments to test weapon components, validate our understanding of how these systems function, benchmark the computer codes used to design component subsystems, and assess the safety of weapon comoonents in accident scenarios.

There are eight key capabilities within this program element that form the basis of much of our weapons actwitiec. These capabilities sustain and support virtually every defense mission within $\mid(x)$ : These capabilities are discussed below along with some examples of their applications in resciarch, development, and testing activities:

- Hydrodynamics focuses on understanding the detailed effects of high-explesive detomations and material flow. It is critical to predicting the response of weapon cases and components in accident scenarios. 
- Radiation Physics models the flow of photons and $x$-rays and their interactions with matter. This capability is vital to assessing weapons effects, to designing $x$-ray sources used to evaluate the vulnerability of components to weapon effects, and to interpreting complex development tests.

- Atomic Physics forms the basis of calculations of the interaction of electrons, ions, $x$-rays, and photons with matter. It is used extensively in designing intense $x$-ray sourcen, lasers, and pulsed-power devices, and it is an essential foundation of plasma physics and weapon effects simulations and models.

- Plasma Physics underlies the behavior of many pulsed-power components, inertial confinement fusion, weapons effects on the atmosphere, plasma processes used to make microelectronic devices or deposit thin films on surfaces, and $x$-ray sources.

- Condensed Matter Physics includes work in equations of state of materials for conditions of severe temperature and pressure, which underlies our ability to understand the behavior of weapon components when exposed to such conditions, and semiconductor and dielectric physics, which underlies the design, fabrication, and testing of weapon components, such as microelectronic and photonic devices.

- Chemical Physics underpins gas laser research and development, the development of chemical processes for materials processing, and the simulation and modeling of explosive chemistry.

- Optical Physics supports research and development of lasers, photonic devices, direct optical initiation, materials processing witil lasers, remote lidar detection of trace species in the atmosphere, and laser imaging and ranging.

- Pulsed-Power Technology enhances laboratory capabilities to assess the effects of ionizing radiation on weapon components, to benchmark weapon design codes (with the assistance of Los Alamos and Lawrence Livermore national laboratories), to qualify components for radiation hardness, and to avoid technological surprise in tailored-output nuclear devices.

\section{Computation and Modeling}

This program element ensures the development and maintenance of computational capabilities that are essential to the design, production, testing, and certification of nuclear weapons.

A nuclear weapon is a complex system consisting of a large number of components and subsystems. The actions of many of these components and subsystems are tightly coupled when the weapon is fired. The complexity of structure, function, and interaction of these components prevents their efficient design, at any reasonable cost, without the use of extensive computational support. In addition, these systems and components must consistently meet the most demanding requirements for safety and reliability and continue to function with high precision throughout the course of a stockpile service life that may last several decades and involve exposure to severe envirommental, handling, and transportation stresses.

Once a weapon enters the stockpile, opportunities for direct inspection and testing are limited and expensive. Maintaining this extremely high level of product reliability with minimal direct testing and at reasonable cost requires computational modeling at every stage in the design, production, and service life of the weapon.

Virtually all of the program elements are heavily dependent on computation and modeling. In fact, these capabilities are critical to every element of our nuclear weapon activitics, inciuding: 
- Testing required to assess system performance

- Experimentation to understand the underlying physics

- Correlation of simulations to actual threats

- Design of engineered materials and processes

- Control of intelligent manufacturing equipment and robotics for

handling hazardous materials and assembling systems

- Safety assessments, and

- Assistance with emergency response.

Computation and modeling play a particularly important role in several areas. Computational analysis is critical to safety assurance studies. These studies ensure that weapon systems neither function nor expose the environment to hazardous materials in accident scenarios. In addition, with testing of nuclear weapons suspended, our ability to certify the vulnerability of components to radiation will be even more important than in the past. Computation and modeling are also critical in designing weapon transportation and storage systems and in evaluating weapon survivability when subjected to nuclear defense measures.

With regard to the production or manufacture of replacement components, modeling will be a fundamental element of agile manufacturing and the reconfigured nuclear weapons complex. In the reconfigured complex, production processes will be modeled and integrated through computeraided design (CAD) and computer-aided manufacturing (CAM) to ensure product reliability at low cost under low volume and to provide flexible production conditions. Computation and modeling also play a vital role in addressing environmental safety and health concerns. For example, modeling is widely used to design less hazardous substitute materials and alternative processes.

One of the difficulties in using massively parallel computers is efficiently distributing the compuiation across multiple processors. Sandia researchers have discovered an important result in an area of mathematics known as spectral graph theory that has led to a faster method for decomposing large problems. The graphic shows the decomposition for a

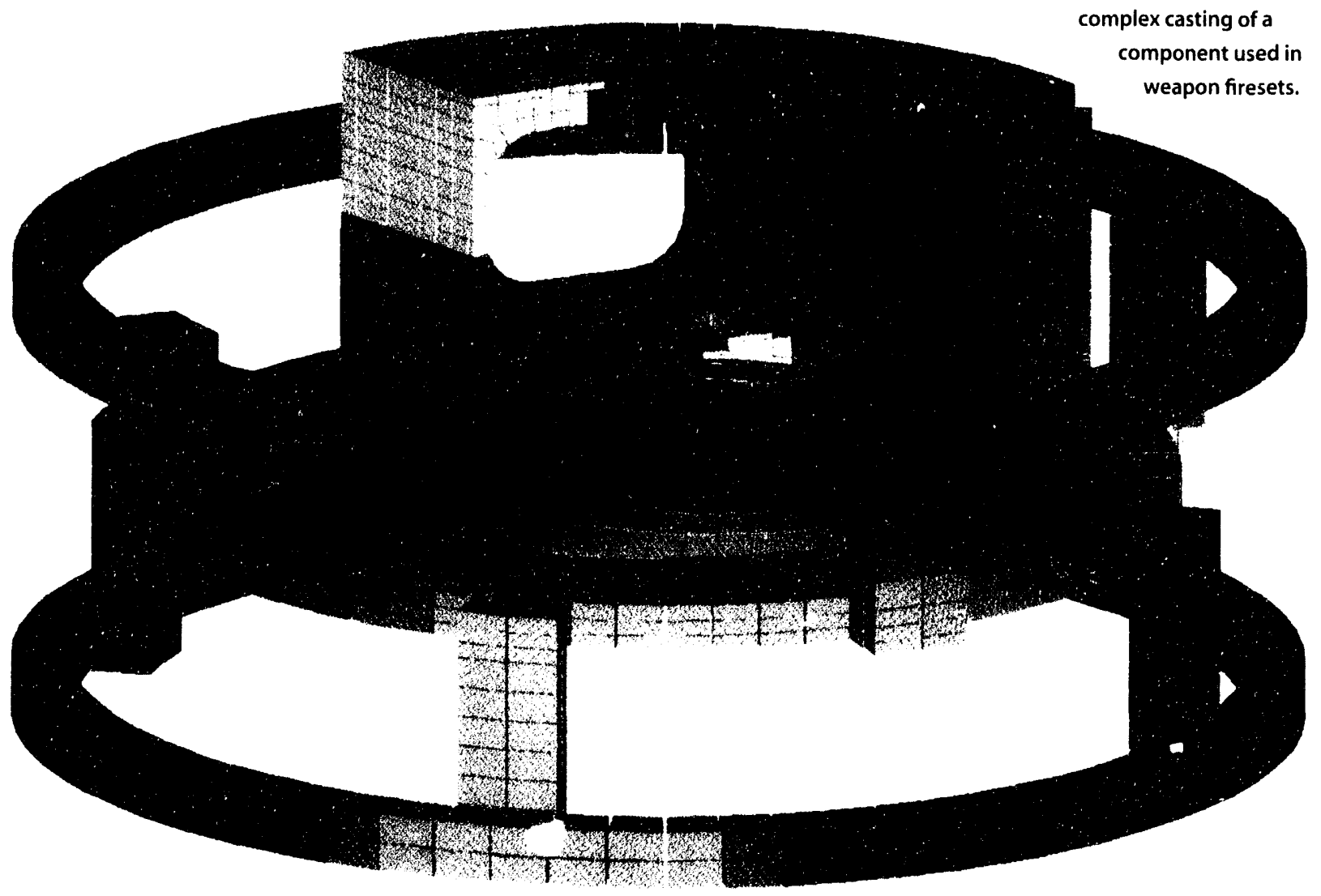

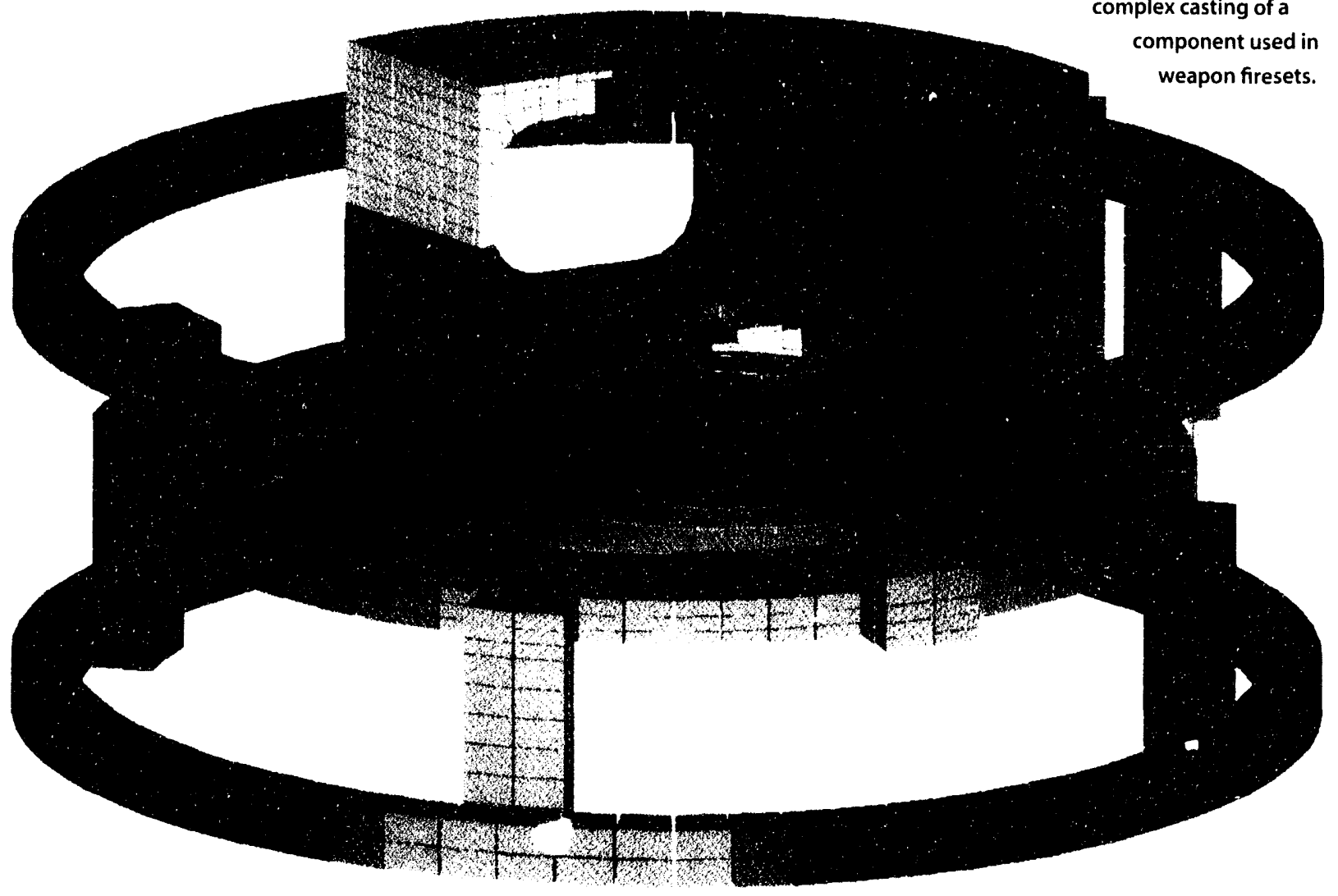


Virtually all DOE missions are heavily dependent on computation and modeling. 'The offices of Intelligence and National Security and Envirommental Restoration and Waste Management rely on the capabilities maintained by this program element. In the broadest terms, computation and modeling, through the simulation and modeling of complex systems, reduce overall program costs by assisting with risk reduction carly in the system life cycle and reducing the need for physical testing.

\section{Systems Engineering Science and Technology}

System Enginering Science and Technology assembles and integrates fundamental and enabling technologies to create forward-looking core products and capabilities that respond to shifting requirements, keep pace with the rapid evolution of technology, and meet the critical systems needs of the Department of Energy. This program element ensures the maintenance of those comprchensive systems engineering and production capabilities that are essential to supporting and integrating multiple research and technology development programs.

The boundaries between System Engineering Science and lechnology and some of the other program elements are, in many cases, not well defined. However, the activities in System Engineering Science and Technology emphasize the integration of multiple technologies, many of which are developed through the other program elements or through the Defense Programs initiatives. While other program elements focus on the development of a specific set of technologies to meet a specific set of performance goals, System Engineering Science and Technology pursues more comprehensive goals by sclecting among alternative technologies and integrating them to yield desirable characteristics in broad systemic categories, including manufacturability, affordability, environmental safety and health, case of dismantlement and disposal, ease of certification, and maintenance of core product capabilitics.

An important consideration in selecting activities to be supported by this program element is the need to constantly introduce new or emerging technologies into mainstream design efforts and to regularly update, ensure, and enhance the technological superiority of the stockpile. Tomeet this need, systems engineers seek to pull the work being done in other program elements and initiatives in directions that best support I) OE's stratcgic needs and intent. In addition, the efforts in (onceptual Design and Assessment are monitored and assessed with particular care as a means of identifying those new concepts that have the highest potential for further devidopment. A high priority is then given to the development of enabling technologies that best support these promising concepts. Although general scientific and technological feasibility is determined in (onceptual D)esign and Assessment, engineering and production feasibility and the merit of each new concep is assessed in System Engineering Science and Technology.

Most important, this program element maintains the design, enginecring, and testing infrastructure needed to sustain and enhance the stockpile and respond to challenges as they arise.

System Engineering Science and l'echnology also benefits a number of other defense missions within $D() E$, including, programs for the safe and secure transportation and physical security of weapons and materials, dismantlement, and arms control.

\section{Electronics, Photonics, Sensors, and Mechanical Components}

Electronic, mechanical, and aerodynamic components largely determine the precision of the delivery of a weapon to a target, the reliability of the system, and the operability of weapons in the potentially' severe environments caused by defensive measures by the targeted country. The use of electronics in nuclear weapons is pervasive. Special-purpose dectronic components in nuclear weapons include coded switches that prevent unauthorized use, tamper delectors, programmers that control the arming and firing sequence of the weapon, radars, and furing and firing sets. These devices must operate reliably over a large temperature range, survive strong mechanical shock, and be fully functional following exposure to intense pulses of ionizing and electromagnetic radiation caused 
by nearby nuckar detonations. The latter may be caused either by defensive systems of the targeted country or by fratricide.

Nany of the requirements on devices cann not be met with commercial products. This limitation is also true for many of the mechanical and aerodynamic components that determine the reliability of a weapon after an extended period of time in stockpile, as well as the maintenance requirements of weapons in stockpile.

Photonics represents an emerging technology that uses visible light energy to execute functions normally performed by eketrical energy. On account of the inherent immunity of photonic devices to electromangetic interference and their tolerance to the effects of ionizing radiation and intense pulses of electromagnetic radiation, photonic devices offer unique advantages over electronic devices for a wide varicty of applications in nuclear weapons.

Photonies is the enabling technology in the optical firing set, which is being researched as a possible replacement for the traditional electrical system. This firing set offers greatly enhanced safety should a weapon be exposed to severe abnormal environments such as a crash or a direct hit of lightning. It uses a laser and optical fibers to initiate detonators that in turn initiate the nuclear explosion. It also lends itself to unique photonic-based use-control subsystems that would greatly reduce the threat of unauthorized use of a weapon should it fall into the hands of another country or terrorists.

While the research into the enabling laser photonies technology has been performed under this program element, the development of this innovative firing set is performed in the program element for Explosives. Following proof of feasibility and practicality, development will move to the System Fngincering Science and Technology program element for full-scale engineering and certification.

Sensor research and development supported by this program element includes radars used to command the firing of a weapon and provide precision terminal guidance, components that detect unauthorized tampering, use-control devices, accelerometers, chemical sensors to assess the state of health of weapons in stockpile, and other components.

The technology base sustained by this program element is critical to almost every deferise mission, initiative, and program of the Department of Energy. Satellites that monitor compliance of other countries to treaties on weapons of mass destruction require microelectronic devices that are hardened against the ionizing radiation of space. Application-specific microprocessors and embedded computers are needed by many of the systems used to verify treaty compliance and assess activity in forcign countries that may indicate work on weapons of mass destruction. Also, advanced sensors, such as chemical microsensors, lidar, and high-performance synthetic aperture radars developed under this program element offer new capabilities for arms control and proliferation assessments.

These technologies are also critical for the safeguards and security efforts of D)(OE. (Chemical sensors ancilidar have application for assessment of chemical hazards in nuclear waste sites in support of programs of the Office of Environmental Restoration and Waste Management. Also, many' of these capabilities are of primary importance in the limergency Response program of Department of Energy. Furthermore, strengths in electronics, microelectronics, and photonics sustained by this program element are promoting national economic growth thre wgh technology' transfer.

\section{Chemistry and Materials}

Meeting the demanding reliability, safety, and physical security requirements of nuclear weapons requires a diverse range of materials expertise and capabilities, many of which are unique to the nuclear weapon laboratories. Nuclear weapons must operate reliably in the severe environments of strong mechanical shock, intense electromignetic fields and ionizing radiation, and large temperature excursions. Also, they must not detonate or disperse nuclear materials in accidental exposure to severe abl, urmal environments of fire, mechanical shock, electrical shock and static charge, electromagnetic fields, or their combinations. At the same time, ultra-high-reliability requirements must be met by weapons that have been in storage for decades with little or no maintenance or 
testing. In the future, it will be necessary to certify reliahility without full-scale underground testing. The activities supported by this program element are central to meeting these requirements.

This program element also maintains the infrastructure needed to assess materials-related deficiencies uncovered in weapons in stockpile. Such troubleshooting and failure analysis requires special expertise and capabilities because of the special nature of many of the components.

Meeting the materials development and analysis requirements for nuclear weapons engincering and stockpile support requires broad strengths in synthesis and processing, materials characterization, theory, and modeling and simulation. This knowledge base must span a wide range of materials, including metals, ceramics, glasses, organics, composites, and semiconductors (semiconductor materials are covered in 4 . Electronics, Photonics, Sensors, and Mechanical (components program element).

Current activities focus on materials and process substitution to reduce the cost of component production and weapon dismantlement; produce longer-lifetime components so as to reduce maintenance requirements for weapons in stockpile; ameliorate or eliminate sources of harmful effects on the environment; and realize the highest practical safety in the workplace. These capabilities in materials technologies are a cornerstone of the evolving agile product realization process that will be the hallmark of the new production complex, Complex 21 .

The technologies and facilities sustained by this program element are of direct benefit to many DOE defense projects that fall outside of the direct responsibility of the Assistant Secretary of Defense Programs. Projects under the direction of the (Office of Environmental Restoration and Waste Management and projects supporting Safeguards and Security initiatives are direct beneficiaries. Both programs have needs for special-purpose materials and processes, and each relies heavily on the materials characterization capabilities that are sustained by this program element.

\section{Tritium}

Tritium is an essential material in nuclear weapons as currently designed. Sandia's activities in this program element include the design of tritium reservoirs and the associated gas transfer sy'stems. 'These systems require bottles, valves, actuators, and piping designed for long life under extremely' high pressures. Fundamental and applied research on materials degradation in these sy'stems is performed by the Chemistry and Materials program.

Tritium is radioactive and has a half-life of 12.3 years. As tritium decays, helium is produced, which invades and weakens the containing material. Research on improved alloys for reservoirs and neutron generators, stable storage of tritium, and management of the decay product is expected to kead to greatly increased lifetimes for these components, improved safety, and maintenance cost silvings.

\section{Explosives}

There is great potential and great need for improving the performance and safety of explosives and associated components. A fundamental understanding of the processes of localized mechanical and thermal energy buildup and dissipation for all kinds of abnormal stimuli is paramount in evaluating safety and performance characteristics. This process must include tradeoffs of arailability and cost, dynamic and mechanical properties, chemical and thermal stability, initiability, durability, convironmental concerns, and issues associated with the inevitable retirement, recycling, and disposal of assemblies containing explosive materials. Irom these studies will emerge safer high-energy explosives offering improved performance.

Activities in this program element span the range from fundamental physics and chemistry of explosive materials to prototype engineering of explosive components and their cvaluation for weapons uses. Issues associated with retirement of systems and disposal of materials must be considered at all phases in the cycle. Normally, once a new concept proves to be feasible, full-scale engineering and certification is done under the Steckpile Stewardship program or by System 
Engineering Science and Technology program element. Current emphases include firing systems that offer greatly enhanced safety, such as direct optical initiation firing sets employing lasers and optical fibers, and a concept for physically separating the explosive material from the nuclear assembly until authorized.

The technologies and infrastructure sustained by this program element are of direct benefit to many defense projects of the Department of Energy that fall outside of the direct responsibility of the Assistant Secretary of 1 )efense Programs. The (Office of Environmental Restoration and Waste Management takes advantage of the research and development related to explosives characterization and demilitarization processes in the environmental restoration of l)( )E sites contaminated by explosives and their byproducts. The Safeguards and Security program utilizes dalabases on explosives and models to assess the vulnerability of transportation systems and to design transportation containers. The Stockpile Support program will benefit from the development of explosives that have longer lifetimes and lower costs for both production and disposial.

\section{Dual-Use Benefits}

Activities in the foregoing program elements have made possible a large number of transfers of technology to the private sector, including many cooperative research and development agrements with private companies. These agrements have resulted in the development of a large number of enabling, pre-competitive technologies and manufacturing processes that have been privatized. Our past successes in identifying dual-use opportunities in weapons research and development and then working with industry to transfer the capabilities to them, is the basis of our new policy that every project will integrate dual-use technologies into its fabric. Some selected examples or recent dual-use successes are discussed below:

- Research on plasma etching systems of the type used in the manufacture of microelectronic devices to define transistor features and electrical interconnects between transistors led to an explanation of why seemingly identical systems occasionally do not function the same and why the response surface of a specific system sometimes changes. Technical solutions worked out by our staff are now incorporated in commercial equipment.

- Sandia studies of the response of lithographic equipment to vibation, as well as new protocols for stage movement to minimize structural vibrations, have resulted in recommendations for improvement that are being utilized in the design of new commercial lithographic equipment. Such equipment is used to define intricate electronic circuit patterns for microelectronic devices.

- A new process to produce printed circuit boards without using ozone-depleting chlorofluorocarbons was developed by Sandia engineers working with Motorola. 'This new process has the potential to eliminate more than 25 percent of the workdwide release of such compounds into the atmosphere.

- Protocols developed by Sandia for the design of the gates and runners for investment casting have led to substantial reductions in the time required to develop casting systems for complex shapes. This work was accomplished with the aid of thermal, structural, and fludd dynamics codes to simulate the casting process. The technology is being rapidly picked up and used by industry.

- Sandia's advanced funciamental understanding of the parameters of welding, together with the development of enhanced adaptive process-control sensing and protocols, have been 
transferred to industrial partners. ()ngeing activities are aimed at integrating predictioc models into both computer-aided design and addaptive control instrumentation.

- The Sandia-invented R() I.AMITT switch and semiconductor bridge are used in automobile air-bag release mechanisms. Sandial's acrodynamic codes are being used to design new, low-cost airbags with improved performance.

- Semiconductor strained-layer superlattice materials pioncered by Sandia have led to a new generation of microelectronic and optoelectronic devices with improved performance. Commercial dev ices based on these new materials are beginning to reach the marketplace, including the next-gencration cellular telephones by Motorola.

- Sandia advances in statistical analysis of chemical spectroscopy have led to the development of a prototype noninvasive serum glucose sensor for use by diabetics. Protctype devices have been used in patient studies at the University of New Mexico School of Nedicine, and an affordable commercial device may soon be available.

- Sandia developments in chemical microsensors have potential application in automobiles for monitoring the state of motor and transmissions fluids. Replacement of engine fluids based on viscosity change, rather than on an arbitrary periodic schedule, could reduce life-time servicine cost, increase engine efficiency, and enhance engine life.

- A Sandia-invented glass developed for the weapons program is now used in nost commercial lithium rechargeable batteries.

- Sandia advances in the hardening of microclectronic circuits to ionizing space radiation and energetic particles are used in the manufacture of robust electronic systems for satellites. Their use reduces the incidence of single-event upsets of microclectronic circuits, which cause both functional and informational loss.

- Sandia expertise in weapon surety assessment and certification methodologies, nondestructive testing, and materials analysis, testing, and evaluation is being applied to the evaluation of the structural safety of aging aircraft.

\section{Stockpile Stewardship (GB010302)}

A principal mission of Sandia is stewardship of the nuclear weapons stockpile. Stewardship encompasses directing and managing the total life-cycle affairs of the nuclear weapons stockpile. Duties include: maintaining the weapons in the stockpile; monitoring, testing, and assessing stockpile health; developing and retrofitting nuclear weapons as required; developing and maintaining eruipment required to support nuclear weapon logistics and operations; developing and maintaining capabilities for safe and secure transportation and storage of nuclear weapons; and supporting the dismantlement of nuclear weapons retired from the stockpile.

\section{Weapon Development}

In today's world environment, Sandia's principal thrusts in the weapon development program are to support the downsizing of the nuclear weapons stockpile; consure the continuing health of weapons remaining in stockpile; identify areas where surety improvements in the stockpile should be made: support the departments of Energy and Defense in incorporating surety improvements to the 
stockpile; and support 1 )ol ) requirements for improved operational capabilities when they aceur. Toensure that these thrusts are apprepriately addressed, the objectives of the weapons develepment program at Sindia for stewardship of the stockpile are as follows:

- Provide stockpile stewardship leadership in support of the departments of linergy and l nefense

- Ensurc that all programs and projects arecustomer-oriented

- Ensure that l )epartment of linergy resources are applied to explicit and anticipated I)( )l:/I)ol) recyuirements

- Assure maintenance of a credible nuclear weapons stockpile with a thrust of enhancing surety (safety, security, and control) and operational flexibility

- Support an expanded 1 )epartment of Energy role in the logistics and maintenance support of the stockpilc

- "upport dismantlement of nuclear weapons

- Maintain within Sandia a viable weapons component development capability (and supporting technologies) in order to ensure the continuing health of the stockpile and to support improvements, as repuired, to the stockpile

Nuclear weapon development at Sandia is carried out in close cooperation with L.os Alamos and Lawrence livermore national laboratories, which design the nuclear explosive subsystems. Sandia designs the remainder of the warhead or bomb and integrates the nuclear explosive subsystem with many Sandia-designed components to achieve the desired military capabilities.

Sandia interfaces closely with the I epartment of I efense in the critical area of weapon surety (salfety, command and control, and security). (component manufacture and weapon assembly are performed by other 1$)$ () E contractors using design definitions furnished by Sandia, Los Alamos, and Lawrence livermore.

Sandia's nuclear weapon responsibilities principally include the safing, arming, fuzing, and firing systems; use-control systems; external neutron initiation systems; gas transfer systems; delivery system interfaces; military liaison; stockpile support; and related testing and instrumentation. In addition, Sandia is responsible for ancillary equipment used worldwide by I ool ) to stpport nuclear weapons operations in the areas of use control, handling, shipping, storage, and maintenance.

Nuclear weapon development programs may be initiated to correct problems or make improvements to weapons in the stockpile or the ancillary equipment that supports weapons in the stockpile. New nuclear weapon systems are developed in response fo changing military reyuirements. Whether for existing weapons or new weapon developments, the Sandia, Los Alamos, and Lawrence livermore laboratories work on behalf of the l epartment of Energy in support of l Department of l )efense requirements. The laboratories work closely with Dol ) to understand their requirements for nuclear weapons and develop solutions. The reyuirements and needs are the basis for development activitics at Sandia.

The lefense Programs laboratorie's and production plants are responsible for the design, development, testing, certification, production, maintenance, stockpile surveillance, and retirement of the warheads and ancillary equipment provided to the Department of Defense by the Department of Energy. In addition, the laboratories and the production plants are responsible for providing the retrofit kits (components and materials) that are used by l)ol ) to upgrade the capability of weapons in stockpile. These life-cycle activities occur in seven phases:

- Phase 1 evaluates new concepts and advances in technology for possible application to nuclear weapons.

- Phase 2 involves a technical feasibility study examining the military recuirements and cost-effectiveness of a new weapon system. 
- Phase 2A is a detailed design and cost study for a selected system.

- Phase 3 commences when the Department of Defense or the Department of linergy decides to proceed with a weapon system. It involves the engineering development work for the life cycle of a nuclear weapon, induding overall design definition and component development.

- Phase 4 is production enginecring. 1)esign and manufacturing development are completed, and environmentally conscious manufacturing processes are established.

- Phase 5 begins with first production. These first units are rigorously checked in the laboratory and in the field. Ancillary equipment and manuals are completed.

- Phase 6 is quantity production of the weapon and maintenance of the weapon in the stockpile. Upgrades or modifications may be performed if required. Stockpile evaluation sampling and surveillance continue throughout stockpile life.

- Phase 7 retires the weapon from stockpile and reclaims nuclear material and reusable parts.

Sandia is involved in all of these phases of the life cycle of nuclear weapons. Applied research and development is the principal activity in Phases 1 through 4 and continues to support the stockpile activities of Phases 5 through 7 .

\section{Stockpile Evaluation, Maintenance, and Support}

Sandia supports the DOE Stockpile Evaluation program by conducting analyses and tests of weapons as they enter stockpile and by testing weapons withdrawn from the stockpile for evaluation. Results from the evaluation program clearly indicate that nuclear weapons do not wear out. Weapons do, however, age. When aging does occur in the stockpile, Sandia and the nuclear design laboratories take corrective action to ensure that performance and safety of the stockpile does not degrade. Corrective actions can take the form of changes during new weapon builds or retrofits to weapons in the stockpile.

The evaluation program has shown over the last four decades that serious defects in nuclear weapons have been relatively rare. As defects or problems are identified, changes are made to the weapons to fix the defects or problems and improve operations and maintenance. The Stockpile Evaluation Program at Sandia relies heavily on the basic skills recuired to develop nuclear weapons. Examples of these skills are materials science, electronic piece-part and subassembly design, electromechanical component design, structural design, applied mechanics analysis, and environmental testing.

During the last four decades, tens of thousands of weapons in the stockpile have been addressed by the evaluation program. Of those, approximately 13,5(0) have been tested. A total of 2,344 defects have been found during the program, a portion of which could be categorized into 252 actionable defect types. "Actionable" defects are those that impact reliability or safety and reguire corrective action. ( )verall, the stockpile evaluation program has indicated that stockpile reliability has been excellent for the last four decades.

An important thrust for this program in the future will be to refine the sampling and testing program to ensure that the reliability and surety of the stockpile are maintained at a high level as the stockpile is reduced in size.

Sandia provides the technical military manuals and training that enable the armed services to maintain the readiness of the stockpile at a high level while ensuring safety and control. Thaining is conducted at Sandia for military logistics specialists who, in turn, provide training to other military personnel. Sandia also provides on-site field training for the military in response to military needs and reepuirements. 
Most weapons require periodic maintenance, such as replacing limited-life components. Sandia supports this routine maintenance requirement through the training and technical manuals program and with field engineering staff as appropriate. When problems with nuclear weapons occur in the field, Sandia provides technical support to the military to resolve them. In most cases, problems are resolved in the field without having to return weapons to the DOE production complex.

\section{Retirement, Dismantlement, and Storage}

National policy and Department of Defense military requirements establish weapon retirements. With the dissolution of the Soviet Union and the signing of the STAR'l agreements, the size of the U.S. nuclear stockpile has been significantly reduced and will continue to be reduced. Many weapons are being retired, and ultimately more than 10,000 weapons will be dismantled by the I)( )E production complex during the next ten years. Dismantlement will be a major effort for the production complex. Sandia is providing significant support to DOE for this task.

Dismantlement begins when the military designates a weapon for retirement and ends when D) () has disposed of the weapon components,

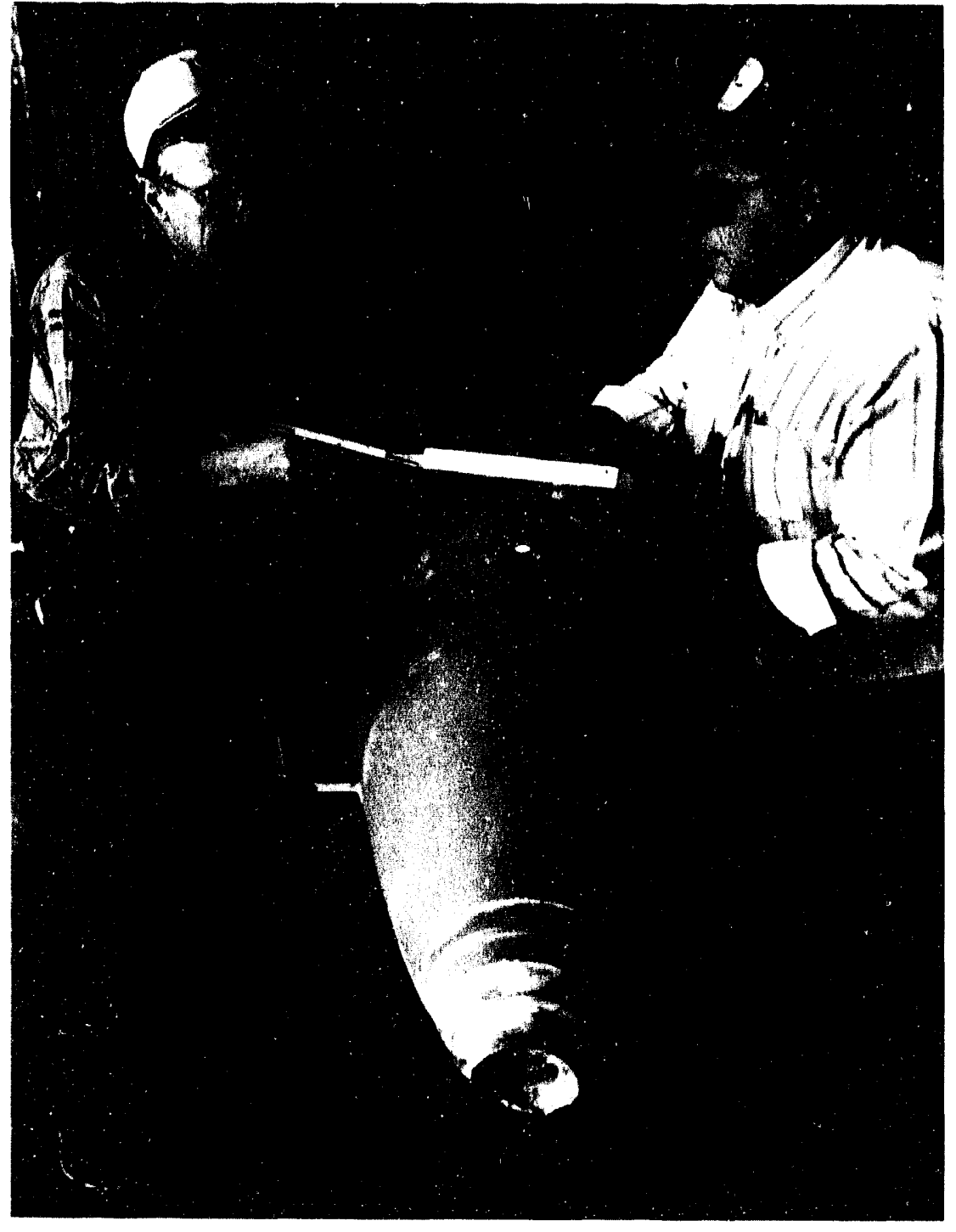

A denuclearized B83 gravity bomb is examined by Duane Smith and Roy Johnston after a stockpile surveillance flight test at Sandia's Tonopah Test Range.

trainers, handling equipment, and associated hardware. The procedure indudes transportation, storage, and disassembly into subsystems and components that are recycled, staged for reuse, or disposed.

Many issues must be addressed by Sandia in support of this dismantlement effort: Where and how will weapons be safely and securely stored while awaiting dismantlement? How will materials be safely and securcly transported? What are the best approaches for the safe dismantlement of large yuantities of weapons and disposal of weapon materials while ensuring the environmental safety and health of the work force, facilities, and the public?

Sandia conducts development programs to address such issues. These programs are coordinated by the DOE Albuquerque ( )perations ()ffice and with D()E:'s Pantex plant in Amarillo, Texals, to ensure that safe and efficient processes are developed.

Sandia is developing automated processes using robotics and computer modeling to support dismantlement. In particular, the Stage Right project is underway to establish feasibility of a robotic 
system for materials movement and inventorying. Stage Right woukd move, stack, and retrieve fissile pits from dismantled nuclear weapons. In addition, the system will have the capability to remotely inventory pits in storage. 'This system will permit higher pit storage densities in storage facilities while' climinating the requirement for persomnel to enter storage facilities for purposes of material handling and inventory operations. Thus, personnd can avoid exposure to radiation environments within pit storage facilities.

In addition, we conduct joint projects with $\left.D_{0}\right)$ ) to examine methods for disposing explosive and energetic components and materials and using robotics for disassembly and dissection of electronic components. Studies of automated hazardous material removal systems, robotic disassembly of explosive components, and arms control are also underway. The payoff from these projects could contribute to a modern, safe, and cost-effective dismantlement operation at Pantex with possible dual-use spin-ofts for U.S. industry.

\section{Studies, Engineering Development, and Technology Demonstrations}

\section{Studies}

Studies are underway to address improved nuclear weapon surety and to address improvements in military operational capability. Phase 1 concept studies and Phase 2 feasibility studies are normally joint I)( E/Lol) undertakings. Phase I studies can, however, be conducted by either the Department of Defense or the Department of Energy. A Phase 2 study may be requested by either the l department of Energy or Department of Defense. Each study normally involves the military services, the I)( )E: Deputy Assistant Secretary for Military Application, the I)( )E Albucuercue (Operations ()ffice, and the three nuclear weapon laboratories. 1)uring the study period, two competing design teams one Lawrence Livermore-Sandia/California and one Los Alamos-Sandia/New Mexico-consider a range of design options, emphasizing conformance to surety initiatives. The teams evaluate the tradeoffs among the physical, cost, and military characteristics of the proposed weapon as well as the environmental, manufacturing, assembly, and retirement requirements that would be imposed.

There are five Phase 1 studies currently in progress: a high-power radio frequency (HPRF) warhead; sea-launched ballistic missile warheads (Mark 4 and Mark 5); a precision low-yield warhead (PLYW1)); a B6I diameter bomb; and a cruise-missile-size warlead. The high-power radio frepuency warhead study for Dol) is currently in Phase 2 and emphasizes vulnerability and lethality studies and testing. The Air Force-sponsored precision low-yield warhead study is ongoing with completion anticipated for July 1993. The B6I diameter bomb and cruise-missile size warhead studies are both I)( )E:initiated for purposes of enhanced surety. A Phase 1 study has recently been completed for the Minuteman III warhead.

In addition, Sandia participates in informal, joint 1)oL/1)( )E nuclear weapon studies for weapon options that will be examined in the fy' 1993-98 time frame. Such studies include revolutionary improsements in surety, robust nuclear weapons, suitability of weapons in a decreased stockpile, hypersonic delivery, nonstrategic nuclear forces, and advanced technology warheads. Several prePhase 1 internal studies are in progress.

\section{Engineering Development}

A number of engineering development projects are underway in direct support of the weapons currently in the stockpile. The driving forces behind such projects are one or more of the following: surety "soft spots" (i.e., areas where safety and/or use control should be improved to be consistent with modern safety reguirements and evolving adversary (heats to weapons); reliability soft spots (i.c., areas where reliability reductions are cither identilied or anticipated); stockpile changes that reguire new approaches for ensuring continued support of I)( )I:'s Stockpile Lialuation Program (i.c., replacing flight instrumentation systems with those that can obtain the recuired flight lest (ata); components to support required future limited-life component change-outs; and replacement 
of use-control equipment that has either reached the end of its supportable life or has vulnerabilities that should be corrected. Examples of these projects are:

- Redesign of the 1353, W87, and W88 joint test assemblies to ensure continued support of stockpile evaluation flights

- Development and fabrication of limited-life components for weapons in the stockpile. Near-term needs are the $B 61$ parachute gas generator, W76 reservoir, and W76 and W78 neutron generators

- Reliability, safety and use-control factory upgrade for the B83

- Development of an encrypted recode permissive action link and secure inventory capability that can be incorporated in fielded weapons to improve security and operational Hexibility

- B61-3,4 field retrofit to incorporate a new safety device (trajectory sensing signal generator) and an encrypted recode permissive action link

- Development of secure recode systems' ancillary equipment for the U.S. military's Strategic, European, and Pacific commands

Several development initiatives are now under consideration or anticipated for which we expect requirements from DoD) and DOE. These initiatives cover all weapons in the enduring stockpile not now being addressed by engineering development projects and fall into the categories of improving safety and use control or improving stockpile reliability.

\section{Technology Demonstrations}

Development engineering for new weapons or for improvements to weapons in stockpile occurs in Phase 3. Currently, there are no Phase 3 projects in progress. During the FY 1994-99 time frame, we are planning for Phase 3 starts for systems with greatly enhanced surety features. We are preserving our essential development engineering competencies through internal programs in technology maturation and systems engineering.

For example, over three years ago Sandia established the Focal Point/STEP process for the maturation of components and subsystems for stockpile upgrades and for modular use in future weapon systems. The program was structured to respond to three predictions: (1) stictiy requirements will be upgraded; (2) fewer new weapon development programs will be introduced; and (3) future development budgets will be limited. In the face of these constraints, we needed a technology development process that would generate a variety of high-quality, state-of-the-art components that could be applied to specific weapon system programs with a minimum of development risk and cost.

The first level of this program, Focal Point, is advanced development in a system context. Focal Point evaluates new system architectures and components to meet long-term or emerging needs. It draws upon technologies with demonstrated feasibility and seeks to determine their suitability for weapon applications.

The second level, STEP (Stockpile Transition Enabling Program), selects from Focal Point outputs and advances them through full-scale engineering to production readiness. STEP demonstrates functionality and producibility with detailed designs and component testing. The development environment is not associated with a specific weapon system. Rather, it seeks to develop standardized, modular, advanced subsystems and components for multiple system applications.

The Focal Point and STEP programs precisely define the stages of component or subsystem development and impose formal milestone reviews to ensure that all components in development offer significant improvements in surety, reliability, waste minimization, environmentally conscious manufacturing, and cost. The reviews not only involve Sandia's designers and technical management, but also representatives from production agencies and DOE offices. Advanced components and subsystems resulting from the focal Point/STEP process are then available for system application if needed. 
MAST (Multiple Application Surety 'Technologies), a current warhead prototype system, uses improved surety components and subsysiems in a product realization process conducted with Phase-3 rigor. Product realization teams composed of laboratory design engineers and production plant manufacturing and process engineers exercise modern industrial techniques, such as concurrent engineering, computer-aided design and process tools, and environmentally conscious manufacturing to emulate production within targeted cost, schedule, and waste minimization parameters. This activity assures that the laboratory/production-agency interface remains intact and fully capable of supporting a quality weapon system production program.

The MAST program will advance critical nuclear weapon surety technologies and help assure nuclear weapon development and production competence in the absence of Department of Defense programs. It incorporates safety features as emphasized by the Drell Panel recommendations in a multiple application system. Possible applications include cruise missiles, standoff weapons, and single reentry vehicles, although the program is being conducted primarily in the context of a laydown bomb.

Similar to MAST, the PRESS (Pit Reuse for Enhanced Safety and Security) program is a technology demonstration that can provide near-term options to upgrade the surety of the nuclear weapons stockpile while maintaining capability at the weapons laboratories and the DOE production plants. PRESS is being developed for several applications, with current emphasis on a cruise missile warhead.

In PRESS A, DOE would select a small number of warhead designs to develop technology demonstrations similar to actual warhead developments but on a smaller scale. New technologies would be developed at the Defense Programs laboratories and incorporated into PRESS projects as they mature. These projects would cul:ninate in the fabrication of a few prototype weapon configurations that would be examined and disassembled. 'The results of this work would then be stored "on the shelf" so the designs could be put into production rapidly should the need arise. The emphasis is on establishing capability, not capacity, for mass production.

\section{Enhanced Surety}

Surety includes safety, use control, and security. Several developmental activities are underway that will support significant enhancements in surety for the extant nuclear weapons stockpile as well as provide for improved capabilities in new weapon developments that may be required in the future.

\section{Weapon Nuclear Safety}

Safety is of paramount importance in warhead development. The goal of safety design is to provide predictable, safe response at all times, even during and after exposure to unpredictable events such as accidents.

This goal is achieved through a combination of design features. The nuclear explosive, detonators, and other critical components of a warhead's electrical system are contained in an exclusion region isolated from power sources by protective physical barriers. The transfer of energy through the barriers for normal operation is controlled by "strong link" components to ensure electrical isolation in abnormal environments. Other vital components are designed as "weak links" that become irreversibly inoperable in accident environments at levels well below the projected failure levels for strong links.

Weapon safety is an increasingly critical area involving issues raised by House Armed Services Committee Panel on Nuclear Weapons Safety (the Drell Panel) in 1990. Concerns included transportation and handling, the logistics of retirement and dismantlement, and sensitivity to the environment, safety, and health.

Sandia has begun a major safety technology and engineering program to enhance demonstrable safety architectures for future nuclear weapons. The long-term goal is to bring new safety technology for warhead designs and components into weapon product lines, provide improved analytical tools for modeling weapon systems response in abnormal environments, and assess probabilistic risk. 
A project for improved electrical detonation safety will provide the technology to enhance electrical detonation safety products in support of future committed development programs and stockpile improvement programs. Improvements are focused on safety enhancements and manufacturability. Included in this activity is the development, demonstration, and evaluation of advanced electrical nuclear detonation safety (ENDS) systems. Improved exclusion-region barriers, weak links, strong links, environmental sensing devices (ESD)s), lightning-arrest connectors (LACs), and trajectory-sensing signal generators (TSSGs) are being developed.

In the future, significant improvement in nuclear safety will be realized if electrical firing sets can be replaced with optical subsystems in which the high-power signals required to initiate detonators are transmitted in the form of photonic energy carried by optical fibers, rather than as electrical energy. The weapon detonators are designed so that they will fire only when proper and sufficient photonic energy is applied. There will be no path to the detonators for electrical energy. The required photonic input does not occur in nature and thus cannot be created by an accident environment. As part of Sandia's Direct Optical Initiation project, a prototype optical firing system has recently been developed and is being used to determine operability in various weapon environments.

In a related area, we have recently completed exploratory development of Laser Diode lgnition technology, which uses low-power optical signals for controlling and initiating various weapon pyrotechnic functions. Through the use of optical fibers to transmit the ignition stimulus from the laser diode to the energetic material, concerns over electrostatic discharge, electromagnetic susceptibility, and conductance after fire are eliminated.

An improved Detonator Safety Strong Link is being tested to reduce potential lightning paths to the detonators and to reduce costs and improve manufacturability. In the next three years, improvement in the design of trajectory-sensing signal generators, advanced solenoid mechanisms, and mechanical weak links will be pursued. We anticipate continuous improvement on electrical nuclear detonation safety architectures.

Sandia's Probabilistic Risk Assessment (PRA) Technology Development project will improve probabilistic risk assessment of nuclear weapons subjected to abnormal environments. The ability to identify vulnerabilities in designs and set priorities in safety technology research and development will be improved by these methods. In the next three years, an initial methodology suitable for routine use in risk assessr ment of nucleat weapons subjected to abnormal environments will be completed.

\section{Use Control}

Weapon use control and physical security are complementary measures contributing to weapon surety. Weapon use-control features and use-control ancillary equipment support the national nuclear command and control system to ensure that nuclear weapons can only be used when authorized by the President. A number of projects are in place to support DoD and DOE consistent with the national : Vuclear Command and Control System as defined in the 1987 National Security Decision 'Directive signed by the President. Sandia is the principal laboratory supporting DOE in fulfilling these responsibilities.

Sandia pioneered the development of permissive action links (PALs) to provide use control. A permissive action link is a coded device within a weapon that protects against terrorists or persons with access authority but without command authority. Permissive action links were introduced in the early 1960s into U.S. nuclear weapons deployed overseas. Sandia is continuing to advance the design of permissive action link devices and use-control ancillary equipment to provide greater operational capability and flexibility as well as improved use control.

Sandia recently completed development of a new permissive-action-link coded switch that will support recode and verification operations with encrypted communications. This new device, the Code-Activated Processor (CAP), entered into production in 1989 and is now being incorporated into a surety upgrade in the 1383 bomb. The Code-Activated Processor will provide a significant 
improvement in code security for all permissive-action-link operations, will allow the military to conduct electronic inventory of nuclear weapons, and will significantly enhance operational command and control flexibility for military commanders and national decision authority.

Sandia is now developing a variant of the code-activated processor that can be incorporated into weapons in the stockpile that have an existing permissive-action-link coded switch. 'This new device, the Multiple-Code Coded Switch Encryption Translator (MET), can be incorporated into weapons with a field retrofit, resulting in significant savings as compared to returning the weapons to the $\mathrm{DOCE}$ production complex for factory modification. The CAP and MET cryptographic permissive-actionlink devices will enable the Department of Energy to meet Dol) requirements and statements of need for end-to-end encryption within those weapons that contain a permissive-action-link usecol trol capability.

Modern permissive-action-link coded switches are, in reality, made up of two components: an electronic component for code storage and processing (such as CAP and MET), and an electromechanical output device component. Development is underway to replace the current output device that has been in production for two decades. The new output device will be available to support surety improvements for weapons now in stockpile and for any new weapon developments that may be required.

Sandia is developing a Secure Recode System (use-control ancillary equipment) for the Strategic Command that will support encrypted recoding of weapons' permissive-action-link devices. 'This system will meet an Air Force requirement for a new secure permissive-action-link recode system. The new system will be delivered to the Air Force in late 1993.

In addition, an encrypted secure recode system is being developed to support all nonstrategic weapon recode operations. This new system, the Theater Secure Recode System, will provide the military with greater permissive-action-link code security and enhanced management flexibility and efficiency for the nuclear weapons stockpile and any future weapons deployments. This system will meet statements of need as identified by military commanders and high-level studies such as the DoD Fail-Safe Risk Reduction Study.

The most effective weapon use-control systems for protecting against unauthorized use are active protection systems. An active protection system consists of a system of sensors that detect unauthorized access to weapon components. When an unauthorized access is detected, the system automatically disables the weapon. The recently completed Fail-Safe and Risk Reduction Study recommended that weapon use control be improved. Efforts are underway for improving the effectiveness of active protection systems. Specifically, technologies are being developed to support the incorporation of this important capability into a wider range of weapons than has been possible in the past.

Nuclear command and control system architectures are under study in three separate but related projects. The first is characterizing and refining architectural elements to meet present, near-term, and future nuclear command and control requirements. The second project will develop and prototype advanced command and control elements in a nuclear command and control test bed. The third is the first application of the test bed and will develop and demonstrate remote, real-time permissive action link recode as well as remote, real-time inventory and command disablement.

In a broader command and control sense, Sandia provides support directly to D)(O) headquarters for command and control initiatives. In 1990, DOE published its Use Control Policy in response to the Nuclear Command and Control System Decision Directive 1987, which established national policy and government agency requirements. The DOE use control policy requires a system of integrated positive measures within DOE to ensure against unauthorized use of nuclear weapons in DOE custody.

Sandia, at the request of DOE, has established assessment teams with representaiion from Los Alamos and Lawrence Livermore national laboratories and DOE management for D()E facilities for which assessments are being conducted. An assessment was completed in 1992 for operations at the 
Neradal Test Site. This assessment wals conducted for and provided to the I)( )E Manager at the test site. An assessment is currently underway for the I)()L: Albuguerque ()perations ()ffice Transportation System.

\section{Weapon Security}

Weapon security encompasses those positive measures that protect against unauthorized access to nuclear weapons. Security systems include features such as sensors, alarms, communications, and penalty responses, as integrated into weapon transportation systems and weapon storage installations.

Sandia has systems under development for enhancing the security of weapons during transportation while they are in D(OE custody. One such project is the development of a replacement for 1)OE's Safe Secure l' railer that is used for transportation of weapons and weapon materials. Other work is developing advanced sensors, alarms, and communications that can be applied to DOE fixed installations or provided to the DoD on a reimbursable basis for military installations and deployable site security systems.

\section{Stockpile Improvement Programs}

Every year, the departments of Energy and I efense review the surety status of the stockpile to identify areas where improvements should be made. These reviews may result in stockpile improvement programs (SIPs) within DOE and, where applicable, Dol). In addition, areas of needed improvement are identified through the normal exercise of Sandia's stockpile stewardship responsibility. These areas of improvement can result in Sandia generating a product change proposal for a weapon in the stockpile. The product change proposal is coordinated with the DOE and Iol) and, if approved, results in a stockpile improvement program.

Tiwo stockpiled weapons are currently undergoing stockpile improvement programs. The 1883 bomb is being upgraded at Pantex for reliability, safety, and use control improvements. Development is underway for a new safety device (a Trajectory-Sensing Signal (ienerator) for the B61-3,4 bomb. The new safety device will be incorporated into the B61-3,4 stockpile weapons by a field retrofit starting in 1995. Plans are being finalized to also incorporate a cryptographic permissive-action-link capability during the safety retrofit as a use-control upgrade.

Future stockpile improvements will occur as needed to meet military requirements and address surety concerns.

\section{Stockpile Technology}

Nuclear weapons utilize a large number of electronic, mechanical, and electromechanical components. Most of these components are unique, in that their function or some significant aspect of their envirommental capability is not available from commercial sources. To maintain nuclear competence, it is necessary to support the capability to develop and maintain a set of essential core products.

Each core product has some unicue technology or property necessary for performing its function in a weapon. These products include explosive components and detonation systems, batteries, electromechanical components, microelectronics and optesectronic subsystems, neutron generators, switch tubes, reservoirs and valves, radars, and electrical interconnections.

Adranced electronic subsystems provide many of the modern surety features and functional control in nuclear weapons. U'se control is provided by miniature electronic locks buricd deep within the weapon and by sophisticated operator-interactive controllers used to manage and enter release codes to unlock the weapons under Presidential authorization. Trajectory-sensing electromechanical subsystems discriminate between the intended-use environment and abnormal environments and may produce unique signals for driving strong-link switches or otherwise permitting the final arming and firing of a weapon. The firing signals themselves are developed by etectronic firing sets. 
Embedded microcomputers control the various weapon components and the fuzing and other functional characteristics. In bombs and some warheads, fuzing may be done by timers or radars developed and manufactured by D()E. Finally, clectronic subsystems are used extensively in the evaluation of stockpiled and developmental weapons.

Arming, fuzing, and firing systems make use of a variety of weapon subsystems such as radars, programmers, firing sets, trajectory sensors, and contact fuzes. A need exists for continued fuzing advancements to meet the repuirements for versatility, reliability, and accuracy of a smaller stockpile. Advanced sensors and hardened guidance and control components will be needed to accurately navigate weapons that will locate and strike mobile targets and avoid countermeasures. Future development will focus on the full spectrum of potential missions in a changing world with deliberate attention to the role of commercial industry and technology transfer opportunities.

Sandia also develops and designs gas boosting systems for many of the nuclear weapon systems in stockpile. We expect the need for reservoir design and surveillance to persist so long as tritium reservoirs are in the stockpile. Consequently, we will continue to emphasize improving our understanding of metallurgical and fabrication topics for reservoir components, especially degradation associated with prolonged tritium exposure.

More work needs to be done to determine performance criteria in the areas of design and production, as well as the chemistry and physics associated with the aging of metals and alloys. These efforts will advance our understanding of the major fabrication processes, metal joining (welding), and forging. This understanding will facilitate the selection of commercial suppliers, reduce reliance on long-time aging tests to certify new vendors, and increase stockpile surety.

The current weapon component development process will be strengthened in two ways. First, applied research and advanced development will be focused on technologies critical to meeting weapons program priorities, for example, surety. Ongoing and new projects with the focal Point and surety technology programs will help focus resources on critical technologies and system architectures that address multiple nuclear weapon needs. Second, we will strive for greater continuity in the spectrum of products developed. "Product lines" will increasingly consist of standard and modular components. The goal is for more rapid and flexible response to new weapon system needs, reduced weapon development and production cost and risk, and more privatization and consolidation throughout the complex.

\section{Special Projects (GB010304)}

\section{Weapon Protection Projects}

Special weapon protection projects at Sandia develop security system concepts and applications to assure future nuclear weapon security and survivability in all phases of the life cycle. In response to the drastic changes in the nuclear mission of the Air Force (personnel and aircraft reductions, combined nuclear and conventional mission, and elimination of alert operations), a conceptual underground storage loading and handling facility for strategic aircraft has been developed. 'The Integrated Nuclear Operations Facility concept integrates technology developed for the Weapon Storage and Security System (WS3) vault with airc'.'ft operations. The need for rapidly deployable, high-security protection of valuable assets was evident during Desert Shield. The Rapid Deployment Access Delay System has been developed to provide a modular vault that can be constructed in the field using manpower alone. The closed WS3 provides high-level security; however, when the vault is opened for required inventory, security becomes manpower-intensive and safety is reduced by exposing the weapon. The Video Radiation Inventory System is being developed to provide remote inventory of weapons in closed vaults. Given the likelihood that the dismantlement process will be accelerated, we are placing special emphasis on protection of nuclear assets in activities such as transportation, staging, disassembly, and storage. 


\section{Foreign Technology Assessments}

Sandia has for many years applied its nuclear ordnance engineering expertise to the analysis of foreign weapon systems. The current world environment is providing us with the opportunity to significantly increase the nation's understanding of systems and technologies of particular significance to our efforts in dealing with proliferant countries. While we have focused our activities in areas that reflect Sandia's nuclear weapon development responsibilities, we are evaluating systems parameters such as warhead and propulsion system performance of conventional weaponry. This effort continues to provide an expand:. o understanding of systems of concern, and it permits us to estimate the technological threat posed by systems under development. A detailed understanding of forcign technology threats will allow development of effective countermeasures by applying technology developed for nuclear weapons to conventional weapons.

\section{Cooperative Projects with the Former Soviet Union}

Cooperative measures with Russia and other independent states of the former Sovier Union have been encouraged by U.S. policy. Sandia is involved with projects to support safety, security, and dismantlement of Russian nuclear weapons and to engage former weapon scientists in peaceful endeavors.

We are involved in six agreements with Russia for the safety, security, and dismantlement of nuclear weapons. We are designing and will procure modification kits to improve the safety and security of 115 Russian rail cars intended to transport nuclear weapons for dismantlement. Sandia has been assigned design and quality-assurance responsibility for up to 45,000 containers for safe and secure storage of fissile material from dismantled Russian nuclear weapons. The Laboratories also provides assistance to the Russians in the security and materials-handling aspects of the design of an underground storage facility for these containers after they are loaded with fissile material.

We are also providing emergency response equipment, originally designed for U.S. use, to Russia. Sandia designed and is assisting the U.S. Defense Nuclear Agency in the procurement of 2,500 flexible armor blankets for protecting material or weapons being moved for dismantlement. We also provide technical assistance to a project assisting Russia with the development of a national control and accountability system for nuclear materials.

Collaboration with Russian weapons 'istitutes and other entities in the former Soviet Union is being pursued to obtain unique technologies for our programs and technology transfer. This goal is consistent with the national goal of providing weapon scientists and engineers of the former Soviet Union with opportunities to redirect their talents to peaceful activities. Collaborations have been initiated in environmental sciences, computational sciences, pulsed power, space power systems testing and development, specialty metals research and development, shock-wave physics research and testing, and materials sciences. We are also exploring collaborations in research, development, and

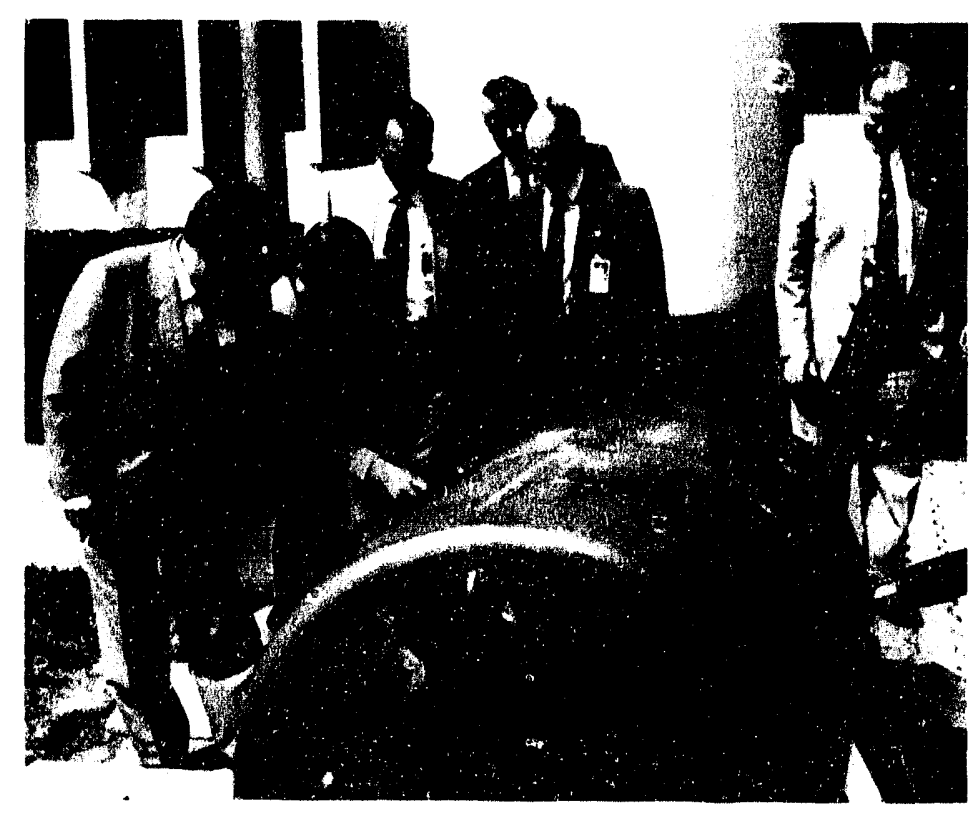

Three leaders of Russian nuclear weapon laboratories visited Sandia/California in May 1993 for discussions on possible areas of collaboration. Examining one of Sandia's hardened accident-resistant containers designed for safely transporting nuclear weapons are (from the left): Yuri Trutnev, deputy scientific director for Arazmus; Vladimir Mordvintsev, representing the Committee of International Relations at MINATOM, Moscow; Sandians Rob Rinne and Jim Wright; Evgeny Avrorin, chief scientist at Chelyabinsk; and Sandia vice president John Crawford. 
testing of reactor-driven lasers, nuclear propulsion, and nuclear power safety technicunes and technologies.

Most of these collaborations have been initiated sine the break-up of the former Soviet Union, when new U.S. policies were developed to encourage cooperation with the newly-independent states to support democracy and shift their focus from the military to the civilian economy. As we continue our interactions with entities in the former Soviet Union, we will identify new areas of joint interest in science and technology, and our collaborative efforts to exploit these new areas for mutual benctit will grow.

\section{Transportation Surety}

The Department of Energy's 'Transportation Safeguards I Division is responsible for the safe, secure transport of all DOE-owned nuclear weapons and nuclear-weapon-related special nuclear material within the continental United States. As the original design agency for much of the equipment currently in service, Sandia provides the Transportation Safeguards Division with day-to-day operational engineering support for all major elements of the system, including safe secure trailers, armored tractors, the mobile communications system, and the secure communications command/ control center. Sandia is also responsible for the design, prototyping, fabrication, testing, validation, and subsequent implementation of all upgrades associated with these subsystems. In addition, we provide the Transportation Safeguards Division with analytical support for long-range planning, security analysis, and probabilistic risk assessment; fleet maintenance support; and support for small-quantity production runs.

\section{Accident Response Readiness}

Jandia provides technical support to DOE for its mission of developing and maintaining readiness to respond to accidents involving nuclear weapons. Sandia participates in the readiness mission carried out by the DOE Accident Response Group. The primary support provided by Sandia in the event of an accident is the ready availability of nuclear weapon, nuclear weapon safety, and health physics experts, all of whom are specially trained to support field efforts for the safe recovery of damaged nuclear weapons. Sandia also provides specialty equipment for use in these endeavors.

In supporting the Accident Response Group in maintenance of a readiness capability, Sandia assists in the development and presentation of training for its members, the development of field equipment for use in weapon recovery operations, systems program planning, the planning and implementation of field exercises, and the nuclear safety evaluation of specialized equipment and procedures.

We are actively developing systems using proven, modern methodologies and technologies to provide greater operational flexibility, safety, and training and exercises that are comprehensive and cost-efficient. One near-term example is development of a field system known as the Portable Integrated Video System, which provides remote observation and recording from a command post several kilometers away. Longer-term activity is to incorporate this kind of technology into an integrated, interactive multimedia training system. This capability would allow for visual simulation of weapon accident exercise scenarios that incorporate multiple recovery activities and allow exercise simulation training for all personnel. In addition, remotely controllable robotic technology is being adapted to systems for access and observation to reduce the personnel hazard of recovery operations.

\section{Radiological Assistance Program}

The Radiological Assistance Program (RAP) at Sandia maintains the capability to respond to on-site and off-site radiological emergencies as part of the 1 )OE Region 4 Radiological Assistance Program. The DOE Region 4 is applicable to the states of Arizona, Kansas, New Mexico, Oklahoma, and Texas as well as the Waste Isolation Pilot Plant transportation corridor. The Sandia RAP would respond, if called to do so, to any radiological emergency in any D()E region regardless of the magnitude of the 
emergency. RAP would respond to tramsportation accidents or nudear power plant energencies, and in the event of a nuclear weapon accident or incident where the 1) () ) : Accident Response ( Froup woukd be deployed, they would provide support to help mitigate any radiological hasard associated with the emergency. RAP also provides support to the 1 ) () A Acident Response (iroup training and exercise programs.

\section{Extraordinary Envirunment, Safety, and Health Activities}

In the area of "extraordinary ES\&H (Enviromment, Safety, and Health) activities," one-time corrective actions to sites and facilities are undertaken to correct ES\&H problems associated with past prograns funded by Defense Programs to bring them into compliance with current ES\&H standards. 'These' corrective actions do not meet the funding criteria for these funded by the Assistant Secretary of Environmental Restoration and Waste Management. Rather, they are the responsibility of the Deputy Assistant Secretary for Military Application. Included herein are itens such as identification of deficiencies, establishment of initial Quality Assurance, audit, and programs to measure and assure that corrective actions meet requirements. Examples of recent activities include asbestos abatement, installation of fire protection systems, monitoring of vells in remote sites to determine damage done by septic tanks, removal of inactive underground oil storage tanks, decontamination of buildings scheduled for decommissioning, and dean-up of former waste sites.

\section{Consolidation of Tritium Activities}

In order to alleviate concerns over local environmental issues and at the same time reduce long-term cost to the nuclear weapons program, we will support the centralization of tritium-related research and development activities at other $\mathrm{DOE}$ facilities by decommissioning the Tritium Research Laboratory at Sandia/California and performing the work necessary to move it from the present low hazard (Category III) nonreactor status to a nonnuclear status. This work includes maintaining the $\mathrm{D})(\mathrm{)E}$ Defense Programs mission capability, reducing the accountable tritium to zero, relocation active experiments to other DOE facilities, reallocating excess equipment, and planning and documenting all cleanup and transition activities. Normal operations will be maintained until the tritium mission is ended by the $\mathrm{DCE}$.

\section{Education Outreach}

The education activities supported in this budget category are covered in the section for the "Office of Science Education and Technical Information" on page 7-80.

\section{Nuclear Emergency Search Team (GB010305)}

The Sandia Nuclear Emergency Search Team effort has historically been focused primarily on mitigation of radioactive aerosols generated during violent disablement of improvised nuclear devices, predicting the consequences of such dispersals, devising methods of rendering improvised nuclear devices safe, and developing field-portable methods of determining the type of explosive in such a device.

More recently, Sandia has been assigned the responsibility to develop a program to provide training for all people involved in a Nuclear Emergency Search Team field response and in assuring that these people are knowledgeable in their responsibilities and duties. A considerable portion of the effort in the past year has been dedicated to getting this training program started.

World events have exacerbated nuclear terrorism concerns, and the budgetary requirements package for future 'years identifies a need for additional funding and delineates the expansion of the Nuclear Emergency Search Team effort that would occur if this increased funding occurs. 


\section{Test and Experimental Capabilities (GB0104)}

Sandia is the lead 1$)($ ) E laboratory for aboveground test simulation of radiation effects and cortification of nuclear weapons to operate reliably in hostile radiation environments. We integrate experimentation and computational simulation in support of radiation effects testing, radiation transport, diagnostics, analysis, and computation development to certify electronic components to operate in hostile radiation environments.

As a consecuence of recent budget cuts in the lest program, support of the core capabilities at the Nevada Test Site has necessarily been reduced. The reduced capabilities maintain Nuclear l'esting Safeguards consistent with $\mathrm{D}$ )()E directives and the continuation of the testing moratorium announced by President Clinton. Sandia will support the Los Alamos and Lawrence livermore hydrodynamic experiments and will maintain the capability to resume underground nuclear test ing in eighteen months if directed.

looking to the future, Sandia is consciously shifting resources from underground nuclear testing to aboveground simulation. With the permanent loss of underground testing in ( october 1996, Sandia's aboveground capability will be the strong link in ensuring that the enduring stockpile remains survivable. As such, every effort is being made to enhance the aboveground testing program and to collaborate with the key agency within the 1 ) ol) (the Defense Nuclear Agency) that has similar mission requirements.

\section{Test Simulation and Aboveground Experiments}

Sandia's radiation effects testing program certifies that weapon components and subsystems will function reliably in the hostile nuclear burst environments that may be encountered in its specified stockpile-to-target sequence. These threats include the nuclear radiation outputs of $x$-rays, gamma rays, and neutrons. Formerly, we employed a combination of aboveground testing, analysis, and underground testing for this development and certification process.

A recent presidential directive extends the moratorium on underground nuclear testing. However, stockpile improvement programs, including upgrades in safety and reliability, will need to be certified to operate in hostile radiation environments. Moreover, it is extremely important that single-mode failures be avoided in the much smaller stockpile of the future.

Sandia's radiation facilities are recognized as national resources for high-fidelity simulation of nuclear weapon effects. (our aboveground experimental facilities, the Saturn and HERMES III accelerators and the SPR-III and Annular Core Research reactors, are primarily used to simulate $x$-ray, gamma ray, and neutron environments. Saturn and HERMES III are pulsed power machines that generate low or high voltage bremsstrahlung, electron beams, or radiation from plasma sources, and are used to simulate the $x$-ray and gamma ray portions of conventional nuclear weapon threats. We test strategic reentry vehicles, missile and satellite components and subsystems, and tactical subsystems and systems in these simulated $x$-ray and gamma ray environments.

The Annular Core Research Reactor is a pool-type reactor with an annular-shaped core formed around the dry, central irradiation cavity. The spectrum and timing of the reactor is representative of most endoatmospheric engagements. The reactor is also used to simulate high-level gamma environments. It is the only facility in the United States capable of properly simulating a fireball fly-through for total dose. 'The SPR-III fast pulse reactor is an unmoderated cylindrical assembly of fully enriched uranium alloyed with 10 percent molybdenum. These facilities are major, unicue aboveground experimental capabilities and are used to test the hardness of the stockpile.

We are not, however, able to certify future or reconfigured strategic systems without underground tests. In 1991, we began a program in cooperation with the Defense Nuclear Agency to assess our ability to correlate aboveground and underground test results for electronic systems and extrapolate them to realistic hostile environments. The goal of this work is to develop a test protocol for certilying nuclear survivability without underground testing. 
To reach this goal, we will need to improve our aboveground testing cappabilities, including rise time, pulse width, and Huence in Saturn and IIERMES III, and build a new x-ray simulation facility to cover testing that now can only be condected underground. This new facility, Jupiter, will be a cold and warm $x$-ray source that would permit testing of materials and structures currently possible only with underground testing.

The Jupiter $x$-ray simulation facility will generate 20 megajoules of $x$-rays using a plasma radiation source. The plasma radiation source will be controlled to provide excellent testing capability at 8 thousand electron volts and below, and good capability at 14 thousand electron volts. It will also have weapons physics research applications, $x$-raly physics testing with 5-20) megajoules of thermal $x$-rays, and will provide the next reasonable developmental step toward an $x$-ray source capalle of testing large systems. Materials survivability testing in hostile $x$-ray environments is an area that has only been approached in a underground testing. Jupiter is key to future evaluation of materials in $x$-ray environments under a test moratorium.

Even with these improvements in our aboveground testing capabilities, testing for thermonuclear weapon effects in full reentry vehicle or reentry body structures could not be accomplished. Nevertheless, by enhancing our aboveground testing capabilities and constructing the lupiter aboveground testing facility we believe that we can certify weapon nonnuclear subsystems without underground testing.

\section{Nevada Test Site Core Capabilities}

Sandia maintains underground testing core capabilities in support of both weapons safety and reliability tests and $\mathrm{D}$ ol)-sponsored weapon-effects reliability tests. Since a moratorium will continuce to be in effect indefinitely, these core capabilities are being maintained to support the Nuclear Testing Safeguards sanctioned by Congress. These safeguards require that DOE maintain the scientific resources and technical capabilities to resume underground tests if directed. Test capabilities will be kept in a state of readiness consistent with Nuclear Testing Safeguard requirements to support hydrodynamic experiments and resume underground nuclear testing in eighteen months.

The principle core capability supporting the Nevada Test Site is in the arming and firing systems used in every test. These systems for DOE safety or reliability tests, including complex multiples, are provided and fielded by Sandia. Additionally, the arming and firing systems for Dol)-sponsored reliability tests, including integration with the closure systems and experimenter firing and timing requirements, are also provided and fielded by Sandia In each case, an inventory of the required electronics, power supplies, supporting hardware, and limited-life components is maintained to ensure that all planned tests are fully supported and may be executed without delay.

The core capability to design, fabricate, and field closures for the Dol)-sponsored tests is now being jointly supported by the Defense Nuclear Agency and Sandia. This capability is critical, both to protect effects experiments and to ensure that containment is successful.

The core capability for ground motion and seismic measurements on all DOE and DNA (Defense Nuclear Agency) tests is maintained by Sandia. Additionally, DNA and Sandia jointly support containment diagnostics, developed and fielded by Sandia, for DNA weapon effects tests involving horizontal line-of-sight pipe flow measurements, stemming response, fast closure performance, ground shock, air blast, cratering, and free-field ground shock measurements.

\section{Laboratory Underground Test Core Capabilities}

Rounding out the core capabilities at the Nevada Test Site that are critical to performing underground testing is the instrumentation group. The Sandia Data Acquisition System and its supporting personnel ensure the execution of any Defense Nuclear Agency-sponsored effects test. We are currently implementing a nuclear effects safeguards program to make repairs and improvements that can enhance quality, maximize efficiencies, and improve system performance, while minimizing the impact on costs, staffing, and schedule. 


\section{Stockpile Stewardship Support}

The aboveground and underground testing capabilities at Sindia are utilized extensively in the developmental phases of every nuclear weapons system in the stockpile to build-in hardness and survivability. Once systems are in the stockpile, they are subject to a detailed surveillance program that has historically identified a number of new problems cach year that must be corrected. When the corrective action reguires replacement of a component within a system, then that compenent is certified to the integrated hardness level required for the system, primarily using Sandia's aboveground testing capabilities.

In the future, with a significantly smaller stockpile, the survivability of each system will be even more critical. Therefore, maintenance actions will be dependent on the aboveground testing capabilities at Sandia to ensure that the stockpile remains hard and survivable.

Additionally, a prudent program being examined is a periodic verification of the certified radiation hardness of stockpiled systems. Such a program was sponsored for earlier systems, the Mark 3 and Mark 4, and ensured that they would operate as recuired. Knowing that the stockpile life span of a weapon system will be much greater than the current twenty-year average places additional responsibility on surveillance to ensure that no "surprises" develop that are not obvious with current nonradiation testing.

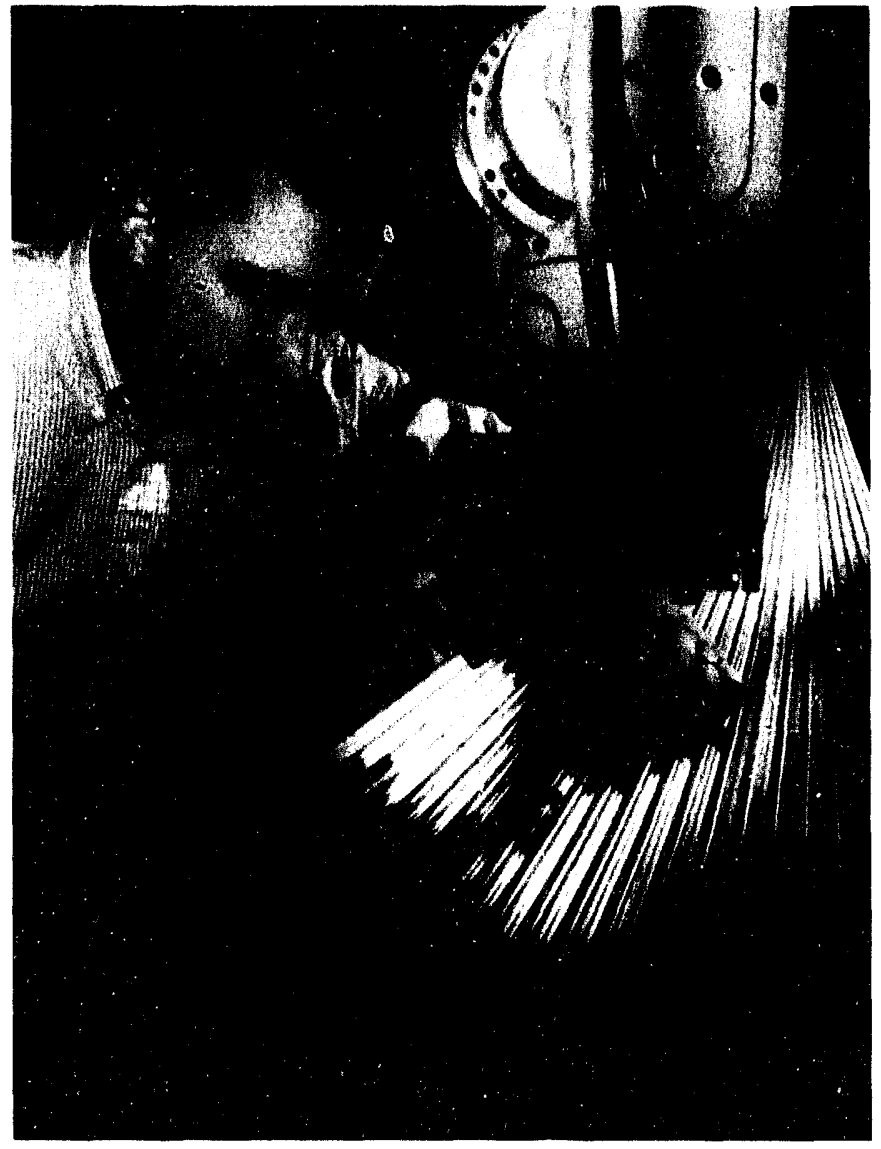

Jim Novak adjusts a Sandia-developed sensor system that will speed the brazing of tubes for a rocket engine thrust chamber and save material costs. This process technology developed in the nuclear weapons program is being transferred to industry.

\section{Technology Transfer Initiative (GB0106)}

Technology transfer is a congressionally mandated mission of the DOE national laboratories. The Defense P'rograms Technology Transfer Initiative carries out this mandate by sponsoring the transfer of technologies, skills, and know-how between the D) ()E nuclear weapons complex and the private sector. The goal is to make certain nonnuclear technologies available to U.S. private industries in a manner that will help strengthen the core competencies of D) OE Defense Programs and enhance the competitiveness of U.S. industry. The initiative supports Sandia's participation in cooperative research and developmerit igreements with individual companies and other cost-shared collaborative projects involving entire industries. There are currently five major areas of focus.

\section{Advanced Manufacturing and Precision Engineering}

Sandia's mission of implementing the nation's nuclear weapon policies involves research, development, and testing related to nuclear weapons, arms control, and weapon surety. Sandia works closely with production plants during and after development to ensure that designs will be manufactured cost-effectively and that products will meet design intent.

As a result of this work, Sandia has developed a suite of manufacturing capabilities that allow it to respond to a variety of national needs. Cooperative research and development agreements in the area of 
advanced manufacturing and precision enginecring focus on manufacturing systems design and development, manufacturing processes, computer-integrated manuficturing, machine tool design, precision measurements, precision engineering, and instrumentation and sensing. Critical industries targeted for FY 1994 include automotive, acrospace, machine tools and machine tool utilization, and lithography and lithographic equipment for both semiconductor and that-panel display manufacturing.

Several companies are already working with Sandia on specific projects in the'se areas, as shown in the table.

Technology Transfer Initiative Participants in Advanced Manufacturing and Precision Engineering

$\quad$ Company
Amax Plating, Inc.
AT\&T
City of Albuquerque
Cray Research
Digital Instruments
General Motors
General Motors
Kaehr Plating \& Metal Finishing
Pratt \& Whitney
Pratt \& Whitney
Precision Fabrics Group, Inc.
Rocketdyne
University of New Mexico

Technology

Electropidting process control Noncontact atomic level interface force microscope Volatile organic monitor for industrial effluents Environmentally safe manufacturing of printed wiring boards Noncontact atomic level interface force microscope Knowledge-based system for materials selection Simulation \& analysis of robotic assembly devices \& fixtures Electroplating process control Automated surface and edge finishing Intelligent processing of thin-section welded assemblies Lightweight safety restraint Intelligent processes for welding, machining, and assembly Noncontact atomic level interface microscope

\section{High-Performance Computing and Applications}

Sandia's computational science research is aimed at developing massively parallel computing methods and a software infrastructure for parallel computing. Advanced computing technologies will play a critical role in the future of U.S. national defense and economic security. Cooperative research and development agreements in this area focus on high-performance computing and networking, simulation and modeling, pattern recognition and image analysis, and high-density data storage and transmission.

\begin{tabular}{|ll|}
\hline \multicolumn{2}{|c|}{ Technology Transfer Initiative Participants in High-Performance Computing and Applications } \\
\multicolumn{1}{c|}{ Company } & \multicolumn{1}{c|}{ Technology } \\
Amoco 0il Company & Simulation of residual oil hydroprocess units \\
AT\&T & Experimental high-speed network test bed \\
BIOSYM Technologies & Mathematical libraries for modeling materials \\
BIOSYM Technologies & Molecular design of polymer alloys \\
Fluid Dynamics International & Sandia mesh-generation computer software \\
Ford Motor Company & Sandia mesh-generation computer software \\
MacNeal-Schwendler Corp. & Sandia mesh-generation computer software \\
PDA Engineering & Sandia mesh-generation computer software \\
Photonics Imaging & Plasma flat-panel video monitors \\
\hline
\end{tabular}




\section{Energy and Environment}

Sandia implements the National Energy Strategy by researching and developing concepts for increasing efficiency in energy utilization, storage, and transmission and by ensuring future energy supplies through improved recovery techniques, conversion technologies, and the development of alternative energy sources. Sandia has developed extensive ties with industry and universities in this work. Cooperative research and development agreements in these areas sponsored by the Defense Programs Technology Transfer Initiative involve environmentally conscious manufacturing technologies that minimize the generation of wastes at the source, systems integration technologies (including life-cycle design, materials recycling, and value-impact assessments), environmental characterizations and monitoring instrumentation, nonintrusive diagnostics and controls, energy conservation, and emission control technologies.

\begin{tabular}{|ll|}
\hline \multicolumn{1}{c}{ Technology Transfer Initiative Participants in Energy and Environment } \\
\hline Company & \multicolumn{1}{c|}{ Technology } \\
$\begin{array}{l}\text { General Motors } \\
\text { General Motors } \\
\text { RIMtech }\end{array}$ & $\begin{array}{l}\text { Reduction of nitrogen oxide emissions } \\
\end{array}$ \\
\hline
\end{tabular}

\section{Materials and Processes for Manufacturing}

Cooperative research and development agreements in the area of materials and processes for manufacturing focus on the development of new materials and material processing techniques, as well as the characterization and certification of advanced materials. Some projects involve the development of materials and processes used in the manufacture of aircraft engines and the application of Defense Programs joining technology to aerospace and aircraft industry needs.

\begin{tabular}{|ll|}
\hline \multicolumn{1}{|c|}{ Technology Transfer Initiative Participants in Materials and Processes for Manufacturing } \\
\multicolumn{1}{|c|}{ Company } & \multicolumn{1}{c|}{ Technology } \\
Aluminum Company of America & Processing of aluminum alloys \\
Amoco Chemical Co. & Polymeric non-linear optical meters and devices \\
AT\&T & Gold-sulfite electroplating \\
Carpenter Technology & Joining technology for borated stainless steel \\
Dow Corning Corp. & Micro-engineered materials \\
Dupont & Diamond reinforced composites \\
GE Superabrasives & Synthetic diamond substrates \\
General Motors & High-temperature electronics \\
General Motors & Intelligent systems for induction hardening processes \\
General Motors & Light-weight material for automotive applications \\
General Motors & Thermal spray technology for cylinder bore coatings \\
GeoCenters & Intelligent sensors for composite materials manufacturing \\
Natl. Center for Manufacturing Sciences & Prediction models for distortion \\
Natl. Center for Manufacturing Sciences & Wiring board interconnect systems \\
Norton Co. & Large area polycrystalline diamond substrates \\
Permacharge & Microcellular foam filtration media \\
TN Technologies & Mercuric iodide sensor technology \\
Xsirius Inc. & Mercuric iodide sensor technology \\
\hline
\end{tabular}




\section{Microelectronics and Photonics}

Because microelectronics is critical to the development of components for nuclear weapons, Sandia conducts research to understand the fundamental electrical, mechanical, magnetic, and structural properties of electronic materials and explores new techniques for fabricating and selectively altering thin-film layers, surfaces, and surface regions to aid in controlling the properties of microdevices. We also pursue research and development in compound semiconductors such as gallium arsenide and indium arsenide, materials that will play a greater role in future weapon systems for improved safety and use control.

\begin{tabular}{|ll|}
\hline \multicolumn{1}{|c|}{ Technology Transfer Initiative Participants in Microelectronics and Photonics } \\
\multicolumn{1}{|c|}{ Company } & \\
\hline & \\
Advanced Micro Devices & Technology \\
Alpha Industries & New integrated circuit manufacturing technologies \\
Analog Devices & Manufacturing of monolithic microwave memories \\
AT\&T & Microelectronics quality reliability center \\
Charles Evans \& Associates & Projection x-ray lithography using a laser plasma source \\
Conductus & Advanced detector for light element profiling \\
Hewlett Packard & Confocal resonator imaging systems for surface assembly \\
Hewlett Packard & Advanced manufacturing techniques for optoelectronics \\
Hewlett Packard & Field emission source with phosphor screen \\
Hewlett Packard & Properties of visible light-emitting diodes \\
J.W. Harley & Wafer-level accelerated reliability testing software \\
LAM Research Corp. & Fiber optic hydrogen sensing \\
LSI Logic & Advanced intermetal dielectric technology \\
Microelectronics \& Computer Technology & Development of failure analysis for integrated circuits \\
National Semiconductor & Field-emission flat-panel display \\
Radiant Technologies & Characterization of silicon gate oxides \\
Radiant Technologies & Ferroelectric read/write optical disc \\
Schlumberger Technologies & Nondestructive readout nonvolatile memories \\
Schumacher Inc. & Failure analysis system for integrated circuits \\
SEMATECH & Chemical vapor deposition of copper \\
SEMATECH & Benchmarking microelectronics and manufacturing equipment \\
SEMATECH & Contamination-free semiconductor manufacturing \\
Signetics & Semiconductor equipment reliability, modeling, and design \\
Texas Instruments & Characterization of failure analysis for integrated circuits \\
Texas Instruments & Chemical vapor deposition of copper \\
Thunder Scientific & Semiconductor plasma processing \\
University of New Mexico & Fabrication of porous silicon humidity sensors \\
Watkins-Johnson & Fabrication of microreactors in silicon \\
& Chemical vapor deposition of copper \\
\hline
\end{tabular}

A competitive domestic microelectronics industry is vital not only to U.S. national security but to the U.S. economy in the broadest sense. A major concern is the length of time required to effectively translate research developments into manufacturing advantages. Sandia is involved in numerous cooperative research and development agreements to speed up this process.

In addition to conperative research and development agreements involving individual companies, Sandia's work under the Defense Programs Technology Transfer Initiative also supports cost-shared collaborations that involve large segments of specific industries or consortia. Three examples of such collaborations include: 
Specialty Metals Processing Consortium - The primary goal of the Specialty Metals Processing Consortium is to conduct research that will improve the technology base for melting processes used in the specialty metals industry. The purposes of this research are to assist the U.S. specialty metals industry and to strengthen the nation's industrial base. The program will support Sandia's participation in a joint, five-year program with industry and universities. An interdisciplinary team comprising Sandia experts, industrial interns and students, will study generic problems of melting processes such as vacuum arc remelting, electroslag remelting, and electron beam melting. Developments will be evaluated with industrial experiments at consortium member plants.

FASTCAST $^{\text {TM }}$ - FASTCAST ${ }^{\text {MM }}$ is a Sandia program to rapidly produce investment cast prototype hardware. The program is structured to support Sandia organizations that design and fabricate hardware for internal and external customers. The technical goal of the program is to integrate experimental and computational technologies into the investment casting process. The effort should reduce the time required tu produce prototypical castings from fourteen weeks to possibly three weeks. The work involves developing the experimental rules to design gating systems, integrating those rules into a database, verifying computer models to predict casting processes, and developing a database of material properties as they relate to investinent casting.

Sandia capabilities in investment casting include an airfoil-quality ceramics laboratory for mold preparation, a rapid prototyping laboratory for wax pattern production, a vacuum foundry, extensive diagnostic and computational capabilities, and state-of-the-art materials research facilities. Over the past three years, Sandia has integrated these technologies into a comprehensive base to support investment casting process research.

Semiconductor Equipment Technology Center - Sandia's Semiconductor Equipment Technology Center (SFTEC) applies research in reliability modeling and process technology to the development of new integrated circuit production equipment by U.S. manufacturers. The objective of this microelectronics technology and benchmarking project is to strengthen the infrastructure of the semiconductor manufacturing industry. The work is in collaboration with SEMATECH, a consortium involving the federal government and major U.S. semiconductor manufacturers.

\section{Inertial Confinement Fusion (GBO2)}

Funding for inertial confinement fusion has provided the principal pulsed-power technology and facilities for our exploration of inertial fusion as a future $x$-ray source for nuclear weapon effects testing, weapon physics studies (in collaboration with Los Alamos and Lawrence livermore national laboratories), and fusion power production.

The low cost and high efficiency of the pulsed-power approach to inertial fusion have permitted unique megajoule-class facilities to be constructed and utilized for inertial confinement fusion research. Two of these facilities, the Particle Beam Fusion Accelerator I (PBFA I) and Proto II, have fulfilled their original research purposes and have been converted into new machines, Saturn and Proto II - major national facilities for nuclear weapon effects simulation, $\mathrm{x}$-ray atomic physics research, radiation flow research, and survivability testing.

Pulsed power is a core competency of Sandia. Applications contribute to national security today as we develop the pulsed-power-driven light-ion approach to inertial confinement fusion for even greater utility. The lower cost per unit energy of light ion beams, as compared to lasers, offers potential savings for the Laboratory Microfusion Facility (LMF), a future aboveground testing facility that will provide a thermonuclear yield exceeding 500 million joules. The fundamentally different $x$-ray production mechanism with light ions provides prudent risk management of potentially severe laser-plasma interactions in the hohlraum for the laser approach to inertial confinement fusion. 


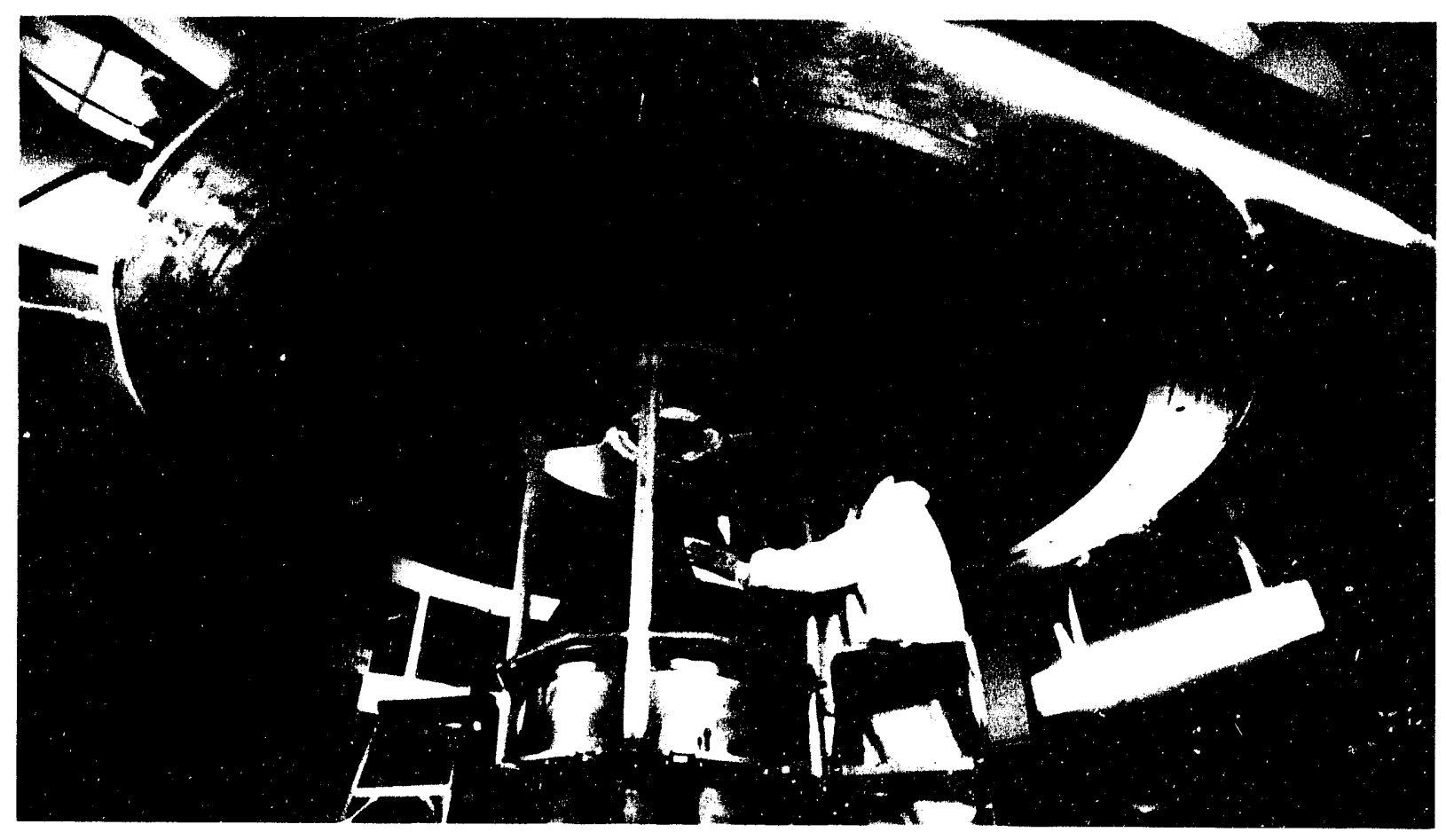

Jimmy Ryan cleans a cathode as part of routine maintenance between accelerator shots at PBFA II (Particle Beam Fusion Accelerator II). The machine uses short pulses of energy aimed at a central fuel target to study nuclear fusion. The technology grew out of weaponeffects studies and is now helping researchers investigate controlled fusion as a possible energy source.

Our responsibilities include technical direction of all DOOE-funded activities for the light-ion inertial confinement fusion approach. Sandia directs light-ion efforts in accelerator development, intense ion-beam generation and transport, beam focusing, beam-target interaction, radiation production and symmetrization, and target hydrodynamics.

Sandia's Particle Beam Fusion Accelerator II (PBFA II) is the world's most powerful particle accelerator and is being used for ion-beam-driven target experiments. The SABRE accelerator enables us to develop the beam generation and transport techniques which are in the geometry needed for high yield. This work is determining the feasibility and cost-effectiveness of the light-ion approach for the Laboratory Microfusion Facility.

Recent experiments give us confidence that a 500 -megajoule laboratory source of thermonuclear radiation may be obtainable through inertial confinement fusion if six major technology milestones can be further developed and integrated.

1. Multimodular synchronized pulsed power was developed in FY 1988.

2. Intense ion-beam generation and focusing were advanced in FY 1989 with the completion of the five-terawatt-per-square-centimeter major milestone.

3. The plasma opening switch met its milestone in FY 1990).

4. The lithium ion source decision milestone was met in FY 1990.

5. Beam divergence has been reduced from about forty milliradians to about twenty milliradians in FY 1992 and 1993, and a unified understanding of beam focusing has been achieved.

6. High-quality, radiation-dominated target experiments with ion-heated hohlraums began in FY 1992 with focused prown beams, and were extended considerably in FY 1993 with focused lithium beams. In FV 1992, beam-target interaction experiments were completed at 120 trillion watts/gm. In FY 1993, this level was increased to 700 trillion watts/gm. 
Advances in the science of ion-beam generation, beam focusing, and target experiments were reviewed in a 1993 "go/no-go" decisional review in March 1993 by the Inertial Confinement Fusion Advisory Committee. The committee found that "the quality of science in the light ion inertial confinement fusion program has been increased, as evidenced by the real progress." The committee endorsed Sandia's broad science program for inertial confinement fusion.

The near-term goal of the program is to establish the feasibility of inertial confinement fusion using ion beams produced directly from a pulsed-power generator. This goal will be approached through target experiments on PBFA II, SABRE, Hermes III, and supporting experiments at the collaborating institutions, Cornell University and the Naval Research Laboratory.

In the intermediate term, we will continue to collaborate with other DOE laboratories to assess the potential of the National Ignition Facility for ignition and gain in the laboratory with a glass-laser driver. Sandia is participating in the conceptual design, and Sandia's contributions to this effort include pulsed-power conditioning, design of the target chamber, and development and integration of radiation-hardened target diagnostics, as well as work on internally pulse-shaped targets for ignition and gain.

The longer term, fifteen- to twenty-year goal of the program is to provide the driver for a Laboratory Microfusion Facility for the Office of Military Application in the first decade of the next century. Plans for technology development of a Laboratory Microfusion Facility using SABRE and Hermes III have been presented to the Inertial Confinement Fusion Advisory Committee. Ultimately, the low cost and high efficiency of the pulsed-power approach may provide fusion power generation for electricity.

\section{Stockpile Support (GB03)}

Stockpile Support is divided into three major, interrelated thrusts. These thrusts are (1) maintaining stewardship of the stockpile, (2) preserving and modernizing a design and manufacturing capability, and (3) assisting DOE with several change initiatives, including dismantlement, privatization of component manufacturing, environmentally conscious manufacturing, and migration toward the reconfigured complex. Success across all fronts requires a sound investment strategy that preserves the foundation of nuclear design and manufacturing capability.

\section{Stockpile Stewardship}

Weapons System Engineering

The U.S. nuclear weapons stockpile continues to evolve in response to dramatic changes in global security. New weapons are not expected to be introduced into the stockpile in the near future, and stockpiled weapons are being reduced or eliminated, which will result in a stockpile that is significantly smaller but with greater expectations for surety, reliability, and longevity to maintain the U.S. nuclear deterrent.

The public's expectations for safety, security, and environmental protection in all phases of managing the nation's nuclear weapon stockpile continue to evolve to higher levels. Supporting this evolving stockpile in an era of declining budgetary resources demands that Sandia be innovative and efficient.

Stockpile support involves two broad activities: maintenance and appropriate improvement of those weapons that will remain in stockpile; and dismantlement and disposal of those weapons that are excess to national nuclear deterrent requirements.

Weapons will most likely remain in stockpile well beyond their original design lives. Weapon delivery systems will evolve in response to technology advancement, budgetary constraints, obsolescence, or treaty actions. These changes will necessitate continuous assessment of the surety, military effectiveness, delivery system compatibility, and longevity of the stockpile, which will be accompanied by programs that evaluate and implement value-adding improvements. 
Specifically, recent reductions and changes in our strategic nuclear forces have dictated changes to the intercontinental ballistic missile force structure that may stretch out until 2003. By then, the force will be configured entirely with Minuteman III missiles loaded with single warheads. During the interim, several warheads need to be qualified to the new environments associated with single reentry vehicle loads on the Minuteman III missile.

A similar restructuring is scheduled for submarine-launched ballistic missile warheads, air-delivered strategic weapons, forward-deployed weapons, and Navy fleet weapons. All of this redeployment activity will require certain alterations for reduced maintenance and special initiatives that will provide an adequate quantity of storage containers as weapons wait for redeployment or dismantlement.

Concurrently, some limited-life components will be replaced to extend the interval between changes. Product improvements (to maintain surety, reliability, and longevity) will be the principal activity for the foreseeable future, as exemplified by the current change-out of radars and trajectorysensing signal devices in several nuclear bombs.

Support of the stockpile will also have to be compatible with the changing infrastructure of the military services. Base closures and consolidations and the overall reduction of service personnel will have a significant impact on the services' capability to maintain the stockpile and implement improvements. Our maintenance and improvement programs must remain compatible with the services' capabilities.

Weapons in excess of national needs for nuclear deterrence require similar oversight to maximize the safety and surety from the time they are designated for retirement until their constituent components are disposed of. The limited capacity to dismantle nuclear weapons means that some weapons with older, limited surety features will remain assembled for many years. Safe storage and transportation of these weapons is one of our primary concerns. (ur limited understanding of the constituent materials in some of the older weapon systems will limit the capability to dispose of the components that make up those weapons. It is our responsibility to provide engineering expertise and oversight to DOE to overcome these limitations to help achieve the national dismantlement goals.

Military Liaison

In the area of military liaison, the surety and effectiveness of the nuclear stockpile remain crucial to U.S. security. Sandia's stockpile stewardship has ensured this surety and effectiveness for more than forty years. However, as a significant portion of the stockpile is retired and the remaining portion is structured for a new era, the pace of new challenges and the dctivities to address them are accelerating rapidly.

Serving as the DOE focal point for integrating military operational needs and surety requirements is part of Sandia's mission. In support of maintaining stockpile integrity, we provide a broad range of quality support services to ensure that the stockpile remains safe, secure, reliable, and maintainable. Sandia is the recognized leader of operations, maintenance, and logistics for nuclear weapons from concept through dismantlement.

We provide stockpile support through classroom and field training in weapons handling for Department of Energy, Department of Defense, and laboratory personnel. Scheduled training classes are provided to $\mathrm{DoD}$ weapons instructors, operational staff, and maintenance technicians. Weapon refresher training is also provided to DOE personnel and other DoD personnel. We maintain a staff of trained instructors sn. I modern training facilities for this purpose.

Sandia writes, produces, and supports over 200 technical manuals for DoD operational elements on how to use, maintain, inspect, and transport nuclear weapons. By using a new publication system that complies with the requirements of the Dol) (Computer-aided Acquisition and Logistics Support (CALS) system, we will reduce costs while improving timeliness and quality of our technical publications. We also produce a variety of video tapes to aid instructors in weapon maintenance, special renair procedures, and permissive-action-link operations. Sandia's military liaison group represents DOE on the Joint Nuclear Weapons Publications System (JNWPS) Council. 


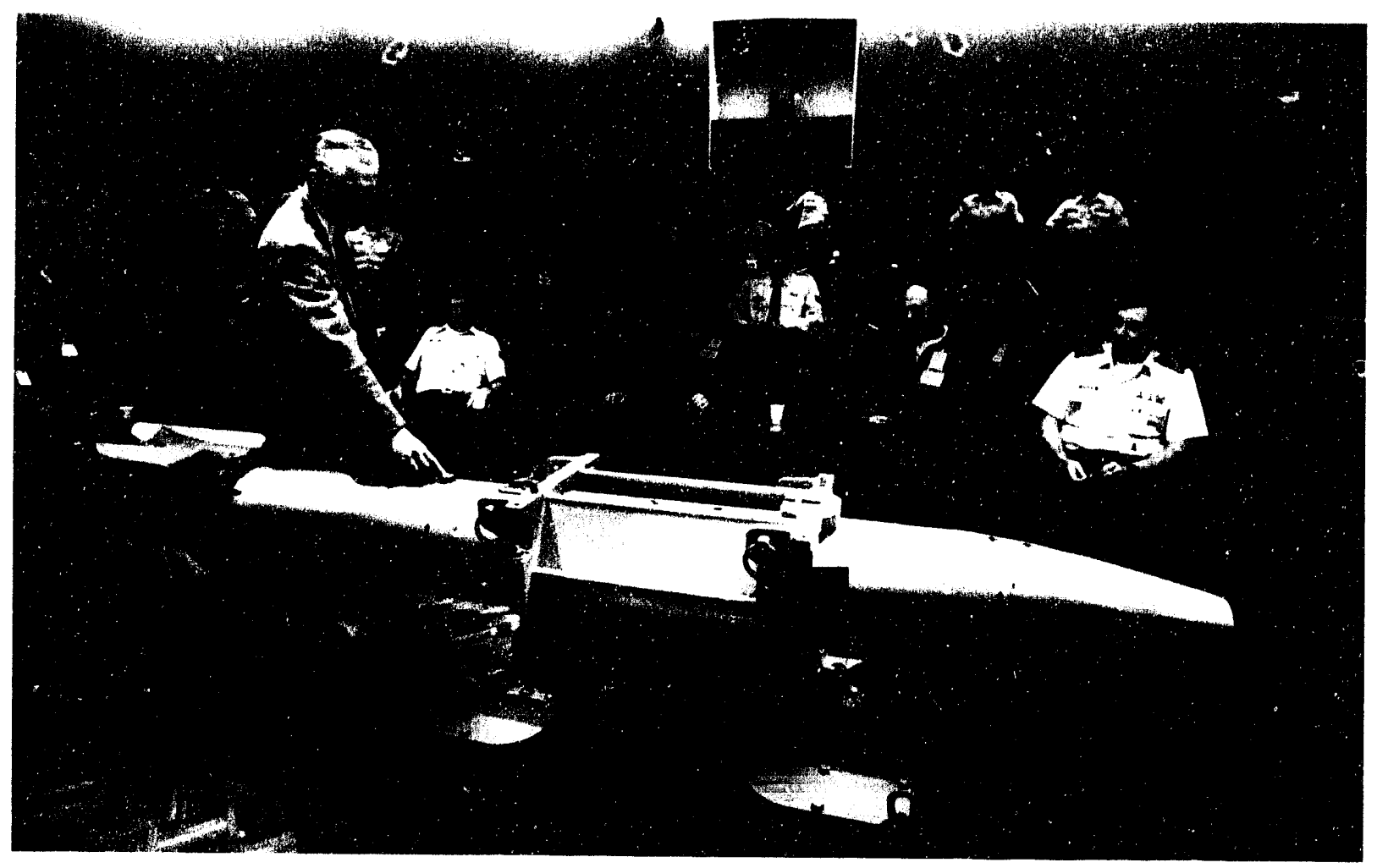

The nuclear stockpile is getting smaller, but intensive training of U.S. and Allied military personnel who maintain the stockpile and handle nuclear weapons is an enduring requirement. Sandia's Military Liaison activity routinely conducts such training for military instructors. Here, Sandian Don Benoist conducts a class for U.S. Air Force personnel.

New deployment postures require more attention to the stockpile. Limited-life components are now being exchanged in the field using new equipment and procedures that improve reliability and safety.

Sandia's stewardship activities reflect increased concern for the environment. Maintenance procedures have been revised to eliminate hazardous materials, and better containers are being designed for transporting components that contain radioactive materials, making operations in the field as safe as possible for both personnel and the environment.

These activities must keep pace with the rapid changes taking place in the world --changes that will continue to evolve and redefine the old meaning of stewardship. Thus, Sandia will continue to meet its responsibility to the nation for the surety and effectiveness of the nuclear stockpile.

\section{Independent Assessment of Nuclear Safety}

The first priority of the weapons program at Sandia is to assure nuclear detonation safety in the design, development, production, and military deployment of nuclear weapons. The highest levels of nuclear safety assurance are achieved by a process in which independent safety assessments are conducted by organizations and personnel expert in nuclear weapon design and nuclear safety disciplines. A strategic goal is to provide incrensingly comprehensive assessments of nuclear safety from system concept through warhead retirement.

We are committed to the concept that nuclear safety at the system level starts with safety features in the nuclear weapon that prevent unintended detonations in normal operating environments and in credible accident environments. The independent assessment function for weapon safety is focused on evaluation and implementation of design safety themes and the quality of safety-critical 
weapon components. This activity supports both the development of new weapon design concepts and safety upgrades in the enduring weapon stockpile. This evaluation requires unique test and evaluation prograns to determine the response of components and systems to normal and abnormal environments, including fires, crashes, lightning, and so forth.

The variety of nuclear weapon systems and the environments encountered in system operations complicate the nuclear safety assessment process. The matrix of conditions includes multiple weapon configurations and launch platforms, numerous locations that may be scattered worldwide, many procedures involving a wide variety of personnel and special equipment, and exposure to a myriad of energy sources. It is a continuing challenge to recognize where the greatest potential for enhancing nuclear safety exists and how enhancements are to be best implemented.

We recognize our responsibility for comprehensive nuclear safety assessment of nuclear weapons and continue to take the initiative in joint $\mathrm{DOE} / \mathrm{D}$ ) D assessments of nuclear safety. Future efforts will include the further development of methodologies for conducting safety assessments of complex systems and gathering important system-related data to support these assessments.

Sandia possesses unique experience and capability in safety cvaluations and in the testing and analysis of wcapon and system response in complex and abnormal environments. This capability will continue to be supported by an extensive nuclear safety test and evaluation program, the development of evaluation methodologies, and an expanding information base on nuclear safety technology and methods. Information will continue to be integrated into a state-of the-art, multi-media database. This information system will provide the basis for training the cadre of personnel responsible for nuclear explosive safety and for the transfer of nuclear safety technology into the private sector. This unique experience and information system will also continue to support nuclear accident response activities and cooperative efforts with Russia and other countries of the former Soviet Union.

\section{Quality Assessment and Engineering}

Sandia conducts qualit, evaluation and qualification of weapon designs, weapon hardware (parts, apparatus, components, assemblies), associated software, controllers, field handling and test equipment, and joint test systems hardware and software during design, production, and after production has begun whenever significant changes occur. We perform acceptance of product and maintenance of records for Sandia-procured product. We administer a Qualification Evaluation Information Center to maintain a database of the qualification history and lessons learned. We t. elip develop quality plans, furnish support to suppliers, provide service to development groups, and conduct supplier surveys and audits. We conduct process evaluation as well as product evaluation by characterizing the manufacturing processes and equipment, especially process transfers and new suppliers. We also qualify acceptance equipment, testers, gages, and associated software. We conduct internal quality assessment against our sponsor's quality criteria for production activitics and research and development (test and evaluation) reviews within the Laboratories. Our goals are to assure that the product will meet the requirements of the intended use, and that acceptance equipment adequately supports achieving this product goal.

Sandia also conducts weapon quality process activities and software quality development and evaluation. Our quality activities are incorporated into the weapon design and development process using early involvement, new quality tools, and team concepts. We have established, and continue to develop, a software management program to ensure that a consistent approach is applied to the management of all software assets being acquired, developed, supported, and used.

Our goal is to establish good business practices to encourage organization-specific, resultsoriented software management plans that promote software improvement and incorporate concepts of software quality assurance and software quality control. We help guide software project designers through software engineering processes to produce quality product. In-house software engincering courses are offered and software guidelines are promoted. We plan to establish a software mutrics 
methodology for war-reserve embedded computer systems. The results will be integrated into the overall reliability of the system and ultimately used to improve the software reliability of the enduring stockpile.

\section{Stockpile Surveillance}

Sandia conducts an independent assessment program to verify that the reliability and safety of the nuclear weapons in the stockpile are maintained at the levels required by the departments of Energy and Defense. The entire testing and evaluation program is formulated by a joint Sandia/DOE/LOD) team.

Nuclear weapons are selected from the stockpile, returned to DOE's Pantex plant, denuclearized, instrumented, and then tested. Some are exercised at environmental extremes in the Weapons Evaluation Test Facility at Pantex. Others are shipped to Dol sites, mated to their delivery systems, and flown in test flights. If problems are detected or failures occur, a team is formed to find the cause of the anomaly, assess its impact, and recommend resolut:on. A data bank of all system tests and problems is maintained to provide the proof-of-system reliability and safety data as well as a record for engineers to use on future designs.

Major changes to the stockpile surveillance program are being made to adjust to a smaller number of weapons in stockpile and a declining budget. Handling, shipping, and disassembly costs will be reduced by coordinating the selection of weapons to be tested with weapons operations such as scheduled maintenance. Tests are being replanned to place more emphasis on aging effects due to the longer-than-expected lifetimes that will have to be maintained. A closer look at critical safety components is being made, due to the growing concern with thıs issue reflected in higher standards of environmental safety and health.

More realistic test configurati is are being generated in our effort to continuously improve our ability to detect subtle problems in ultra-high-reliability systems. We are redesigning the denuclearized test units for Weapon Evaluation Test Laboratory testing to be able to test more than one type of weapon system. This capability will provide more flexibility during routine maintenance, or breakdowns, and a more interchangeable, economical tester mix.

We are responding to increased personnel safety requirements during test activities by performing test operations safety reviews with independent assessors and by replacing test equipment built to former, less stringent safety standards. The hydraulic-driven centrifuges at the Weapons Evaluation Test Facility are being converted to electrical systems.

Our objective is to support a highly reliable and extremely safe stockpile with a lean, timely, cost-effective, highly coordinated, and mutually beneficial stockpile evaluation program.

\section{Manufacturing Capabilities}

Engineering Information Support

Our objective of supplying engineering information systems merges existing and anticipated stockpile support requirements with practical and cost-effective information technology. This mission is challenged by the reality of a reduced stockpile and very limited new build opportunities. Modernization of information systems, downsizing to more cost-effective platforms, and alignment to industrial, national, and international standards is essential to meeting these future demands.

The goal of this program is to establish a "state-of-the-technology" design and unalysis capability built on standard hardware and software products. Conformance to industry standards will assure that solutions adopted today will maintain flexibility with options of tomorrow. Reduced time cycles and operative cost reductions will be realized.

Engineering information support strategies are based on multifunctional teams. Agility and economies of scope will allow the teams to apply their expertise to a heterogeneous computing environment. Data will be managed, stored, and distributed on a network that is accessible from engineering desktops. A structured effort to evaluate the processes of creating and sharing data will result in solutions 
aimed at global optimization consistent with established business plans. (Our commitment to "conceptto-product" systems using consensus software and hardware will climinate the need to re-input information and enable sharing of data across multidisciplined design and manufacturing teams.

Numerous initiatives are underway to realize the engineering information system vision. Tools for mechanical design were identified by the ACCORI) selection that focuses on a tightly integrated solid-modeling foundation. This approach promotes the concepts of rapid prototyping and early product visualization to contain cost in the development stage.

The NIRVANA tools for electrical design and fabrication provide the necessury flexibility and infrastructure. Record-of-assembly and product test databases will migrate from mainframe systems to smaller, less expensive, and more easily maintained workstation environments. Engineering information created at Sandia's New Mexico and California sites will be stored electronically at a single location while allowing for managed access by both sites.

An electronic configuration management system is being developed to monitor and control design changes. Native electronic files and scanned images will be stored in an optical disc storage system and allow for the off-line storage and recall of electronic drawings, documents, and models to engineering workstations. An escalating trend is a shift from a secure computing network to restricted and open environments that will facilitate the principles of concurrent engineering with outside agencies thro .ghout the product development cycle.

\section{Primary Standards}

Sandia's responsibilities also include providing primary physical, electrical, and radiation standards for equipment calibration for the entire nuclear weapons complex. Sandia's Primary Standards Laboratory provides a metrology program to ensure accurate measurements for the nuclear weapons program. In addition, it provides support for other DOE programs, government agencies, industry, and universities. It develops and maintains primary standards that are traceable to national standards, and calibrates and certifies customer reference standards. It also provides technical guidance, support, and consultation; develops precision measurement techniques; provides oversight activities, including technical surveys and measurement audits; and anticipates needs.

Development programs ensure the timely introduction of standards for new technologies. A current development is the portable Josephson volt, which will permit this intrinsic standard to be operated in many field applications, ensuring quantum-level accuracy on voltage standards, digital dividers, and other ultra-precise test equipment.

Sandia's Primary Standards Laboratory (PSL) performs over 2,000) calibrations of top-level standards each year in more than 80 different areas of technology for the integrated contractor facilities within the nuclear weapons complex. The standards laboratories at the various contractor sites use these standards to perform as many as 300,000 calibrations a year on their own instruments. Primary Standards Laboratory operations are being relocated to a new facility with state-of-the-art environmental control.

The future focus of the Primary Standards Laboratory will include support for the reconfigured nuclear weapons complex, advanced manufacturing initiatives, and new requirements in general operations, including environmental safety and health, security, and facilities. These demands will require the PSL to develop new metrology disciplines, such as chemical and ionizing radiation standards.

This standards program ensures the accuracy of all the metrology equipment used in the research, development, design, test, stockpile evaluation, and retirement of nuclear weapons.

\section{Container Development and Production}

In the area of (Container Development and Production, the emphasis on safety and environmental regulatory compliance will continue to increase for the foreseeable future. With this emphasis as a driver, the need for accident-resistant radioactive material transportation containers will increase. 
Containers for the safe transport of nuclear weapons, weapon components, and weapon materials will be required in increasing numbers. This need will be met by developing low-cost, regulatory-compliant containers produced through agile manufacturing and concurrent engineering design. By taking the lead in this area, we will assure that 1$)($ )E will be able to meet program objectives in weapons development and production, stockpile maintenance, and dismantlement. Several container designs will be developed to assure that DOE policy can be made on a sound technical basis.

We have recently completed the production of over 2,300 tritium reservoir containers. The technology used to design and fabricate these containers is serving as a basis for the design of new U.S. nuclear weapon component and warhead containers. The methodology chosen was so successful that the technical approach provided the basis for a warhead component container recently developed for the Russian Federation. By capitalizing on additional design techniques, opportunities exist for even lower costs and enhanced safety margins. The pursuit of these container design and development activities will assure that $D O E$ can comply with all national and international regulatory requirements and meet the ever-changing programmatic goals of the nuclear weapons program.

\section{Materials Capabilities}

The analysis and modeling of materials, semiconductors, printed circuit boards, and all other production processes for the enduring stockpile is maintained under this program. We have interacted closely with the nuclear weapon production agencies and, as a result of activities associated with Complex 21, it is expected that the resources and expertise maintained within this program will be fully utilized to assist in the transition of production responsibility.

This program has traditionally provided a rapid response capability to address material and process issues arising within the production cycle or discovered during stockpile surveillance activities. There will be more demanding needs in the future to develop and maintain a capability to produce prototypes and limited quantities of war-reserve semiconductors, neutron generators, batteries, and switch tubes. Associated with this maintenance of capability will be strong efforts to develop advanced, agile investment casting processes that will be utilized both within the streamlined production complex and shared with U.S. industry.

Semiconductor efforts are focused on maintaining a very strong analytical modeling capability (associated with radiation behavior, tolerance, design and fabrication), preserving and improving experimental failure analysis capability, and maintaining and improving the technology base that can be applied to reliability and semiconductor life expectancy predictions. In the future, we expect that conditions will dictate that weapons systems be maintained for a much longer service lives. In addition, there will be strong interaction with semiconductor manufacturers to assist in the future privatization effort. The ability to experimentally evaluate radiation hardness is another differentiating capability that needs to be preserved.

Many materials analysis capabilities and facilities are utilized in the Stockpile Support program. In addition, there is a significant effort to continue to qualify new materials and processes for printed circuits, hybrids, and encapsulants for future application.

Further development of the FASTCAST ${ }^{\text {M }}$ process will provide a concurrent design and manufacturing platform for the production of electronic housings. Sandia's accomplishments in developing the system architecture, thermal code, as 1 , omplete integration into an agile manufacturing platform is well recognized by industry.

Because of our enduring commitment to stewardship of the nuclear weapons stockpile, it is important that we maintain the test facilities critical to the evaluation of nuclear weapon power sources and neutron generators. As required by new safety mandates, or forced beciuse of technology obsolescence, tester hardware and software modifications will continue as long as there is a nuilear weapons stockpile. 


\section{Change Initiatives}

\section{Dismantlement Support}

Under the terms of STAR'T I and STARTI II, the United States will be required to dismantle more than 10,000 nuclear weapons during the next ten years. In the past, the volume of weapon retirements was, in general, low enough that disassembly operations were performed as a work filler between assembly operations. The development of new dismantlement processes is essential to meet the workload schedule and to provide a better way of supporting future operations.

Dismantlement begins when the military designates a weapon for retirement and ends when DOE has disposed of the weapon components, trainers, handling equipment, and other associated hardware. The procedure includes transportation, storage, and disassembly into subsystems and components that are recycled, staged for reuse, or disposed.

Sandia works closely with DOE's Pantex plant in Amarillo, Texas, to design safe and efficient dismantlement processes. Automated processes using robotics and computer modeling are being developed to safely and cost-effectively handle the increased dismantlement volume. Sandia systems analysts are helping to automate dismantlement scheduling to provide early forecasts of the return and staging of retired weapons. They are analyzing the processes for security and safeguards, retirement and disassembly prioritization, and risk assessment management. Engineers are developing computer simulation models to improve the transportation and staging of weapons.

Robotics are being used to mitigate personnel hazards, particularly those associated with radioactive material. Sandia is developing and implementing a system called Stage Right that uses remotely controlled forklifts to load, unload, and inventory weapon nuclear material stored in igloos at Pantex. Plans are in place to use robots for cleaning, leak checking, and weighing nuclear weapon parts. The feasibility of using robotics for disassembly of explosives and radioactive parts and for the separation of materials for disposal is being pursued.

Concern for the environment introduces new challenges in the disposal of materials. For example, new federal and local regulations require that certain materials scheduled for disposal be identified - materials such as lead in solder, copper in electrical wiring, and cadmium in plated metal parts. Because original assembly drawings do not describe materials in sufficient detail, materials sampling and analysis techniques are being developed. A common materials database to be used by all design and production agencies is being developed by Sandia.

Disposal of subsystems and components often requires declassification, demilitarization, and sanitization. Sandia engineers are exploring several new processes that perform these functions simultaneously. Because of the immediate need, two commercially available technologies, forge hammer fracture and waterjet cutting, have been installed at Sandia and Pantex. Improved, automated technologies are being investigated for the future.

\section{Manufacturing Development Engineering}

Under the Manufacturing Development Engineering (MDE) concept, the design laboratory works directly with commercial vendors to develop and manufacture nonnuclear weapon components within the private sector. This concept requires high-level interaction between the design laboratory and private industry, including identifying and developing private sector suppliers, transferring technology, and maintaining an involvement with process design and manufacturing engineering.

MDE will provide the following advantages to DOE in the anticipated, very-low-volume production environment of the future nuclear weapons complex.

- By relying on private industry for production of weapon components, the nuclear weapons complex will require less overall production capability. 
- With weapons component technologies maintained at the design laboratory rather than at a production agency, the maintenance cost of MDIE technologies is reduced.

- Components manufactured using high-volume, standard industrial processes will be more cost-effective and better characterized than components manufactured using low-volume, custom processes.

The strategic objectives of the Manufacturing Development Engineering program are to:

1. Develop an infrastructure that will demonstrate Sandia's ability to manage the production of nuclear weapon components, both in-house (as for neutron generators) and by using commercial suppliers.

2. Increase design engineers' general understanding of manufacturing issues and industry standards, products, and processing.

3. Provide a vehicle to move Sandia toward concurrent engineering and agile manufacturing.

4. Facilitate the reconfiguration of the nuclear weapons complex by transferring appropriate activities formerly performed at the Mound and Pinellas facilities to private industry.

\section{Complex 21 Technologies}

Our work in the development of technologies for Complex 21 derives from the fact that consolidating the current nuclear weapons complex will require an investment in the development and demonstration of advanced manufacturing technologies. Sandia is developing these advanced manufacturing technologies, working closely with the private sector to enhance the relevance of the developed technologies, and demonstrating the agility of advanced manufacturing technologies in meeting the demanding requirements of nuclear weapons production and U.S. industrial needs. We are investing in enabling technologies such as computer-aided design and manufacturing, current engineering, information-driven architectures, environmentally conscious manufacturing, and rapid prototyping. These are the same technologies needed by U.S. industry. We are also exploring the integration of manufacturing sites into a virtual factory to meet the requirements of the future complex.

The work associated with Complex 21 will reach beyond the needs of the nuclear weapons community. Sandia's program is directed towards becoming a test bed for research, development, and manufacturing integration and a place for developing new industrial processes. It can serve as a working model of fully integrated manufacturing technologies and a centerpiece for 1$)($ )E contributions to advanced manufacturing.

\section{Environmentally Conscious Manufacturing}

The Environmentally Conscious Manufacturing program is a deliberate attempt to reduce the environmental impacts of manufacturing activities without reducing the quality or performance of the product in question. Sandia has a strong commitment both to the environment and to the quality of product, the nuclear weapon stockpile. Therefore, we will continuously develop the materials and processes used in the fabrication of weapon components to minimize their impact on the environment.

Environmentally conscious manufacturing is focused on manufacturing activities for which the environmental by-products have yet to occur (as opposed to clean-up and restoration activities for which the offending by-products have already been released). Even though remediation technologies are essential for correcting past mistakes, reliance on "end-of-pipe" solutions must not form the basis for future manufacturing decisions. Any attempt to nullify an environmental threat after it has been created is almost certain to be less effective than avoiding that threat from the very beginning.

Considering that our principal product is nuclear weapons, we cannot allow any manufacturing initiative, including the initiative in environmentally conscious manufacturing, to degrade the safety 
or reliability of the stockpile. Even though weapon production cuantities are declining drastically, opportunities for reducing waste and environmental damage remain pervasive. For the foreseeable future, Sandia's environmentally conscious manufacturing efforts relative to weapon component production will be directed toward needs that are specific to the long-term stockpile.

A major benefit to Sandia's environmentally conscious manufacturing technology development will be the cultivation of materials and processes that are vital to commercial enterprises. Maintaining a robust domestic economy with substantially less waste and resource consumption will be one of the greatest challenges of the next century. Sandia's unique blend of manufacturing and environmental experience is well suited to addressing this challenge.

\section{Reconfiguration (GB03 and GB0508)}

The aging nuclear weapons production complex is a widely-distributed, environmentally outdated, expensive collection of production sites built to meet peak cold war production requirements. As the nuclear weapons stockpile and production requirements decrease, the production element of the nation's nuclear deterrent must consolidate to a smaller, less costly complex while maintaining its technical competence.

DOE has embarked on a program to consolidate the complex while increasing its efficiency by integrating the essential competencies that exist in the weapons laboratories, the private sector, and the remaining weapons production sites (Kansas City, Y-12, Savannah River, and Pantex). Under the consolidation plan, Sandia has been assigned responsibility for prototyping and smalllot fabrication of neutron generators, code-activated processor assemblies, and thermal batteries. Conceptual design studies and activity transfer plans have been prepared to examine the feasibility of producing these components at Sandia.

During the past two years, DOE planning to reconfigure and consolidate the nuclear weapons complex has included a tighter integration of the weapons laboratories with the production complex, including the designation of lead laboratories to oversee and sustain a number of key production process technologies. DOE, along with the Defense Programs laboratories, has developed the lead laboratory concept to respond to the realization that a smaller nuclear weapons complex will not be capable of supporting the technical overhead that curre itly exists at the production plants.

The relationship between the production plants and the laboratories will change under the lead laboratory concept. To facilitate the implementation, Defense Programs is developing a lead-laboratory protocol to define roles and responsibilities of the lead laboratories, the plants, and DOE departmental elements.

Sandia, Lawrence Livermore, and Los Alamos, as lead laboratories, will be responsible for production process development and production support for Complex 21. Sandia's lead laboratory assignment will include nonnuclear components, system assembly, and the Center of Excellence for Automation and Robotics. Current programs include the development of process flow charts for Complex-21, the development of environmentally acceptable processes, and the development of an integrated program plan to assess facility requirements and demonstrate critical production processes. 


\section{Office of Intelligence and National Security}

Sandia supports the Department of Energy with research, development, and analysis for intelligence, nonproliferation, arms control and verification technology, and policy development. Sandia has one of the oldest and largest programs of such work in support of U.S. arms control and nonproliferation policies. This work has always been an important corollary to our nuclear weapon research and development responsibility, which provides requisite expertise for knowledgeable nomproliferation and arms control work.

\begin{tabular}{|c|c|c|c|c|c|}
\hline \multicolumn{6}{|c|}{$\begin{array}{l}\text { Summary of Programs for Office of Intelligence and National Security } \\
\text { (Operating BA in \$ million) }\end{array}$} \\
\hline B\&R Code & Program Title & FY92 & $\underline{F Y 93}$ & FY94 & FY95 \\
\hline GC & Verification and Control Technology; and & & & & \\
\hline GJ & Export Control, Nonproliferation, and International & 51.4 & 67.6 & 87.3 & 82.5 \\
\hline GD & Nuclear Safeguards \& Security & 11.6 & 9.1 & 9.4 & 8.6 \\
\hline NT & Intelligence & 3.5 & 3.1 & 3.4 & 3.4 \\
\hline & Total & 66.5 & 79.8 & 100.1 & 94.5 \\
\hline & Percent of total operating funds & $5 \%$ & $6 \%$ & $7 \%$ & $7 \%$ \\
\hline
\end{tabular}

\section{Verification and Control Technology (GC)}

\section{Proliferation Detection and Verification Technologies}

The Proliferation Detection and Verification Technologies Program includes research and development of a variety of systems and technologies applicable to the detection of proliferation of weapons of mass destruction, verification of agreements for arms limitations, and Open Skies (reciprocal surveillance of defense installations from aircraft); technical support of veritication and arms control activities; assessment of foreign weapons technology and other intelligence issues; development and deployment of satellite-borne remote sensing systems to verify compliance with the Limited Test Ban Treaty and to demonstrate technologies applicable to the detection and characterization of proliferation activities; and development and evaluation of seismic systems and technologies for verification of threshold or other limitations on underground nuclear testing. An important aspect of all these program areas are the activities in information management, fusion, and analysis.

We are developing new nuclear detonation sensors for improved detection of low-yicld explosions in the atmosphere, even through clouds. Instrumentation systems currently being deployed on the Global Positioning System constellation of satellites will soon provide continuous worldwide coverage. Data from these instruments is also used by Department of Defense (which shares system costs) to support their tartical warning and attack assessment mission.

We have initiated development of satellite-based systems and technology for detecting and characterizing nuclear proliferation activities, with direct application to chemical and biological weapon development as well. In conjunction with Los Alamos National Laboratory, we are developing an advanced multispectral thermal imager. Working with Los Alamos, Lawrence Livermore, Pacific Northwest, and Brookhaven national laboratories, we are developing laser-based techniques for remote detection and identification of chemical species in effluent plumes emanating from suspect sites. Both of these concepts will be developed into operational integrated systems and demonstrated 
in space aboard small satellites. Dual-use applications for these technologies, particularly in environmental remote sensing, are also being considered.

Sandia has projects to develop chemical sensors related to nuclear and chemical weapons, ultraviolet light detection and lidar ranging technology, radiation detection sensors, remote video surveillance systems, and the nondestructive determination of particulate compositions. In some instances, component technology will be incorporated into unattended, and

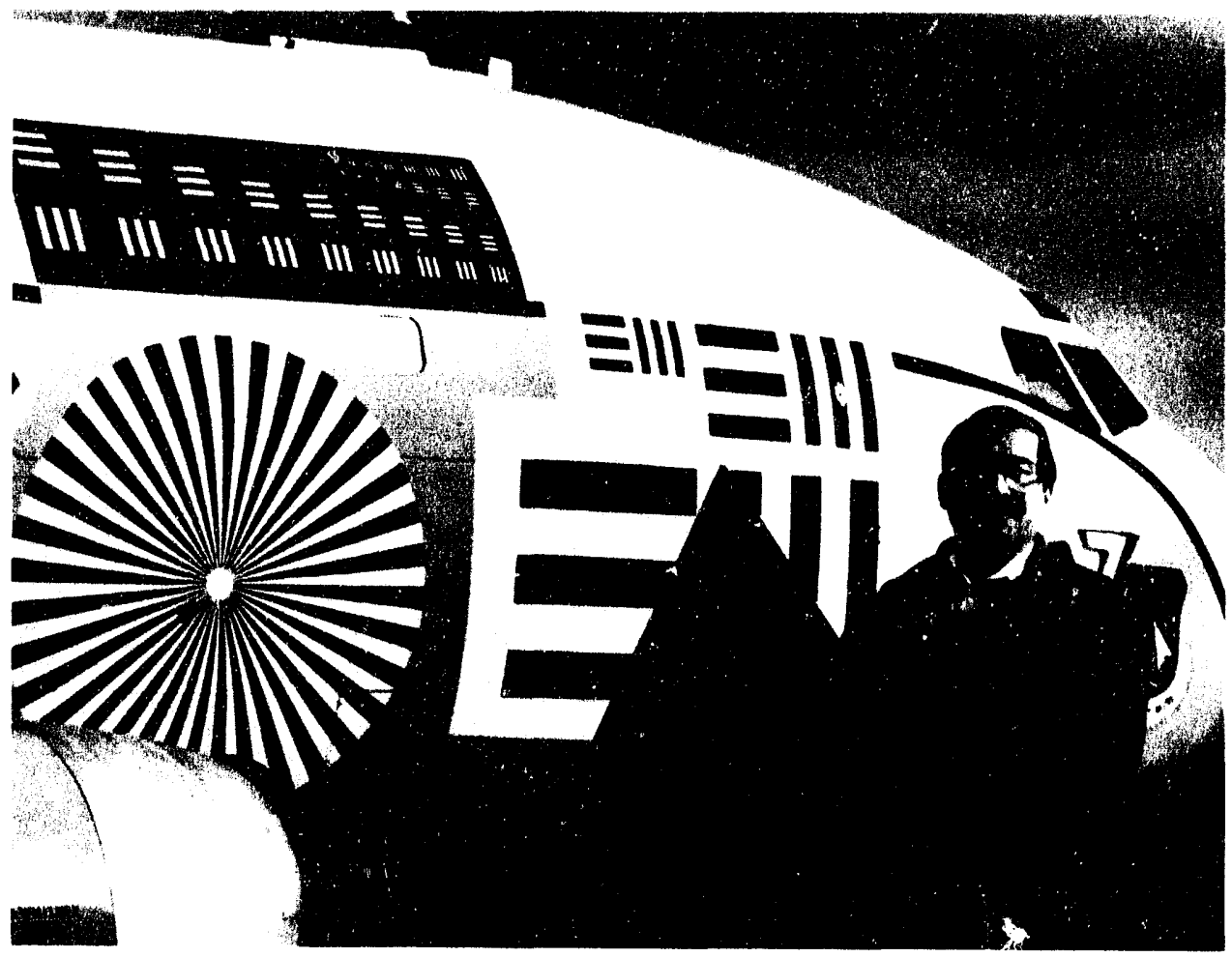
possibly remote, ground-based sensor systems.

We develop synthetic aperture radar systems for." : 'ithorne Multisensor Pod System, a data collection platform for treaty verification and no: evaluate such parameters as radar resolution and aperture radar system designs for Open Skies and $\mathrm{n}$. n. We will conduct experiments to suration that will influence synthetic $g$ of the Conventional Forces in Europe Treaty. We are also exploring the integration of synthetic aperture radar with other imaging data and automated data analysis as methods for dealing with the deluge of data from such systems. Synthetic aperture radar will be used to evaluate all-weather as well as day and night aerial inspection capabilities required for U.S. and international community needs.

Tags and seals are currently being considered for use in securing key elements associated with the Chemical Weapon Convention, weapon dismantlement, and the containers designated to transport and store Russian highly enriched uranium purchased by the United States. Sandia has a number of projects for developing tags and seals for these applications. We have also broadened the tag and seal effort to include the technological area of information integrity, which covers the general application of tags and seals over a wide range of monitoring applications. New data authentication techniques are being developed to provide security for remotely monitored, sensor-based sealing systems.

In FY 1993, Sandia initiated development of a technology base for fiber optic tags and seals and advanced tamper-indicating packaging. The development of the technology base for these applications will, to the extent possible, embrace inputs from private industry, the university community, other national laboratories and the appropriate centers of excellence within Sandia.

Studies are underway to investigate the impact on Department of Energy facilities of nuclear weapon dismantlement that could be performed under a system of controis related to the START treaties. In a related effort, we are investigating ways of accounting for special nuclear materials from dismantled weapons. One of our tasks is the design and development of a secure container for the safe transportation and storage of special nuclear materials. This work provides some of the background necessary to support discussions with the former Soviet republics on nuclear weapon dismantlement.
Sandian Max Sandoval, the U.S. technical expert on imaging radar to the international Open Skies Treaty negotiations, holds a trihedral corner reflector similar to the ones that will be used to verify aircraft radar performance as part of the new Open Skies Treaty. The United States plans to use C135 aircraft like this one, outfitted with optical cameras, infrared line scanners, and synthetic aperture radar, to monitor conventional military activities in treaty signatory nations. 
We are increasing our activities on the gencral problem of managing potentially large volumes of proliferation-related information. () ur aim is to develop technologies that an analyst can use to turn the vast quantity of data into useful information. Advanced data authentication techniques are employed when information security is paramount.

Development and evaluation of seismic technology for detection, location, and identification of underground and underwater nuclear explosions are continuing. In line with the emerging geopolitical climate, the emphasis of this program has shifted from the monitoring of bilateral test limitation agreements to global monitoring of proliferation-related nuclear testing and of a comprehensive test ban, should one be implemented. Our research and development activities are focused on verification-quality seismic and hydro-acoustic data acquisition and data processing that is affordable, easily deployable, and flexible enough to meet the demands of the new world order. Our technology development activities are being coordinated, and in many cases co-funded, by the Department of Defense, which has operational nuclear test monitoring responsibility within the U.S. government. We are also coordinating our efforts through the United Nations Conference on Disarmament, Group of Scientific Experts, whose charter is to define and demonstrate techniques for the collection and exchange of global seismic data for the purpose of monitoring underground nuclear tests.

\section{Nonproliferation Policy}

The Office of Nonproliferation Policy is a newly energized component in IOE's Office of National Security and Intelligence. Sandia has been identified as a major supplier to this office with support in two areas: regional arms control and International Atomic Energy Agency analytical support. In the area of regional security, Sandia has been asked to initiate a program to evaluate the applicability of various arms control technologies and procedures to regional security issues. Eventually, it is envisioned that prototype monitoring facilities can be developed so that representatives of regional parties (for example, persons from South Asia, the Middle East, the Korean Peninsula, and so forth) would have an opportunity to perform hands-on evaluation of various technologies as well as use models and simulations to evaluate the appropriateness of various technological solutions to their particular regional problems.

The other important feature of Sandia's support for the Office of Nonproliferation Policy is analytical support for International Atomic Energy Agency activities. Analysis includes evaluation of various proposed inspection regimes, evaluation of International Atomic Energy Agency information management technology and procedures, and assistance in preparation for the $1995 \mathrm{Nomproliferation}$ Treaty Review Conference.

It is anticipated that this program will expand, particularly in the area of regional security analysis, for the rest of the decade.

\section{Policy Analysis}

Sandia's policy support activities are targeted at both sides of the policy-technology interface. We support technical analysis of policy options for 1 )(OE's ()ffice of Intelligence and National Security, and we provide policy insight to Sandia organizations working in areas of national security. ()ur direct support includes furnishing technical advisors at the international science and Technology Center in Moscow and at the United Nation's Special Commission in New York. In addition, a full-text-retrieval database of documents related to the Iraci nuclear program is being compiled.

Analytical support for the DOE's ( )ffice of Policy and Technical Analysis includes treaty implementation analysis, temporary technical advisor support, nuclear testing analysis, and dismantlement analysis. Sandia has been a mainstay of 1 )( )E's on-site evaluation program since 1986, and we continue to support evaluations of $41 \mathrm{c}$ impact of on-site inspections on sensitive industrial facilities, as well as other issues related to implementation of various treaty regimes. 
With the renewed interest in restrictions on nuclear testing, Sandia has been called upon to participate in various evaluations of the impact of further testing restrictions on our ability to at as responsible stewards of the residual nuclear weapons stockpile. It is anticipated that the pressures for testing restrictions will continue, at least through the 1995 Nonproliferation 'Treaty Review Conference, so Sandia will continue to provide analytical support in this area.

As the stockpiles of the superpowers are reduced and their respective infrastructures are consolidated, numerous issues will arise with respect to verification and monitoring of the reduction process and the residual weapons and dismantled components and materials. Sandia has long been a principal evaluator of the processes, procedures, and technologies associated with these dismantlement activities, and this support is expected to continue for the next several years.

\section{Export Control, Nonproliferation, and International (GJ)}

\section{Export Control}

Sandia supports DOE's Office of Export Control Operations in two principal areas, export license review and approval and information management. Sandia recently activated a classified, on-line data system to review export license applications and suggestions for modifications to the Militarily Critical Technologies List and other export control regulatory regimes.

In addition to day-to-day operations, Sandia is a major participant in the Proliferation Information Network System. When completed in 1994 or 1995, this system will be a large network of computer workstations designed to permit analysts at widely separate locations to access and process large amounts of disparate data in support of proliferation-related evaluations. Sandia is charged with designing the overall architecture and providing a prototype system. In addition, Sandia is supplying direct temporary duty support to the Proliferation Information Network System program at Department of Energy Headquarters. The Proliferation Information Network System is a multiyear project which is expected to expand over the next several years as a result of the burgeoning interest in proliferation information management.

\section{International Safeguards}

Sandia is the Department of Energy's lead laboratory for the development of containment and surveillance technology, concepts, and applications for international safeguards use. We have ongoing development efforts in advanced digital video surveillance systems, authenticated item monitoring systems, network technology for use in on-site integrated safeguards systems, and engineering of lower-cost reusable electronic seals for the International Atomic Energy Agency. We are the Department of Energy technical advisor on containment and surveillance for projects conducted under bilateral programs of cooperation in safeguards technology development with Germany, Japan, the United Kingdom, Australia, and the Conmission of European Communities.

We participate in the new Enhanced Safeguards Initiative, which is structured to provide more direct D(OE support to the International Atomic Energy Agency. This new initiative is directed toward anticipating enhanced safeguards needs of the international safeguards community and investigating, developing, and transferring new and enhanced safeguards approaches and technology to international, regional, and bilateral safeguards regimes.

We assist the Department of Energy in demonstrating advanced physical protection technologies to states of the former Soviet Union. This effort supports the U.S. Comprehensive Threat Reduction Program 'formerly known as the Safety, Security, and Pismantlement Program).

In addition, Sandia regularly conducts an extensive training course that addresses techniques, technology, policy, and procedures for physical protection of nuclear facilities and materials. Students are selected for this course from member states of the International Atomic Energy Agency that have less well-developed nuclear programs. 


\section{Nuclear Safeguards and Security (GD)}

In view of the potential adverse consequences of nuclear energy or materials being used for malevolent purposes or contaminating the environment and endangering personnel health, and the adverse impact on national security resulting from the compromise of classified information, the I) partment of Energy's Office of Security Affairs sponsors a program to develop technologies and systems for protecting nuclear materials and D) (OE facilities. The focus of this program is the development of physical security technologies to address a spectrum of threats for protection against these events.

In this context, Sandia is the principal laboratory for research and development on physical protection technology. Program objectives are to support the development and application of advanced technology to the protection of $D$ OE facilities to prevent:

- theft or diversion of nuclear materials that could endanger the public,

- radiological or toxicological sabotage that could endanger the public health and safety, and

- theft or compromise of information or material that could adversely impact national security.

Technologies being investigated include those directed at detection, delay, and response for outside adversaries, and those that deter and prevent insider attempts at sabotage, theft, or diversion of material or information.

New concepts are developed and analyzed to identify the most promising approaches. Concepts with high potential performance are engineered, implemented, and operationally evaluated to provide balanced, effective, integrated safeguards and security systems. Systems and components that provide effective protection with reduced operational cost are a major thrust as the nuclear weapons complex responds to a reduction in nuclear weapons, tighter fiscal budgets, and an increased emphasis on the health and safety of employees and the public and protection of the environment.

Development of new intrusion detection technologies includes the use of optical fiber sensing technology to yield more effective detection with low false and nuisance alarms. In addition, advanced development is being performed for laser radar detection and imaging as well as early warning radar systems. New sensors that could more readily discriminate human intruders are being investigated.

Technologies and systems are being developed to monitor the movement of personnel and materials within a facility for the purpose of thwarting the insider threat. Techniques that reduce the opportunity for personnel to come into contact with nuclear materials are being developed, such as self-testing sensor systems and material or item monitoring systems.

Advanced technologies in image processing are being pursued for purposes of tracking personne] and materials within a facility. Through a cooperative research and development agreement (CRADA), image processing algorithms are being developed to detect bulk explosives and contraband covertly carried on a person.

Advances are being madc on vapor-explosive detection technology. Development of a vapor generator that can produce sample quantities tracedble to national standards is continuing. A portal system, together with a vapor preconcentrator, is being developed for application at Department of Energy facilities to provide an efficient way of searching for explosives carried on a person and made visible through $x$-ray imagery.

Systems for electronically controlling access to classified documents and performing inventory management have been developed and implemented at several DOE facilities. Future enhancements will allow the system to operate in a network environment and provide the capability to perform fulltext retrieval from documents scanned into the system. Future research will focus on the definition of information surety concepts and technologies which will have broad application to many national security, industrial, and personal privacy problems.

Access control technologies are critical to achieving security in the l)epartment of Energy as manpower is reduced. The requirement to automate access control at I)OE facilities has placed a 
high priority on the advancement of access control technologies, including biometric devices, badge technologies, and automated entry control systems.

Access delay technologies play a major role in achieving balanced and cost-effective security systems. Current developments are focused on inexpensive, activated, access-denial obscurants and modular access delay systems, such as portable vaults capable of protecting against aggressive explosive attacks. The access delay technology is also being extended to other applications, such its development of nonlethal weapons for application by other federal agencies.

Evaluation methodologies, vulnerability analysis tools, and modeling tools are being developed to assist system engineers and security managers in assessing the performance of their systems and to explore options for enhancing the protection of a facility. The models and analysis tools of the future will be used to perform broad system cost/benefit analyses and radiological/toxicological sabotage analy'ses.

A key purpose of the program is the transfer of technology to industry and government agencies through technology reports and handbooks, seminars, workshops, implementation assistance, and equipment performance specification and standardization. Instructional support is provided to the Department of Energy Central Training Academy by developing and presenting training materials for vulnerability assessment and physical protection systems engineering. With the end of the cold war and growing concern regarding proliferation of weapons of mass destruction, especially nuclear weapons, the technology developed in this program is being applied through technical exchanges to the protection of nuclear materials internationally.

\section{Intelligence (NT, NB04)}

Sandia's role as the nation's engineering laboratory responsible for nuclear weaponization activities and continuing stewardship of the U.S. nuclear stockpile uniquely positions it to support the DOE intelligence program in areas of foreign weapon program evaluation. With increasing international uncertainty, our expertise will continue to be of critical value in the assessment of the safety, security, proliferation, and dismantlement of foreign weapons of mass destruction.

Proliferation is an area in which significant program growth is expected. We are currently engaged in studies of proliferant weaponization options with an initial focus on nuclear weapon firing system technologies. We also perform related proliferation analysis tasks and evaluations of foreign weapon safety and security for DOE's Office of Intelligence. 


\section{Office of Environmental Restoration and Waste Management}

Work performed for the Office of Environmental Restoration and Waste Management includes Environmentally Conscious Manufacturing Technology, Waste Management Technology, Hazardous Material Transportation, Waste Repository (including the Waste Isolation Pilot Plant and the Greater Confinement Disposal project), and Waste Management and Waste Minimization for Sandia. Work performed for this office also includes site-specific corrective actions under the Environmental Restoration program.

\begin{tabular}{|c|c|c|c|c|c|}
\hline \multicolumn{6}{|c|}{$\begin{array}{l}\text { Summary of Programs for Office of Environmental Restoration and Waste Management } \\
\text { (Operating BA in } \$ \text { million) }\end{array}$} \\
\hline B\&R Code & Program Title & FY9? & FY93 & FY94 & FY95 \\
\hline \multirow[t]{2}{*}{ EW } & Environmental Restoration and Waste Management & 87.9 & 126.6 & 138.3 & 144.4 \\
\hline & Percent of total operating funds & $7 \%$ & $10 \%$ & $10 \%$ & $10 \%$ \\
\hline
\end{tabular}

\section{Defense Waste and Environmental Restoration (EW)}

\section{Environmentally Conscious Manufacturing}

Sandia is playing a key role in developing and demonstrating environmentally conscious manufacturing technologies and using a systems approach to apply them to the manufacture of nonnuclear weapons components. This program is focused on electronic assemblies and electromechanical components, with the goal of reducing the use of hazardous or environmentally injurious materials during weapons production. A concurrent goal is to transfer these environmentally conscious manufacturing technologies to U.S. industry after their successful demonstration for weapons production, resulting in increased competitiveness and decreased environmental cost during manufacture.

The cornerstone of this effort is the Environmentally Conscious Manufacturing Integrated Demonstration, a collaborative program with the Allied Signal/Kansas City Plant. In this program, the total systems approach is beirg used to eliminate generation of hazardous wastes during the manufacture of electronic components. The systems approach is used to identify areas where hazardous waste is generated or where workers could be exposed to hazardous materials and to identify opportunities for replacing these materials and processes with environmental'" benign environmentally conscious manufacturing technologies. This includes the replacement of hazardous organic compounds such as chlorofluorocarbons and chlorinated hydrocarbons with semiaqueous and aqueous cleaners; application of urethane foams and elastomers that do not contain carcinogenic precursors; use of no-clean fluxes and fluxless soldering, methylenedianiline-free printed wiring boards, chromium-free metal coatings and safe marking inks. Life-cycle analyses, including the costs and benefits associated with the new technologies, are an integral part of this demonstration.

This program involves research and development of technologies and methodologies for life-cycle analysis and decision-making at Sandia; coordination of complementary development and demonstration of the technology and life cycle methodologies at Allied-Signal/Kansas City; coordination of research at U.S. universities; and technology transfer through ongoing, aggressive development of partnerships with companies in the U.S. microelectronics industry.

Other current environmentally conscious manufacturing progran ins include the Environmentally Conscious Manufacturing Technology Transfer and Training Initiative, which focuses on the 
needs of small businesses; the Assessment of Waste Minimization for Common 1)(OE-Wide Waste Streams, which focuses on providing information to effect significant waste reduction across monitoring and control; and replacement of hazardous materials in surface coating, metal finishing, and precision machining.

\section{Waste Management Technology}

Sandia is involved with a wide variety of waste management technology activities. Our Waste Component Recycle, Treatment, and Disposal Integrated Demonstration for DOE focuses on developing regulatory-compliant technologies that can be demonstrated as complete systems for disposing and recycling electronic components.

The focus of this program is on electronic components from dismantled nuclear weapons. Many of these components contain hazardous materials, such as heavy metals, PCBs, self-contained explosives, radioactive materials, and gas-filled tubes. In addition, those with classified significance

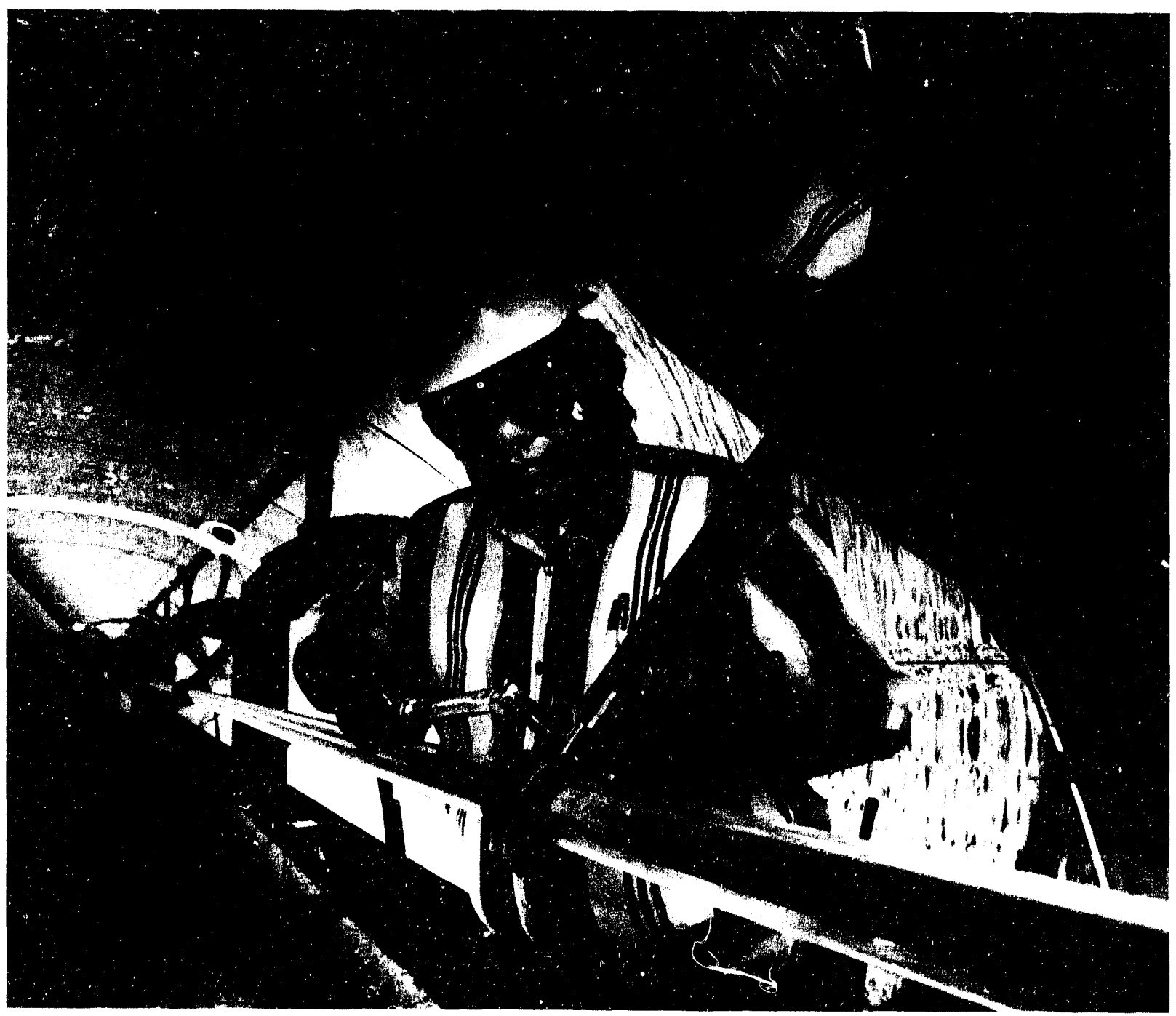

Larry Yellowhorse makes adjustments to a solar detoxification system that destroys organic toxins in groundwater. The system uses a reflective parabolic trough to focus the sun's energy on a long glass tube through which contaminated water, mixed with a catalyst, passes. Sandia and the National Renewable Energy Laboratory shared a 1992 R\&D 100 Award for the system's development. 
are generally sealed in a potting compound, making them difficult to separate. To carry out this demonstration, we are using not only Sandia's knowledge of systems engineering and techniques for separating hazardous materials, but we are also integrating a variety of technologies from other industries and laboratories to help destroy unusable hazardous materials and recycle valuable portions of the weapon electronic components.

Other waste management technologies under development include silica crystalline titanates for treatment of radioactive waste removed from the Hanford underground storage tanks; steam reforming for destroying organics and nitrates found in a variety of waste streams; monitoring and control systems for metal emission control systems for incineration processes; waste dislodging and conveyance technologies for underground storage tanks; supercritical water oxidation destruction of explosives and propellants; and solar detoxification of waste.

\section{Environmental Restoration}

The DOE Environmental Restoration Program was initiated in 1987 to consolidate and coordinate regulatory compliance activities designed to identify and remediate inactive sites at DOE installations contaminated with hazardous, radioactive, or mixed waste.

The goals of the Fnvironmental Restoration program are to address environmental problems resulting trom past practices, assess the extent and nature of these problems, and remediate affected sites, if needed, using the most effective and cost-efficient methods. Activities include identifying inactive hazardous-waste release sites, developing an environmental restoration investigation and remediation program, coordinating NEPA (National Environmental Policy Act) documentation, obtaining necessary permits, evaluating surface and groundwater contamination potential, reviewing practices affecting sites with underground storage tanks, evaluating other waste management practices, and ensuring compliance with federal, state, and local environmental regulations. Projects involve the investigation and remediation of inactive waste-handling, disposal, and spill sites in accordance with the provisions of the Resource Conservation and Recovery Act (RCRA), the Comprehensive Environmental Response, Compensation, and Liability Act (CERCLA), and relevant DOE orders.

Three primary regulatory drivers form the basis for environmental restoration program investigation and remediation. These include (l) Section 3004(u) provisions of the Resource Conservation and Recovery Act (RCRA) which require corrective actions for releases from solid waste management units; (2) RCRA provisions requiring closure and post-closure care for inactive treatinent, storage, and disposal units; and (3) requirements of the Comprehensive Environmental Response, Compensation, and Liability Act (CERCLA) addressing remediation of releases of hazardous substances in accordance with the National Contingency Plan. Most of the Environmental Restoration sites fall under RCRA, while some will be addressed in a manner consistent with the National Contingency Plan.

Sandia's environmental restoration efforts are grouped in the following three categories:

1. RCRA Corrective Actions: Efforts required to address re leases of RCRA hazardous waste or constituents from solid waste management units.

2. RCRA Closure Actions: Efforts pertaining to the closure of inactive RCRA treatment, storage, and disposal units that will not be permitted for continuing operation.

3. Other Actions: Assessment or remediation of sites from which there has been a release or where a substantial threat of a release of a hazardous substance exists.

In 1992, Region VI of the Environmental Protection Agency issued Sandia a permit that established a schedule for the assessment and remediation of environmental restoration sites under RCRA corrective action authority at Sandia/New Mexico. 


\section{Hazardous Material Transportation and Crosscut Technologies}

The principal program for the Office of Environmental Restoration and Waste Management is contained in a group of technical tasks that make up the Transportation Technology Development Program. This program embraces projects in the following areas:

- Advanced Technology Development - Characterizing vaterials (especially casting metals and brittle materials) that could be useful in transportation and waste management

- Packaging Development - Working with projects to evaluate packaging applications, and working out design features and materials compatibility issues

- Engineering Analysis - Fine tuning of thermal and structural analysis codes, developing code modules, and creating databases specific to transportation problems

- Certification and Regulatory Support - Providing technical expertise to DOE elements involved in packaging certification efforts and supporting DOE efforts in clarification, analysis, and change to regulations at the international and national levels

- Environmental and System Planning - Developing system analysis techniques, risk assessment codes, and data relating to transportation systems operations (including material flows, modal options, accident data and phenomenology)

- Testing - Performing tests to support package certification and confirmation of new design concepts and provide confirming results for code confirmation

- Transportation Automation and Technical Assistance - Providing the TRANSNET technology transfer facility to furnish the results of DOE work to a variety of users

- Transportation Intelligent Monitoring Systems - Developing technologies to improve the emergency response systems for DOE activities

- Geographic Information Systems - Developing geographic information systems links for routing preferred route determination algorithms and accident rate prediction codes

- Source Term Containment Evaluation - Developing information and analysis techniques for setting the requirements for allowable package leakage

\section{Waste Repository}

The Waste Isolation Pilot Plant

Sandia is responsible for the testing, modeling, and performance assessment required to demonstrate the long-term behavior and containment properties of the Waste Isolacion Pilot Plant repository. We are also responsible for assessing the long-term waste properties and performance sufficient to determine if the Waste Isolation Pilot Plant is a suitable disposal facility for the Department of Energy's transuranic waste.

Sandia will support DOE by providing a detailed geotechnical understanding of the Waste Isolation Pilot Plant Site (located in Carlsbad, New Mexico), research on issues related to disposal of transuranic mixed waste in bedded salt (necessary to provide data for performance assessment calculations), and detailed performance assessment research to evaluate compliance with. Environmental 
Protection Agency standards for disposal of transuranic and transuranic-mixed waste in geologic repositories. Sandia will provide scientific assistance for completion of the test phase of the overall the Waste Isolation Pilot Plant project (expected to last for at least five years) and activities to meet the requirements of the Legislative Land Withdrawal Bill signed into law in late 1992.

The scope of Sandia's activities to support the Waste Isolation Pilot Plant Project includes: (1) disposal room and drift system, (2) transuranic waste experiments, (3) sealing systems and rock mechanics, (4) hydrologic transport properties of the Salado (salt) formation, (5) flow and transport properties of non-Salado components of the formation, (6) performance assessment, and (7) other activities.

1. The disposal room and drift system activities utilize backfills, brine, simulated waste, waste containers, simulated disposal rooms, test designs, equipment, and instrumentation necessary for laboratory and field experiments to provide an understanding of important waste interactions to support development of radioactive source term and gas generation models. This activity addresses transuranic mixed waste and backfill interaction with the surrounding rock for the various chemical environments that are possible in a waste room. The combined interactions of the waste, waste containers, emplaced backfill and admixtures, brine inflow that results in gas gener: 'ion, and dissolution of radioactive and hazardous constituents are studied through laboratory testing, modeling, and field testing. The behavior and performance of possible backfills and additives to be emplaced in access drifts as part of the facility decommissioning are also being investigated.

2. The transuranic mixed waste experiments utilize mined rooms, bins, transuranic mixed waste, waste containers, test facilities, test designs, equipment, and instrumentation necessary for gathering data on gas generation and the interaction of waste in a simulated repository environment. This activity includes all tests that use actual transuranic waste, as well as necessary sampling, data gathering, analysis, and interpretation. The tests include bin-scale tests, simulated-scale tests, and liter/drum-scale experiments at Los Alamos National Laboratory for acquisition of gas generation information and solubility waste interactions data from actual transuranic waste.

3. The sealing systems and rock mechanics activity utilizes seal materials such as salt, concrete, clays, and other fillers in laboratory and field settings. They include test designs, equipment, and instrumentation for the seal studies and the evaluation of rock mechanics properties of the repository and overlying host rock formations penetrated by shafts, boreholes, and disposal rooms. Seals will be developed for use in drifts to isolate waste panels, in access shafts to isolate the repository from accessible environments, and in exploratory boreholes. This activity also includes evaluation of waste room and drift structural response, shaft closure, and healing of fractures in the disturbed rock zone outside excavations and around seals in shaft and access drifts. Laboratory and in situ tests will provide data for models to evaluate the behavior of potential seal material such as crushed salt, salt/clay admixtures, and concretes, as well as excavation closure, fracture behavior, and the behavior of penetrations through the repository host rock.

4. The Salado hydrology and transport activities utilize test designs, equipment, and instrumentation for laboratory and field studies measuring a variety of hydrologic parameters of the repository host rock. This activity includes laboratory and field experimentation and modeling studies of fluid flow characteristics of the Salado Formation such as permeability, threshold pressure, and two-phase characteristics. Data from the experiments will be input to databases and models of brine and gas transport into and away from the repository. 
5. The non-Salado and transport flow activities utilize test designs, equipment, and instrumentation for laboratory and field studies measuring a variety of hydrologic and chemical transport parameters of the formations overlying the repository host rock. This activity includes fundamental separate effects laborator' experiments for the development of models of radionuclide transport properties in $t_{i}:$ Rustler Formation under present and future conditions. Integral-effects laboratory studi $s$ of radionuclide retardation in the Rustler host rock are also included, as well as in situ hydrologic and tracer tests. Also included is the development of mechanistic models of flow and transport in the units above the Salado, examination of alternative conceptual models, validation of models against data, and verification of models.

6. The performance assessment activities utilize input from databases and models of the preceding five activities. This activity designs, develops, and implements the comprehensive performance assessment model, including hardware and software interfaces with the research and development elements for modeling, verification, validation, sensitivity analysis, documentation, and the interface with regulatory agencies. This activity includes documentation and demonstration of the calculations that comprise the model that assesses performance of the Waste Isolation Pilot Plant as a geologic repository for nuclear waste. The model results will be compared to the regulatory requirements of Code of Federal Regulations, Title 40, Part 191 and portions of the requirements of the Resource Conservation and Recovery Act. The comparisons will be a significant part of the basis of the disposai phase decision.

7. The other activities are generally concerned with integration and management. These activities include: interfaces with program oversight groups for responses to inquiries and audits, and industrial safety; integration with waste acceptance criteria functions for transuranic waste experiments and the definition of the inventory needed for performance assessment; and quality assurance, general program management, administrative support, and support for institutional activities.

\section{Greater Confinement Disposal Project}

Sandia was recently selected by the DOE Nevada Operations Office as lead laboratory for conduc liu:? the assessment of compliance for the Greater Confinement Disposal site. The Greater Confinemk in Disposal site, located in the southeastern corner of the Nevada Test Site, is being considered for permanent disposal of uncertifiable defense transuranic waste, greater-than-Class-Clow-level waste, performance-limited waste, nondefense-generated transuranic waste, and other DOE sealed-source wastes.

Sandia's role in the Greater Confinement Disposal project includes (1) technical program integration, (2) development of overall project strategy, (3) development and implementation of compliance assessment strategy, (4) model development and application, and (5) systems configuration.

\section{Waste Management Operations}

Sandia's program for waste management includes staff training, equipment and supplies, contractor support, and costs associated with the management, collection, packaging, storage, transportation, treatment, and disposal of chemical, radioactive, and mixed wastes in Albuquerque, New Mexico and Tonopah, Nevada. The scope of the waste management program includes providing guidance to Sandia gener'tors of waste; performing surveillance on compliance; providing qualified personnel to interact with DOE and the EPA and states on matters concerning waste issues; preparing or reviewing waste permit applications; and reviewing requirements changes to assess programmatic impact. The waste management program is also responsible for collecting, storing, and arranging 
for off-site shipment, treatment, and disposal of wastes. RCRA storage occurs at 90-day accumulation areas, interim status facilities, and at the permitted hazardous waste management facility.

Radioactive and toxic wastes are stored on-site at various facilities.

\section{Waste Minimization Operations}

The purpose of this activity is to plan and coordinate a program that will minimize the generation of hazardous, radioactive, and mixed wastes and to develop a culture in which waste minimization concepts become an integral part of all considerations. These efforts offer increased protection of employee welfare, public health, and the environment.

The waste minimization program formally began in FY 1989. The waste minimization network, made up of technical personnel in waste-generating organizations, was later created to facilitate education and program implementation in Sandia organizations. A Waste Minimization Steering Committee was also formed to advise and direct policies and procedures of the program and aid in the allocation of waste minimization implementation funding. 


\begin{tabular}{|c|c|c|c|c|c|c|c|}
\hline \multicolumn{8}{|c|}{$\begin{array}{l}\text { EM Anticipated Requirements } \\
\text { (Budget Authority in } \$ \text { million) }\end{array}$} \\
\hline & \multicolumn{7}{|c|}{ (\$FY 1995) } \\
\hline & FY93 & FY94 & FY95 & FY96 & FY97 & FY98 & FY99 \\
\hline \multicolumn{8}{|l|}{ Environmental Restoration } \\
\hline Operating & 28.3 & 46.6 & 34.5 & 34.5 & 34.5 & 34.5 & 34.5 \\
\hline \multicolumn{8}{|l|}{ EM Corrective Actions } \\
\hline Operating & 1.7 & & & & & & \\
\hline Capital equipment & 0.4 & & & & & & \\
\hline General Plant Projects & 0.5 & & & & & & \\
\hline Total & 2.6 & & & & & & \\
\hline \multicolumn{8}{|l|}{ Waste Management* } \\
\hline Operating & 64.8 & 56.0 & 74.2 & 74.2 & 74.2 & 74.2 & 74.2 \\
\hline Capital equipment & 1.5 & 3.3 & 4.1 & 4.1 & 4.1 & 4.1 & 4.1 \\
\hline General Plant Projects & 0.6 & 4.3 & & & & & \\
\hline Total & 66.9 & 63.6 & 78.3 & 78.3 & 78.3 & 78.3 & 78.3 \\
\hline \multicolumn{8}{|l|}{ Technology Development } \\
\hline Operating & 25.1 & 23.7 & 23.7 & 23.7 & 23.7 & 23.7 & 23.7 \\
\hline Capital equipment & 1.2 & 1.1 & 1.1 & 1.1 & 1.1 & 1.1 & 1.1 \\
\hline Total & 26.3 & 24.8 & 24.8 & 24.8 & 23.7 & 23.7 & 23.7 \\
\hline \multicolumn{8}{|l|}{ Transportation } \\
\hline Operating & 6.7 & 9.5 & 9.5 & 9.5 & 9.5 & 9.5 & 9.5 \\
\hline Capital equipment & 0.2 & 0.3 & 0.3 & 0.3 & 0.3 & 0.3 & 0.3 \\
\hline Total & 6.9 & 9.8 & 9.8 & 9.8 & 9.8 & 9.8 & 9.8 \\
\hline \multicolumn{8}{|c|}{ Transition Planning and Implementation } \\
\hline Operating & & 2.5 & 2.5 & 2.5 & 2.5 & 2.5 & 2.5 \\
\hline \multicolumn{8}{|l|}{ Total EM Funding } \\
\hline Operating & 126.6 & 138.3 & 144.4 & 144.4 & 144.4 & 144.4 & 144.4 \\
\hline Capital equipment & 3.3 & 4.7 & 5.5 & 5.5 & 5.5 & 5.5 & 5.5 \\
\hline General Plant Projects & 1.1 & 4.3 & & & & & \\
\hline Proposed construction & & & & & 3.6 & 3.7 & 8.0 \\
\hline Total & 131.0 & 147.3 & 149.9 & 149.9 & 153.5 & 153.6 & 157.9 \\
\hline *Includes WIPP & & & & & & & \\
\hline
\end{tabular}




\section{Energy Programs}

Sandia supports the Department of Energy's goals of providing secure and environmentally acceptable energy supplies improving energy production, conversion, and use. Drawing upon more than twenty years of broad experience in energy research and technology development, Sandia now specializes in certain areas within this arena.

Our current programs comprise high-temperature superconductor research for electric power systems, stationary battery storage system for utilities, geothermal energy systems, the solar electric technologies (photovoltaic and solar thermal), wind energy, and industrial and transportation applications. These programs provid a bridge to industry, allowing Sandia to develop a strong record in technology transfer.

\section{Assistant Secretary for Energy Efiiciency and Renewable Energy}

Sandia's energy programs bring creative solutions to global energy problems, including the environmental consequences of energy use. We place particular emphasis on nurturing renewable energy technologies that establish a partnership with U.S. industry and provide economical, practical, environmentally friendly answers to worldwide energy issues. We base our assessment of these attributes on years of practical field experience, laboratory studies, and systems analysis.

Our programs are in the areas of energy management, renewable energy technology, industrial technology, and advanced transportation. This work strives to establish technology bases that will support the efforts of the private sector and to build confidence with industry and users to accelerate their acceptance. Major activities include engineering studies to identify preferred system applications and configurations, and fielding and evaluation of prototype systems.

\begin{tabular}{|c|c|c|c|c|c|}
\hline \multicolumn{6}{|c|}{$\begin{array}{l}\text { Summary of Programs for Assistant Secretary for Energy Efficiency and Renewable Energy } \\
\qquad \text { (Operating BA in \$ million) }\end{array}$} \\
\hline B\&RCode & Program Title & FY92 & FY93 & FY94 & FY95 \\
\hline AK & Electric Energy Systems & 1.3 & 1.5 & 2.5 & 3.5 \\
\hline $\mathrm{AL}$ & Energy Storage Systems & 3.0 & 3.7 & 5.0 & 6.5 \\
\hline AM & Geothermal Systems & 5.0 & 7.1 & 7.5 & 7.4 \\
\hline EB & Solar Energy & 30.0 & 26.5 & 31.3 & 31.2 \\
\hline ED & Industrial Sector & 7.9 & 4.8 & 8.3 & 9.8 \\
\hline EE & Tran portation Sector & 1.7 & 2.4 & 3.3 & 2.5 \\
\hline EC & Buildings Sector; and & & & & \\
\hline \multirow[t]{3}{*}{ EF } & State and Local Programs & 0.3 & & & \\
\hline & Total & 49.2 & 46.0 & 57.9 & 60.9 \\
\hline & Percent of total operating funds & $4 \%$ & $4 \%$ & $4 \%$ & $4 \%$ \\
\hline
\end{tabular}

\section{Electric Energy Systems (AK)}

Sandia is developing $\mathrm{p}$. actical, high-temperature superconducting wire and magnets that can be used to improve the efficiency of electric motors, generators, and transmission lines and provide fast-discharge energy storage in the form of superconducting magnetic energy storage. 
This work contributes to optimized high-temperature superconducting materials, conductor fabrication technology, and to the design and evaluation of prototype devices that can improve the economics and energy efficiency of electric power generation and distribution systems. We actively involve industry in all of this work.

\section{Energy Storage Systems (AL)}

Sandia is working with industry to develop advanced rechargeable battery systems for utility energy storage applications as part of the DOE Utility Battery Storage Systems program, which Sandia manages and directs. Cost-shared contracts with industry partners provide the vehicle for systems development in this area. Sandia's technical expertise is used to analyze the benefits of battery storage in utility systems, to evaluate prototype batteries, and to do applied research.

\section{Geothermal Systems (AM)}

Sandia's geothermal systems work is designed to increase the nation's proven geothermal reserves and assist industry in expanding geothermal power on-line. We are developing new drilling and completion technologies to help expand the commercial use of U.S. geothermal resources. The technologies we develop in this area can also be used in petroleum and mineral extraction.

Slimhole drilling is a new technique Sandia is perfecting to reduce drilling costs in assessing hydrothermal reservoirs. Our major work in geothermal systems includes developing high-temperature instrumentation for geothermal wells, acoustic telemetry to transmit downhole data through the drill pipe while drilling, and drilling a deep exploratory well in an active volcanic caldera in California.

\section{Solar Energy (EB)}

\section{Solar Thermal}

Engineers in Sandia's solar thermal programs work with users and manufacturers of solar thermal electric systems to increase the acceptance of solar thermal technologies as cost-competitive candidates for power generation and to further their commercialization. Sandia operates the National Solar Thermal Test Facility, where it evaluates solar thermal technologies and performs specialized tests requiring high heat, a capability both government and industry use. Sandia provides technical support to Solar Two, a cost-shared project with a consortium of utilities to upgrade the Solar One power tower pilot plant using molten salt heat collection and storage technology.

Sandia conducts research and technology development with advanced solar thermal components, dishes, heliostats, and receivers for dish and central receiver systems and performs systems design and analysis and testing of components and systems. In a joint venture with industry, Sandia is developing the first commercial dish-Stirling system. We operate a Design Assistance Center that promotes the use of solar thermal technologies through services to manufacturers, operators, and decision-makers and through educational outreach.

\section{Photovoltaics}

Sandia's work with photovoltaics is centered on developing cost-effective, reliable photovoltaic energy system technology, produced by U.S. industry, that is used for worldwide energy supplies. Through its Design Assistance Center, Sandia teams with other agencies to accelerate development and acceptance of the technology at home and abroad by offering technical expertise and evaluations.

Sandia uses its engineering skills to assist industry in developing high-performance, low-cost one-sun and concentrator cells, designing cost-effective module technologies, and perfecting balance- 


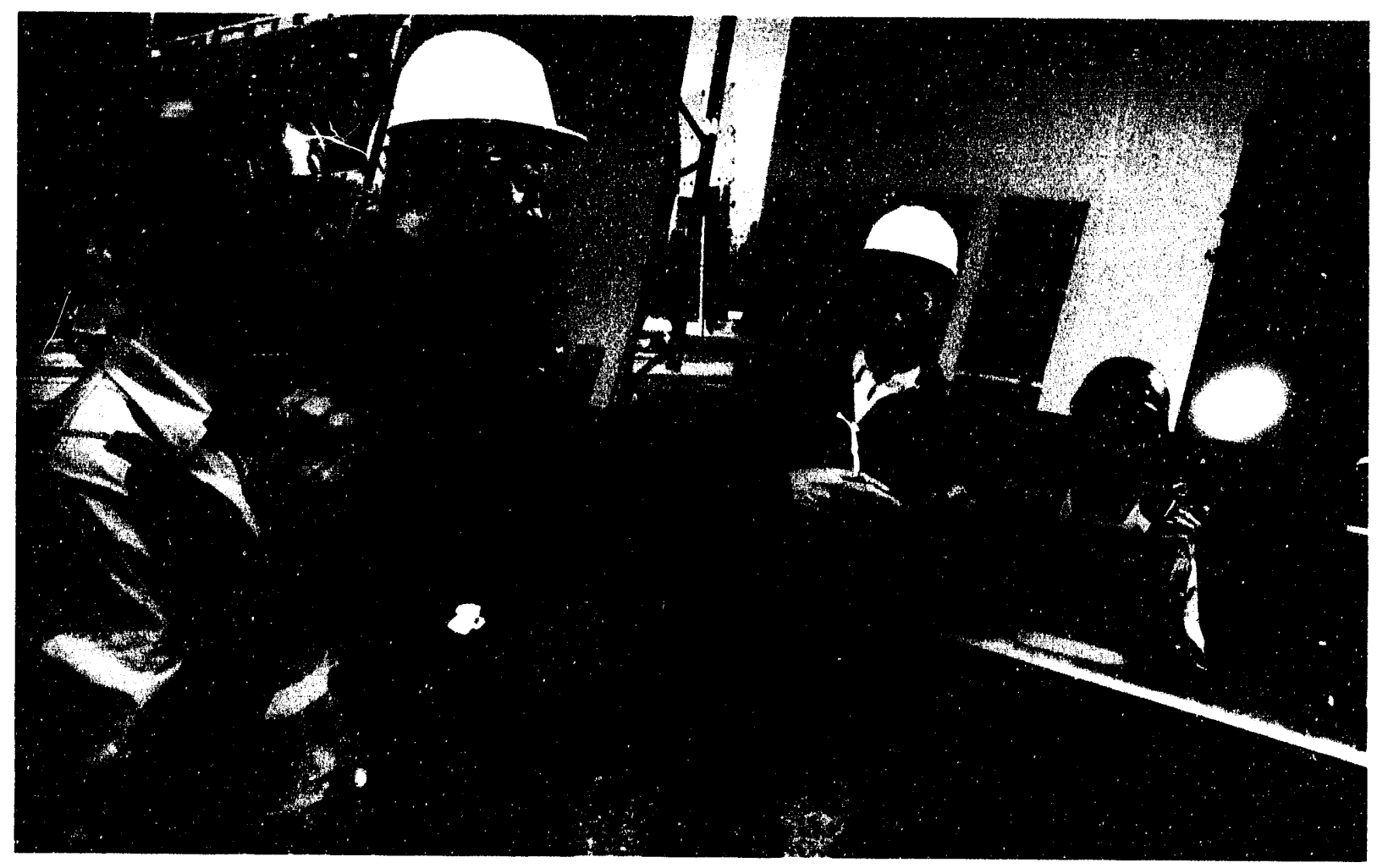

Sandia researchers have played a key role in developing solar thermal power technology since the early 1970s. Jim Chavez and Greg Kolb are seen here examining glass on a 25-foot-square suntracking heliostat. Similar heliostats will be used at "Solar Two," the upgraded commercial solar power plant near Barstow, California. of-systems hardware. It assists industry by providing accurate performance measurements, and reliability testing and evaluation.

\section{Wind Power}

Sandia is developing wind turbine technologies to provide viable and economical systems for commercial power generation. Sandia conducts applied research in aerodynamics, structural dynamics, fatigue, materials, and controls, including the systems integration of these areas, to increase understanding of phenomena and provide more effective design tools.

Sandia has lead laboratory responsibility for Vertical Axis Wind Turbine technology and is also developing appropriate cooperative activities with industry to transfer this technology to the U.S. wind power industry. Sandia engineers are developing user-friendly analytical tools for industry use, as well as identifying additional research needs.

\section{Industrial Sector (ED)}

\section{Combustion Technology}

Combustion work is performed at Sandia/California's Combustion Research Facility and includes experimental, theoretical, and computational investigations aimed at reducing energy consumption, preserving the environment, and fortifying science and engineering foundations. This work utilizes the unique laser diagnostic capabilities of the research facility.

Sandia collaborates on its combustion projects with industry and concentrates on work that will reduce toxic emissions without compromising the efficiency of fuel use, developing improved technologies for high-efficiency, low-emission internal combustion engines, and improved environmental tcchnology systems for destruction of hazardous wastes. 


\section{Materials Processing by Design}

The programs working with industrial and manufacturing processes are striving to improve existing processes and develop new ones that are commercially and environmentally acceptable for the chemicals, petroleum, durable goods, and semiconductor industries.

This work involves exploring the underlying physics, chemistry, thermodynamics, and fluid mechanics of new processes for manufacturing commercially important chemicals, powders, composites, coatings, and membranes. We nake predictive models of high-temperature chemicals and materials synthesis processes that industry can use in its design, organization, and waste minimization efforts. We also use laser-based sensors to monitor and control manufacturing processes in the steel, chemical, petroleum, and semiconductor industries.

\section{Advanced Industrial Concepts/Materials Research}

Sandia's materials research work in the industrial technologies program is tasked with providing computer-aided design, synthesis, characterization, and testing of new enabling mate rials with the potential for energy savings and waste reduction in industrial applications.

Currently, the focus is on developing chemically specific coatings, sensors, and membranes for energy savings through improved processes, synthesizing composites by reactive metal infiltration, producing lightweight structural materials with improved performance, and developing novel catalysts for simultaneous conversion and separation of petrochemicals.

\section{Advanced Industrial Concepts/Biochemical and Chemical Technologies Research}

Sandia supports development of techniques for catalysis by design in projects that use computeraided molecular design of biomimetic carbon dioxide activation catalysts. The goals of the research include computer-aided molecular design of catalysts that mimic carbon-dioxide-activating enzymes, development of improved molecular modeling techniques, structural studies of carbon-dioxideactivating enzymes, synthesis, characterization, and testing of designed biomimetic catalysts, and integration of successful catalysts into a solar-driven process.

The project involves collaborative work with several industrial and university groups.

\section{Industrial Waste \\ Reduction Program}

Sandia acts in partnership with industry to develop and commercialize cost-effective waste reduction technologies and practices. The program focuses its combined resources on the problems of reducing wastes generated in manufacturing processes and improving energy efficiency of industrial processes. The broad goal is to stimulate, facilitate, and coordinate development and transfer of waste reduction and energy savings technologies to industry.

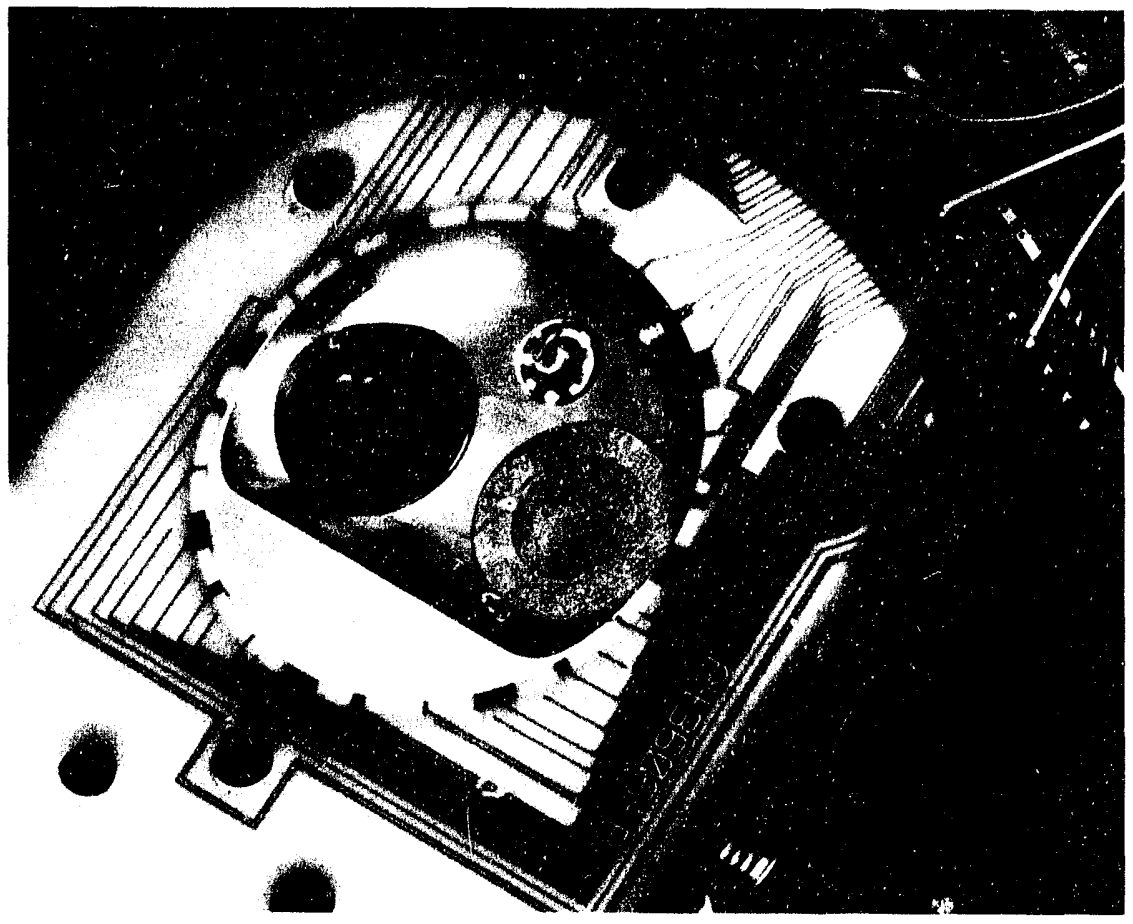


The program is being carried out in cost-shared projects with industry and involves characterizing waste, assessing promising opportunities for waste reduction, and analyzing barriers to implementation of waste-reduction strategies. We transfer industrial waste reduction technologies to specific companies and to industry as a whole.

\section{Transportation Sector (EE)}

Sandia is working to reduce the environmental impacts of the automobile by working on advanced batteries, hybrid systems, and such activities as the clean-car initiatıve. Engineers at Sandia are developing more efficient engine technology, improved emission catalyst and emission systems, and improved batteries for electric vehicles.

Sandia has a cooperative research and development agreement with the U.S. Advanced Battery Consortium for research and development on electric vehicle battery technologies. The objective is to advance these technologies to a level of maturity that will encourage industry to become a partner in the development program. If successful, industry would then pursue manufacturing development and commercialization of batteries for electric vehicles. 


\section{Office of Civilian Radioactive Waste Management}

Effort for the Director of Civilian Radioactive Waste Management is expected to peak between FY 19)3 and 2001. Sandia's major activities address transportation and geologic disposal of spent fuel and high-level radioactive waste.

\begin{tabular}{|c|c|c|c|c|c|}
\hline \multirow[b]{2}{*}{$\underline{B \& R \text { Code }}$} & \multicolumn{5}{|c|}{$\begin{array}{l}\text { Summary of Programs for Office of Civilian Radioactive Waste Management } \\
\text { (Operating BA in } \$ \text { million) }\end{array}$} \\
\hline & Program Title & FY92 & $\underline{\text { FY93 }}$ & FY94 & FY95 \\
\hline DB & Nuclear Waste Fund & 16.6 & 15.6 & 25.2 & 25.4 \\
\hline & Percent of total operating funds & $1 \%$ & $1 \%$ & $2 \%$ & $2 \%$ \\
\hline
\end{tabular}

\section{Nuclear Waste Fund (DB)}

The dominant effort in this program is the Yucca Mountain Project, an investigation to determine the feasibility of siting a commercial nuclear waste repository in the volcanic tuffs of Yucca Mountain on the Nevada Test Site. Sandia's responsibilities in this multifaceted project are to:

- Assess the performance of the repository system by modeling based on the design of the system and the known characteristics of the site;

- Use the assessments to determine the system's ability to comply with regulations;

- Use the assessments to guide the collection of data at the site and w support the further design of the system;

- Perform laboratory tests and develop theoretical understanding of properties of tuff for repository design and performance assessment;

- Develop predictive models that describe water migration in tuff and identify the important parameters;

- Perform field tests to measure some properties of the rock in the repository system;

- Develop and evaluate conceptual designs for borehole, shaft, and drift seals for the repository.

The repository design resulting from this effort will be capable of handling high-level commercial and defense wastes as well as spent fuel. Sandia published the conceptual design to support the Site Characterization Plan in FY 1989. (Our current role is to use our performance-assessment capabilities to help set requirements for site characterization and design and examine the design for its ability to comply with regulations.

Our role in testing and performance assessment will be to help develop a license application that the 1)OE expects to submit to the Nuclear Regulatory (Commission in 2001. 'Test results and analyses of performance will be major contributors to the Commission's examination of the repository system?'s ability to meet regulations.

Sandia's Transportation Technology (enter continues to support the program mission to develop safe and efficient systems for transporting spent fuel and for handling packages. The design and production of actual systems for transporting commercial wastes to storage or repositories are being performed in the private sector. Sandia will continue to participate in te hnology-base and technology-transfer activities that will be needed to certify the new generation of waste packagings. 


\section{Assistant Secretary for Fossil Energy}

The primary objective of Sandia's fossil energy work is to develop technologies that will promote the clean use of the nation's coal resource and maintain a secure economic supply of natural gas and crude oil. Sandia is obtaining basic information to use in designing, optimizing, and cleaning up the current and next-generation coal combustion systems, developing advanced catalysts and process concepts to convert coal to environmentally compatible liquid fuels, providing scientific support to assure reliable design and safe performance of undererround storage systems, and providing geophysical instrumentation systems for improved fossil energy reservoir diagnostics. Sandia also works in research and development partnerships with the coal utilization industry and with the petroleum industry. Sandia supports the Department of Energy Office of the Strategic Petroleum Reserve. Our coal combustion programs interact strongly with U.S. industry through our Combustion Research Facility users' programs.

\begin{tabular}{|c|c|c|c|c|c|}
\hline \multirow[b]{2}{*}{ B\&R Code } & \multicolumn{3}{|c|}{$\begin{array}{l}\text { Summary of Programs for Assistant Secretary for Fossil Energy } \\
\text { (Operating BA in \$ million) }\end{array}$} & \multirow[b]{2}{*}{$\underline{\text { FY94 }}$} & \multirow[b]{2}{*}{ FY95 } \\
\hline & Program Title & FY92 & FY93 & & \\
\hline$A A$ & Coal & 4.5 & 3.5 & 4.1 & 2.5 \\
\hline$A B$ & Gas & 0.4 & 0.6 & 1.3 & 1.0 \\
\hline$A C$ & Petroleum & 2.9 & 2.6 & 4.2 & 2.5 \\
\hline \multirow[t]{3}{*}{$S A$} & Strategic Petrcleum Reserve & 1.9 & 2.1 & 2.5 & 2.5 \\
\hline & Total & 9.7 & 8.8 & 12.1 & 8.5 \\
\hline & Percent of total operating funds & $1 \%$ & $1 \%$ & $1 \%$ & $1 \%$ \\
\hline
\end{tabular}

\section{Coal (AA)}

\section{Coal Conversion}

Sandia supports the research program implemented by the 1)epartment of Energy/Pittsburgh Energy Technology Center through leading efforts in catalyst development for direct and indirect liquefaction processes. This work involves studying coal reactivity, understanding the relationship of reactivity to the molecular and macroscopic structure of coal, and developing advanced catalysts and catalytic processes for coal con ersion.

Research is focused on the catalytic conversion of coal to liquid fuels at more moderate temperatures and pressures with optimum hydrogen use and with effective removal of sulfur and nitrogen. We are also using computer-aided molecular design techniques to study coal structure and design catalysts for the direct conversion of light hydrocarbons to alcohols and other liquid fuels. Sandia is establishing a center for the evaluation o. 'catalysts for the Department of Energy's Fine Particle Catalyst Program.

\section{Coal Combustion}

Sandia uses its (combustion Research Facility in conjunction with the Department of Energy's ()ffice of Fossil Energy and with industrial partners in the United States to acquire the basic information necessary to develop predictive models of the be havior of the organic and inorganic constitu 'nts in commercially important coals from the United States to use in designing, optimizing, and cleaning up the current and next generation of coal combustion systems. 
The work includes determining the chemical kinetics and mechanisms of coal pyrolysis and char oxidation, determining the significance to the quality of coal on unburned carben in the exhaust, conducting pilo, cale research to establish the mechanisms of transformation, release, and deposition of inorganic species during coal combustion, developing user-oriented models to predict the combustion and behavior of the ash of coals from the United States in current and in the next-generation coal combustors, and developing and validating optical diagnostic sensors for in situ measurement of state properties, gas species composition, and particulate loads in coal combustors.

\section{Gas (AB), Unconventional Gas Recovery}

The objectives of the natural gas program are to improve the production of natural gas from lowpermeability gas reservoirs by combining comprehensive geologic characterization with the development of new reservoir stimulation technology.

Sandia performs geotechnical studies in the areas of sedimentology and natural fractures, geomechanies and in situ stress, and reservoir stimulation. Sandia is developing a methodology to aid industry in understanding and exploiting natural fracture systems in western basins.

\section{Petroleum (AC)}

The petroleum program has two parts: advanced extraction process technology and improved oil recovery. Sandia is developing superior geophysical techniques for improved reservoir characterization and in situ process monitoring. A key effort is the development of advanced computational capabilities for design and assessment of the many different source receiver variations that are possible, and the interpretation of field data by both forward and inverse analyses. Selected methods are evaluated in field experiments conducted at various sites in conjunction with other national laboratories, industry, and universities.

In addition, Sandia is developing technologies that will improve production and recovery of the domestic oil resource. A reservoir simulation capability has been developed and applied that describes and predicts resistivity changes. Sandia measures in situ stresses and other long-term phenomena at the Ekofisk Field in the North Sea, in conjunction with Phillips Petroleum, which has led to a concept of geomechanics for reservoir management that views reservoirs as dynamic systems that must be studied with full awareness of their changing conditions over their lifetimes. Sandia participates in the ( )il Recovery Technology Partnership, a joint program with Los Alamos National Laboratory, to match technology with the needs of the petroleum industry.

\section{Strategic Petroleum Reserve (SA), Storage Facilities Development}

Sandia is developing technology to enable safe underground crude oil storage for the U.S. Strategic Petroleum Reserve and to support commercial underground storage of petroleum liquids and natural gas. The program involves site characterization, engineering design assistance and evaluation, and it fields instrumentation to provide long-term cavern monitoring, validate cavern creep closure models, assess the integrity of wells and casings penetrating the caverns, and certify the integrity of caverns. In addition, engineers address specific geotechnical problems, such as the potential impact of water leaks on withdrawal of oil from mines, and conduct studies to determine optimum cavern drawdown scenarios based on geotechnical considerations.

The technology developed for cavern creation, testing, and operation is currently being applied tocommercial cavern development for natural gas storage under a technology transfer program. 


\section{Office of Nuclear Energy}

Current efforts fo: the Office of Nuclear Energy focus principally on existing and advanced light water reactor technology. Nuclear power is an essential component of this nation's encrgy supply mix, and its environmental advantages are becoming appreciated considering worldwide concern over the emission of greenhouse gases from fossil-fuel power plants. The United States has invested over $\$ 200$ billion in nuclear power facilities that generate 20 percent of its electricity. Nuclear power plants are licensed for 40 years, but studies indicate that plant life could be extended by an additional 20 to 30 years. If an average of 10 years additional operation could be gained, $\$ 170$ billion would be saved.

Specific activities emphasizing Sandia's strengths include studies of systems concepts and technology evaluation, safety and reliability analyses, electronic devices operating in severe environments, aging management techniques to ensure equipment functionality, component testing, engineering of high-reliability components, and knowledge of materials behavior and degradation. Sandia has devised a step-by-step methodology for evaluating plant equipment (focusing on systems, structures, and components that are subject to age-related degradation) that may pave the way for safe, extended operation of nuclear power plants. The methodology is endorsed by the nuclear power industry as its technical approach to license renewal.

These efforts are expected to remain steady at current funding levels for Sandia given new administrations' goals to support only the light water reactor concepts.

\begin{tabular}{|c|c|c|c|c|c|}
\hline \multirow[b]{2}{*}{ B\&R Code } & \multicolumn{3}{|c|}{$\begin{array}{l}\text { Summary of Programs for Assistant Secretary for Fossil Energy } \\
\text { (Operating BA in \$ million) }\end{array}$} & \multirow[b]{2}{*}{$\underline{\mathrm{FY} 94}$} & \multirow[b]{2}{*}{$\underline{F Y 95}$} \\
\hline & Program Title & $\underline{\text { FY92 }}$ & $\underline{\text { FY93 }}$ & & \\
\hline$A A$ & Coal & 4.5 & 3.5 & 4.1 & 2.5 \\
\hline$A B$ & Gas & 0.4 & 0.6 & 1.3 & 1.0 \\
\hline$A C$ & Petroleum & 2.9 & 2.6 & 4.2 & 2.5 \\
\hline \multirow[t]{3}{*}{ SA } & Strategic Petroleum Reserve & 1.9 & 2.1 & 2.5 & 2.5 \\
\hline & Total & 9.7 & 8.8 & 12.1 & 8.5 \\
\hline & Percent of total operating funds & $1 \%$ & $1 \%$ & $1 \%$ & $1 \%$ \\
\hline
\end{tabular}

\section{Nuclear Energy Research and Development (AF)}

The objectives of this work are to improve the safety, reliability, and cost-effectiveness of commercial light water reactors, to enable license renewal of existing light water reactors and demonstrate new, simplified regulations $f$, $r$ siting of advanced light water reactors.

Sandia operates the Light Water Reactor Technology Management (Center for I)()E. Activities are focused on developing and implementing reactor safety features and concepts that offer significant safety improvements and longer operating lives, and on developing approaches for improving the reactor licensing process. Projects include studying the technical, institutional, and economic aspects of extending the licensed lifetimes of commercial nuclear power plants, conducting technical studies in support of DOE's nuclear regulatory reform activities and evaluation of Nuclear Regulatory Commission regulations under development, and applying new techniques to the reactor licensing process.

We work with the nuclear power industry to resolve technical issues associated with extending the useful lives of operating light water reactors and demonstrating the carly site approval for advanced light water reactors. In addition, we will be investigating improved approaches to the licensing of nuclear power generation plants and exploring technological developments in support of future 
nuclear plant designs. This work is closely coordinated with industry, universities, and other national laboratories.

These programs form a basis for closer cooperation with industry. We have formed technology alliances with industry to couple Sandia's strengths with the nuclear power industry's experience and knowledge to address issues of importance to current and future nuclear power plants.

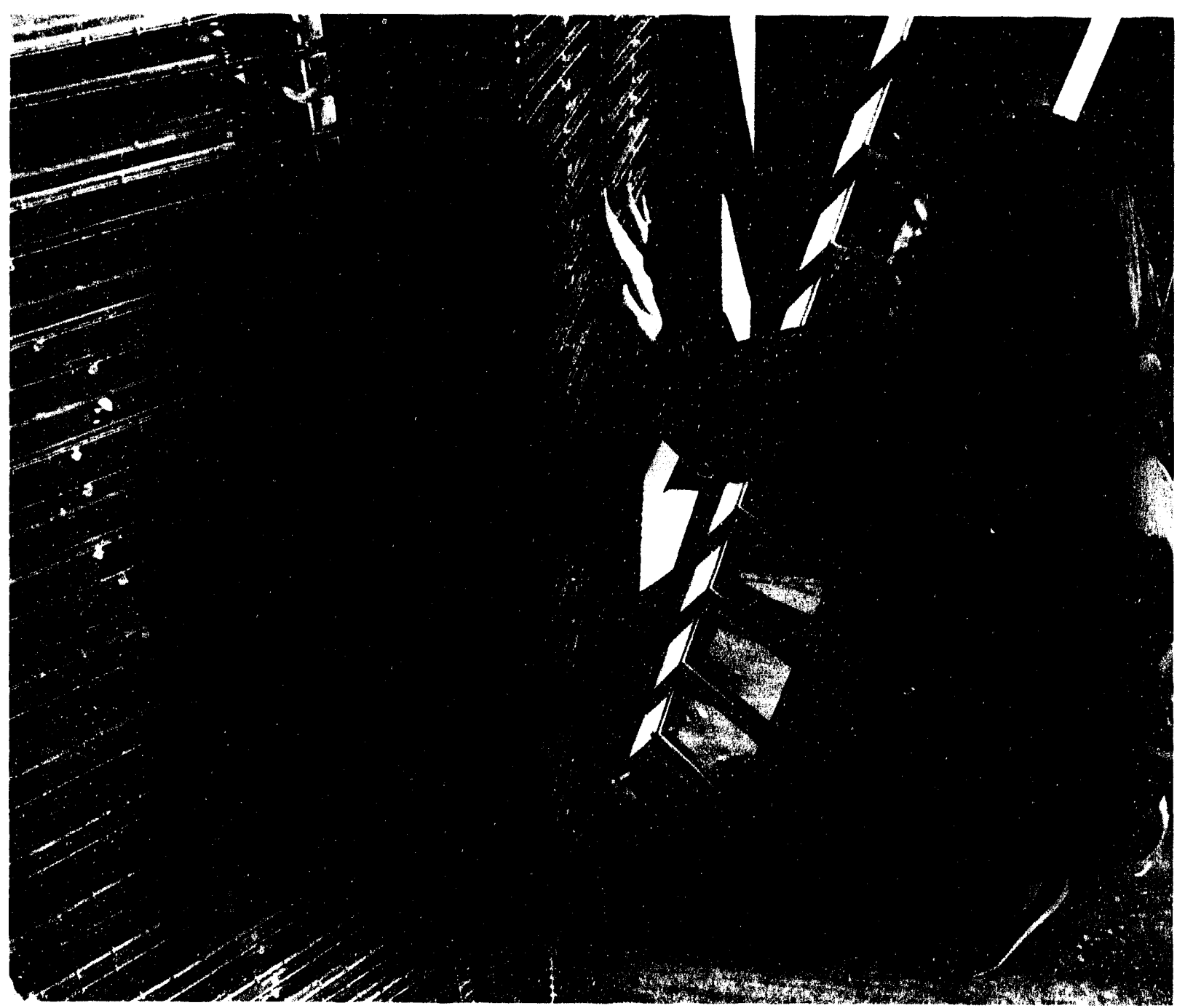

A radiant heat array designed by Keri Sobolik and her colleagues is the heat source for simulating hypothetical accidents in nuclear reactors. A similar array will be configured within Sandia's new cylindrical boiling test facility and will simulate various heat patterns that may be created in a reactor accident. The facility will test the flooded-cavity passive safety design. 


\section{Science and Technology Programs}

Sandia conducts numerous projects that contribute to the Department of Energy's science and technology mission. They indude established activities in Scientific Computing, Basic Energy Sciences, and Magnetic Fusion Energy. Research in global climate change for the ()ffice of Health and Environmental Research (OHER) is an emerging responsibility. The use of advanced computational techniques pervades all of these activities. Also, a robust suite of educational outreach efforts promote improvements in the nation's science and mathematics education infrastructure.

These science and technology activities are found in every phase of Sandia's development cycle, which develops solutions by integrating rescarch, development, and application. Examples include geoscience and technology, combustion science and technology, and scientifically tailored materials. In each of these cases, basic research is integrated directly into achieving the objectives of 1$)($ ) technology programs. Also, each of these areas is characterized by numerous, vigorous interactions with U.S. industry. In the coming years, these activities are expected to provide a basis for new $\mathrm{D}$ ()E: initiatives, missions, and roles.

\section{Office of Energy Research}

Sandia's Basic Energy Sciences activities provide a solid scientific foundation for many energy and manufacturing related technologies. Underpinning these activities is a vigorous research program - supported by the Office of Scientific Computing - in the development and application of advanced computational techniques. The Basic Energy Sciences projects include a national responsibility in combustion science.

We expect to expand basic research during the planning period. Our magnetic fusion energy projects support both a long-term, nationally coordinated program and U.S. participation in the International Thermonuclear Experimental Reactor design project. In support of the Office of Health and Environmental Research, we are developing instrumentation and algorithms for measuring water vapor and cloud distributions. Sandia also provides DOE-wide technical direction of the emerging program in unmanned aerospace vehicles and small satellites.

\begin{tabular}{|c|c|c|c|c|c|}
\hline \multirow[b]{2}{*}{$\underline{B \& R \text { Code }}$} & \multicolumn{3}{|c|}{$\begin{array}{l}\text { Summary of Programs for Office of Energy Research } \\
\text { (Operating BA in } \$ \text { million) }\end{array}$} & \multirow[b]{2}{*}{$\underline{\text { FY94 }}$} & \multirow[b]{2}{*}{$\underline{\text { FY95 }}$} \\
\hline & Program Title & $\underline{F Y 92}$ & FY93 & & \\
\hline AT & Magnetic Fusion & 5.6 & 6.5 & 6.2 & 6.8 \\
\hline KC & Basic Energy Sciences & 22.4 & 21.8 & 21.1 & 26.0 \\
\hline KP & Biological and Environmental Research & 0.8 & 0.4 & 0.1 & 0.3 \\
\hline \multirow[t]{3}{*}{ KS } & Superconducting Super Collider & & & 0.1 & 0.1 \\
\hline & Total & 28.8 & 28.7 & 27.5 & 33.2 \\
\hline & Percent of total operating funds & $2 \%$ & $2 \%$ & $2 \%$ & $2 \%$ \\
\hline
\end{tabular}

\section{Magnetic Fusion (AT)}

The goal of Sandia's magnetic fusion program is to develop a lechnology base to support the design of components that will perform satisfactorily in fusion plasma environments. To achicve this goal, we study the interactions of plasmas and materials, the behavior of materials exposed to high heat fluxes, and the interfaces of plasmas and fusion reactor walls. 
Extensive analysis of prototypes is required before components can be qualified for operation in fusion machines. This activity involves selecting, specifying, and developing materials for plasmafacing components exposed to high heat and particle fuxes. Materials samples and prototype components are tested in Sandia's Plasma Materials Test Facility. This facility utilizes high-energy electron beams to generate high heat fluxes that simulate fusion reactor environments.

Sandia provides direct support to U.S. and international fusion machines. This support includes diagnostics, tritium inventory assessments, and materials studies for the Princeton Tokamak Fusion Test Reactor; material analysis and diagnostic development for (ieneral Atomics 1) III-1) Advanced Divertor Project; and a full toroidal belt Advanced Limiter Test (ALT-II) system for the TEXTYR tokamak in Germany. Sandia has recently designed and installed on the Tora Supra tokamak iu France an actively cooled pumped limiter capable of steady-state operation at heat fluxes of 30 million watts per square meter.

In all of these experiments, Sandia participates in machine operation and provides specialized diagnostics and data analysis for evaluating plasma material interaction processes, boundary layer plasma control, and plasma-facing components. In addition, Sandia continues to collaborate on plasma material interaction and high-heat-Hux issues with both the Joint European 'Torus in Abingdon, United Kingdom, and the JT-60U in Japan. Recently, at the direction of the Department of Energy, Sandia has entered into cooperative exchanges on plasma-facing component development with several laboratories in Russia.

In 1992, an international agreement was reached between the United States, Japan, the European Community, and Russia to embark on a six-year engineering design activity for the International Thermonuclear Experimental Reactor (ITER). Sandia is supporting this project by providing personnel to manage the program at the ITER in Garching, Germany. Sandia also has a major role in research, development, and design of plasma-facing components for the U.S. effort.

Continued international cooperation is essential to the success of the International Thermonuclear Experimental Reactor project. I omestically, development of plasma-facing components for ITER will be a cooperative effort between Sandia and other national laboratories (Argonne, Oak Ridge, Idaho, Lawrence Livermore, and Los Alamos), universities (UCLA, Princeton Plasma Physics Laboratory, University of Illinois, University of Wisconsin, University of New Mexico, North Carolina State University, Pennsylvania State University), and industry (headed by $\mathrm{Mcl}$ ) onnell Douglas and including Ebasco, General Atomics, Westinghouse, Rocketdyne, and others). Sandia is coordinating this multisector cooperative effort for the U.S. ITER Home Team.

Sandia's expertise in development of materials and components for magnetic fusion systems will also be utilized in support of the Tokamak Physics Experiment, which has been proposed as the next major U.S. plasma confinement experiment, and in support of the large Helical Device, a stellarator confinement device being built by the Japanese National Institute for Fusion Science.

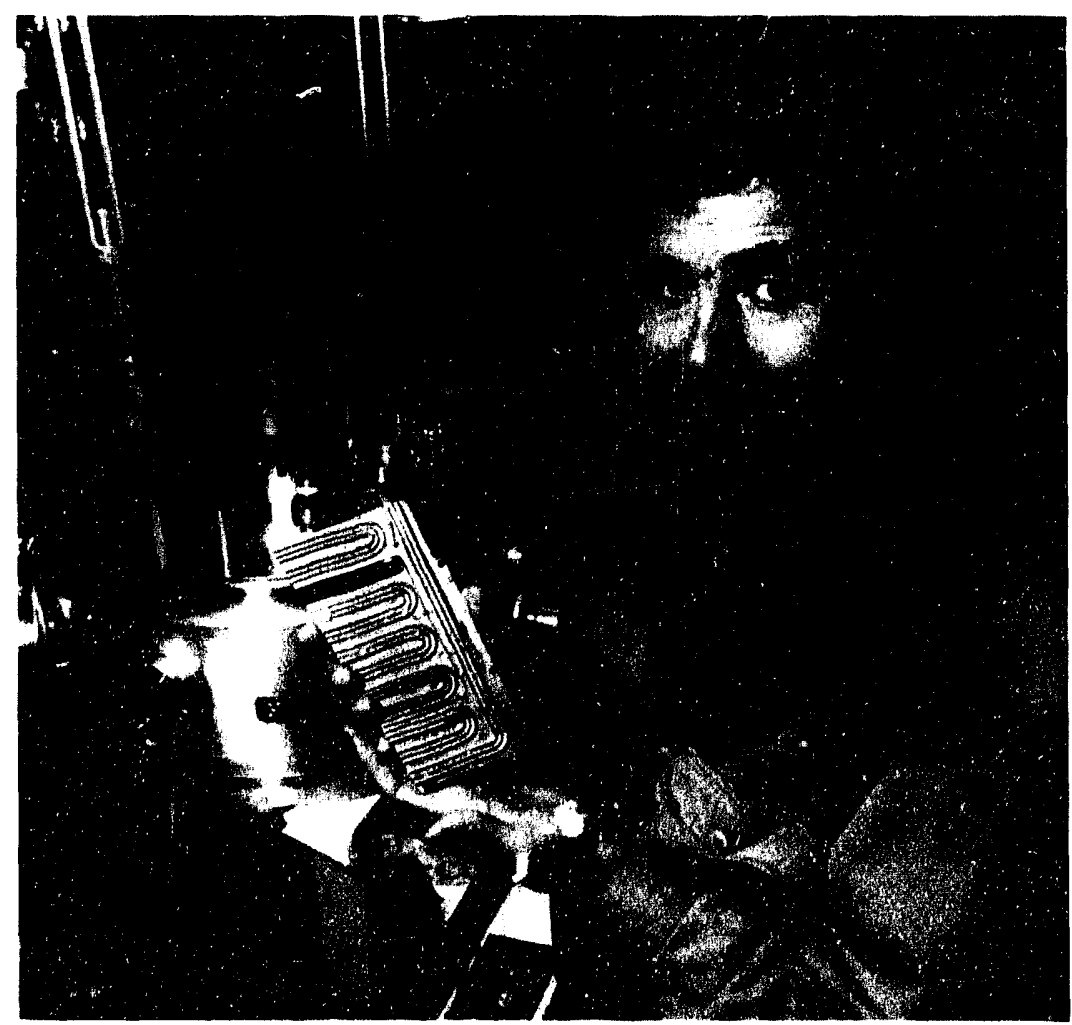




\section{Scientific Computing (Massively Parallel Computation) (KC07)}

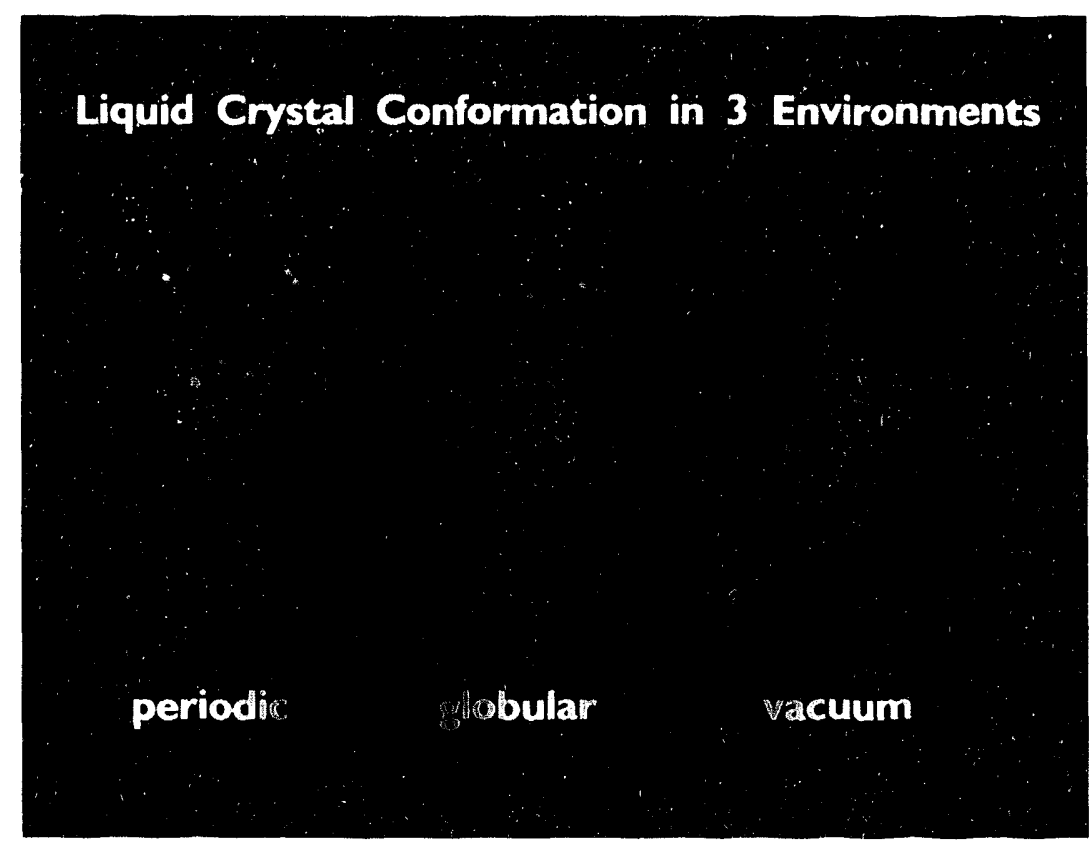

Molecular dynamics is a powerful simulation tool for studying the microscopic properties of organic molecules such as polymers, proteins, and DNA. Simulations of even small organic molecules are computationally demanding. The functional and catalytic actions of such molecules are often determined by their three-dimensional shapes; consequently, one must model the molecule in its medium (e.g., in solution or in arrangement with other molecules). In this representation, a siloxane-based liquid-crystal molecule is simulated in three environments: in a periodic crystal, in a globular cluster of $\mathbf{2 7}$ molecules, and in a vacuum. The equilibrium shape of the molecule after hundreds of picoseconds is shown. With continued advancement in algorithm development and hardware, the "holy grail" of organic molecule simulation - the study of large-scale protein folding - may be within reach in a few years.
Sandia's computational sciences research is aimed at developing massively parallel computing methods and a software infrastructure for parallel computing. Research in parallel computing focuses on the development of parallel algorithms for solving the partial differential equations of physics and engineering. Research in software infrastructure for parallel computing covers such areas as graphics methods and visualization, static and dynamic load balance methods, parallel operating systems, performance evaluation methods, and hybrid programming models and languages. This program is designed to unleash the performance and cost performance advantages of massive parallelism on important I)E problems.

Advanced computing technologies are very important to national and economic security. Sandia has made a commitment to play a leading role in the national High-Performance Computing and Communications Program. Sandia has leadership of two Department of Energy Grand Challenges: Computational I)esign of (atalysts and Biocatalysts and Rational Drug Design. We also have a major algorithm development responsibility for ( Hobal

Climate Modeling, a grand challenge led by L.os Alamos. Our work on massively parallel computing has been recognized by several national and international awards, including the Gordon Bell Award, the Karp Prize, and two R\&D 100 awards.

The Massively Parallel Computing Research Laboratory at Sandia/ New Mexico provides prototypes of advanced, high-performance computing technology, including advances in scalable massively parallel algorithms, graphics and visualization, and systems software. Pa!! of our strategy is to form interdisciplinary partnerships with Sandia's DOE Defense Programs applications to create new, breakthrough simulation capabilities. It is also part of our strategy to move such advances quickly into industry through appropriate technology transfer mechanisms.

The Center for Computational Engineering at Sandia/California is chartered to help scientists and engineers in industry make use of massively parallel processing to solve problems that are impracticable on conventional machines. The center focuses primarily on software engineering for applications. Applications currently being pursued include pharmaceutical design (for example, drug/organism interactions and "designer chemotherapy"), and global climate change. Rescarch at the Center for Computational Engineering includes methodologies for problem specification, code generation, data management, and theorems for performing proofs of software correctness. 


\section{Basic Energy Sciences (KC)}

Projects that support the ()ffice of Basic Energy Sciences comprise several leading research efforts. Larger projects include combustion research and scientifically tailored materials. Smaller projects include engineering and yeoscience research.

\section{Chemical Sciences}

Combustion Research

Sandia's largest project for the Office of Basic Energy Sciences is conducted by the Combustion Research Facility in Livermore, California. In this designated DOE user facility, Sandia staff and visiting researchers develop advanced research methods and apply them to the study of fundamental combustion processes.

The Office of Basic Energy Sciences supports both basic research in combustion sciences at the Combustion Research Facility and the operation of the facility as a research center available to a wide variety of users. Among the major users are staff supported by the DOE offices of Fossil Energy and Energy Efficiency and Renewable Energy, who conduct industry-oriented research in transient and continuous combustion, including coal and biomass processes, and in advanced materials synthesis. One measure of the impact of these programs is the award by Research and Development magazine of a 1992 R\&D 100 award for the development and application of advanced internal combustion engine diagnostics.

DOE sponsorship and policies facilitate a vigorous visiting scientists program that attracts approximately seventy long-term users to the Combustion Research Facility every year. Visiting scientists conduct and publish basic and applied combustion research. Visitors come from industry, universities, and government-sponsored organizations such as the national laboratories. Their participation in activities of the Combustion Research Facility is an important vehicle for transferring new combustion technology to a large user community. An active postdoctoral research program contributes both to advanced training of combustion scientists and engineers and to the facility's research productivity.

The continuing research programs at the Combustion Research Facility help maintain U.S. preeminence in the science and technology of combustion. Facility staff represent the United States in the International Energy Agency programs on Energy Conservation in Combustion. International Energy Agency activities involve collaboration with foreign scientists in engine studies and coal research through an informal exchange program.

The long-range objective of the Combustion Research Facility is to accelerate the development of combustion technology to maximize its impact on energy efficiency, fuel utilization, environmental protection, industrial productivity, and equipment design. Principal research conducted for the Office of Basic Energy Sciences' Chemical Sciences Division includes combustion diagnostics, combustion chemistry, reacting flows, and combustion modeling.

Combustion Diagnostics - One of the primary thrusts of the combustion research program is the development of advanced diagnostic techniques. Because of their nonintrusive nature and great versatility, laser-based optical techniques receive the strongest emphasis. Laser-induced fluorescence, Raman spectroscopy, and multiphoton wave mixing are among the diagnostic methods being developed. These techniques are used to measure temperatures, species concentrations, and other parameters of importance to the understanding of combustion phenomena.

Combustion Chemistry - The work in combustion chemistry improves our understanding of the complex chemical processes involved when fuels burn. The program emphasizes determining the rates and mechanisms of elementary chemical processes, and it stresses the close coupling 
of experiment, theory, and modeling. The modeling of experiments conducted in low-pressure flames yields insight into the dominant chemical reactions involved in combustion.

Related efforts address fundamental guestions of molecular dynamics that must be answered to develop models of processes important to energy-producing technologies. 'Themes of current emphasis include the formation and destruction of nitrogen-containing pollutants, the oxidation of hydrocarbons, and chemical paths leading to soot precursors in rich flames.

Reacting Flows - A multidisciplinary program in reacting flows establishes an important link between fundamental studies of combustion chemistry and the "real world" of practical combustion. The objective of this program is to increase our understanding of the fundamental interactions between chemistry and fluid dynamics in combustion. Research results are being used to improve predictive capabilities for turbulent combustion of hydrocarbon fuels. Experimental studies include flows involving complex fluid mechanics but simplified chemistry. These flows are used to probe primary turbulent transport mechanisms.

Combustion Modeling - Sandia's combustion modeling program emphasizes the development of numerical methods to predict the mutual influences of reactions and fluid transport mechanisms. Our current modeling research is developing a fundamental understanding of important subprocesses so that future simulations will contain more realistic chemical and physical descriptions of combustion phenomena. We are directing growing emphasis on the inclusion of fully detailed chemical mechanisms in advanced combustion models that require state-of-the-art computational capabilities for their execution.

\section{Materials Sciences}

Sandia's Materials Sciences program comprises three clements: Scientifically Tailored Materials, Defects and Impurities in Solids, and the Synthesis and Processing (enter. The effort in scientifically tailored materials has a strong research theme that supports the development of advanced manufacturing technology relevant to the semiconductor industry.

\section{Scientifically Tailored Materials}

Our program in scientifically tailored materials combines Sandia's expertise and experimental and theoretical capabilities in solid-state sciences, atomic-level diagnostics, and materials synthesis and processing to produce new classes of materials that can be tailored for specific propertics and applications.

An important goal of the scientifically tailored materials program is to explore how capabilities developed in various projects can be used to enhance the competitiveness of U.S. industry. Toward this goal, we frequently interact with representatives from industry, universities, and the national laboratories to define critical needs and plan collaborative efforts. Many cooperative research and development agreements with industry have grown out of rescarch performed under this program.

Current research includes the physics and chemistry of ceramics synthesis and processing, the use of energetic particle beams for the synthesis and study of materials, high-temperature and organic superconductors, tailored surfaces and interfaces for materials applications, chemical vapor deposition sciences, strained-liyer and artificially structured semiconductors, advanced growth techniques for improved semiconductor structures, boron-rich solids, and atomic level science of interfacial adhesion. Considerable synergy exists among these program elements, and most of them share common themes based on either the science or the use of common synthesis and processing approaches. These themes are: synthesis and processing, epitaxial materials growth, surfaces and interfaces, energetic particle beams and high-transition-temperature superconductivity. 
Physics and Chemistry of Novel Superconductors - The novel superconductors project investigates electronic, structural, and chemical properties of inorganic, high-temperature superconductors and organic superconductors. The goal is to develop a fundamental understanding of the physics of superconductivity in these materials. These studies are integrated closely with an extensive synthesis and processing program designed to produce materials with tailored properties.

Strained-Layer Semiconductors - Research on compound semiconductor strained-layer superlattice structures represents pioneering, award-winning work in this area. A strained-layer superlattice consists of many thin layers, each a few tens of angstroms thick, of alternating singlecrystal semiconductor materials. They typically are made from the more common periodic table class III-V semiconductors, such as GaAlAs, GaAsP, InGaAs, or InAsSb. The multiple thin layers behave macroscopically like new semiconductor materials. Their structures exhibit electronic and optical properties entirely different from those of the constituent materials. The combination of the thin layers and lattice strain allows flexibility in tailoring the properties of these "new" materials. Sandia is applying these new semiconductors to the development of highspeed, field-effect transistors to provide world record performance, as well as optoelectronic emitters, detectors, and novel optoelectronic mirror devices.

Chemical Vapor Deposition Sciences - The objective of the chemical vapor deposition sciences project is to explore the basic physics and chemistry of chemical vapor deposition as it is used in the synthesis of materials, particularly thin films. Our research thus far has concentrated on semiconductors and other materials used to make semiconductor devices. However, the understanding gained in this research is applicable to other classes of materials such as coatings resistant to corrosion and wear, high-temperature superconductors, optical materials, and reduced-friction coatings. The work will be extended to these materials.

Energetic Particle Synthesis and Science of Materials - Basic research in the energetic particle synthesis and science of materials project is conducted on the interactions of ion, electron, laser, and plasma beams with metals, semiconductors, and dielectrics. The objectives of the project are to explore materials synthesis and modification with energetic particles, to create new materials and determine their properties, and to advance materials processing by elucidating relevant fundamental processes using the unique capabilities of energetic beams.

Physics and Chemistry of Ceramics - The objective of this project is to develop a fundamental understanding of the atomic and molecular processes that govern the structure and properties of ceramics. The ultimate goal is to improve ceramic processing by gaining a better understanding of the underlying chemical and physical principles.

Atomic-Level Science of Interfacial Adhesion - This new scientifically tailored materials initiative deals with the atomic-level science of interfacial adhesion. Despite the pervasive nature of adhesion problems in materials science and engineering, solutions are almost al ways the result of trial and error. Significant technological and economic gains can be realized by developing a scientific basis for the field of interfacial adhesion. This will allow the selection of material combinations to provide specific interfacial characteristics. Motivated by this need, the purpose of this initiative is to understand - at the atomic level of detail - the nature of the physical and chemical interactions that bind solid surfaces together.

In other research in the Scientifically Tailored Materials program, we are investigating the atomic-level processes that control the growth and properties of thin-surface layers, as well as 


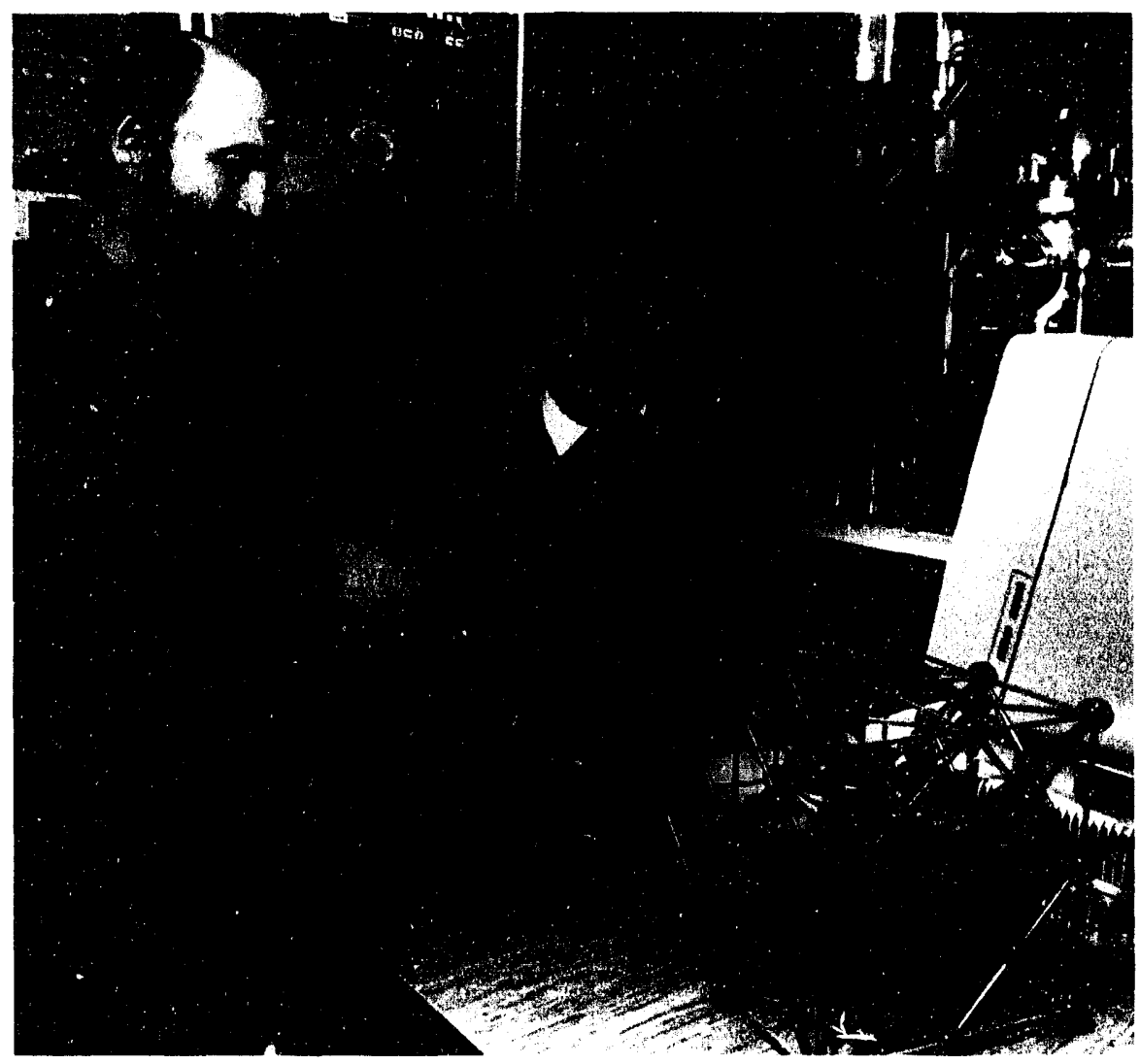

exploring the use of ion, laser, and electron-beam excitation of surfaces during epitaxial growth of semiconductors to control the kinetic energy of surface atoms to extend the range of tailorable epitaxial materials. We are also exploring potential applications of boronrich solids, which have unicyue bonding, electronic, and transport properties when used as high-temperature semiconductors. 'l hese refractory materials appear promising for use in high-efficiency thermoelectric energy generators and as neutron detectors.

Defects and Impurities in Solids (Computational Materials Science)

(rystalline defects and impurities often determine the properties of solids. Thus, the understanding and control of these imper-

Peter Feibelman and Gary Kellogg view a model of a stepped metallic surface.

Stepped or terraced surfaces are the subject of research that won a BES Materials Sciences award. On the table is a model representing the face-centered cubic structure of metals such as aluminum, platinum, and nickel. In the background at right is a field ion microscope similar to the one used to verify that atoms move on certain metal surfaces by a process of substitution. fections are crucial to technological applications of solid materials. I eveloping fundamental understanding of these defects and impurities is the goal of this project.

Unique experimental and theoretical tools developed in this program are combined to study structural defects and impurities in solids and on surfaces. The experimental tools are high-resolution transmission clectron microscopy, high- and medium-energy ion scattering facilitics, video lowenergy electron diffraction with I-V capability, surface analytical tools, scamning tunneling microscopy, and low-energy electron microscopy. Theoretical tools developed and employed include quantum chemistry codes, local density approximation/pseudopotential methods, the embedded atom method, and cluster functional methods for large-scale atomistic computer simulations.

These experimental and theoretical capabilities are used to study grain boundaries, interfaces, and surfaces in metal alloys and intermetallic compounds; impurity segregation to thesc boundaries; and the interactions with dislocations, gas bubbles, and defect clusters. (irowth of metal layers on substrates is investigated using scanning tunneling microscopy, low-energy electron diffraction, and low-energy electron microscopy. Theoretical models are developed for the nucleation and growth kinetics of thin film layers. High-resolution transmission electron microscopy, in conjunction with large-scale computer simulations, is used to resolve the dislocation core structure in intermetallic compounds, and to analyze the dislocation network configuration and evolution during plastic deformation.

Many of the results generated by this research project are utilized in concurrent development and enginecring projects at Sandia and other national laboratories. In addition, the dissemination to materials science programs at universities and industrial research and development laboratories is conducted through the Sandia visiting scientist program in computational materials science. (o) laburations with industry are also carried out via cooperative research and development agreements. 


\section{Synthesis and Processing Center}

Sandia has overall responsibility for coordinating activities within the DOE Center of Excellence for the Synthesis and Processing of Advanced Materials. This center is a coordinated, cooperative venture among the following institutions: Ames Laboratory, Argonne National Laboratory, Brookhaven National Laboratory, Idaho National Engineering Laboratory, University of Illinois Materials Research Laboratory, Lawrence Berkeley Laboratory, Lawrence Livermore National Laboratory, Los Alamos National Laboratory, National Renewable Energy Laboratory, Oak Ridge National Laboratory, Pacific Northwest Laboratory, and Sandia. The center brings together elements of the existing basic Energy Sciences Materials Sciences core programs at these laboratories that emphasize materials synthesis and processing. The center's objective is

to enhance the science and engineering of materials synthesis and processing in order to meet the programmatic needs of the Department of Energy and to facilitate the technological exploitation of materials.

Synthesis and processing are essential elements of materials science and engineering that deal with the assembly of atoms or molecules to form materials, the manipulation and control of the structure at all levels from the atomic to the macroscopic scale, and the development of processes to produce materials for specific applications. Synthesis and processing span the range from fundamental research to technology application.

The goals of basic research in this area range from the creation of new materials and the improvement of the properties of known materials to the understanding of such phenomena as diffusion, crystal growth, sintering, and phase transitions. On the applied side, the goal of synthesis and processing is to translate scientific results into useful materials by developing processes capable of producing high-quality, low-cost products.

\section{Geosciences}

Sandia's basic research in geosciences includes activities in the areas of geology, geophysics, geochemistry, geomechanics, energy resource recognition and utilization, and scientific drilling. Research focuses on dynamic processes in the earth's crust. Individual research projects are supported for investigations in the following areas: instrumentation development, geophysical imaging, fluid flow, in situ stress determination, and mincral surface interactions.

Sandia is developing an instrument for sampling hydrothermal Huids and gases directly from boreholes. This tool will have application in both sea-floor and deep continental drill holes.

In a cooperative project with the Massachusetts Institute of Technology, Sandia is developing a down-hole seismic source for cross-borehole shear-wave imaging, with application to oil and gas exploration.

Computational algorithms are being developed for inversion of electromagnetic data for threedimensional structure. These codes will have application in both energy extraction and environmental remediation.

Through computer simulation with a lattice gas automata algorithm, Sandia is modeling fluid flow through complex geologic media. An experimental approach to fluid flow characterization is being applied at Carlsbad Caverns. Travel times through fractured limestone from the surface to the cave are being documented in a unique field study of oxygen isotopic data collected from drip waters. Another field-based experiment, in cooperation with lawrence livermore National Laboratory, uses hydraulic fracture to study stress in a deep borehole in the volcanic Long Valley caldera of California.

Sandia's geochemical investigations study the kinetics of silicate mineral reactions in the presence of water anu ermine the rates at which selected ions diffuse into minerals at geologically 
Jeff Morgan displays the electronics of the receiver unit of an oil exploration borehole seismic system developed by Sandia. The system is designed to do high-speed seismic mapping from boreholes up to 15,000 feet deep at temperatures up to 400 degrees $F$ and pressures exceeding 8,000 psi. relevant temperatures. Advanced amalytical techniques and computer simulations of molecular interactions are utilized in these investigations.

We also provide lead engineering support for research drilling in the Continental Scientific Drilling Program. Eight drilling projects have been completed to date. Current wort: is focused on a project to drill into the plumbing system of Katmai Volcano in Alaska, which erupted in 1912. Sandia is working with the United States (ieological Survey and the National Park Service on portions of the Environmental Impact Statement related to drilling operations.

The objective of the geosciences basic research activity is to develop an understanding of geologic processes at a fundamental level. Projects change every two to four years, so the focus of the program evolves to support changes in DOE interests. The program is coupled closely to related technology programs, with objectives such as nuclear waste facility design, petroleum exploration and storage, environmental restoration, and geothermal energy exploration.

\section{Engineering Sciences}

Sandia research in support of engineering sciences includes several projects that seck to improve our understanding of the physics of fluids. As part of a study of multiphase flow problems, we have teamed with the Massachusetts Institute of Technology and Los Alamos National Laboratory to investigate suspensions of particles in Newtonian and non-Newtonian liquids by developing new theories, conducting numerical simulation, and carrying out experiments. This work has resulted in determining the effects of microstructures on the macroscopic properties of suspensions.

Sandia is also developing and validating a statistical model of molecular mixing in turbulent flow. This modal will be used to predict and interpret experimentally observed phenomena. In a recent effort, we are using optical techniques to investigate the supercritical water oxidation process. This process holds promise in applications to destroy toxic and hazardous wastes.

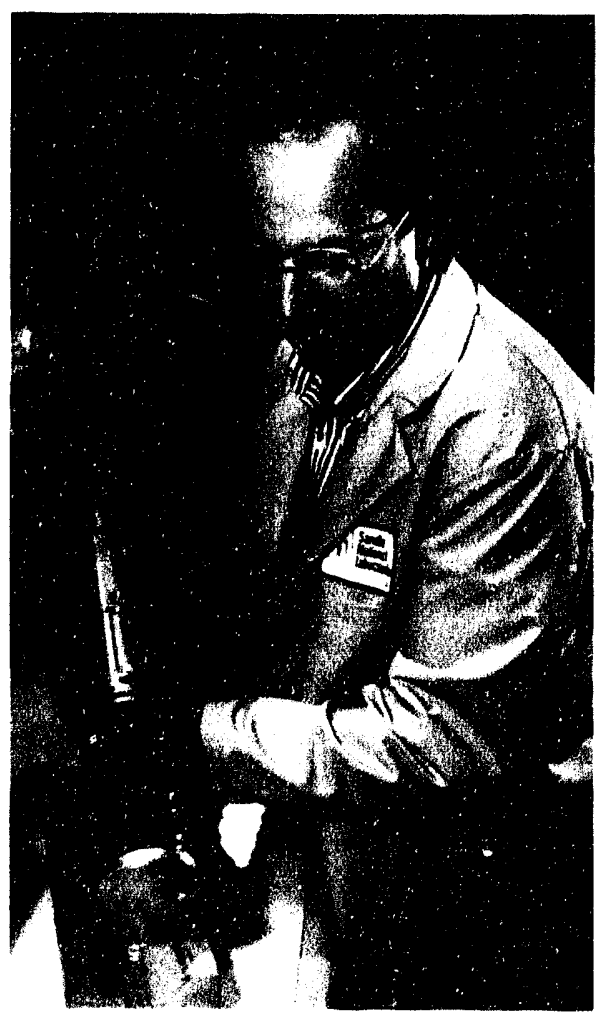

\section{Biological and Environmental Research (KP)}

During the past several years, global climate change has come to the forefront of the world's and the nation's science and policy agendas. While most scientists agree that energy-related emissions will give rise to a man-made "greenhouse" warming effect, there is uncertainty about the magnitude and timing of this phenomenon and its distribution.

To better understand these issues, the government has embarked on a U.S. Global Change Research !rogram, with the Department of Energy a major participant. Seeking to support 1 )OE in this role, we have drawn on Sandia expertise in remote sensing (from ground, air, and space), ficld testing, systems engineering, and massively parallel computing to perform the following program elements:

\section{Develop novel instruments and algorithms for measuring water vapor and cloud distribution - two of the key uncertainties in} current climate models.

Water vapor is the major "greenhouse" gas playing a key role in cloud formation and in driving atmospheric circulation through the release of latent energy. Yet, available instruments lack the vertical and temporal resolution required to adequately study water vapor profiles.

Working with NASA, we have developed the next generation of a laser-remote sensing technique, Raman lidar, for providing those high-vertical-resolution water vapor profiles, both at night and 
during the day. We plan to implement this technique at one of the I) ()L Cloud and Radiation Testbed sites, to study yuestions related to the distribution of upper tropospheric moisture - an important but poorly understood issue.

While Raman lidar is a particularly robust way of measuring water vapor profiles from the ground, different laser techniques are required for the longer ranges characteristic of air and space measurements. To this end, we are developing a miniature-package water vapor differential-absorption lidar for small aircrait or unmanned aerospace vehicles.

Clouds are the other key feedback parameter. Uncertainty in radiation-cloud feedback accounts for most of the uncertainty in predicted temperature rise for a doubling of atmospheric carbon dioxide. Yet, it is very difficult to measure even the most basic of cloud parameters, its shape, let alone measure the microscopic properties that affect the interaction of the cloud with the earth's radiation field. Therefore, we have developed a novel set of algorithms that make use of the motion of the clouds for extracting geometric information about cloud fields (for example, the cloud base heights) from sets of whole-sky imaging cameras.

We are now embarking on using Sandia's experience in massively parallel computing to develop novel ways of fusing these data with complementary data from sources such as satellites and radars to produce true three-dimensional maps. We also are developing a miniature clou' radiometer to provide key radiative properties such as cloud albedo, droplet size, and phase (ice or water). This miniature cloud radiometer will be compatible with both small unmanned aerospace vehicles and small satellites.

\section{Manage one of DOE's planned atmospheric radiation measurement sites.}

The Department of Energy's Atmospheric Radiation Measurement program seeks to improve the understanding of radiation-cloud interactions by studying these processes at a series of intensively instrumented cloud and radiation test-bed sites. The third of these sites, scheduled to begin operation in FY 1996, will be located on the North Slope of Alaska. This locale was chosen both because the polar region is the heat sink in the overall climate engine, and because the pole, with its extremes of insolation (six months of claylight, six months of night), humidity (wet summers, dry winters), and surface albedo (highly reflective snow which then melts), provides a stringent test of the understanding of radiation-cloud interaction gained at the earlier sites. Sandia is the manager for this site and is responsible for its planning, in plementation, and operation. Also, we work closely with se jentists at the University of Alaska to formulate the science plans and coordinate the Atmospheric Radiation Measurement program with other research activities in the Arctic.

3. Serve as technical director of the Department of Energy's multi-laboratory thrusts in unmanned aerospace vehicles and small satellites for climate studies.

While the initial phases of atmospheric radiation measurement have emphasized groundbased measurements, it was recognized from the start that one also needs air-and space-based measurements to provide information about radiative fluxes, water vapor profiles, and cloud top properties in the atmosphere and to extend the range of these measurements to regional and global scales.

While conventional aircraft and satellites can meet part of these needs, they cannot meet all of them. For example, current aircraft camnot operate for multiple days at the tropopause. 1)(OE has proposed major initiatives to use a new generation of small unmanned aerospace vehicles, small satellites, and associated miniature instruments to fill these key measurement gaps. DOE has selected a Sandian as technical director and coordinator of this multi-laboratory/multi-agency program. Sandia's role includes program formulation and direction, payload integration, and instrument development. Initial phases will emphasize the use of unmanned aerospace vehicles. 


\section{Office of Science Education and Technical Information}

The San ducational Outreach program consists of an extensive, interrelated set of projects supporting scientific and technical education for students, teachers, and faculty. Each of these projects helps improve scientific and technical education. Sandians interact with students, teachers, parents, and institutions to enhance public understanding of science and mathematics and increase the number of students choosing careers in science and technology. 6 . pport programs exist for all educational levels, from kindergarten through post-baccalaureate, and across a range of constituencies, local, state, and national.

These efforts are funded by the Assistant Secretary for Defense Programs, the (office of Energy Research, and other program secretarial offices, as well as the ()ffice of Science Education and Technical Information, which administers the DOE educational initiatives.

\begin{tabular}{|cccccc|}
\hline \multicolumn{5}{|c|}{$\begin{array}{c}\text { Summary of Programs for Office of Science Education and Technical Information } \\
\text { (Operating BA in S million) }\end{array}$} \\
B\&RCode & Program Title & FY92 & $\underline{F Y 93}$ & $\underline{F Y 94}$ & $\underline{F Y 95}$ \\
KV & University and Science Education & 1.0 & 3.0 & 2.1 & 2.0 \\
& Percent of total operating funds & $<1 / 2 \%$ & $<1 / 2 \%$ & $<1 / 2 \%$ & $<1 / 2 \%$ \\
\hline
\end{tabular}

\section{University and Science Education (KV)}

Sandia's science and mathematics education programs are varied and address the needs of educational populations at all levels. Examples include the Hands ( )n/Minds (On Technology Program for fifth through twelfth-grade minority students; the 1)()E Teacher Research Associates summer employment program; and local sponsorship of the Math/Science Network's Expanding Your Horizons conferences that encourage high school girls to pursue technology carcers.

The innovative Science Advisors ( $S(\mathrm{C} I \mathrm{D})$ ) project focuses primarily on support for teachers as the most efficient way to achieve outreach goals. With the direct support of D()t, S(CIAI) places Sandia technical staff in public elementary and middle schools, as well as in Bureau of Indian Affairs schools, one day a week. Sandia personnel enhance science teachers' understanding of scientific principles, contribute to the science curriculum, and develop demonstrations and experiments for the classroom. Now in its third year, the project serves more than 150) schools and is being emulated by other agencies.

Sandia interacts extensively with universities for research services, technical expertise, campus recruiting, faculty development, facility sharing, and technology transfer. As an active corporate citizen, Sandia also supports local educational institutions. Universities provide continuing educational opportunities for on-roll employees and help shape the cultural climate of the communities in which we live.

\section{Outreach to Underrepresented Groups}

Sandia extends outreach opportunities in (alifornia and New Mexico to populations that historically have low rates of participation in technical professions. Several initiatives targeted to minorities, girls, and women encourage accelerated education in mathematics and science as well as career exploration and teacher training. 
Sandia programs, such as Adventures in Supercomputing, train teachers of minority populations and offer participating schools the use of supercomputers and other forms of assistance. This and other programs (for example, the Bay Area Science and Technology Education Collaboration) support curriculum development in science and mathematics for diverse student populations. Sandia cosponsors local "Expanding Your Horizons in Science and Mathematics" conferences for high school girls to introduce them to career opportunities in science and technology. A documentary cosponsored by Sandia entitled "Breaking Through" is intended to spark career interest in science and technology among girls in junior and senior high school and will appear on public television. Sandia extends itself wherever possible to introduce future mathematicians, scientists, and engineers to career opportunities.

Many undergraduate, graduate, and training programs help bridge the gap between secondary school and career. These efforts include Summer Employment for Minority Youth and students from Historically Black Colleges and Universities, One-Year-On-Campus, the National Consortium for Graduate Degrees for Minorities in Engineering, and the National Physical Science Consortium for female and minority doctoral fellows.

Although statistics on minority group participation are not collected, the scope of Sandia's math and science outreach program grows annually, both in numbers of programs and individuals who benefit

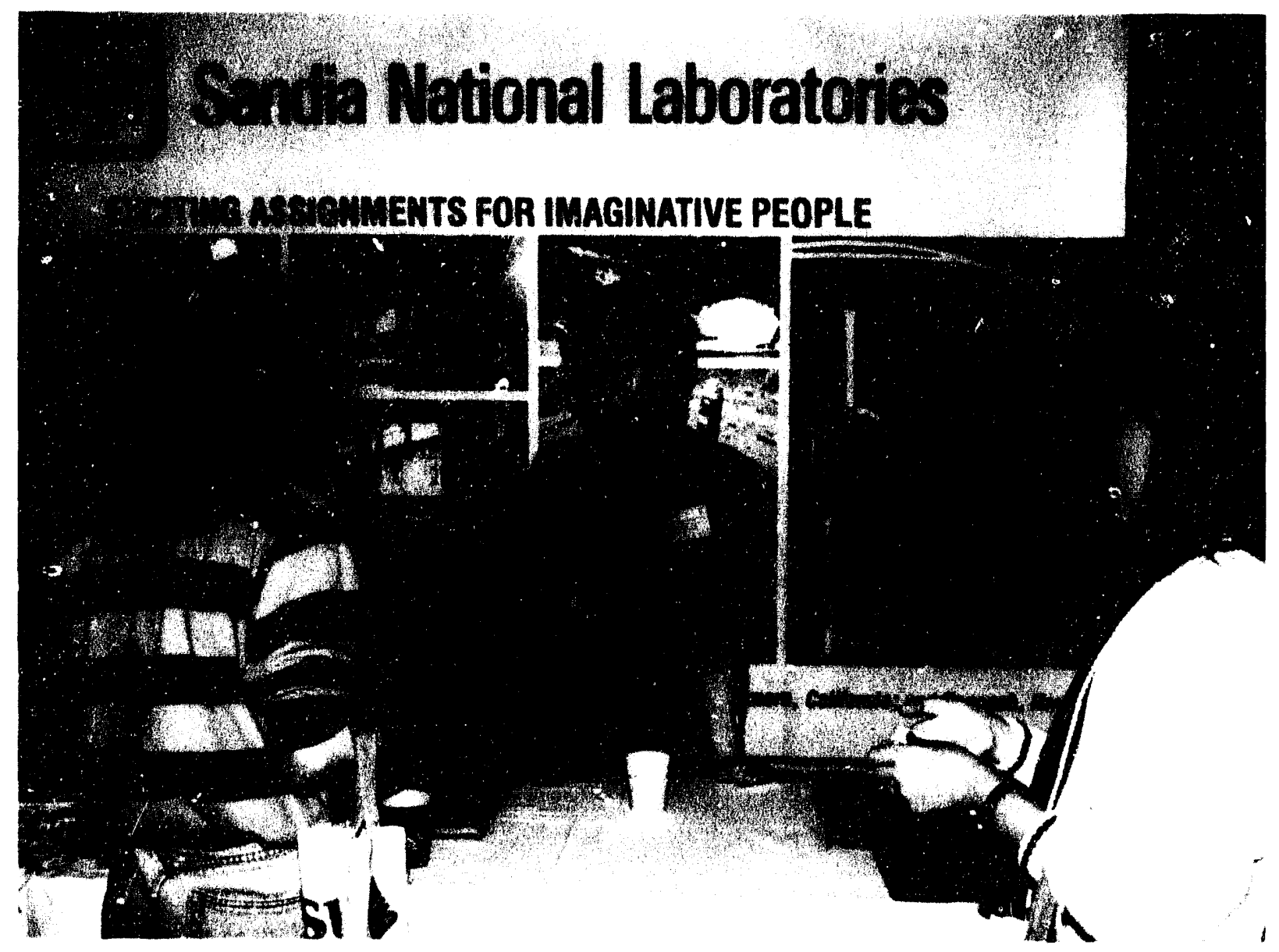

Sandia technical staff member Mary Clare Stoddard talks to two high-school women at the Expanding Your Horizons career fair in San Ramon, California. This event, which Sandia helps sponsor locally every year, introduces young women to the variety of technical careers. 


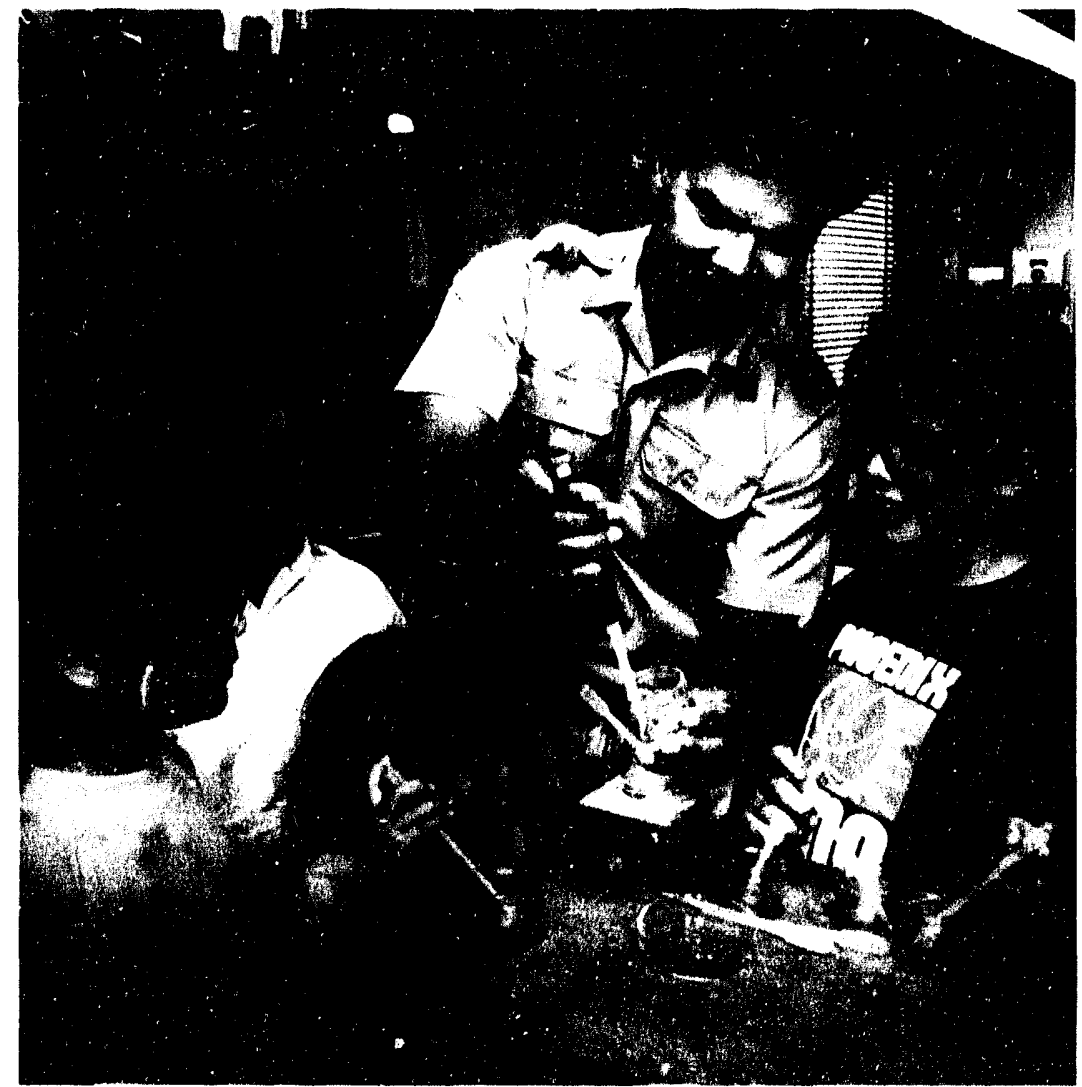

\title{
Pre-College Projects
}

\author{
Science and Mathematics \\ Education Enhancem int
}

Hands On/Minds On Technology

- Sandia offers three individual projects in the llands ()n/Minds ( ) Technology program: Hands On/Minds On liechnology for fitth through twelfth grade Black students, Dream (atcher Science P'ogram for American Indian students, and MANOS for Hispanic students. These projects are offered to middlo school Black, American Indian, and Hisparic students, who take classes during the evening for several weeks. Classes are taught principally by Sandia employees in subjects such as physics, chemistry, geology, electronics, mathematics, and computer literacy and general science.

National Science Bowl - As part of the National Science Bowl, Sandia hosts regional competitions for

Students at Sandia Base Elementary School in Albuquerque learn principles of math and science from Sandian Larry Salgado. Larry received the Secretary of Energy's 1991 Community Service Award for outstanding service to the community. high school students in New Mexico and California. In 1992, 22 high school teams from New Mexico and 15 from Califormia participated in this science, mathematics, and technology question-and-answer tournament. The Sandia team from New Mexico placed second while the Sandia team from California placed fifth in the national finals held in Washington, D.C.. Nationwide, the program involves more than 12,000 students from 2,0(0) high schools.

New Mexico Supercomputing Challenge - In New Mexico, more than 500 high school students design and run programs through the New Mexico Supercomputing (hallenge. Sponsored by a number of statewide organizations, the program involves youth in mathematics and computational science projects, then offers scholarships to promising students to altend New Mexico universities. The pre gram fosters student creativity in applying computational solutions to scientific problems. Open to all secondary schools, this statewide competition brings students together in problem-solving teams. Experts from national laboratories and research universities coach students in supercomputer use. San al provides instructors for the challenge and finds coaches for teams.

Rural/American Indian Science Education Project - Sandia scientists, enginecrs, and technicians serve as long-distance consultants to science and mathematics teachers in rural and American Indian schools. Sandia personnel enhance instruction by providing guidance on the implementation of classroom experiments and providing examples of state-of-the-art, practical, scientific applications. The Sandian assigned to a sichool will visit it one each semester and interact with faculty from the school on a weckly basis by phone or teleconference. Schools currently in the project are located in Arizona, Maine, New Mexico, North Carolina, North and South 1)akota, and ()regon. 
Science/Math Carnival - Science play at the Science/Math ( arnival makes learning fiun for elementary school stedents and encourages teachers to teach science and mathematics. The carnival offers up to 1 thands-on activities. Staffed by volunters from a pool of 180 ( ) alifornia Sandians, the Science/Math (arnival visited 80 schools during the 1992-93 school year. (auriculum materials for before and after the carnival are being developed for the classroom.

School Links Program - Sandia/C alifornia places voluntecrs math and science tutors, as well as other volunteers, in local schools. Last year 68 volunterers participated.

High School Science Student Honors Program-This two-weck stmmer program is designed to introduce high school honor students in science to a diverse range of engineering research topics, including solar energy, waste management, microdectronics, optoelectronics, robotics, and other areas. Through laboratory activities, lectures, and tours, we bring the excitement of engineering research to these students and offer them a deeper appreciation of the challenges and rewards of technical achievement. In all activities under this program, we stress the importance of respect for the environment, safety, and health.

\section{Career Exploration for Students}

Albuquerque Public Schools Career Exploration Program Half-Time - This program provides half-time employment at Sandia/New Mexico for senior high school students. Students work independently on projects with assistance and mentorship from enginecrs and scientists.

Work-Study Trainee Project - This project is directed toward economically disadvantaged students enrolled in occupational education programs.

Youth Opportunity Training (YOT) Program - The Y' ('T program is directed toward economically disadvantaged high school and post-secondary students. Program goals are for students to understand principles learned in the classroom, determine occupational indinations, identify career options, experience the disciplines and rewards of work, and earn income to continue their educations.

\section{Teacher Training and Curriculum Development}

Science Advisors Project - This project is designed to enhance the mathematics, science, and engine ring education of large numbers of students by helping teachers become more knowledgeable and comfortable in teaching those subjects. The project assigns an engineer, technician, or scientist to support the faculty at an elementary or midelle school one day a week for an entire school year. Currently, about 200 Sandians and 178 schools in New Mexico participate in the program. (One unique benefit of the Science Advisors Project is that it does not target a particular group of students, but rather maximizes the benefit for all children.

Summer Teacher-Enrichment Project - This project provides an opportunity for middle school and high school teachers to upgrade their knowledge and skills through practical work experience in areas related to their educational specialties and through exposure to programs and projects at Sandia.

Teacher Research Associates (TRAC) - This 1) ()E-sponsored program provides opportunities for scientific and engine ring rescarch during the summer for outstanding high school science and mathematics teachers. Under the auspices of the $A$ ssociation of Western Universities, TRAC coffers summer research opportunities throughout the nation. 
Adventures in Supercomputing - This I) ()E-funded effort bolsters computer literacy and scientific understanding among teachers. At no cost to schools, Sindia and wo other national laboratories offer participating schools the use of high-performance computers, software, networks, and expertise. A two-week summer institute--at Sandia for New Mexico teathers-introduces instructional materials for teaching computational science. It also demonstrates software applications and examples of high-level tools for modeling scientific problems.

Bay Area Science and Technology Education Collaboration (BASTEC) - Sandia/California has joined with three other Bay Area 1)()E laboratories, the ( akland Unified School District, local businesses, inclustries, and other groups to improve mathematics, science, and technology education in the ()akland schools. A Summer Technology Institute explores curriculum development based on Science/Math Carnival exhibits. Under BASTEC sponsorship, Sandia also offers opportunitics for summer employment to teachers and students and maniges minigrants to support selected class projects.

Science Seminars -- ( )pen to all teachers in the San Francisco Bay area, Sandia Science Seminars comprise a series of lectures that describe the science behind the headlines. Sample lectures in 1992 were (iroundwater (leanup, The Search for Extraterrestrial Intelligence, and Nuclear Archeology in Iraq.

Science Education for Public Understanding Program (SEPUP) CollaborationDirected by the Lawrence Hall of Science, SEPUP develops strategies for teaching middle school science in a societal context. In a stimulating, hands-on format, it presents the science behind current events. Using SEPUP materials, Sandia/California has sponsored training for master-teacher teams. They in turn train middle school science teachers in livermore and ()akland, California. Sandia staff provide technical expertise as part of the SEPUP curriculum development team and furnish continuing support to schools in (Oakland and Livermore. "The success of this collaboration has led to the creation of a month-long institute for teachers at Sandia, "SUPER!" (Science Understanding Promotes Environmental Responsibility).

Math Through Applications - This program improves students' mathematics competency and shows them how math relates to everyday life. The 1 )( I) and NSF-funded project is a collaboration between Sandia and the Institute for Research on Learning in Palo Alto, California, as well as the School of Education at Stanford University. 'The project applies real-life perspectives to math projects for sixth through ninth grade students in inner-city schools. Instruction modules comprise experimental demonstrations, computer simulations, and computer programming. At a Summer Institute, hands-on projects show inner-city teachers how mathematics is used in various real-world applications. 


\section{Educational Program Participation \\ (Estimates of individuals participating or affected)}

Pre-College Projects:

Hands On/Minds On Technology

National Science Bowl

New Mexico Supercomputing Challenge

Rural/American Indian Science Education Project

Math/Science Carnival (California)

School Links Program (California)

Albuquerque Schools Career Exploration Half-Time

Work-Study Trainee and Youth Opportunity Trainee

Science Advisors Project

Summer Teacher Enrichment Project

Teacher Research Associates*

Adventures in Supercomputing

Bay Area Science and Technology Education Collaboration (California)

Science Seminars (California)

Science Education for Public Understanding Program

Math Through Applications (California)

High School Science Student Honors Program

$\begin{array}{rr}130 & 250 \\ 150 & 150 \\ 500 & 550 \\ \text { indeterminate } & \\ 30,000 & 41,000 \\ \text { indeterminate } & \\ 25 & \\ 265 & 198 \\ 50,000 & 53,000 \\ 10 & 8 \\ 15 & 3 \\ 17 & 32 \\ 50,000 & 51,000 \\ 50 & 50 \\ 69 & 69 \\ 10 & 10 \\ & 60\end{array}$

Undergraduate Projects:

Co-op Education

Historically Black Colleges and Universities*

Las Positas College Scientific Honors Program (California)

Minority Engineering Program

Outstanding Student Summer Program

Science and Technology Alliance*

Summer Employment for Minority Youth

$\begin{array}{rr}13 & 3 \\ 2 & 2 \\ 300 & 300 \\ 115 & 96 \\ 32 & 32 \\ 92 & 107\end{array}$

Graduate Projects:

Graduate Engineering Interns

National Consortium for Graduate Degrees for Minorities in Engineering

One-Year-on-Campus

Postdoctoral Internship

Postdoctoral Program

107

University Faculty Projects

Partnership for Environmental Technology Education (California)

University Faculty Summer Employment/Sabbatical

Sandia/UNM Distinguished Professor Program

Doctoral Study Program

* Program sponsored by DOE HEadquarters 


\section{Undergraduate Projects}

Co-op Education - This program provides opportunities for undergraduate students to acquire meaningful laboratory experience by alternating work experience with college studies. Work assignments are carefully matched to individual interests, and the technical challenge increases as a student's education advances.

Historically Black Colleges and Universities - Sandia is an active participant in this I)()Esponsored summer program that offers sumner employment to exceptional junior, senior, and graduate engineering and science students, as well as faculty, from historically Black colleges and universities. Students earn academic credit for participating in research and preparing technical papers.

Las Positas College Scientific Honors Program - Through this initiative, academically outstanding and financially disadvantaged, first-generation college, or minority students gain summer work experience at the Sandia/California facility.

Minority Engineering Program - The program provides advising, tutoring, and mentorship for Hispanic and American Indian engineering students at the University of New Mexico.

Outstanding Student Summer Program - Students of engineering and science from the junior level through Ph.D. are offered opportunities for summer work experience in a laboratory environment.

Science and Technology Alliance - Sandia is a major participant in this D)( F-sponsored program. It is a consortium of three national laboratories (Sandia, Los Nlamos, and ( )ak Ridge) and three educational institutions (Fundacion Bducativa Ana (i. Mende\%, New Mexico Highlands University, and North ( Garolina A\&T State University). AT'\&T has joined as the first industry participant. The Science and Technology Alliance was created in November 1987 for the purpose of increasing the representation of Blacks, American Indians, and Hispanics in the scientific and engineering programs of $D()$ E and other government agencies and private industry. It was established as a developmental effort to assist participating universities in upgrading their infrastructures and increasing collaboration with national laboratories.

Summer Employment for Minority Youth - Begun in 1990, this program provides summer employment for minorities who are high school juniors and seniors or university freshmen and sophomores. The program is designed to provide real-world work experiences in technology fields. It targets only students with mathematies and science interests and imposes no financial criteria.

\section{Graduate Projects}

Graduate Engineering Interns - Similar to a co-op program, this program provides opportunities for graduate students to acquire meaningful laboratory experience by alternating work and academic experience. It is available during the academic year.

National Consortium for Graduate Degrees for Minorities in Engineering - Sindia participates in this consortium of university and industry members. It provides opportunities for minority students to obtain masters degrees in engineering through a program of paid summer engineering internships and financial aid. 
One-Year-on-Campus - To help meet Sandia's need for minurity engineers and scientists, bachelor-degree candidates are hired and allowed to attend school full-time for a year. In specific disciplines where Sandia has difficulty recruiting at the masters level, bachelor-level employees are hired and allowed to attend school full-time for two years to complete their masters degrees.

Postdoctoral Internship - Sandia hosts postdoctoral students in areas of research where Sandia expertise or facilities provide a good match for students' interests.

Postdoctoral Program - Outstanding job candidates with Ph.D.s in technical fields are exposed to the Sandia work environment through this postdoctoral program. The program encourages a continuous flow of top scientists and engineers into Sandia.

\section{University Faculty Projects}

Partnership for Environmental Technology Education (PETE) - In partnership with other DOE facilities, Sandia works with community colleges in five western states to develop environmental and waste management programs. Sandia manages the PETE Summer Internship Program, an eight-week, in-depth opportunity for college instructors to study hazardous-waste management practices at DOE, NASA, and EPA facilities.

University Faculty Summer Employment and Academic Year Sabbatical - These two programs attract outstanding professors from universities nationwide. Participating individuals make meaningful contributions to Sandia's technical expertise. At the same time, they have the opportunity to engage in interesting, mission-oriented work. These professors are brought on-roll as temporary employees to work on research and development projects specified by Sandia organizations.

Sandia/UNM Joint Appointments Program - This collaborative program seeks new faculty members for positions in fields important to both the University of New Mexico and Sandia. Appointees devote half-time to teaching at the university and half-time to research at Sandia for two years.

Sandia UNM Distinguished Professor Program - Under this arrangement, outstanding professors join the University of New Mexico and are permitted to perform research at Sandia under contract.

Sandia University Research Program - This faculty development program provides research funds for faculty members at the three Ph.D.-granting institutions in New Mexico. The program is limited to new faculty and is usually the first funding they have received. This "seed money" is sufficient only to fund one graduate student, pay the summer salary of the faculty member, and reduce the teaching load during the academic year. Funding is limited to research that is of interest to the sponsoring Sandia organization and has a maximum duration of two years. 


\section{Work for Other Department of Energy Locations, Contractors, and Oífices}

Sandia performs work for other Department of Energy elements as requested to support programmatic and institutional requirements. These elements may include field operations and facilities of the nuclear weapons complex as well as special programs administered by DOE headquarters offices.

\begin{tabular}{|c|c|c|c|c|c|}
\hline \multicolumn{6}{|c|}{$\begin{array}{l}\text { Summary of Programs for Work for Other Department of Energy Locations, Contractors, and Offices } \\
\text { (Operating BA in \$ million) }\end{array}$} \\
\hline B\&RCode & Program Title & FY92 & $\underline{\text { FY93 }}$ & $\underline{\text { FY94 }}$ & $\underline{F Y 95}$ \\
\hline \multicolumn{6}{|c|}{ Office of Economic Impact and Diversity } \\
\hline WA50 & Minority Economic Impact Program & 0.5 & 0.7 & 0.7 & 0.6 \\
\hline \multirow[t]{3}{*}{ All Other } & & 33.1 & 30.8 & 39.4 & 41.2 \\
\hline & Total & 33.6 & 31.5 & 40.1 & 41.8 \\
\hline & Percent of total operating funds & $3 \%$ & $2 \%$ & $3 \%$ & $3 \%$ \\
\hline
\end{tabular}

\section{Minority Economic Impact Program (WA50)}

Sandia conducts or participates in several minority education development and support programs under the sponsorship of DOE's Office of Minority Economic Impact and Diversity. They include: DOE's Science and Technology Alliance; the University of New Mexico Minority Engineering Program Model; a joint Sandia/Los Alamos Middle School Rural Teacher Training Program;

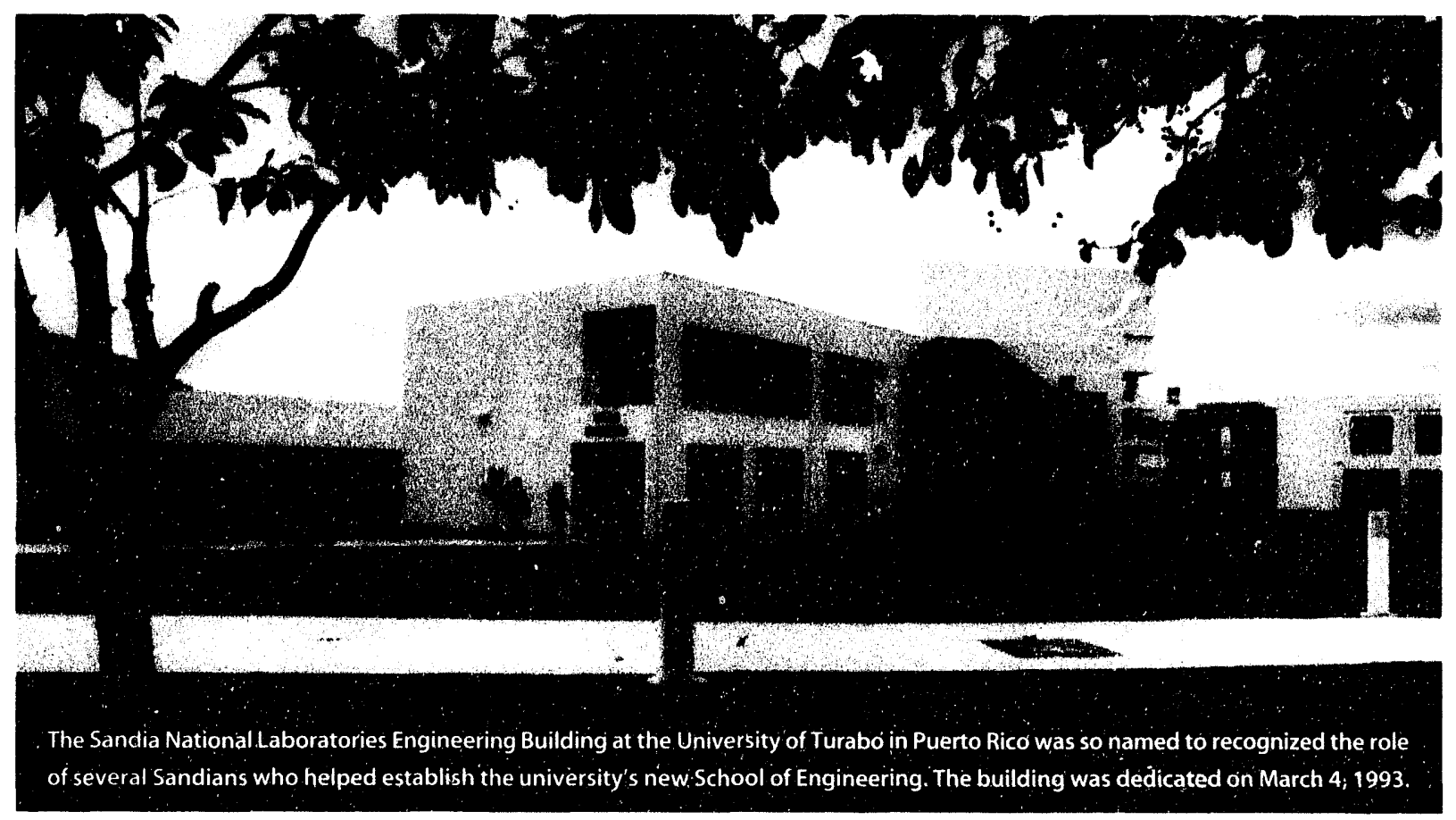


Sandia's Science Advisors Program; and support of the engineering program at the University of Turabo in Puerto Rico. Sandia played a major role in the development of the school of engineering at the University of Turabo. These and other education outreach programs are discussed beginning on page $7-80$.

\section{All Other}

We assist other DOE locations with facility safeguards and security. We have a broad base of experience in this field as it relates to nuclear materials and operations.

Sandia developed and delivered the Device Transport Vehicle (DTV) to DOE's Nevada Operations Office for use at the Nevada Test Site (NTS). This vehicle substantially upgrades the safety and security of nuclear explosive test devices from their point of assembly at NT'S to their point of emplacement for detonation.

We also developed a software security system evaluation tool called ASSESS. This tool has been used at many DOE sites to help identify security needs and the adequacy of upgrades.

Sandia is involved with the Portsmouth Gaseous Diffusion Plant in the design and implementation of their alarm communications and display system. We are providing an integrated safeguards system with Los Alamos National Laboratory at the Argonne National Laboratory West that will provide physical security and materials accounting features. We are also consulting with a number of other sites, including Savannah River, Y-12, Pantex, Allied Signal, Mound Laboratories, Lawrence Livermore, and Bettis Naval Reactors.

We are playing a major role in the Waste Energy Conservation program sponsored by DOE's Office of Waste Reduction. This program is an alliance between DOE, including Sandia and Los Alamos national laboratories, and industry for the purpose of stimulating the development and transfer of waste reduction and energy saving technologies to industry. 


\section{Work for Non-DOE Entities ("Work for Others")}

Approximately 25 percent of Sandia's programmatic effort is work for agencies other than 1)()E; about 80 percent of that effort is for the Department of Defense. These programs exercise and strengthen the capitalized resources we maintain for the nuclear weapons programs. They also make cost-effective use of existing federal investment for technological needs in areas such as conventional defense, strategic defense, treaty verification, microelectronics, manufacturing, transportation, biotechnology, and space. The technology base developed through our work for I)(O) has established expertise and capabilities not usually found in industry or in other government agencies; hence, opportunities to contribute technological solutions to agencies other than DOE not only help solve national needs, but also help maintain our abilities to perform our I)OE missions.

Before undertaking a work-f $r$-others project, we ascertain that no interference with $\mathrm{DOOH}$. weapon programs will result. Acceptable projects will involve problems of national importance that reasonably match our DOE missions and capabilities and are feasible in terms of program goals and availability of required assets. We are allowed to undertake only work for which we have special capabilities as a consequence of our technical expertise or facilities. Many of our work-forothers sponsors utilize Sandia's strong systems integration capabilities to provide rapid prototypes to quickly identify and resolve critical technical issues. Often, this work is completed jointly with or transferred to private industry, requiring our involvement only so long as needed to meet the sponsor's objectives.

\begin{tabular}{|c|c|c|c|c|}
\hline \multicolumn{5}{|c|}{$\begin{array}{l}\text { Summary of Programs for Work for Non-DOE Entities ("Work for Others") } \\
\text { (Operating BA in \$ million) }\end{array}$} \\
\hline Agency & FY92 & $\mathrm{FY} 93$ & FY94 & FY95 \\
\hline ?epartment of Defense & 291.2 & 295.0 & 275.0 & 260.0 \\
\hline Nuclear Regulatory Commission & 13.8 & 14.5 & 13.2 & 14.3 \\
\hline Department of Transportation & 3.3 & 5.5 & 7.0 & 7.5 \\
\hline National Aeronautics and Space Administration & 3.2 & 4.2 & 3.0 & 3.1 \\
\hline Department of State & 0.5 & 0.5 & 0.3 & 1.0 \\
\hline Environmental Protection Agency & 0.2 & 0.6 & 0.7 & 1.5 \\
\hline Other Federal Agencies & 26.3 & 51.3 & 18.9 & 34.6 \\
\hline All Other & 13.6 & 6.6 & 29.4 & 34.8 \\
\hline Total & 352.1 & 378.2 & 347.5 & 356.8 \\
\hline Percent of total operating funds & $27 \%$ & $29 \%$ & $25 \%$ & $26 \%$ \\
\hline
\end{tabular}

\section{Department of Defense}

\section{Air Force}

Sandia has long collaborated with the Air Force in the development of satellite instrumentation, weapon subsystems, and physical security systems.

We are continuing to support Air Force satellite programs with special Hight instrumentation systems, sensors, and ground processing capabilities to meet unique reguirements. These activities include providing sensors and data processors for satellite tactical and surveillance missions and 
providing ground-based calibration and data processing systems to support these nissions. (urrently, a nuclear burst detection sensor is being developed for the Air Force Space and Missile Systems Center that will work in conjunction with the D)E-funded (ilobal Burst Detector deployed on the Global Positioning System satellite constellation.

Sandia has developed and is now installing and testing an Integrated (Correlation and Display System (ICAI)S) for processing data from nuclear detonation sensors. Both space- and ground-based detection systems are under development. We are also developing a distributed network of computer systems to assist in the monitoring of subsurface phenomena (underground and underwater).

In programs for the protection of space assets, we are developing a laser sensor system and a ground station capable of detecting, characterizing, and reporting laser irradiation directed toward a satellite from ground-based or airborne sources. Sandia has achieved a state-of-the-art capability in the design of high-data-rate, survivable, radiation-hardened, integrated communication systems and is in the process of codifying the design rules for such devices for the benefit of defense electronics manufacturers.

Sandia has unique technical capability in the area of mobile command and control centers that can survivi a nuclear environment. We are engaged in a proof-of-concept project for a transportabi, survivable, multi-shelter command center for the Strategic Command and the Strategic Target Planning Staff. Similar work will produce a prototype command center to meet the requirements for mobile, survivable command centers for the North American Aerospace Defense Command and the United States Space Command.

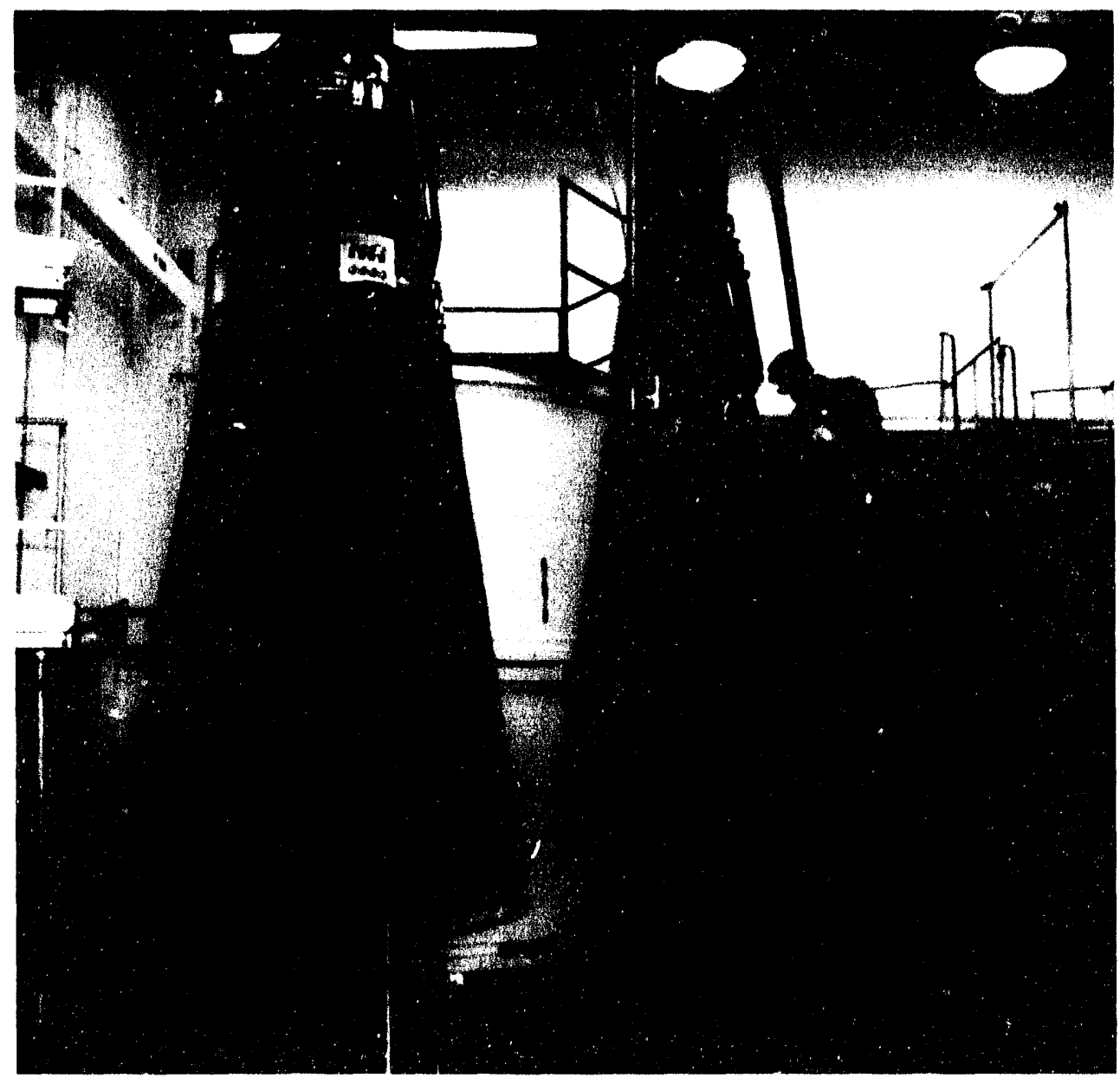

Two Topaz II space nuclear power systems, shipped from Saint Petersburg, Russia, arrived in Albuquerque in May 1992.

Researchers from the Air Force's Phillips Laboratory, Sandia and LoS Alamos national laboratories, and the University of New Mexico are studying the reactors. 
Sandia and the Air Foree (entral Inertial (indance l'est Facility are continuing the development of a small, high-accuracy, ring laser gyro inertial navigation system. This system is being developed for maneuvering reentry vehicle applications but will be used by the dir force in a scoring system to evaluate other missile guidance systems.

Sandia is working closely with the Air Force Phillips Laboratory to support the I epartment of 1)efense thermionic space reactor program. The Thermionic System Livaluation and Test program involves nomnuclear testing of a Soviet TOPA\% II reactor. We are developing the test schedule and providing the test director and technicians. In addition, we are developing computer software that can be used to predict test results as well as the response of thermionic space reactor systems under various transient conditions. Finally, we provide technical expertise to assess the potential of various thermionic space reactor designs.

A. tivities in support of U.s. Air loore physical security programs include systems design and development of weapon storage vaults; intrusion detection, communications, and assessment technology; and participation in evaluating the needs and appropriate application of these technologies to specific sites. Air Force organizations with whom these activities are undertaken indude liectronic Systems Division of Systems Command Electronic Security Command, Tactical Air Command, U.S. Air Force Europe, and other smaller organizations. These afforts draw directly upon and supplement our experience in providing security technologies for the D)E nuclear weapone complex. We are now soliciting proposals to transfer some of these technologies to private industry.

\section{Navy}

Building on the successtul relationship with the Navy that produced integrated arming, fuzing, and fi, 'ig systems for the Mark 3 and Mark 4 reentry bodies, Sandia developed an integrated arming, fuzing, and firing system for the 'Trident II/Mark 5 weapon program that provides fuzing options to enhance effectiveness against hardened targets. The 'T'rident II/Mark 5 development program was completed in 1991, and first production to support initial operating capability is nearly complete.

Sandia supports the Submarine-Launched Ballistic Missile Effectiveness Enhancement Program (sponsored by the Navy Strategic Systems Projects (Office) with development and characterization of flight processors and sensors and technical support for experiments. The effort utilizes Sandia's experience base in nuclear weapon development engineering and applies it to a related area that could have significant strategic importance. 'The Laboratories' experience in navigational guidance and control with radiation-hardened microelectronics will be used in the development of a new flight computer. In addition, alternative warhead designs for SLBMS are being prepared.

We are also providing engineering services and technical evaluations of ordnance and explosive components used on the ( $, 3,(, 4$, and 155 missiles and 155 launch and closure dome removal systems. The work involves conducting ordnar e failure investigations and assisting in development of corrective actions where required.

Materials modeling and structural analysis, developed by Sandia in earlier weapons development work for 1$)(\mathrm{E}$ and $\mathrm{Dol}$ ), are being applied to Navy problems of assessing the lethality of conventional warheads against various targets. This work for the Naval Underwater Systems (enter uses analytical and experimental techniques to determine the onset of material failure and the propagation of damage.

Sandia has performed reimbursable work in support of Marine Corps expeditionary force capabilities. Drawing upon our expertise in sensor technology and rugged microelectronies, we developed a family of remote, unattended ground sensors for perimeter security, battlefield route surveillance, and support of amphibious assaults.

Our experience with deployable sensor systems has led to the development of a Mini Intrusion 1)etection System for the armed services and other federal agencies. 'This system provides advanced, cost-effective patrol security for small installations. Sandia's competency and experience basc in sensor-based security systems may have application to a variety of unique government recuirements. 
Our capabilites in providing robotics for the physical security of 1 )( )l: sites have led to the development and demonstration of tele-operated battlefield vehicles. We are also providing consultation as these concepts are pursued by the Marine Corps and private industry for further development and production.

\section{Army}

Because of our unique expertise in analysis, design, numerical modeling, gun testing, and e'valuation of nuclear projectiles, the Army Human Engineering Laboratory and Army Research Development and Engineering Center requested that Sandia provide hardware, test support, and data processing for a demonstration of the Video Im sing Projectile designed and tested by Sandia.

The Army has further requested that Sandia assist in the precompetitive phase of a development program for a reconnaissance projectile that will provide target identification, target location, and damage assessment for field artillery units. This capability will be developed by integrating the Sandia Video Imaging Projectile concept (which provides video images of a target area) with the Harry Diamond Laboratories' Global P'ositioning Satellite fuse program (which provides spatial location of the projectile). This joint program will provide the Army with surficient data to generate requirements and performance specifications for a competitive development of the recommaissance projectile.

Sandia has unique experience in the design of safe, secure transportation containers for havardous and radioactive materials. The Army has asked Sandia to apply this expertise to the design, testing, and development of a container for the transportation of chemical munitions on military installations. Private sector fabrication of a fleet of such containers will be supported by Sandia.

We are also developing and qualifying a container for safe air transportation of the Army's tactical nuclear weapons, which must be returned to the continental United States for destruction.

We have developed an improved, all-electronic sating and arming system for the Patriot missile. The safing and arming technology embodied in the Patriot system was developed in the 1$)($ ) 1 : nuclear weapons program. The design is being transferred to industry for production, and we are currently qualifying a supplier for the Army.

Sandia also has unique experience in the design, integration, and testing of ferrain-referenced navigation algorithms. Using this experience base, we are applying the Defense Mapping Agency's Digital Land Mass System Level-1 I)igital Elevation Data to the terrain-referenced navigation and terrain capabilities of the Army's I()1158( ' helicopter.

Sandia's parachute and control system technologies are being used to develop high-speed, low-level, airdrop resupply systems. We are exploring guidance concepts to defeat high-valuc battlefield targets and are studying the effects of low-observable materials on survivability in the battlefield of the future.

\section{Ballistic Missile Defense Organization}

The Ballistic Missile I efense ( )rganization sponsors a broad range of research on technolegies relevant to Sandia's prime mission as well as to its own programmatic goals. We provide support in a number of areas where we either have special capabilities or unique facilities and where the work complements our 1)( )E mission responsibilities. We plan to continue working in the areats of discrimination, countermeasures, space power, pulsed power, threat definition, space survivability, space experiments, and theater ballistic missile detense.

The countermeasures evaluation activity stems from our experience in nuclear weapon design, our previous activities in reentry vehicle technology, and the application and evaluation of concepts that could make strategic and the atter nuclear weapons more robust against a strategic defense. This work will help provide a baseline from which may be evaluated the cost-effectiveness 
and cost to the adversary of deploying countermeasures should any specific concept be fiedded by the United States. (Our activities in threat definition help provide a better understanding of both near-term and long-term strategic and theater ballistic missile threats.

The Missile Defense Act of 1991 provided (ongressional direction to develop the capability to deploy limited ballistic missile detenses by 1906 or when technically feasible. This mandate placed a premitum on the timely execution of rocket missions that are needed in the development of ballistic missile defense technology. Sandia's rocket launching test facilities in 'Tonopah, Nevadia, and Kauai, Hawaii, allow tight testing of instrumented vehicles. The Kaluai facility has been upgraded and is capable of launching ST'ARS (Strategic Target Systems) boosters. Sandia will Hy up to four ST'ARS missions per year during the next ten to twelve years. We anticipate continuing to use this upgraded facility to support flight tests for both the Ballistic Missile Defense ()rganization and the D() I: nuclear weapons program.

Sandia builds unique, instrumented targets for experiments conducted for the Ballistic Missile Defense (Organization and the U.S. Army Strategic Defense Command. In order to provide more uniform assessment of proposed strategic defense system elements, a baseline target set has been defined consisting of target vehicles and potential penetration-aiding articles developed by Sandia. The experiments are launched from Vandenburg Air Force Base and from Kauai l' lest fiacility. The ( perational Deployment Experiment Simulator (ODES) is a target deployment platform being bult for several experiments that will be flown on the STARS missile system.

Sandia has expertise in weapon system analysis that will be used to evaluate the utility of smart mines in the Theater Missile Defense application. We will evaluate and demonstrate this innovative concept for intercepting missiles during the boost phase of flight. The work will require detailed concept definition of all subsystems; rigorous analysis of the concept with regard to sensors, command and control, and launch detection; and test planning and execution for several demonstrations against simulated targets. We will contract with industry for technical and hardware support in the demonstration tests.

We have continued to develop our capabilities to model space nuclear power systems for strategic defense applications, and we have produced comparative evaluations of the various systems for the Ballistic Missile Defense Organization, 1)(OL, Air Force, and Army. (Our work also involves developing instrumentation and control technology and independent analyses of safety features.

Sandia's capabilities in the area of radiation hardening serve as a foundation for evaluating methods and penalties for enhancing the survivalility of objects in space through hardening of the electronics and structure, as well as evaluating methods for maneuverability, shootback, and other features.

Capabilities developed primarily for the inertial confinement fusion program and for aboveground effects simulation are being applied for a future need to launch many satellites into low earth orbit. The Sandia coil gun project, sponsored by the Ballistic Missile I Cefense ()rganization, has advanced through concept feasibility. In addition, new split-cavity oscillator microwave sources for high-power microwates are being developed in the interest of more compact jammers, radars, and weapons.

Finally, we provide direct support to the Ballistic Missile Defense ( )rganization's Phase ()ne

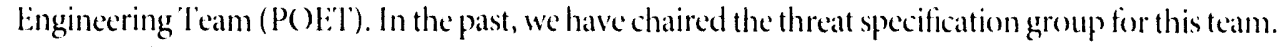
We provide advanced computing capabilities and have developed massively parallel tracking and correlating programs that can handle scenarios thousands of times larger and more complex than was possible in previous efforts. The potential for real-time tracking and corrclation in realistic strategic defense scenarios will be demonstrated soon. We expect to continue to participate both in threat specification evaluation and command and communications issues. 


\section{Advanced Research Projects Agency}

Beginning in 1993, the Advanced Research Projects Agency (ARPA) is sponsoring the Nattonal

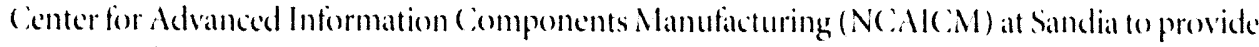
a resource for integrating federal and commercial rescarch and development of advanced information components. This integration will provide the capability for the L'nited stattes to greatly compress the time to translate resear h and development into commercial and defense products. The center will complement other Dol) microelectronics, optockectronics, and small-areal, liquidcrystal-based display programs. Los Alamos and Lawrence Livermore national laboratories will also support the center, along with representatives from industries and universities.

By providing space and equipment to support development of agile manufacturing processes for large flat-panel opticial displays and microdectronics, the center will allow ind ustry and government researchers to exploit a wide variety of disciplines and competencies alvailable at the Laboratories. These competencies indude microdectronics and photonics, advanced electronics systems packaging, materials science and processes, printed-circuit fabrication, and other product development tools.

Research will concentrate on agile manufacturing technologies associated with advanced silicon integrated circuits, high-speed optoelectronic communications, and electronic systems and subsy'stems. Research in large flat-panel displays will benefit from the consolidation of supporting technologies at a single site. Manufacturing research will focus on developing agile manufacturing processe's for that-pancel products for both defense and industry.

Information components manufacturing programs will benefit from several I)( )E manuficturing development facilities at Sandha, such as the Process Development Laboratory. Microelectronics 1) crelopment Laboratory, (Compound Semiconductor Research Laboratory, (Center for Advalnced Manufacturing Technology, Microelectronics Quality/Reliability (Center, and the recently announced Center for Microelectronics Technologies.

Beyond technology-specific assistance for the production of essential components, the center is expected to address a systematic L.S. weakness in the development of advanced manufacturing technolegies. It will pioneer and refine approaches to assist the transformation of L'.S. manufacturing to knowledge-based distribution and control systems for the factories of the future. By integrating lessons learned from its three associated pilot manufacturing centers, the center will develop rules and sy'stems for distributed knowledge-based production methodologies featuring open architectures and universal comnectivity.

() ther work for ARPA includes the evaluation of kinetic energy penetrators and the exploration of the technical issues related to hypersonic weapon systems. Sandia's Rocket Sled Hacility provides a unicue testing capability to evaluate the key technical issues associated with deployment and lethality at hypersonic speeds.

\section{Othar Department of Defense Organizations}

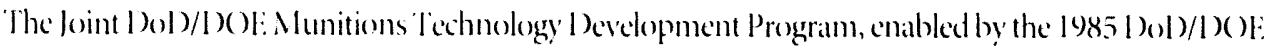
Memorandum of Linderstanding, is a jointly funded effort of research and development to pursuc innovative warhead, explosive, and fuze technologies and to improve nonnuckear munitions technology across all service mission areas. Projects pursued under this program include energetic materials, armor/anti-armor, guidance and control, smart mines, countermines, and systems studies.

Each topical area under this program is oversecen by a Technology' (Coordination (iroup that acts as liaison between Dol) and I) ()E and estahlishes a channel for technology exchange. (composed of technical experts from each agency, these groups work to ensure maximum benefit from the program. Technology (ioordination (iroups establish measurable deliverables and realistic schedules, coordinate multiservice reguirements, establish classification guidance, monitor activity, and 
provide semianmual reports on project status and potential new projects. They also conduct tedmical

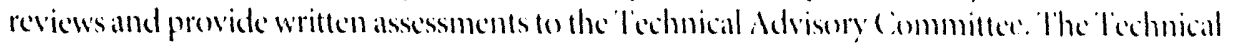
Advisory committer administers the program and provides policy guidance. It reviews lechnical assessments from the lechnology condination (iroups, evaluates new proposals, and establishes the program plan.

Because much of the technology base developed in nuclear weapons werk is directly applicable (1) Dol ) needs in conventional munitions, this program has brought about major improvements in conventional munitions. The program is consistent with long-range planning at the l epartment of tofense and is an effective mechanism for leveraging cappitalized research and development resources. At the same time, the costs asso "ated with maintaining many of the core competencies required for the nuclear weapons program are shared by 1 )ol ), and the resources are further exercised, challenged, and strengthened.

Sandia's Microdectronics I evelopment Laboratory supports several I )ol ) agencies with technology development, custom device design, and limited production items through 1)( )E or commercial vendors. Similarly, Sandia provides unicjue components, such as high-soltage switch tubes, and the consultation of various technology experts (c.g. pyrotechnic device experts) as repuested by Dol ) agencic's

As an outgrowth of our research on novel warhead technologies, we are conducting research and development on methods for quicting future U.S. submarines. We are also using our extensive computer simulation facilities and expertise to demonstrate more lethal warheads for future torpedoes.

Sandia performs aboveground simulation of nuclear weapon effects for the I efense Nuclear Agency (I)NA) using the Saturn $x$-ray and Hermes $I I I$ gamma-ray facilities. We are also providing explosively actuated closures for use on Defense Nuclear Agency lests at the Nevada lest Site and are making diagnostic measurements related to experiment protection and containment. Also under sponsorship by the I efense Nuclear Agency, we are developing improved security hardware, operational concepts, and tactics for military security forces.

With sponsorship from the (Office of the Secretary of I)efense, Defense Nuclear Agency, and D) (), we are exploring means by which the survivability and security of nonstrategic nuclear forces can be assured in the twenty-first century. The Defense Nuclear Agency is also sponsoring the research, development, and adversary analysis of new systems and technologie's for portal and perimeter monitoring.

For the I etense (ommunication Agency, we have developed a broad range of technologies for survivable command and control centers. These technologies - including a broadband data bus with computer-aded remote control and monitoring - are being used for classified operational systems and proof-of-concept applications.

Fxtensive studies are continuing in the areal of precision, yuick response weapons in a regional conflict context. The Sandia approach would provide a highly integrated target acequisition, data fusion, retargeting, and hypersonic warhead delivery system to address time-critical targets in a regionalconflict.

\section{Nuclear Regulatory Commission}

Since 1973, Sandia has conducted a broadly based research program for the Nuclear Regulatory Commission (NRC) in probabilistic risk assessment, severe accidents of nuclear reactors, reactor safety rescarch experiments, engineering technology, low-level waste managenent, and sateguards alod security. We also provide technical assistance in the safety assessment and resolution of reactor safety issues.

We have pertormed many of the risk assessments sponsored by the commission, developed state-of-the-art methods, participated in major technology transfer efforts, and addressed important 
regulatory issues amenable to solution by risk alssessment. We halle developed methods to analy power plant systems, operations, human performance, accident processes, transport of radionctive materials, and health and economic impacts. We have placed major emphasis on the treatment of uncertainties in analyaing potential plant accidents.

()ur severe accident research program funded by the Nuclear Regulatury (ommonission involves participation with the incernational reactor satety rescarch community. Several anicpece experimental facilities have been developed at Sandia for inestigating the diverse physical phenomena that may be important in postulated severe accidents. In-pile experiments tostudy core-medt acident progress are performed using Sandia's Annular (ore Re'search Reactor. ()ut-pile experinents to inve'stigalte the loads imposed on reactor containment buildings by high-pressure melt injection accidents are performed in the Surety ' lest facility and in a one-sixth scale model of a nuclear power plant containment. The theoretical work centers on the development and validation of mechanistic codes

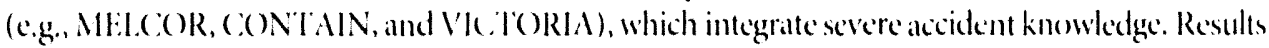
of the severe accident research are used for developing databases and models for improving hardware and procedures to decrease plant risk, resolve safety issues, and provide the basis for accident mataigement and emergency response.

Sandia has conducled an a vensive analytical and experimental containment integrity program, including major tests on a onc-eighth scale model sted building and a one-sixth-scale reinforced concrete building. Testing has been performed to evaluate the havards of turbine and external missile impacts. Evaluations of seismic and fire risks are conducted in conjunction with testing where needed. Test facilities have been developed for performing quantitative measurements of fire behavior and the effects of smoke and combustion products. We have performed extensive testing on nuclear power plant electrical equipment and components under simulated accident conditions. Such tests support equipment qualification and plant life-extension activities.

Sandia is the lead laboratory researching the development and application, if performance assessment methodologies used in evaluating the suitability of nondefense, low-level waste disposal facilities. We are also evaluating methods for classifying waste streams as "below regulatory concerns" for use in setting de minimus standards for radioactive and mixed wastes.

Sandia continues to support the Nuclear Regulatory (ommission in transferring lechnology developed in D) ():-sponsored safeguards programs to (ommission staff and inspectors and the nuclear utilities. () ther technologies transferred to industry or other entities indude advanced computer codes and technicues for materials and component design and evaluation.

\section{Department of Transportation}

Sandia performs rescarch and consultation for the l)epartment of l'aumportation on issues related to the transportation of havardous materials, the developenent of intelligent vehickes and highwaly systems (IVISS), aircraft salety, and airport security.

The objectives of the hazardous materials program are to recommend packaging performance requirements for hazardous materials transportation and review specifications for radionctive materials packaging. We are also developing a microcomputer-based hazardous materials highwaly routing guidelines decument, incorporating a user-friendly model and a tusers' mantal to assist in the application of the guidelines.

Experimental work on the thermal characteristics of shipping casks supports the lepartment of Transportation's efforts to assure the integrity of hazardous material containers in fires. We are secking to determine if a generic boundary condition description can be obtained that will be usable for both thermally massive and nommassive shipping casks. The work also assesses the effects of the thermal mass of a shipping cask on the heat transfer characteristics of a sooty engulfing fire. Sandia's radiant heat facility is being used to understand the radiative and consective bethavion of 


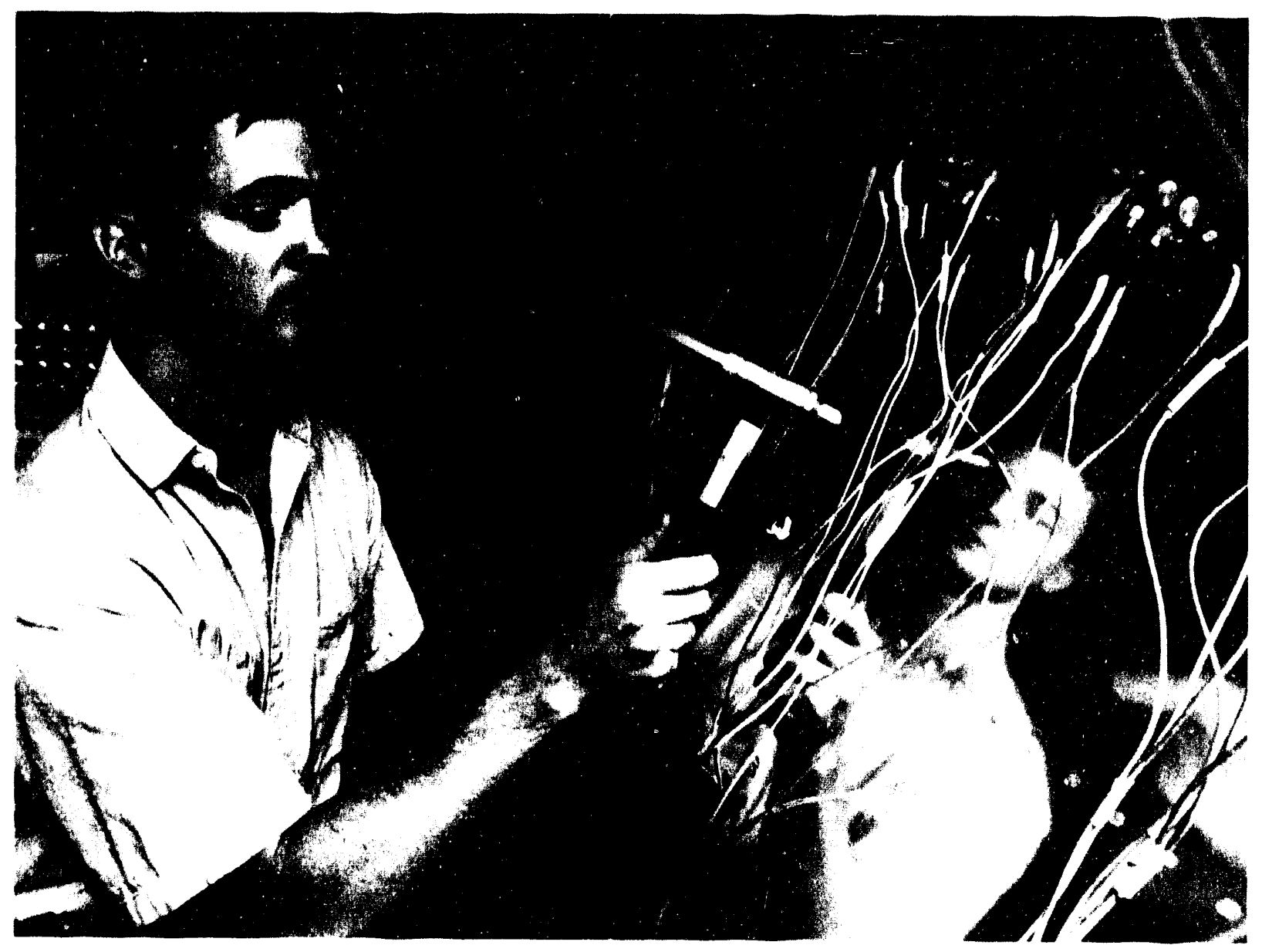

Modal analysis uses vibration test data to determine a structure's natural frequencies, mode shapes, and damping values. Dennis Roach vibrates a section of aircraft fuselage with an instrumented hammer. Accelerometers on the surface collect modal data that can reveal subsurface damage. The technique is one of many used at the Aging Aircraft Non-Destructive Testing Development and Demonstration Center at Sandia.

heat transfer in such a fire. W'e have recently initiated a program with the Federal Aviation Administration Technical Center to apply this technology to aircraft safety.

W'e are assisting the Federal $A$ viation Administration by bringing our expertise in nondestructive testing to bear on the problem of aging aircraft. There is insufficient knowledge about the effects of age on the performance and safety of aircraft to accurately forecist when components should be repaired or replaced. The program will develop procedures for commercial utilization of advanced inspection equipment al ready in use at facilities of the Department of Defense. New instrumentation will also be developed as required. 'The program is designed for rapid technology' transfer, and Sandia is collaborating closely with industry and academia.

W'e are also alssisting the federal Aviation Administration to derelop and demonstrate advanced airport security system concepts at Baltimore-W'ashington hoternational Airport.

Sandia provides support to the United States Coast ( iuard to develop systems for its intelligence and law enfercement operations. The $\mathrm{Al}) \mathrm{V}$ anced Image (communication and linhancement (AD)'L(E) project was successfully completed in 1992. This study was directed at determining whether the speed and efficiency of transmitting digitized images was an effective trade-off for the reduced resolution inherent in digital images als compared to 35 millimeter photography. 
The Coast Guard Research and Development Center has requested a follow-on project to study various electro-optical sensor devices and their applicability to Coast (juard missions. The work will involve integrating sensor information from a number of sensors on a $\mathrm{C}-130$ aircraft. The objective of this project is to provide improved surveillance information for Coast (juard intelligence, counternarcotics, illegal immigration, and marine fisheries missions.

Sandia is currently a leader in the field of intelligent vehicles and highway systems. Our years of experience in safely transporting and tracking nuclear weapons shipments and in the development of tele-operated robotic vehicles have provided a technology base that is unique in the nation. For example, we have a digitized database of all highways and roads in the United States. The Federal Highway Administration is interested in applying this database in its Intelligent Vehicles and Highway Systems program. The intent is to use this data in conjunction with our vehicle tracking system based on the Global Positioning System to help develop intelligent vehicle and highway systems that will reduce traffic congestion. In addition, our robotic vehicle work provides a source of sensor and intelligent control systems technology that is currently being applied to improve the safety of commercial vehicles.

We are assisting the city of Denver to improve its ability to track and control the movement of buses. Working with private industry, we provide design support for tracking systems that use Global Positioning System satellites. This work is sponsored by the Federal Transit Authority.

\section{National Aeronautics and Space Administration}

Sandia provides a variety of technical support to the National Aeronautics and Space Administration (NASA) and NASA-funded projects. Through previous collaborations on space instrumentation with Los Alamos National Laboratory, Sandia has acquired unique capabilities in certain implementations of signal processing and data handling applicable to astrophysical investigations. We provide instrumentation to support experiments aboard rockets and space probes for which the science partner is often an educational institution performing work with NASA funding.

For example, we support the Columbia University Astrophysics Laboratory in developing an $\mathrm{x}$-ray polarimeter experiment for the Russian Spectrum-X-Gamma satellite. We are providing design support for the Mechanics of Granular Materials instrument, a microgravity experiment in collaboration with the University of Colorado and NASA. Similar design support is being furnished for the optical monitor experiment for the European Space Agency X-ray Multispectral Mission satellite.

The Comet Nuclear Penetrator will be part of a larger mission sponsored by the NASA Jet Propulsion Laboratory called the Comet Rendezvous and Asteroid Fly-by. The University of Arizona was selected to be the lead laboratory in cooperation with Ball Aerospace Systems Division. Sandia has been asked to participate in the program by acting as a consultant on penetrator technology and performing development testing of the penetrator.

We have a unique capability in radiation-hardened microstructures that we developed in the nuclear weapons program. Such devices are useful for space applications. We design, fabricate, and produce radiation-hardened engineering prototypes of selected microprocessors for NASA.

Another of Sandia's unicue strengths in microclectronics is compound semiconductors. We are working with NASA's Jet Propulsion Laboratory to employ this technology to develop longer wavelength photovoltaic arrays for electrical power supplies in space. We seck to grow stable, strainedlayer superlattices that exhibit significant optical absorption at wavelengths to 15 microns and beyond. The work includes buffer design and growth, $x$-ray verification of structure and composition, analysis of defects, and photoluminescence characterization of the resulting superlattice. This work is a critical phase of materials development for demonstration of reproducible, spatially uniform material with the desired infrared characteristics. The follow-on task will be fabrication and optimization of detector and array structures. 
Sandia is the world leader in the theory and design of high-performance parachute systems. We advise NASA on the conceptualization, definition, and design of the high-speed parachutes used to decelerate the Space Shuttle's solid-fuel rocket boosters and other payloads. We are working with the Johnson Space Center to develop a strategy for developing a capability for soft landing and recovery of spacecraft and reusable launch vehicle hardware. The strategy will identify critical technology issues and improve the understanding of landing systems problems.

Drawing on yet another expertise developed in the nuclear weapons program, Sandia is using two- and three-dimensional finite element modeling to redesign the explosively driven separation systems used on the Space Shuttle booster.

Sandia's Robotic Vehicle Range has been asked by NASA's Langley Research Center to join with them as the DOE element in a tri-agency consortium to develop a lunar rover program proposal for the NASA Exploration Program Office. Sandia's design, a four-wheel articulated Robotic AllTerrain Lunar Exploration Rover (RATLER), provides high agility, reasonable payload capacity, and good overall stability in a small, simple package. The unique chassis articulation permits all four of the drive wheels to remain in contact with the ground, even while climbing over obstacles such as boulders or depressions as large as one wheel diameter. Sandia's project responsibilities are primarily the vehicle control hardware and software.

Under joint sponsorship by NASA and the Ballistic Missile Defense (Office, Sandia is evaluating concepts for space power systems. The evaluation addresses three principal concerns: (1) power system concept and technology evaluation and comparison; (2) safety; and (3) reliability, availability, and maintenance.

Sandia's one-of-a-kind hypervelocity gas gun facility is being used to evaluate proposed debris shield designs for Space Station Freedom. The tests will determine the ballistic limits of various shielding hardware at velocities up to 12 kilometers per second.

Also for NASA, we are investigating the feasibility of developing a 21-foot Sandia Winged Energetic Re-entry Vehicle Experiment (SWERVE) as a hypersonic test-bed. The vehicle would be launched from a Pegasus booster and potentially acquire data on engine performance. The feasibility of flying nonintrusive instrumentation to measure flow field properties and validate computational fluid dynamic codes is also being considered.

\section{Department of State}

Under sponsorship of the Department of State, Sandia provides direct technical support to the International Atomic Energy Agency (IAEA) in its role of verifying compliance with the provisions of the Non-Proliferation Treaty (NPT). The agency employs both material accounting procedures and containment and surveillance techniques to provide the safeguards measures required by the treaty. Currently, we are developing unattended closed-circuit television optical surveillance equipment, verifiable seals, and monitoring equipment. Newly developed containment and surveillance equipment is being demonstrated. We will assist in implementing the new equipment by providing training, maintenance, and documentation. We will continue to provide containment and surveillance consultants as requested. We will also assist the IAEA with training and inspection of physical security systems.

\section{Environmental Protection Agency}

Under an interagency agreement and other developing cooperative efforts between the l)epartment of Energy, the Environmental Protection Agency (EPA), and various other government agencies, Sandia provides technical assistance and proposes technical courses of action involving approaches 
for site characterization, sensor technology, remediation technologies, advanced analysis approaches, and risk-based decision approaches.

DOE and EPA have a long history of coordinating science and technology projects, including the Energy and Environment Program of the early 1970s, the National Acid Precipitation Assessment Program of the 1980s, and the National Laboratory Consortium formed by the National Acid Precipitation Act of 1980. EPA and DOE have entered into thirty-five memorandums of understanding (MOUs) over the past two years for joint research and development under DOE's environmental restoration program. There have also been several MOUs on general cooperation and technology transfer. These efforts are expected to accelerate, since DOE has recently committed to work closely with the National Resources Cluster of the Cabinet to address national environmental issues.

For example, DOE and EPA have recently initiated a Joint Laboratory Directors' Forum to foster more cooperative environmental research efforts between the two agencies. The forum consists of the directors of each agency's research and development laboratories and is addressing active collaboration in ongoing research and identifying topics for joint research for FY 1995 and beyond in the areas of pollution prevention, waste minimization, environmentally sensitive engineering and manufacturing, hazardous and mixed waste treatment, ecological research, monitoring and assessment, and environmental risk assessment - all in support of the shared goals of the DOE and EPA in environmental cleanup, pollution-prevention, and waste management. Sandia, as one of DOE's major research laboratories, will be expected to provide technical assistance and leadership in improving site characterization, sensor technology, remediation technologies, analysis approaches, risk based decisions, and public outreach.

Sandia has established a number of initiatives with the EPA to assist regulators and encourage the use of innovative environmental technologies. An example is a joint effort with Sandia, industry, DOE, and EPA to demonstrate innovative cleanup technologies at a DOE site. The program provides an opportunity to develop a model for accelerated environmental cleanup operations throughout the nation.

As part of a more regional effort, Sandia is supporting efforts by DOE, EPA, the Department of Defense, the Department of Interior, and the Western Governors' Association to accelerate environmental technology development and cleanup activities while enhancing economic development in the West. Beyond these broad-scope activities, Sandia is also providing focused technical support to the EPA in decision support systems and air pollution measurements.

\section{Other Federal Agencies}

Sandia provides support and certain space-qualified hardware for NASA and the European Space Agency. We are providing a number of radiation-hardened, large-scale, integrated circuit devices for the Venus Radar Mapping Mission. We also provide support to NASA for the development of recovery systems for instrumentation sent into orbit. Sandia advised on the design of the high-speed parachutes that decelerate the space shuttle's solid-fuel rocket boosters as they fall to earth.

Sandia continues to support the National Security Agency in adversary analysis. This work involves evaluation of communications security equipment, components, and design proposals to determine and identify vulnerabilities having a potential for exploitation by an adversary.

A Sandia-developed safe diversionary grenade has been in use by military and law enforcement agencies for several years. A practice version of this device has been requested and is now under development.

Sandia's experience in safeguards and security for nuclear materials and facilities has been applied to other federal security needs. We are developing force protection systems for use by military and nonmilitary personnel in special-operation, low-intensity conflict environments. We helped develop and install an automated entry control system for the White House, and we have been tasked to participate in a security upgrade of the Hoover Building of the FBI. 
Sandia National Laboratories is responding to requirements being brought forward by federal, state, and local law enforcement agencies involved in the war against illegal drug trafficking. Sandia was explicitly named a national technical resource in the Drug Abuse Act of 1989. Our response has been sharpened by extensive interactions with interested agencies at all levels, from individual agents patrolling the border to headquarters units involved in enforcement and research and development.

This effort has three focuses: attempting to match available technologies with requirements in order to provide immediate solutions; defining and proposing long-term development efforts in areas where Sandia has expertise; and offering systems analysis support to better define and prioritize drug interdiction approaches. Immediate support is available in such areas as ground sensors, communications, and radio-frequency beacons. Developmental areas include laser-induced fluorescence, compressed video communications, and passive beacons.

The results of these efforts are contractual arrangements with several agencies, and it is expected that these programs will expand as agency research and development budgets grow and the drug war becomes better organized.

\section{All Other Reimbursables}

When appropriate, Sandia also enters into projects involving state governments, private industry, universities, foreign governments, or other nonfederal entities. Criteria for these arrangements are the same as for other work-for-others endeavors. Current projects comprise a variety of activities and Sandia resources, including development of numerical models for rock blasting, computer modeling to predict chemical behavior in methane-air jet flames, microelectronics development, and studies to improve nuclear reactor safety. 


\section{Laboratory-Directed Research and Development Program}

Laboratery-Directed Research and Development (LI)RID) became a permanent program at Sandia in FY 1983 as permitted by federal liw (Public Law 95-39, Section 303) and D)(OE Order 500(0.4A. The LDRI program provides support for science and technology activities related to I)OE's missions. Projects emphasize early exploration of forefront science and technology that enhance Sandia's research and development capabilities and core competencies.

LDRD projects must be relatively small, well-specified, short-term (one to three years) projects that look forward in terms of technology and application (i.e., projects that establish new capabilities, test new concepts, or investigate innovative approaches). LI)RD funds are not used to substitute or increase funding for tasks otherwise funded by DOE or other agencies or to carry projects beyond the exploratory stage.

LDRD funds are derived from a tax on funding from all sources, including DOE programs. The tax on DOE funds is being introduced gradually. In FY 1993, the program was funded at about $\$ 53$ million.

The LDRID program permits Sandia staff to explore innovative scientific and technological opportunities that hold high potential for payoff in applications. Some of these projects have led to tangible new DOE tasks and projects; others have enhanced the Laboratories' core capabilities.

For example, an FY 1991 LDRD project led to the development of a mobile robotic manipulation and retrieval system. The project aovances the state of the art for machine intelligence in mobile systems. This technology should find early application in hazardous waste removal operations at DOE facilities. In addition, the work has implications for U.S. economic competitiveness, and we are examining potential industrial applications. This project was beyond the scope of interest of funded robotics projects and thus could not have been pursued without L.DRD funding.

An FY 1992 project looked at developing biomimetic processes to grow ceramic materials in ways analogous to the biological processes that occur in living organisms. Ultimately, the goal is to develop biomimetic processing methods to produce materials for medical, semiconductor, optoelectronic, and "smart" materials applications. For example, biomimetically grown calcium phosphates could be used for biologically compatible interlayers for joint and bone replacements. For advanced ceramics applications, biomimetic processing may facilitate fabrication of oriented crystalline ferroelectric films.

Selecting LDRD projects is a formal process. Each fall, the Sandia Program ('ouncil identifies a number of core competencies and strategic initiatives that will comprise the L.D RLI) program elements for the following fiscal year. At this time, the Council also establishes L.DRI) budget targets for the program elements. Next, a call for proposals is issued describing the intent of the program, the program elements, and requirements for submittals. Investigators who wish to extend a project beyond one year must submit a renewal proposal for continuation of funding. The renewal repuest must detail progress achieved to date toward project milestones and describe the tasks to be performed in the next year.

Proposals are subjected to two independent evaluations. A technical appraisal team evaluates the content of the proposed work, the technical approach proposed, and the technical potential of the project. Proposals are also subject to a programmatic evaluation by one of several review boards. In this evaluation, proposals are reviewed with regard to growth potential, impact on future laboratory activities, and agreement with the Laboratories' strategic intent. 'The programmatic appraisal team ranks the proposals in its program area in order of funding preference.

Based on the review rankings and budget targets established by the Sandia Program Council, the Laboratories' LDRD program manager prepares a proposed I.DRD program. A program plan is then prepared and submitted to DOE: for a project-by-project review. Sandia and DOE then jointly modify the proposal to develop a plan that meets all D)()E requirements. D()E: is respensible for final authorization of the program. 
Summary of Projected Investment in Laboratory-Directed Research and Development Program (Operating BA in \$ million)

Total funding

$\underline{\text { FY93 }} \underline{\text { FY94 }} \quad \underline{\text { FY95 }} \quad \underline{\text { FY96 }} \quad \underline{\text { FY97 }} \quad \underline{\text { FY98 }} \quad \underline{\text { FY99 }}$

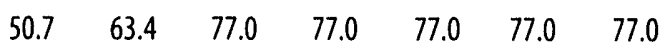

Note: Planned LDRD amounts are subject to approval in accordance with DOE Order 5000.4 



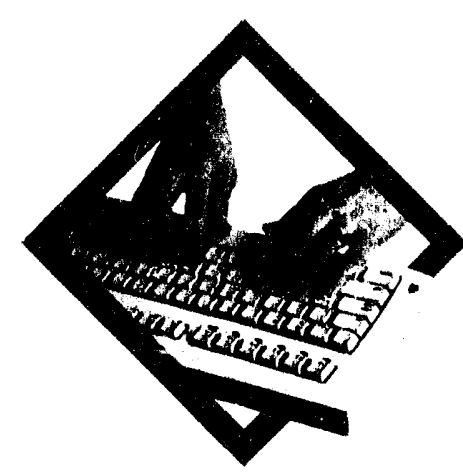

\section{Information Resources Management}

\section{Goals and Objectives}

Sandia is dedicated to providing its scientists and engineers with a strategic computing capability that can significantly affect the future of Sandia and play a major role in providing "exceptional service in the national interest." This dedication implies a vision of a high-performance computing environment ranging from advanced workstations to the latest supercomputer. The vision supports a fully integrated distributed system that ties together all the computational resources required to solve problems and perform program work, including computational analysis, storage, multimedia, computer-aided engineering (CAE), databases, billing services, and electronic mail/signature capability.

\section{Information Resource Environment}

\section{Computational Facilities}

\section{Scientific Computing Resources}

Sandia's supercomputers include large vector architecture machines, such as the Cray Y-M!P systems, and a growing number of massively parallel systems. Supercomputers are used primarily for solving large scientific and engineering problems. Application areas include materials studies, nuclear safety calculations, particle-beam calculations (for pulsed power and other research), weapon systems development, missile defense and countermeasures analysis, facilities vulnerability analyses, combustion chemistry, and more. With supercomputers it has become possible to model three-dimensional effects and perform increasingly higher-resolution approximations.

In order to accommodate the computational demands of its missions, Sandia has developed a number of interlinked networks of computers based upon increasingly more capable communications. Linkage of desktop computers and workstations to central systems is accomplished through reliable, high-speed networks. Ethernets and Fiber Distributed Data Interface (FDDI) rings are the preferred local area network technologies at Sandia. Higher-speed dedicated lines are used for special applications; FDDI is used for connectivity between centrally residing systems. Asynchronous 'Transfer Mode (A'TM) switches and Synchronous Optical Network (SONE'T) technologies are being actively pursued as promising network technologies.

The major delineation in the networking realm is the separation of secure (classified) and restricted (unclassified) computing resources. Individual computer systems reside in one or the 
other of these domains. The secure domain is capable of processing classified information through Secret Restricted Data.

Sandia supercomputer systems have recently been consolidated at the New Mexico site.

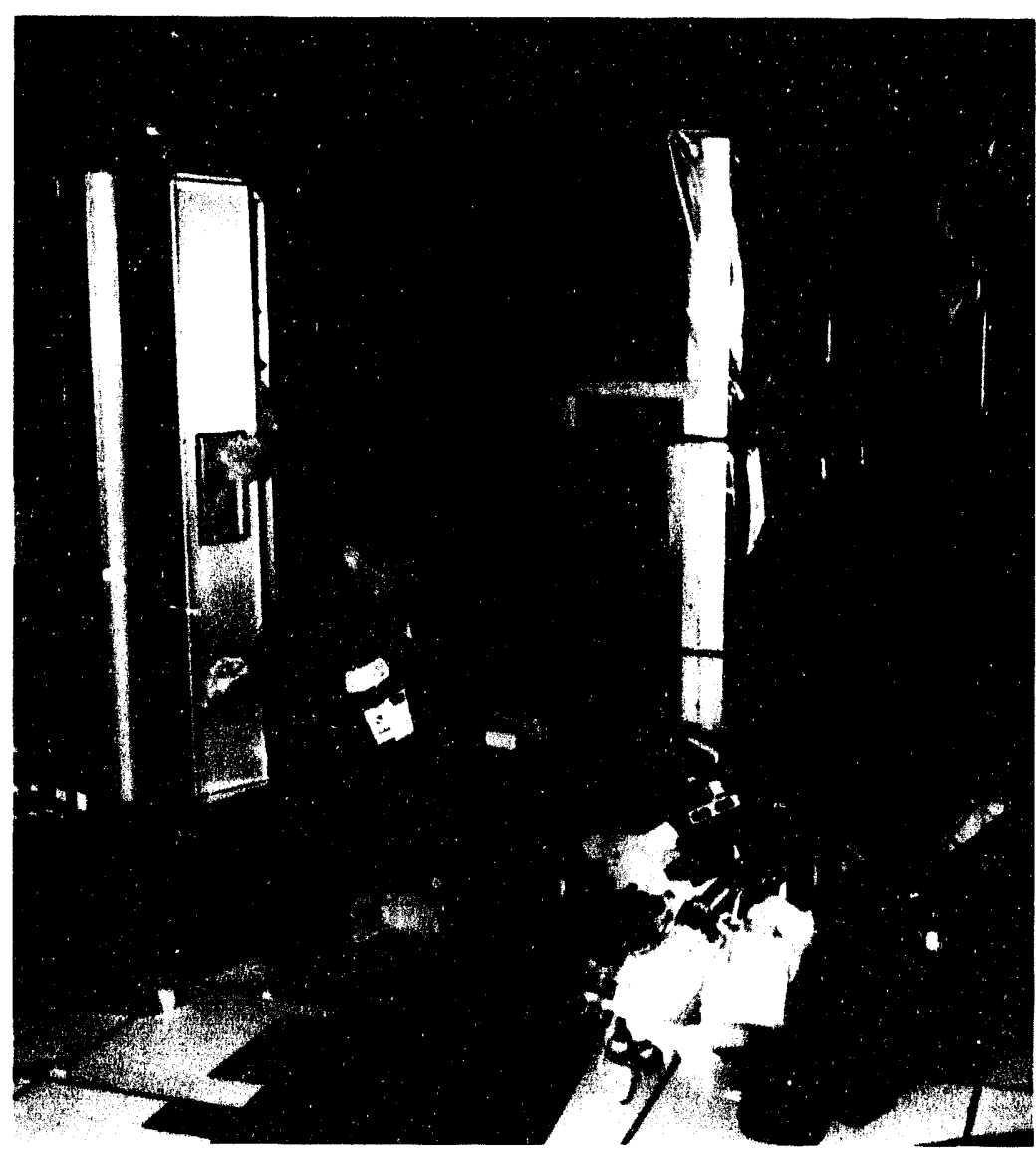

This Cray supercomputer was noved from Sandia/California and installed at Sandia/ New Mexico in May 1993, completing the Laboratories' plan to consolidate supercomputers at a single location. Users at Sandia/California will be linked by high-speed data telecommunications.
Data communication capabilities are available at $4.5 \mathrm{~N} / \mathrm{bs}$ (megabits per second) in order to facilitate the use of these systems by staff in New Mexico and California. The secure network houses a Cray Y'-MP8/ 264 along with a two-terabyte Notwork Storage Service. 'These machines are linked to other systems within the secure partition. The restricted network houses a Cray Y'-MP/864. A terabyte file server will be acquired to support this system. Sandia/California has Central File Storage to facilitate data caching for local access.

Massively parallel systems are also on the unclassified network and are thereby accessible to our industrial partners. In this network we currently have a 1,024node nCUBE with 4 gigabytes of memory operating at a peak rate of 2.5 gigaflops, two 64-node Intel iPSC/860s with a peak rating of 3.8 gigatlops, and a newly acquired Intel Paragon with 1,827 nodes operating at a peak rating of 130 gigatlops.

Sandia's scientific computing accuisitions during the FY 1994-1999 time frame are intended to dramatically increase computational power and simulation capability and improve the performanec of support servers looth at the central facility and within distributed local area networks. Plans are also being implemented to bring Sandia's network technology into the gigabit range during this frame.

Early in the planning period, massively parallel systems will become the major compute servers.

It is our vision to implement leading-edge, industry-supported standards in all of our computing environments. In order to realize this obiective, we will conduct integrated research in communications, networking, algorithm development, and computing technologies to lead in the development and establishment of such standards.

This effort will recuire many collaborations with industry and with other national laboratories. Several cooperative agrements are al ready in place. By integrating fiber optics, $A T M$ (Asynchronous Transfer Mode) protocols, SONET (Synchronous ( )ptical Network) technology, scientific algorithms, and massively parallel systems, it will be possible to create a computing environment that will allow customers to solve a vast array of engineering and scientific problems and visualize results in a timely, effective manner. 'The advent of $A T M$ and similar technologies will also permit distributed workstations to be clustered together as a single logical resource. Ultimately, it will be possible for a customer to log on to a network and have at her disposal any tool that is required to perform her job in a seamless computing enviromment. 


\section{Computer-Aided Engineering (CAE)}

The business plan for Sandia' Engineering Integration Center calls for continued acquisition of resources in sufficient yuantities to furnish appropriate computer assistance in the analysis, design, and fabrication of products for which the Laboratories has responsibility. This thrust comes at the intersection of two areas of technological expertise: information modeling and the application of design-oriented software. These areas are developing independently but offer the largest contribution where there is overlap. Computer-aided engineering is an integral part of Sandia's programmatic responsibilities in nuclear weapons production and stockpile support.

An integrated computer-aided engineering capal "ty provides for the application of computeraided engineering (CAE) technology to the configuration management, information modeling, design, analysis, definition, and prototype manufacturing processes. Projects include the participation of various engineering design organizations at Sandia's New Mexico and California sites and manufacturing groups at Allied Signal Aerospace, Kansas (City Division.

Integr.tion of engineering information systems is an important goal. Integration will provide project continuity from one phase of development to the next as well as flexibility in applying computer-aided tools to a broad spectrum of needs. NIRV ANA, a project for electrical design and fabrication, was implemented in 1991. A second project that addresses mechanical design, ACCORI), was started in 1991 and is being implemented in 1993. The foundation of the project is a tightly integrated solid-model production definition that will be useful throughout the development cycle without data translations.

As NIRVANA and ACCORI users learn the capabilities of their tools, the desire to exchange design information between systems increases. The management of data for the ACCORI) and NIRVANA projects will be controlled by the Definition Configuration Management Project. After the design data is complete, the information will be maintained in the Image Management $S ;$ stem for future access.

To complete the integration of such widespread systems requires close collaboration and full development of an ubiquitous classified and unclassified network infrastructure. Other requirements to support the integration include design and test databases and a configuration management system.

The integration effort reflects the need for concurrent engineering - the simultaneous participation of all contributors to a project, including design, fabrication, test, analysis, and manufacturing. This need is addressed in an advanced network development project, Interactive Collaborative Environments, that will allow real-time, shared use of computer-aided design and other engineering tools by all project members, regardless of location. All integration activities are conducted in close concert with Allied Signal, Kansas (ity Division. The integrated environment and associated informaltion systems will support future Department of Energy reconfiguration and dismantlement activities.

\section{Administrative Information Systems}

The Laboratory Information Systems Center strives to ensure that Sandia is capable of operating as a successful business entity. Over the next year, we will complete our UNiSYS-to-IBM migration, complete Phase 2 of the Financial Infor mation System, continue redevelopment of the Sandia Reimbursement and Vouchering System, complete development of the Human Resource Information System, and support development of the Library Information ()n-line Network (LION). As we conduct these development projects, we will continue to support production systems as required by the needs of the business and the new contractor.

Sandia's administrative application projects are managed under the Information Services Program and are sponsored by the Administrative Management Committee. Projects are identified, selected, and prioritized by the Computer Advisory (Committee chaired by the director of the Laboratory 
Information Systems Center. Projects endorsed by these committees are typically accomplished by project teans. The teams use system project methodologies, such as the system development methodology SD M/Structured by A ( S S Management Systems and Information Eingincering Facility (IEF) by ' lexas Instruments. Application systems are developed with full customer participation through the use of joint application design sessions and iterative prototyping technicues.

The administrative computer systems at Sandia/New Mexico are: IBM 9021-500 (1.1S), UNiSYS 1 100-72, IBM 9121-190 (CIS); IBM +381 (OV'), IBMI +381 (CVM); others may be added in the future or existing systems removed as the business needs dictate.

In the future, all applications currently residing on smaller IBM machines will be candidates for movement to a client/server architecture based upon the results of cost/benefit studies. An important strategic goal in the planning for application development is greater accessibility of administrative information at the desktop.

\section{Telecommunications}

\section{Data Communications}

An era with emphasis on parallel computing, outside collaboration, consolidation, technology transfer, total quality management, and ES\&H management makes data communications vital to Sandia's future. To meet the challenge, a variety of technologies are being investigated and deployed. Fiber optic cables to the desk, very-high-speed local area networks, modern broad-band switches, high-speed intersite links, video teleconference facilities, and mode' network management systems are all part of the arsenal of communications technologies being applied to this challenge. Sandia's recent initiatives have necessitated a new focus on unclassified communications while its traditional mission demands ongoing support of secure communications.

Sandia operates an extensive internal secure communications system. A large customer base receives services ranging from asynchronous terminal access through 100 -megabit Fiber I istributed Data Interface (FI) I) support. Numerous intersite links to a variety of I) (OE and Dol) facilities exist as well as video teleconferencing capabilities to several I) OE facilities.

Sandia's Engineering Science Center recently moved to a refurbished building. As part of the move, we installed an extensive, state-of-the-art, optical-fiber distribution system to every desk in the new facility. While full-bandwidth Ethernet on optical fiber will initially be installed, the distribution system will support FDI)I local area networks and video. This distribution system and the highspeed networks will serve as a model for several other facilities at the Sandia/New Mexicolocation.

An architecture that consists of T'3 (45 megabits per second) intersite links, asynchronous transfer mode switches, switched multimegabit data service protocols, and high-performance routers is being implemented as part of Sandia's plan to locate all of its supercomputers at Albuquerque. This architecture will become the standard for high-speed networking at Sandia. Additionally, the Laboratories is a participant in the Experimental University Network (XUNE:T) sponsored by AT\&', which is a test bed for cross-country gigabit networking.

These activities constifute an aggressive approach to bringing the data communications infrastructure of the Laboratories up to the state of the art. The technical excellence and quality commitment of Sandia's networking and communications staff is evidenced by a number of recent accolades, including an R\&D 100 Award, "best paper" at the NEXUS 9() and NLXUS 91 conferences, the 1991 INTEROP Achievement Award in the government sector, and several patents. 


\section{Voice Communications}

In the past, the Kirtland Air Force Base Communications Squadron provided local voice telecommunications service for Sandia's New Mexico site as well as for all other Kirtland Air Force Base tenants. However, recognizing the importance of telecommunications service to corporate existence, Sandia is assuming direct responsibility for providing quality, state-of-the-art services. Sandia is moving and expanding the AT \&T 5 ESS digital electronic switch that forms the cornerstone of its voice and unclassified data telecommunications services. This switch will provide ubiquitous, enhanced digital voice, video, and data services using Integrated Services Digital Networks (ISI)N).

The Sandia 5ESS switch consists of a host system and optical remote modules (ORM) to service the Laboratories' remote areas. We have constructed a building to house the host SESS switch and we have upgraded conduit systems to provide customer access. Over 1,200 lines are in service on the first optical remote module, and over 1,100 lines are in service on the 5ESS host, which also services other Department of Energy facilities on Kirtland Air Force Base, such as the Albuquerque Operations Office, the Inhalation Toxicology Research Institute, EG\&G, and Ross Aviation.

Sandia's strategy for communications at the New Mexico site is to move the host into the new switch building expeditiously, expand the 5ESS switch to serve all Sandia/New Mexico customers, and assume operational control of all unclassified voice and data communications services. Preparations for this project began in FY 1989 and funding will continue through FY 1996.

Sandia/California operates an AT\&T $5 E S S$ switch for its unclassified voice/data communications. The $5 \mathrm{ESS}$ is an Integrated Services Digital Network (ISDN) switch capable of handling voice, data, and signaling information over the same luce. It provides access to FT'S 2000 and the commercial network for long-distance communications.

The Tonopah Test Range local voice telecommunications system terminates in a Northern Telecom SL-1 switch with 24 trunks to the SL-100 switch at the Department of Energy Nevada Operations Office. Tonopah Test Range personnel use the Federal Telecommunications System and the Nevada Test Site tie-line network for the majority of their long distance telephone requirements.

A Motorola radio trunking system (selected by competitive bid) was installed at Sandia/New Mexico in 1991. It is a basic five-channel system and will be expanded as necessary as users are moved to the system from their current frequencies. The basic system has a capacity of approximately 600 radio users. The site currently has about 2,200 radio transceivers in use.

Initial radio networks that will be placed on the trunking system will include the motor pool, transportation and storage, and reclamation services. The radio frequencies currently in use by these organizations will be made available for other uses. As funding becomes available, most other services, such as plant maintenance, safety, emergency operations, and health physics, will have their radio communications transferred to the trunking system.

When fully implemented, the trunked radio system will become a part of Sandia's National Security Emergency Preparedness communications system. It will fulfill emergency communications requirements mandated by the Specification for Emergency Operations Centers in the Department of Energy Albuquerque Operations Office Complex.

\section{Initiatives}

Initiatives related to information resources are incorporated in Sandia's coordinated strategic initiatives described in Chapter 5, "Major Initiatives." Initiatives related to information resources and high-performance computing are described beginning on page 5-25. 

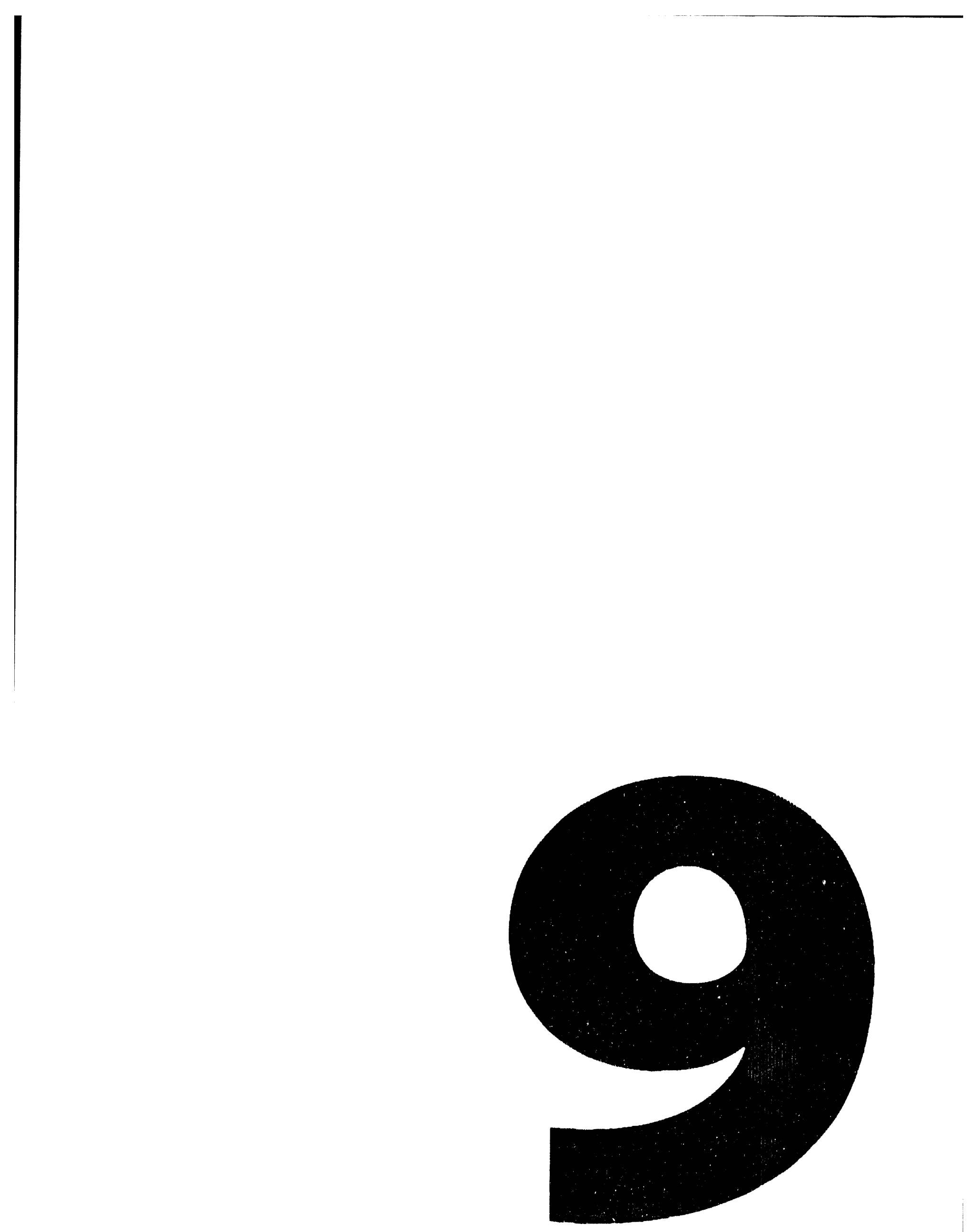


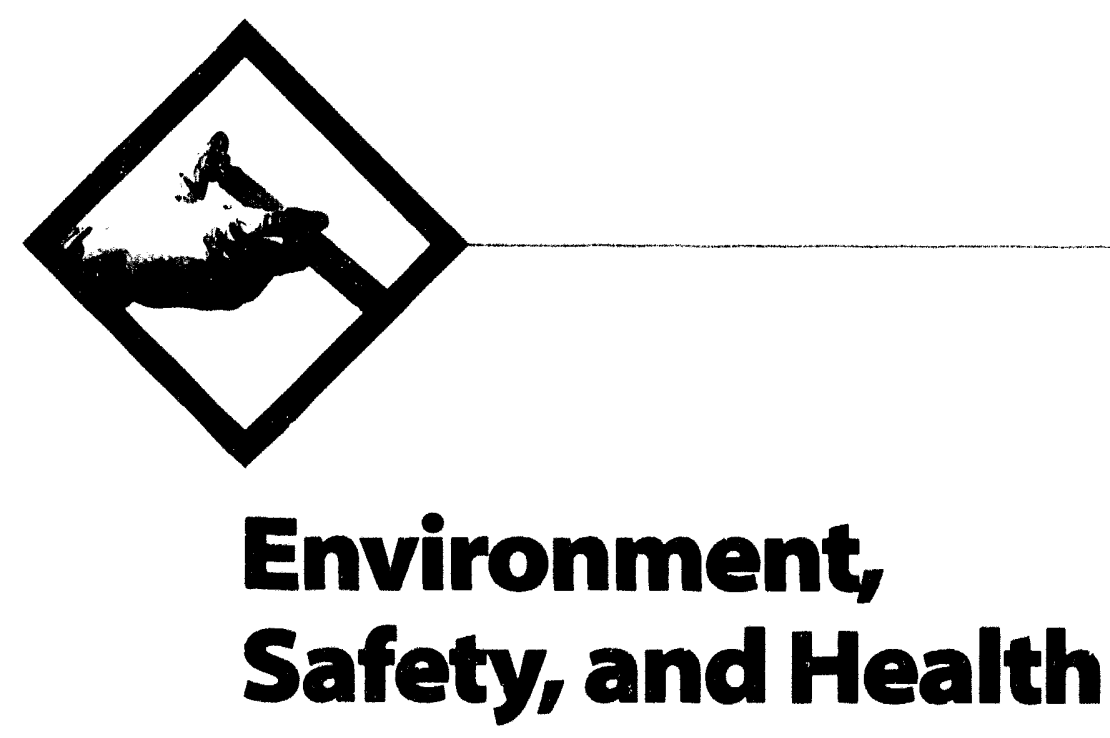

Sandia is committed to protecting the environment and preserving the health and safety of individuals and the community. The Laboratories conducts a comprehensive program to assure that operations are in compliance with all applicable laws and regulations on environment, safety, and health (ES\&H). Our program has been structured to address environmental problems in a timely fashion and thereby maintain public confidence in Sandia's ability to conduct its operations without harming the environment. A major part of our vision is to provide leadership within the DOE complex by setting the example for a safe and healthful workplace.

\section{ES\&H Program Goals and Objectives}

Sandia's ES\&H program has three gencral goals:

1. Make Sandia a safe, healthful, and environmentally sensitive workplace;

2. Comply with applicable laws, orders, and regulations; and

3. Demonstrate this capability to DOE and the public.

A set of seven objectives supports achievement of these goals. These objectives employ both long-term and short-term strategies.

Objective: Ensure safe and healthful workplaces for our employees, contractors, visitors, and communities.

The focus of all ES\&H activities in areas where we work is to protect all individuals and the environment. This focus requires compliance with applicable laws and regulations. DOE orders, directives, and requests are also requirements directed toward meeting this objective.

Objective: U'se our quality process to achie've excellence in our ESerH program and to meet our customers' requirements.

Sandia will continue to employ recognized Total Quality Management methodologies for all ES\&H activities. Such methodologies will be used for developing and improving ES\&H processes, identifying root causes of ES\&H problems, and applying lessons learned. Sandial' 'T'otal Quality Management Initiative establishes an overarching quality implementation strategy for all laboratories activities, including those in the ES\&H program.

Objective: Require open, timely communicution of ESé H problems, lessons learned, pluns, and stutus to achieve appropriate, uniform actions throughoul Sandiat. 


\section{Sandia safety and health professionals assist staff in establishing safety procedures and prescribing appropri- ate personal protection equipment.}

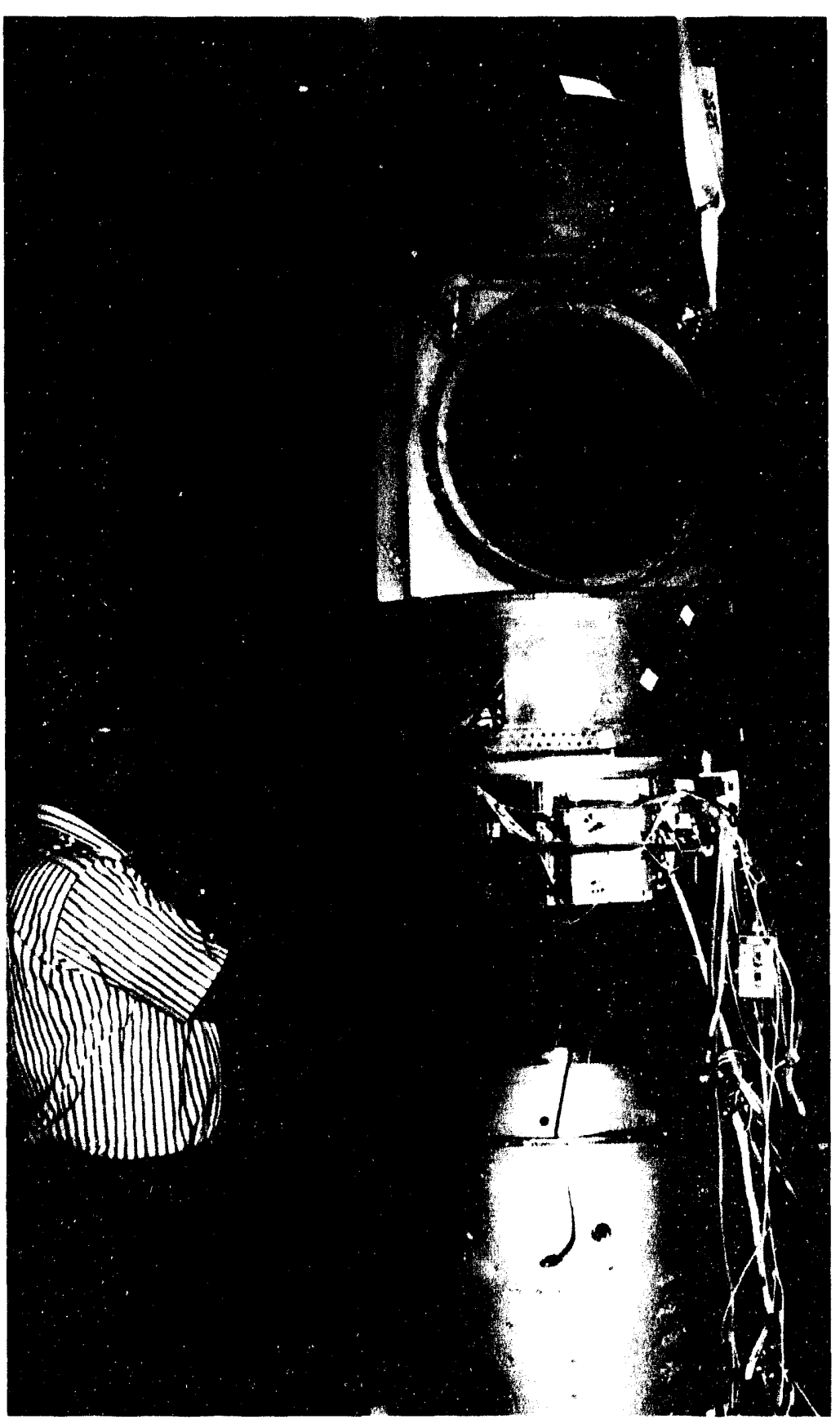
lem or condition.
We continue to enhance communications on LS\&H issues both to Sandia's LSEH professionals and to other staff. Current communications on new requirements are achieved through a working group representing all Sandia divisions and bargaining units, through lessons-learned processes, and through training courses. Sandia has also established procedures wherehy any employee may anonymously express an ES\&H-related complaint or concern or report an LS\&l I-related prob-

Objective: Team Sandia e'mployes customers, suppliers, and communnity represe'ntative's to assure protection of the e'mironment and the safety' and health of all.

() ur goal is to effectively use the capabilities of all staff in ES\&H activities. Current cross-organizational projects with staff haring materials expertise, instrumentation backgrounds, geoscience understanding, field operation processes, and others are continually being reviewed and increased. University interactions occur through temporary employment of students, Sandia participation in the university-based I'asteManagement fducation and Rese ech (onsortium (WER(,), and contracts to) teachers. Sandians serve on various state and local government organizations, and staff from Sandia's ES\&H organizations interact with regulatory agencies both formally and informally.

Objective: Mannge LSedH risks and hazards through formul, established processes coupled with the mindfillation of e'very Sorndian.

A key step in identifying hazards is the Preliminary Hazard Assessment ( $P H A$ ) required to be completed by line organizations for all facilities and activities. The PHA identifies all harards present in the workplace or encountered in an activity. F.S\&H Standard (operating Procedures (SOPs) describe processes to control the hazards identified in the PHA. FS\&H SOPS are intended for use by one or more organizations, and must include the following:

- Responsibilitices

- Specific training/experience requirements

- Waste management reguirements

- llazand identification and mitigation

LS\&H ()perating Procedures (()P's) are written and owned by organizations conducting the operations. They provide 
step-by-step instructions for specific operations (normal, postulated abnormal, and emergency operations) to ensure that activities are performed correctly, safely, and consistently.

To assist in a graded approach in management of risks, all Preliminary Hazard Assessments are assigned a Preliminary Hazard (Classification (PHC) and all activities are assigned a Programmatic Risk (lassification (PRC). The combination of PHC and PRC values is used as guidance in establishing the appropriate level of rigor with which a facility or activity is managed and when facilities or activities are reviewed by upper management. Additionally, the PHC ratings establish both a Sandia corporate and () ()E understanding of the relative hazard level of all Sandia facilities.

Objective: Support our e'mploye'es in personalizing Sandia's vision both at work and at home. The Laboratories will continue disseminating ES\&H information helpful to the families of Sandia employees, such as the periodicals TLC Newsletter, Family Safety, and Harvard Medical School Newsletter. A recycling committee has been established to coordinate a recycling program for the Laboratories. We have defined and implemented a process for recognizing and rewarding wutstanding ES\&H contributions at the corporate level and working level.

Objective: Ensure that e'very' Sandian has necessary' and sufficient ESorH training, and require' that visitors and contrators comply with our ESe-H requirements.

We maintain a record keeping system for tracking ES\&H training requirements and the training status of employees. A basic ES\&H awareness module is included as part of the orientation process for new employees. Experts from Sandia line organizations are involved in developing and improving facility or function-specific training courses. Trainers will train additional trainers where possible to allow staff to instruct their own organizations in good ES\&H practices. Management is responsible for ensuring that all visitors and contractors in their operations receive appropriate training regarding the presence of hazards and protection from those hazards.

\section{Regulatory Environment}

\section{Laws and Regulations}

There are many federal environmental laws and implementing regulations to which Sandia must adhere. These law's include the Clean Air and Clean Water Acts; the Resource Conservation and Recovery Act; the Federal Insecticide, Fungicide, and Rodenticide Act; the loxic Substance Control Act; the Comprehensive Environmental Response, Compensation, and Liability Act; the Safe Drinking Water Act; the Oil Pollution Control Act; the Marine Protection, Research, and Sanctuaries Act; the Noise Control Act of 1973; and others.

DOE orders implement other federal laws affecting Sandia, including the National Environmental Policy Act, the (ocupational Safety and Health Act of 1970, the National Historic Preservation Act, the Coastal \%one Management Act of 1972, and the Mine Safety and Health Act. Finally, the contract for the operation of Sandia National Laboratories by Sandia Corporation requires that Sandia's environmental, safety, and health operations be conducted in accordance with all applicable $D O$ OE orders and directives communicated to Sandia by the $\mathrm{D}) \mathrm{OE}$ contracting officer.

Sandia must also comply with state and local legislation applying to laboratory sites in New Mexico, California, Nevada, and Hawaii, as well as diverse field locations in the United States and other countries. Examples of such legislation in New Mexico include the New Mexico Air ( Quality Control Act, the Environmental Compliance Act, the Water Quality Act, the Hazardous Waste Act, and the Solid Waste Act. In addition, there are local regulations for air quality and sewage pre-treatment. 
Examples of applicable legislation in California include the California Clean Water Act, the Air Toxics "Hot Spots" Information and Assessment Act, and the 'Tanner Act. Sandia's California site must also comply with such local regulations as the Bay Area Air Quality Management District rules. Similar laws in Nevada and Hawaii affect Tonopah Test Range and the Kauai Test Facility.

An example of cooperation between Sandia and environmental agencies is the 1990 Agreement in Principle between New Mexico and DOE to monitor cleanup and environmental activities. The agreement was the result of an initiative called for in 1989 by the governors of several states with $\mathrm{DOE}$ nuclear facilities. The agreement gives state officials access to DOE facilities to monitor (but not to regulate) cleanup operations. Under this agreement, New Mexico's Environmental Department has five full-time employees stationed at Sandia/New Mexico. DOE provides about $\$ 3$ million per year to the state for staff and equipment for this on-site monitoring at DOE sites in New Mexico.

\section{Sandia ES\&H Requirements Documents}

The contract between Sandia's operating contractor and DOE specifies that Sandia National Laboratories will comply with all applicable federal, state, and local laws and regulations and all applicable DOE directives.

Requirements from laws, regulations, DOE orders, and other documents pertaining to ES\&H are forwarded to Sandia's ES\&H Program Management Center for action. The Director, ES\&H Program Management Center, assigns a responsible individual who determines whether laboratory ES\&H documents need to be amended or a new document needs to be written. If action is necessary, the document owner becomes involved. If requested, the Line Implementation Working Group assists in developing implementation approaches. This process assures that requirements are identified, assigned to an individual, tracked through the various stages, assessed for effectiveness, and monitored for compliance.

Requirements are translated into specific actions that are delineated in Sandia ES\&H requirements documents. The first of these documents is the Sandia Laboratories Policy (SLP) 2001, Environment, Safety, and Health (ES\&H), which defines the Laboratories' ES\&H policy. It also defines a hierarchy of ES\&H requirements documents through which requirements flow from sources (i.e., laws, regulations, DOE orders) to Sandia employees, on-site contractors, and visitors. Other ES\&H documents, such as Preliminary Hazard Assessments (PHAs), Safety Assessments, Safety Analysis Reports, and plans for achieving compliance, augment the documents in the hierarchy.

Sandia's $E S \& H M a m$. $/$ interprets requirements and delineates responsibilities and procedures designed to ensure (1) 1 fety and health of employees, on-site contractors, and the general public; (2) the preservation of the environment; and (3) performance of work activities in compliance with applicable laws, regulations, DOE orders, and best management practices. The requirements in the ESeH Mamual and its supplements are implemented by Sandia organizations.

The legal and regulatory environment affecting Sandia's ES\&H activities is likely to remain dynamic with changes occurring as public concerns and government administrations evolve. For example, the Federal Facilities Compliance Act of 1992 clarified the ability of the EPA and states to enforce hazardous waste regulations at federal facilities such as Sandia. We anticipate a general trend of laws and regulations requiring more attention to procedures, processes, and documentation to ensure a greater degree of auditability in environmental compliance. 


\section{ES\&H Policies, Organization, and Management}

Sandia's policy with respect to ES\&H is set forth in the following statement:

Sandia National Laboratories considers the protection and preservation of the environment and safety and health of its personnel, contractors, visitors, and the public to be critical to its success.

Accordingly, Sandia personnel shall design products, develop manufacturing processes, and conduct operations while chcouraging recycling, waste minimization, and reduction of the use of hazardous materials. Sandians shall also ensure the protection of people and the environment while complying with applicable federal, state; and local laws and regulations; agreements; consent decres;; and DOE Edircetives.

Sandia employees who oversee contractors and who are hosts to site visitors shall assure that they are adequately informed of this policy and of their obligation to comply with it. In addition, Sandia shall contimuously evaluate regulatory requirements, corporate policies, customer needs, and lessons learned, and shall adjust its operations to meet these changing needs as we seek to continuously improve ESe H processes.

Concern and conduct in matters pertaining to the environment, safety, and health are the responsibility of all Sandia employees, on-site contractors, and visitors. No job is more important than your health, your safety, and the protection of our environment.

The president of Sandia National Laboratories has overail responsibility for environment, safety, and health. He is advised on ES\&H matters by the Sandia ES\&H Council, which he chairs. The president is ultimately responsible for promoting, communicating, and establishing a culture that recognizes environment, safety, and health as top priorities.

All management levels and staff have the responsibility to assure the health and safety of participants and communities invilved in Sandia operations. Professional ES\&H staff provide technical support for safe and environmentally responsible operations. An ES\&H Program Management Center provides the laboratory-wide focus for $\mathrm{ES} \& \mathrm{H}$ requirements and processes.

The vice president, fnviromment, Safety, and Facilities Management Division, has overall responsibility for developing and implementing Sandia's ES\&H program. The directors of the ES\&H Program Management (enter, the New Mexico Safety and Health Center, and the New Mexico Environmental Operations (enter report to this vice president. The directors of the New Mexico and California Medical Centers, and of the California Facilities and ES\&H Center, report to their respective vice presidents. The indirectly funded core programs for all centers are managed through the ES\&H Program Center.

The ES\&H Program Management Center is responsible for overall management of Sandia's ES\&H activities, including:

- Developing corporate ES\&H strategic and business plans;

- Managing the ES\&H work breakdown structure and the ES\&H portion of Sandia's indirect budget;

- Defining processes and practices to meet laws, regulations, and orders;

- Integrating processes and practices into laboratory operations through the Line Implementation Working Group;

- Providing an effective interface with external customers and stakeholders of Sandia's ES\&H activities;

- Developing NEPA (National Environmental Policy Act) and other risk assessment processes, and supporting Sandia organizations in their implementation; 
- Managing emergency preparedness and occurrence reporting processes, including investigation of occurrences, notification of the appropriate agencies, root cause analysis, and development of tracking actions, to prevent future occurrences; and

- Providing the main interface with external assessors, leading the development of responses to assessments, tracking the progress on assessments, and maintaining appropriate records.

ES\&H professionals at both the New Mexico and California sites support Sandia organizations in improving the safety of work activities. This support includes:

- Occupational medicine

- Industrial hygiene

- Radiation protection

- Safety engineering

- Fire, electrical and building codes integration

The Environmental Operations Center at Sandia/New Mexico and the ES\&H and Facilities Management Center at Sandia/California are responsible for managing Sandia's environmental restoration projects, ensuring that all permit requirements are met, and working with federal and local environmental regulators. A major portion of their activities is coordinated with the DOE Office of Environmental Restoration and Waste Management through Sandia's Energy and Environment programs sector (see page 7-52).

Independent internal assessments are performed by a department that reports directly to Sandia's vice president for Environment, Safety, and Facilities Management. In addition, each level of management provides periodic self assessments to review its own operations.

Each of Sandia's corporate divisions is responsible for the ES\&H activities in its area. Every division has a designated ES\&H coordinator who works closely with the ES\&H Centers at New Mexico and California to assure that effective environmental, safety, and health processes are incorporated into the programs for which it has responsibility. The division ES\&H coordinator also serves on the Line Integration Working Group. In addition, all of Sandia's center directors (center directors report to division vice presidents) have also designated ES\&H coordinators who are available to work directly with researchers doing studies of ES\&H issues. Each level of management is responsible for oversight and assessment of its own ES\&H processes to ensure safe operations and to comply with requirements.

\section{ES\&H Plans and Initiatives}

The DOE ES\&H Tiger Team assessments of Sandia/California in 1990 and Sandia/New Mexico in 1991 led to major changes in Sandia's ES\&H effort, including significant increases in financial and human resources. Emphasis on compliance with DOE orders and directives resulted in major restructuring of ES\&H activities. Formal processes are currently in place or being developed to achieve compliance and to accommodate expanding requirements.

A laboratory-wide ES\&H strategic plan is being developed to provide direction for further improvements in our processes. The plan will emphasize the safety and health of employees, contractors, visitors, and residents in surrounding communities. ES\&H responsibilities will be increasingly assumed by Sandia line organizations as a part of their normal operations. ES\&H professionals will become integrated into the line operations for more effective communications and support.

ES\&H training is operated as a service center. Formal prioritization processes are being implemented to focus training resources on areas of greatest importance. Training intensity will increase as greater emphasis is placed on on-the-job training. 
Changes in DOE programs and Sandia management initiatives will influence the direction of ES\&H activities at the Laboratories. 'The growing number of requirements and requests occurring during this period of diminishing budgets requires a strong prioritization system to identify the critical activities to support. Regulatory inconsistencies between federal, state, and local agencies will continue to require resources for resolution. We must improve our processes for handling the diverse ES\&H requirements at our permanent facilities as well as at many field operational sites throughout the world.

ES\&H activities at Sandia are classified among four major categories of sponsorship and funding:

1. Environmental Restoration and Waste Management Operations - The DOE (iffice of Environmental Restoration and Waste Management directly funds specific environmental restoration and waste management projects. Program plans and budgets are defined directly with DOE through Sandia's Energy and Environment programs sector.

2. Core Program - The core activities of the Laboratories' ES\&H program are funded through its indirect budget under the management of Sandia's Administrative Management Committee.

3. Landlord-- DOE Defense Programs (DP) has the "landlord" responsibility for Sandia National Laboratories. Accordingly, DP provides support for specific ES\&H facility changes that require upgrading to meet requirements.

4. Internal Direct - Individual projects support ES\&H professionals directly for services unique to their operations. This budget line also supports the ES\&H service centers.

\section{ES\&H Work for the Office of Environmental Restoration and Waste Management}

The DOE Office of Environmental Restoration and Waste Management manages research and technology development programs for environmental cleanup and waste management processes (including the Waste Isolation Pilot Plant). A portion of this funding is for Sandia operations and is managed as part of our ES\&H program. Details of ES\&H work performed for the Office of Environmental Restoration and $W^{\prime}$ aste Management are discussed on pages 7-52 through 7-58 in the chapter, "Research and Technology Development Programs."

This funding by the Office of Environmental Restoration and Waste Management (EM) is for the remediation of hazards at waste sites and the development of processes to handle hazardous wastes. Projects are managed and updated annually by EM. Guidance and support of nonEM activities are then funded directly by other programs or through Sandia's indirect budget.

EM-sponsored environmental remediation of waste sites is expected to continue during

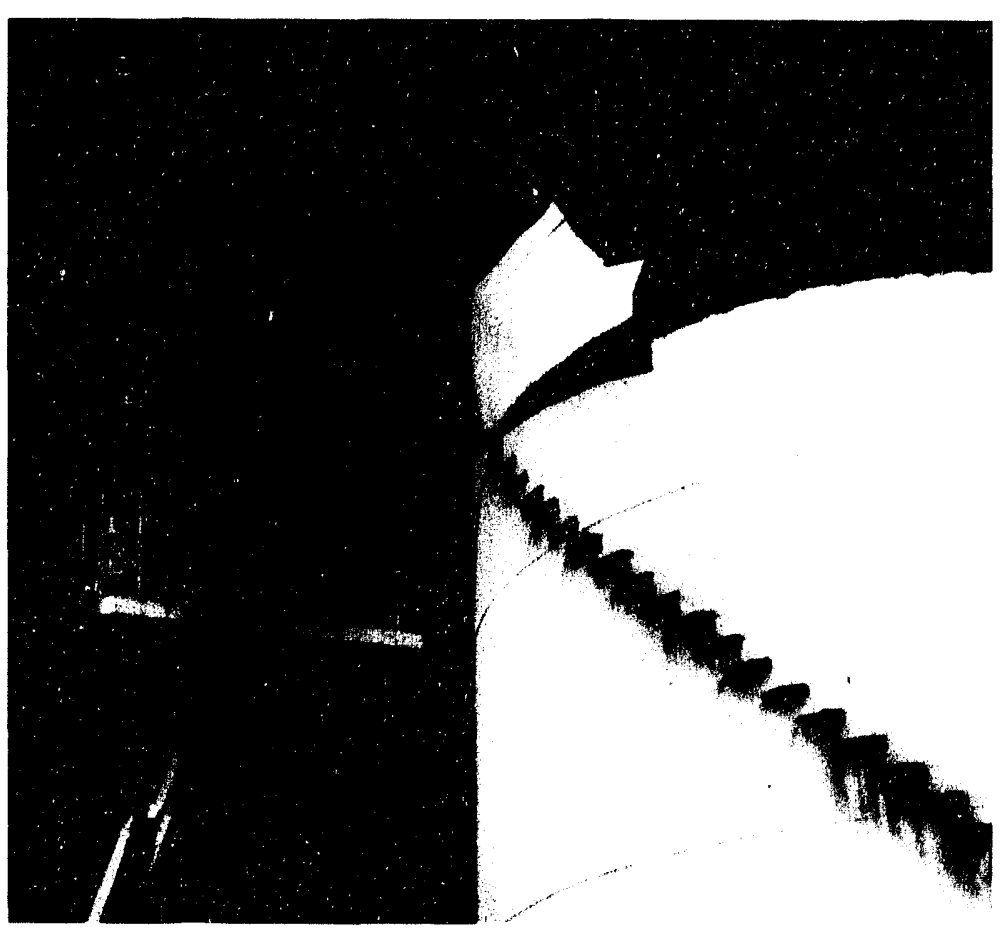


cleanup of critical sites and then decline. As processes are developed to handle hazardous wastes, direct EM support is expected to decline while the indirect budget sustains funding to improve the developed processes. Waste handing costs will be charged to the generating organizations.

\section{Core ES\&H Programs}

The core programs supported by Sandia's indirect budget provide the base for all laboratory ES\&H efforts. 'This base includes the majority of activities in policy development and implementation, safety and health, and specific activities in environmental operations. In addition, this budget supports independent assessment and core training. The ES\&H Program Management Center is responsible for the processes to allocate and control $\mathrm{ES \& H}$ programs sponsored through the indirect budget.

\section{Program Management}

Development of an ES\&H strategic plan, including benchmarking with industry, will be a major thrust for the next several years. Continued translation and integration of new laws, regulations, orders, directives, and requests into effective operations is increasing in complexity due to changes in requirements. New requirements are integrated into operations through Sandia organizational ES\&H coordinators as a part of the Line Integration Working Group.

Development and application of an effective prioritization system is a high priority as requirements continue to increase and budgets decrease. The prioritization effort is being done as a part of the DOE prioritization project. Key to effective resource utilization is the development of a risk management program and improved line implementation of hazards assessments.

The overall tracking and management of occurrences and assessment responses is being reviewed along with other management information systems to define the most cost-effective way for maintaining and interconnecting databases. Better ways must be found to interface with the data systems used by various $\mathrm{DOE}$ and other regulatoiy agencies.

Risk management, including safety assessment and analysis reporting, is a growing effort. Programs for managing risks and hazards are being implemented in compliance with DOF orders. Hazard assessments of all sites are being completed to upgrade emergency preparedness.

\section{Assessments}

ES\&H assessments of Sandia by external organizations are coordinated through the ES\&H Assessments Management Department. The department interacts with assessors to assure that their logistical needs are met, works with all parties to develop appropriate responses to assessment findings, tracks the status of all responses, submits closure documents, and is the official records manager for assessment documents. Emphasis is now being placed on assuring that the multiple assessments that occur are appropriately documented and tracked and that records storage requirements are met. Quality review processes are being developed to assure that responses to completed actions meet the intent of the findings.

The ES\&H Assessments Department provides independent internal assessments of Sandia operations and reports directly to the vice president for Environment, Safety, and Facilities Management. A major emphasis of this department is to develop effective root cause analysis, lessons learned, and metric processes to reduce the need for assessments.

Self assessments are made in all Sandia organizations at all levels of management. Results are reviewed by the Sandia ES\&H Council, and information is provided to all vice presidents so they can improve the processes under their own purview. 


\section{Training}

The ES\&H Training Department, a part of Sandia's Human Resources Center, is responsible for developing and maintaining the structure and records sy'stem for ES\&H training. Department staff work with ES\&H professionals to develop and present specific courses. Emphasis on training will continue to increase and new methods will be developed.

\section{Waste Management}

Waste management projects implement steps to safely and efficiently manage the Laboratories' hazardous, radioactive, and mixed wastes. This effort includes projects in minimization, treatment, storage, disposal, and project management.

Sandia/New Mexico holds an operating permit for hazardous waste management issued in 1992 and an interim permit for thermal treatment of energetic and mixed wastes. Radioactive, hazardous, and mixed wastes are generated. All radioactive waste is either stored on-site or sent to disposal facilities authorized by DOE. Hazardous waste is temporarily stored in the Hazardous Waste Management Facility, then transported off-site for recycling, treatment, or disposal at commercial facilities with EPA permits. Mixed wastes are currently held on-site in storage areas that were included in the interim status permit application for mixed waste units submitted to the New Mexico Environmental Department in 1990. Also included in the permit application was a facility, not yet operational, that will be used for repackaging and storage of low-level radioactive waste and mixed waste.

Sandia/California has received a Part B RCRA (Resource Con.ervation and Recovery Act) permit for op ration of its hazardous waste management facility. Hazardous wastes at Sandia/California are disposed of at various pernitted, commercial disposal facilities. Compatible waste streams are consolidated at Sandia's hazardous waste storage facility to decrease costs. These consolidated streams are analyzed before disposal in accordance with the hazardous waste facility permit that was approved by the federal EPA and the California EPA. Low-level waste is disposed of at the Nevada Test Site (NTS) in compliance with DOE orders, EPA and State of California requirements, and NTS criteria (NV0-325). "Scintillation cocktails" (small vials of low-level radioactive liquids) from the Tritium Research Laboratory are transported to a permitted commercial facility for incineration. Other low-level mixed waste streams will be stored at Sandia/California until off-site disposal options are developed.

Hazardous materials generated at the Tonopah Test kange are shipped to commercial facilities for disposal within ninety days of generation. The Nevada Test Site has stopped accepting radioactive wastes, and several drums of legacy radioactive materials are stored on-site pending determination of a repository. No radioactive wastes are currently generated by operations at Tonopah. No mixed wastes have been or are generated at the site.

The Kauai T'est Facility generates small quantities of hazardous wastes, which are handled through the Navy Pacific Missile Range waste management program. No radioactive or mixed wastes have been or are being generated at this facility.

In addition to the need for adequate funding to perform waste management operations, there is an acute need for approved, off-site treatment and disposal facilities for hazardous, radioactive, and mixed wastes. Such facilities are particularly needed for mixed wastes. The lack of treatment and disposal facilities for mixed wastes is a significant problem for the entire DOE complex and results in the storage of mixed wastes beyond the legally allowable time.

This problem was recognized in the 1992 Federal Facilities Compliance Act, which exempted DOE from penalties for excessively long storage of mixed waste. However, the act did not exempt DOE contractors, such as Sandia, from such penalties. Sandia, rather than DOE, has physical possession of its mixed wastes. Discussions are being pursued with EPA, the state of New Mexico, DOE, and other parties to resolve this issue. 


\section{Safety and Health}

The occupational safety program at Sandia makes the safety of personnel its first priority. The bases of our technical support are the programs and procedures developed to reflect I)(O) orders, regulations of the Occupational Safety and Health Administration (OSHA), and other safety laws and

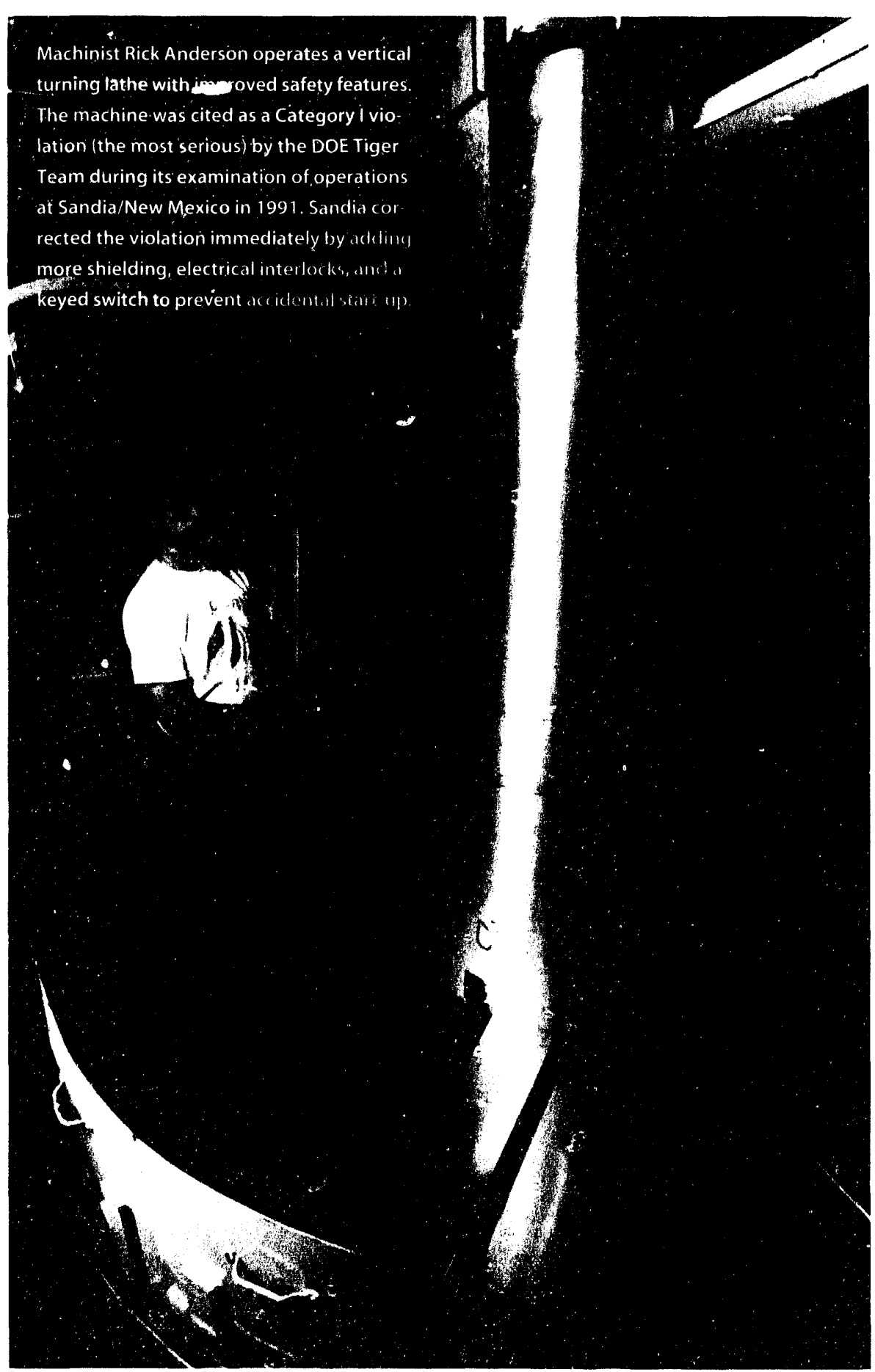

best practices.

We are working to institutionalize safety training and procedures. Risk management activities, including support for safety assessments and safety analysis reports, is a large effort that will continue to grow. Sandia is completing a hazard assessment for all sites so emergency plans and procedures can be upgraded. We are continuing our efforts to improve programs in fire protection and emergency preparedness as well as electrical, pressure, traffic, hoisting and rigging, reactor, and other areas of safety.

We are giving increased attention to upgrading safety procedures and implementing safety programs at remote sites such as Tonopah Test Range. In addition, an acute need exists to modify older facilities and obtain proper equipment for safe operations at such sites.

We have initiated a longterm ergonomics effort that will meet the requirements of DOE orders and upcoming OSHA regulations. This program has the potential to interface with other preventive medicine programs such as Total Life Concept and Employee Assistance Program and provide a vehicle for addressing ES\&H concerns. In addition, the precepts of the Americans with Disabilities Act will be embodied in this program. 
The objective of the health management program is to maintain the physical and psychological health of Sandia's work force through timely evaluation, diagnosis, and management linked to analysis and intervention of the work site and occupational environment. This objective requires that we interpret and apply health codes, standards, and regulations promulgated by several federal and state agencies and national standards organizations. Core activities provide protection from chemical and physical hazards in the workplace and furnish oversight, monitoring, contamination control, and other radiation protection assistance for workers. A medical services program provides health examinations and emergency medical services, including counseling lo promote safe and healthful worker lifestyles.

A Radiation Control Officer maintains oversight of all activities involving radiation sources. The officer is also responsible for assuring that processes are developed to comply with the Radiation Control Mamual. Planning for compliance with this initiative began in 1992 and will be modified as requirements change.

Safety and Health program compliance activities conduct remedial actions necessary to move Sandia toward compliance with applicable (OSHA regulations and DOE orders. Specific remedial activities address audit findings and concerns in accordance with a completion schedule approved by DOE or other audit groups.

\section{Environmental Protection}

Environmental protection activities provide Sandia organizations the support necessary for compliance with the Clean Water Act, the Clean Air Act, DOE Order 5400.1, and various other requirements and permits issued by local, state, and federal agencies. Activities include management of sanitary sewer waste, storm water cuscharges, spills, air quality, and environmental compliance. 


\section{Tiger Team Corrective Action Plan Incremental Cost Estimates* (Operating BA in \$ million)}

Total requirements

$$
\begin{array}{lllllll}
\text { FY93 } & \text { FY94 } & \text { FY95 } & \text { FY96 } & \text { FY97 } & \text { FY98 } & \text { FY99 } \\
34.4 & 28.5 & 22.5 & 15.2 & 11.5 & 10.0 & 8.0
\end{array}
$$

* These "cross-cut" cost estimates are included in the functional area funding requirements reported in the tables below.

Indirect-Funded Waste Management Plan Funding Requirements

(Operating BA in $\$$ million)

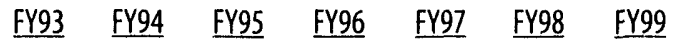

Total requirements

$4.7 \quad 5.1 \quad 6$

$6.9 \quad 6.9$

6.9

6.9

\section{Safety and Health (S\&H) Plan Funding Requirements}

(Operating BA in \$ million)

FY93 $\underline{\text { FY94 }}$ FY95 $\underline{\text { FY96 }}$ FY97 $\underline{\text { FY98 }}$ FY99

Total requirements

$33.3 \quad 34.7 \quad 46.2$

45.

$41.4 \quad 41.4$

41.4

\section{Indirect-Funded Environment Plan Funding Requirements}

(Operating BA in \$ million)

$\begin{array}{lllllll}\text { FY93 } & \text { FY94 } & \text { FY95 } & \text { FY96 } & \text { FY97 } & \text { FY98 } & \text { FY99 } \\ 7.4 & 14.2 & 13.5 & 13.4 & 13.5 & 13.6 & 13.7\end{array}$

Total requirements

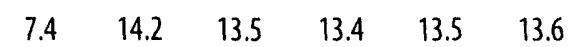

Notes: 1. Funding from the ()ffice of Finvironmental Restoration and Waste Manngement for lis\& Hatetivilies is included in the table on page 12-10.

2. "landlord" funding is not included in the tables ahose.

3. Internally funded l:S\&H support direcily charged to projects is not included in these tables.

4. The budget numbers shown here differ trom those in the March 1993 1 edense Programs Five-Year Plan. due to recent changes in the indirect budget. 


$$
10
$$




\section{$A$. \\ 4

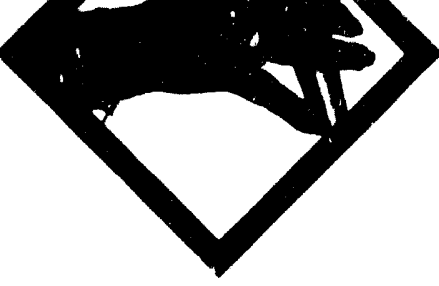 \\ Human Resources Management}

Sandia's people are key to the Laboratories' ability to succeed in its mission. In the current environment of evolving work priorities, continual change, and fluctuating budgets, Sandia's intent is the maintenance and full utilization of a workforce of talented, creative people dedicated to "exceptional service in the national interest."

Toward this end, Sandia has developed a Strategic Human Resource Planning process for evaluating and improving the management of human resources to achieve long-term programmatic goals within the context of changing work requirements and evolving demographic and societal trends. This process is employed as the mechanism by which workforce composition and utilization, workplace environmental requirements, and the ongoing humban resource processes to support programmatic goals and to meet legal and regulatory requirements are forecasted, planned, and delivered. The planning process is carried out in a partnership between human resource program managers and line executives, who are jointly responsible for strategy formulation and implementation. The process is modeled on the Malcolm Baldrige approach to quality improvement, and the resultant strategies embed the key Baldrige elements for Human Resource Development and Management.

The first Sandia National Laboratories Strategic Human Resource Plan (SHIRP), covering the time horizon from FY 1993 through 1997, was published in ()etober, 1992. 'The plan outlined a set of critical issues obtained from the analysis of laboratory requirements and employee needs. Four areas of strategic focus were established to address the critical issues: (1) Laboratories Staffing, (2) Leadership and Management Development, (3) Performance Management, and (4) Diversity. A fifth focus on Human Resource Cost Management has been identified and will be published in IFY 1994. The implementing initiatives for the four areas of strategic focus include:

1. Integrating the hiring, internal movement, and labor contracting processes to place the right person in the right job at the right time based on near- and long-term forecists of the required skills mix and consideration of cost, morale, and other factors.

2. Continually improving the ability of people at the Laboratories to lead others and manage organizations, programs, and projects in an environment of constant change and evolving work priorities.

3. Establishing a line-of-sight for expected performance outcomes from the strategic through the operational level and continually improving the performance (both output and behavior) of individual employees throughout the Laboratories.

4. Making those strides in diversity which will improve employees' experience of fairness in the workplace as well as our ability to attract the future workforce.

Present actions and future initiatives to implement the plan are discussed in the following sections. 


\section{Laboratory Personnel}

Sandia National Laboratories' management is committed to preserving the vitality and quality of the Laboratories' technical, management, and support staff. In general, Sandia has followed the personnel practices of AT' \&' and Bell laboratories, allowing for unicpue provisions to accommodate locial conditions and precedent. 'These practices include:

1. Conducting nation-wide recruiting efforts at leading universities for the best qualified technical candidates from all disciplines of engincering and the physical sciences;

2. Continuing education, training, and related skills development for all segments of the workforce, based on needs assessments of current job performance requirements and career paths;

3. Fostering a work environment that emphasizes customer focus and quality improvement, participation in local decision making, open communications, and self-management;

4. Compensating people based on performance results and recognizing specific accomplishments through both monetary and non-monetary award programs; and

5. Providing cost-effective employee benefits and services, such as work and family services, health maintenance programs, and employee assistance programs.

Several initiatives are now underway to implement the Strategic Human Resource Plan. 'The first of these is a Laboratories' Staffing Initiative to critically examine the skills, education, and experience needed over the next two-to-five years and the desired composition for the year 2000), based on the changes in our revenue streams. For this purpose, the Laboratories' Strategic Plan, business planning outlooks, investment/disinvestment decisions, and core competencies will supply the data for near- and longer-term determinations of skill mix requirements. At the same time, the composition of the current population will be assessed both in terms of the inventory of skills and projections of attrition and capabilities lost. This information will determine both the near-and long-term gaps between needed and available skills. The present Laboratories' workforce composition is shown in the table below.

To fill the near-term gap, as well as to address the staff surpluses that will result as the Military Application program downsizes, a staff realignment strategy is being developed. 'This strategy will include policy formulation on staff retraining and retention, specific identification and implementation of retraining programs, and modification of internal movement processes. An Employec Development Center will open in Summer 1993 to implement the policies and coordinate retraining and movement.

For the longer term, a process and structure will be established to dynamically assess the gap between current and needed future skills mix, factor-in workforce projections and cost data, determine hiring requirements, provide input to training and development needs assessments, and update guidelines for the procurement of contract personnel. A major function of the Employee Development (Center will be to provide information to managers and other employees on the trends in programmatic directions and their impact on skill needs, thus encouraging employee responsibility for maintaining and developing relevant skills and capabilitics.

The second major initiative is a Performance Management process based on an annual cycle of performance planning, employee development and ongoing feedback, and formal performance evaluation of achievements against the planned outcomes. From these evaluations, compensation and other reward decisions can be made. A design team has completed development and implementation 


\begin{tabular}{|c|c|c|c|c|}
\hline \multicolumn{5}{|c|}{ Laboratory Staff Composition } \\
\hline & $\underline{\text { PhD }}$ & MS/MA & $\underline{B S / B A}$ & Other \\
\hline \multicolumn{5}{|l|}{ Professional Staff: } \\
\hline Engineers & 645 & 1165 & 258 & 17 \\
\hline Scientists & 681 & 378 & 116 & 19 \\
\hline Other Technical & 2 & 50 & 22 & 398 \\
\hline Management and Administrative & 47 & 518 & 198 & 67 \\
\hline \multicolumn{5}{|l|}{ Support Staff: } \\
\hline Technicians & 1 & 11 & 149 & 1379 \\
\hline All Other & & 29 & 193 & 2242 \\
\hline Laboratory Total Staff & 1376 & 2151 & 936 & 4122 \\
\hline
\end{tabular}

of a process for the exccutive levels of management. These personnel have been trained in the process, and initial performance plans are documented. Managers and employees in represented job categories, in collaboration with union officials, have also developed and implemented a performance management system. Iesign teams are being formed to implement performance management for the remainder of the Laboratories' population.

Future phases of the Performance Management initiative will integrate the process more fully with the larger human performance system, including identification of competencies supporting position roles and responsibilities, succession planning, career management, revised compensation strategies, training and education, and work and organization design. As with Laboratories staffing, the total human performance system will be driven by the Laboratories' strategic and business planning forecasts.

The l.eadership and Management Development strategy is discussed in the section, "Continuous Professional Education," in this chapter. The Diversity Strategy is being formulated by the Corporate Diversity Team as discussed in the section on Affirmative Action and Equal Employment ()pportunity.

\section{Affirmative Action and Equal Employment Opportunity}

The Diversity and Equal Employment (Opportunity/Affirmative Action vision for Sandia is to become a national leader in valuing the diversity of all employees and integrating diversity into all aspects of conducting business. At Sandia, diversity means creating a work environment in which differences are valued and utilized to improve laboratory performance. Sandia continually strives for a work environment where mutual respect and opportunity are fostered for all employees.

Respect for the individual, one of five corporate values articulated in Sandia's strategic plan, continues to be the foundation for human resources policies, including affirmative action and equal employment opportunity. Although compliance with applicable employ'ment law's and regulations (such as 'Title V'Il of the (ivil Rights Act of 1964, as amended, Executive order 11246, the Age D) iscrimination in Employment Act of 1967, the Rehabilitation Act of 1973, the Vietnam Era Veterans Readjustment Act of 1973, and the Americans with Disabilities Act of 1990) is legally mandated, Sandia's commitment goes beyond mere compliance and is based on a moral commitment to all 


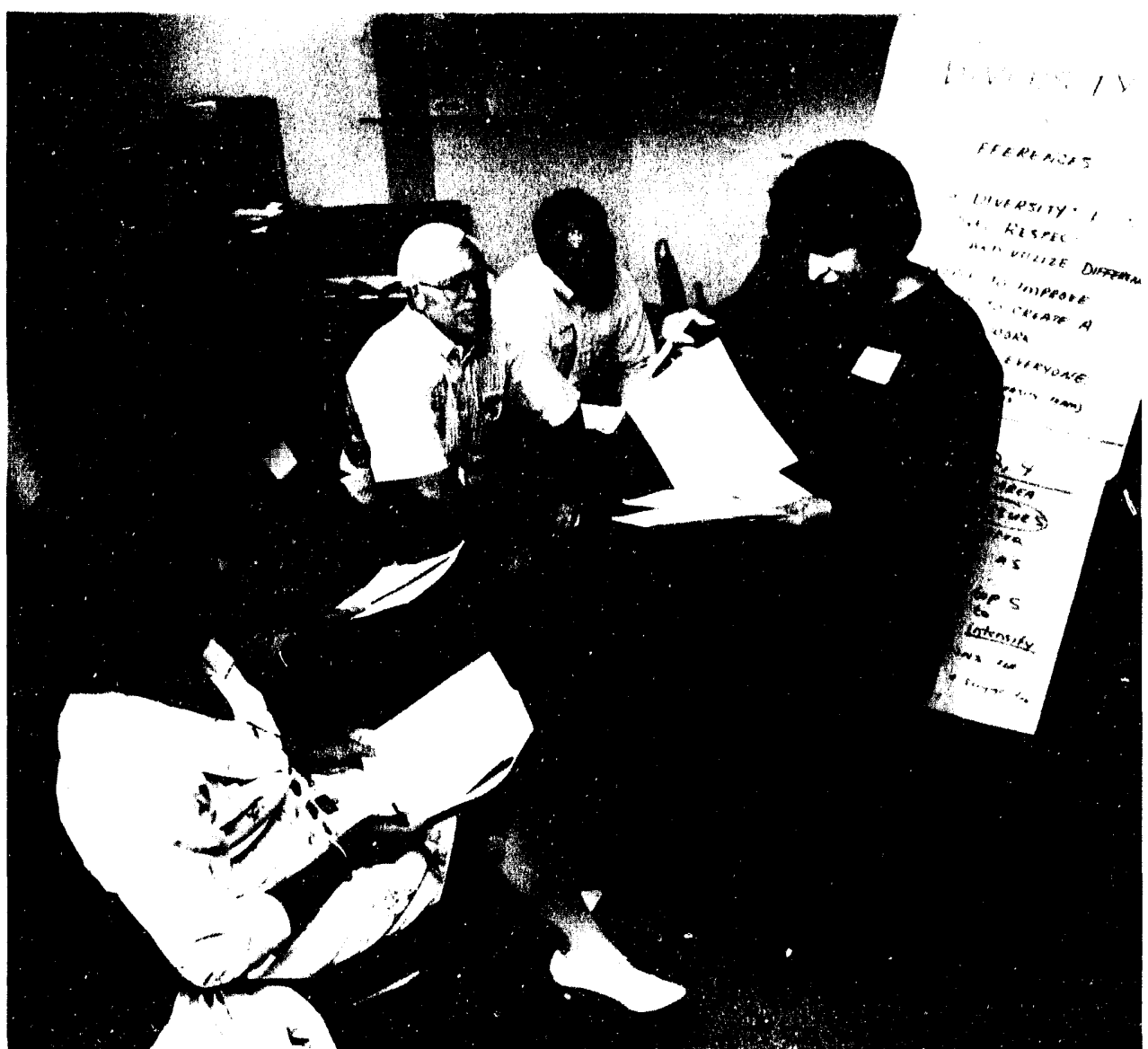

Members of a subgroup of Sandia's 15 -member Corporate Diversity Team discuss some of the issues they're addressing as they help develop a strategic corporate diversity plan for the Laboratories. From left: Brenda Barajas, Anthony McDonald, Bob Eagan, Gary Randall, and Gina Bell. individuals regardle'ss of race, religion, gender, age, national origin, veteran slattus, or nom-job-related disability. Me'msurc that our employment and promotional actions are in accord with the principles of equal cmployment opportunity and affirmative action by basing employment decisions on valid jobrelated criteria. 'lerms and conditions of cmployment affected by Sandia's Equal Eimployment (opportunity/Affirmative Action commitment include recruiting, hiring, training, promotion, compensation, bencfits, transfers, layoffs, returns from layoff, Sandia-sponsored training, education, tuition assistance, and social and recreational programs.

It is Sandia's policy to prohibit sexual harassment of its employees in any form. Policies and practices conform to the Sex Discrimination Guidelines for Government Contractors (4) CFR 60-20). Both supervisors and employees are subject to complying with Sandia's policy on sexulal harassment. Complaints of sexual harassment (or other forms of harassment or discrimination) are investigated immediately. Appropriate sanctions may range from warning to termination.

With respect to job applicants or employees with disabilities, Sandia's persomnel process assures a thorough and systematic consideration of qualifications, job requirements, and possible accommodations. When appropriate, physical and mental job requirements are reviewed to ensure that such requirements are job-related and consistent with business necessity and safety.

\section{Self Assessment and Progress}

The representation of women and minorities in all job classifications increased by $15.6 \%$ and $4.1 \%$ respectively over the past five years. Based on U.S. census data for 1990, Sandia has not reached full utilization of women and minorities in all job classifications. However, goals have been established for each Sandia corporate division in which underutilization currently exists. These goals are a part of each vice president's affirmative action plan. 
During FY 1992, goals for women were met in 15 of the 19 underutilized job groups while minority goals were met in 10 of 13 . At the beginning of FY 1993, using the 1990 census data, women were underutilized in 21 of the 45 job groups. During the first six months of FY 1993, progress in hires, promotions, and transfers was made in 11 of these job groups. (of the 293 placement opportunities for women, $34.8 \%$ were made in job groups that were underutilized.

At the beginning of FY 1993, minorities were underutilized in 19 of the 45 job groups. Progress was made in 15 of these job groups during the first six months of FY 1993. Of the total number of minority placements, $61.0 \%$ were made in underutilized job groups.

A detailed profile of Sandia's diverse work force and a description $0^{\circ}$ sur progress toward meeting affirmative action objectives may be found in the Laboratories' 1993 Affirmative Action Program.

Another method for assessing progress toward affirmative action goals is the Internal Compliance Review. This process involves an in-depth review and analysis of each component of the Affirmative Action Plan and other relevant data, such as compensation and formal charges. An internal compliance review is planned for FY 1993.

Sandia makes every effort to ensure equal employment opportunity for people with disabilities. Employees who choose to identify themselves as disabled are also asked to provide information necessary for possible accommodations. Self-identification is purely voluntary, and information provided is used only in accordance with regulations. Consequently, it is not possible to provide an accurate figure for the number of disabled persons employed by Sandia. However, based on data from Sandia's invitation to self-identify, approximately 117 individuals have self-identified as being disabled. In addition to these, 30 individuals are currently employed through Sandia's contract with Career Services for Persons with Disabilities. In our efforts to ensure that all appropriate accommodations are considered and made for individuals with either permanent or temporary work restrictions, cases are reviewed by the Disability Accommodation Committee. Its purpose is to review job requirements and work restrictions to ensure that they are specific to the job sought by the disabled individual and to determine what reasonable accommodations can be made given the required work restrictions. In addition, the committee may review laboratory-wide issues affecting a group of disabled employees or applicants.

Researcher Carol Ashley prepares a solution of inorganic polymers using chemical synthesis procedures. Sandia is increasing its numbers of women and minorities in all job classifications.

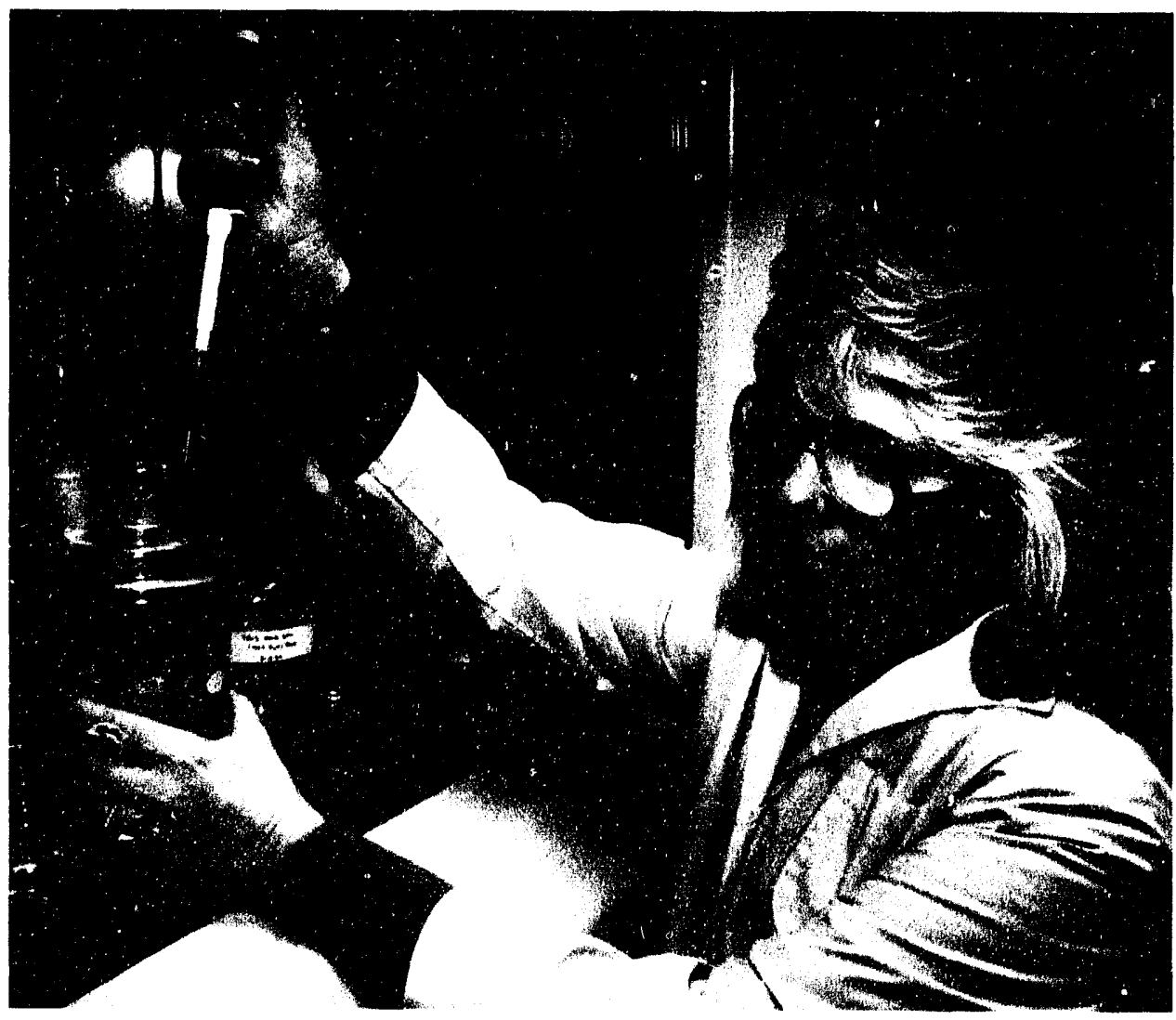




\section{Plans for Accomplishing Goals}

Plans for achieving a diverse work force and full compliance with equal employment opportunity and affirmative action regulations have included some recent changes in the management structure in order to facilitate accomplishment of the established objectives. The new structure, which is described below, involves those members of management who are in positions most critical to effect the desired results.

The Diversity Leadership (enter was established in 1992 to give higher-level visibility to diversity issues and to implement a comprehensive diversity plan for the Laboratories. This new organization comprises two departments, the Equal Employment (opportunity/Affirmative Action Department and the Diversity Planning Department. The Diversity Leadership (Center staff was increased during FY 1993 in order to be more responsive to the needs of all customers and accomplish the goals and objectives of the organization.

This center has also identified the need for tha development and implementation of an information system to meet the needs of all users of Equal Employment Opportunity/Affirmative Action data. Reliable and timely reporting and access to data are critical in achieving full compliance. The current affirmative action management system is being upgraded and will be used to track and monitor status and trends of formal and informal complaints filed by employees. The development and implementation of an affirmative action information system and local area network are continuing.

Sandia Management Council's Forum on Equal Employment Opportunity, Affirmative Action, and Diversity meets quarterly and is composed of Sandia's vice presidents. The purpose of this group is to bring executive focus to affirmative action issues, plans, and programs.

A Diversity Leadership Committee was appointed by this Forum. It consists of a director from each division and is co-chaired by an executive vice president and the director of the Diversity Leadership Center. This committee meets monthly to review corporate equal employment opportunity, affirmative action, and diversity issues and make recommendations to the Sandia Management Council. As necessary, it also charters teans to accomplish established objectives. Currently chartered teams include Vice President Affirmative Action Program teams and a Corporate Diversity Team.

The purpose of the Vice President Affirmative Action Program teams is to support implementation of corporate and division affirmative action plans. An Affirmative Action Plan is developed for each division. These affirmative action plans include goals based on business and staffing plans and projected opportunities. The goals are published and communicated to staff, and progress is monitored and reported to the division vice president.

The Corporate Diversity Team was chartered to assist with the development of a strategic corporate diversity plan and support the implementation of such a plan. Successful implementation of this plan will improve employees' experience of fairness in the workplace and the Laboratories' ability to attract the future work force. This fifteen-member committee represents a cross section of employees from all areas and job classifications.

We are confident that with this new structure (including the contributions of the action-oriented programs described below) and continued employee support of Sandia's equal employment opportunity/affirmative action objectives, Sandia will continue to move toward full compliance and diversity.

\section{Action-Oriented Programs}

Outreach/inreach and other action oriented programs play a vital role in achieving and maintaining a work force that values individuals' differences and recognizes diversity as a competitive ad'anntage. At Sandia, outreach/inreach committees have been established for American Indians, Asians, Blacks, Hispanics, women, and the disabled. Each committee is composed of between 12 and 75 
members from both the technical and administrative staffs. The outreach programs contribute to Sandia's affirmative action efforts by using community contacts to identify women and minorities for possible employment at Sandia and increasing sensitivity and cultural awareness. Lxamples of committee activities include participation in career fairs, conferences, providing tours and lectures, and sponsoring cultural celebrations.

Sandia also sponsors eight affirmative action employment programs in addition to the regular recruiting program. The One-Year-()n-Campus program, for example, has resulted in the employment of approximately 91 minorities at Sandia since 1983. For over ten years, Sandia has also contracted with Career Services for Persons with Disabilities for employment and training of pesple with disabilities.

In addition to the employment related programs noted above, Sandia continues to receive recognition for its achievements in affording maximum opportunity to minority and womenowned business enterprises to participate as suppliers and contractors. Sandia has had a very active disadvantaged, women-owned, and small business program for many years and has received awards from organizations such as the Small Business Administration, Department of Energy, and others for its accomplishments. 
Sandia National Laboratories/New Mexico

Equal Employment Opportunity

\begin{tabular}{|c|c|c|c|c|c|c|c|c|c|c|c|c|c|c|c|}
\hline \multicolumn{16}{|l|}{ Fiscal Year 1987} \\
\hline & & \multicolumn{2}{|c|}{ Grand Total } & \multicolumn{2}{|c|}{ Minority } & \multicolumn{2}{|c|}{ Other } & \multicolumn{2}{|c|}{ Black } & \multicolumn{2}{|c|}{ Hispanic } & \multicolumn{2}{|c|}{ Native American } & \multicolumn{2}{|c|}{ Asian } \\
\hline EEO Category & $\begin{array}{l}\text { Total } \\
\text { Workforce }\end{array}$ & $\begin{array}{c}\text { Male } \\
\# \quad \%\end{array}$ & $\begin{array}{l}\text { Female } \\
\# \quad \%\end{array}$ & \begin{tabular}{cc}
\multicolumn{2}{c}{ Male } \\
$\# \quad \%$
\end{tabular} & $\begin{array}{l}\text { Female } \\
\# \quad \%\end{array}$ & $\begin{array}{c}\text { Male } \\
\# \quad \%\end{array}$ & \begin{tabular}{|l|} 
Female \\
$\# \quad \%$ \\
\end{tabular} & $\begin{array}{l}\text { Male } \\
\# \quad \%\end{array}$ & $\begin{array}{l}\text { Female } \\
\# \quad \%\end{array}$ & $\begin{array}{c}\text { Male } \\
\# \quad \%\end{array}$ & $\begin{array}{l}\text { Female } \\
\# \quad \%\end{array}$ & $\begin{array}{l}\text { Male } \\
\# \quad \%\end{array}$ & $\begin{array}{l}\text { Female } \\
\# \%\end{array}$ & $\begin{array}{l}\text { Male } \\
\# \quad \%\end{array}$ & $\begin{array}{l}\text { Female } \\
\# \quad \%\end{array}$ \\
\hline Officials \& Managers & 924 & $\begin{array}{ll}863 & 93.4 \\
\end{array}$ & $\begin{array}{ll}61 & 6.6\end{array}$ & 10911.8 & 1415.0 & 74581.6 & $47 \quad 1.5$ & 1415.0 & 20.2 & $82 \quad 8.9$ & 80.9 & 60.6 & 20.2 & 70.8 & 20.2 \\
\hline Scientists \& Engineers & 2739 & 250891.6 & 2318.4 & $229 \quad 8.4$ & $\begin{array}{ll}33 & 1.2\end{array}$ & 227983.2 & $198 \quad 7.2$ & $17 \quad 0.6$ & 50.2 & 139 & 90.3 & 110.4 & 20.1 & 622.3 & 170.6 \\
\hline Management \& Administrative & 514 & 31360.9 & 20139.1 & 5811.3 & $\begin{array}{ll}46 & 8.9\end{array}$ & $255 \quad 49.6$ & 15530.2 & 101.9 & 91.8 & $\begin{array}{ll}35 & 6.8\end{array}$ & $26 \quad 5.1$ & 91.8 & 61.2 & 40.8 & 51.0 \\
\hline Technicians & 1999 & $\begin{array}{ll}1722 & 86.1\end{array}$ & $277 \quad 13.9$ & 36118.1 & $68 \quad 3.4$ & 136168.1 & 20910.5 & $47 \quad 2.4$ & 120.6 & 25512.8 & $38 \quad 1.9$ & 301.5 & 80.4 & 291.5 & $10 \quad 0.5$ \\
\hline All Others & 2221 & $\begin{array}{lll}1059 & 47.7\end{array}$ & 116252.3 & 59226.7 & 50322.6 & 46721.0 & 65929.7 & $51 \quad 2.3$ & 663.0 & 46420.9 & $342 \quad 15.4$ & $\begin{array}{ll}60 & 2.7\end{array}$ & & 170.8 & $\begin{array}{ll}16 & 0.7\end{array}$ \\
\hline Totals & 8397 & 645577.0 & 193223.0 & $\begin{array}{lll}1349 & 16.1\end{array}$ & $\begin{array}{ll}664 & 7.9\end{array}$ & $5116 \quad 60.9$ & 126815.1 & $\begin{array}{ll}139 & 1.7\end{array}$ & 941.1 & $975 \quad 11.6$ & $423 \quad 5.0$ & $\begin{array}{ll}116 & 1.4\end{array}$ & $\begin{array}{ll}97 & 1.2\end{array}$ & 1191.4 & 500.6 \\
\hline
\end{tabular}

\begin{tabular}{|c|c|c|c|c|c|c|c|c|c|c|c|c|c|c|c|}
\hline \multicolumn{16}{|l|}{ cal Year 1992} \\
\hline \multirow[b]{2}{*}{$\mathrm{EEOC}$} & \multirow[b]{2}{*}{$\begin{array}{l}\text { Total } \\
\text { Workforce }\end{array}$} & \multicolumn{2}{|c|}{ Grand Total } & \multicolumn{2}{|c|}{ Minority } & \multicolumn{2}{|c|}{ Other } & \multicolumn{2}{|c|}{ Black } & \multicolumn{2}{|c|}{ Hispanic } & \multicolumn{2}{|c|}{ Native American } & \multicolumn{2}{|c|}{ Asian } \\
\hline & & $\begin{array}{l}\text { Male } \\
\end{array}$ & $\begin{array}{l}\text { Female } \\
\# \quad \%\end{array}$ & & $\begin{array}{l}\text { Female } \\
\# \quad \%\end{array}$ & $\begin{array}{l}\text { Male } \\
\# \quad \%\end{array}$ & $\begin{array}{r}\text { Female } \\
\# \quad \% \\
\end{array}$ & $\begin{array}{c}\text { Male } \\
\# \quad \%\end{array}$ & \begin{tabular}{|l|} 
Female \\
$\# \%$ \\
\end{tabular} & $\begin{array}{l}\text { Male } \\
\# \quad \%\end{array}$ & $\begin{array}{l}\text { Female } \\
\# \quad \%\end{array}$ & $\begin{array}{l}\text { Male } \\
\# \quad \%\end{array}$ & $\begin{array}{l}\text { Female } \\
\# \%\end{array}$ & $\begin{array}{l}\text { Male } \\
\# \%\end{array}$ & $\begin{array}{l}\text { Female } \\
\# \%\end{array}$ \\
\hline fficials \& $M_{z}$ & 1028 & 92189.6 & $107 \quad 10.4$ & 15515.1 & $26 \quad 2.5$ & 76674.5 & 817.9 & $\begin{array}{ll}20 & 1.9\end{array}$ & 50.5 & 111010.7 & 18. 1.8 & 70.7 & 00.0 & 187.8 & \\
\hline & 3035 & 268588.5 & 350 & 2628.6 & $\begin{array}{ll}58 & 1.9\end{array}$ & 242379.8 & 2929.6 & $\begin{array}{ll}17 & 0.6\end{array}$ & $\begin{array}{ll}6 & 0.2\end{array}$ & $153 \quad 5.0$ & $18 \quad 0.6$ & 160.5 & 0.2 & 762.5 & 28 \\
\hline & 587 & 29550.3 & 29249.7 & $\begin{array}{lll}66 & 11.2\end{array}$ & $\begin{array}{lll}77 & 13.1\end{array}$ & 22939.0 & 21536.6 & $\begin{array}{ll}13 & 2.2\end{array}$ & 132.2 & $\begin{array}{ll}40 & 6.8\end{array}$ & & $\begin{array}{ll}7 & 1.2\end{array}$ & $12 \quad 2.04$ & 61.0 & 71.2 \\
\hline echni & 1705 & 148284.7 & 26815.3 & 33519.1 & $\begin{array}{ll}73 & 4.2\end{array}$ & $1147 \quad 65.5$ & 19511.1 & $42 \quad 2.4$ & 120.7 & 22813.0 & $\begin{array}{ll}44 \quad 2.5 \\
\end{array}$ & 372.1 & 70.4 & 281.6 & $10 \quad 0.6$ \\
\hline & 2231 & 94942.5 & 128257.5 & 55324.8 & 54824.6 & $\begin{array}{ll}396 & 17.7\end{array}$ & 73432.9 & $\begin{array}{ll}53 & 2.4\end{array}$ & 582.6 & 43919.7 & 39617.7 & $\begin{array}{ll}50 & 2.2\end{array}$ & $\begin{array}{ll}76 & 3.41\end{array}$ & 110.5 & 180.8 \\
\hline Totals & 8631 & 633273.2 & 229926.6 & 137115.9 & $\begin{array}{ll}782 & 9.1\end{array}$ & 496157.5 & 151717.6 & $\begin{array}{ll}145 & 1.7\end{array}$ & 941.1 & 97011.2 & $521 \quad 6.0$ & $117 \quad 1.4$ & $101 \quad 1.17$ & 1391.6 & $\begin{array}{ll}66 & 0.8\end{array}$ \\
\hline
\end{tabular}




\section{Continuous Professional Education}

Sandia's corporate education policy states:

Sandia is firmly committed to the continuous improvement of all Sandians through education and training and views it as a strategic investment in Sandia's future. Sandia demonstrates that commitment by providing corporate funds and other resources for educational activities which enhance Sandia's competitiveness and support the achievement of Sandia's strategic intent.

Sandia's corporate training and development function is directly aligned with corporate strategies and business plans and supports the corporate mission, values, and objectives. This alignment and support is provided by offering individuals and groups a wide variety of high-quality, job-related performance improvement and development opportunities. The scope of performance improvement opportunities includes gaining and applying knowledge, skills, and abilities in the advancement of technology, quality human processes, personal health and safety, and nrotection of the environment.

Training needs of the staff are determined through ongoing assessments. Curricula are developed to target specific job performance improvements. Current emphasis is on curricula in Agile Manufacturing; Software Engineering; Project Management; Quality; Environment, Safety, and Health; and Leadership and Management Development.

Leadership and Management Development is one of four top priorities spelled out in the Laboratories' Strategic Human Resources Plan (SHRP). The initiative will result in a corporate policy, development model, and curriculum for leaders and managers to improve their skills based on specific competencies required in Sandia's changing culture. A design team with laboratory-wide representation is currently engaged in the planning and design of these outputs, and implementation will begin during the first quarter of FY 1994. This important work will augment existing training and skills enhancement related to leadership and management. Traditionally, we have provided a combination of internal courses and university or institute-based seminars and workshops. We have also provided individual coaching of newly promoted managers and team supervisors.

Corporate training and development services for internal customers include:

1. Design, development, implementation, delivery, and evaluation of job-related training and development courses, using a systematic design and development process for each course or curriculum request; and

2. Administration of major training and development programs, including:

In-Hours Technical Education Courses (INTEC) - INTEC's purpose is to support Sandia's mission and goals, to ensure continued technical expertise of the staff, to develop the staff's technical and analytical capabilities, to satisfy technical demands of current programs, and to expand technical capabilities for future programs.

Tuition Assistance Program (TAP) — TAP provides tuition payment for eniployees who are pursuing university-based continuing education.

Doctoral Study Program (DSI a Ph.D. degree by attending school full time and by paying their expenses and a stipend.

One-Year-On-Campus (OYOC) Program-OYOC serves Sandia's affirmative action objectives by permitting bachelor-degreed new-hires to attend school full time to carn a master's degree and by paying their expenses and a stipend. 
The Distance Learning Program - This program provides the delivery' of live seminars and full semester courses transmitted via video link from off-site universities or other locations to Sandiia sites.

Environment, Safety And Health Training - This program offers a very large curriculum of courses recpuired to comply with D) ()E orders related to environnent, safety, and health.

In 1992-93, the Corporate Training and D evelopment Program had 48,207 course completions. Sandia is committed to continuous improvement in its professional development activitics. This commitment is evidenced in the recent formation of the Corporate Education I Directors' Committee and the Corporate Education Process Manngement 'leam. 'These groups are focused on the development, implementation, and management of training and development policies, practices, and procedures. Goals include ensuring strategic alignment of all professional development activities with Sandia's corporaie values, mission, and objectives, including alignment with Malcolm Baldrige National Quality Award criteria. 



\section{Sites and Facilities}

Sandia's executive management offices and larger laboratory location are on Kirtland Air Force Base on the southeastern edge of Albuquerque, New Mexico. Another Sandia laboratory complex in Livermore, California, adjoins Lawrence Livermore National Laboratory. Test ranges are operated near Tonopah, Nevada, and on the Navy Pacific Missile Range, Kauai, Hawaii.

\section{Laboratory Description}

A generalized description of Sandia National Laboratories' facilities appears on page 3-10 of the chapter, "Executive Overview." Cond tition, age, and categories of use of Laboratories' buildings are illustrated in the charts on this and the next page.

\section{Facilities Plans and Options}

\section{Site Development}

Sandia's Site Development Plan, updated annually, contains a comprehensive description of planned facility changes. The plan describes an optimum site development projection with short-range and long-range plans for the three principal Sandia sites. In the current dynamic environment, this plan is becoming an evolutionary document in which site locations shown for future facilities are tentative. Exact locations of luture facilities, site inirastructure, and the types of activities they will support are determined both through business planning and the results of site evaluations.

The intent of Sandia's site development planning is to relieve space shortages and construct permanent buildings to replace temporary ones, while providing for the conversion of the site to support more open access and unclassified activitics. As the construction prograin permits, we will retire mobile offices, trailers, transportable buildings, and other substandard space.

\section{Condition of laboratory space}

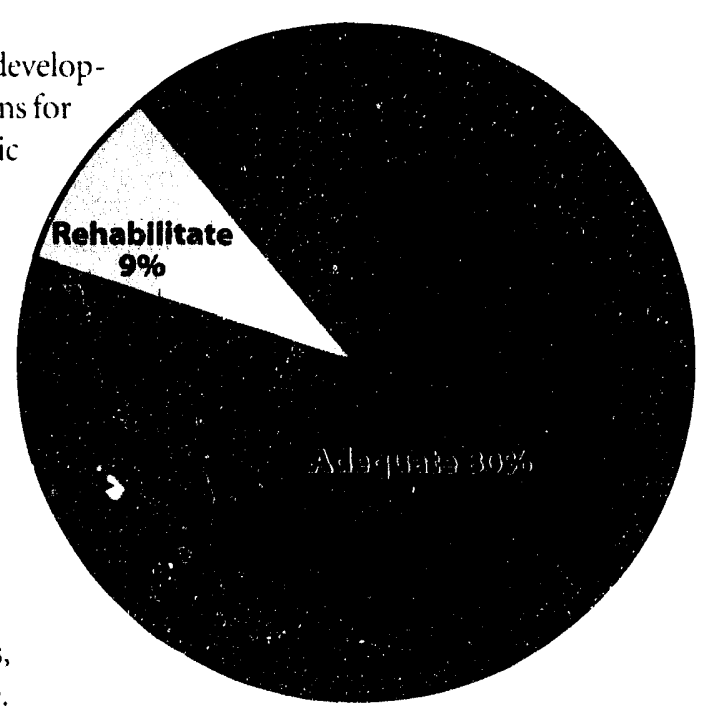


In addition, our site development planning will be mindful of the requirements of the National Environmental Policy Act and site environmental restoration activities.

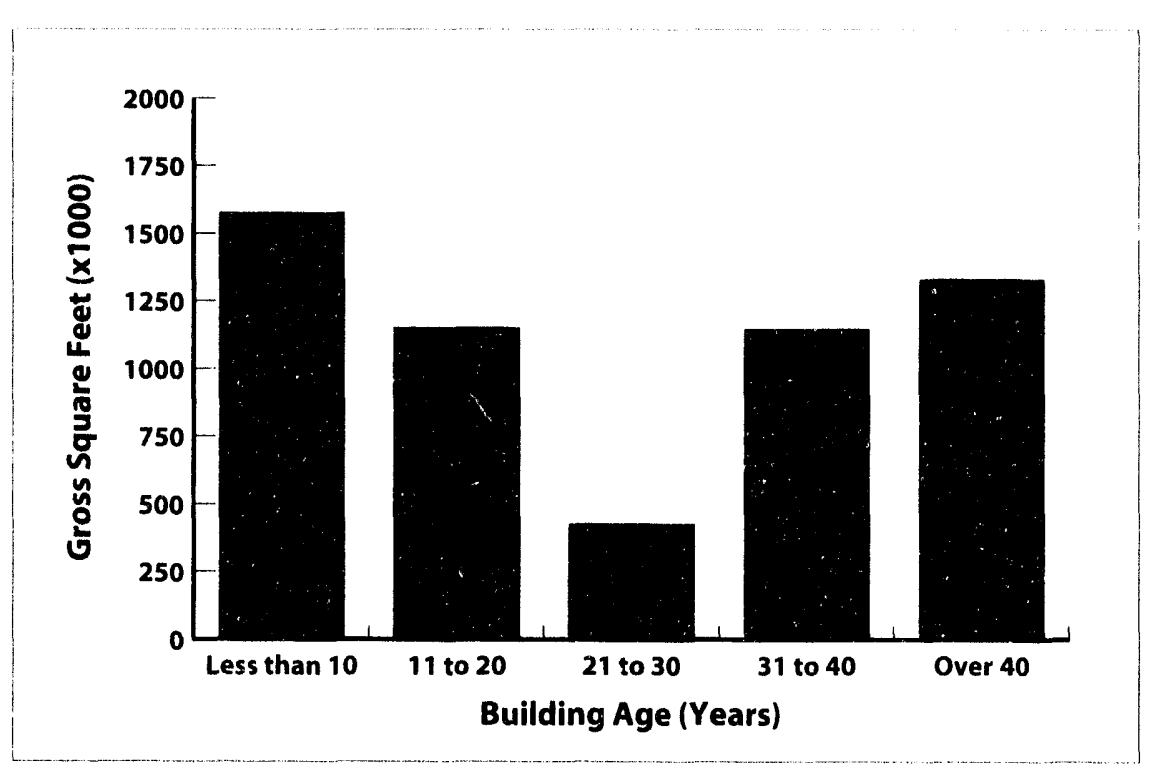

There essential factors underlie Sandia's site and facilities plan. ()ne is a problem that has existed from the Laboratories' founding when the nation was in grealt urgency to build a nuclear arsenal. The Laboratories did not have adequate permanent buildings then, and the problem has never been fully corrected.

The second factor recognizes that profound change's have occurred in engineering practice and the supporting scientific disciplines since Sandia was founded. 1) uring the 1950)s, much of Sandia's engineering work was straightforward and was checked with extensive ficld testing. But for many years now, cost-conscious engineering has been intensely analytical, relying heavily on elaborate, sophisticated instrumentation that requires control of temperature and vibration to achieve repeatability and reliability. With this evolution, staff moved from the field to the laboratory. Laboratory work proliferated, the complexity of measurements and apparatus increased, and professional requirements for staff were raised. The recent suspension of underground nuclear testing, coupled with Sandia's continuing responsibilities for ensuring stockpile reliability and nuclear weapons surety, will increase requirements for both laboratory simulation and computational capabilities. These changes create new facility needs.

The third factor recognizes the dramatic changes in the international environment, including the demise of the Soviet Union and Warsaw Pact and the shift from military to economic competitiveness,

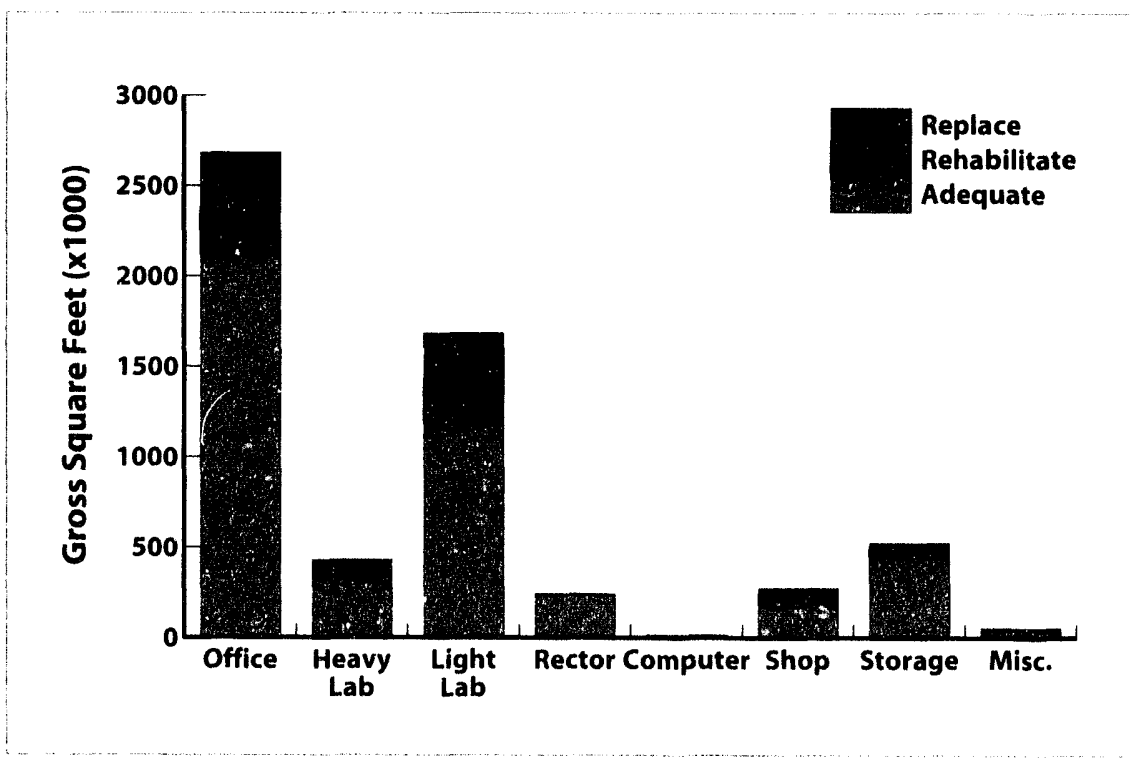
and the consequent impacts on Sandia's future missions. (ireater emphasis on technology transfer. economic competitiveness, and teamwork with private sector partners in unclassified research and development will require conversion of the New Mexico and California sites to more open campus and research park environments. This change will include site improvements to ease access for unclassified activities, new facilities to support changing missions, and accompanying infrastructure investments to support site conversion.

Sandia, like other national laboratorics, is working much 
more dosely with U.S. industry, especially non-defense industry. 'These close associations repuire extensive on-site interactions with uncleared personnel and are generating much new unclassified work. The fact that Sandia's primary location is on a military installation can make doing business with private-sector partners awkward. If this sector of the Laboratories' business is to grow significantly and if industry is to have better aceess to the substantial government insestment at the laboratories, we must develop innowative means for overoming these impediments while continuing to meet our reguirements to protect both classified and proprictary information as well as the security recuurements of the host military installation.

This change will likely involve subdividing the New Mexico site into classified and unclassified business areas and making improvements in public access, traffic circulation, parking, and other infrastructure. It will also recuire reconfiguring the (alifornia site to increase the areas of unclassified access. Adequate funding to allow conversion to this more cost-effective and accessible configuration is not currently available. Significant investment will be required to allow Sandia to convert portions of its site to unclassified areas.

The changes in our mission and customer mix also provide an overarching requirement to) increase the timeliness of our responses to new initiatives. (onstruction is sometimes necessary to provide laboratories, prototyping lines, and other facilities to support technology transfer and economic competitiveness. The amount of time required to request and gain approval for construction

This illustration of Sandia's New Mexico facility shows envisioned improvements in public access, traffic circulation, parking, and other infrastructure that will allow the private sector to interact on-site more easily with the Labs.

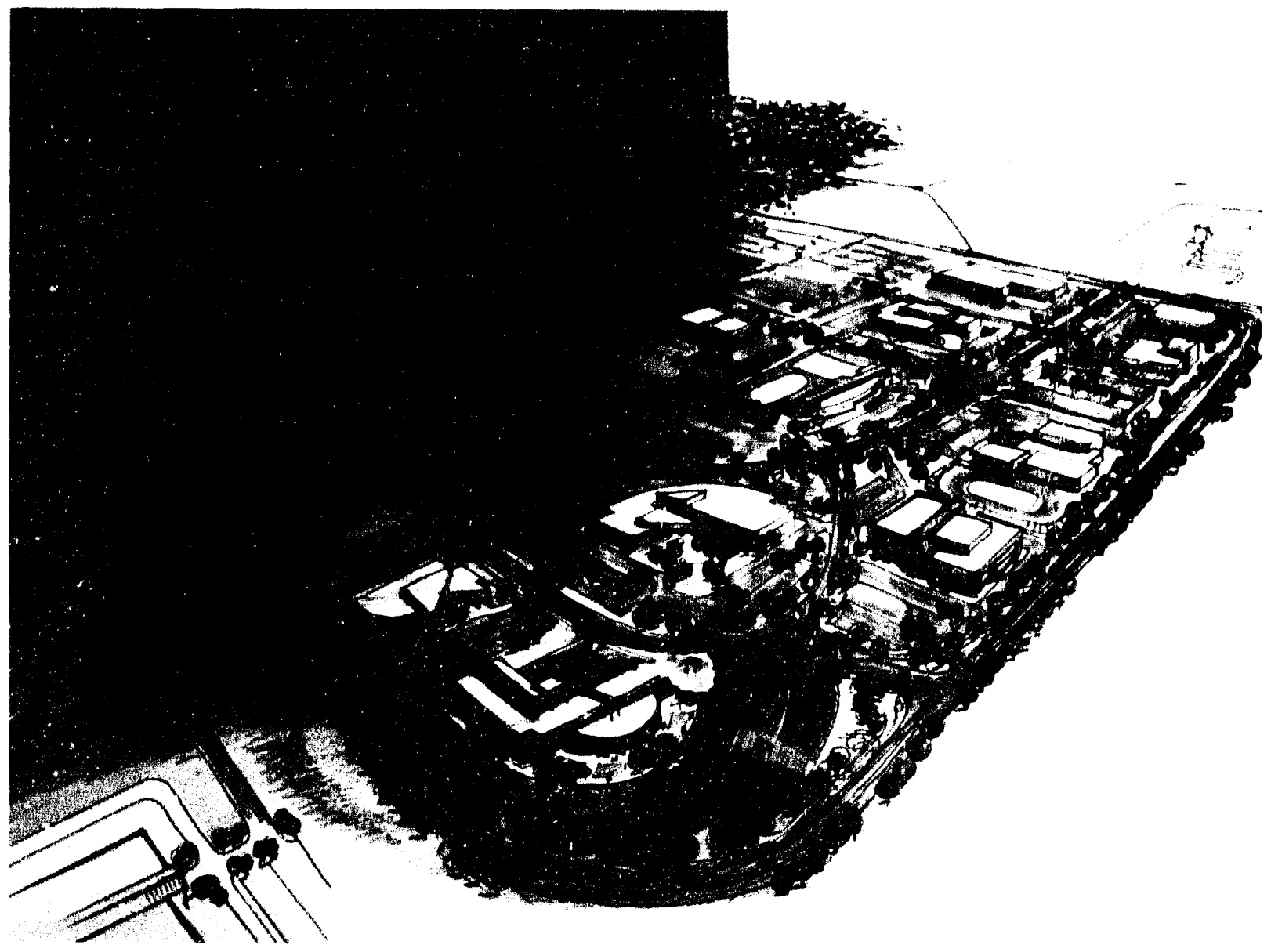


funding is incompatible with the needs of this dynamic environment. Therefore, to better respond to these new missions and customer balse, we must find a way to shorten the request-to-approval time on construction projects to about two years and total project time to no more than five years.

Other important factors we must consider in our facilities planning are the need to conserve energy; new ES\&H (environment, safety, and health) regulations; changing physical security requirements; and the requirement to provide special purpose buildings for certain applications.

Older structures, particularly temporary buildings, waste energy and are expensive to maintain. More stringent requirements for providing for the protection of the environment and the safety and health of our employees and visitors make continued use of some of these facilities impractical. Shifts in physical security regulations (allowing the use of concepts such as islands of security) and in the nature of the materials and data being protected (from weapons-related to proprictary information) will allow for dramatic reconfiguration of the existing limited areas. New technologies and activities will demand that facilities be designed to support unique' requirements. Examples are buildings for ecuupment to fabricate microstructures, inertial confinement fusion machines, special instrumentation systems, environmental and energy research laboratories, fabrication facilities to support rapid prototyping and the development of advanced manufacturing techniques, and computer centers to support all of these applications.

The Laboratories must also reduce dependency on buildings borrowed from the military and should consider reducing its use of off-site commercial leased space. Sandia's New Mexico location relies heavily on borrowed or leased Air Force buildings and sites for testing and warehousing, and

\section{Sandia National Laboratories, Albuquerque, New Mexico}

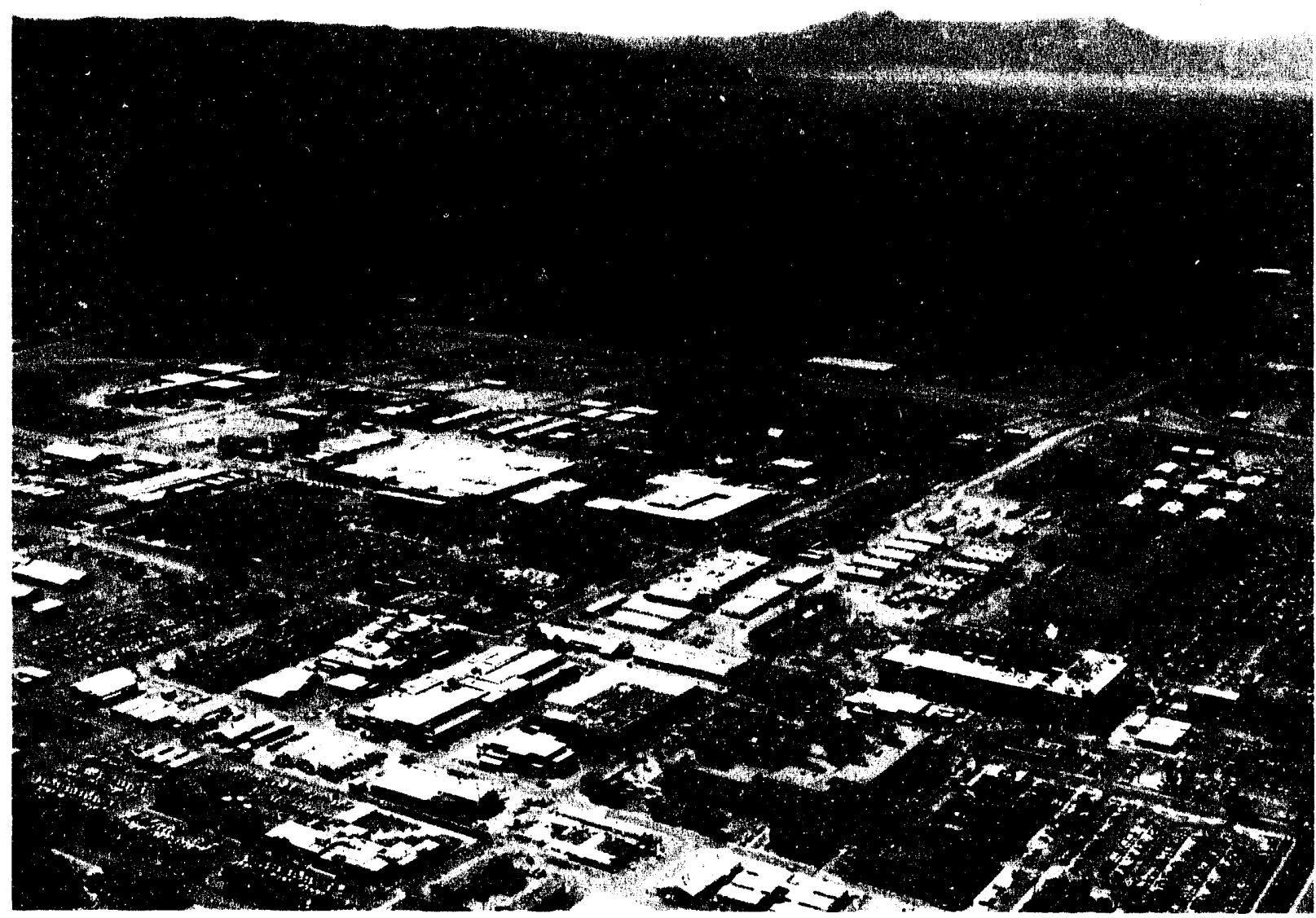


should the Air force need the'se buildings and sites, they would hate to be returned. While planned construction will help relieve problems of huilding anailability and accessibility consideration should be given to consolidation of test locattions and/or pursuit of land transfers from the Air force to l () )t: to accommodate future needs.

The amount of off-site commercial leased space utilized in New Mexion hals grown dramatically: While certain types of space, such as a hangar for aircraft aging testing, are impractical to duplicate on site, other types, such as general office and light laboratories, could be accommodated. The primary' drivers causing some Sandia organizations to move off-site have been the Laboratories' persistent space shortages and the impediments to public acess presented by the current site configuration. The impacts of these moves include both the costs involved in obtaining and oceupying leased spalce and the dispersion of personnel, leading to increased travel time and a loss of synergy among related organizations and activities. Proposed construction and conversion of the site to better support unclassified public access activities will help relieve these problems.

\section{Facilities Maintenance}

Sandia's site maintenance plan was prepared in accordance with DOE (Order 4.330.4A, Maintenami' Management Program. The maintenance plan is intended to manage activities to reduce the maintenance backlog and identify special maintenance requirements likely to impact site missions,

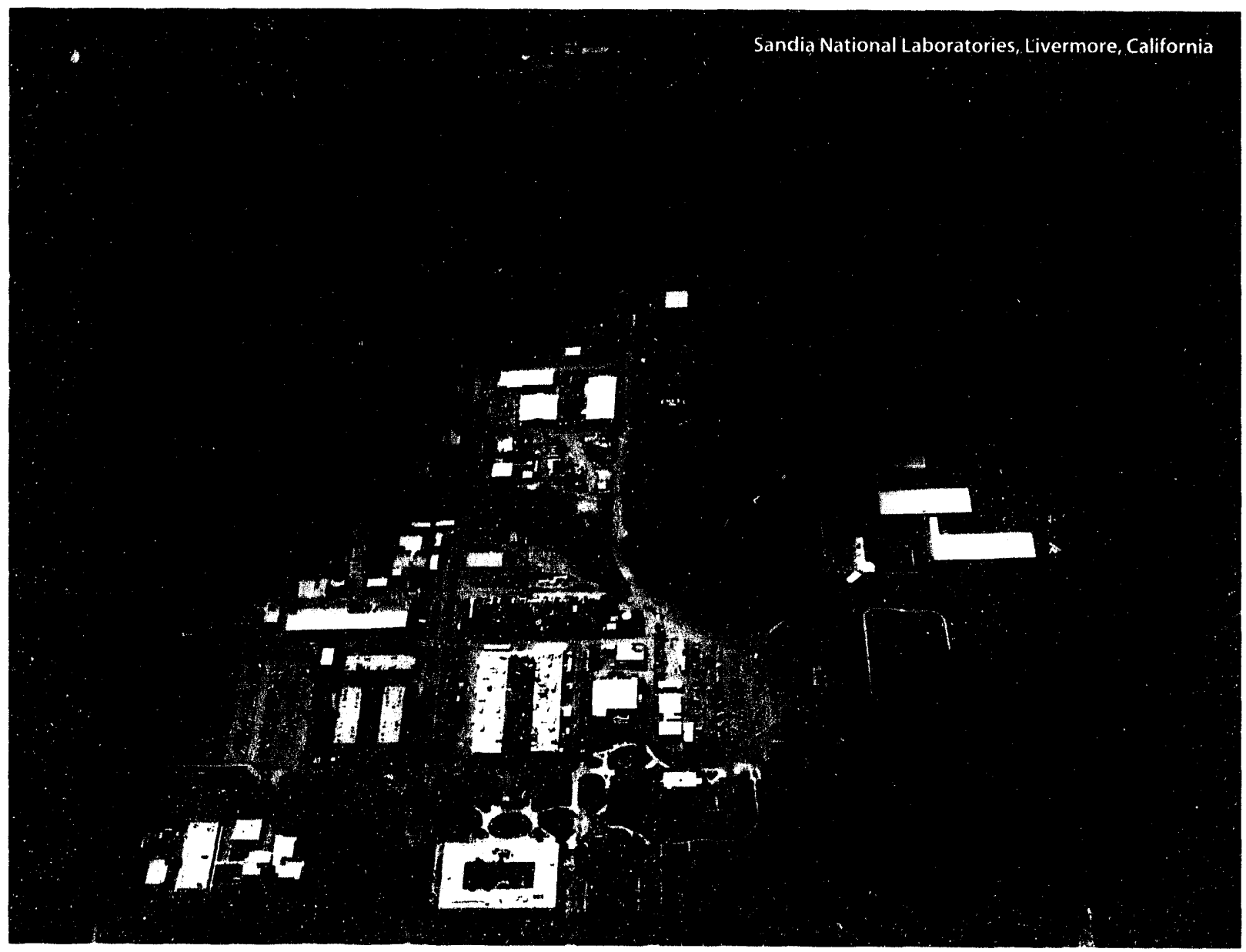


functional unit availability, or functional unit material condition. Major cost factors of site maintenance are identified, and site-wide maintenance program costs are summarized. The effectiveness of the site's preventive and predictive maintenance programs is analyzed, as well as the site's pertormance with regard to obtaining the maximum useful life from its functional units. Improvements to the maintenance program that have potential to lower costs or extend functional unit useful lifetimes are also discussed.

\section{Energy Management}

Sandia conducts a formal In-House Energy Management(HHEM) program to adhere to the repuirements of DOE. Order 4330.2D. The IHEM program is managed by $S_{i}$ india's Facilities Program Management (enter as a part of the Maintenance Management Program ()ffice. The Energy Program Manager reports to the Maintenance Management Program (Office and oversees the operation for the Laboratories' New Mexico, California, and Nevada sites. In addition, an Energy Conservation Coordinator has been assigned for each site, responsible for day-to-day operations.

The IHEM program has established a comprehensive Energy Management Plan that maps out the strategy to be used to attain the FY 1995 and FY 2000 efficiency goals set forth in DOE. (Order 4330.21). These goals mandate energy efficiency improvements for buildings, metered processes, vehicle fuels, and petroleum use against 1985 baseline consumption.

\section{Condition Assessment}

Sandia has been selected as one of four 1 )(OE sites to test and evaluate all aspects of the (ondition Assessment Survey (CAS) process under development as part of the (apital Assets Management Program (CAMP). CAS is a consistent, credible, and auditable process of assessing facility conditions using standard industrial practices. The process involves the development and implementation of deficiency standards, inspection methods, a Condition Assessment Iıformation System (CAIS), an inspector training program, and a quality assurance program. C.AS is intended to evaluate the condition of all DOE propert: 's visual and analytical standard inspection methods. The CAIS will record annual inspection data and facility deficiencies related to safety, security and the environment.

\section{General Purpose Facilities Plans}

\section{General Purpose Plant Requirements}

Consistent funding of general plant projects (CPP) is crucial for facility changes, structural improvements, and non-line item buildings to meet special programmatic needs and upgrades to meet new standards. Funding requirements approximate between $1.0 \%$ and $1.5 \%$ of total operating funds. Nearly all of the required funding is provided by the Assistant Secretary for I )efense Programs. However, for the 1994 and 1995 fiscal years, D)efense Programs funding for (iPp projects will be reduced to $\$ 3$ million per year - less than half of what has been provided previously and well below our requirement of $\$ 7$ million per year. 'These reductions will have significant impacts on the implementation of planned site and facilities ES\&H, infrastructure, and programmatic projects.

We expect substantial (iPP support from the (Office of Environmental Restoration and Waste Management in the future to support projects for environmental, safety, and health compliance. Projected (iPP requirements are shown in chapter 12, "Resource Projections." 


\section{General Purpose Equipment Requirements}

General Purpose Equipment (CiPl) is that equipment used by laboratory administrative and management activities. Funding is provided by applying a surcharge of $10 \%$ on 1 ) ( ) l: capital equipment and $0.5 \%$ on non-1)( ) F funding.

\section{Inactive Surplus Facilities Plan}

To identify surplus facilities, Sandia has taken a inventory of each of its major buildings and their primary missions, then cattegorized them according to their condition and status of mission. This process revealed that a majority of the buildings housed multiple programs which change often. The usc ful life of a specific building may be shortened more by mission change than by facility ange or obsolescence.

Buildings judged to be surplus must be substandard or contaminated to such an extent that they are unfit for reuse once they have been vacated. Because of the shortage of permanent space in satisfactory condition, any satisfactory space that becomes available through organizational movement or program reductions is quickly filled.

\section{Facilities Resource Requirements}

Some of our laboratory facilities are being upgraded and new ones are being proposed. Several new construction projects address long-standing insufficiencies. (Other projects accommodate changing functions and requirements.

Environment, safety, and health concerns are actively addressed in planning for all facilities. Accordingly, all new buildings and major renovations are reviewed internally and by 1 ) ()E for adequacy of ES\&H design features. In the area of environmental protection, 1) OE now requires that all contractors comply with the provisions of the National Envirommental Policy Act. 'This law stipulates that major construction projects be reviewed for potential impacts on the environment and for compliance with envirommental laws. For each new facility and major renovation, Sandia prepares an Action Description Memorandum for circulation within I)( ) E. If I)( ) E deems that further documentation is necessary, an environmental assessment or an environmental impact statement is prepared and made available to the public.

Projects required to meet environmental laws, regulations, and 1 )( )E orders are included in Sandia's Five-Year Plan for Waste Management ( )perations and Environmental Restoration. 1)()E also requires a safety review of new construction projects and major renovations.

Adecuate funds to allow comersion to a more cost-effective operation involving unclassified areas are not currently available. Environment í remediation activities are already placing a serious burden on operating funds. Conversion oi portions of our sites to accommodate conomic competitiveness and other unclassificd activities will repuire significant investment and should be budgeted and appropriated in line with our evolving integrated site planning.

\section{Funded Construction}

The principal goals of Sandia's construction plan are of provide facilities needed to achieve programmatic objectives, eliminate substandard conditions, and replace temporary space with permanent facilities. Items listed in the table of major construction projects (pages 11-10 through 11-11) are briefly discussed below. In addition to these items, a number of major renovation projects with an average total project cost of less than half a millien dollars are performed using expense funds. 


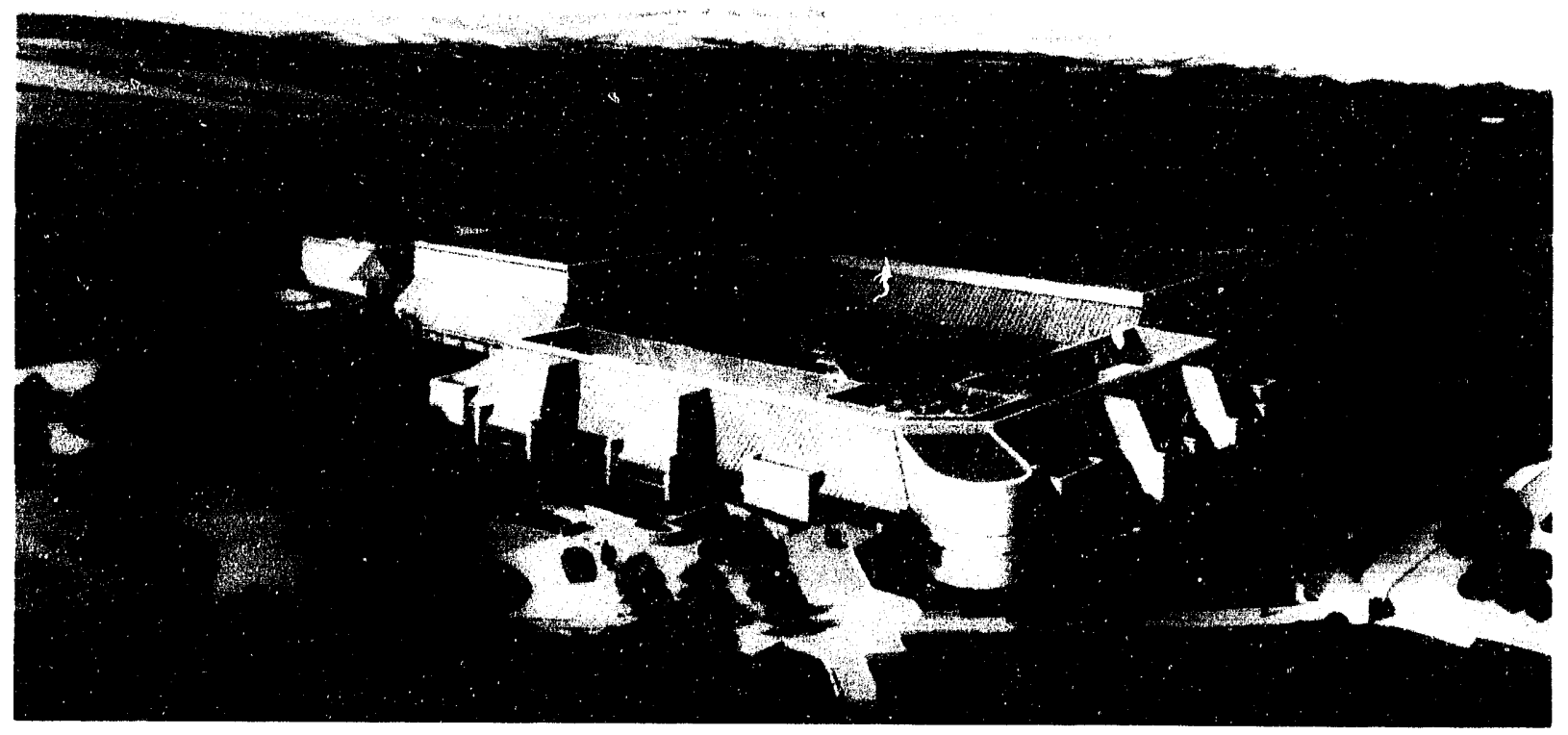

The Integrated Manufacturing Technologies Laboratory at Sandia/ California was completed in 1992. The building will be dedicated to programs that develop advanced manufacturing technologies for defense and civilian industry.
Integrated Manufacturing Technologies Laboratory (IMTL) (California) - This facility, now complete, will focus on the development and integration of advanced manufacturing technologies for DOE nuclear weapon programs. It will house activities in materials and process research and development, process simulation, engineering design, and manufacturing technology support. In addition, significant space will be dedicated to prototype fabrication research and a demonstrati: a a for agile manufacturing, both for $\mathrm{DOE}$ and for the domestic industrial sector. Initial fi in metal removal and welding, weld process simulation, composites fabrication, his $\quad$ munication of manufacturing data, and on-line monitoring and control. Special i anclude energy conservation, environmental monitoring and control systems, and personncl access control.

Explosive Components Facility (ECF) (New Mexico) - Sandia is DO)E's technology center for ordnance for nuclear weapon systems. Four of Sandia's departments will utilize the ECF: Explosive Components, Neutronic Components, Power Sources, and Weapons Evaluation. ECF capabilities include internal test-fire chambers, an $x$-radiographic diagnostic laboratory, an explosive mild detonating fuze and timer development laboratory, remote postmortem and disassembly areas, and a pulse heat laboratory. A significant feature of the EC C.F will be improved explosives handling and safety.

Technology Support Center (New Mexico) - This center will reduce the Tech Area V population to minimize potential radiation exposures by providing a new office, light-laboratory, and conference center for staff who support the reactor facilities. An improved facility is particularly. important because Tech Area $V$ receives many visitors as a consequence of its development and testing programs for $\mathrm{DO}, \mathrm{OF}, \mathrm{OL}$ ), and other agencies.

Main Electrical Service and Switchgear (California) - The main electrical service and asso)ciated switchgear are being upgraded to supply all site power requirements for the foreseeable future. The proposed service is dual-source, separate-direction, and will provide backup capability. and additional capacity when required. 
Robotics Manufacturing Science and Engineering Laboratory (New Mexico) - This laboratory will facilitate progress in the development of robotics and automation technologies, which have been identified as strategically important. It is evident that these technolegies can minimize the need to use humans in hostile environments or near potentially hazardous materials; accomplish tasks that stretch normal human capabilities for complexity and reliability; and reduce production and operating costs with in both the weapons production complex and the domestic industrial sector.

Investment Casting Addition (New Mexico) - 'This addition to Sandia's melting and solidification laboratory will provide space for a new casting furnace along with ancillary equipment, a closed-loop cooling system, and a control center.

Nonnuclear Reconfiguration (New Mexico) - Extant Sandia buildings will be renovated and modified to accommodate the functional requirements for assembly of neutron generators, cap assemblies, and power sources.

Power Systems Modernization (New Mexico) - Electrical distribution systems at Sandia/ New Mexico are aging and obsolete, as is the series-connected security lighting system. The project includes converting to higher distribution voltage, replacing aging and obsolete transformers and switchgear, and replacing cable as required. It will also replace the remaining series security lighting system and begin replacement of aging master unit substations.

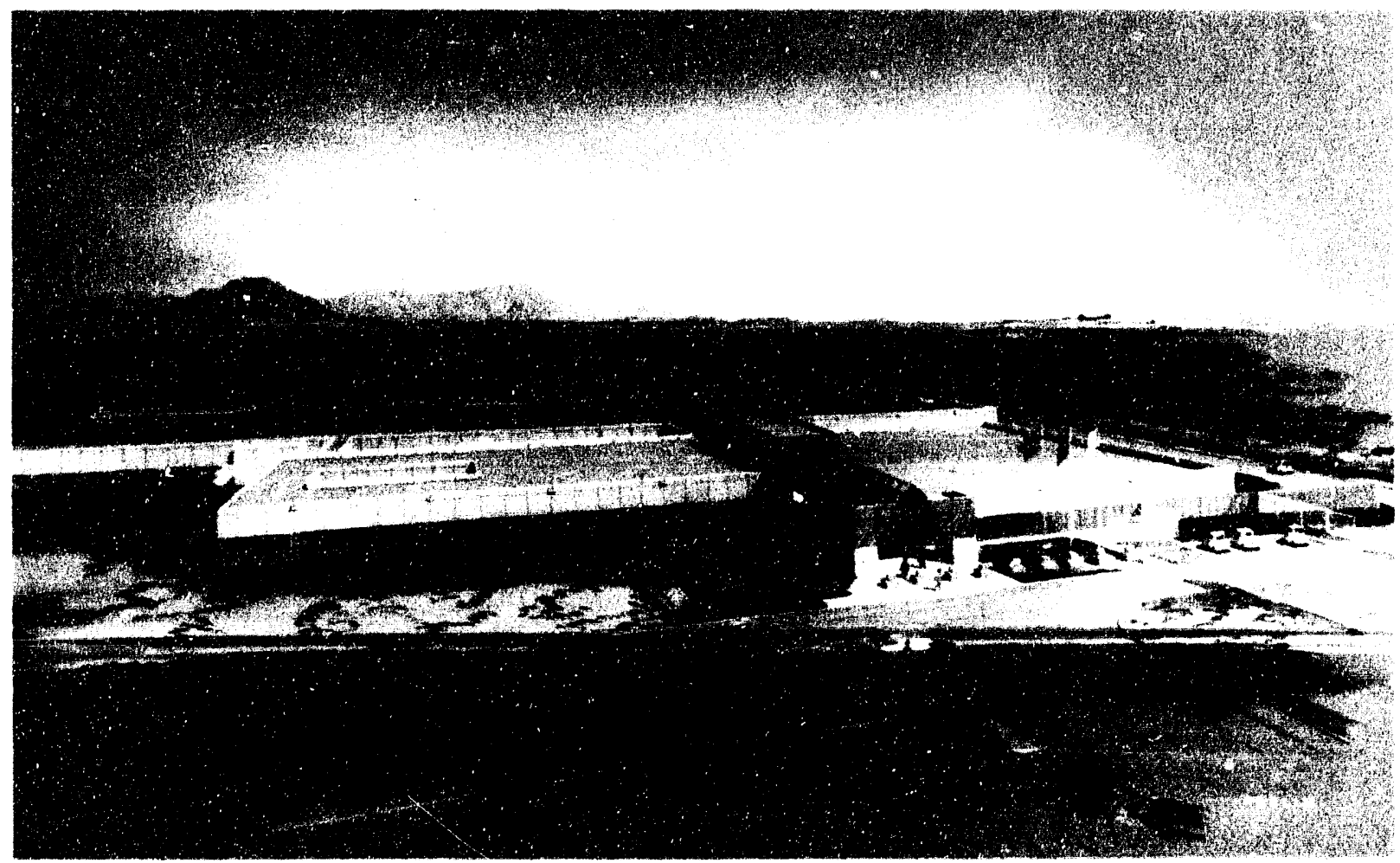

The Explosive Components Facility at Sandia/New Mexico is under construction and will be occupied in 1995. The building will contain an explosive components testing area, chemical and physical testing laboratories, propellant and pyrotechnic areas, a battery testing area, a neutron-generator testing area, and other special facilities. The facility will provide the capability to support component development for nuclear weapons. 


\begin{tabular}{|c|c|c|c|c|}
\hline \multicolumn{5}{|c|}{$\begin{array}{l}\text { Major Construction Projects } \\
\text { (Fiscal Year Budget Authority in Millions) }\end{array}$} \\
\hline & Site & Sponsor & $\begin{array}{c}\text { Total } \\
\text { Estimated } \\
\text { Cost }\end{array}$ & $\begin{array}{c}\text { Total } \\
\text { Project } \\
\text { Cost }\end{array}$ \\
\hline \multicolumn{5}{|l|}{ Funded Construction } \\
\hline Integrated Manufacturing Technologies Laboratory & $C A$ & DASMA & 45.6 & 45.8 \\
\hline Explosive Components Facility & NM & DASMA & 27.8 & 27.9 \\
\hline Technology Support Center & NM & DASMA & 30.0 & 30.2 \\
\hline Main Electrical Service \& Switchgear & $C A$ & DASMA & 5.3 & 5.4 \\
\hline Robotics Manufacturing Science and Engineering Laboratory & NM & DASMA & 33.0 & 33.3 \\
\hline Investment Casting Addition & NM & DASMA & 3.7 & 3.7 \\
\hline Nonnuclear Reconfiguration & NM & DASMA & 74.8 & 95.3 \\
\hline Power Systems Modernization & NM & DASMA & 34.2 & 34.6 \\
\hline \multicolumn{5}{|l|}{ Total DASMA } \\
\hline Center for National Security and Arms Control & NM & is & 34.5 & 34.5 \\
\hline Combustion Research Facility, Phase II & CA & ER & 24.6 & 26.0 \\
\hline \multicolumn{5}{|l|}{ Total Funded } \\
\hline \multicolumn{5}{|l|}{ Proposed Construction } \\
\hline Site Conversion & $\mathrm{NM} / \mathrm{CA}$ & DASMA & 35.8 & 47.0 \\
\hline Processing and Environmental Technologies Lab & NM & DASMA & 43.6 & 48.8 \\
\hline Jupiter X-Ray Simulation Facility & NM & $\begin{array}{l}\text { DASMA } \\
\text { DNA }\end{array}$ & 30.0 & 240.0 \\
\hline Program Support Center & NM & DASMA & 21.0 & 21.1 \\
\hline Siorm and Sanitary Waste Systems Modernization & NM & DASMA & 10.5 & 10.6 \\
\hline Infrastructure Modernization & $C A$ & DASMA & 26.7 & 27.0 \\
\hline Water Systems Modernization & ALL & DASMA & 6.6 & 6.8 \\
\hline \multicolumn{4}{|l|}{ Laboratory for Industrial and National Security } & 8.3 \\
\hline Applications of Computing and CAE & NM & DASMA & 50.0 & 50.3 \\
\hline Aerodynamics Laboratory Building & NM & DASMA & 65.0 & 65.5 \\
\hline Warehouse Complex & NM & DASMA & 12.0 & 12.3 \\
\hline \multicolumn{5}{|l|}{ Total DASMA* } \\
\hline Consolidated Waste Management Complex & NM & EM & 93.6 & 105.0 \\
\hline Geoscience Research Laboratory & NM & ER & 27.6 & 27.6 \\
\hline \multicolumn{5}{|l|}{ Total Proposed } \\
\hline * DNA contributions are not included in DASMA total & & & & \\
\hline
\end{tabular}




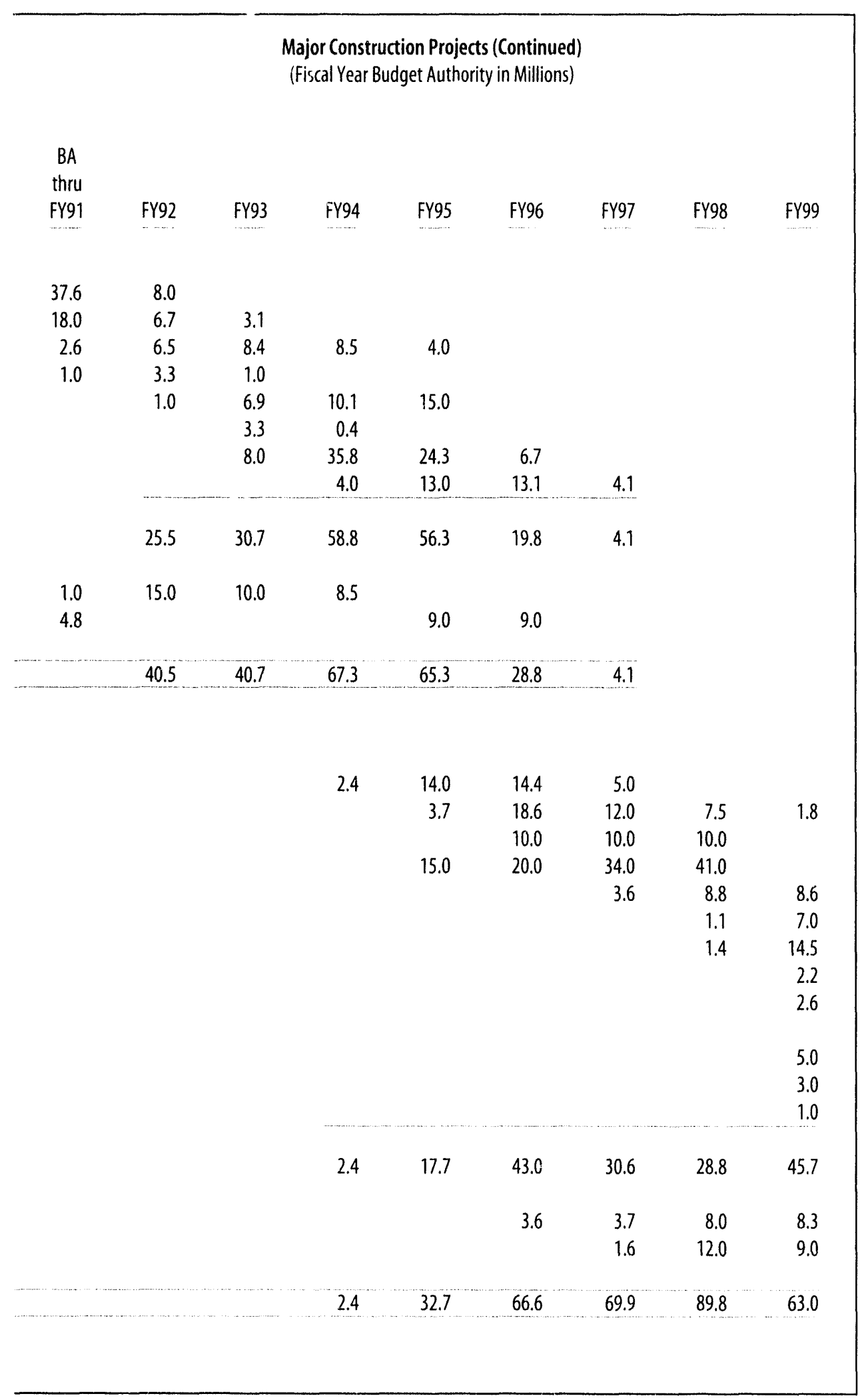


Center for National Security and Arms Control (New Mexico) - This facility will bring together work in four areas: (1) systems analysis and advanced concepts; (2) arms control and verification technology; (3) intelligence; and (4) threats and countermeasures. The new facility will substantially improve Sandia's ability to respond creatively and effectively in these areas.

Combustion Research Facility, Phase II (California) - This facility will provide resources to adequately deal with the critical combustion research needs of the 199()s. It will emphasize centralized, next-generation laser diagnostic facilities and specially designed laboratories, including a high-repetition-rate laser system. Phase 11 will also provide additional offices required to support visiting researchers and staff.

\section{Proposed Construction}

As part of the last Capital Assets Management Program (CAMP) report cycle, all proposed line-item projects were re-evaluated for sponsorship and validity in light of evolving DOE missions. The process catlsed a number of projects to be deleted. Since the FY1995 CAMP report and the 1993 Site Development Plan were published, other changes have occurred which are noted in the following updated list of proposed construction projects.

Site Conversion (New Mexico, California) - This two-phased project is intended to accelerate the plan for transforming Sandia's New Mexico and California sites into more open, research park environments to better support new DOE missions in technology transfer and industrial competitiveness. The resulting site features will achieve greater flexibility and create an open and accessible research park image while maintaining appropriate assets-protection and administrative controls. The project includes various infrastructure improvements, communications upgrades, and the construction of a business outreach/visitor's center at each site.

Processing and Environmental Technologies Laboratory (PETL) (New Mexico) - This construction item is part of the Nuclear Weapons Research, Development, and Testing Facilities Revitalization project. The goal of the PETL is to maintain and enhance Sandia's capability to provide high-quality enginecring research and development to support the nuclear weapons program while satisfying new requirements for environment, safety, and health and reconfiguration of the nuclear weapons complex. Work in the facility will develop, characterize, and apply modern processes to ensure the safety of personnel and preserve the environment. This research will provide direct support to the DOE Complex 21 reconfiguration program.

Jupiter X-Ray Simulation Facility (New Mexico) - Jupiter will be a cold and warm x-ray facility which will permit testing of materials and components that currently can only be tested in underground tests. It will produce $x$-ray energies from 1-20 thousand electron-volts over much larger exposure areas than are now possible with aboveground simulators. This capability will provide excellent simulation fidelity for radiation effects testing, weapon physics research, and $x$-ray physics testing with 5-20) megajoules of thermal $x$-rays. A fast-track schedule is being pursued to support operational goals for this project. Facility costs will be shared with the Defense Nuclear Agency.

Program Support Center (New Mexico) - This facility will centralize external interface activities for the New Mexico site. It will serve as an information center and a central check-in point for persons requiring access to the site. It will also serve as an initial meeting place for visitors and their hosts, provide conference rooms for unclassified activities, and furnish temporary, 
private work space and communications for visitors. Work arcas will be provided for several public interface and laboratory support organizations such as Public Affairs, Technology 'Transfer, Educational Outreach, Purchasing, Benefits, Personnel, Medical, and Safety.

Storm and Sanitary Waste Systems Modernization (New Mexico) - This project will rehabilitate storm drains and sanitary sewers, construct storm water monitoring stations to check for contamination before discharge, and eliminate remaining septic systems.

Infrastructure Modernization (California) - This modernization project is a multiphase effort to renew site systems, modify and add to infrastructure facilities, and upgracle structures to meet current and anticipated regulations.

Water Systems Modernization (New Mexico, California, Tonopah) - 'This project will rehabilitate water systems at the three principal Sandia sites.

Transportation Systems Modernization (New Mexico) - This project will upgrade and replace roads, parking lots, and pedestrian circulation facilities.

\section{Laboratory for Industrial and National Security Applications of Computing and} Computer-Aided Engineering (LISAC) (New Mexico)-Formerly called the Computing/ CAE Laboratory, LISAC will support Sandia's thrusts in defense and industrial applications of high-performance computing and communications and computer aided engineering (CAE). It will be a hybrid open/secure facility for both national security and dual-use programs.

Aerodynamics Laboratory Building (New Mexico) - This building will correct the limiting, crowded conditions that exist in the present facility and will provide adequate space for a more desirable configuration of wind tunnel and parachute laboratory operations.

Warehouse Complex (New Mexico) - The warehouse complex will provide approximately 120,000 gross square feet for storage of classified and unclassified materials and property. It will also include four igloos of approximately 2,000 square feet each for rocket motors and Class-B explosives.

Consolidated Waste Management Complex (CWMC) (New Mexico) - The CWMC will support all waste management activities at the New Mexico location, including radioactive and mixed waste, waste oil, explosive waste, and supporting facilities. Currently the complex is scoped as a major systems acquisition project, but it is being re-evaluated for possibly being divided into multiple other-line-item projects. Though it is expected that the project may slip, the implications of re-scoping and the effects on the funding profile are not yet determined.

Geosciences Research Laboratory (New Mexico) - The (ieosciences Research Laboratory will provide a unicue center for use by Sandia and the scientific community to study active processes in the earth's crust. 'This facility will allow Sandia to meet both its research and I rilling Research Office responsibilities in the (ontinental Scientific Drilling Program. The laboratory will also perform work in fossil and geothermal energy research as well as waste disposal and seismic verification programs. The proposed facility will accommodate mechanical and geophysical testing of large samples, as well as development and testing of advanced instrumentation systems. 

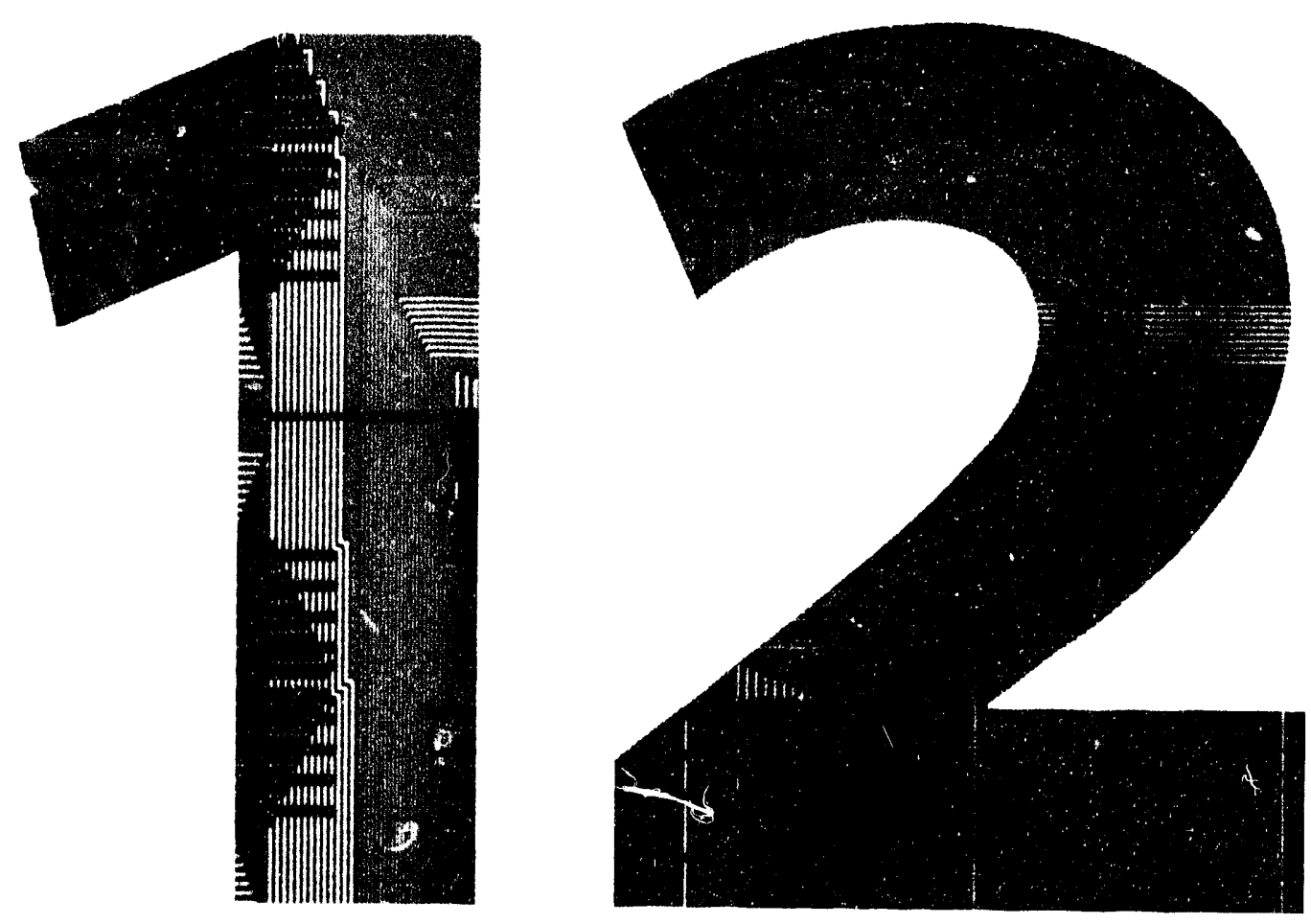


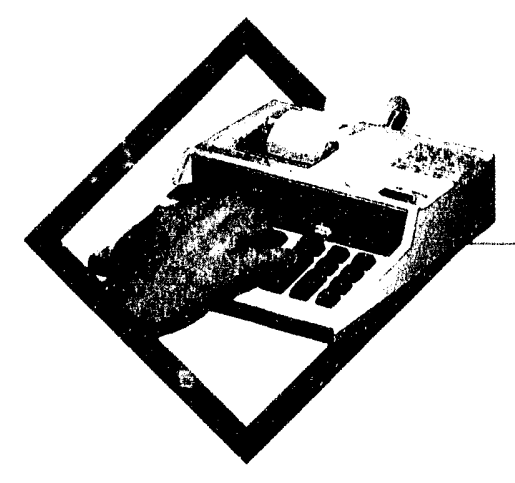

\section{Resource Projections}

This section presents a five-year budget projection for Sandia National Laboratories. Budgct authority dollars are in millions; personnel are in annual average full-time equivalents (FTEs).

Amounts for operating, capital equipment, and general plant project (GPP) funds in fiscal years 1992-1995 are expressed in the dollars of their respective years. For FY (fiscal year) 1996 and beyond, op rating, capital equipment, and GPP estimates are in FY 1995 dollars. Estimates for major construction projects are expressed in dollars of the year of commencement of each project.

Figures shown for fiscal years 1993 through 1995 are based on our FY 1995 Annual Budget Submission. Amounts for fiscal years 1993, 1994, and 1995 conform to targets provided by DOE. Because there is great difficulty in the current environment in estimating requirements for later years, program projections for the fiscal years 1996-1999 are shown at the FY 1995 target level. W'e will manage our resources and programs to live within the constraints of actual funding levels as they become known.

Our strategy during the uncertain times ahead will be a conservative one. We will conserve resources by encouraging outsourcing and entering into cost-sharing partnership arrangements with other public and private entities. W'e anticipate a continued substantial level of cooperative research and development agreements (CRADAs) with industry; however, CRADA efforts cannot be anticipated and budgeted in the same manner as other work. We will manage the flow of work into the laboratory to maintain a reasonable backlog that can ameliorate the impact of a sudden shift in funding levels. Staffing will be controlled within a range appropriate for anticipated conditions. 


\section{Organization Chart}

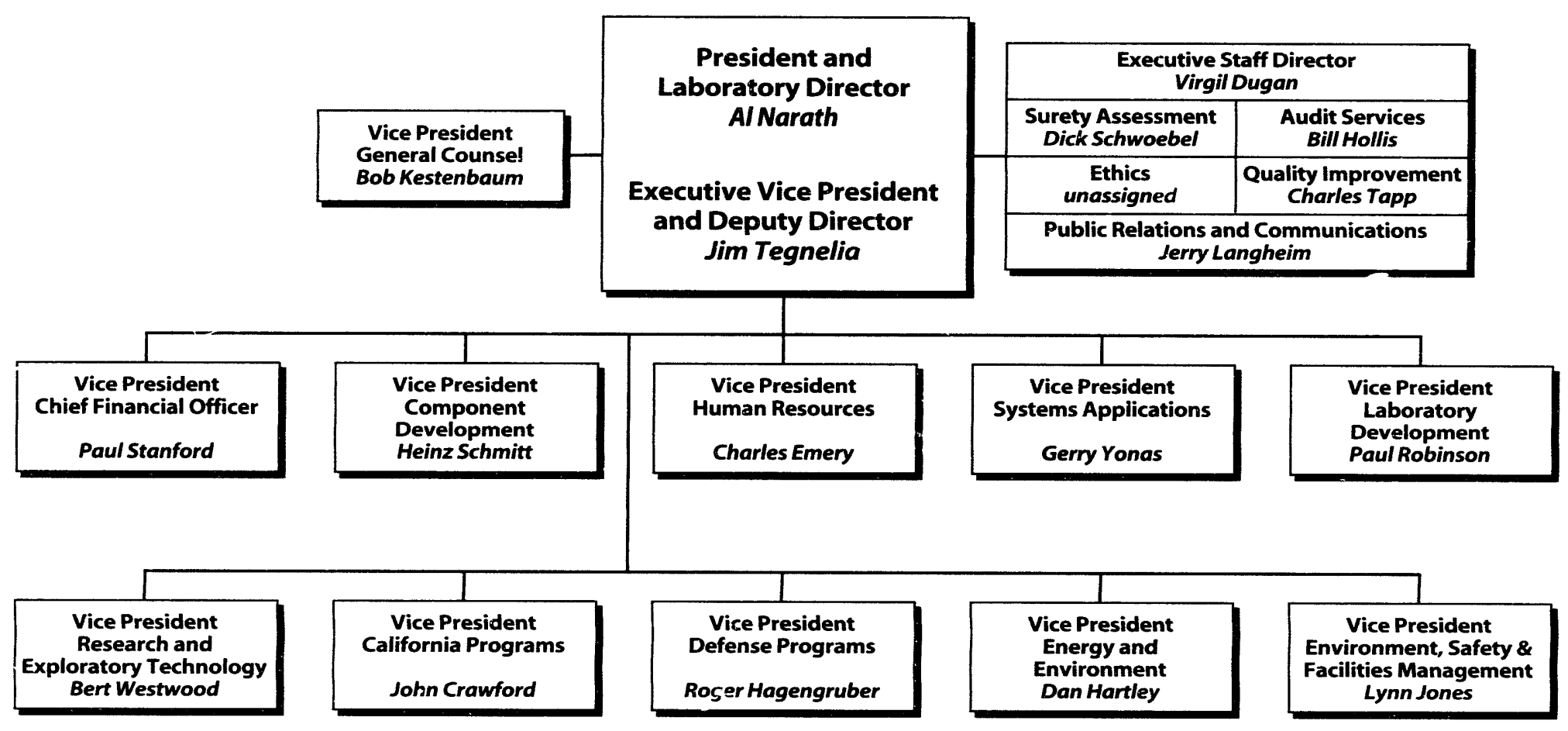




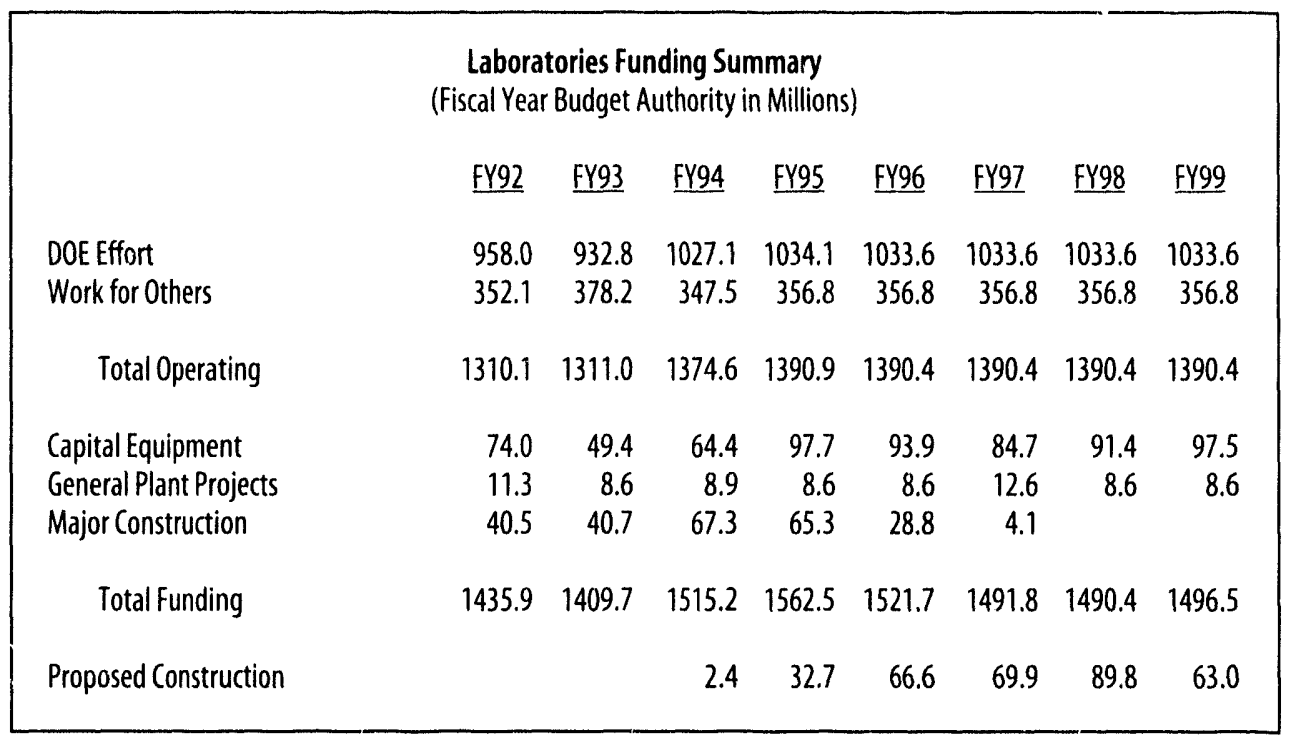




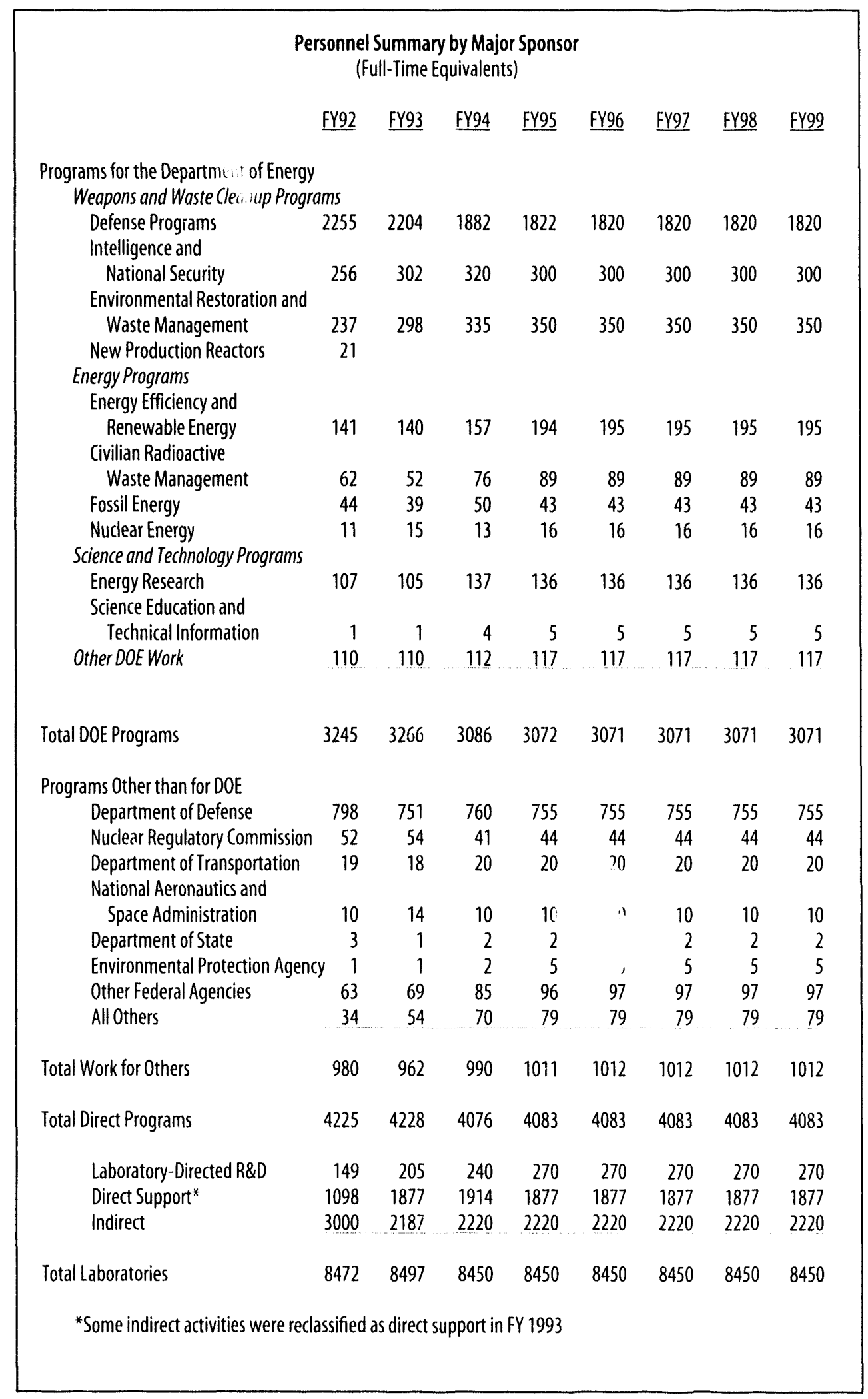




\section{Funding by Assistant Secretarial Office \\ (Fiscal Year Budget Authority in Millions)}

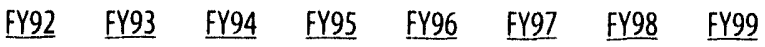

Weapons and Waste Cleanup Programs

Total, Assistant Se c tary For Defense Programs

$\begin{array}{lrrrrrrrr}\text { Operating } & 651.8 & 591.0 & 617.4 & 616.1 & 615.6 & 615.6 & 615.6 & 615.6 \\ \text { Capital Equipment } & 61.7 & 39.3 & 44.8 & 75.0 & 74.1 & 66.3 & 73.4 & 79.6 \\ \text { General Plant Projects } & 8.6 & 7.3 & 4.0 & 8.0 & 8.0 & 12.0 & 8.0 & 8.0 \\ \text { Major Construction } & 25.5 & 30.7 & 58.8 & 56.3 & 19.8 & 4.1 & & \\ \quad \text { Total Cost } & 747.6 & 668.3 & 725.0 & 755.4 & 717.5 & 698.0 & 697.0 & 703.2\end{array}$

Total, Office of Intelligence and National Security

$\begin{array}{lrrrrrrrr}\text { Operating } & 66.5 & 79.8 & 100.1 & 94.5 & 94.5 & 94.5 & 94.5 & 94.5 \\ \text { Capital Equipment } & 2.9 & 3.2 & 6.6 & 7.3 & 4.4 & 3.0 & 2.6 & 2.5 \\ \text { Major Construction } & 15.0 & 10.0 & 8.5 & & & & & \\ \quad \text { Total Cost } & 84.4 & 93.0 & 115.2 & 101.8 & 98.9 & 97.5 & 97.1 & 97.0\end{array}$

Total, Office of Environmental Restoration and Waste Management

$\begin{array}{lrrrrrrrr}\text { Operating } & 87.9 & 126.6 & 138.3 & 144.4 & 144.4 & 144.4 & 144.4 & 144.4 \\ \text { Capital Equipment } & 4.5 & 3.3 & 4.7 & 5.5 & 5.5 & 5.5 & 5.5 & 5.5 \\ \text { General Plant Projects } & 2.6 & 1.1 & 4.3 & & & & & \\ \quad \text { Total Cost } & 95.0 & 131.0 & 147.3 & 149.9 & 149.9 & 149.9 & 149.9 & 149.9\end{array}$

Total, Office of New Production Reactors

$\begin{array}{ll}\text { Operating } & 7.1 \\ \text { Capital Equipment } & 1.3 \\ \text { Total Cost } & 8.4\end{array}$

Energy Programs

Total, Assistant Secretary for Energy Efficiency and Renewable Energy

$\begin{array}{lrrrrrrrr}\text { Operating } & 49.2 & 46.0 & 57.9 & 60.9 & 60.9 & 60.9 & 60.9 & 60.9 \\ \text { Capital Equipment } & 0.8 & 1.0 & 2.5 & 2.7 & 2.7 & 2.7 & 2.7 & 2.7 \\ \text { Total Cost } & 50.0 & 47.0 & 60.4 & 63.6 & 63.6 & 63.6 & 63.6 & 63.6\end{array}$

Total, Civilian Radioactive Waste Management

$\begin{array}{lrrrrrrrr}\text { Operating } & 16.6 & 15.6 & 25.2 & 25.4 & 25.4 & 25.4 & 25.4 & 25.4 \\ \text { Capital Equipment } & 0.2 & & 0.3 & 0.4 & 0.4 & 0.4 & 0.4 & 0.4 \\ \quad \text { Total Cost } & 16.8 & 15.6 & 25.5 & 25.8 & 25.8 & 25.8 & 25.8 & 25.8\end{array}$

Total, Assistant Secretary for Fossil Energy

$\begin{array}{lllrlllll}\text { Operating } & 9.7 & 8.8 & 12.1 & 8.5 & 8.5 & 8.5 & 8.5 & 8.5 \\ \text { Capital Equipment } & & & 0.4 & 0.5 & 0.5 & 0.5 & 0.5 & 0.5 \\ \quad \text { Total Cost } & 9.7 & 8.8 & 12.5 & 9.0 & 9.0 & 9.0 & 9.0 & 9.0\end{array}$

Total, Assistant Secretary for Nuclear Energy

$\begin{array}{lllllllll}\text { Operating } & 5.8 & 2.0 & 6.4 & 7.3 & 7.3 & 7.3 & 7.3 & 7.3\end{array}$


Funding by Assistant Secretarial Office (Continued)

(Fiscal Year Budget Authority in Millions)

FY92 FY93 FY94 FY95 FY96 FY97 FY98 FY99

Science and Technology Programs

Total, Office of Energy Research

$\begin{array}{lrrrrrrrr}\text { Operating } & 28.8 & 28.7 & 27.5 & 33.2 & 33.2 & 33.2 & 33.2 & 33.2 \\ \text { Capital Equipment } & 2.6 & 2.6 & 4.8 & 6.1 & 6.1 & 6.1 & 6.1 & 6.1 \\ \text { General Plant Projects } & 0.1 & 0.2 & 0.6 & 0.6 & 0.6 & 0.6 & 0.6 & 0.6 \\ \text { Major Construction } & & & & 9.0 & 9.0 & & & \\ \quad \text { Total Cost } & 31.5 & 31.5 & 32.9 & 48.9 & 48.9 & 39.9 & 39.9 & 39.9\end{array}$

Total, Office of Science Education and Technical Information

$\begin{array}{lllllllll}\text { Operating } & 1.0 & 3.0 & 2.1 & 2.0 & 2.0 & 2.0 & 2.0 & 2.0 \\ \text { Capital Equipment } & & & 0.3 & 0.2 & 0.2 & 0.2 & 0.2 & 0.2 \\ \quad \text { Total Cost } & 1.0 & 3.0 & 2.4 & 2.2 & 2.2 & 2.2 & 2.2 & 2.2\end{array}$

Work for Other DOE Locations, Contractors, and Offices

Total, Office of Economic Impact and Diversity

Operating

$\begin{array}{llllllll}0.5 & 0.5 & 0.7 & 0.6 & 0.6 & 0.6 & 0.6 & 0.6\end{array}$

Total, All Other

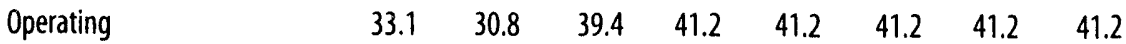

Total DOE Programs

Operating

Capital Equipment

$\begin{array}{llllllll}958.0 & 932.8 & 1027.1 & 1034.1 & 1033.6 & 1033.6 & 1033.6 & 1033.6\end{array}$

General Plant Projects

$\begin{array}{llllllll}74.0 & 49.4 & 64.4 & 97.7 & 93.9 & 84.7 & 91.4 & 97.5\end{array}$

Major Construction

$\begin{array}{rrrrrrrr}11.3 & 8.6 & 8.9 & 8.6 & 8.6 & 12.6 & 8.6 & 8.6\end{array}$

Total Cost

$\begin{array}{llllllll}1083.8 & 1031.5 & 1167.7 & 1205.7 & 1164.9 & 1135.0 & 1133.6 & 1139.7\end{array}$

Proposed Construction

$\begin{array}{llllll}2.4 & 17.7 & 46.6 & 35.9 & 48.8 & 63.0\end{array}$ 


\begin{tabular}{|c|c|c|c|c|c|c|c|c|}
\hline \multicolumn{9}{|c|}{$\begin{array}{l}\text { Assistant Secretary for Defense Programs } \\
\text { Deputy Assistant Secretary for Military Application } \\
\text { Resources by Major Program } \\
\text { (Fiscal Year Budget Authority in Millions) }\end{array}$} \\
\hline & FY92 & FY93 & FY94 & FY95 & FY96 & FY97 & FY98 & $\underline{\text { FY99 }}$ \\
\hline \multicolumn{9}{|c|}{ GB0103 Research and Development } \\
\hline Operating & 401.9 & 339.0 & 309.6 & 279.7 & 279.7 & 279.7 & 279.7 & 279.7 \\
\hline Capital Equipment & 35.5 & 34.9 & 23.5 & 39.5 & 43.3 & 32.4 & 39.3 & 43.0 \\
\hline General Plant Projects & 6.8 & 7.0 & 3.0 & 7.0 & 7.0 & 11.0 & 7.0 & 7.0 \\
\hline Major Construction & 25.5 & 19.4 & 22.6 & 32.0 & 13.1 & 4.1 & & \\
\hline Total Cost & 469.7 & 400.3 & 358.7 & 358.2 & 343.1 & 327.2 & 326.0 & 329.7 \\
\hline Direct Personnel & 1413 & 1274 & 910 & 800 & 800 & 800 & 800 & 800 \\
\hline \multicolumn{9}{|l|}{ GB0104 Testing } \\
\hline Operating & 49.0 & 37.2 & 43.9 & 43.6 & 43.6 & 43.6 & 43.6 & 43.6 \\
\hline Capital Equipment & 6.1 & 5.4 & 5.0 & 2.5 & 2.5 & 2.5 & 2.5 & 2.5 \\
\hline Total Cost & 55.1 & 42.6 & 48.9 & 46.1 & 46.1 & 46.1 & 46.1 & 46.1 \\
\hline Direct Personnel & 181 & 153 & 135 & 125 & 125 & 125 & 125 & 125 \\
\hline \multicolumn{9}{|c|}{ GB0106 Technology Transfer Initiative } \\
\hline Operating & 19.4 & 50.2 & 76.6 & 100.8 & 100.8 & 100.8 & 100.8 & 100.8 \\
\hline Capital Equipment & & & 8.0 & 8.0 & 8.0 & 8.0 & 8.0 & \\
\hline Total Cost & 19.4 & 50.2 & 78.9 & 108.8 & 108.8 & 108.8 & 108.8 & 108.8 \\
\hline Direct Personnel & 30 & 108 & 200 & 250 & 250 & 250 & 250 & 250 \\
\hline \multicolumn{9}{|c|}{ GB02 Inertial Confinement Fusion } \\
\hline Operating & 31.4 & 30.0 & 27.9 & 27.9 & 27.9 & 27.9 & 27.9 & 27.9 \\
\hline Capital Equipment & 3.0 & 1.6 & 0.7 & 0.7 & 0.7 & 0.7 & 0.7 & 0.7 \\
\hline Total Cost & 34.4 & 31.6 & 28.6 & 28.6 & 28.6 & 28.6 & 28.6 & 28.6 \\
\hline Direct Personnel & 82 & 74 & 65 & 65 & 65 & 65 & 65 & 65 \\
\hline \multicolumn{9}{|l|}{ GB03 Stockpile Support } \\
\hline Operating & 142.0 & 122.0 & 149.0 & 160.0 & 160.0 & 160.0 & 160.0 & 160.0 \\
\hline Capital Equipment & 17.1 & -2.9 & 13.2 & 24.2 & 19.5 & 22.6 & 22.8 & 25.3 \\
\hline General Plant Projects & 1.8 & 0.3 & 1.0 & 1.0 & 1.0 & 1.0 & 1.0 & 1.0 \\
\hline Major Construction & & j.3 & 0.4 & & & & & \\
\hline Total Cost & 160.9 & 122.7 & 163.6 & 185.2 & 180.5 & 183.6 & 183.8 & 186.3 \\
\hline Direct Personnel & 529 & 562 & 540 & 570 & 570 & 570 & 570 & 570 \\
\hline \multicolumn{9}{|l|}{ GB05 Program Direction } \\
\hline Operating & 7.3 & 11.2 & 9.8 & 3.6 & 3.6 & 3.6 & 3.6 & 3.6 \\
\hline Capital Equipment & & 0.3 & 0.1 & 0.1 & 0.1 & 0.1 & 0.1 & 0.1 \\
\hline Major Construction & & 8.0 & 35.8 & 24.3 & 6.7 & & & \\
\hline Total Cost & 7.3 & 19.5 & 45.7 & 28.0 & 10.4 & 3.7 & 3.7 & 3.7 \\
\hline Direct Personnel & 17 & 30 & 30 & 10 & 10 & 10 & 10 & 10 \\
\hline
\end{tabular}




\begin{tabular}{|c|c|c|c|c|c|c|c|c|c|}
\hline \multicolumn{10}{|c|}{$\begin{array}{l}\text { Assistant Secretary for Defense Programs (Continued) } \\
\text { Resources by Major Program } \\
\text { (Fiscal Year Budget Authority in Millions) }\end{array}$} \\
\hline & & FY92 & $\underline{\text { FY93 }}$ & FY94 & FY95 & $\underline{\mathrm{FY} 96}$ & FY97 & FY98 & FY99 \\
\hline \multirow{7}{*}{ 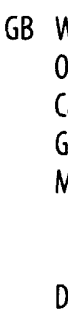 } & Weapon Activities & & & & & & & & \\
\hline & Operating & 651.0 & 589.6 & 616.8 & 615.6 & 615.6 & 615.6 & 615.6 & 615.6 \\
\hline & Capital Equipment & 61.7 & 39.3 & 44.8 & 75.0 & 74.1 & 66.3 & 73.4 & 79.6 \\
\hline & General Plant Projects & 8.6 & 7.3 & 4.0 & 8.0 & 8.0 & 12.0 & 8.0 & 8.0 \\
\hline & Major Construction & 25.5 & 30.7 & 58.8 & 56.3 & 19.8 & 4.1 & & \\
\hline & Total Cost & 746.8 & 666.9 & 724.4 & 754.9 & 717.5 & 698.0 & 697.0 & 703.2 \\
\hline & Direct Personnel & 2252 & 2201 & 1880 & 1820 & 1820 & 1820 & 1820 & 1820 \\
\hline \multirow{3}{*}{ GE $\begin{array}{r}M \\
0\end{array}$} & Materials Production- & r Operations & & & & & & & \\
\hline & Operating & 0.8 & 1.4 & 0.6 & 0.5 & & & & \\
\hline & Direct Personnel & 3 & 3 & 2 & 2 & & & & \\
\hline \multicolumn{10}{|c|}{ Total, Assistant Secretary for Defense Programs } \\
\hline & Operating & 651.8 & 591.0 & 617.4 & 616.1 & 615.6 & 615.6 & 615.6 & 615.6 \\
\hline & Capital Equipment & 61.7 & 39.3 & 44.8 & 75.0 & 74.1 & 66.3 & 73.4 & 79.6 \\
\hline & General Plant Projects & 8.6 & 7.3 & 4.0 & 8.0 & 8.0 & 12.0 & 8.0 & 8.0 \\
\hline & Major Construction & 25.5 & 30.7 & 58.8 & 56.3 & 19.8 & 4.1 & & \\
\hline & Total Cost & 747.6 & 668.3 & 725.0 & 755.4 & 717.5 & 698.0 & 697.0 & 703.2 \\
\hline & Direct Personnel & 2255 & 2204 & 1882 & 1822 & 1820 & 1820 & 1820 & 1820 \\
\hline & Proposed Construction & & & 2.4 & 17.7 & 43.0 & 30.6 & 28.8 & 45.7 \\
\hline
\end{tabular}




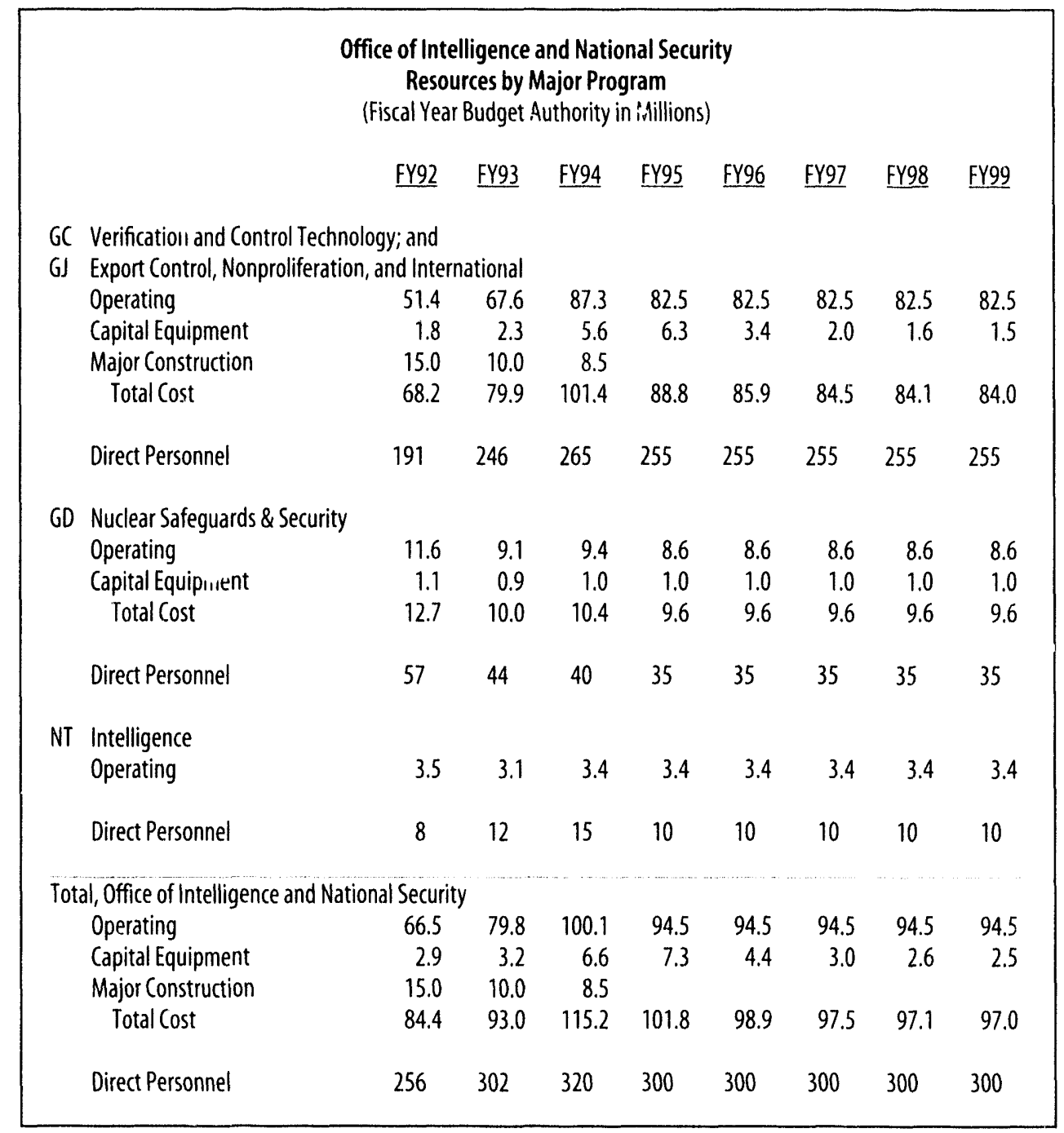




\begin{tabular}{|c|c|c|c|c|c|c|c|c|}
\hline \multicolumn{9}{|c|}{$\begin{array}{l}\text { Office of Environmental Restoration and Waste Management } \\
\text { Resources by Major Program } \\
\text { (Fiscal Year Budget Authority in Millions) }\end{array}$} \\
\hline & FY92 & FY93 & FY94 & FY95 & FY96 & FY97 & FY98 & FY99 \\
\hline \multicolumn{9}{|c|}{ EW Environmental Restoration and Waste Management } \\
\hline Operating & 87.9 & 126.6 & 138.3 & 144.4 & 144.4 & 144.4 & 144.4 & 144.4 \\
\hline Capital Equipment & 4.5 & 3.3 & 4.7 & 5.5 & 5.5 & 5.5 & 5.5 & 5.5 \\
\hline General Plant Projects & 2.6 & 1.1 & 4.3 & & & & & \\
\hline Total Cost & 95.0 & 131.0 & 147.3 & 149.9 & 149.9 & 149.9 & 149.9 & 149.9 \\
\hline Direct Personnel & 237 & 298 & 335 & 350 & 350 & 350 & 350 & 350 \\
\hline Proposed Construction & & & & & 3.6 & 3.7 & 8.0 & 8.3 \\
\hline
\end{tabular}

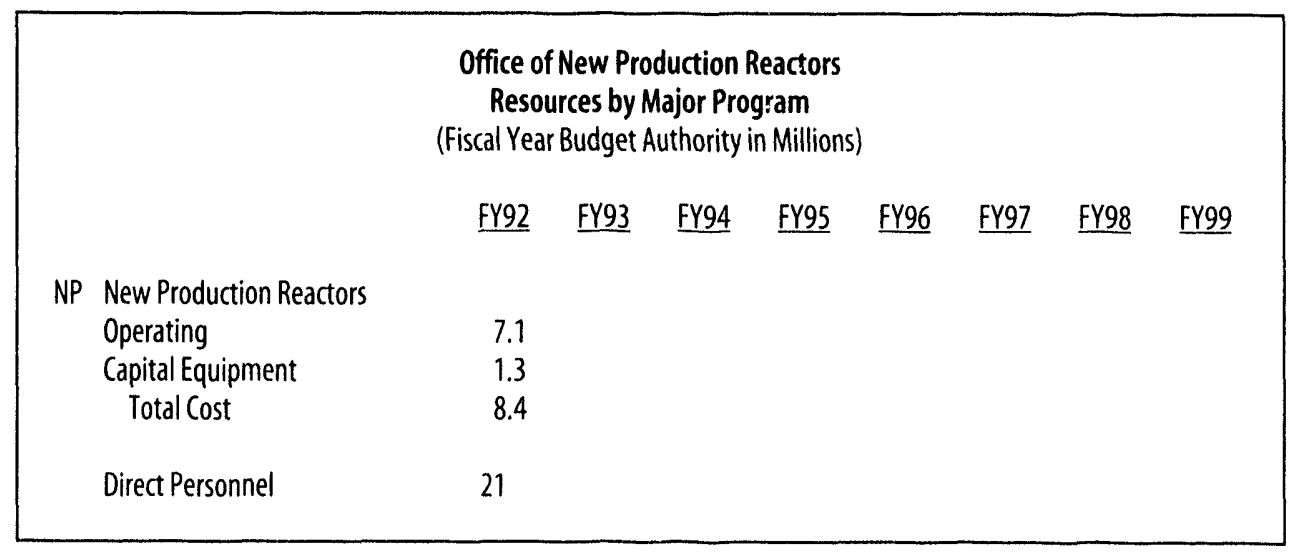




\section{Assistant Secretary for Energy Efficiency and Renewable Energy Resources by Major Program \\ (Fiscal Year Budget Authority in Millions)}

FY92 $\underline{F Y 93} \quad \underline{F Y 94} \quad \underline{F Y 95} \quad \underline{F Y 96} \quad \underline{F Y 97} \quad \underline{F Y 98} \quad \underline{F Y 99}$

AK Electric Energy Systems

Operating

Capital Equipment

Total Cost

$\begin{array}{llllllll}1.3 & 1.5 & 2.5 & 3.5 & 3.5 & 3.5 & 3.5 & 3.5 \\ 0.1 & & 0.1 & 0.2 & 0.2 & 0.2 & 0.2 & 0.2 \\ 1.4 & 1.5 & 2.6 & 3.7 & 3.7 & 3.7 & 3.7 & 3.7\end{array}$

Direct Personnel

$\begin{array}{llllllll}5 & 5 & 8 & 12 & 12 & 12 & 12 & 12\end{array}$

AL Energy Storage Systems

Operating

Capital Equipment

$\begin{array}{ll}3.0 & 3.7\end{array}$

$0.2 \quad 0.3 \quad 0.2$

$3.2 \quad 4.0 \quad 5.2$

$6.5 \quad 6.5$

0.20 .2

Total Cost

$$
\begin{array}{llllllll}
5 & 6 & 8 & 9 & 9 & 9 & 9 & 9
\end{array}
$$

AM Geothermal Systems

Operating

Capital Equipment

Total Cost

$\begin{array}{ll}5.0 & 7.1 \\ 0.2 & 0.3 \\ 5.2 & 7.4\end{array}$

$\begin{array}{lll}7.5 & 7.4 & 7.4\end{array}$

$\begin{array}{ll}7.4 & 7.4\end{array}$

7.4

Direct Personnel

$\begin{array}{llllllll}16 & 18 & 20 & 22 & 22 & 22 & 22 & 22\end{array}$

EB Solar Energy

Operating

Capital Equipment

Total Cost

$\begin{array}{llllllll}30.0 & 26.5 & 31.3 & 31.2 & 31.2 & 31.2 & 31.2 & 31.2\end{array}$

$\begin{array}{llllllll}0.2 & 0.2 & 1.0 & 1.4 & 1.4 & 1.4 & 1.4 & 1.4\end{array}$

$\begin{array}{llllllll}30.2 & 26.7 & 32.3 & 32.6 & 32.6 & 32.6 & 32.6 & 32.6\end{array}$

Direct Personnel

$\begin{array}{llllllll}85 & 81 & 88 & 97 & 98 & 98 & 98 & 98\end{array}$

ED Industrial Sector

Operating

Capital Equipment

Total Cost

Direct Personnel

$\begin{array}{llllllll}7.9 & 4.8 & 8.3 & 9.8 & 9.8 & 9.8 & 9.8 & 9.8\end{array}$

$\begin{array}{llllllll}0.1 & 0.2 & 0.9 & 0.6 & 0.6 & 0.6 & 0.6 & 0.6\end{array}$

$\begin{array}{llllllll}8.0 & 5.0 & 9.2 & 10.4 & 10.4 & 10.4 & 10.4 & 10.4\end{array}$

$\begin{array}{llllllll}24 & 25 & 26 & 48 & 48 & 48 & 48 & 48\end{array}$

EE Transportation Sector

Operating

Capital Equipment

Total Cost

$\begin{array}{llllllll}1.7 & 2.4 & 3.3 & 2.5 & 2.5 & 2.5 & 2.5 & 2.5\end{array}$

$\begin{array}{llllllll}1.7 & & 0.3 & 0.3 & 0.3 & 0.3 & 0.3 & 0.3 \\ & 2.4 & 3.6 & 2.8 & 2.8 & 2.8 & 2.8 & 2.8\end{array}$

Direct Personnel

$\begin{array}{llllllll}6 & 5 & 7 & 6 & 6 & 6 & 6 & 6\end{array}$




\section{Assistant Secretary for Energy Efficiency and Renewable Energy (continued) Resources by Major Program \\ (Fiscal Year Budget Authority in Millions)}

FY92 FY93 FY94 FY95 FY96 FY97 FY98 FY99

EC Buildings Sector; and

EF State and Local Programs Operating

0.3

Total, Assistant Secretary for Energy Efficiency and Renewable Energy

$\begin{array}{lrrrrrrrr}\text { Operating } & 49.2 & 46.0 & 57.9 & 60.9 & 60.9 & 60.9 & 60.9 & 60.9 \\ \text { Capital Equipment } & 0.8 & 1.0 & 2.5 & 2.7 & 2.7 & 2.7 & 2.7 & 2.7 \\ \quad \text { Total Cost } & 50.0 & 47.0 & 60.4 & 63.6 & 63.6 & 63.6 & 63.6 & 63.6 \\ & & & & & & & & \\ \text { Direct Personnel } & 141 & 140 & 157 & 194 & 195 & 195 & 195 & 195\end{array}$

\section{Office of Civilian Radioactive Waste Management \\ Resources by Major Program \\ (Fiscal Year Budget Authority in Millions)}

FY92 1193 FY94 FY95 FY96 FY97 FY98 FY99

DB Nuclear Waste Fund

$\begin{array}{lrrrrrrrr}\text { Operating } & 16.6 & 15.6 & 25.2 & 25.4 & 25.4 & 25.4 & 25.4 & 25.4 \\ \text { Capital Equipment } & 0.2 & & 0.3 & 0.4 & 0.4 & 0.4 & 0.4 & 0.4 \\ \quad \text { Total Cost } & 16.8 & 15.6 & 25.5 & 25.8 & 25.8 & 25.8 & 25.8 & 25.8 \\ & & & & & & & & \\ \text { Direct Personnel } & 62 & 52 & 76 & 89 & 89 & 89 & 89 & 89\end{array}$




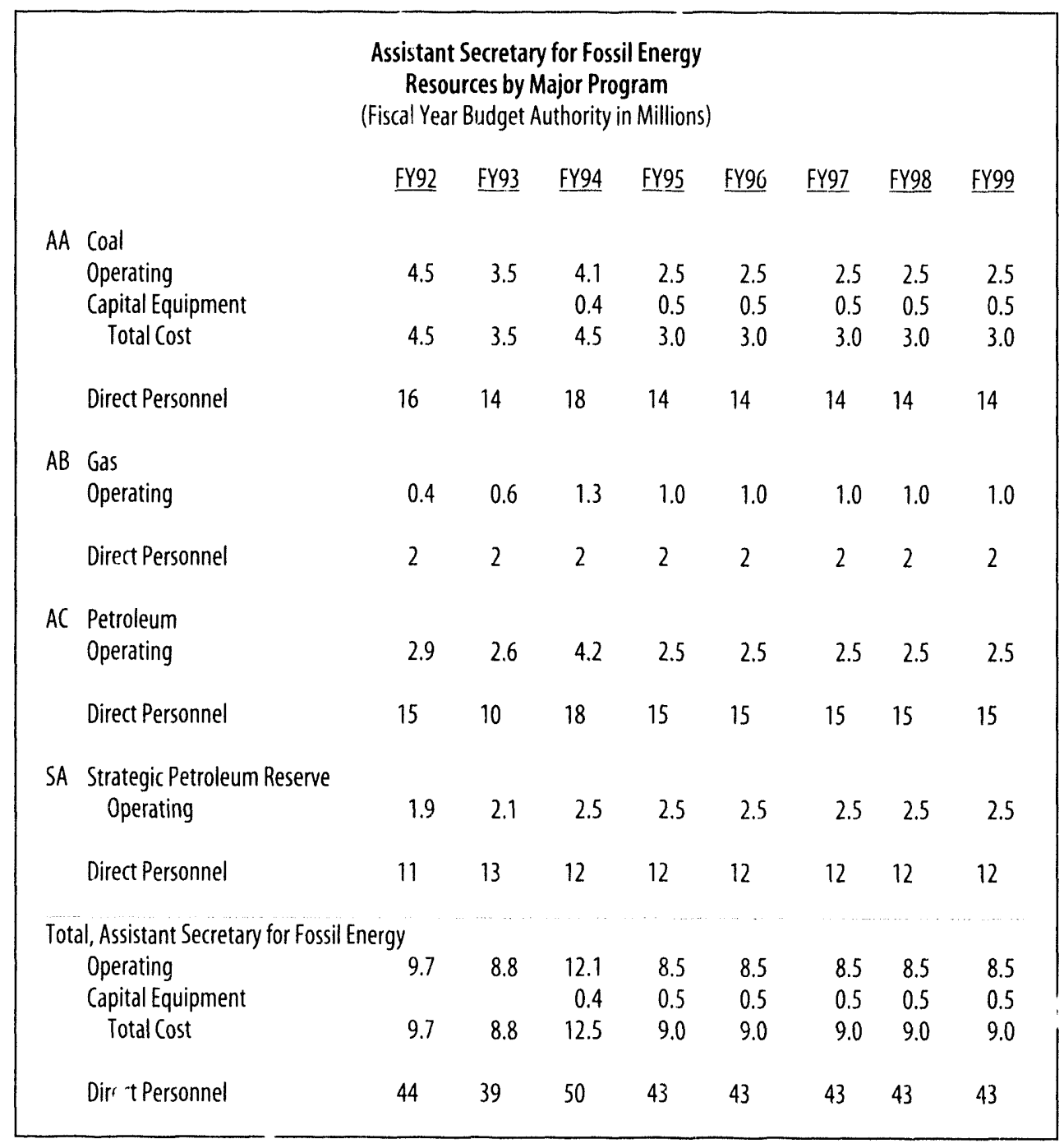




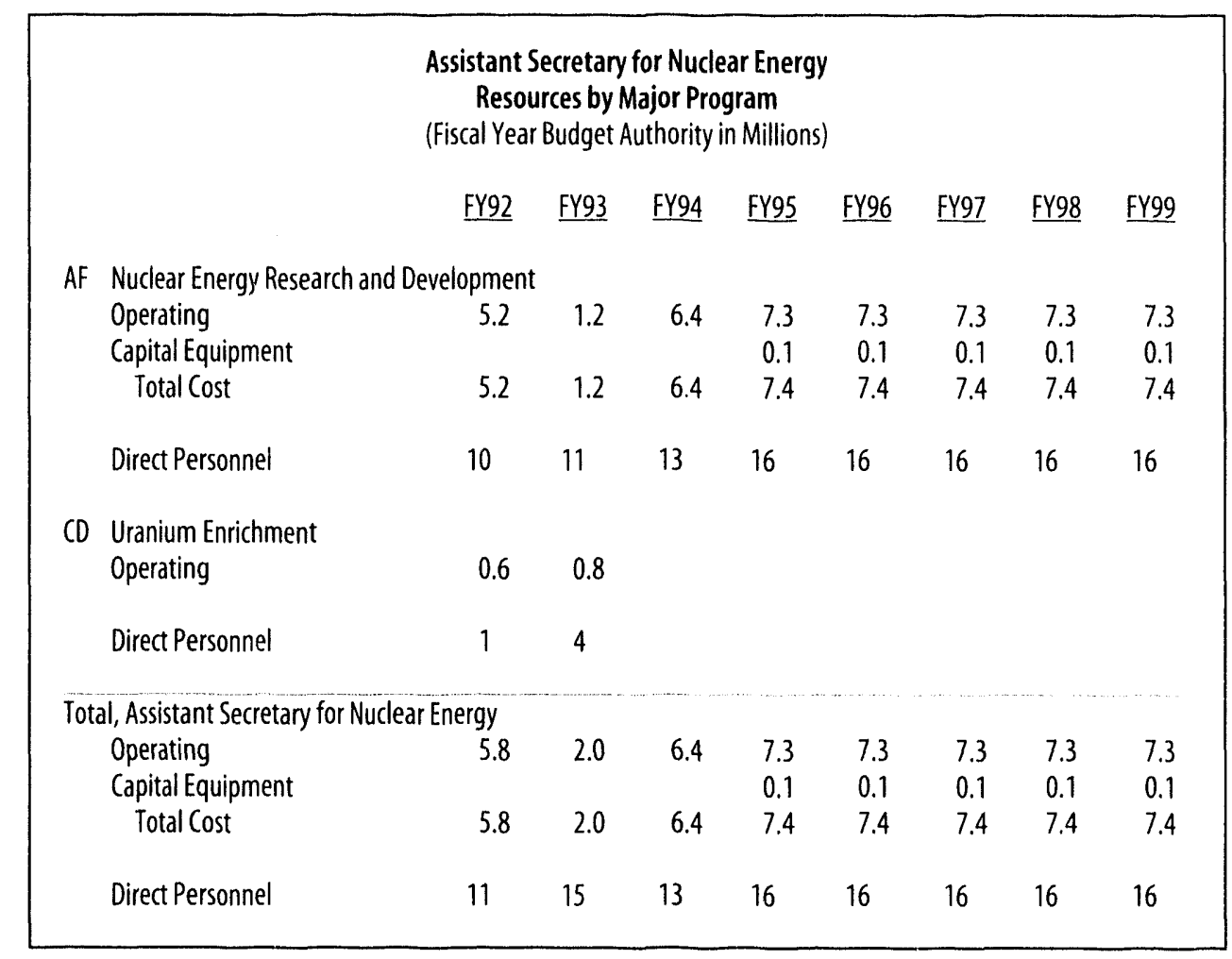




\begin{tabular}{|c|c|c|c|c|c|c|c|c|c|}
\hline \multicolumn{10}{|c|}{$\begin{array}{c}\text { Office of Energy Research } \\
\text { Resources by Major Program } \\
\text { (Fiscal Year Budget Authority in Millions) }\end{array}$} \\
\hline & & FY92 & FY93 & $\underline{\text { FY94 }}$ & FY95 & $\underline{F Y 96}$ & FY97 & $\underline{F Y 98}$ & FY99 \\
\hline \multirow{5}{*}{ AT } & Magnetic Fusion & & & & & & & & \\
\hline & Operating & 5.6 & 6.5 & 6.2 & 6.8 & 6.8 & 6.8 & 6.8 & 6.8 \\
\hline & Capital Equipment & 0.3 & 0.7 & 0.9 & 0.9 & 0.9 & 0.9 & 0.9 & 0.9 \\
\hline & Total Cost & 5.9 & 7.2 & 7.1 & 7.7 & 7.7 & 7.7 & 7.7 & 7.7 \\
\hline & Direct Personnel & 22 & 25 & 32 & 30 & 30 & 30 & 30 & 30 \\
\hline \multirow{7}{*}{ KC } & Basic Energy Sciences & & & & & & & & \\
\hline & Operating & 22.4 & 21.8 & 21.1 & 26.0 & 26.0 & 26.0 & 26.0 & 26.0 \\
\hline & Capital Equipment & 2.3 & 1.9 & 3.9 & 5.2 & 5.2 & 5.2 & 5.2 & 5.2 \\
\hline & General Plant Projects & 0.1 & 0.2 & 0.6 & 0.6 & 0.6 & 0.6 & 0.6 & 0.6 \\
\hline & Major Construction & & & & 9.0 & 9.0 & & & \\
\hline & Total Cost & 24.8 & 23.9 & 25.6 & 40.8 & 40.8 & 31.8 & 31.8 & 31.8 \\
\hline & Direct Personnel & 84 & 76 & 103 & 104 & 104 & 104 & 104 & 104 \\
\hline \multirow{3}{*}{ KP } & Biological and Environmental Res & search & & & & & & & \\
\hline & Operating & 0.8 & 0.4 & 0.1 & 0.3 & 0.3 & 0.3 & 0.3 & 0.3 \\
\hline & Direct Personnel & 1 & 3 & 1 & 1 & 1 & 1 & 1 & 1 \\
\hline \multirow[t]{3}{*}{ KS } & Superconducting Super Collider & & & & & & & & \\
\hline & Operating & & & 0.1 & 0.1 & 0.1 & 0. & 0.1 & 0.1 \\
\hline & Direct Personnel & & 1 & 1 & 1 & 1 & 1 & 1 & 1 \\
\hline \multicolumn{10}{|c|}{ Total, Office of Energy Research } \\
\hline & Operating & 28.8 & 28.7 & 27.5 & 33.2 & 33.2 & 33.2 & 33.2 & 33.2 \\
\hline & Capital Equipment & 2.6 & 2.6 & 4.8 & 6.1 & 6.1 & 6.1 & 6.1 & 6.1 \\
\hline & General Plant Projects & 0.1 & 0.2 & 0.6 & 0.6 & 0.6 & 0.6 & 0.6 & 0.6 \\
\hline & Major Construction & & & & 9.0 & 9.0 & & & \\
\hline & Total Cost & 31.5 & 31.5 & 32.9 & 48.9 & 48.9 & 39.9 & 39.9 & 39.9 \\
\hline & Direct Personnel & 107 & 105 & 137 & 136 & 136 & 136 & 136 & 136 \\
\hline & Proposed Construction & & & & & & 1.6 & 12.0 & 9.0 \\
\hline
\end{tabular}




\begin{tabular}{|c|c|c|c|c|c|c|c|c|c|}
\hline \multicolumn{10}{|c|}{$\begin{array}{l}\text { Office of Science Education and Technical Information } \\
\text { Resources by Major Program } \\
\text { (Fiscal Year Budget Authority in Millions) }\end{array}$} \\
\hline & & FY92 & FY93 & FY94 & FY95 & FY96 & FY97 & FY98 & FY99 \\
\hline \multirow[t]{5}{*}{ KV } & University and Science Education & & & & & & & & \\
\hline & Operating & 1.0 & 3.0 & 2.1 & 2.0 & 2.0 & 2.0 & 2.0 & 2.0 \\
\hline & Capital Equipment & & & 0.3 & 0.2 & 0.2 & 0.2 & 0.2 & 0.2 \\
\hline & Total Cost & 1.0 & 3.0 & 2.4 & 2.2 & 2.2 & 2.2 & 2.2 & 2.2 \\
\hline & Direct Personnel & 1 & 1 & 4 & 5 & 5 & 5 & 5 & 5 \\
\hline
\end{tabular}

Work for Other DOE Locations, Contractors, and Offices

(Fiscal Year Budget Authority in Millions)

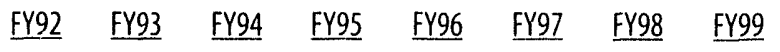

Office of Economic Impact and Diversity

WA50 Minority Economic Impact Program

$\begin{array}{lcccccccc}\text { Operating } & 0.5 & 0.7 & 0.7 & 0.6 & 0.6 & 0.6 & 0.6 & 0.6 \\ \text { Direct Personnel } & 1 & & 1 & 2 & 2 & 2 & 2 & 2 \\ \begin{array}{lccccccc}\text { Other } \\ \text { Operating }\end{array} & 33.1 & 30.8 & 39.4 & 41.2 & 41.2 & 41.2 & 41.2 & 41.2 \\ \text { Direct Personnel } & 110 & 110 & 112 & 117 & 117 & 117 & 117 & 117\end{array}$

Total, Other DOE Locations, Contractors, and Offices

$\begin{array}{lcccccccc}\text { Operating } & 33.6 & 31.5 & 40.1 & 41.8 & 41.8 & 41.8 & 41.8 & 41.8 \\ \text { Direct Personnel } & 111 & 110 & 113 & 119 & 119 & 119 & 119 & 119\end{array}$




\begin{tabular}{|c|c|c|c|c|c|c|c|c|}
\hline & \multicolumn{8}{|c|}{$\begin{array}{l}\text { Work Other than for Department of Energy } \\
\text { Resources by Major Reimbursable Sponsor } \\
\text { (Fiscal Year Budget Authority in Millions) }\end{array}$} \\
\hline & $\underline{F Y 92}$ & $\underline{\text { FY93 }}$ & $\underline{\text { FY94 }}$ & $\underline{\text { FY95 }}$ & FY96 & FY97 & FY98 & FY99 \\
\hline \multicolumn{9}{|l|}{ Department of Defense } \\
\hline Operating & 291.2 & 295.0 & 275.0 & 260.0 & 260.0 & 260.0 & 260.0 & 260.0 \\
\hline Direct Personnel & 798 & 751 & 760 & 755 & 755 & 755 & 755 & 755 \\
\hline \multicolumn{9}{|l|}{ Nuclear Regulatory Commission } \\
\hline Operating & 13.8 & 14.5 & 13.2 & 14.3 & 14.3 & 14.3 & 14.3 & 14.3 \\
\hline Direct Personnel & 52 & 54 & 41 & 44 & 44 & 44 & 44 & 44 \\
\hline \multicolumn{9}{|l|}{ Department of Transportation } \\
\hline Operating & 3.3 & 5.5 & 7.0 & 7.5 & 7.5 & 7.5 & 7.5 & 7.5 \\
\hline Direct Personnel & 19 & 18 & 20 & 20 & 20 & 20 & 20 & 20 \\
\hline \multicolumn{9}{|c|}{ National Aeronautics and Space Administration } \\
\hline Operating & 3.2 & 4.2 & 3.0 & 3.1 & 3.1 & 3.1 & 3.1 & 3.1 \\
\hline Direct Personnel & 10 & 14 & 10 & 10 & 10 & 10 & 10 & 10 \\
\hline \multicolumn{9}{|l|}{ Department of State } \\
\hline Operating & 0.5 & 0.5 & 0.3 & 1.0 & 1.0 & 1.0 & 1.0 & 1.0 \\
\hline Direct Personnel & 3 & 1 & 2 & 2 & 2 & 2 & 2 & 2 \\
\hline \multicolumn{9}{|c|}{ Environmental Protection Agency } \\
\hline Operating & 0.2 & 0.6 & 0.7 & 1.5 & 1.5 & 1.5 & 1.5 & 1.5 \\
\hline Direct Personnel & 1 & 1 & 2 & 5 & 5 & 5 & 5 & 5 \\
\hline \multicolumn{9}{|l|}{ Other Federal Agenc } \\
\hline Operating & 26.3 & 51.3 & 18.9 & 34.6 & 34.6 & 34.6 & 34.6 & 34.6 \\
\hline Direct Personnel & 63 & 69 & 85 & 96 & 97 & 97 & 97 & 97 \\
\hline \multicolumn{9}{|l|}{ All 0ther } \\
\hline Operating & 13.6 & 6.6 & 29.4 & 34.8 & 34.8 & 34.8 & 34.8 & 34.8 \\
\hline Direct Personnel & 34 & 54 & 70 & 79 & 79 & 79 & 79 & 79 \\
\hline \multicolumn{9}{|l|}{ Total Work Other than for DOE } \\
\hline Operating & 352.1 & 378.2 & 347.5 & 356.8 & 356.8 & 356.8 & 356.8 & 356.8 \\
\hline Direct Personnel & 980 & 962 & 990 & 1011 & 1012 & 1012 & 1012 & 1012 \\
\hline Proposed Construction & & & & 15.0 & 20.0 & 34.0 & 41.0 & \\
\hline
\end{tabular}




\begin{tabular}{|lrrrr|}
\hline & $\begin{array}{c}\text { Subcontracting and Procurement } \\
\text { (Budget obligation dollars in millions) }\end{array}$ & & & \\
& $\underline{\mathrm{FY} 91}$ & $\underline{\mathrm{FY} 92}$ & $\underline{\mathrm{FY} 93}$ \\
Supplier type: & & & \\
$\quad$ Commercial business & $\$ 490$ & $\$ 596$ & $\$ 718$ \\
$\quad$ Government transfers & 62 & 57 & 79 \\
$\quad$ Educational/nonprofit/GSA/ & & & & \\
$\quad$ state, local, and other governments & 36 & 49 & 51 \\
$\quad$ Total activity & $\$ 588$ & $\$ 702$ & $\$ 848$ \\
\hline
\end{tabular}

Small and Disadvantaged Business Procurement

(Budget obligation dollars in millions; percent of total commercial procurement)

FY91 FYY92 $\quad$ FY93

Small

Disadvantaged

Woman-owned

$\begin{array}{rr}\$ 287 & 56 \% \\ 51 & 10 \% \\ 49 & 10 \%\end{array}$

$\$ 427 \quad 59 \%$

$79 \quad 11 \%$

$58 \quad 8 \%$ 


\section{A Note on Acronyms}

In an effort to make this document easy to read, acronyms are generally avoided. When unfamiliar acronyms must be used, they are explained in the proximate text. Acronyms that occur freely in popular or news publications-acronyms such as DOE, DOD, EPA, and NASA-occur in the document without explanation.

This report was prepared as an account of work sponsored by an agency of the United States Government. Neither the United States Government nor any agency thereof, nor any of their employees, makes any warranty, express or implied, or assumes any legal liability or responsibility for the accuracy, completeness, or usefulness of any information, apparatus, product, or process disclosed, or represents that its use would not infringe privately owned rights.

Reference herein to any specific commercial product, process, or service by trade name, trademark, manufaciurer, or otherwise, does not necessarily constitute or imply its endorsement, recommendation, or favoring by the United States Government, any agency thereof. The views and opinions expressed herein do not necessarily state or reflect those of the United States Government or any agency thereof.

This work performed at Sandia National Laboratories under contract to the US Department of Energy. 

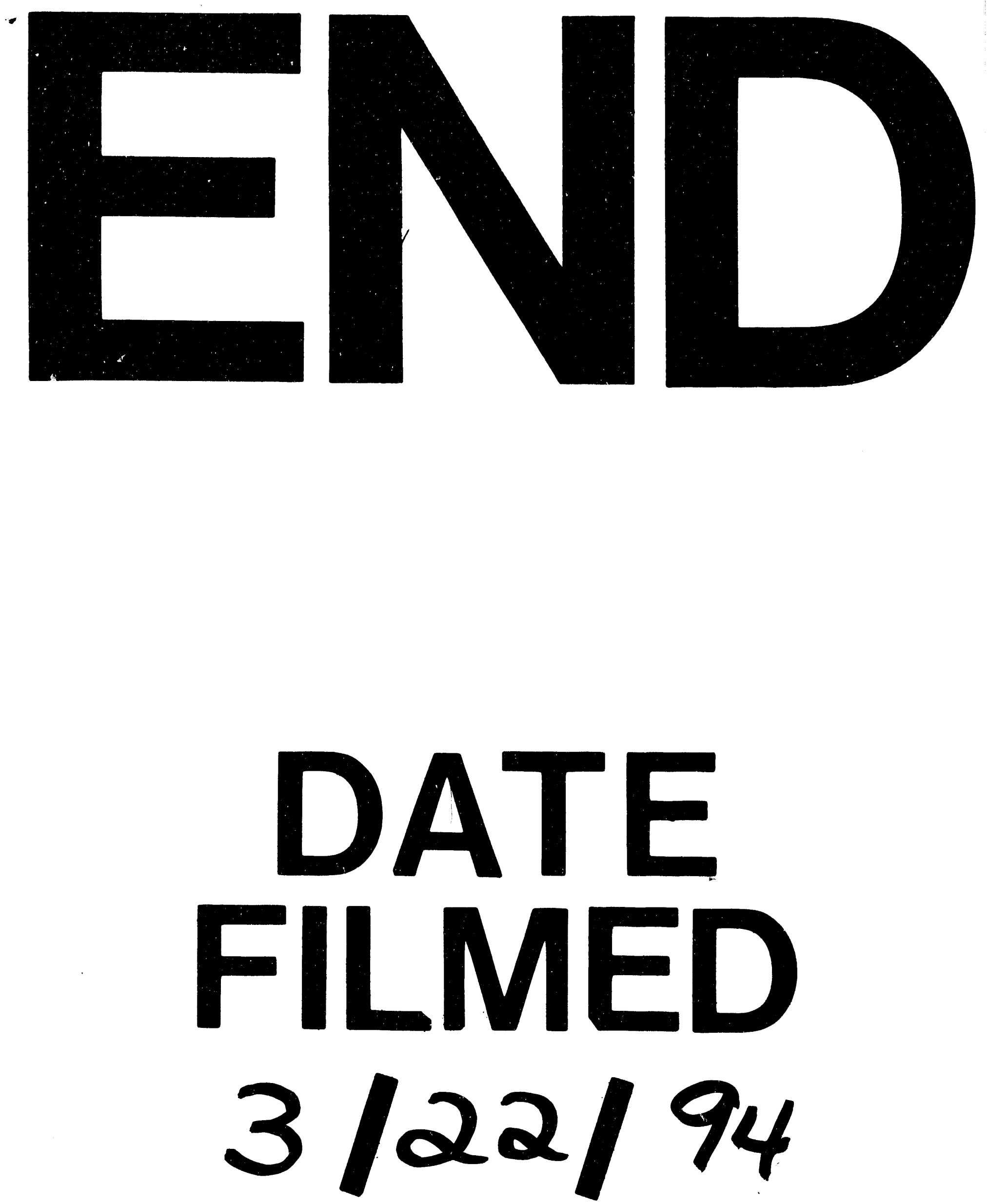

1 
